Guide

\title{
Guide de gestion des dunes et des plages associées
}

Sous la direction de Loïc Gouguet

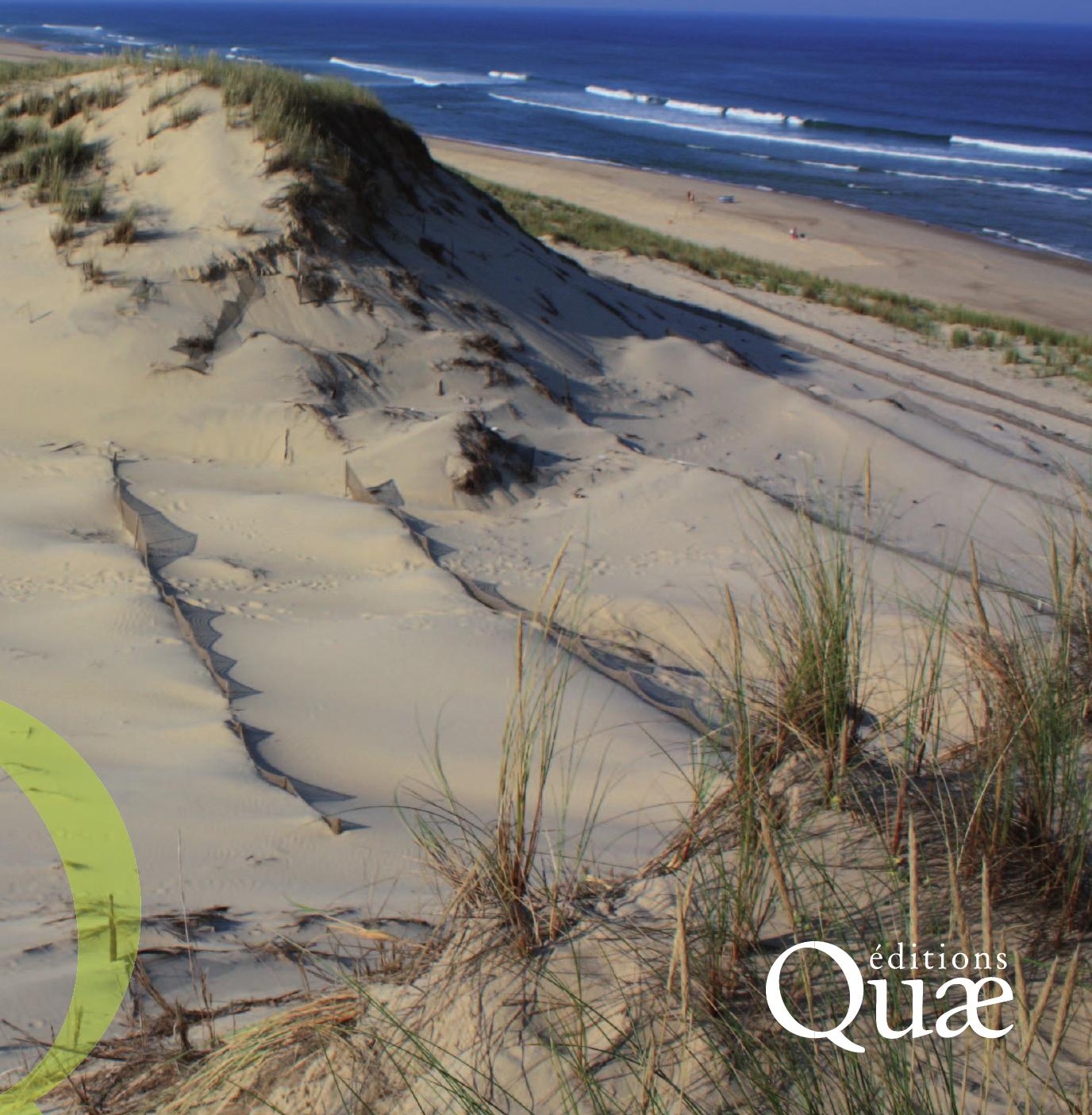





\section{Guide de gestion des dunes}

et des plages associées

Loïc Gouguet, sous la dir. 
Mieux intégrer la biodiversité dans la gestion forestière (nouvelle édition) Marion Gosselin, Yoann Paillet

$$
\text { 2017, } 160 \text { p. }
$$

Les animaux utiles au jardin

Guide lutte biologique (nouvelle édition)

Vincent Albouy

2017, 104 p.

Insectes et acariens des cultures maraîchères en milieu tropical humide

Reconnaissance, bioécologie et gestion agro-écologique

Philippe Ryckewaert, Béatrice Rhino

$$
\text { 2017, } 152 \text { p. }
$$

Atlas des bois tropicaux

Caractéristiques technologiques et utilisations

Jean Gérard, coordinateur

2016, 1000 p.
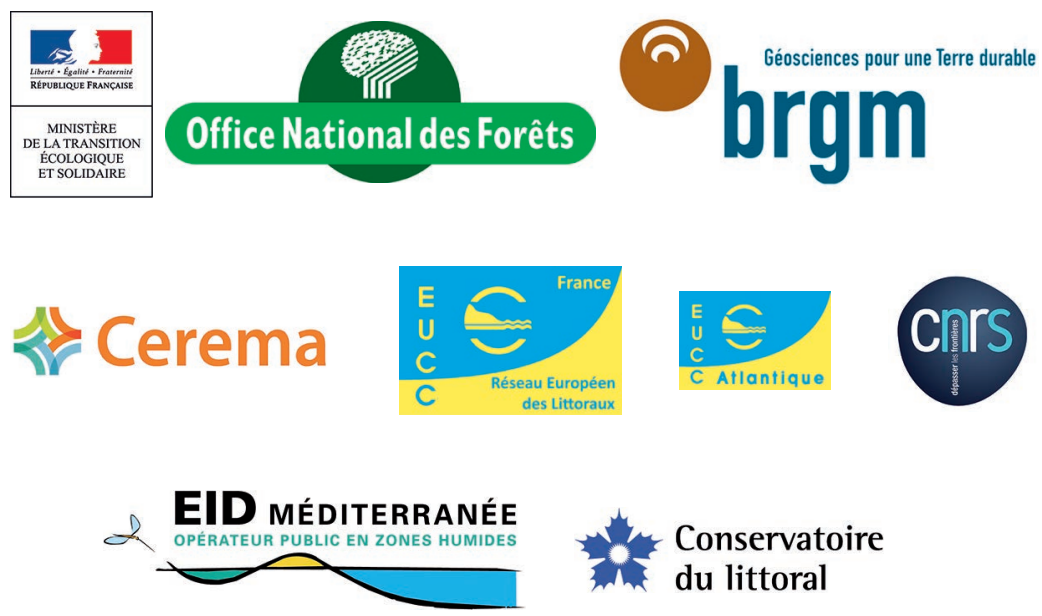

(C) Éditions Quæ, 2018

ISBN : 978-2-7592-2482-1

ISSN : $1952-2770$

Éditions Quæ

RD 10

78026 Versailles Cedex

Le code de la propriété intellectuelle interdit la photocopie à usage collectif sans autorisation des ayants droit. Le non-respect de cette disposition met en danger l'édition, notamment scientifique, et est sanctionné pénalement. Toute reproduction partielle du présent ouvrage est interdite sans autorisation du Centre français d'exploitation du droit de copie (CFC), 20 rue des Grands-Augustins, Paris 6. 


\section{Remerciements}

Cet ouvrage a été réalisé à l'initiative du ministère de la Transition écologique et solidaire, et plus particulièrement de la Direction de l'eau et de la biodiversité conjointement avec la Direction générale de la prévention des risques. Cette tâche a été coordonnée par l'Office national des forêts, en faisant appel à de nombreuses compétences scientifiques, gestionnaires et expertes.

Il a été conçu et rédigé par, et grâce à l'aide de :

- Alfred Peter (paysagiste);

- Yvonne Battiau-Queney, Marie-Claire Prat et Jean Favennec (EUCC-France, Réseau européen des littoraux) ;

- Christine Clus-Auby (EUCC Atlantique);

- Emmanuel Garnier (UMR CNRS Chrono-Environnement, Besançon) ;

- Yann Deniaud, Boris Leclerc et François Hedou (Cerema);

- Franck Desmazes, Éric Palvadeau, Manuel Garcin et Ywenn de La Torre (BRGM) ;

- Patrick Bazin (Conservatoire du littoral);

- Hugues Heurtefeux et Philippe Richard (Entente interdépartementale pour la démoustication du littoral méditerranéen);

- Jean Magne (Communauté de communes Océan-Marais de Monts) ;

- Florian Geffroy (Rivages de France);

- Vicky Cormier (Collectivité territoriale de Saint-Pierre-et-Miquelon);

- Martine Blondin, David Rosebery, Christophe Rollier, Valentin Metereau, Romain Perrot, Frédéric Séjourné et Loïc Gouguet (ONF).

Avec I'appui de Sabine Moraud, Mireille Guignard (DEB), Jean-Victor Michel et Jean-Philippe Lalande (DGPR).

Que tous les auteurs soient ici chaleureusement remerciés pour leur engagement en faveur des milieux dunaires et de leur préservation. Une mention toute particulière à Yvonne, Marie-Claire, Christine, David, Valentin et Jean pour leur relecture attentive et leurs précieux conseils, et à Romain Perrot pour les illustrations.

Loïc Gouguet Coordinateur du projet 



\section{Préface}

Alfred Peter

Pour nombre d'estivants, la traversée des dunes*1 côtières est un passage obligé, le plus court possible, pour rejoindre les plages*. C'est aussi un joli fond pour selfies à poster sur Facebook, voire un terrain de jeu pour toutes sortes de pratiques, surtout quand les plages sont bondées. Cela s'explique par le fait que le paysage des dunes côtières a une forte puissance évocatrice de la nature sauvage. Mais qui sait que ce paysage est le résultat de l'action conjuguée de I'eau, du vent et des plantes? Que c'est un paysage dynamique en mouvement constant? Que la stabilité de la plage en dépend? Que cette dynamique est aussi sa vulnérabilité ?

Récemment, j'ai eu à intervenir sur deux grands sites dunaires où cette chaîne eau/vent/plantes a été brisée par la construction de routes qui ont coupé la plage de son réservoir de sable*. Deux routes, entre Sète et Marseillan d'une part, entre Carnon et la Grande Motte d'autre part, offraient la mer, presque de façon indécente, aux baigneurs : tracées entre la plage et les dunes, elles ont eu pour conséquence d'accélérer spectaculairement l'érosion des plages. Une fois les routes supprimées et le contact plage/dunes rétabli correctement, le processus naturel de ré-engraissement des plages s'est remis en route tout seul... Ces deux exemples symboliques de repli stratégique préfigurent un travail nécessaire de plus grande ampleur sur nombre de sites côtiers en France. Dans ce processus, une attention particulière doit être portée au milieu dunaire, objet de ce guide.

Mais pourquoi ce paysage est-il si intéressant ? Dune vient du mot néerlandais duin qui veut dire colline. Les petites collines côtières parallèles à la côte, on les doit au vent, et le vent sculpte bien. L'échelle est à taille humaine, ce qui donne l'impression de se promener dans une maquette. Les parcours offrent un nombre inouï de points de vue, de surprises; plus on se rapproche de la mer et plus le paysage semble dynamique; de temps en temps, des petites dépressions font voir la nappe phréatique toute proche et font penser à des petites oasis en plein désert... En plus de cette échelle si subtile, elles ont donc un côté ludique, apprivoisable. En interdire tout accès serait une grande frustration pour le public.

Comment alors protéger ces complexes dunaires tout en les révélant? Comment faire comprendre ce qu'est une dune verte, blanche ou grise ? II est tout à fait nécessaire et possible de concilier forte fréquentation humaine des bords de mer avec une politique de protection de ces milieux fragiles. L'approche de la mer à travers les dunes doit faire partie de l'expérience de la baignade. Pour cela, il est nécessaire de reculer progressivement les infrastructures d'accueil (parkings, toilettes), de renforcer l'accessibilité en modes doux des plages, et de créer des passages très contrôlés des complexes dunaires. L'idéal serait de créer des "tapis volants ", c'est-à-dire des estacades ne touchant pas le sable, une sorte de réplique de ponton sur l'eau; leur simple existence souligne la fragilité et la grande valeur du paysage traversé... Le traitement des abords du Mont-Saint-Michel auquel j'ai activement participé est un excellent exemple à suivre.

1. Les mots marqués d'un astérisque sont expliqués dans le glossaire final. 
Avec la pression humaine de plus en plus forte, il faut inventer des mesures adaptées qui replacent l'homme dans ces milieux à sa juste place... Le défi sera de le faire de façon à éveiller un large public à ces milieux fragiles de manière festive et non punitive. En associant notre énergie créatrice à celle du vent et de l'eau, il est possible de faire des dunes côtières une expérience inoubliable et respectueuse.

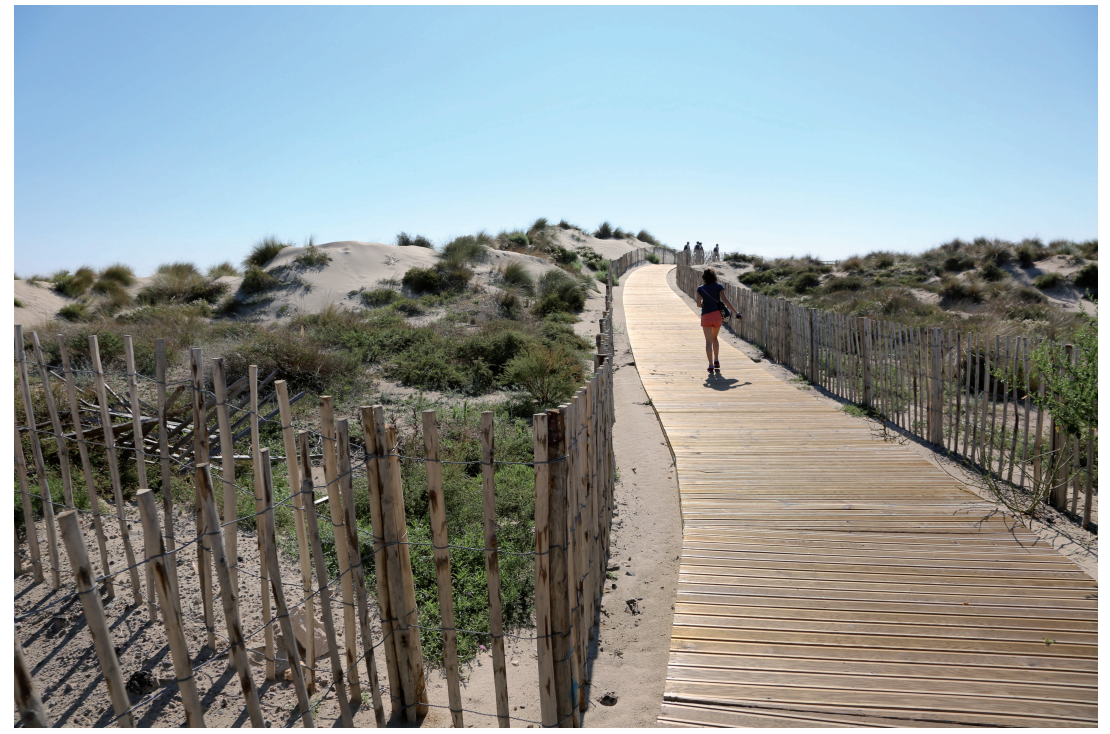

Figure 0.1. Un tapis volant pour découvrir la dune.

(c) A. Peter. 


\section{Sommailire}

Remerciements

Introduction 9

Présentation du guide $\quad 9$

À qui s'adresse ce guide ? 10

$\begin{array}{ll}\text { Plan du guide } & 10\end{array}$

\section{Les différents types de dunes, leur formation}

\section{et leur évolution}

La formation des dunes, le système plage-dune

La naissance

Les phénomènes naturels en jeu

Le fonctionnement du système plage-dune :

le bilan sédimentaire

Les différents types de dunes littorales

28

Les formes dunaires globales $\quad 29$

Les différents profils des dunes littorales $\quad 38$

La dynamique des dunes $\quad 41$

L'évolution du contact entre la plage et la dune $\quad 41$

Exhaussement et bossellement

sur la dune bordière $\quad 45$

Le rôle de la végétation $\quad 51$

Une adaptation remarquable $\quad 51$

La végétation de haut de plage 52

La végétation de la dune embryonnaire $\quad 52$

La dune blanche 52

La dune de transition $\quad 53$

La dune grise 53

De la mer à la forêt : des habitats naturels bien

différenciés 54

La dune : un milieu rude $\quad 54$

Les milieux dunaires secs 54

Les milieux dunaires humides 61

Les dunes françaises 64

Les dunes de la Manche et de la mer du Nord 64

Les dunes atlantiques $\quad 76$

Les dunes méditerranéennes $\quad 86$

Les dunes ultramarines $\quad 91$ 
Du vide au trop-plein! 97

Des zones inhospitalières... 97

... à une ruée vers le littoral $\quad 99$

Des usages traditionnels et contemporains multiples 102

Les usages agricoles et forestiers $\quad 102$

Des lieux de passage largement empruntés $\quad 105$

Les prélèvements de sable $\quad 108$

L'urbanisation 110

Les ouvrages et les systèmes de défense

contre la mer

113

Protéger les dunes : les politiques publiques

de protection $\quad 120$

Préserver une biodiversité remarquable $\quad 120$

Prendre en compte les risques naturels $\quad 125$

Les dunes face aux tempêtes 133

Le cas aquitain : protection et vulnérabilité, $\mathrm{XIX}$ - $\mathrm{xx}$ e siècles

... et l'avenir?

\section{Les modalités de gestion}

139

Acteurs et stratégies de gestion des dunes $\quad 139$

Les principaux gestionnaires et propriétaires $\quad 139$

Les stratégies de gestion $\quad 141$

Organisation de la gestion $\quad 158$

La connaissance et le diagnostic 158

La surveillance et l'évaluation $\quad 159$

Les entretiens 159

Les travaux d'aménagement 163

La gestion des situations d'urgence 166

Fiches des techniques d'intervention 169

Utiliser le vent et la végétation

pour piéger le sable

169

Organiser la fréquentation $\quad 187$

Gérer le stock de sable $\quad 199$

Conclusion 209

Glossaire $\quad 211$

Bibliographie $\quad 217$ 


\section{Introduction}

Riche de 20000 km de côtes, la France dispose d'une grande diversité d'écosystèmes littoraux (falaises, zones humides, cordons dunaires, mangroves, récifs coralliens...), hauts lieux de biodiversité et sources de paysages remarquables. Au-delà de ce patrimoine exceptionnel, ces écosystèmes constituent des lieux de dissipation de l'énergie de la mer et limitent l'impact de l'érosion des côtes, contribuant ainsi à la protection de la population et des activités situées sur le littoral. La protection et la restauration de ces écosystèmes constituent par conséquent un enjeu important à prendre en compte dans les stratégies d'intervention mises en place dans les espaces littoraux.

Parmi ces écosystèmes, les côtes d'accumulation (galets, sables, vases) occupent une place importante avec 39 \% du linéaire côtier en métropole. Sous l'effet de facteurs naturels (courant, tempêtes, vent...), elles évoluent, formant un espace mobile, parfois appelé espace de respiration* du système, qu'il s'agit de préserver pour maintenir le bon fonctionnement de ces écosystèmes et les services qu'ils apportent.

Le guide de gestion des dunes et des plages associées a été conçu pour répondre à ces objectifs. II propose à la fois un socle de connaissances pour la compréhension de ces écosystèmes complexes et les éléments techniques nécessaires à la constitution d'une stratégie d'intervention adaptée articulant gestion des risques littoraux et préservation de la biodiversité. Il offre ainsi un cadre d'intervention favorisant le maintien des capacités d'adaptation des milieux dunaires, essentiel dans un contexte de changement climatique.

Cet ouvrage s'inscrit pleinement dans les objectifs de la Stratégie nationale de gestion intégrée du trait de côte, adoptée par la France en 2012, et participe à la concrétisation de son programme d'actions.

Sa réalisation a été confiée par le ministère de la Transition écologique et solidaire à l'Office national des forêts, gestionnaire de près de $380 \mathrm{~km}$ de dunes pour le compte de l'État. De nombreux scientifiques et techniciens ont apporté leur contribution afin d'établir une synthèse des connaissances sur le fonctionnement des dunes et des plages associées et leur gestion passée, et constituer une boîte à outils opérationnelle pour une gestion durable des milieux dunaires littoraux.

\section{Présentation du guide}

Lorsque le 25 août 1774, le chanoine Desbiey présenta à la Société académique de Bordeaux son long mémoire sur "la fixation des dunes par les semis de pins », il expliqua comment il avait résolu avec son frère, sur ses propres terres, la difficile tâche "d'arrêter ces montagnes de sable ». Pour immobiliser les sables, il proposait de favoriser la végétation : après avoir semé des graines de pins, de genêts et d'ajoncs, il avait tout simplement étendu sur le sol des branches d'arbres qu'il fixait au moyen d'un crochet de bois enfoncé dans les sables. Les graines semées sous ces abris avaient germé aussitôt. Tout était dit, c'était le début de la longue histoire de la fixation des dunes !

Les fondements étant décrits, il ne restait plus qu'à généraliser ces pratiques, en prenant des mesures administratives, sociales et financières pour entreprendre 
cette grande œuvre. Cela s'est fait sur plusieurs dizaines d'années, au gré des évolutions des institutions et de la demande de la société.

Même si les conditions sédimentaires ont progressivement changé, si les usages du littoral ont radicalement évolué, et alors que la perception de ces milieux est passée d'un sentiment de rejet il y a quelques siècles à une attraction sans faille aujourd'hui, la nécessité de contrôler les mouvements de sable reste nécessaire dans bon nombre de cas. Ce guide est là pour présenter les bases de la gestion des dunes.

\section{À qui s'adresse ce guide?}

Ce guide est à destination de tous les gestionnaires de milieux dunaires, collectivités locales, services de l'État, prestataires et opérateurs techniques, milieu associatif. Il doit leur permettre, en leur donnant les outils de connaissance pour analyser les conditions écologiques des milieux dunaires dont ils ont la responsabilité, de gérer ces espaces rares et riches. Ni traité de botanique, de sédimentologie ou de géomorphologie, il décrit toutefois les notions nécessaires à la mise en œuvre d'une gestion éclairée et pragmatique. Ces notions nécessitent parfois un vocabulaire un peu technique, nous souhaitons que le lecteur ne nous en tienne pas rigueur!

Ce guide est aussi bien entendu à la disposition de tous ceux qui veulent connaître les paysages littoraux familiers, leur fonctionnement complexe et les différentes façons de les préserver.

\section{Plan du guide}

Lorsqu'il se promène tout au long du littoral, l'observateur attentif est frappé par la diversité des formes de dune qu'il découvre. Nous présenterons donc tout d'abord, dans le chapitre 1, les types et les formes des dunes rencontrées, puis nous expliquerons les différents processus en jeu dans la formation de ces espaces, subtile alchimie entre la mer, le vent et la végétation, et les différents stades de leur évolution.

Un panorama des différents types de dunes rencontrés en France sera ensuite présenté, chaque façade maritime ayant ses propres particularités.

Dans le chapitre 2 nous retracerons l'évolution des usages des milieux dunaires, et les transformations des attentes de la société, d'un refus de ces zones jugées inhospitalières avant le $x{ }^{\mathrm{e}}$ siècle à une ruée vers les littoraux à partir du $x x^{e}$ siècle, jusqu'à une certaine prise en compte de la biodiversité.

Le chapitre 3 sera consacré à la gestion des dunes. Qui les gère ? Quelles stratégies doit-on mettre en place ? Enfin, comment intervenir concrètement ?

Fruit de l'expérience de plusieurs auteurs et experts (Cerema, EUCC-France, EID Med, BRGM, EUCC Atlantique, ONF...) dans la gestion des milieux dunaires littoraux et la prévention des risques naturels, ce guide présente des outils utiles pour résoudre les problèmes liés à la gestion quotidienne des dunes. Que tous ces auteurs soient ici remerciés pour leur contribution sans laquelle ce guide ne serait pas si complet. 


\section{Les différents types de dunes, leur formation et leur évolution}

\section{La formation des dunes, le système plage-dune}

Yvonne Battiau-Queney

La dune côtière ne se comprend et ne peut se gérer efficacement que si on la replace dans un système complexe intégrant la plage et les petits fonds marins et faisant intervenir conjointement de multiples facteurs.

En milieu terrestre, une dune est une accumulation de sable par le vent (contrairement aux dunes " hydrauliques » formées en milieu marin ou fluviatile). Comme on trouve du sable dans tous les domaines climatiques, des pôles à l'équateur, et que le vent peut souffler partout, il est normal de voir des dunes dans tous les milieux terrestres, du froid au chaud et de l'aride à l'humide. Néanmoins, en dehors des zones arides (froides ou chaudes), c'est surtout le long du littoral qu'elles sont les plus fréquentes, des régions circumpolaires aux régions équatoriales, en passant par les grands déserts littoraux américains et africains et les côtes des moyennes latitudes, sur les cinq continents. Ce constat d'ubiquité soulève la question de l'origine et de l'évolution des dunes littorales. Pourquoi sont-elles si fréquentes quel que soit le climat ambiant? Quelles sont leurs particularités?

Revenons au point de départ : il faut du sable et du vent. Le sable est-il plus abondant le long des côtes qu'à l'intérieur des terres? La réponse est oui pour au moins trois raisons :

- la charge alluviale des fleuves qui aboutit à la mer est (ou a été) très souvent riche en sable ;

- l'érosion des falaises maritimes peut fournir des quantités importantes de sable si la roche attaquée s'y prête ;

- le milieu littoral est propice à la création de sables d'origine biologique.

On passe alors à une deuxième particularité du littoral qui sera analysée dans ce guide : ce sable arrivant à la côte ou voyageant le long des côtes est remanié par la mer, les vagues et les courants, et tend à s'accumuler pour former des plages. C'est là que le vent prend le relais de la mer pour remobiliser les grains de sable qu'il peut soulever (il y a un tri dans le matériau), transporter et redéposer ailleurs.

La dune va naître de ce travail sélectif du vent sur la plage. Toutes les plages ne sont pas également propices à engendrer une dune puisque deux conditions sont nécessaires :

- que le vent puisse soulever les grains de sable, ce qui dépend de la taille et de l'humidité des grains, de la vitesse du vent, mais aussi de la largeur des aires d'envol qui dépend de la marée ; 
- que le vent (dominant ou " efficace ») souffle dans la bonne direction, généralement vers la terre (avec le cas particulier des dunes de Méditerranée, où le Mistral souffle depuis la terre).

Il peut donc exister des plages sans dunes, par exemple le long de la côte méditerranéenne ou en Bretagne (les plages de poche), au fond de petites baies presque fermées et sans marée où le sable est peu abondant et trop grossier pour être mobilisé par le vent. Par contre, il est très rare de trouver une dune littorale sans plage sableuse adjacente. Lorsque cela existe, comme sur la rive sud-est de l'isthme de Courlande en Lituanie, le sable dunaire provient de dépôts morainiques abandonnés par les glaciers il y a plus de 20000 ans. En dehors de ces exceptions, la dune est indissociable de la plage : elle naît du sable de la plage. Encore faut-il qu'une troisième étape soit franchie : le sable transporté par le vent doit se redéposer pour former la dune. On expliquera ci-après le rôle décisif de la végétation dans ce processus de piégeage.

Si la dune a besoin de la plage pour naître et se développer, la plage se nourrit de la dune pour perdurer et résister aux assauts de la mer. Pendant les tempêtes, la dune va lui restituer du sable qu'elle aura provisoirement mis en réserve. Ces échanges de sable sont essentiels à la "bonne santé " du couple plagedune, par essence extrêmement mobile, et ils se traduisent sur le terrain par une remarquable mobilité paysagère qui sera analysée dans ce guide. C'est un perpétuel combat entre la mer, le vent et la végétation.

Dans cette lutte incessante qui met aux prises des acteurs "naturels ", I'homme n'est pas inactif : il agit parfois inconsciemment, sans réfléchir aux conséquences, mais il cherche de plus en plus à contrôler les éléments. La réalité et l'importance des déplacements et des échanges de sable ont été longtemps sous-estimées, voire ignorées, ce qui a engendré des mauvaises pratiques, provoquant ou aggravant une pénurie de sable et la disparition de la plage et de la dune. Tout cet aspect sera analysé dans la troisième partie, mais il faut souligner ici que toute bonne gestion des dunes littorales nécessite une bonne connaissance de leur fonctionnement, en association avec les plages, mais aussi avec les ressources sableuses en mer. Les recherches se sont intensifiées ces dernières années pour essayer de quantifier les transferts de sable dans le système côtier et d'évaluer le bilan sédimentaire à l'intérieur d'un compartiment qu'on appelle la " cellule sédimentaire* ». L'autre thème majeur des recherches, étroitement lié au bilan sédimentaire, concerne la mobilité du trait de côte*, ses indicateurs et les techniques et modalités de suivi.

Tous ceux qui se sont promenés sur le terrain à travers le monde ont pu constater que les dunes littorales sont extraordinairement variées dans leur morphologie, leur couverture végétale, leur degré de mobilité. Cela fait partie de leur attrait. Pour apprécier l'ampleur de cette diversité, il suffit de parcourir les façades littorales françaises, métropolitaines et ultramarines, qui offrent toute la palette des dunes littorales existant à travers le monde. On essaiera ci-après d'en proposer une typologie raisonnée.

Ce chapitre 1 est un préalable indispensable pour comprendre les conséquences des usages que l'homme a fait et veut faire de la dune (chapitre 2). Longtemps ignorée, voire considérée comme un espace malsain, la dune a brusquement pris une nouvelle valeur quand le tourisme balnéaire s'est développé à partir du XIXe siècle, et cela a continué jusque dans les années 1970-1980. Cet espace délaissé est devenu un espace convoité aisément constructible, recherché pour sa proximité avec la mer. Il fallait bâtir le plus près possible de la plage, donc sur la dune. Mais en sacrifiant la dune, nous n'avons pas vu qu'on menaçait aussi la plage. Les temps ont changé, le rôle de la dune est désormais mieux compris et de nouvelles pratiques sont à rechercher (chapitre 3). 


\section{La naissance}

Tout commence sur la plage, là où la mer a accumulé du sable. Dès qu'un souffle de vent apparaît, selon la taille du sable et son humidité, des grains peuvent rouler et se déplacer. Si le vent est plus puissant, des grains vont décoller du sol, être projetés de quelques centimètres, voire de quelques décimètres, et retomber plus loin : c'est la saltation* qui crée des rides de sable de taille centimétrique. Pour un sable sec de taille moyenne (250 microns), un vent de 5 à $6 \mathrm{~m} / \mathrm{s}$ suffit pour provoquer ces sauts de puce. Si le vent forcit, les grains vont rester plus longtemps en suspension dans l'air et se déplacer de plusieurs mètres, créant non pas des rides centimétriques mais des croissants plurimétriques (figure 1.1). En cas de gros coups de vent, un vent de sable se forme, soulevant suffisamment les grains pour aveugler un individu de taille normale et capable de déplacer des volumes énormes de sable en quelques heures (le temps d'un cycle journalier de marée) en créant des bourrelets d'accumulation en haut de plage (figure 1.2). Grâce à leur orientation, leur profil et leur taille, les rides et les croissants de sable éoliens (qu'il ne faut pas confondre avec les formes voisines créées dans l'eau par les courants et les vagues) sont pour un observateur averti les meilleurs indicateurs de la direction et de la vitesse du vent pendant sa dernière période d'activité (figure 1.3). Ce sont des enregistrements extrêmement précieux permettant de reconstituer la dernière séquence venteuse sur les hauts de plage et dans les couloirs transversaux des dunes côtières : le vent rebondit d'un mur à l'autre du couloir faisant se juxtaposer secteurs d'accumulation et secteur d'érosion mécanique (ou « corrasion »). Tout cela tient de la mécanique des fluides, mais une observation fine du terrain peut donner des résultats fiables et complémentaires à des enregistrements aérométriques sophistiqués, généralement de courte durée et délicats à réaliser en cas de gros coup de vent. II faut souligner la très grande discontinuité de l'action du vent sur une plage de sable : I'essentiel du déplacement du sable se déroule sur de courtes périodes séparées par de longues phases de répit.

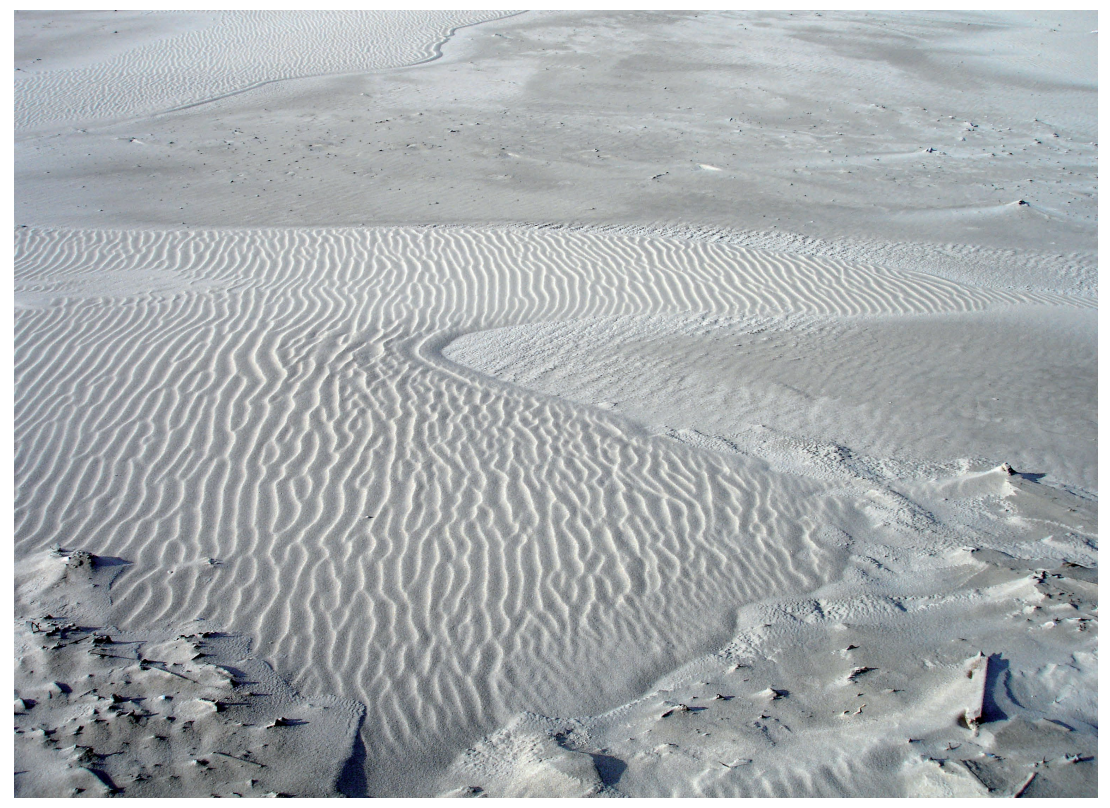

Figure 1.1. Rides et croissants de plage. C Y. Battiau-Queney/EUCC-France. 


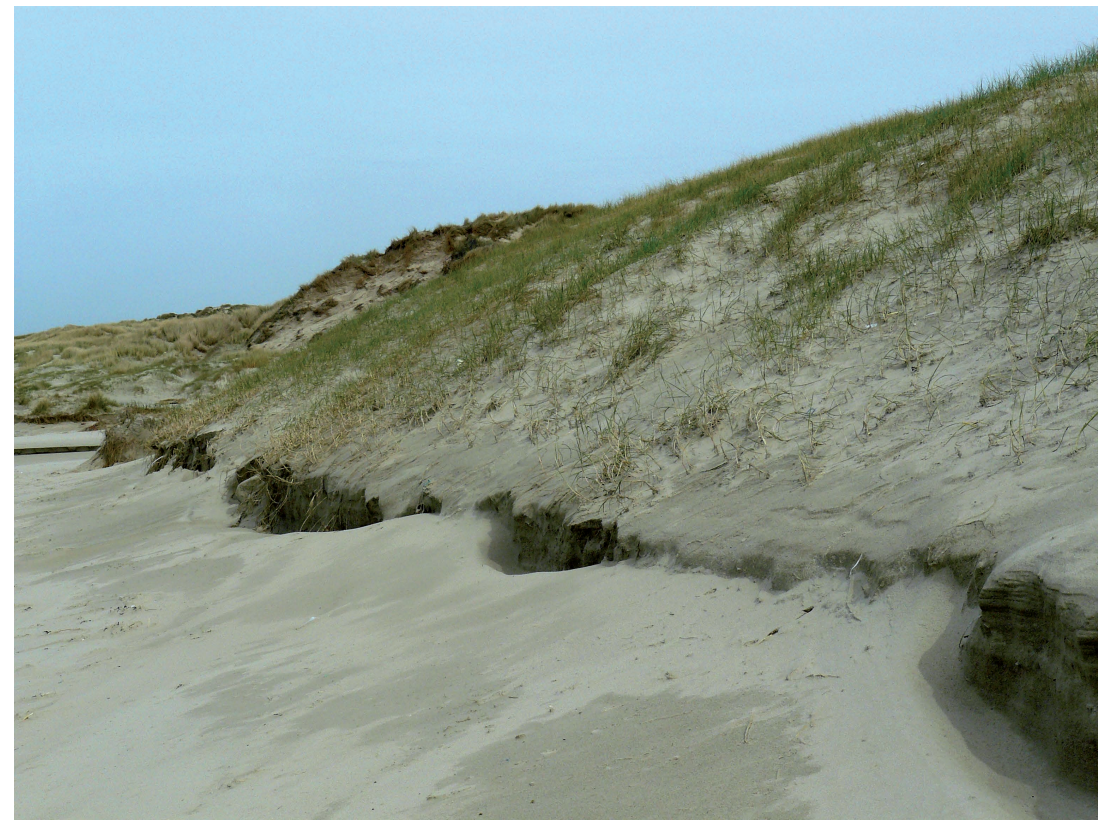

Figure 1.2. Bourrelet d'accumulation en haut de plage.

(C) Y. Battiau-Queney/EUCC-France.

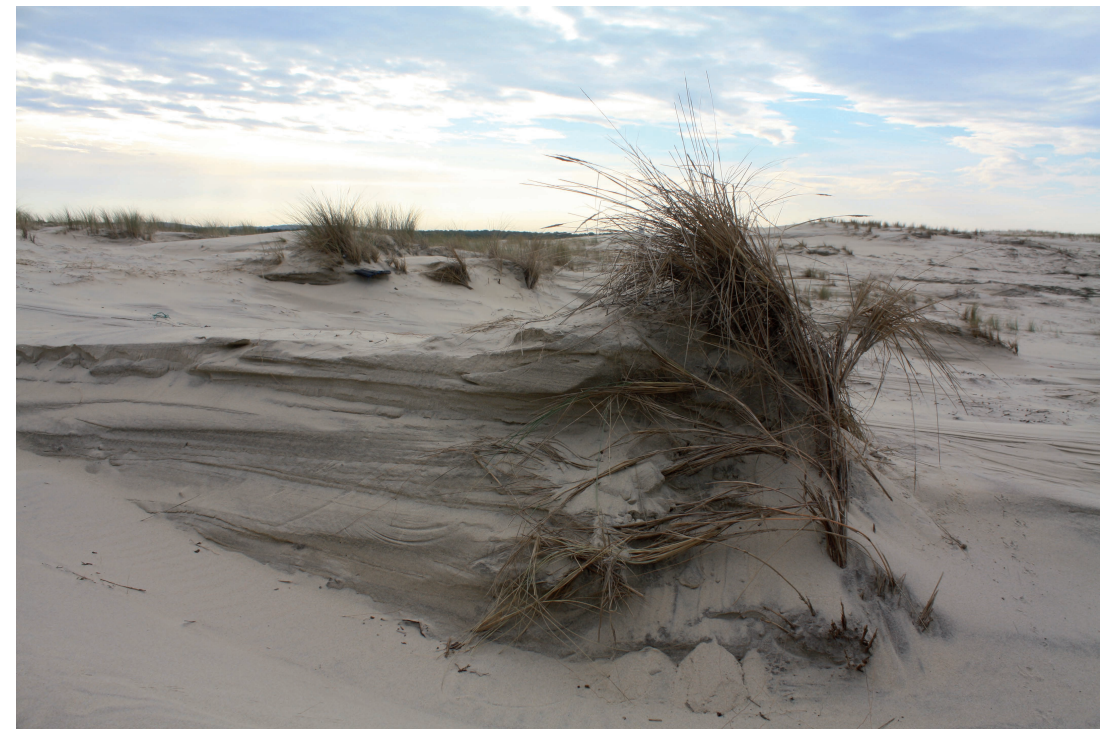

Figure 1.3. Rides formées par le vent.

(C) L. Gouguet/ONF.

À ce stade, il n’y a pas encore de dune. Celle-ci naît lorsque le sable soufflé par le vent est piégé au sol par des laisses de mer*, des paquets d'algues, des bois flottés ou une touffe de végétation. Les modalités pratiques sont variées. Il faut insister sur le fait que le vent est un aspirateur sélectif : il va soulever les grains les plus légers et laisser au sol les particules plus grossières. Un bel exemple de tri éolien caractérise les plages de sable coquillier de la côte normande 
à l'ouest de Cabourg ou celles du Fort-Vert à l'est de Calais. Il se crée un pavage de particules grossières (coquilles surtout) tandis que le sable plus fin forme des monticules qui sont des dunes embryonnaires naissantes vite colonisées par des plantes pionnières (figure 1.4).

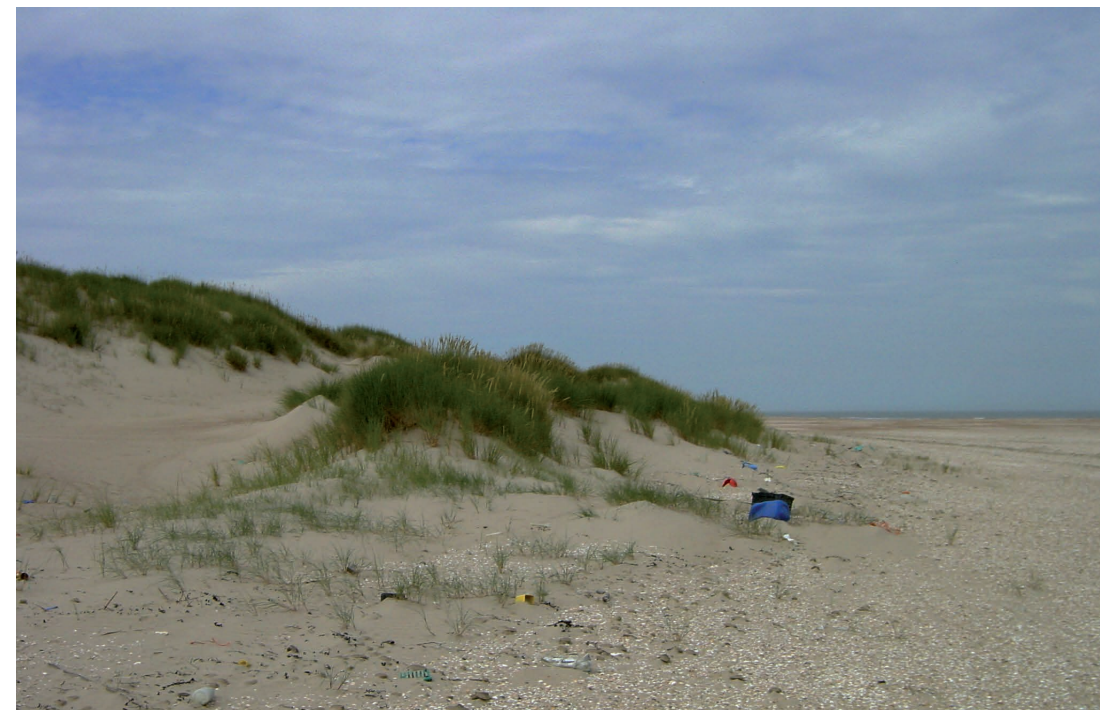

Figure 1.4. Le vent a trié les sédiments.

(c) Y. Battiau-Queney/EUCC-France.

Avec un sable plus homogène, les premières dunes élémentaires se forment sur la plage, au-dessus de la laisse de mer. Dans ce dernier cas, la dune naît et grossit avec la plante qui lui sert de support. Ce peut être un pied de Cakile maritima ou des touffes d'Elytrigia juncea (figure 1.5). Par coalescence, ces dunes élémentaires vont donner une banquette*, puis une véritable avantdune*. Cependant, l'espérance de vie d'une dune embryonnaire est très aléatoire : elle peut être détruite par une grande marée ou/et une tempête quelques jours après sa naissance ; mais elle peut aussi perdurer plusieurs semaines, voire plusieurs mois, et se consolider en avant-dune d'abord naissante, puis bien établie. La séquence dune embryonnaire, banquette et avant-dune n'a rien de linéaire. Comme tout ce qui se passe sur la plage, l'évolution de la dune associée est à la merci de phénomènes prévisibles pour les uns (cycle de la marée) et aléatoires pour les autres (événements tempétueux). C'est pour cela qu'il est très difficile de modéliser une telle séquence. On peut seulement imaginer des scénarios d'évolution selon l'occurrence et la fréquence des tempêtes.

Retenons de ce qui précède que le haut de plage (au-dessus des laisses de mer) est un espace essentiel à la formation des dunes et que toute intervention peut retarder voire empêcher leur naissance. Il est impératif de sensibiliser usagers et gestionnaires des plages à la fragilité de ce domaine particulièrement convoité.

\section{Les phénomènes naturels en jeu}

Yann Deniaud

Les cordons dunaires côtiers sont des accumulations sédimentaires qui résultent d'un processus de transport et de sélection des matériaux sous les actions combinées de phénomènes hydrodynamiques maritimes, puis éoliens. Leurs 

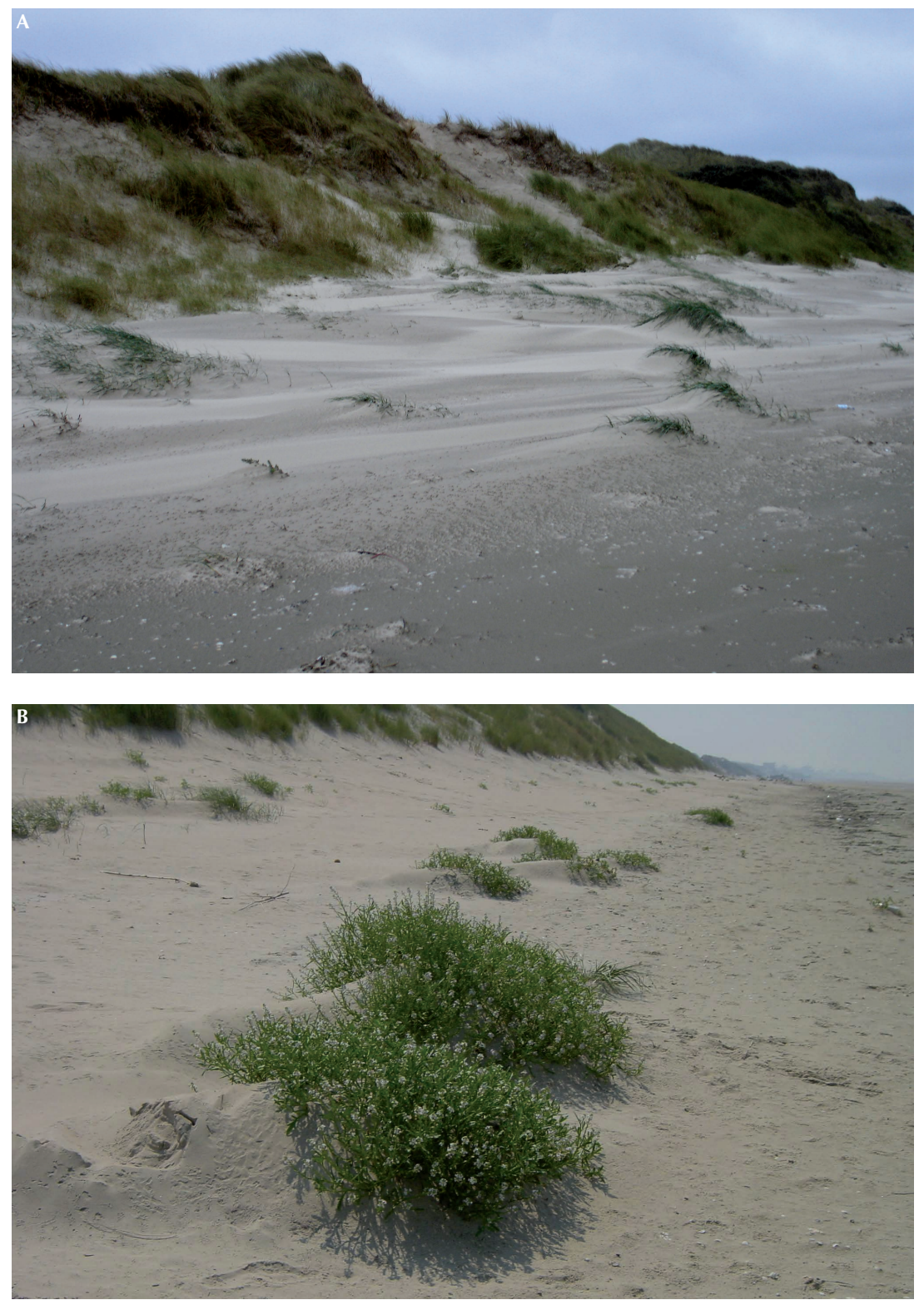

Figure 1.5. A. Touffes d'Elytrigia juncea. B. Le Cakile maritima piège le sable. C Y. Battiau-Queney/EUCC-France.

évolutions sont en relation directe avec la nature, la morphologie et l'évolution des plages qui les bordent et avec lesquelles ils constituent un système morphodynamique en continuelle adaptation.

Le principe de formation est le suivant : la mer apporte du sable, qui est transporté par le vent et piégé par la végétation. Mais ce processus requiert des conditions particulières sur lesquelles nous allons revenir :

- I'action de la mer ;

- I'action du vent ;

- I'action de la végétation. 


\section{Le rôle de la mer dans le transport des sédiments à la côte}

Les profils des plages et des petits fonds dépendent de nombreux paramètres, et notamment des caractéristiques des houles*, de la granulométrie des sédiments*, de la force et de la direction des vents, de la morphologie générale des fonds et de la topographie.

Les sédiments apportés par les fleuves ou issus de l'érosion des côtes rocheuses et de la production biologique (fragments coquilliers) sont redistribués le long des rivages sous l'effet des processus hydrodynamiques. Les houles et les courants opèrent un tri granulométrique entre la côte et le large. Les sédiments les plus fins sont entraînés à des profondeurs d'autant plus grandes que leur vitesse de chute dans la colonne d'eau est faible et que les houles et les courants sont forts.

Au large des zones de déferlements des vagues, lorsque les mouvements orbitaux de la houle sont supérieurs au seuil critique de mise en mouvement, ils génèrent des déplacements alternatifs et un brassage des sédiments sur place (figure 1.6). Ces mouvements sont sensibles à des profondeurs proportionnelles à la hauteur et à la période des vagues et inversement proportionnelle à la granulométrie des particules sédimentaires.

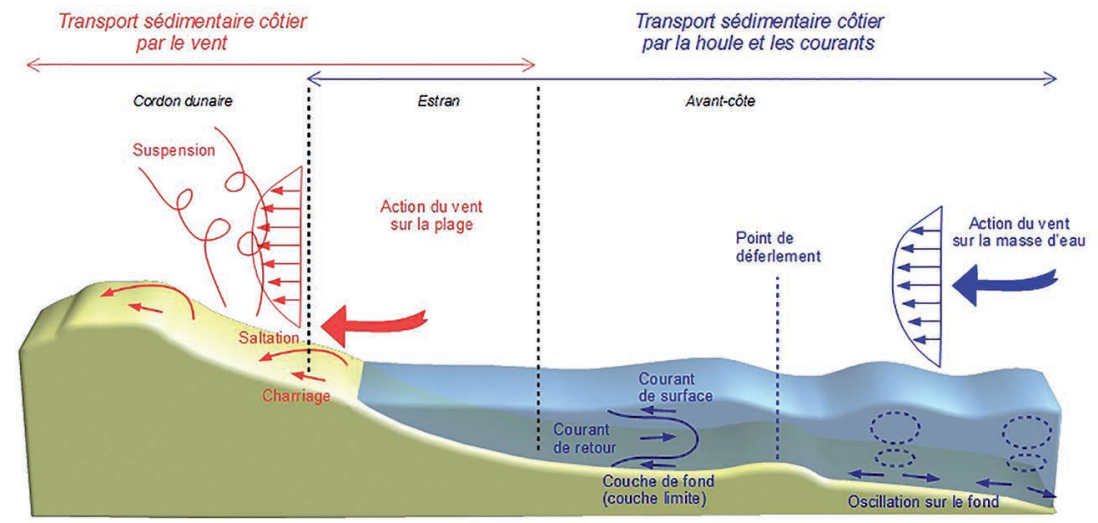

Figure 1.6. Déplacement des sédiments par la houle et le vent. Source : R. Perrot/ONF d'après Deniaud/Cerema.

Au large, la houle a peu d'effet sur le transport de sédiments : ceux qui sont mis en mouvement (car n'étant pas situés trop profondément) n'arrivent pas à la côte.

Le déplacement des matériaux perpendiculairement au rivage dépend de I'importance et de la répartition des courants dans la colonne d'eau.

Suivant les cas, les sédiments brassés par la houle à proximité du fond peuvent subir un transport net vers la côte par charriage* et saltation dans la couche limite de fond, tandis que les particules remises en suspension sont susceptibles d'être évacuées vers le large sous l'effet des courants de compensation ou de retour se développant en milieu de colonne d'eau.

Dans la zone de déferlement et dans les petits fonds, les lames déferlantes génèrent des apports d'eau à la côte contrebalancés par des courants de retour sur le fond ou concentrés en des points particuliers et réguliers du rivage sous la forme de courants très rapides ("rip-current» ayant des vitesses de plusieurs mètres par seconde) (figure 1.7). Le point 
de déferlement constitue un point de convergence sédimentaire entre les phénomènes au large et au niveau de la côte. À son niveau, peuvent se former des barres sous-marines dont l'importance dépendra notamment du type de déferlement, de la pente des fonds et de la hauteur relative de la houle au point de déferlement.

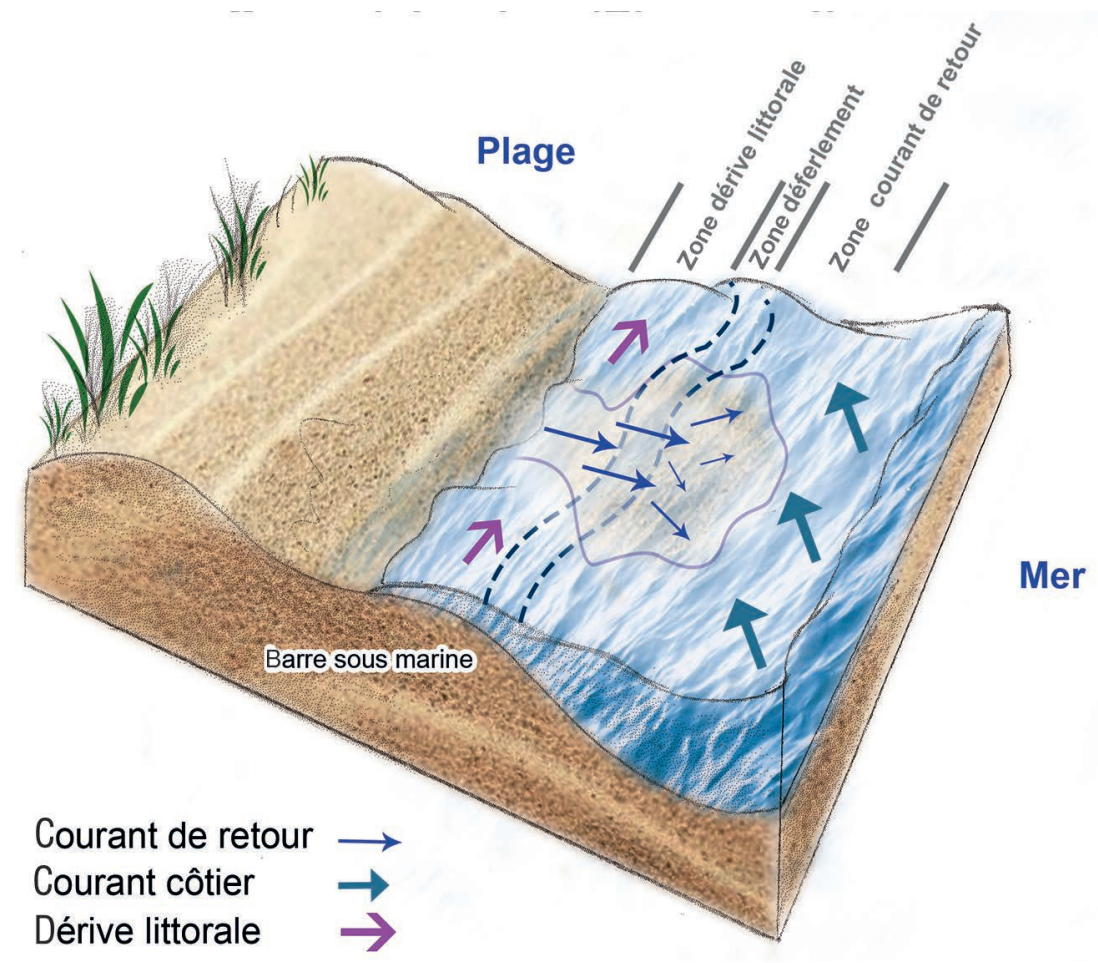

Figure 1.7. Les courants de retour (rip-current).

Source : R. Perrot/ ONF d'après Deniaud/Cerema.

Lorsque la houle est oblique au rivage, un courant de dérive littorale* se développe parallèlement au rivage entre le point de déferlement et la côte. II entraîne les matériaux en suspension ou par charriage, suivant leurs caractéristiques granulométriques. L'intensité de ce courant est proportionnelle aux vagues incidentes. Il atteint son maximum à proximité des barres* sous-marines et décroît vers la côte où un transport sédimentaire en dent de scie est généré par la montée des vagues sur l'estran* et leur retrait suivant la ligne de plus grande pente.

Au cours du temps, les variations de direction et d'intensité des houles transforment les profils des plages et la forme des rivages, en modifiant les conditions $\mathrm{d}^{\prime}$ actions des houles sur le fond et les mouvements sédimentaires associés.

Au cours des tempêtes, les actions des houles et des courants se cumulent et peuvent provoquer des mouvements sédimentaires de grande ampleur vers le large, notamment si les matériaux sont fins et peu cohésifs. Les profils topographiques des plages tendent alors à devenir concaves en se raidissant à la côte (la plage s'abaisse). En périodes de faibles conditions hydrodynamiques, les mouvements sédimentaires favorisent l'accumulation des matériaux à la côte et l'engraissement* progressif des plages dont le profil devient convexe (la plage se relève). 


\section{Le rôle du vent}

Les sédiments apportés par la mer et les vagues sur les plages sont remaniés et transportés par charriage, saltation ou suspension sous l'action turbulente des vents. Les volumes transportés dépendent d'abord de la vitesse du vent et des caractéristiques des matériaux (forme, masse volumique), mais de nombreux autres paramètres interviennent également dans le processus, dont l'humidité de l'air, la teneur en eau du sable, l'ensoleillement, la surface de plage exposée au vent, la couverture végétale, la teneur en sel du sol (croûte formée par le sel). Les transports éoliens seront donc tributaires des conditions climatiques, telles que la pluie, la rosée, la température..., et océanographiques, telles que la marée, les surélévations météorologiques, les embruns... Ces paramètres tendront à réduire les transports éoliens mesurables sur des sables parfaitement secs, parfois dans des proportions pouvant aller de 1 à 5 .

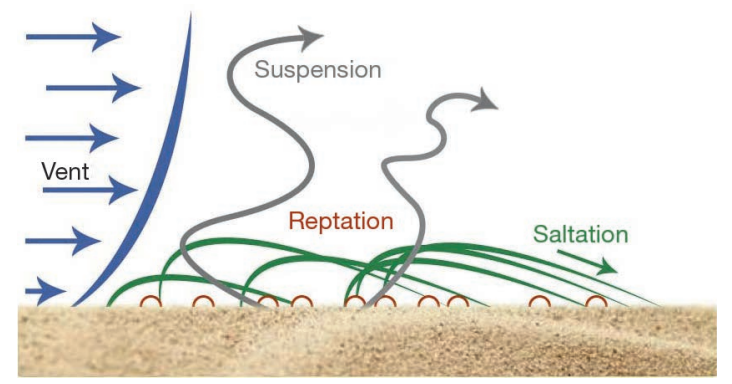

Figure 1.8. Les modes de transport des particules par le vent. Source : R. Perrot/ ONF d'après Y. Reffet.

Les particules sédimentaires se mettent en mouvement lorsque les forces de cisaillement ou de dépression exercées par les vents sont supérieures à la gravité et aux forces de cohésion des matériaux. On considère généralement que le vent doit avoir une vitesse minimale de 4 à 5 mètres par seconde sur la côte atlantique pour mettre le sable en mouvement (force 4 Beaufort). La vitesse limite de mise en mouvement est alors atteinte et les particules décollent et entrent en saltation. Un nuage de grains se propage sur la surface. Les particules suivent une trajectoire parabolique accélérée horizontalement par le vent. À l'impact au sol, elles transmettent une quantité de mouvement à d'autres particules, participant ainsi à leur mise en mouvement dans un processus de saltation successive ou de reptation* à proximité de la surface. Le nombre de grains en mouvement croît alors rapidement. Le flux de masse du transport est maximum à proximité de la surface et décroît rapidement avec l'altitude.

La végétation joue un rôle essentiel dans l'accumulation sédimentaire et la formation des cordons dunaires. Elle génère une couche limite à proximité immédiate du sol, où la vitesse des vents s'annule et favorise les dépôts.

La direction du vent est aussi un élément déterminant : un vent transgressif (perpendiculaire au trait de côte) prélèvera moins de sable sur la plage, et plus au versant externe du cordon, alors qu'un vent latéral (parallèle au trait de côte) permettra des transports de sable sur la plage sèche plus importants, facilitant des accumulations sur le pied de dune (coin sableux).

Comme pour les plages, la morphologie des cordons est un équilibre dynamique façonné et dépendant des variations des taux de transports, et donc des directions et de l'intensité des vents, dans l'espace et dans le temps. 
Durant la saison hivernale où les tempêtes sont fréquentes, les plages et leurs cordons dunaires bordiers sont déstabilisés et érodés par les houles et les turbulences éoliennes. L'étalement des matériaux sur l'avant-plage et dans les barres de tempête favorise alors le déferlement des vagues et l'atténuation de l'énergie incidente sur les plages, dans un phénomène naturel d'auto-adaptation des formes littorales.

Durant la saison estivale, les faibles houles et le jet de rive ramènent progressivement au rivage les particules sédimentaires. Les vents réguliers en provenance de la mer les entraînent vers les cordons dunaires bordiers où la végétation favorise leur sédimentation.

Le système plage-dune constitue ainsi un système morpho-sédimentaire en équilibre dynamique soumis à une évolution permanente et façonné par les conditions hydro-météorologiques et les formes qui résultent des dynamiques antérieures.

\title{
Le fonctionnement du système plage-dune : le bilan sédimentaire
}

\author{
Franck Desmazes et Manuel Garcin
}

La dune n'est pas un élément isolé mais s'inscrit dans un système sédimentaire plus vaste, qui comprend l'avant-plage, la plage et la dune elle-même. Pour comprendre le fonctionnement de ce système sédimentaire, et donc replacer la gestion des dunes dans son contexte plus global, plusieurs notions sont capitales : il s'agit de celles de cellule sédimentaire et de bilan sédimentaire. De même, il faut savoir replacer les phénomènes qui interagissent sur les dunes dans une échelle de temps, afin de suivre les évolutions globales.

\section{Les bilans sédimentaires}

\section{CONCEPTS}

Une cellule sédimentaire côtière peut être définie comme un système naturel ouvert formé par un segment de trait de côte allant de plusieurs centaines de mètres à plusieurs dizaines de kilomètres d'extension, les zones côtières associées et des flux d'énergie et de sédiments. Les cellules sédimentaires côtières sont délimitées par des frontières plus ou moins fixes (cap rocheux, estuaires, etc.) et perméables aux échanges sédimentaires (figure 1.9).

Si la cellule est au moins partiellement confinée, les mesures de gestion prises dans la cellule n'affecteront que faiblement les cellules voisines. Inversement, si la cellule a des échanges sédimentaires importants avec les cellules adjacentes, les mesures de gestion auront des répercussions importantes sur celles-ci. Toute action de gestion sur un segment de côte doit donc prendre en compte ces effets potentiels. Quels que soient les fonctionnements spécifiques des milieux littoraux meubles, les cellules sédimentaires côtières constituent des unités de gestion hydro-sédimentaires cohérentes pour l'étude et la mise en œuvre de projet de développement durable du littoral (MEEDDM, 2010 ; Desmazes et al., 2015).

Dans le cas d'un système littoral sableux en équilibre dynamique, la morphologie des structures sédimentaires qui le constituent évolue en permanence pour s'adapter aux variations des conditions environnementales. Des cycles évolutifs peuvent être observés à différentes échelles temporelles (saisonnières, annuelles, pluriannuelles). Des transferts entre les différents 


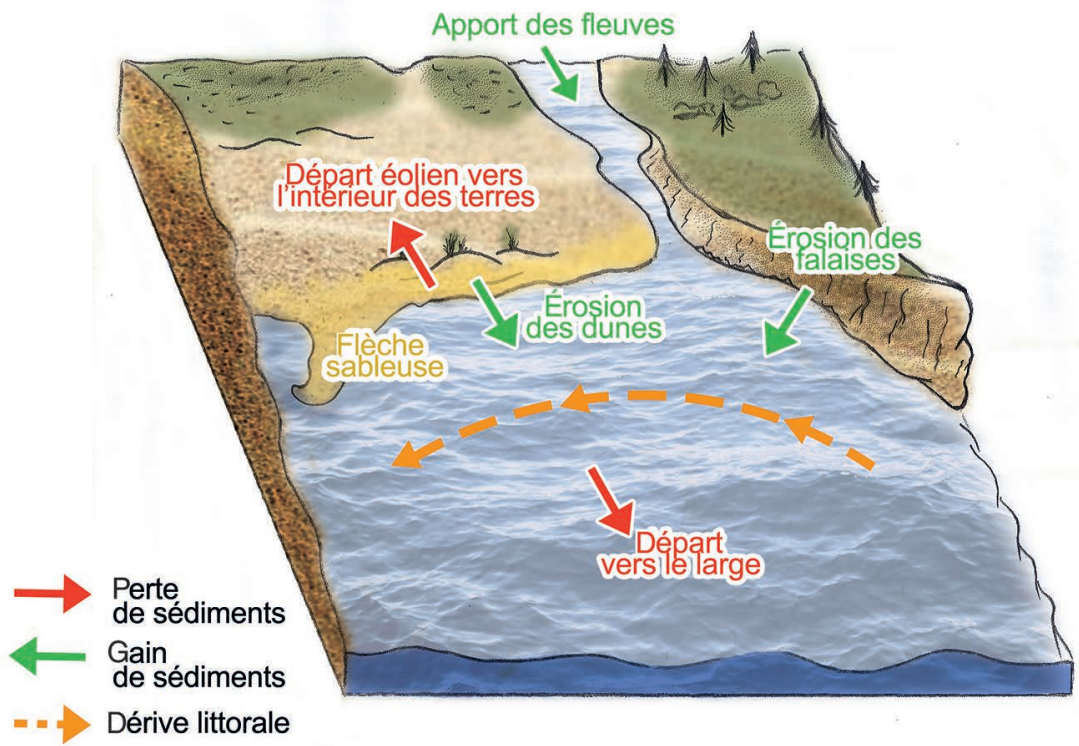

Figure 1.9. Les échanges dans une cellule sédimentaire.

Source : R. Perrot/ONF.

compartiments (terrestres ou marins) peuvent se produire. Cependant, le volume total de sédiments reste stable dans le temps, car les flux entrants dans la cellule littorale sont équivalents aux flux sortants : son bilan sédimentaire est équilibré (figure 1.10a).

Les phénomènes d'érosion chronique, de recul régulier du trait de côte, d'abaissement de l'altitude des plages et de dégradation progressive de la dune bordière à l'échelle de la cellule côtière sont liés à des déficits de sédiments.

Un bilan sédimentaire est négatif si les flux de sédiments entrants sont inférieurs aux flux sortants de la cellule (figure 1.10b). Plusieurs facteurs peuvent expliquer

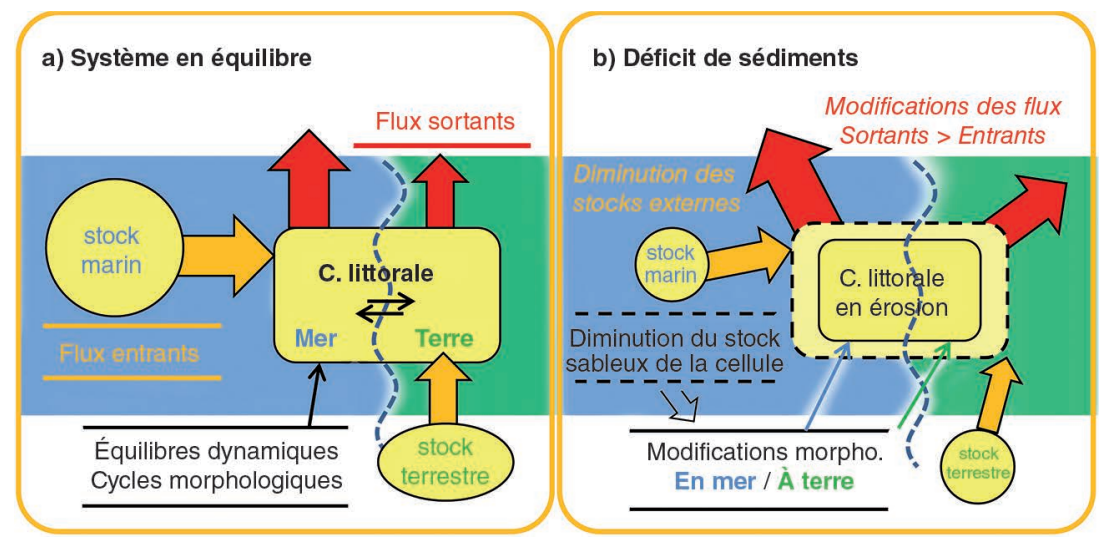

Figure 1.10. Stocks et flux de sédiments au sein d'une cellule sédimentaire en équilibre et en érosion.

À partir d'un système littoral en équilibre dynamique (a), la réduction des stocks de sédiments et les modifications de flux sédimentaires peuvent expliquer les phénomènes d'érosion de la cellule littorale, à terre (dune) et/ou en mer (plage) (b).

Source : BRGM. 
I'évolution de ces flux : la modification sensible des conditions de forçage (vent, courants, houles, fréquence des événements extrêmes) ou la disponibilité des sédiments dans les stocks qui alimentent la cellule littorale (en mer, à terre et dans les cellules adjacentes).

Lorsque les volumes de sédiments qui sortent du système deviennent plus importants que les volumes entrants, le stock sableux de la cellule sédimentaire diminue. L'état du système change alors et passe d'un stade d'équilibre dynamique au déséquilibre. Cette nouvelle condition provoque une adaptation du milieu avec une augmentation de l'érosion littorale qui engendre des modifications morphologiques.

Afin de mettre en œuvre des mesures de gestion adaptées, il est nécessaire de diagnostiquer l'état de la cellule sédimentaire (équilibre dynamique, excédent ou déficit sédimentaire). Le système côtier doit être étudié dans sa globalité, en définissant localement les limites spatiales des cellules sédimentaires et en établissant le bilan sédimentaire de chacune d'elles.

La réalisation du bilan sédimentaire consiste à quantifier les flux de sédiments de chaque compartiment du système littoral. L'analyse doit donc porter aussi bien sur la zone émergée, qui inclut la dune, que sur les domaines marin et intertidal, qui incluent la plage. La connaissance de l'état du système nécessite $d^{\prime}$ une part de suivre régulièrement le stock sableux de la cellule et d'autre part les modifications morphologiques.

À ce jour, la réalisation d'un bilan sédimentaire réaliste et le diagnostic de l'état morpho-sédimentaire à l'échelle d'une cellule côtière sont encore des challenges techniques. Les défis scientifiques sont liés notamment à la détermination des échelles temporelles auxquelles doit être fait le diagnostic pour chaque composante du système ainsi qu'à la quantification des stocks et des flux. Ces éléments doivent de surcroît être mis en relation avec les différents processus dynamiques en action.

\section{ÉVOLUTION DES DUNES BORDIĖRES EN LIEN AVEC LE BILAN SÉDIMENTAIRE}

Le modèle conceptuel de fonctionnement du littoral de Psuty (2004) met en relation le bilan sédimentaire global du système littoral avec le développement morphologique des dunes bordières.

Ce modèle définit une cellule sédimentaire théorique alimentée en sable par une embouchure fluviale et affectée par une dérive littorale induite par un régime dominant de vagues. Le long de cette côte, il définit une succession continue de morphologies de dunes bordières (figure 1.11):

- au niveau de l'embouchure, I'alimentation en sable est importante et montre une succession de rides dunaires parallèles à la côte, dont la hauteur et la largeur sont faibles ;

- en s'éloignant de l'embouchure, le nombre de rides dunaires diminue progressivement jusqu'à former une unique dune bordière linéaire et de large dimension ;

- plus en aval de la dérive littorale, la dune bordière linéaire devient plus sensible à l'action éolienne et prend la forme d'une succession de dunes paraboliques* ;

- à plus grande distance encore de la source de sédiment, les dunes paraboliques disparaissent ponctuellement; elles sont alors remplacées par des épandages sableux qui se mettent en place lors des tempêtes ou par des buttes résiduelles qui marquent l'emplacement des anciennes dunes paraboliques. 


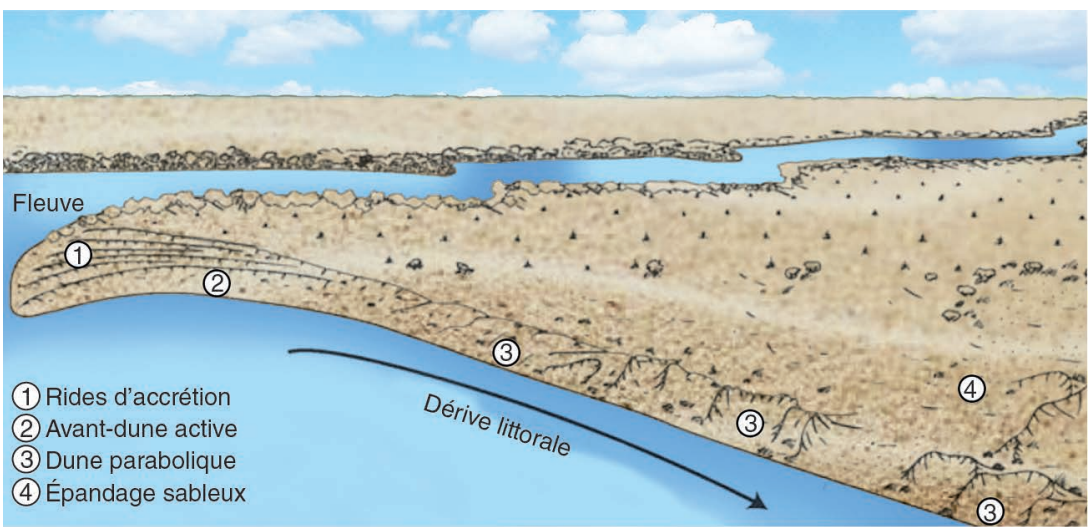

Figure 1.11. Continuum de morphologies dunaires d'un littoral sableux linéaire dominé par la houle, en aval d'une embouchure fluviale sableuse.

Source : R. Perrot/ONF d'après Psuty (2004).

Cette séquence morphologique théorique est utilisée pour illustrer l'évolution du bilan sédimentaire de la dune par rapport à celui de la plage et décrire le développement naturel des dunes littorales (figure 1.12) :

- localisation $\mathrm{n}^{\circ} 1$ : aux abords de l'embouchure et de la source sédimentaire sableuse, une plage large et engraissée se développe. Son bilan sédimentaire est largement positif et la côte est en accrétion*. La hauteur de la dune littorale, située en arrière, reste toutefois limitée car l'avancée du trait de côte est trop rapide pour favoriser le développement d'une large dune littorale.

- Localisation $n^{\circ} 2$ : en s'éloignant de l'embouchure, le bilan sédimentaire de la plage est moins excédentaire. Dans ce contexte, le trait de côte se stabilise, ce qui permet le développement et la mise en place d'une dune littorale plus large et plus haute. Selon le modèle de Psuty, il apparaît qu'un bilan sédimentaire de la plage légèrement déficitaire ne nuit pas nécessairement au

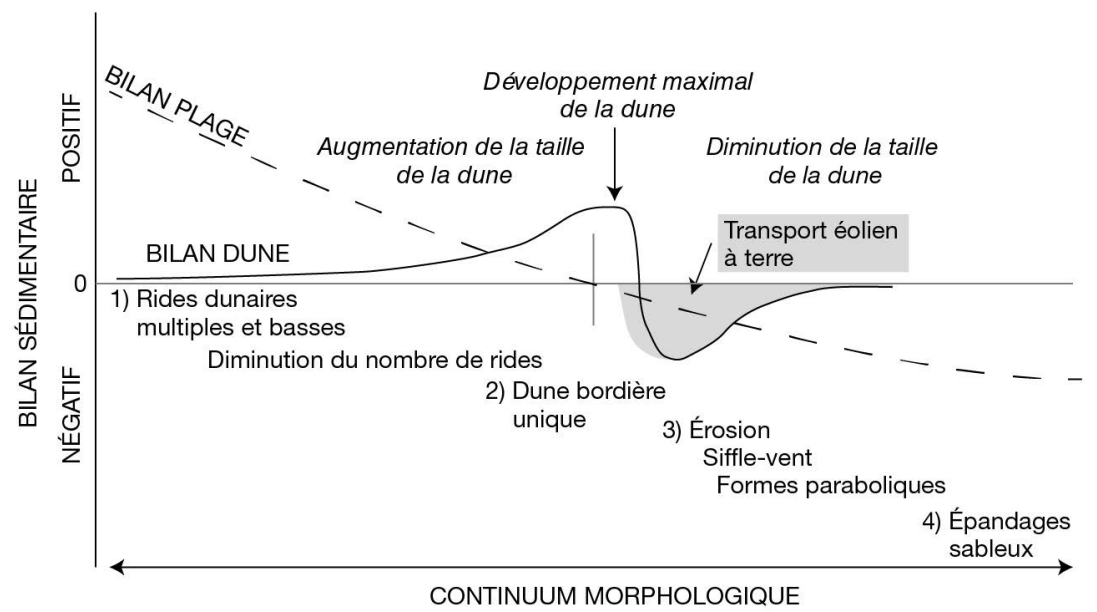

Figure 1.12. Modèle conceptuel reliant le bilan sédimentaire de la plage au bilan sédimentaire de la dune dans le cadre théorique du continuum de morphologies dunaires décrit figure 1.11.

Source : R. Perrot/ONF d'après Psuty (2004). 
développement de la dune car il peut favoriser les dépôts sur la face arrière de la dune par un transport éolien vers la terre.

- Localisation $n^{\circ} 3$ : plus en aval de la dérive littorale, le large développement de la dune peut permettre un fort transfert éolien vers I'arrière-pays, notamment suite à l'apparition et au développement de siffle-vent*. Sur de grandes dunes bien formées, la conjonction d'une plage en déficit sédimentaire et d'un transport éolien efficace de la dune vers l'intérieur des terres peut rapidement affecter le bilan sédimentaire de la dune qui devient négatif. Dans ce cas, la morphologie des dunes évolue, leurs tailles diminuent et elles se transforment en dunes paraboliques.

- Localisation $n^{\circ} 4$ : à plus grande distance de la source de sédiment ou en situation de pénurie de sédiments, les dunes peuvent disparaître ponctuellement au profit de dépôts d'épandages sableux mis en place lors des tempêtes.

\section{Les temps de la mobilité}

La dynamique du milieu littoral est conditionnée par des facteurs capables d'agir sur une large gamme d'échelles spatio-temporelles. De façon schématique, il est admis qu'un lien existe entre l'échelle temporelle d'un phénomène et son emprise spatiale : ainsi, une courte rafale de vent permettra de déplacer de quelques millimètres une ride sableuse éphémère, tandis qu'une très forte tempête pourra impacter durablement l'ensemble d'une façade maritime. Cette approche permet de représenter simplement les échelles spatio-temporelles des principaux phénomènes qui agissent sur les différents éléments du système plage-dune (figure 1.13).

Sur de courtes échelles temporelles (de la seconde aux jours), les vagues, les courants et les marées sont des agents dynamiques capables de modifier des morphologies de petites tailles comme les laisses de mer, la berme* ou plus globalement la forme du haut de plage jusqu'au pied de dune.

À moyen terme (des jours aux années), le vent, les cycles saisonniers et le développement de la végétation sont les principaux processus naturels qui vont conditionner la dynamique des avant-dunes et du front dunaire.

Sur des échelles de temps plus longues (décennale à séculaires), le niveau relatif de la mer, le climat, l'évolution des apports sédimentaires et l'impact des tempêtes majeures sont les facteurs qui influencent la mobilité de l'ensemble du cordon dunaire littoral, voire même l'évolution de massifs dunaires entiers.

La progradation* du littoral est une avancée du trait de côte et des dunes en direction de la mer. Elle est associée soit à des phénomènes d'accrétion liés à un bilan sédimentaire positif, soit à une baisse du niveau relatif de la mer (la baisse du niveau marin ou l'élévation du continent) ou à la conjonction de ces facteurs.

La régression des dunes littorales qualifie un recul du trait de côte et du milieu dunaire vers le continent. Elle est associée aux mouvements géomorphologiques naturels, à un bilan sédimentaire négatif, à une montée du niveau de la mer ou à la conjonction de ces facteurs.

Dans un modèle global d'évolution des dunes littorales, Hesp (2002) présente des séquences de mobilité du front dunaire à court et à moyen terme (figure 1.14). Les différents stades d'évolution du front dunaire détaillés dans la figure 1.14 sont ensuite mis en relation avec des hypothèses de mobilité de l'ensemble du cordon dunaire sur une échelle de temps plus longue (figures $1.15,1.16$ et 1.17). 


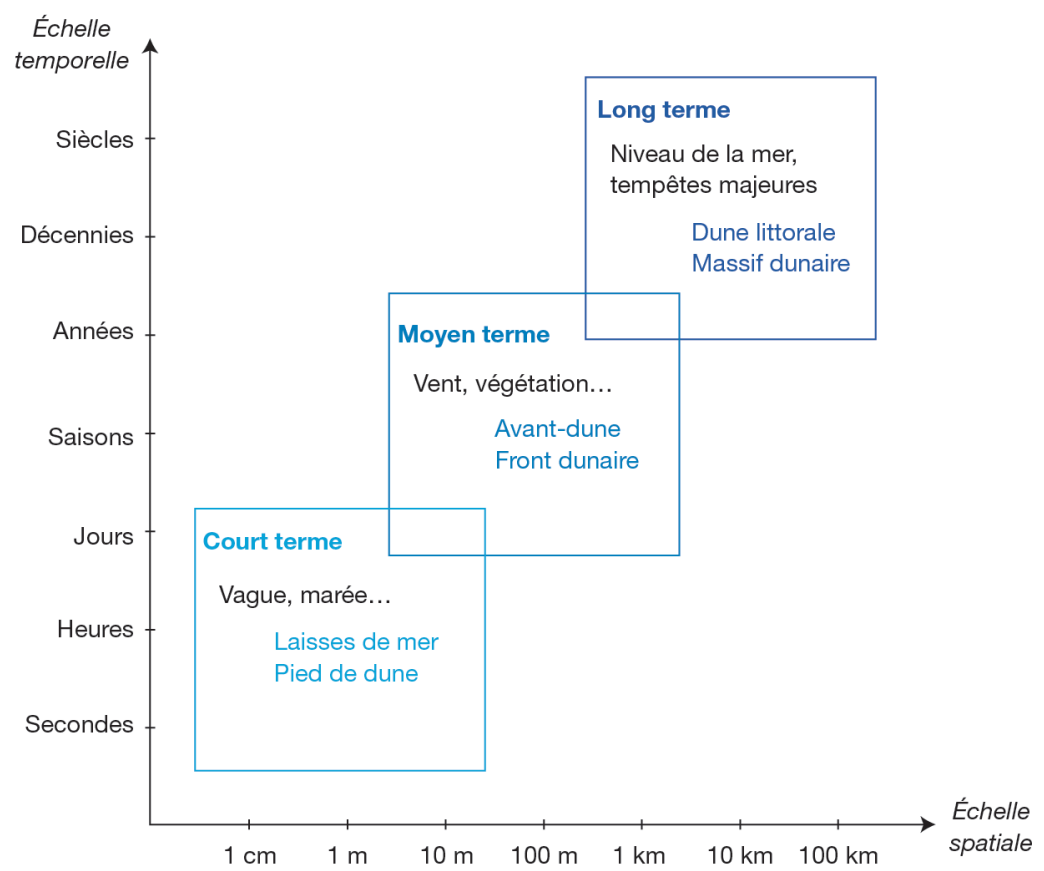

Figure 1.13. Les échelles spatio-temporelles d'évolution des dunes littorales. Source : BRGM.

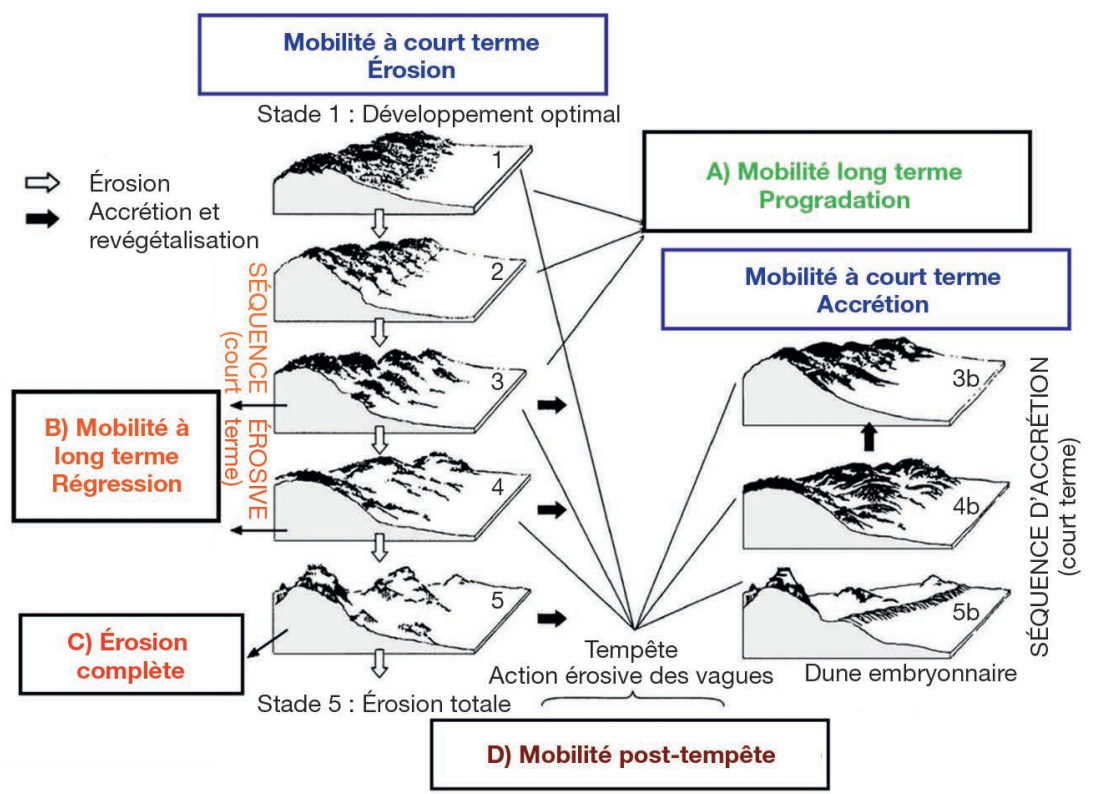

Figure 1.14. Modèle global d'évolution et de mobilité des dunes littorales.

À court terme, la dune est considérée dans une position globalement constante, le modèle présente ces différents stades d'évolutions morphologiques. À long terme, les scénarios intégrant la mobilité de la dune sont présentés pour des situations de progradation (cadre A, figure 1.15) ou de régression (cadres B et C, figure 1.16). Les effets possibles des tempêtes sont pris en compte (cadre D, figure 1.17). Source : modifié d'après Hesp (2002). 
Ce modèle se base sur cinq principaux stades morphologiques qui caractérisent la mobilité du front dunaire. Les différents stades s'étendent entre un état de développement optimal (stade 1 : structure large, linéaire et végétalisée) jusqu'à un état d'érosion quasi complet (stade 5 : épandage sableux et persistance de quelques buttes résiduelles).

En fonction des conditions environnementales qui affectent le système, la séquence érosive des stades 1 à 5 peut se dérouler sur une échelle de temps courte à moyenne (de 1 à 10 ans). Toutefois, ce fonctionnement étant réversible, le passage à une séquence d'accrétion peut intervenir à tout moment. Dans ce cas, on observera le comblement rapide des petites entailles érosives (stade $3 b$ ) ou la végétalisation de zones dégradées plus vastes (stade $4 b$ ). À partir du stade 5 (érosion quasi complète du système dunaire), la séquence d'accrétion débutera nécessairement par l'installation d'une nouvelle structure sédimentaire, la dune embryonnaire (stade $5 b$ ).

Dans le modèle d'évolution à court et moyen terme, les stades 1 à 3 concernent des dunes littorales stables ou en accrétion, pour lesquelles trois scénarios d'évolution à long terme sont envisagés (figures 1.14a et 1.17) :

- scénario A1 : les dunes ont une position stable, mais leur front dunaire et leur crête s'exhaussent; le bilan sédimentaire de la dune est positif ;

- scénario A2 : les dunes sont peu mobiles, leur front dunaire s'exhausse tandis que le pied de dune prograde ; le bilan sédimentaire de la dune est très positif ; - scénario A3 : les dunes sont liées à la progradation rapide de la côte et forment une série de rides dunaires de dimensions modestes. Le bilan sédimentaire de la dune de premier rang est stable, mais il est très positif à l'échelle du champ de rides dunaires.

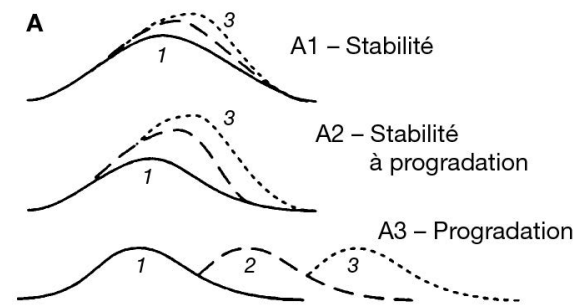

Figure 1.15. Évolution sur le long terme des dunes : exemple de la progradation. Source : modifié d'après Hesp (2002).

Dans le modèle d'évolution à court et moyen terme (figure 1.14), les stades 3 et 4 concernent des dunes littorales stables ou en érosion.

Les scénarios d'évolutions à plus long terme sont présentés dans la figure 1.16 : - scénario B1 : les dunes ont une morphologie stable, mais elles reculent de façon chronique, au rythme de l'évolution du trait de côte ; le bilan sédimentaire de la dune est stable ;

- scénario B2 : le front dunaire est graduellement érodé, mais la position du pied de dune reste globalement stable dans le temps; la crête dunaire peut reculer au niveau des siffle-vent et des entailles d'érosion ; le bilan sédimentaire est négatif ;

- scénario B3 : les dunes sont érodées, marquées par un bilan sédimentaire très négatif ; le recul du pied de dune et de la crête est chronique.

Le stade 5 du modèle d'évolution à court et moyen terme (figure 1.14) caractérise un état d'érosion quasi complet du front dunaire. Le cadre $\mathrm{C}$ de 
la figure 1.16 détaille l'ensemble de cette phase ultime, depuis l'érosion et l'effacement progressif des buttes résiduelles les plus basses, situées à proximité de la plage, jusqu'à l'aplanissement des morphologies plus résistantes, situées en arrière de l'ancien front dunaire. Lorsque toutes les morphologies dunaires ont disparu, il ne reste que des zones planes d'épandages sableux exposées à la déflation* éolienne.
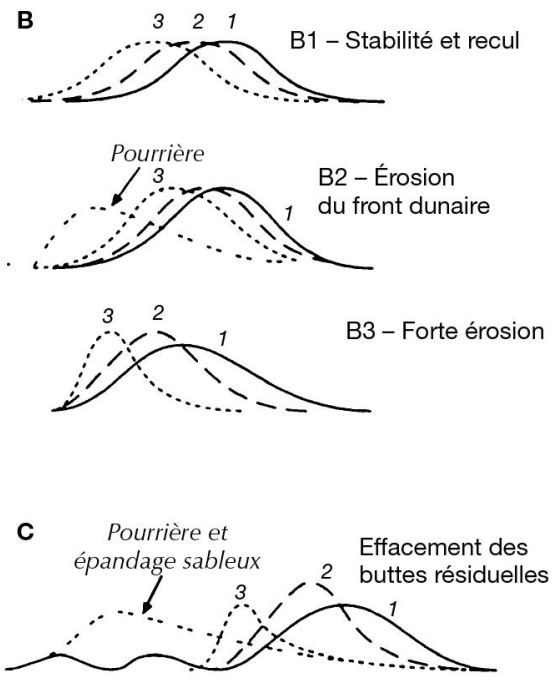

Figure 1.16. Évolution sur le long terme des dunes : exemple de la régression et du stade ultime de l'érosion des dunes.

B. Scénarios de mobilité à long terme : régression. C. Érosion complète. Source : modifié d'après Hesp (2002).

Le modèle conceptuel d'évolution des dunes littorales de Hesp caractérise les phases de mobilité (transgression, régression ou effacement) liées à des phénomènes chroniques qui agissent sur le long terme. Cependant, à très court terme, les tempêtes peuvent à tout moment provoquer des évolutions morphologiques brutales et durables dans le cordon dunaire. La figure 1.17 présente différents scénarios d'évolution post-tempête.

Dans un premier cas, les vagues de tempêtes ont provoqué une érosion majeure du front dunaire et l'apparition d'une falaise dunaire. Deux scénarios d'évolution postérieure peuvent se produire :

- scénario D1 : dans un contexte général de stabilité ou d'accrétion de la côte, le front dunaire se reconstitue lentement à la même position ;

- scénario D2 : dans un contexte de régression chronique, l'érosion générée lors de la tempête favorise la mobilité et le recul de la dune restante.

Dans un second cas, la submersion de la dune a pu provoquer l'érosion complète du cordon dunaire dont la morphologie est " effacée ». En fonction du contexte, deux scénarios d'évolution sont possibles :

- scénario D3 : dans un contexte général de stabilité ou d'accrétion, la dune se reconstruit lentement à la même position ;

- scénario D4 : dans un contexte d'érosion chronique, la dune se reconstruit lentement et en arrière de sa position avant la tempête.

L'observation régulière et fréquente du milieu dunaire permet de suivre et de détailler les séquences évolutives d'érosion et d'accrétion qui affectent 


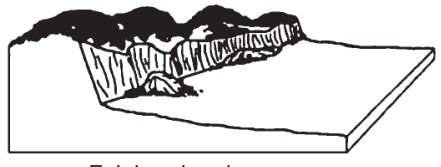

Falaise dunaire
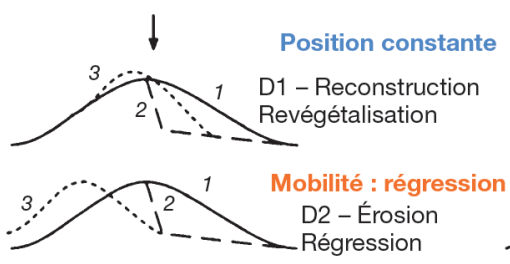

D

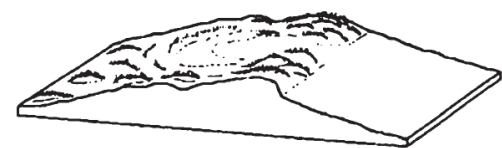

Effets de la submersion ou du débordement par paquets de mer

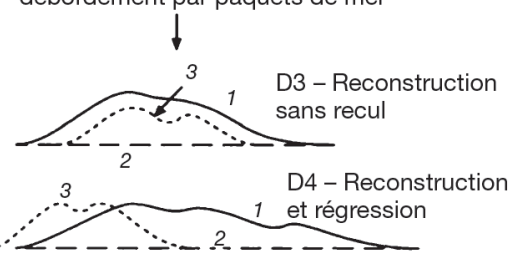

Figure 1.17. Scénarios d'évolution post-tempête. Source : modifié d'après Hesp (2002).

localement les dunes littorales sur de courtes échelles temporelles (figure 1.14). Pour anticiper les mobilités plus importantes et à plus long terme et disposer d'un diagnostic fiable sur l'état de la cellule, il apparaît nécessaire :

- de collecter des observations et des mesures sur des échelles de temps plus longues (plusieurs années à décennies),

- puis de les associer au bilan sédimentaire global de la cellule.

Toutefois, à ce jour, il apparaît encore complexe d'intégrer l'effet des événements extrêmes dans les prévisions d'évolutions chroniques. En effet, les tempêtes génèrent très rapidement $d^{\prime}$ importantes évolutions morphologiques qui, en retour, peuvent modifier le fonctionnement du domaine littoral et du système dunaire sur le long terme. C'est pourquoi une attention toute particulière doit être accordée au suivi et à la compréhension de l'effet des tempêtes exceptionnelles sur le milieu littoral sableux et les dunes (Desmazes et al., 2015 ; DGPR, MEDDE, 2014).

\section{Les différents types de dunes littorales}

Marie-Claire Prat

Les dunes littorales peuvent être étroites ou s'étendre sur plusieurs kilomètres, de la plage vers I'intérieur des terres, comme en Aquitaine, en Charente ou en Picardie. On observe alors plusieurs générations de dunes, formant de véritables massifs dunaires.

Formes d'accumulation éolienne, les dunes littorales présentent des formes différentes selon qu'elles sont naturelles ou semi-naturelles. Dans ce dernier cas, elles sont marquées par les interventions anthropiques qui ont pu modifier les dynamiques naturelles, essentiellement depuis le xIx siècle.

La grande variété des paysages dunaires est liée à cette diversité de formes, engendrée par des contextes morpho-dynamiques différents : géomorphologie des dunes côtières, stocks sableux disponibles, caractéristiques des sables (composition, granulométrie), conditions climatiques locales (direction et intensité des vents). La distance par rapport à la mer, ainsi que la végétation, plus ou moins abondante et pouvant fixer les sables en transit depuis les plages, sont également des paramètres essentiels à prendre en compte.

Basses ou élevées, dénudées ou colonisées par la végétation, les dunes de première ligne jouent un rôle particulièrement important : barrière naturelle 
protégeant de la submersion les terres situées à I'arrière, amortissement de l'énergie marine, réserve de sable pour les plages. S'y ajoute un attrait paysager indéniable.

Pour gérer ces milieux aux fonctionnalités multiples, il est nécessaire dans un premier temps de définir les différentes formes d'accumulations, naturelles ou anthropisées, mais aussi de connaître les éléments morphologiques qui composent ces formations.

\section{Les formes dunaires globales}

Les dunes de première ligne, situées en bordure des plages, peuvent regrouper des formes différentes. Le terme de dune bordière est assez couramment employé, mais il est ambigu car, s'il désigne une dune située immédiatement en arrière de la plage, il peut correspondre à des dunes de différentes origines : formes élémentaires construites autour de touffes de végétation, avant-dunes, dunes profilées par l'homme ou encore dunes anciennes atteintes par le recul du trait de côte.

En arrière des dunes de première ligne, des champs de dunes existent sur certains littoraux ayant disposé, pendant plusieurs millénaires, d'une grande disponibilité en sédiments fins. Le sable, remonté par la mer lors de la dernière transgression marine postglaciaire, a été repris à partir des plages par les vents d'ouest, puissants et réguliers (Aquitaine, Charente, Vendée, Picardie...). Les accumulations dunaires libres correspondent aux dunes formées depuis 5000 ans, avant que I'homme intervienne pour modifier les dynamiques naturelles.

\section{Les dunes de forme libre}

Les dunes élémentaires sont les premières dunes qui se forment en haut de plage. Le sable, repris par le vent, se dépose à l'abri d'un obstacle (bois flotté, épave, touffe de végétation). Une végétation vivace*, comme le chiendent des sables (Agropyrum junceum ou Elytrigia juncea) ou le Cakilier maritime (Cakile maritima), initie le processus d'accumulation du sable (figure 1.18).

Une nebkha, ou nebka* (terme d'origine arabe), est une petite dune (généralement inférieure à $1 \mathrm{~m}$ de hauteur) formée à l'abri d'un obstacle (figure 1.19). Sa durée de vie est très variable, et elle peut disparaître au cours d'une tempête ou d'une forte marée.

En l'absence d'érosion, ces nebkas, alimentées par le sable de la plage, peuvent $\mathrm{s}^{\prime}$ accoler pour former un petit cordon continu. Cette avant-dune embryonnaire est donc une dune de première ligne, formée par l'action du vent qui prélève sur la plage les grains de sable (déflation éolienne) et les dépose ensuite dès que sa vitesse diminue. Seuls les grains fins à moyens sont pris en charge par le vent, qui exerce ainsi une action de tri sur les sédiments de la plage. La dune est donc formée de grains de sable dont la médiane est plus faible que celle des sédiments de la plage.

L'avant-dune se présente sous l'aspect d'un bourrelet parallèle au trait de côte formé par la coalescence de petites dunes élémentaires et séparé de la dune précédente par une dépression. Au printemps, les plantes halo-nitrophiles s'y développent et exercent un effet de peigne, provoquant un nouveau dépôt de sable. L'humidité et l'enrichissement en matière organique par les laisses de mer expliquent la vigueur de cette végétation. Le chiendent des sables, tolérant vis-à-vis du sel, se développe et, grâce à son indice élevé de rugosité, fixe du 


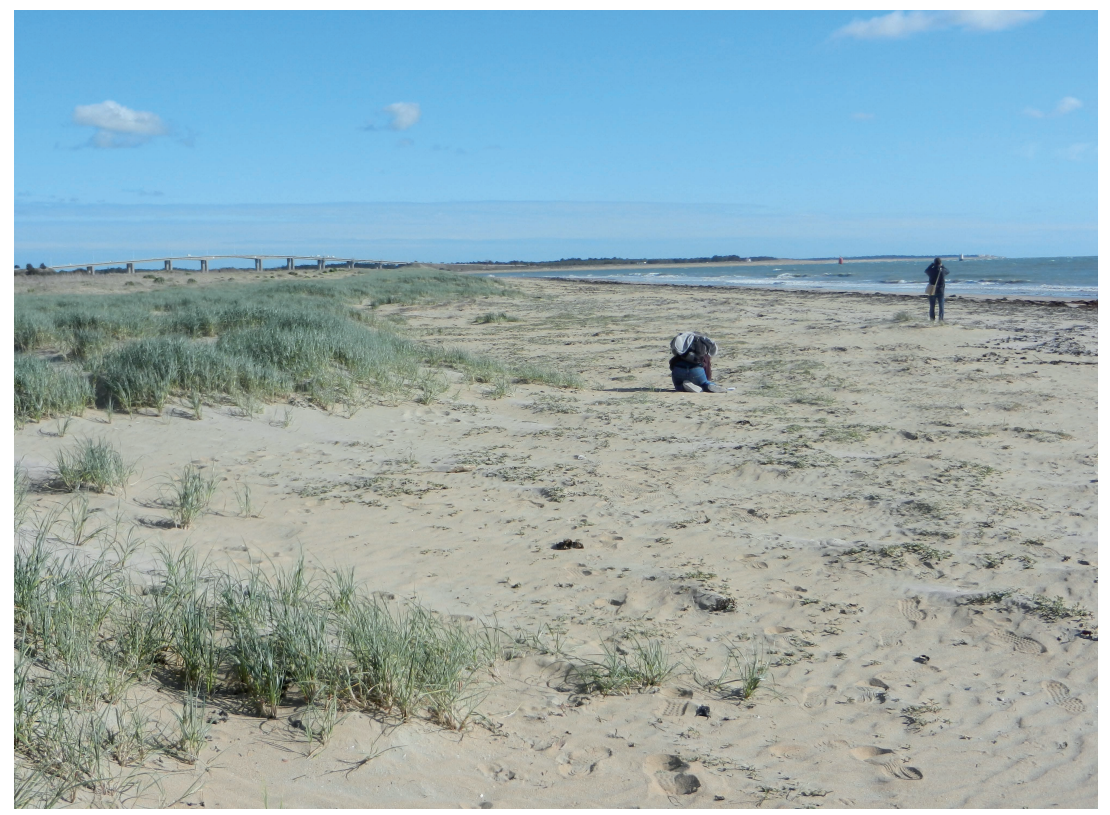

Figure 1.18. Dunes embryonnaires en haut de plage (Noirmoutier).

(c) M.-C. Prat/EUCC-France.

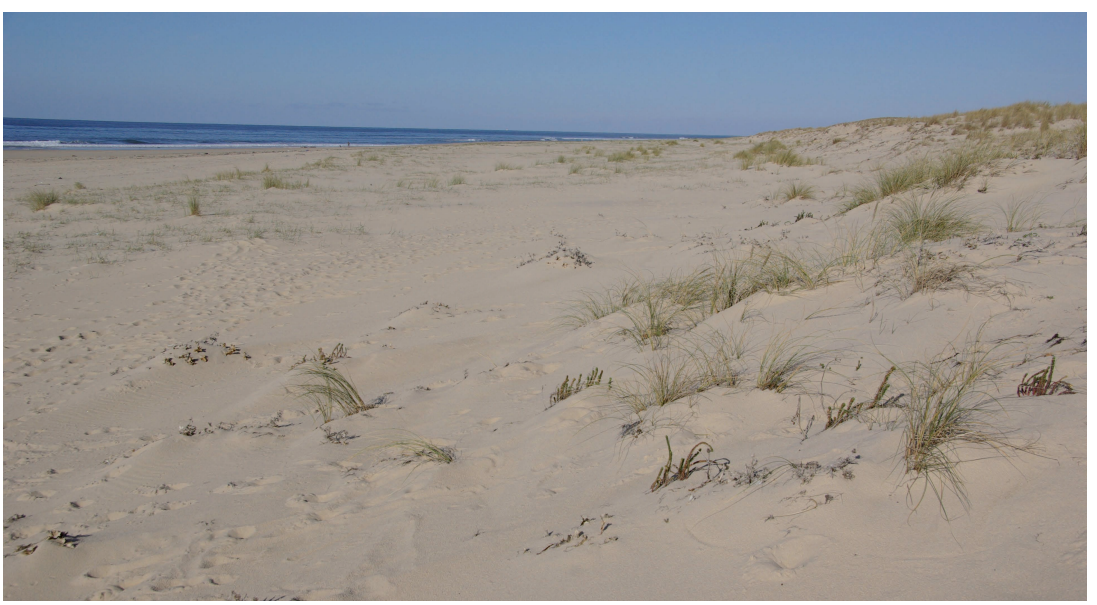

Figure 1.19. Nebkhas au premier plan et, au second plan, banquette de haut de plage colonisée par l'Agropyron (Lège).

(C) M.-C. Prat/EUCC-France.

Piégeage du sable par la végétation

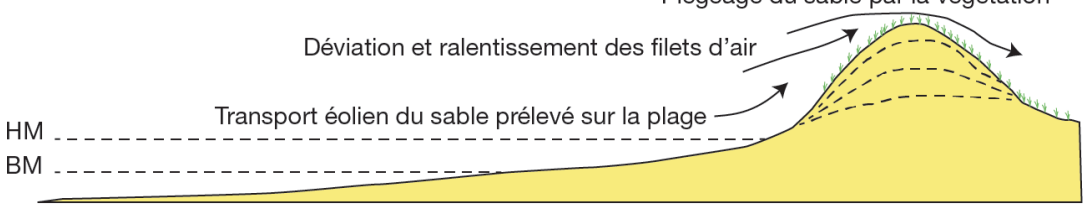

Figure 1.20. La formation d'une avant-dune.

$\mathrm{HM}$ : haute mer ; BM : basse mer.

(C) M.-C. Prat/EUCC-France. 
sable. Dès que la hauteur du cordon devient supérieure au niveau atteint par les eaux marines, l'oyat* (Ammophila arenaria) s'installe. Mais cette avant-dune peut être sujette à l'érosion éolienne* et/ou marine (figure 1.20)

L'avant-dune (forme d'accumulation éolienne) ne doit pas être confondue avec les bermes ou gradins de haut de plage* qui sont des accumulations de sables apportés par la mer en haut de plage. Il existe parfois plusieurs gradins, édifiés par les vagues aux différents niveaux atteints par la marée (figure 1.21). Ces accumulations de sable, apporté par la mer, peuvent former une banquette basse où le chiendent des sables se développe et fixe du sable en transit depuis la plage (sable éolien). Ce peut être alors le point de départ de la formation d'une avant-dune (figure 1.22).

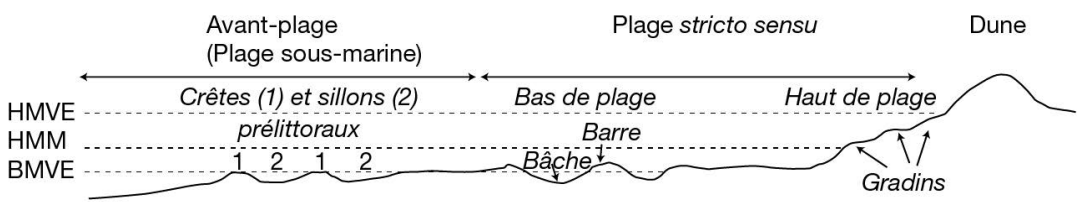

Figure 1.21. Profil d'une plage avec, en haut de plage, la présence de petits gradins correspondant à des accumulations de sédiments déposés lors des niveaux d'eau élevés. Plusieurs gradins correspondent à des apports d'importance décroissante.

HMVE : haute mer de vive-eau; HMM : haute mer moyenne ; BMVE : basse mer de vive-eau. (C) M.-C. Prat/EUCC-France.

Pour qu'une avant-dune se forme, il faut des plages bien alimentées en sable, à faible pente, et des vents de secteurs venus de la mer (cross shore à side shore). Plus la plage est large, plus le volume sableux susceptible d'être mis en mouvement est important. Mais d'autres paramètres interviennent. Pour être mobilisé par le vent, le sable doit être sec. Or, la largeur de la zone où le sable s'assèche entre deux marées est variable selon le marnage*, les coefficients de marée et les conditions météorologiques. Ces facteurs déterminent les limites de la zone sèche et la durée possible du transport sableux à partir de la plage. Les observations montrent qu'il faut une distance minimale d'environ une quinzaine de mètres pour que le transit sableux puisse s'établir. Les mesures, réalisées sur plusieurs sites d'étude, indiquent également que le volume de sable, transporté de la plage vers la dune (de 1 à $30 \mathrm{~m} 3 / \mathrm{ml} / \mathrm{an}$ selon les conditions locales), reste très en dessous des volumes potentiels prévus par les équations de transport standard les plus connues.

Lorsque I'accumulation de sable se poursuit, I'avant-dune s'élève (plusieurs mètres de haut) et s'élargit (jusqu'à plusieurs dizaines de mètres). Lorsqu'elle a atteint son plein développement, $c^{\prime}$ est une avant-dune établie (figure 1.23) dont le rôle est essentiel pour l'équilibre dynamique de la plage. Lors des tempêtes, I'avant-dune est atteinte par les vagues qui y prélèvent le sable. Celui-ci est emporté vers l'avant-plage où il engraisse les barres pré-littorales. À la belle saison, ce sable est remonté sur l'estran par des vagues constructives, moins hautes et moins cambrées que les vagues de tempête. Sur l'estran, asséché entre deux marées, le sable est prélevé par le vent (déflation éolienne), et il alimente ensuite l'avant-dune où le rôle de la végétation est essentiel pour capter le sable. Les échanges sédimentaires réciproques entre la plage et la dune sont donc fondamentaux et, lorsqu'ils ne sont pas perturbés par les activités anthropiques, ils témoignent d'une avant-dune fonctionnelle (figure 1.24).

Le devenir de l'avant-dune, forme dynamique, est étroitement lié au budget sédimentaire* de la plage (bilan des apports et des départs de sable) mais il dépend aussi de la tendance à l'élévation actuelle du niveau marin. 

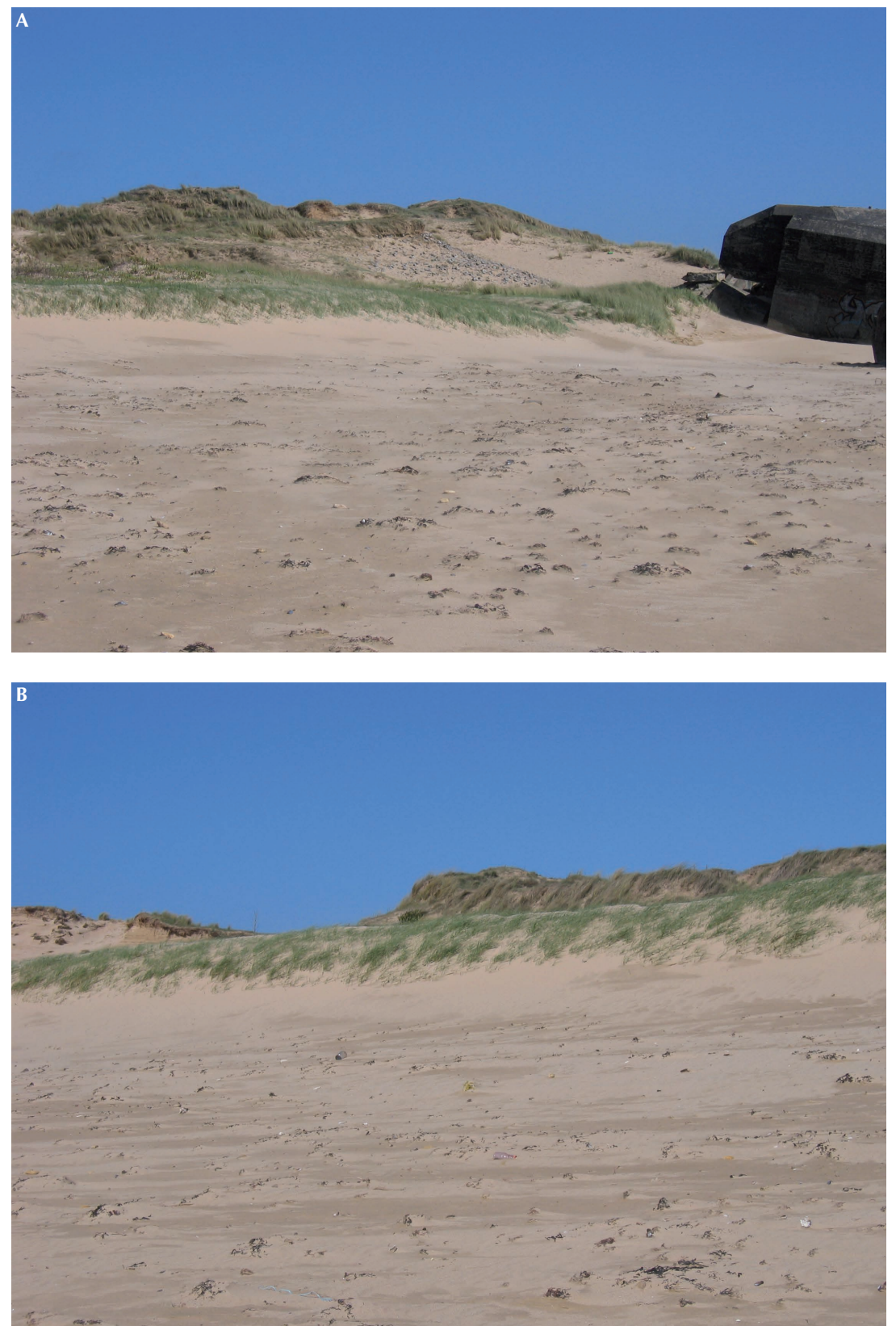

Figure 1.22. A. Banquette à Agropyron (Noirmoutier). B. Avant-dune naissante (Noirmoutier). (C) M.-C. Prat/EUCC-France.

Si le budget sédimentaire de la plage est équilibré ou légèrement positif, et si les échanges entre la plage et la dune sont libres, l'avant-dune est bien développée. Si l'engraissement de la plage persiste sur une longue période, des avant-dunes successives prenant la forme de bourrelets parallèles marquent la tendance à l'aggradation du littoral. Cette situation est aujourd'hui assez rare, comme à la Pointe Espagnole (Charente-Maritime) où un champ de dunes basses témoigne de l'avancée du trait de côte sur la mer depuis les années 1950 (figure 1.25). 


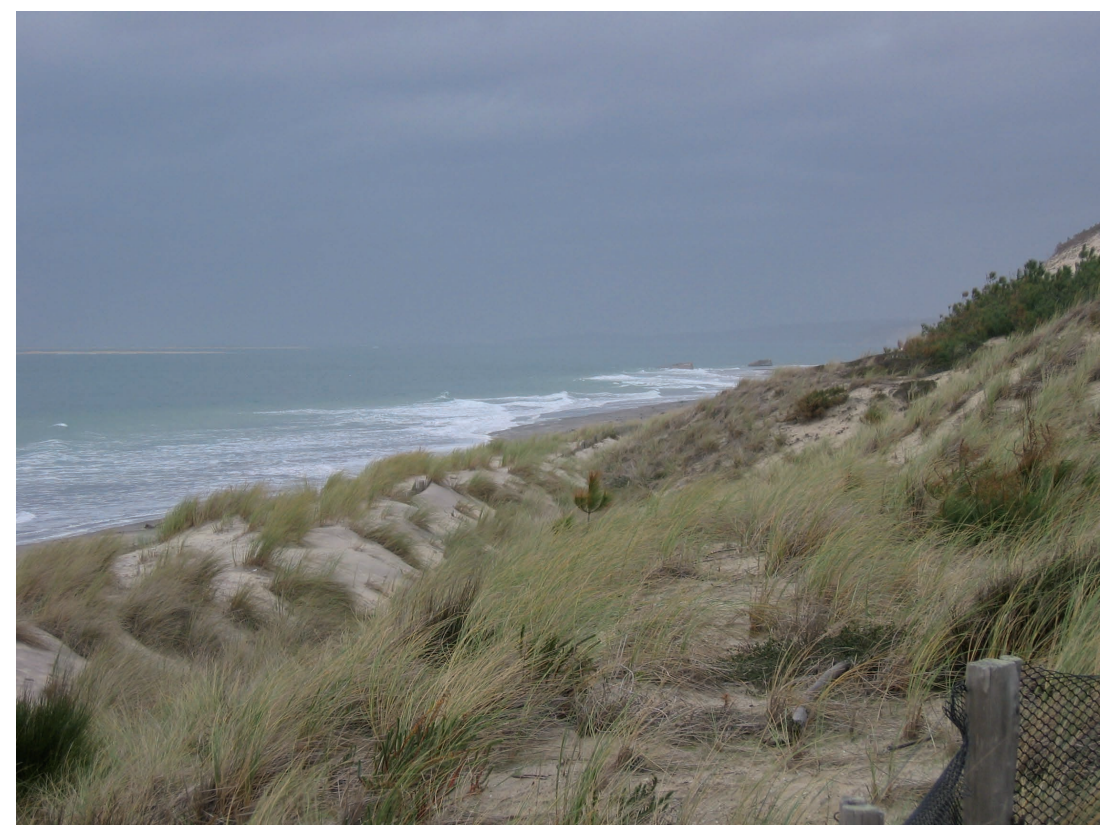

Figure 1.23. Avant-dune établie, séparée par une petite dépression de la dune calibrée (côte landaise).

(C) M.-C. Prat/EUCC-France.

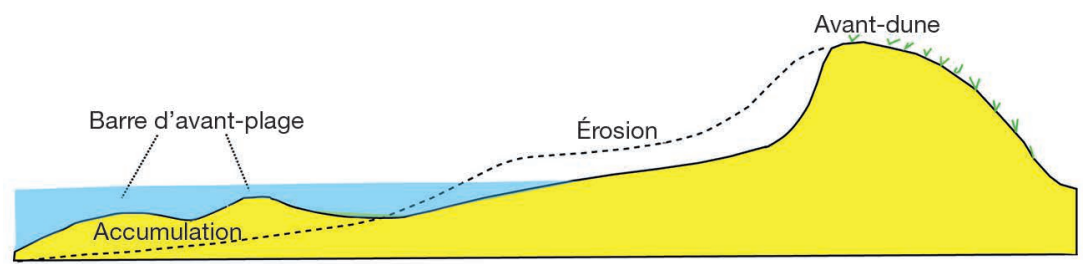

Figure 1.24. Les relations de l'avant-dune avec la plage et l'avant-plage.

Érosion de l'avant-dune et de la plage pendant les tempêtes. Le sable va s'accumuler en barres d'avantplage (toujours immergées). En été, le sable est remonté sur la plage et le transport éolien assure la reconstitution de l'avant-dune si aucun obstacle (perré, enrochement) ne vient perturber ces échanges. Source : M.-C. Prat/EUCC-France.

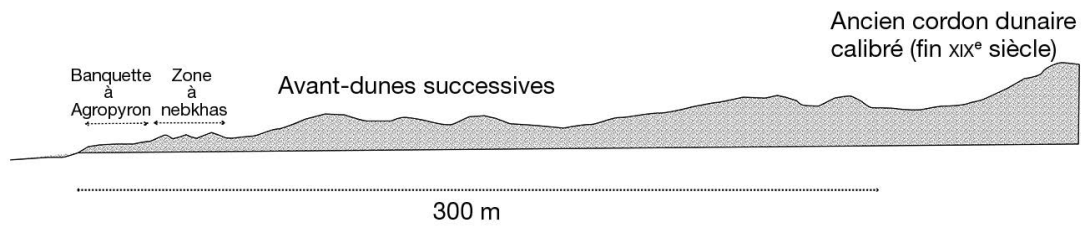

Figure 1.25. Dans une zone d'accrétion, champ de dunes formé depuis les années 1950 par des avant-dunes successives accolées (Pointe Espagnole, presqu'île d'Arvert). Source : M.-C. Prat/EUCC-France.

Si le budget sédimentaire est légèrement négatif, I'avant-dune est entaillée en falaise. Le sable, prélevé par le vent sur l'escarpement, est entraîné à l'arrière de la dune où il s'accumule. L'avant-dune migre alors vers l'arrière à condition qu'aucune installation humaine ne vienne perturber ce recul (figure 1.26). 


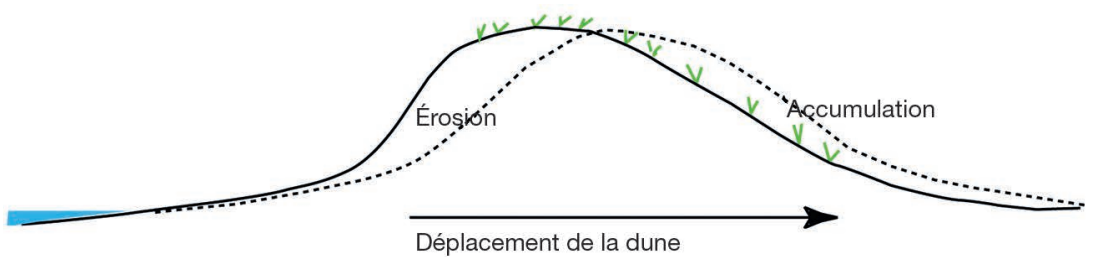

Figure 1.26. Avant-dune migrante (par érosion côté océan et par accumulation côté terre). Source : M.-C. Prat/EUCC-France.

Par contre, si le budget sédimentaire de la plage est très négatif, aucune avantdune ne peut s'établir. La dune littorale est directement exposée aux vagues de tempête et des brèches peuvent s'ouvrir, permettant parfois à la mer de pénétrer à l'arrière.

En arrière des dunes embryonnaires et des avant-dunes, on peut trouver sur certains littoraux des dunes appartenant à différentes générations et présentant des morphologies différentes. Les dunes les plus anciennes ont été naturellement colonisées par une végétation d'arbres indigènes (pins et feuillus) lors de la période humide et plus chaude de la fin du Moyen Âge. Par contre, les dunes modernes étaient encore en partie mobiles à la fin du xvIII siècle. L'homme est alors intervenu pour fixer les sables. Ainsi, la morphologie d'une grande partie des dunes littorales a-t-elle été figée au xix siècle par un boisement monospécifique de pin maritime, mais on retrouve sous la forêt les formes libres originelles (barkhanes* et dunes paraboliques).

Les barkhanes sont des dunes en croissant (convexité au vent), dont les pointes s'étirent dans le sens du vent (figure 1.27). La formation de ce type de dunes est favorisée par l'abondance du sable et l'absence de végétation.

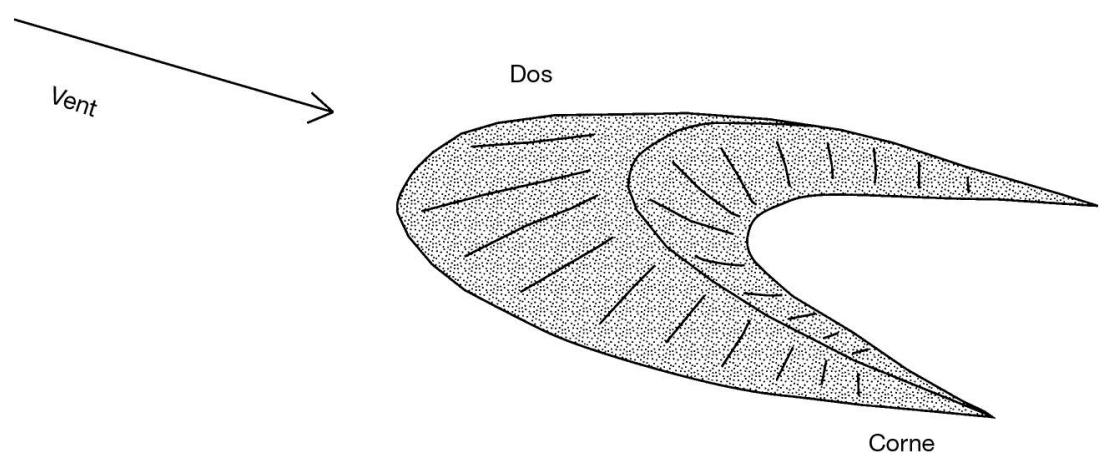

Figure 1.27. Barkhane: dessin en vue aérienne oblique.

Source : M.-C. Prat/EUCC-France.

Les barkhanes peuvent s'accoler pour former de grands cordons dunaires, comme en Aquitaine où l'on trouve 5 à 7 cordons successifs. Perpendiculaires au vent dominant, ils sont formés de dunes barkhanoïdes accolées par les cornes, et la crête est alors sinueuse (figure 1.28). Plusieurs dunes transversales peuvent être parallèles et séparées par des couloirs interdunaires appelés lettes* ou lèdes (terme gascon).

En Aquitaine, les récentes datations par thermoluminescence montrent que les barkhanes et les grands cordons se sont formés à l'époque moderne, dans un contexte de climat froid et sec (Petit Âge glaciaire*), avec de fortes tempêtes 


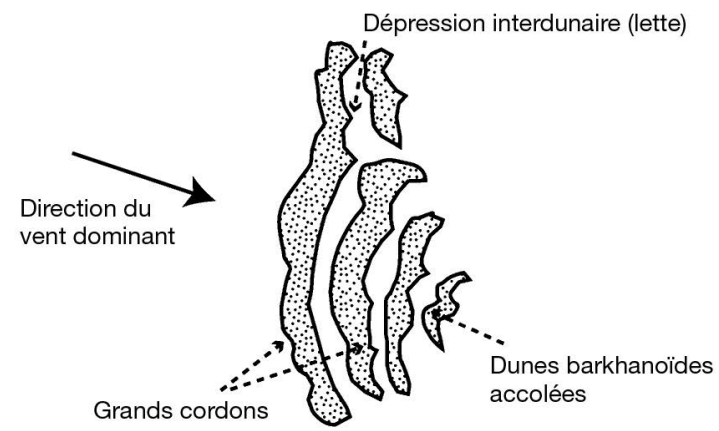

Figure 1.28. Grands cordons formés de dunes barkhanoïdes accolées par les cornes. Source: M.-C. Prat/EUCC-France.

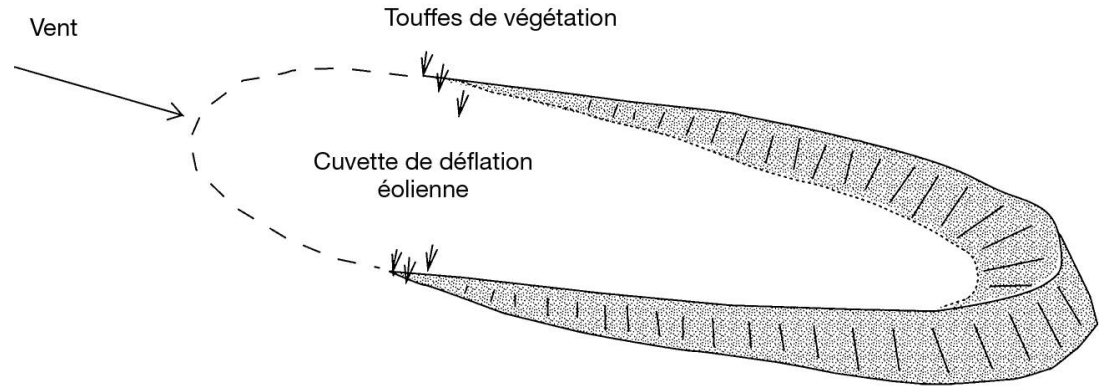

Figure 1.29. Dune parabolique, dessin en vue oblique.

Source : M.-C. Prat/EUCC-France.

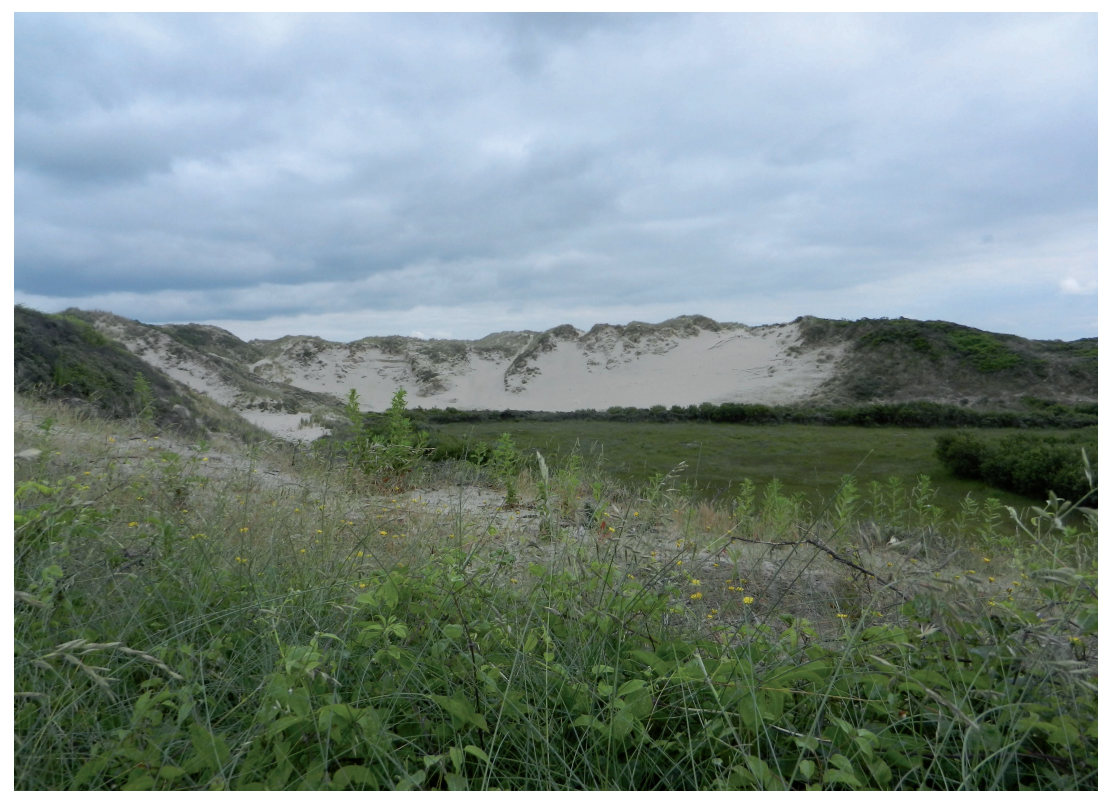

Figure 1.30. Grande dune parabolique (600 m dans son axe le plus long) à Merlimont. Entre les deux cornes de la dune, une cuvette de déflation s'est développée jusqu'à ce que la nappe phréatique soit proche de la surface. L'humidité a alors entraîné l'arrêt de la déflation et la végétation hygrophile s'est développée (panne).

(c) M.-C. Prat/EUCC-France. 


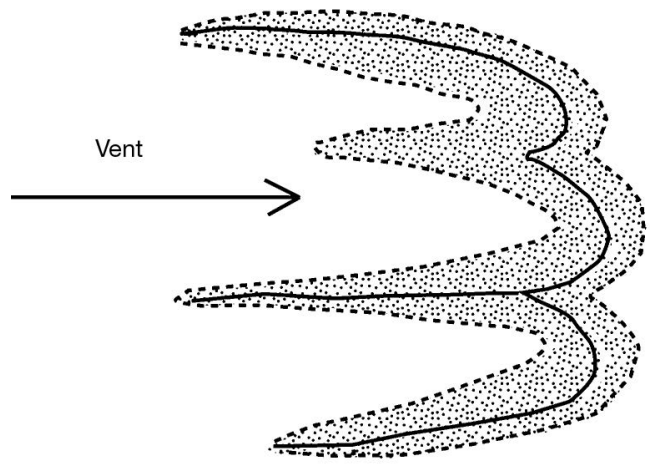

Figure 1.31. Dunes en râteau, formées de dunes paraboliques accolées. Source: M.-C. Prat/EUCC-France.

et des vents puissants. Ces dunes modernes, volumineuses, ont recouvert des dunes plus anciennes dont elles se "nourrissaient » parfois. Elles progressaient sur une topographie à peu près plane et menaçaient les installations humaines. Leur mobilité, signalée par Masse ou Brémontier (15-20 m/an), se rapprochait des vitesses de déplacement des barkhanes mesurées dans les déserts. Le semis d'une forêt de pins maritimes les a stabilisées au cours du xIx siècle.

Les dunes paraboliques sont des dunes en forme de $U$ dont la concavité est orientée face au vent (figure 1.29). Les cornes, parallèles à la direction des vents dominants, s'étirent avec une hauteur décroissante vers les pointes. Ces dernières sont plus ou moins fixées par la végétation qui entrave le mouvement du sable (d'où le nom de dune entravée qu'on donne parfois à ces dunes paraboliques). Les bras de la dune encadrent une partie centrale déprimée qui correspond à une zone de déflation éolienne (figure 1.30). Lorsque la nappe phréatique est atteinte, il y a blocage des processus éoliens. Une dépression humide, appelée panne* dans le Nord de la France, occupe alors la cuvette. Cette zone humide est d'un grand intérêt par la biodiversité qu'elle permet.

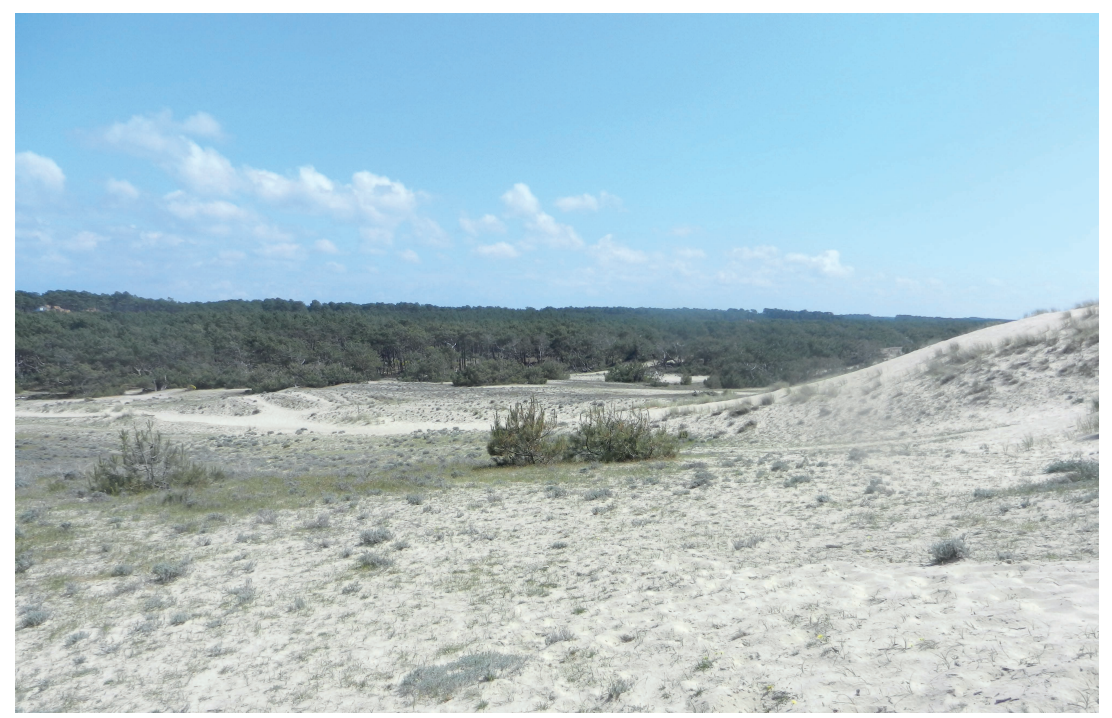

Figure 1.32. Lette en berceau (La Jenny, Gironde). (C) M.-C. Prat/EUCC-France. 


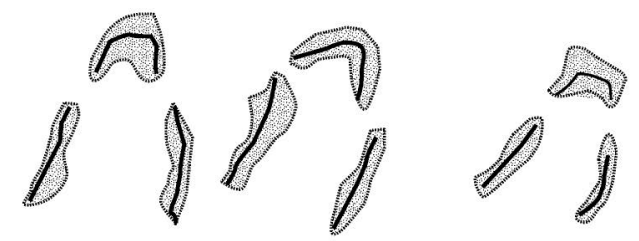

Stade b) évolution vers des dunes en traînées par étirement et ruptures des bras

Stade a) dunes paraboliques accolées (dunes en râteau)

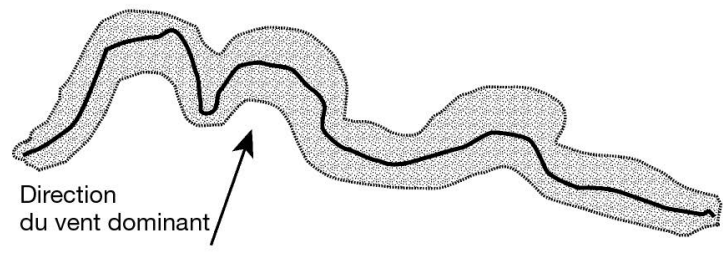

Figure 1.33. Les étapes de la formation de dunes en traînées. Source: M.-C. Prat/EUCC-France.

Il existe des dunes paraboliques de toute taille, de quelques mètres à quelques centaines de mètres. Plusieurs dunes paraboliques accolées latéralement forment une dune en râteau (figure 1.31).

Les dunes paraboliques se forment lorsque le sable en provenance de la plage est en partie arrêté par une végétation discontinue. Ce sont alors des dunes paraboliques primaires. Mais elles peuvent aussi se développer dans d'anciennes dunes dont la végétation disparaît localement, soit à la suite de modifications climatiques (sécheresse), soit lorsque le tapis végétal est détruit par les activités anthropiques ou animales. Une cuvette de déflation (caoudeyre*) est alors ouverte par le vent là où le sable est à nu. Ce phénomène de parabolisation (dunes paraboliques secondaires) concerne souvent les dunes de seconde ligne.

Ces différentes conditions de formation expliquent que l'on trouve des dunes paraboliques anciennes mais aussi des dunes paraboliques plus récentes, certaines (peu nombreuses) formées au moment de la mise en place des grands cordons à l'époque moderne et d'autres actuelles ou subactuelles, situées en arrière de la dune bordière.

À un stade avancé, les dunes paraboliques peuvent perdre leur front par amincissement des bras et rupture du front. Subsistent alors des dunes en traînées, parallèles au vent dominant (figure 1.33).

Les dunes perchées (figure 1.34) correspondent à une accumulation de sable par le vent au sommet d'un escarpement, souvent une falaise tranchant plusieurs

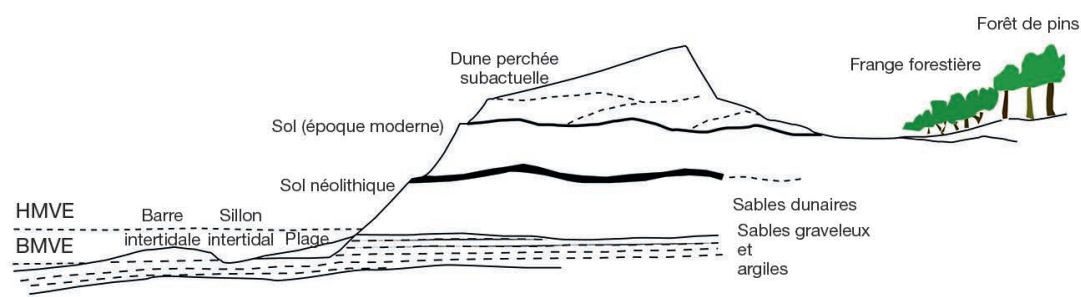

Figure 1.34. Dune perchée (Médoc).

HMVE : haute mer de vive-eau; BMVE : basse mer de vive-eau.

Source : M.-C. Prat/EUCC-France. 
générations de dunes (dunes du Nord-Médoc, dune du Pilat, dunes de certaines plages de poche de la région des Agriates au nord-ouest de la Corse...).

\section{Les dunes liées aux interventions anthropiques}

Au début du xIx siècle, la mobilité des dunes sur la façade atlantique était perçue comme une menace, d'autant que certains villages avaient été partiellement envahis par le sable. Certains avaient même dû être déplacés. La stabilisation des dunes, par les semis de pins maritimes, devint alors le grand chantier du siècle. L'idée que I'homme pouvait dominer la nature était dans I'air du temps et le développement d'une forêt exploitable répondait à un objectif économique. Le boisement des dunes modernes, achevé à la fin du xixe siècle, allait figer leur morphologie et assécher les lettes autrefois inondées en hiver.

Mais le transit éolien à partir des plages restait important car l'érosion marine* libérait du sable immédiatement remobilisé par les vagues, les courants, et par les vents lorsque l'estran s'asséchait entre deux marées. Pour protéger la forêt nouvellement plantée, il fallait arrêter ce sable éolien avant qu'il n'atteigne la lisière forestière. La dune littorale fut donc imaginée comme un rempart contre les sables transportés depuis les plages par les vents d'ouest.

L'intervention des hommes allait modifier les dynamiques naturelles. Selon les instructions de J. S. Goury, ingénieur des Ponts et chaussées, des palissades* furent mises en place pour capter le sable en provenance de la plage. Elles étaient rehaussées au fur et à mesure de l'accumulation. Les travaux, réalisés initialement par le service des Ponts et chaussées, furent poursuivis par I'Administration forestière puis, après 1862, par les Eaux et forêts (figure 1.35).

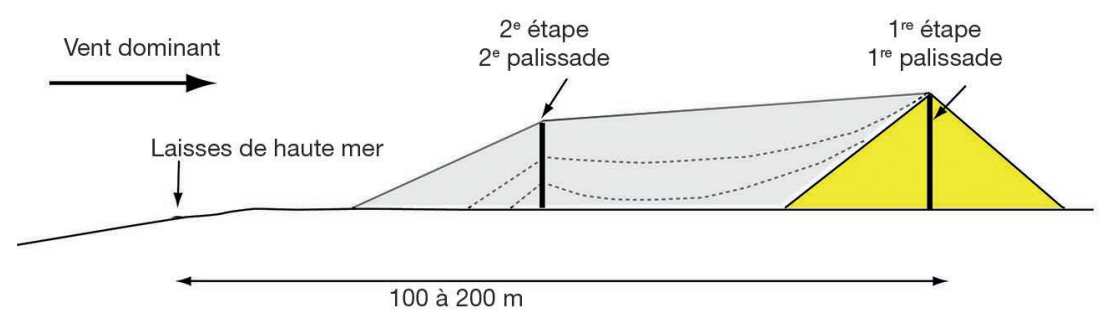

Figure 1.35. Les différentes étapes de la formation d'une dune calibrée par la mise en place d'une première palissade (à environ 100 à 200 m du haut de plage).

Elle capte le sable en provenance de la plage et est progressivement rehaussée, puis une deuxième palissade est mise en place plus près de la plage aboutissant à la formation d'une dune littorale de protection. Une dernière étape consiste à végétaliser la dune par la plantation d'oyats.

Source : M.-C. Prat/EUCC-France.

Ainsi une dune fut-elle édifiée progressivement en arrière des plages et plantée d'oyat, appelés gourbet en Aquitaine (Ammophila arenaria). Si sa forme est liée aux travaux des hommes, sa formation a bénéficié de conditions naturelles favorables: disponibilité en sable et vents réguliers de secteur ouest soufflant de la mer vers la terre (« dune semi-naturelle »). Là où les conditions naturelles n'étaient pas favorables, il y a eu des échecs (par exemple dans le nord-est de l'île d'Oléron).

\section{Les différents profils des dunes littorales}

\section{Les profils des dunes libres}

Ils sont souvent dissymétriques avec des versants au vent à faible pente et des versants sous le vent à pente plus forte. 
Les barkhanes et les dunes barkhanoïdes présentent un versant au vent (versant externe) en pente douce (figure 1.36), légèrement convexe (5 à $\left.12^{\circ}\right)$, et un versant interne à pente plus forte $\left(22\right.$ à $\left.33^{\circ}\right)$.

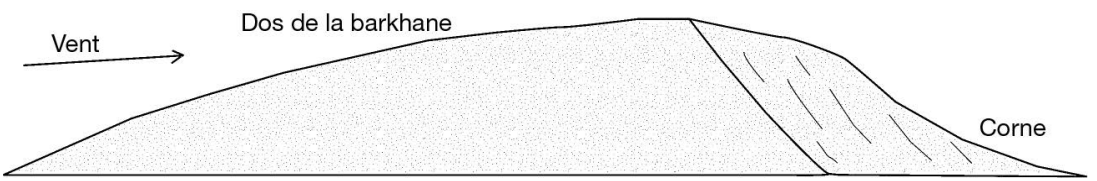

Figure 1.36. Profil d'une barkhane.

Source : M.-C. Prat/EUCC-France.

Les dunes paraboliques présentent généralement des pentes douces vers l'intérieur de la dépression $\left(10-20^{\circ}\right)$ mais qui se relèvent vers la crête $\left(40^{\circ}\right)$. Le front de la dune, partie la plus mobile et tournée vers l'extérieur, est à pente plus forte $\left(30-33^{\circ}\right)$, ce qui correspond à la pente d'équilibre des sables secs (figure 1.37).

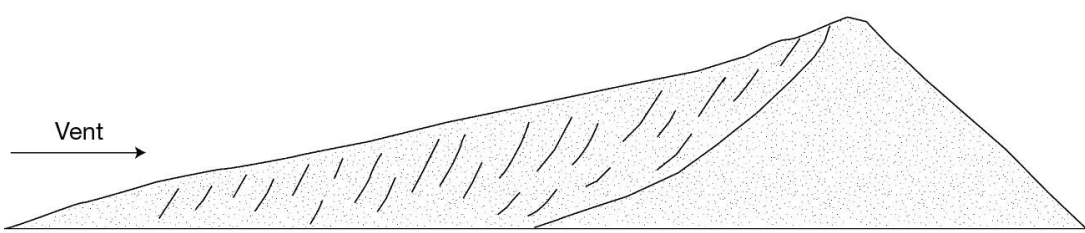

Figure 1.37. Profil d'une dune parabolique.

Source : M.-C. Prat/EUCC-France.

Lorsque l'on a des champs de dunes, comme en Aquitaine, en Charente ou en Picardie, les grands cordons dunaires parallèles sont séparés par des couloirs intermédiaires (lettes). L'altitude des lettes est seulement de quelques mètres au-dessus du niveau de la mer, et leur largeur varie de 100 à 200 m. Si certaines lettes présentent une surface subhorizontale entre le versant interne de la dune bordière et le cordon dunaire interne (lette en berceau, figure 1.32), d'autres sont plus complexes, fragmentées par de petites dunes transversales ou longitudinales ou bien par des dunes paraboliques basses. Selon leur altitude et le niveau de la nappe phréatique, les lettes peuvent être humides, subhumides ou sèches.

\section{Les profils calibrés}

Ils sont liés à l'intervention des hommes, qui souhaitaient faire de la dune bordière un rempart protecteur pour l'arrière-pays et la forêt nouvellement plantée, menacée par les arrivées de sable. La mise en œuvre la plus complète a été initialement faite sur le littoral aquitain.

Le profil imaginé par l'ingénieur Goury au xıxe siècle (1825) était atteint par relèvement progressif de deux palissades, l'une en bordure interne, I'autre en bordure externe. Sur une largeur de 150 à $200 \mathrm{~m}$ et une hauteur d'une dizaine de mètres, la dune calibrée (figure 1.38) comprend :

- un versant externe (glacis externe*) à pente faible $\left(20-25 \%\right.$ soit 10 à $\left.15^{\circ}\right)$, sur environ $75 \mathrm{~m}$ dans la première période d'existence de la dune ; il est planté d'oyats ;

- un plateau* à pente nulle ou très faible (moins de $5 \%$ ) se développant sur 75 à $100 \mathrm{~m}$, à une altitude de 10 à $15 \mathrm{~m}$; comme le glacis, le plateau est planté d'oyats pour stabiliser le sable ;

- un talus interne correspondant au sable retombant sous le vent et dont la pente est celle d'équilibre des sables, autour de 32 à $35^{\circ}$ (environ $60 \%$ ) selon la granulométrie des sables et l'humidité. 


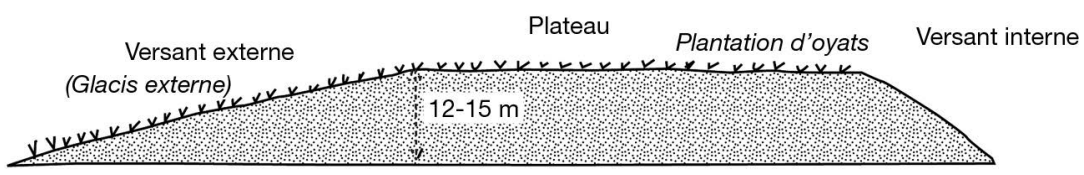

$50 \mathrm{~m}$

Figure 1.38. Profil d'une dune calibrée (d'après les instructions de l'ingénieur Goury au xIx ${ }^{\mathrm{e}}$ siècle). Source : M.-C. Prat/EUCC-France.

Le profil en toit peut se rencontrer lorsqu'une seule palissade est mise en place par les hommes, aboutissant à un profil à deux pentes équivalentes (11 à 14\%, soit 20-25\%). On trouve plusieurs exemples en Charente maritime, en presqu'île d'Arvert ou au sud de l'île d'Oléron (figure 1.39).

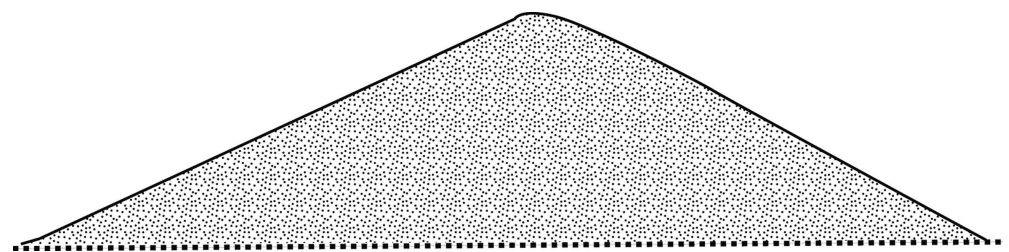

Figure 1.39. Profil en toit.

Source : M.-C. Prat/EUCC-France..

En fait, ce profil de la dune calibrée, considéré par certains comme "idéal », évolue sous I'action des dynamiques marines et éoliennes. Dans les secteurs en érosion, le glacis externe est entaillé en falaise (profil tronqué) et peut à la longue disparaître, le plateau pouvant être à son tour attaqué si le rythme de recul de la côte est rapide.

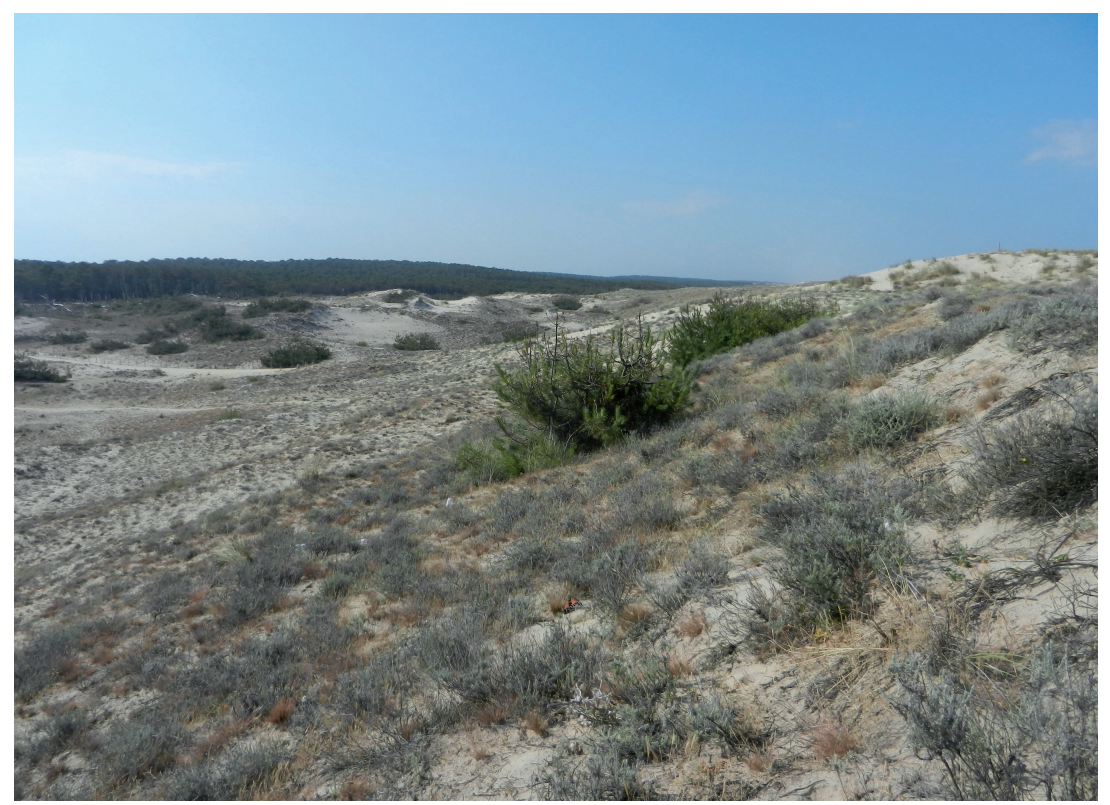

Figure 1.40. Arrière-dune avec dunes paraboliques basses (Le Porge, Gironde).

On voit au deuxième plan la cuvette de déflation de l'une des dunes paraboliques dont les bras sont végétalisés.

(c) M.-C. Prat/EUCC-France. 
La hauteur de la falaise sableuse dépend du type de dune attaquée par la mer et du rythme de l'érosion marine. Selon que la falaise entame le glacis externe ou le plateau, le commandement peut atteindre 10 à $15 \mathrm{~m}$. La falaise peut même atteindre des hauteurs plus importantes dans certains cas exceptionnels, comme pour certaines dunes perchées. C'est le cas de la dune du Pilat où la falaise entaillant le versant externe atteint une quarantaine de mètres.

La dynamique marine est l'initiatrice de la dynamique éolienne, car l'obstacle que constitue la falaise exacerbe l'action éolienne en sommet de falaise et sur le plateau. Lorsqu'une forte érosion littorale et une dynamique éolienne active se conjuguent, une évolution rapide peut conduire à une translation de la dune vers l'intérieur des terres (figure 1.56).

À l'arrière et à l'abri de la dune calibrée, on trouve un ensemble complexe que I'on désigne sous le nom d'arrière-dune* (figure 1.40) et qui comprend la lette et des dunes subactuelles. Ces dernières sont le plus souvent des dunes en traînées ou des dunes paraboliques basses, isolées ou accolées (dunes en râteau).

\title{
La dynamique des dunes
}

\author{
Marie-Claire Prat
}

Les évolutions morphologiques dépendent de la houle pour la dune située juste en arrière de la plage, du vent (fréquence, orientation et vitesse des vents dominants) et de l'état de la végétation sur l'ensemble des dunes, mais aussi des interventions anthropiques.

La morphologie du contact entre la plage et la dune est importante car elle est révélatrice de la tendance évolutive actuelle du littoral (érosion, accrétion ou stabilité).

\section{L'évolution du contact entre la plage et la dune}

Sur les littoraux dunaires en érosion, des falaises sont taillées par l'érosion marine. Lors des tempêtes, la falaise est directement sapée à la base par les vagues, et un coin sableux est prélevé aux dépens de la dune littorale (figure 1.42). Juste après la tempête, I'escarpement présente une paroi subverticale (falaise vive) en raison de la compacité du sable et de son humidité. La végétation d'oyats retient le sable au sommet, donnant une petite corniche. Le vent cisèle les stratifications entrecroisées qui sont liées aux alternances accumulation/érosion/transit des sables (figure 1.41).

Les falaises à paléosols* peuvent trancher, outre le sable, d'anciens sols avec des niveaux plus résistants (alios, lignite) qui raidissent l'escarpement (figure 1.43). Les horizons humifères des anciens sols podzoliques tranchent sur la couleur claire des sables, comme sur la côte du Médoc ou au sud du bassin d'Arcachon. Avec le recul du trait de côte et l'abaissement du niveau des plages, I'érosion peut faire également apparaître des couches plus anciennes comme des couches d'argile ou de tourbe.

Dans les semaines qui suivent la tempête, la falaise évolue (figure 1.44). Progressivement, par coulées de sable et écroulements, par mini-avalanches sableuses, la falaise se régularise avec la formation de petits cônes sableux à la base. Tout le versant, dont la pente est devenue plus faible, se raccorde à la corniche qui s'émousse. On parle alors de falaise régularisée (figure 1.45). 


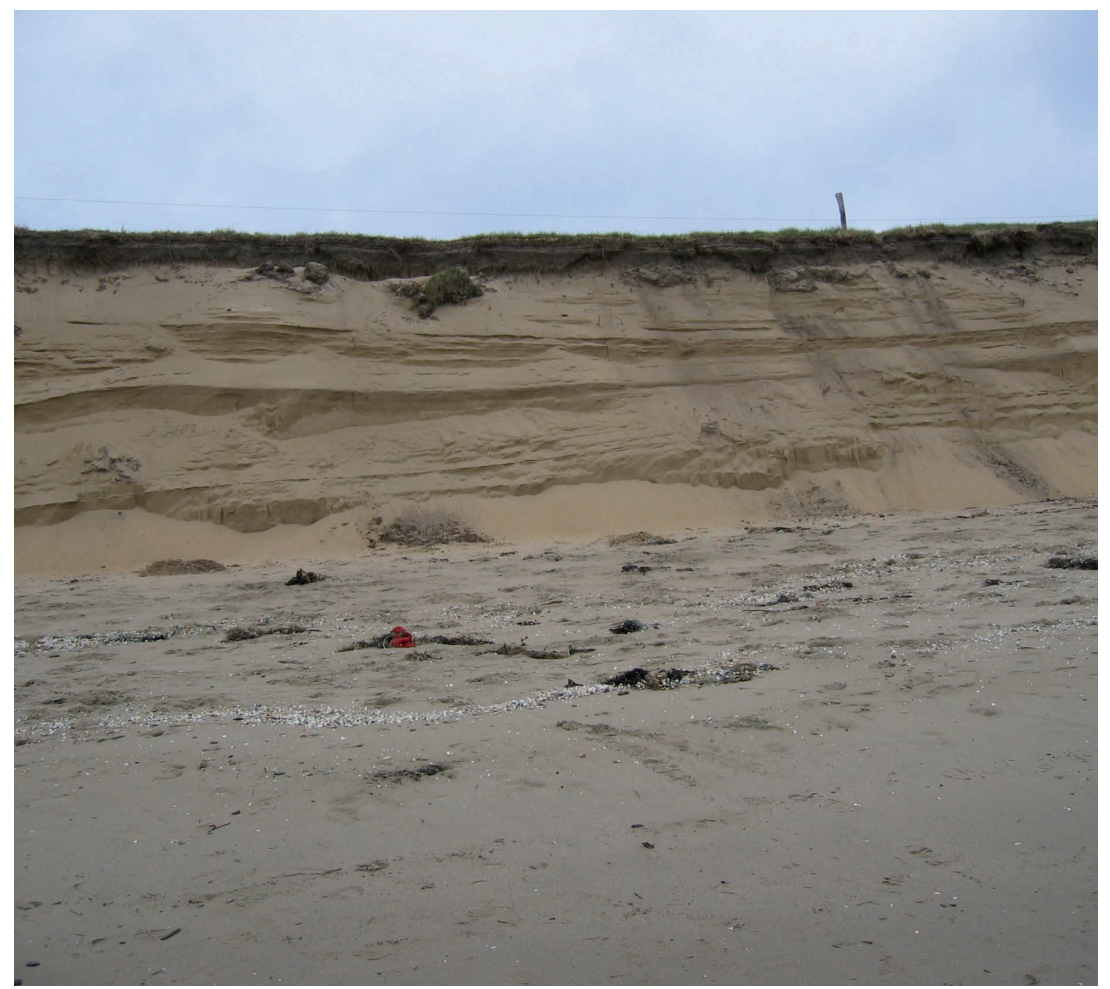

Figure 1.41. Falaise vive et stratifications sableuses entrecroisées visibles sur le talus (Cotentin).

(C) M.-C. Prat/EUCC-France.

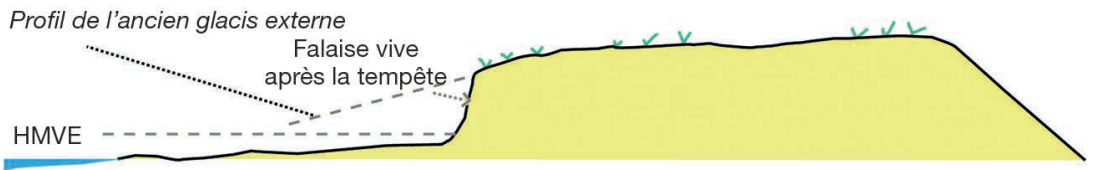

Figure 1.42. Falaise vive.

Elle est directement sapée à la base par les vagues, et un coin sableux est prélevé aux dépens

de la dune bordière. Juste après la tempête, l'escarpement présente une paroi subverticale (falaise vive). Sur une ancienne dune calibrée, on parle de profil tronqué.

HMVE : haute mer de vive-eau.

Source : M.-C. Prat/EUCC-France.

La falaise peut devenir une falaise morte lorsque la base du talus n'est plus atteinte par la mer, dans le cas notamment où une banquette à Agropyrum ou une avant-dune se forme devant I'ancienne falaise, dans une période de stabilisation du trait de côte voire d'accrétion (figure 1.46)

La falaise sableuse représente un obstacle qui accentue les effets du vent dont la vitesse et la turbulence augmentent en sommet de falaise (effet Venturi). Des formes d'érosion éolienne (figure 1.47) sont creusées par le vent dans la partie supérieure (falaise éolisée). Selon la taille de ces formes d'érosion éolienne, on distingue les brèches de dimension métrique, les couloirs de déflation éolienne et les siffle-vent (figure 1.48). Ces derniers, de dimension pluri-décamétrique, peuvent traverser toute la dune bordière, surtout s'ils se situent sur des cheminements utilisés par les touristes pour gagner la plage. 


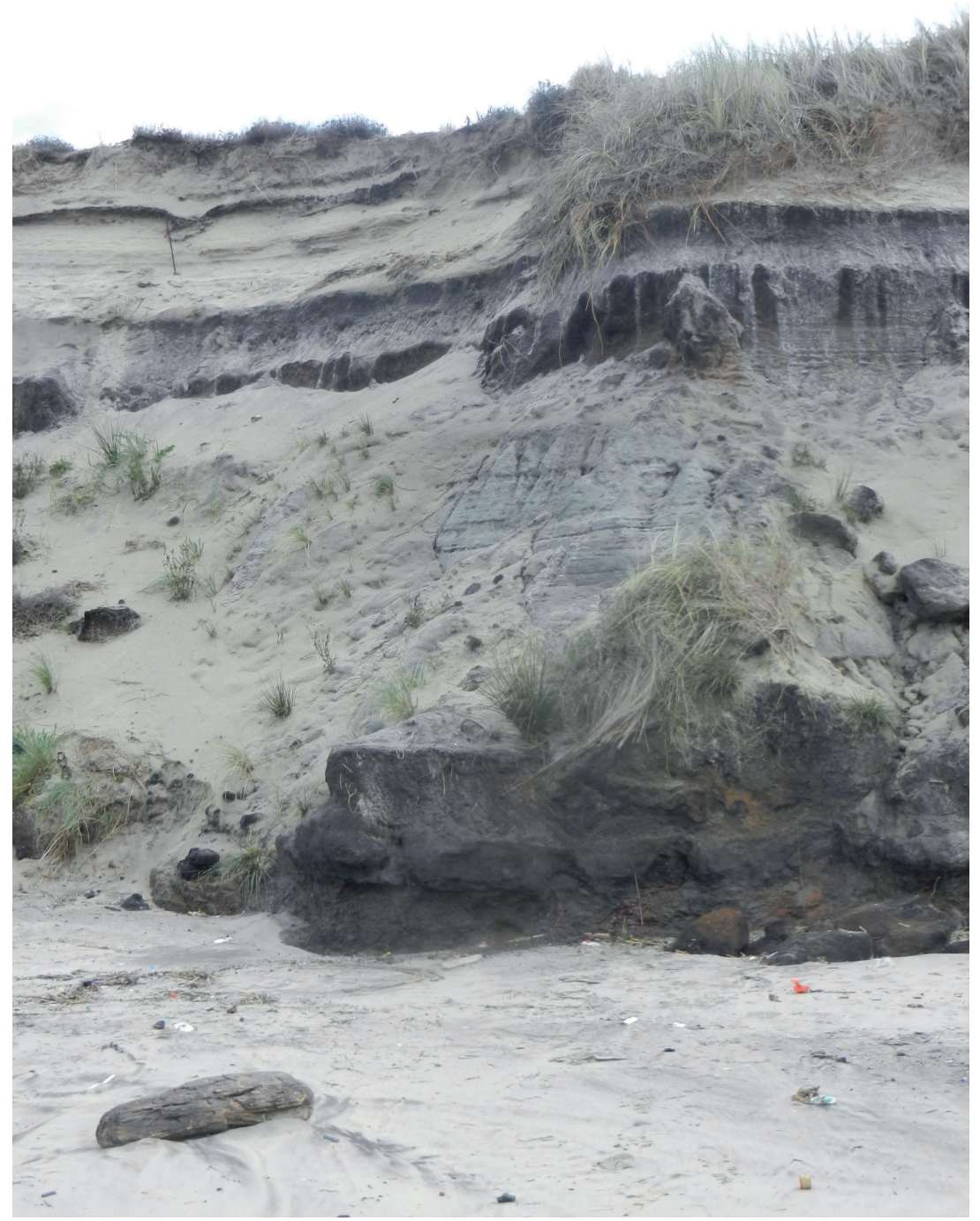

Figure 1.43. Falaise à paléosols (Médoc, Gironde) et dune perchée au sommet. (C) M.-C. Prat/EUCC-France.

Dans les secteurs en répit d'érosion, voire en accrétion, lorsque le budget sédimentaire de la cellule côtière est équilibré ou excédentaire, des gradins de haut de plage se forment. Quand la plage s'engraisse, le vent prend le relais des actions marines et une avant-dune se forme.

Les changements dans l'évolution du littoral (érosion, répit d'érosion, accrétion) sont enregistrés dans les formes de passage de la plage à la dune, avec parfois des morphologies complexes (figure 1.49). En avant d'une ancienne falaise éolisée, le passage à une période de budget sédimentaire excédentaire peut se traduire par le développement d'une large banquette à Agropyron. Une micro-falaise, dont la durée de vie est variable, peut se former aux dépens de la banquette, soit par l'action des vagues à marée haute, soit par la baisse de la pression hydrostatique au moment de la marée descendante. 


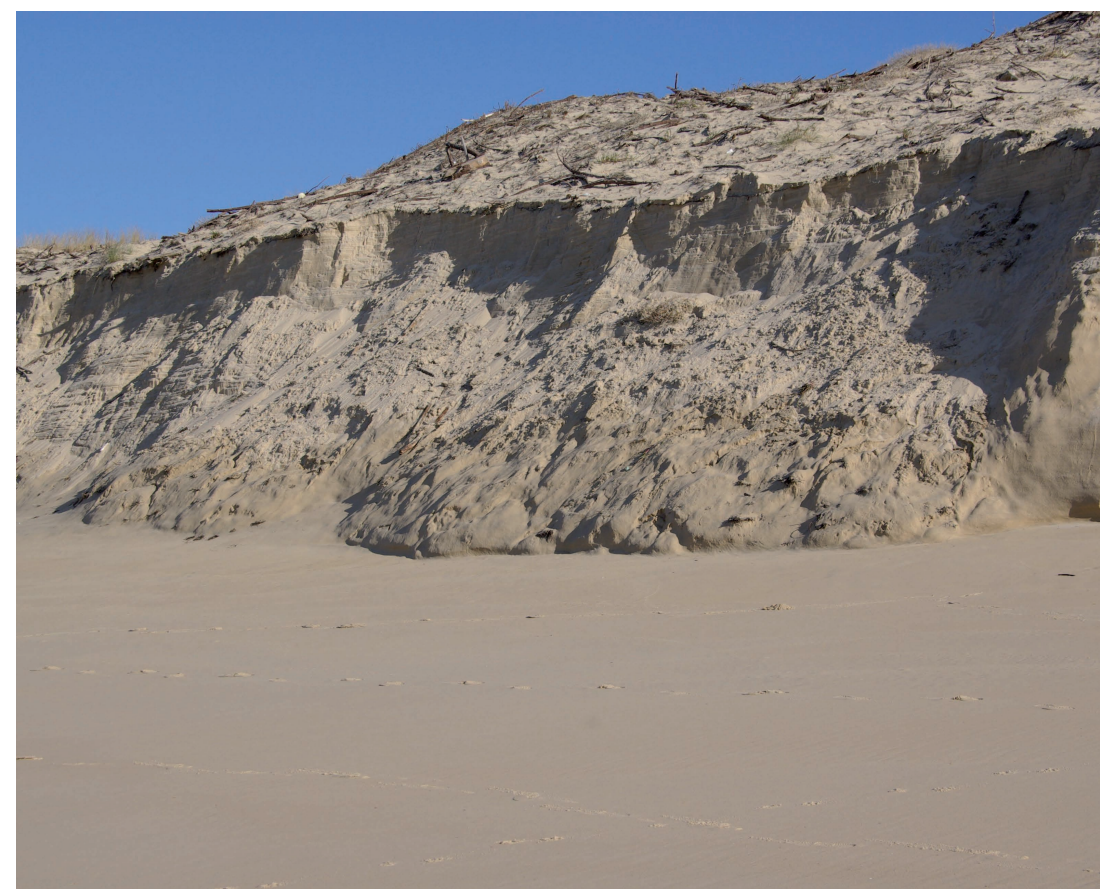

Figure 1.44. Évolution vers la régularisation de la falaise (Lège). Glissement du sable par paquets sur la falaise (Lège). (c) M.-C. Prat/EUCC-France.

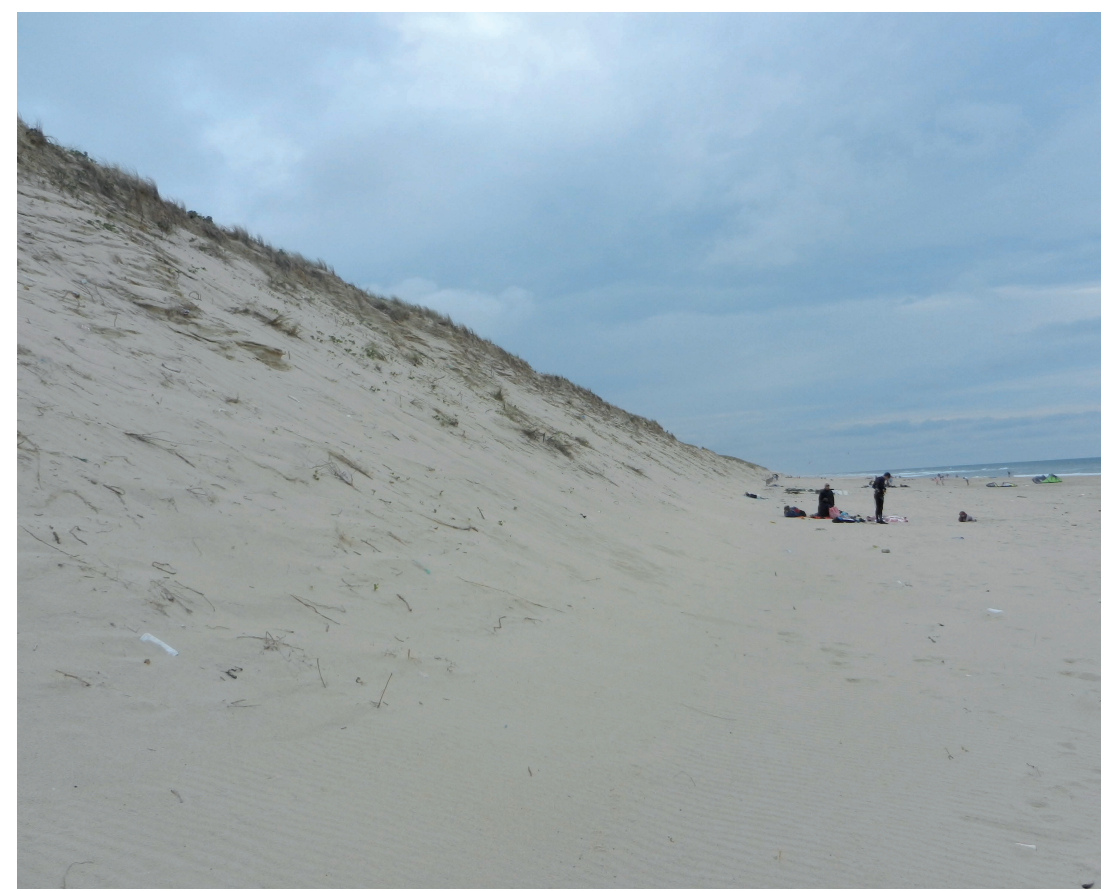

Figure 1.45. Falaise régularisée (Le Truc Vert).

La pente du versant devient plus faible sous la corniche qui s'émousse (Le Truc Vert). (c) M.-C. Prat/EUCC-France. 


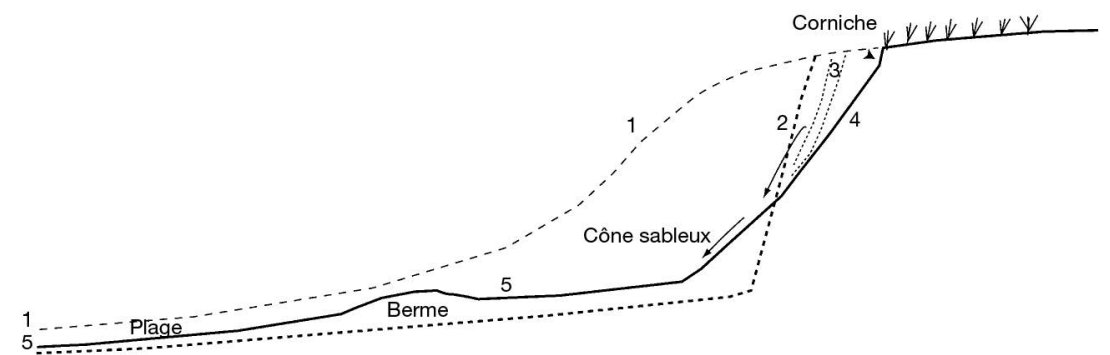

1 Profil initial de la dune et de la plage

2 Falaise sableuse formée après une tempête, avec enlèvement d'un coin sableux à la base

3 Éboulements successifs

4 Falaise régularisée

5 Profil de la plage après réengraissement pendant l'été avec formation d'une berme

Figure 1.46. Attaque de la dune par l'érosion marine et évolution. Source : M.-C. Prat/EUCC-France.

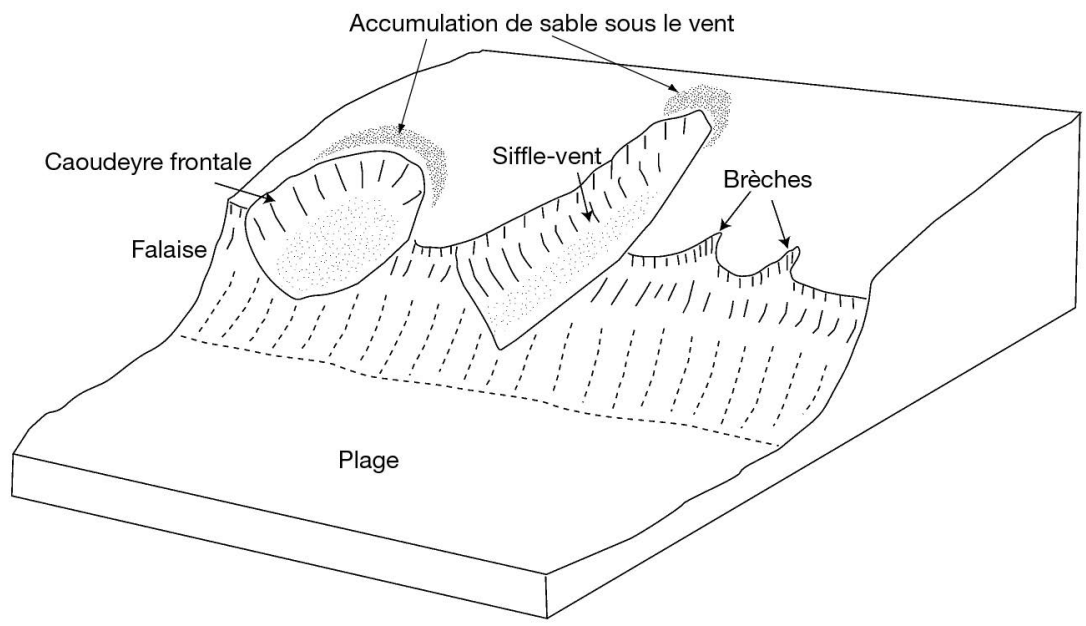

Figure 1.47. Falaise éolisée.

Selon la taille et la forme de ces formes d'érosion éolienne, on distingue brèches, siffle-vent et caoudeyre frontale.

Source : M.-C. Prat/EUCC-France.

\section{Exhaussement et bossellement sur la dune bordière}

Le sable, enlevé sur la falaise, vient s'ajouter au sable prélevé par le vent sur la plage. Il s'accumule à l'arrière, notamment sur le plateau dans le cas d'une dune calibrée. Si la couverture végétale est importante et piège ce sable, la dune s'exhausse. Certaines dunes peuvent ainsi dépasser une vingtaine de mètres de hauteur. Cette surélévation présente des inconvénients car elle favorise l'augmentation des turbulences surtout à l'avant, au niveau de la falaise sableuse, et à l'arrière dans la lette.

Sur le plateau dunaire, l'action éolienne se traduit par des formes de déflation et d'accumulation. L'évolution se fait vers un bossellement qui peut être plus ou moins accentué avec des formes de déflation entre les touffes de végétation 


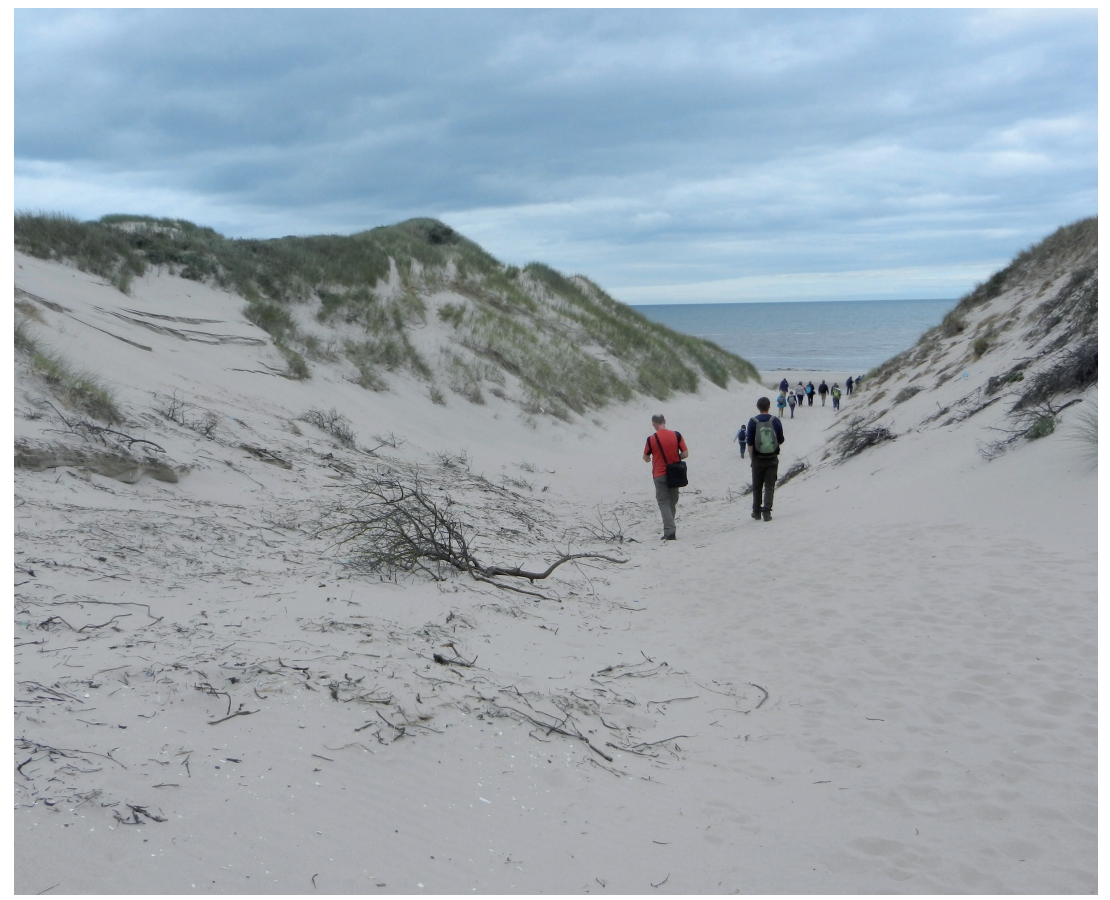

Figure 1.48. Couloir de déflation traversant la dune bordière (entre Merlimont et Berck). (c) M.-C. Prat/EUCC-France.

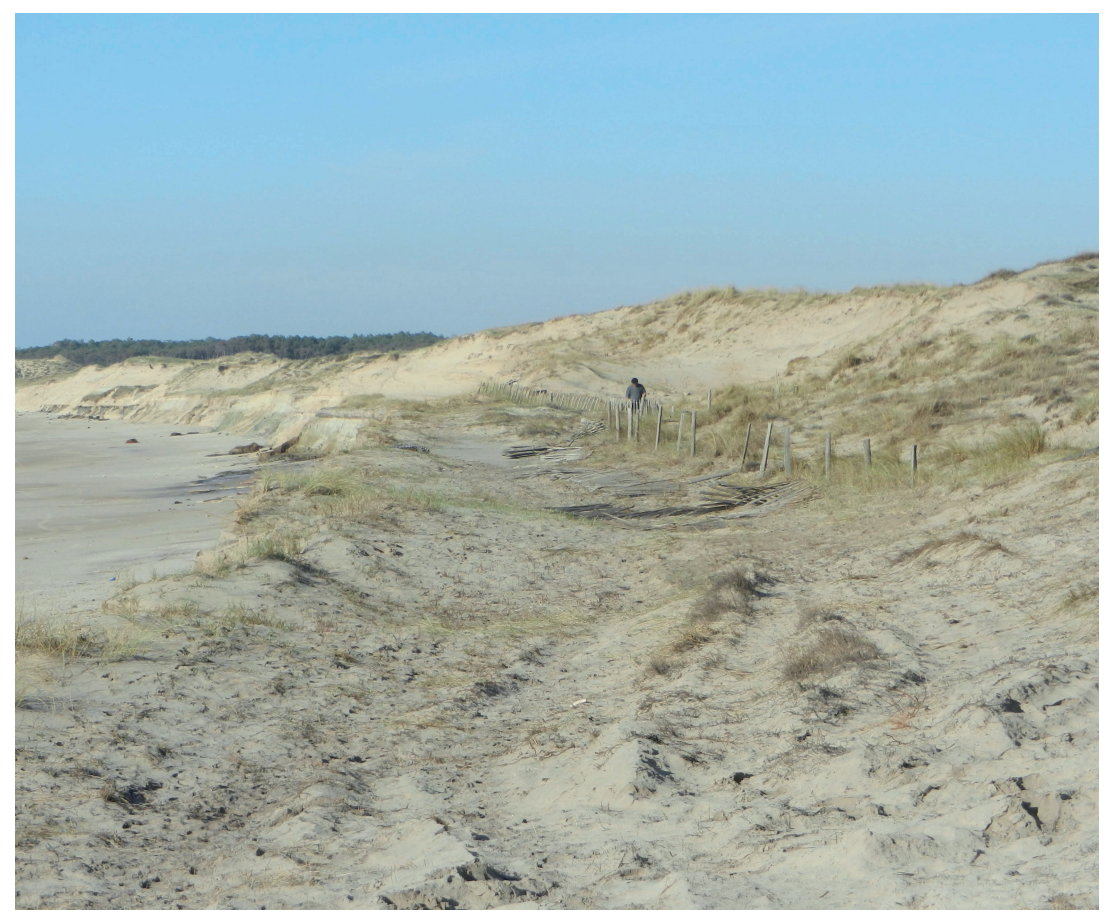

Figure 1.49. Morphologies complexes : période de répit d'érosion et comblement des anciennes entailles d'érosion marine, formation de banquettes en avant. (c) M.-C. Prat/EUCC-France. 


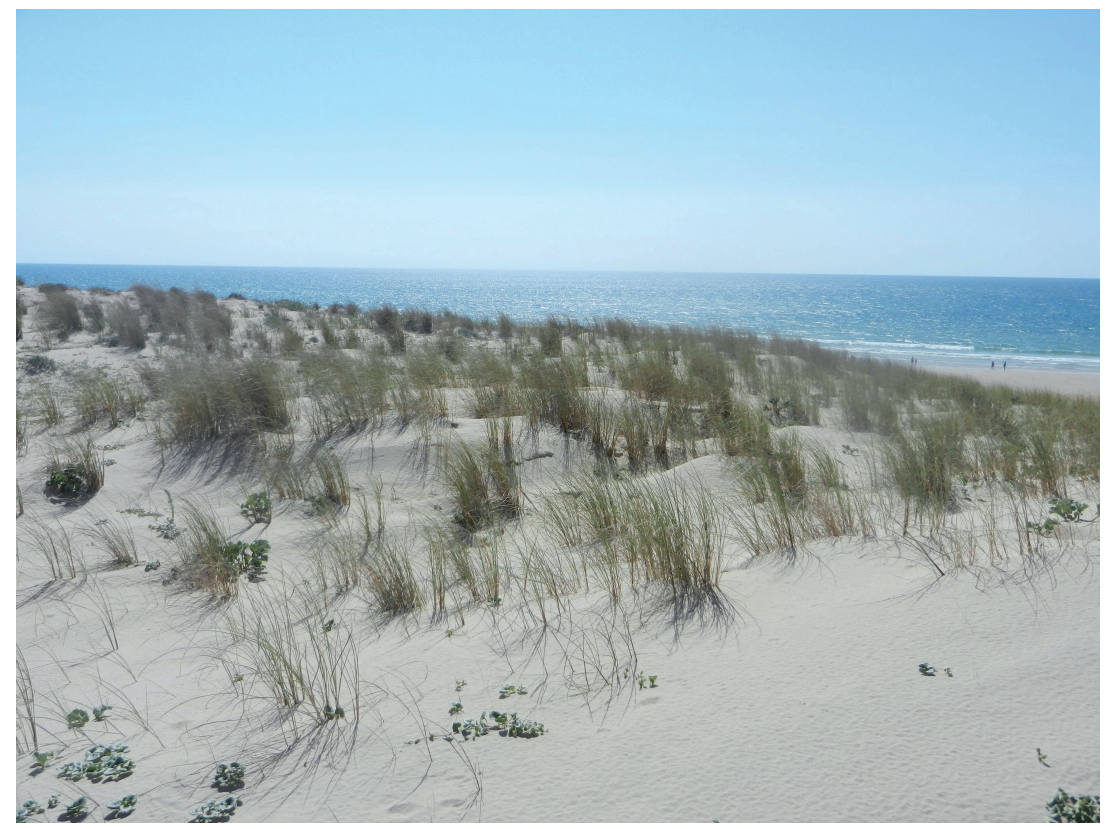

Figure 1.50. Bossellements liés aux actions éoliennes et à la végétation de dune blanche. (C) M.-C. Prat/EUCC-France.

qui piègent le sable (figure 1.50). On distingue donc plusieurs niveaux de bossellement selon la taille des monticules de sable (décimétrique, métrique ou plurimétrique).

Sur la dune bordière, comme dans I'arrière-dune, différentes formes traduisent les actions de déflation éolienne lorsque la végétation est discontinue (figure 1.51). Les plaques de déflation correspondent à un simple décapage du sable, sur quelques mètres carrés, dans des secteurs où la végétation est inexistante ou a été détruite. On utilise parfois le terme de " coups de cuillères » pour désigner de petites cuvettes de déflation éolienne, peu profondes (moins $d^{\prime}$ un mètre) et d'une dizaine de mètres de diamètre.

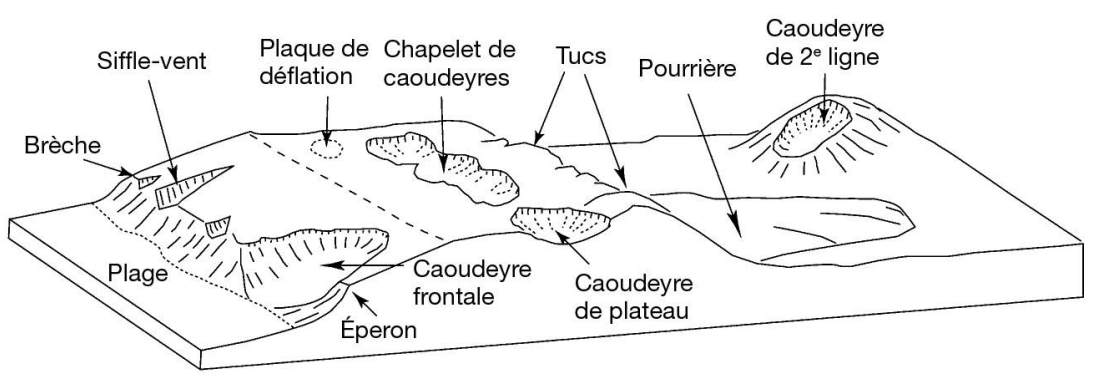

Figure 1.51. Formes éoliennes sur la dune.

Source : M.-C. Prat/EUCC-France d'après Pierre Barrère.

Les caoudeyres (du terme landais " caoudé » signifiant chaudron) sont des cuvettes de déflation, creusées par le vent et dont le fond correspond à du sable nu (figure 1.52). Leur taille est variable (de quelques mètres à quelques dizaines de mètres). Les caoudeyres se localisent dans des secteurs de compression des filets d'air car le profil de la dune calibrée engendre un train d'ondes 


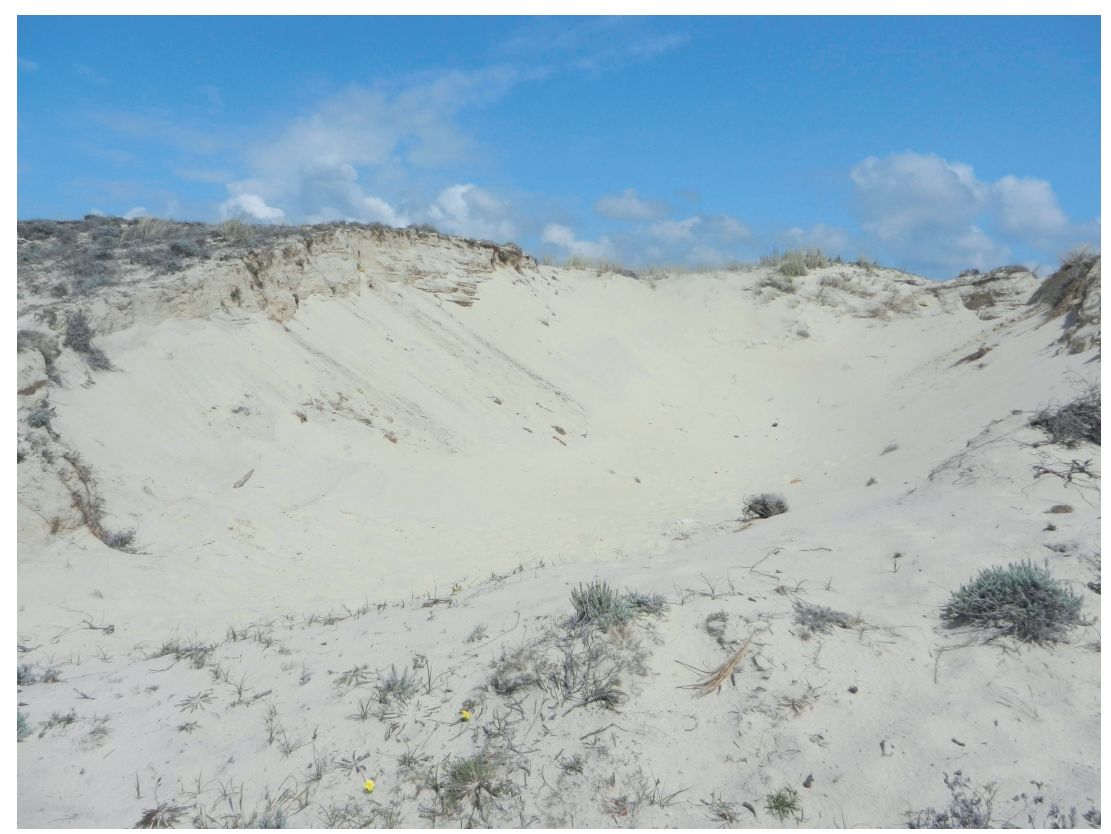

Figure 1.52. Caoudeyre sur le plateau de la dune bordière. (c) M.-C. Prat/EUCC-France.

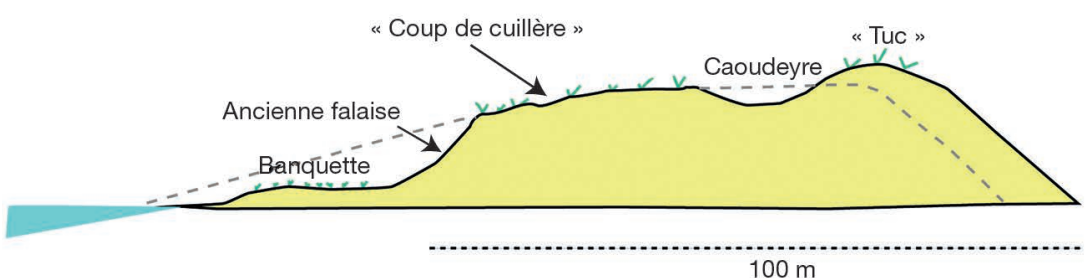

Figure 1.53. Formes de déflation éolienne sur la dune.

Source : M.-C. Prat/EUCC-France.

(figure 1.57), mais on les trouve également là où la végétation est affaiblie. Le sable prélevé dans la caoudeyre s'accumule à l'arrière en monticules sableux appelés tucs.

Les caoudeyres peuvent se multiplier en cas d'insuffisance ou de destruction de la couverture végétale, sous l'effet du piétinement par exemple. Sur le plateau, plusieurs caoudeyres coalescentes peuvent former une caoudeyre majeure, large de plusieurs dizaines de mètres, ceinturée par une corniche maintenue par la végétation (figure 1.51). La multiplication des caoudeyres peut aussi fragmenter la dune bordière en buttes, appelées crocs sur la côte picarde et trucs en Aquitaine.

À l'avant et en bordure du plateau, un siffle-vent peut s'élargir en caoudeyre frontale (figure 1.47). Des caoudeyres peuvent être également creusées par le vent sur les cordons dunaires internes (caoudeyres de deuxième ligne) lorsque la végétation a été partiellement détruite, notamment par les cheminements. Sur le versant externe des petites dunes qui accidentent la lette, le creusement de caoudeyres facilite l'évolution vers des dunes paraboliques (parabolisation). 


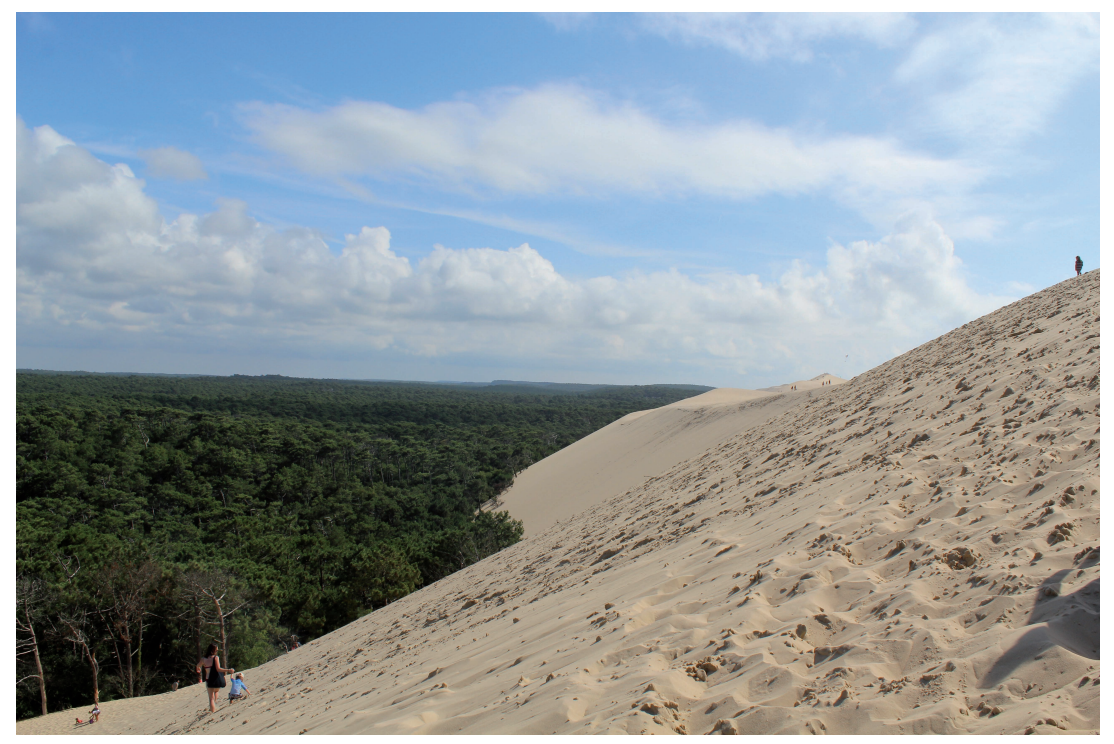

Figure 1.54. Abrupt d'envahissement (dune du Pilat) progressant de plusieurs mètres par an et ensevelissant la forêt à son pied.

(C) M.-C. Prat/EUCC-France.

Le sable, soufflé sur la dune, retombe naturellement sur le versant interne. Lorsque les arrivées de sable sont importantes et régulières, le talus est vif avec une pente de 30 à $35^{\circ}$ qui est la pente d'équilibre des sables, selon leur granulométrie et l'humidité. Le talus évolue par surcharge sédimentaire dans sa partie supérieure, avec des coulées ou des mini-avalanches sableuses, puis la pente d'équilibre se rétablit (figure 1.53). La hauteur du talus dépend de la taille de la dune et peut varier de 2 à $80 \mathrm{~m}$. Cet abrupt d'envahissement* peut progresser à l'arrière de la dune bordière (figure 1.54) avec une vitesse de plusieurs mètres par an (4 à 15 m/an).

Le profil de la dune calibrée peut se déformer lorsque le volume de transport sableux est important, alimentant une forte accumulation à l'arrière du plateau (figure 1.53). Un méplat* présentant une pente faible peut se former au-delà $d^{\prime}$ 'une ancienne palissade, élargissant la dune. Phases d'accumulation et de transit alternent. L'abrupt interne de la dune se déforme parfois, avec des sinuosités (formes barkhanoïdes).

Lorsque les formes d'éolisation accidentant la dune bordière s'élargissent, d'importantes quantités de sable sont mobilisées vers l'arrière de la dune à travers les couloirs de déflation et vont s'accumuler à l'arrière en langues sableuses appelées pourrières* (terme d'origine picarde).

Les pourrières présentent un profil convexe (figure 1.51) et progressent à l'arrière d'une dune littorale où l'érosion éolienne est forte. La racine de la pourrière se trouve alors au débouché des couloirs. Mais les pourrières peuvent aussi se substituer aux abrupts d'envahissement par étalement du sable et allongement des méplats. Formes de déstabilisation, les pourrières sont des formes mobiles (figure 1.55) sans végétation. Cette dernière ne peut s'installer que s'il y a ralentissement de l'arrivée de sable. Dans ce cas, on observe une amorce de colonisation par l'oyat ou bien par l'armoise qui forme des zones bosselées d'abord puis, lorsque la dynamique éolienne se calme, I'armoise devient rampante. 


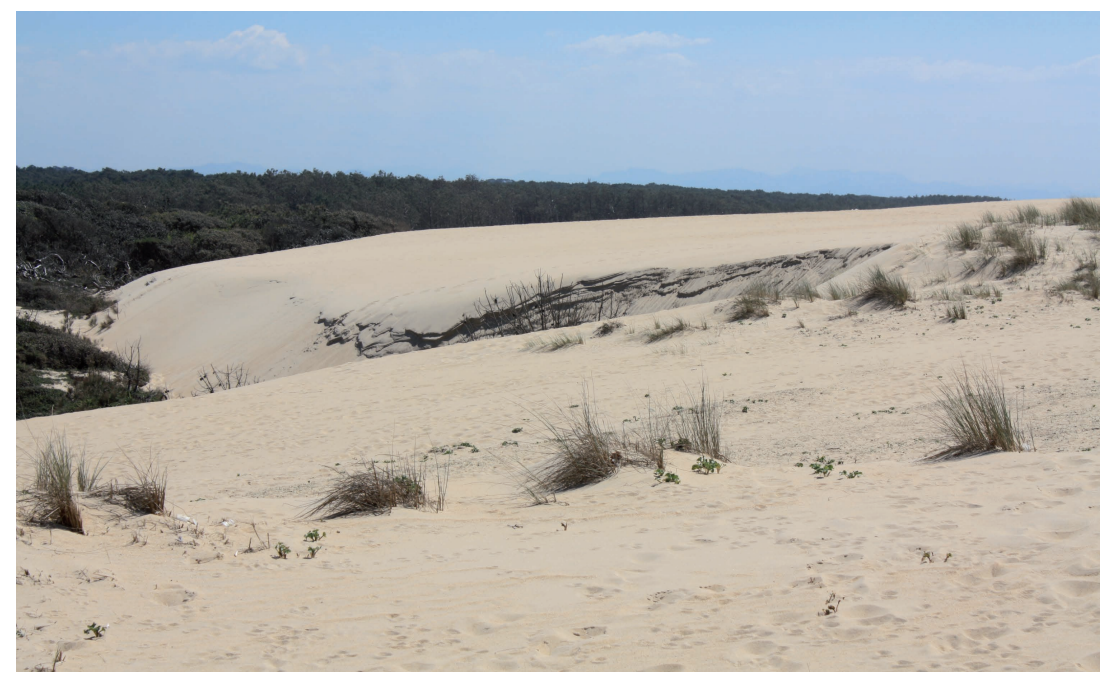

Figure 1.55. Pourrière à l'arrière de la dune bordière (Seignosse, Landes).

(C) L. Gouguet/ONF.

Dans les cas de déstabilisation de l'ensemble dunaire, on peut assister à la translation de la dune vers l'intérieur des terres (figure 1.56), avec la formation d'un large méplat, puis de pourrières qui s'avancent dans la lette. On a pu noter des exemples d'avancée de 10 à 15 m/an à Saint-Trojan-les-Bains (île d'Oléron) dans les années 1990. L'entretien des dunes mis en œuvre par l'ONF tend à faire disparaître ce cas de figure.

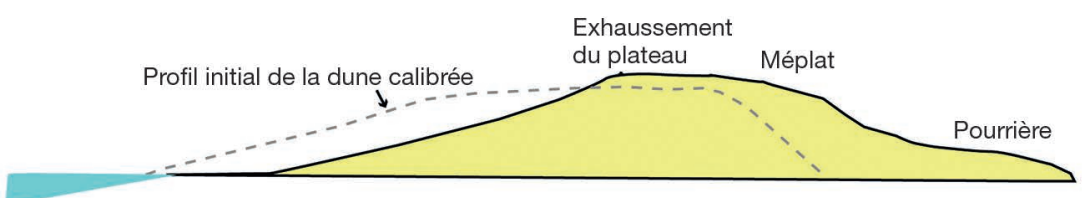

Figure 1.56. Translation de la dune vers l'intérieur des terres avec la formation d'un large méplat puis de pourrières qui s'avancent dans la lette.

Source : M.-C. Prat/EUCC-France.

Lorsque la dynamique éolienne devient moins active sur la dune bordière, l'apport de sable à l'arrière se ralentit et le talus interne est colonisé par la végétation. L'oyat s'installe d'abord, puis viennent les plantes de la dune semifixée, et enfin celles de la dune fixée.

L'arrière-dune voit sa dynamique influencée par le traitement de la dune littorale selon qu'elle est laissée libre ou contrôlée par l'homme. Les contraintes liées au vent, aux apports de sable et de sel y sont moindres que sur la dune bordière mobile, ce qui permet à la végétation de fixer les sables tandis qu'un sol embryonnaire se développe. Dans sa partie externe, au voisinage du talus interne de la dune bordière, la lette reçoit du sable, soit par la progression d'un abrupt d'envahissement ou d'une pourrière en cas de forte dynamique éolienne, soit par simple saupoudrage si l'activité éolienne est faible sur la dune.

Par contre, la retombée des filets d'air sous le vent de la dune peut provoquer une reprise de la déflation éolienne à une centaine de mètres du pied de la dune bordière, où se localisent des plaques de déflation voire des caoudeyres de deuxième ligne (figure 1.57). 


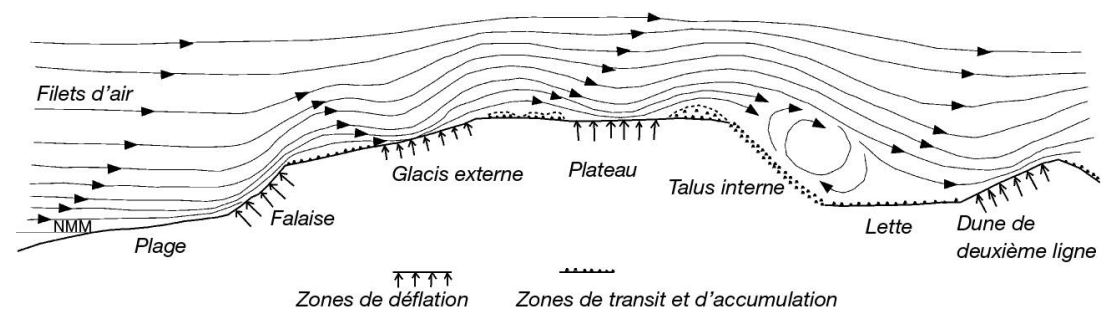

Figure 1.57. Ondes éoliennes liées au profil de la dune.

NMM : niveau moyen de la mer.

Source : P. Barrère.

\section{Le rôle de la végétation}

\section{Loïc Gouguet}

Dans la formation et la stabilisation des dunes, la végétation joue un rôle primordial, et d'ailleurs sans végétation, point de dunes fixées! Sur quelques sites (dune du Pilat, plages du Languedoc...), I'absence de végétation nous donne à voir des dunes très dynamiques. En effet, en freinant le vent, en piégeant le sable, et en le retenant grâce à son système végétatif, la plante va conditionner la forme et le déplacement de la dune. Mais voyons comment...

\section{Une adaptation remarquable}

Pour résister à des conditions de vie particulièrement difficiles, les plantes sur le littoral ont développé des organes et des stratégies afin de résister :

- au mitraillage par le sable en se protégeant par une cuticule épaisse ;

- à la mobilité du substrat en développant un système racinaire fourni ;

- à la forte salinité du milieu grâce à des tissus charnus (plantes succulentes) ;

- à la sécheresse, en piégeant la moindre goutte de rosée avec ses parties aériennes ramifiées ou en allant chercher l'humidité profondément dans le sable grâce à un système racinaire adapté ;

- au dessèchement dû au vent en recréant, notamment, une atmosphère protégée (poils, cuticule...) à proximité de leurs stomates pour réguler leur transpiration.

Toute la végétation se développant sur les différents milieux dunaires présente donc des adaptations particulières, au niveau de l'enracinement, de la gestion de l'eau, de la résistance au sel, de l'endurance au criblage par le sable... Et $c^{\prime}$ est ainsi qu'alors qu'ils ne représentent que moins d'un demi-millième du territoire national, les milieux littoraux possèdent en propre un dixième de la flore française. Certaines espèces, soixante environ, sont strictement inféodées aux milieux dunaires.

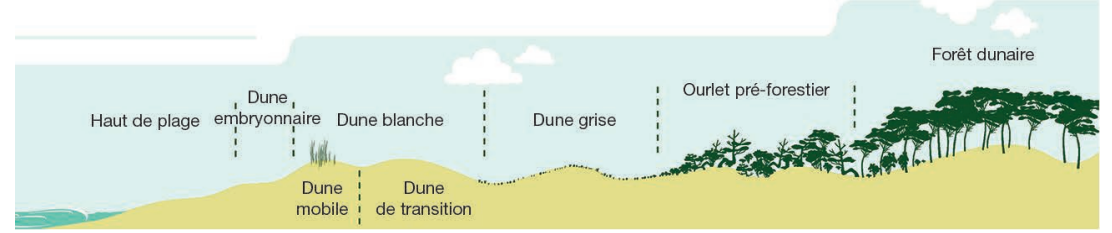

Figure 1.58. Les différents milieux dunaires.

Source : R. Perrot/ONF. 
Selon la distance à la mer, les quantités de sel apportées par les embruns vont décroître, et les conditions favorables à la végétation vont s'améliorer. La richesse en espèces végétales va donc augmenter au fur et à mesure que l'on s'éloigne de la mer.

\section{La végétation de haut de plage}

La mer dépose toute sorte de débris organiques (algues, bois flottés, coquillages, feuilles, cadavres de poissons...) sur un ruban étroit en haut de plage. Ce sont les laisses de mer. Malheureusement, ces déchets organiques sont aussi le plus souvent mélangés à des déchets d'origine humaine apportés par les cours d'eau (bouteilles, sacs plastiques, fragments de filets).

Les déchets organiques accumulés en haut de plage vont avoir un double rôle dans la formation des dunes:

- en offrant un premier obstacle au vent, ils vont faciliter le dépôt du sable transporté par celui-ci ;

- en se décomposant, ils vont libérer des sels minéraux favorables à l'installation d'une flore pionnière (et offrir également un abri à une faune caractéristique).

Cette végétation parfois recouverte par la mer, qui peut se développer dans du sable meuble, supporter le vent, le sel, et vivre dans ce milieu riche en azote (on parle de végétation halonitrophile) en piégeant le sable, va constituer le stade premier de la formation des dunes. Mais elle présente rarement son plein développement, tant en raison de l'érosion marine que de la pression humaine (piétinement, nettoyage des plages...). Grâce à elle, les dépôts de sable vont progressivement s'épaissir et former des bourrelets sableux.

\section{La végétation de la dune embryonnaire}

Ces bourrelets, les banquettes, ne sont qu'occasionnellement submergés, lors des conjonctions de hautes mers et de tempêtes. Une végétation basse à base de chiendent des sables (Elymus farctus, synonyme Agropyron junceum) colonise très vite ces banquettes. C'est la partie aérienne de la plante qui piège le sable apporté par le vent et permet cette élévation. Même si la mer vient recouvrir temporairement ces plantes, leur souplesse et leur tolérance au sel leur permettent de résister à ces conditions difficiles.

\section{La dune blanche}

La dune blanche (ou dune vive) est le cordon de dune mobile ayant une forte accumulation sableuse grâce à l'action des végétaux psammophiles ${ }^{2}$ dominés par l'oyat (Ammophila arenaria). L'oyat (le gourbet des Aquitains) joue un rôle primordial dans la construction des dunes, grâce à ses capacités remarquables : - il supporte l'ensablement car ses tiges souterraines traçantes (les rhizomes) sont capables de prospecter le sable sur de grandes longueurs; elles peuvent aussi produire des drageons qui donnent naissance à de nouvelles pousses; ce lacis de racines contribue au maintien du sable ;

- il est parfaitement "blindé » pour résister au mitraillage par le sable, et il piège donc avec ses feuilles le sable transporté par le vent.

2. Qui aiment le sable. 
Comme le montre la vue de la coupe microscopique dans la figure 1.59, la feuille d'oyat s'enroule sur elle-même, protégeant à l'intérieur de sillons ses stomates, organes lui permettant d'échanger avec le milieu ambiant. En cas de tempête ou de sécheresse, la feuille se recroqueville, limitant sa transpiration et donc sa déperdition en eau.

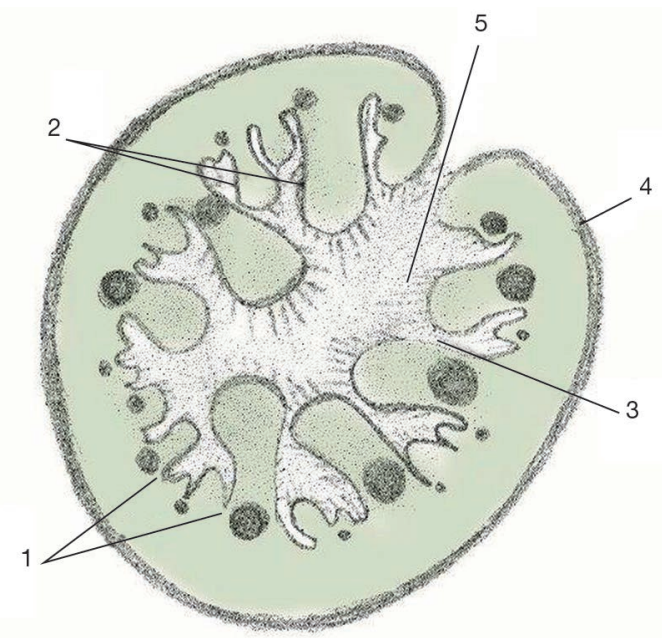

Figure 1.59. Croquis de la coupe d'une feuille d'oyat.

Les cellules bulliformes (1) se gorgent d'eau dans les conditions d'atmosphère favorable et permettent à la feuille de s'ouvrir ; ainsi les stomates (2) protégés au fond des sillons (3) vont permettre les échanges avec l'extérieur. Le dos de la feuille est recouvert d'une cuticule cireuse (4), véritable blindage contre le mitraillage du sable.

(c) L. Gouguet/ONF.

Pendant les phases pionnières, c'est l'oyat qui domine ; il est ensuite rejoint par son cortège habituel de trois espèces omniprésentes : le panicaut (Eryngium maritimum), l'euphorbe (Euphorbia paralias) et le liseron (Calystegia soldanella). Il faut noter que cette végétation de dune blanche peut parfois apparaître dans des zones de remise en mouvement de l'arrière-dune.

Un simple fragment de rhizome peut permettre à l'oyat de se reproduire (reproduction végétative), et cette capacité est utilisée par l'homme pour végétaliser les dunes. Que ce soit en Europe (A. arenaria) ou en Amérique du Nord (A. breviligulata), les végétaux du genre Ammophila ont été des aides précieux pour la fixation des dunes.

\section{La dune de transition}

La végétation de la dune de transition (ou dune semi-fixée) se développe à l'abri du cordon de dune vive où les phénomènes d'accumulation et de transit sont atténués. La physionomie de ce faciès est très marquée par les «moquettes » à fétuque et gaillet, sortes de petites prairies basses relativement planes, d'aspect clairsemé, mais avec des systèmes racinaires en réseau dense et efficace contre l'érosion éolienne.

\section{La dune grise}

La végétation se développe sur des dunes temporairement fixées, arrières-dunes sans transit sableux et assez bien abritées des embruns. Elle est caractérisée par 
une pelouse basse à recouvrement fort ou complet. Les mousses et les lichens constituent une part importante de cette couverture végétale et trouvent leur extension maximale dans les zones les mieux et les plus anciennement stabilisées. Les espèces annuelles à floraison précoce y sont nombreuses : c'est une adaptation à la sécheresse estivale. C'est ici que la diversité des espèces est la plus importante.

Certaines plantes sont caractéristiques de milieux arides ou steppiques (Ephedra distachya) et trouvent dans les dunes littorales les mêmes conditions que dans d'autres milieux plus continentaux.

Pour certaines de ces plantes, la période la plus difficile va être l'été : chaleur extrême au niveau du sol, sécheresse... Elles vont donc se dépêcher de faire leur cycle de végétation dès la fin de l'hiver, afin que par la suite seuls leurs fruits (graines) soient confrontés à ces conditions pénibles.

Toutes les plantes sont particulièrement sensibles au piétinement : des passages répétés entraîneront inévitablement la destruction des parties aériennes, un tassement au niveau du système racinaire, et donc leur disparition. En l'absence de couverture végétale, ceci donne alors au vent la possibilité de décaper le sable, et permet donc la remobilisation de la dune.

\section{De la mer à la forêt: des habitats naturels bien différenciés}

Christophe Rollier

\section{La dune : un milieu rude}

La singularité des milieux dunaires tient aux nombreuses contraintes qui les caractérisent :

- d'origine marine : le sel porté par les marées et les embruns est, à forte concentration, une substance toxique pour les organismes terrestres; les houles et les grandes marées occasionnent une disparition/reconstitution régulière du pied de dune ;

- d'origine éolienne : le vent agit par la force qu'il exerce sur les êtres vivants, il est à l'origine du déplacement régulier et parfois massif des éléments constitutifs du sol, de la déstabilisation régulière du substrat; il a aussi un effet abrasif ; - d'origine pédologique : le substrat sableux drainant restitue peu d'éléments minéraux aux végétaux par ailleurs très exposés au soleil ; il provoque aussi un échauffement ;

- d'origine biotique* : en fonction de la diminution des contraintes écologiques, plus nombreuses sont les espèces qui peuvent s'installer, donc plus forte est la concurrence entre ces espèces.

L'agencement des espèces dunaires est ainsi principalement lié à leur adaptation à ces contraintes. La caractérisation des différents milieux littoraux se base sur la répartition des espèces végétales qui se sont adaptées, et dont certaines d'entre-elles ont la capacité de modeler leur environnement immédiat de manière à réduire une partie de ces contraintes.

\section{Les milieux dunaires secs}

\section{Végétation de haut de plage}

Dans la partie la plus exposée aux marées, il n'est pas question de s'établir durablement. La stratégie adoptée par les plantes est un cycle de vie court : 
I'individu meurt après avoir produit une fructification abondante. Cette stratégie est celle des espèces annuelles. Des espèces, comme l'arroche des sables (Atriplex laciniata), le cakilier maritime (Cakile maritima), le pourpier de mer (Honckenya peploides), la soude épineuse (Kali soda), plus rarement l'euphorbe péplis (Euphorbia peplis), ont une présence fugace en haut de plage. Leur développement rapide est facilité par la richesse en azote liée à la décomposition des laisses de mer.

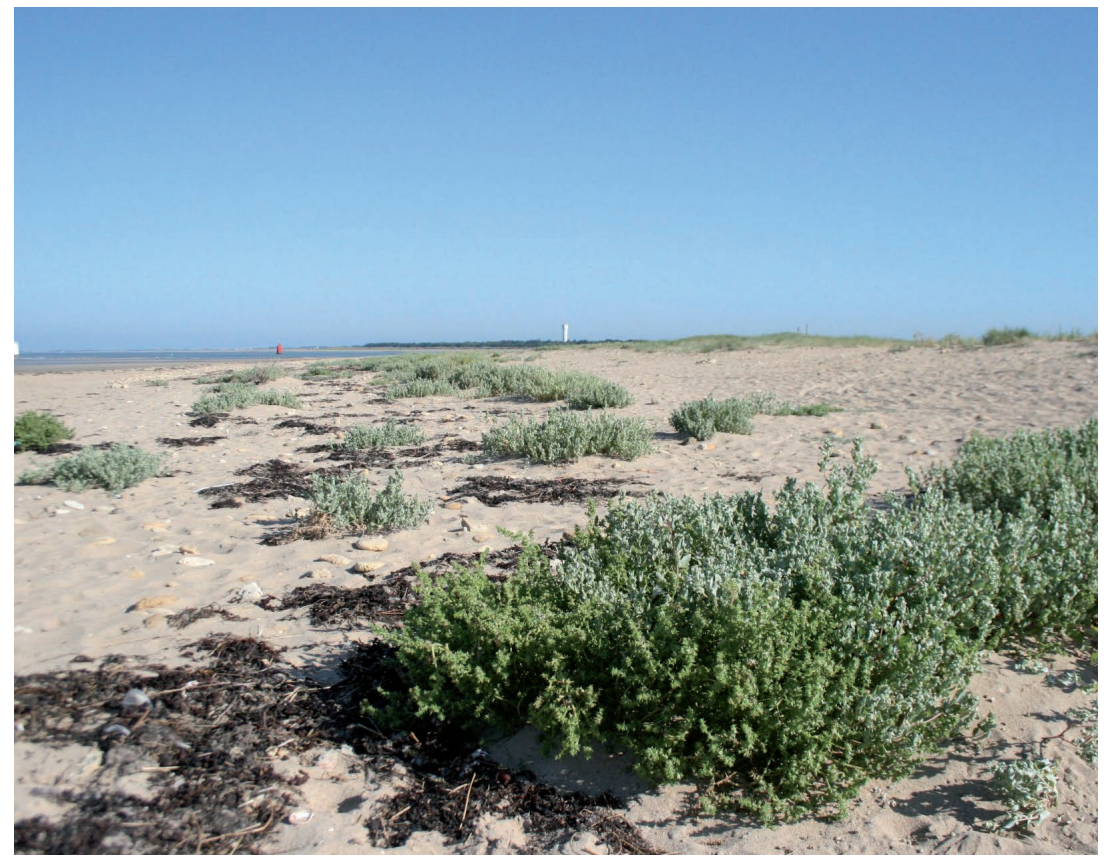

Figure 1.60. Végétation de haut de plage (La Barre-de-Monts, Vendée).

(c) C. Rollier/ONF.

Bien souvent, le piétinement des estivants a atteint le pied de dune et a eu raison des plantes qui ont pu s'y développer. En situation d'érosion, lorsque la mer s'est attardée jusqu'au pied de dune, les espèces de haut de plage ne s'expriment pas. Même si les semences sont présentes et qu'elles parviennent à germer, les plantules dépérissent rapidement car la teneur en sel est trop forte.

Tableau 1.1. Liste des habitats concernés.

\begin{tabular}{|l|l|l|l|}
\hline $\begin{array}{l}\text { Code } \\
\text { EUNIS }\end{array}$ & $\begin{array}{l}\text { Code } \\
\text { EUR 28 }\end{array}$ & $\begin{array}{l}\text { Code Corine } \\
\text { Biotopes }\end{array}$ & Intitulé \\
\hline B1.1 & $1210-1$ & 17.2 & $\begin{array}{l}\text { Laisses de mer sur substrat sableux à vaseux } \\
\text { des côtes Manche-Atlantique et mer du Nord }\end{array}$ \\
\hline B1.1 & $1210-2$ & 17.2 & $\begin{array}{l}\text { Laisses de mer sur cordons de galets } \\
\text { et de graviers des côtes Manche-Atlantique } \\
\text { et mer du Nord }\end{array}$ \\
\hline B1.1 & $1210-3$ & 17.2 & Laisses de mer des côtes méditerranéennes \\
\hline
\end{tabular}

Pour chaque habitat cité, nous préciserons : le code EUNIS (nouvelle classification des habitats européens terrestres et aquatiques) ; le code EUR 28 (issu du Manuel d'interprétation des habitats communautaires européens Natura 2000) ; le code CORINE Biotopes (ancien référentiel européen des habitats naturels et artificiels 1994); l'intitulé de la formation végétale. 


\section{Stade jeune des avant-dunes ou " banquettes à agropyron "}

En s'éloignant un peu de la mer, les espèces vivaces apparaissent. L'agropyron (Elytrigia juncea) est caractéristique du fait de ses longs rhizomes qui peuvent s'étendre de plusieurs mètres par an en direction de la mer. Cette graminée agit comme un piège à sable. La plante est vite recouverte et doit continuer à allonger ses tiges. Le sable s'élève ainsi progressivement pour former un bourrelet dunaire. D'autres espèces accompagnent l'agropyron et contribuent à sa tâche : le liseron des dunes (Calystegia soldanella), l'euphorbe des dunes (Euphorbia paralias), la renouée maritime (Polygonum maritimum)...

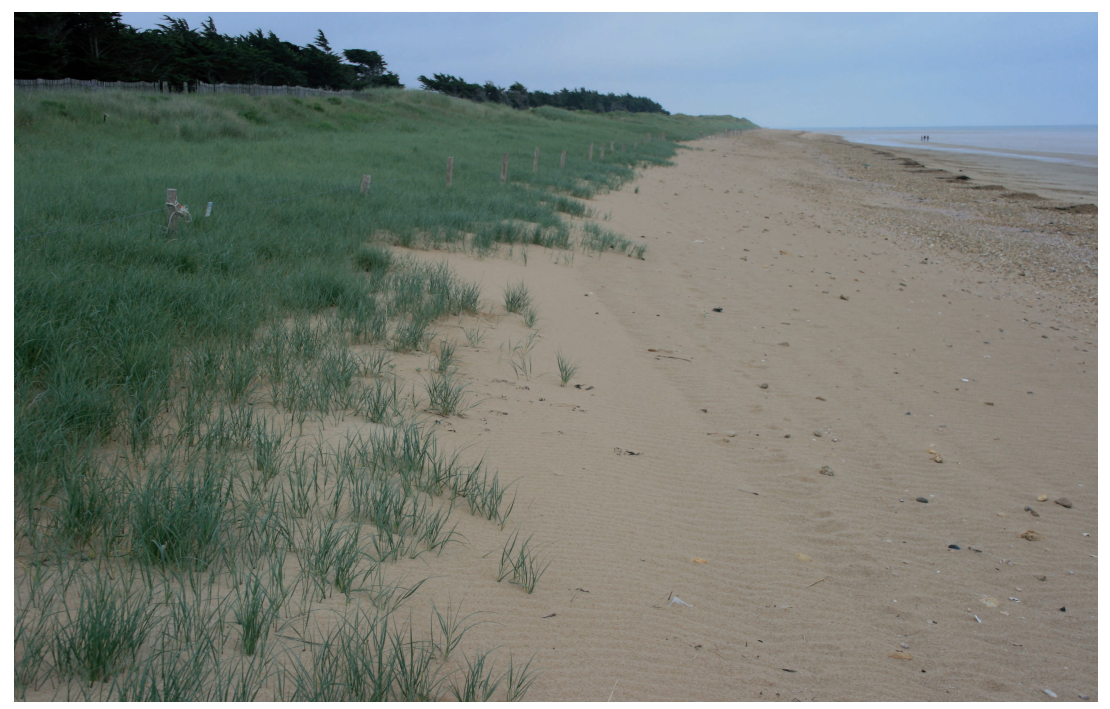

Figure 1.61. Banquette à agropyron (Notre-Dame-de-Monts, Vendée).

(C) C. Rollier/ONF.

L'agropyron tolère d'être immergé sur une courte durée. La reprise se fait alors dès le printemps suivant, en dépit de la salinité encore forte.

En Méditerranée, la dune embryonnaire peut accueillir d'autres groupements avec des espèces comme le sporobole piquant (Sporobolus pungens), le panais épineux (Echinophora spinosa), la spartine bigarrée (Spartina patens), le diotis blanc (Achillea maritima) ou le silène de Corse (Silene succulenta subsp. corsica) en Corse.

Tableau 1.2. Liste des habitats concernés.

\begin{tabular}{|l|l|l|l|}
\hline $\begin{array}{l}\text { Code } \\
\text { EUNIS }\end{array}$ & $\begin{array}{l}\text { Code } \\
\text { EUR 28 }\end{array}$ & $\begin{array}{l}\text { Code Corine } \\
\text { Biotopes }\end{array}$ & Intitulé \\
\hline B1.3 & $2110-1$ & 16.211 & Dunes mobiles embryonnaires atlantiques \\
\hline B1.3 & $2110-2$ & 16.211 & $\begin{array}{l}\text { Dunes mobiles embryonnaires } \\
\text { méditerranéennes }\end{array}$ \\
\hline
\end{tabular}

\section{Dune mobile ou dune blanche}

Si la banquette n'est pas emportée par la mer, elle continue à s'élever et d'autres espèces plus sensibles à la salinité peuvent alors la coloniser. Une concurrence se met en place entre l'agropyron et l'oyat, ou gourbet (Ammophila arenaria subsp. arenaria, A. arenaria subsp. australis en Méditerranée). Ce dernier, plus 
compétitif, est aussi plus dynamique. L'élévation de la dune va donc s'accélérer, le substrat est encore très mobile. Les conditions du milieu devenant moins contraignantes, le nombre d'espèces augmente. L'euphorbe des dunes est encore plus présente, en compagnie du liseron des dunes, du panicaut des dunes (Eryngium maritimum), de la giroflée des dunes (Matthiola sinuata), du gaillet des dunes (Galium arenarium).

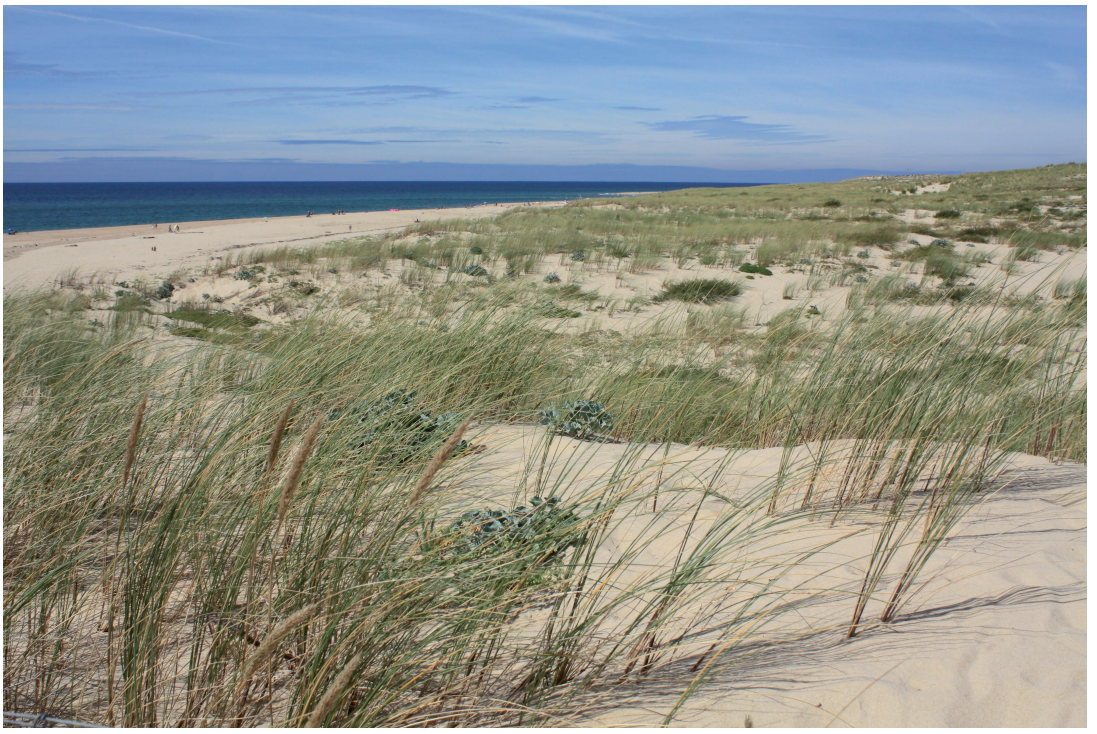

Figure 1.62. Végétation de dune blanche (Cap Ferret).

(C) L. Gouguet/ONF.

Une forme semi-fixée s'observe en arrière, structurée par la fétuque à feuilles de jonc (Festuca rubra subsp. juncea), avec la laîche des sables (Carex arenaria).

Certaines espèces sont des variantes géographiques :

- les côtes de la Manche et de la mer du Nord se distinguent par la présence de l'élyme des sables (Leymus arenarius) ; les espèces thermophiles, comme la Luzerne marine (Medicago marina) ou la crépide bulbeuse (Sonchus bulbosus), y sont absentes ;

- en Bretagne, le nombre d'espèces de la dune mobile est restreint mais l'oyat fortement recouvrant ; la fréquente proximité de côtes rocheuses permet à certaines espèces des pelouses aérohalynes de s'introduire, c'est le cas de la fétuque pruineuse (Festuca pruinosa) et, plus rarement, de la criste marine (Crithmum maritimum) et de l'armérie maritime (Armeria maritima) ;

- en Vendée et en Charente-Maritime, les sables calcarifères sont caractérisés par la dominance de l'armoise maritime (Artemisia campestris subsp. maritima); le diotis maritime (Achillea maritima) s'y rencontre parfois mais il est rare ;

- en Aquitaine, on rencontre l'épervière laineuse (Hieracium eriophorum), la linaire à feuilles de thym (Linaria thymifolia), I'astragale de Bayonne (Astragalus baionensis), le diotis maritime (Achillea maritima), le silène des ports (Silene portensis), le silène de Thore (Silene uniflora subsp. thorei) ;

- en Méditerranée, I'oyat du midi (Ammophila arenaria subsp. australis) se substitue à l'oyat " type » (Ammophila arenaria subsp. arenaria), et on rencontre I'anthémis maritime (Anthemis maritima), le panais épineux (Echinophora spinosa), le diotis maritime, le souchet des dunes (Cyperus capitatus), le lys maritime (Pancratium maritimum)... 
Tableau 1.3. Liste des habitats concernés.

\begin{tabular}{|l|l|l|l|}
\hline $\begin{array}{l}\text { Code } \\
\text { EUNIS }\end{array}$ & $\begin{array}{l}\text { Code } \\
\text { EUR 28 }\end{array}$ & $\begin{array}{l}\text { Code Corine } \\
\text { Biotopes }\end{array}$ & Intitulé \\
\hline B1.3 & $2120-1$ & 16.212 & $\begin{array}{l}\text { Dunes mobiles à Ammophila arenaria subsp. } \\
\text { arenaria des côtes atlantiques }\end{array}$ \\
\hline B1.3 & $2120-2$ & 16.212 & $\begin{array}{l}\text { Dunes mobiles à Ammophila arenaria subsp. } \\
\text { australis des côtes méditerranéennes }\end{array}$ \\
\hline
\end{tabular}

\section{Dune grise ou dune fixée}

Lorsque les apports de sable se réduisent et que les végétaux ont bien ancré leurs racines, le sable est bien fixé. Les espèces intolérantes à la mobilité du substrat peuvent s'installer. Les contraintes relictuelles sont une légère salinité apportée par les embruns et un saupoudrage de sable par vent violent. C'est ici que l'on rencontre la plus grande diversité en espèces.

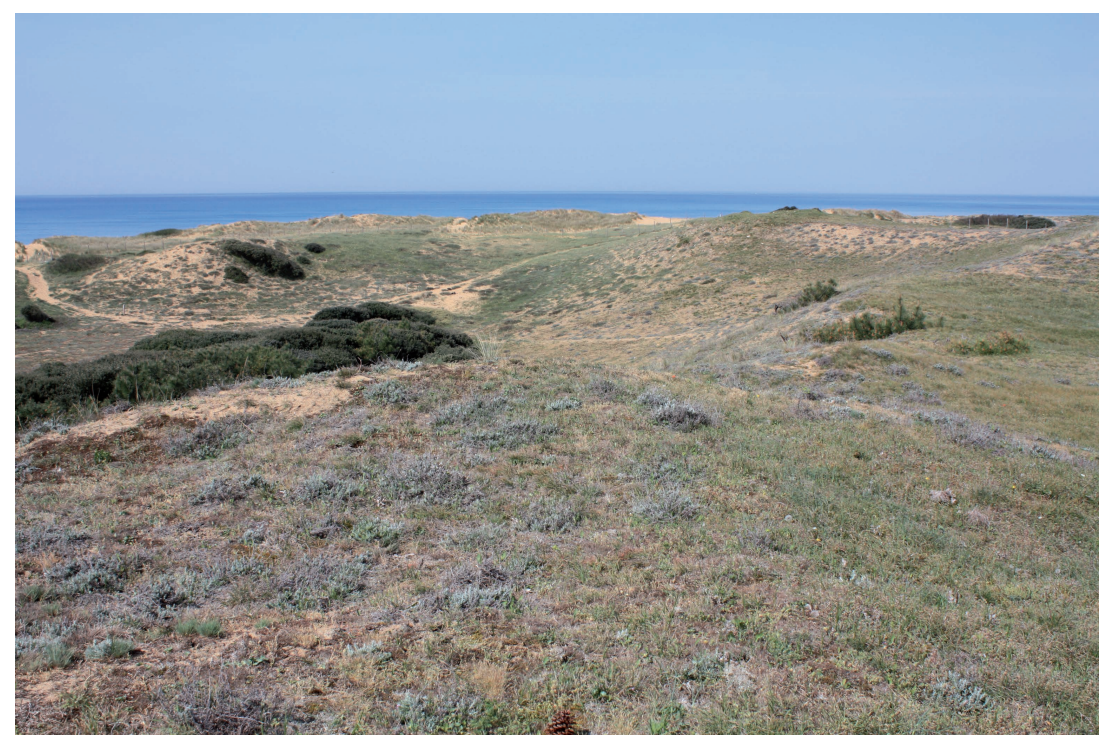

Figure 1.63. Végétation de dune grise avec bouquets pionniers de chêne vert (Olonnesur-Mer).

(C) L. Gouguet/ONF.

La végétation commence à s'étager avec, sur la façade atlantique, une strate prédominante bryo-lichénique très visible en hiver, composée de mousses - la tortule ruraliforme (Tortula ruraliformis), la tortelle jaune-verdâtre (Tortella flavovirens), I'hypne cyprès (Hypnum cupressiforme)... - et de lichens, en particulier de nombreuses espèces de cladonies (Cladonia sp. pl.).

Les plantes vasculaires varient selon les saisons. Au printemps, on observe la floraison colorée des violettes (Viola kitaibeliana, V. curtisii, Viola canina var. dunensis), du lamier amplexicaule (Lamium amplexicaule), de la véronique des champs (Veronica arvensis), des céraistes (Cerastium diffusum, C. glomeratum, C. semidecandrum), du cranson du Danemark (Cochlearia danica)... C'est ensuite au tour de l'armoise de Loyd, du corynéphore blanchâtre (Corynephorus canescens), de la koelérie blanchâtre (Koeleria albescens), de la jasione maritime (Jasione crispa subsp. maritima), de I'hélianthème à gouttes (Tuberaria 
guttata), de l'œillet des dunes (Dianthus gallicus)... C'est également dans ce milieu que se développe la cynoglosse des dunes (Omphalodes littoralis), espèce endémique* de la côte atlantique française, de l'île d'Oléron au sud de la Bretagne.

Les sous-arbrisseaux peuvent avoir une certaine importance et marquent une strate plus haute : I'immortelle des dunes (Helichrysum stoechas), le raisin de mer (Ephedra distachya), avec l'immortelle d'Italie (Helichrysum italicum), le genêt de Salzmann (Genista salzmanii), le genêt de Corse (Genista corsica) en Méditerranée.

En Méditerranée, la flore est assez différente, composée par des espèces comme la malcolmie des côtes (Malcolmia littorea), la crucianelle maritime (Crucianella maritima), la germandrée des dunes (Teucrium dunense), I'armoise poisseuse (Artemisia campestris subsp. glutinosa), l'orcanette des teinturiers (Alkanna matthioli)...

Tableau 1.4. Liste des habitats concernés.

\begin{tabular}{|l|l|l|l|}
\hline $\begin{array}{l}\text { Code } \\
\text { EUNIS }\end{array}$ & $\begin{array}{l}\text { Code } \\
\text { EUR 28 }\end{array}$ & $\begin{array}{l}\text { Code Corine } \\
\text { Biotopes }\end{array}$ & Intitulé \\
\hline B1.4 & $2130-1$ & 16.221 & $\begin{array}{l}\text { Dunes grises de la mer du Nord } \\
\text { et de la Manche }\end{array}$ \\
\hline B1.4 & $2130-2$ & 16.222 & Dunes grises des côtes atlantiques \\
\hline B1.4 & 2210 & 16.223 & $\begin{array}{l}\text { Dunes fixées du littoral du Crucianellion } \\
\text { maritimae }\end{array}$ \\
\hline B1.4 & $2230-1$ & 16.228 & Pelouses dunales des Malcolmietalia \\
\hline
\end{tabular}

\section{Dunes boisées}

Une fois affranchie des contraintes marines, la végétation connaît une dynamique progressive conduisant parfois au boisement. Se succèdent alors ourlets thermophiles, fourrés thermophiles, puis dunes boisées.

La mobilité naturelle des sables dunaires rend cependant difficile la mise en place d'une dynamique aussi complète ; les forêts dunaires actuelles sont donc largement le résultat de la volonté humaine de fixer les sables. Le pin maritime (Pinus pinaster) est l'essence privilégiée pour les boisements. D'autres essences ont été aussi utilisées, en fonction des conditions naturelles.

De la frontière belge à la Somme, le pin maritime est accompagné du pin sylvestre (Pinus sylvestris), du pin laricio de Corse (Pinus nigra subsp. laricio var. corsica), du pin noir d'Autriche (Pinus nigra subsp. nigra), avec un sousétage spontané d'argousier (Hippophae rhamnoides). La végétation y est plutôt hygrophile.

Tableau 1.5. Liste des habitats concernés.

\begin{tabular}{|l|l|l|l|}
\hline $\begin{array}{l}\text { Code } \\
\text { EUNIS }\end{array}$ & $\begin{array}{l}\text { Code } \\
\text { EUR 28 }\end{array}$ & $\begin{array}{l}\text { Code Corine } \\
\text { Biotopes }\end{array}$ & Intitulé \\
\hline B1.7 & $2180-1$ & 16.29 & Dunes boisées du littoral nord-atlantique \\
\hline
\end{tabular}

Du sud de la Bretagne au bassin d'Arcachon, le pin maritime côtoie le chêne vert (Quercus ilex), ce dernier formant souvent un sous-étage continu. Les chênes caducs s'installent dans le peuplement (Quercus pubescens, Q. petraea, Q. robur). 


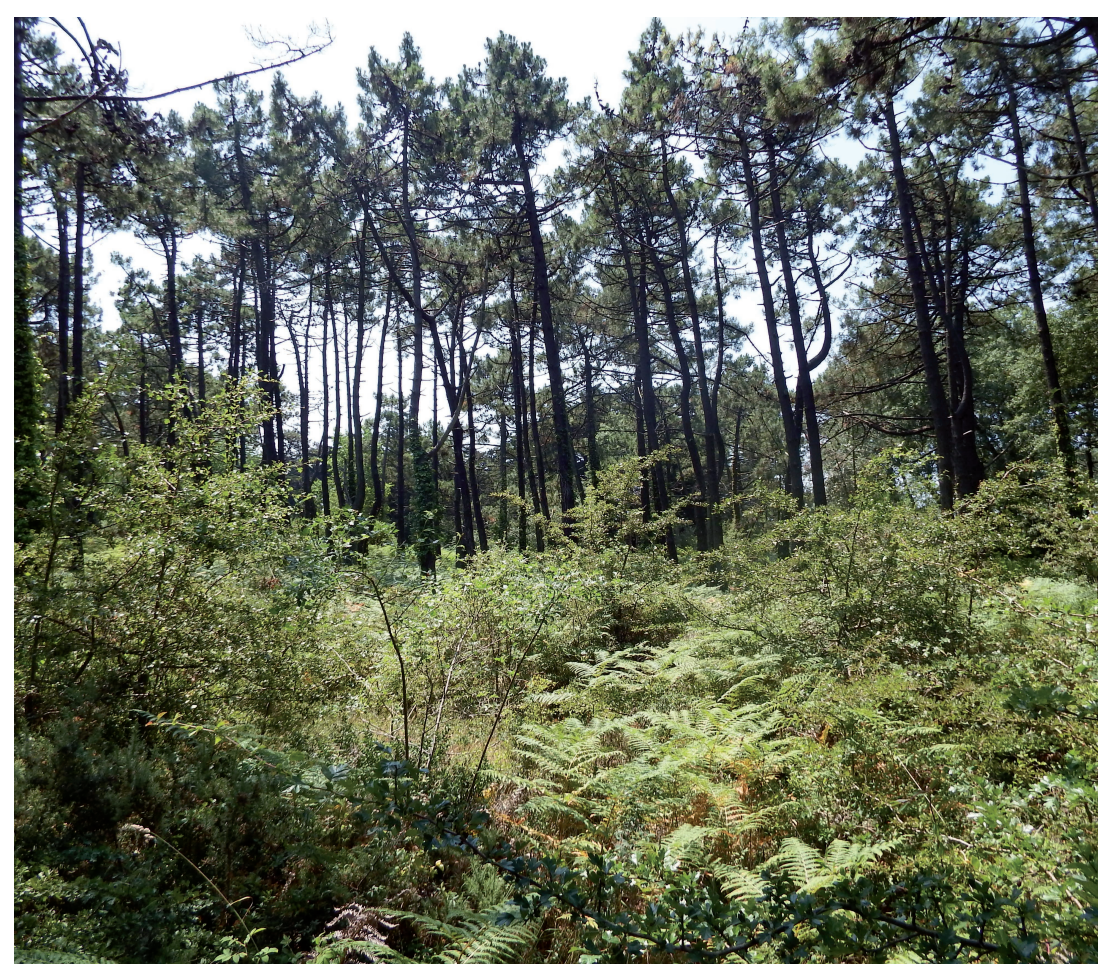

Figure 1.64. Paysage de dune boisée.

(C) C. Rollier/ONF.

Le caractère méridional est affirmé avec en sous-étage l'arbousier (Arbutus unedo) et un certain nombre d'arbustes méditerranéens subspontanés ou indigènes : laurier (Laurus nobilis), nerprun alaterne (Rhamnus alaternus), viorne tin (Viburnum tinus), garou (Daphne gnidium), filaire (Phyllirea angustifolia), ciste à feuilles de sauge (Cistus salvifolius), genêt à balai (Cytisus scoparius), ajonc d'Europe (Ulex europaeus). Au sol, la garance voyageuse (Rubia peregrina), le lierre (Hedera helix), le fragon (Ruscus aculeatus), les polypodes (Polypodium cambricum, P. vulgare), la koelérie blanchâtre (Koeleria glauca), les céphalanthères (Cephalanthera rubra, C. longifolia) sont des espèces fidèles à ces forêts ; elles se développent souvent sur des sables calcarifères entre la Vendée et la rive sud de l'estuaire de la Gironde.

Tableau 1.6. Liste des habitats concernés.

\begin{tabular}{|l|l|l|l|}
\hline $\begin{array}{l}\text { Code } \\
\text { EUNIS }\end{array}$ & $\begin{array}{l}\text { Code } \\
\text { EUR 28 }\end{array}$ & $\begin{array}{l}\text { Code Corine } \\
\text { Biotopes }\end{array}$ & Intitulé \\
\hline B1.7 & $2180-2$ & 16.29 & $\begin{array}{l}\text { Dunes boisées littorales thermo-atlantiques à } \\
\text { chêne vert }\end{array}$ \\
\hline
\end{tabular}

Du sud d'Arcachon jusqu'au Pays basque, les dunes boisées se composent d'un peuplement de pin maritime et de chêne-liège (Quercus suber), ce dernier remplaçant le chêne vert. La flore est assez proche mais moins variée, plus acidiphile. Les espèces nouvelles sont la bruyère cendrée (Erica cinerea), la fougère-aigle (Pteridium aquilinum), la bourdaine (Frangula alnus), avec le chèvrefeuille des bois (Lonicera periclymenum), la salsepareille (Smilax aspera), la germandrée scorodoine (Teucrium scorodonia). 
Tableau 1.7. Liste des habitats concernés.

\begin{tabular}{|l|l|l|l|}
\hline $\begin{array}{l}\text { Code } \\
\text { EUNIS }\end{array}$ & $\begin{array}{l}\text { Code } \\
\text { EUR 28 }\end{array}$ & $\begin{array}{l}\text { Code Corine } \\
\text { Biotopes }\end{array}$ & Intitulé \\
\hline B1.7 & $2180-3$ & 16.29 & $\begin{array}{l}\text { Dunes boisées littorales thermo-atlantiques } \\
\text { à chêne-liège }\end{array}$ \\
\hline
\end{tabular}

On observe aussi en Aquitaine une chênaie pédonculée sur sols plus frais, avec une flore assez proche de la dune boisée de pin maritime.

Tableau 1.8. Liste des habitats concernés.

\begin{tabular}{|l|l|l|l|}
\hline $\begin{array}{l}\text { Code } \\
\text { EUNIS }\end{array}$ & $\begin{array}{l}\text { Code } \\
\text { EUR 28 }\end{array}$ & $\begin{array}{l}\text { Code Corine } \\
\text { Biotopes }\end{array}$ & Intitulé \\
\hline B1.7 & $2180-4$ & 16.29 & Arrière-dunes boisées à chêne pédonculé \\
\hline
\end{tabular}

En Méditerranée, les dunes boisées occupent des surfaces réduites et sont localisées principalement en Camargue sur des dunes fossiles, ainsi qu'en Corse. Plantées de pin maritime ou de pin parasol (Pinus pinea), elles se présentent en général sous la forme de boisements clairs avec une végétation de dune grise. Des espèces du cortège de la chênaie verte occupent généralement le sous-étage : arbousier (Arbutus unedo), clématite flammette (Clematis flammula), pistachier lentisque (Pistacia lentiscus), asperge piquante (Asparagus acutifolius), garou, garance voyageuse. En Corse, les cistes sont bien représentés (Cistus creticus, C. salvifolius).

Les formations à genévrier de mer (Juniperus phoenicea subsp. turbinata) rencontrées sur les dunes fossiles de Camargue et sur le littoral rocheux de Provence-Alpes-Côte d'Azur constituent un aspect particulièrement original de la dune boisée.

Tableau 1.9. Liste des habitats concernés.

\begin{tabular}{|l|l|l|l|}
\hline $\begin{array}{l}\text { Code } \\
\text { EUNIS }\end{array}$ & $\begin{array}{l}\text { Code } \\
\text { EUR 28 }\end{array}$ & $\begin{array}{l}\text { Code Corine } \\
\text { Biotopes }\end{array}$ & Intitulé \\
\hline B1.7 & $2270-1$ & $16.29 \times 42.8$ & Forêts dunales à pin parasol \\
\hline B1.7 & $2270-2$ & $16.29 \times 42.8$ & Forêts dunales à pin maritime \\
\hline
\end{tabular}

\section{Les milieux dunaires humides}

Si la plus grande surface des milieux dunaires est composée de milieux secs, la nappe d'eau douce oscillant dans le sol peut affleurer et des milieux humides être observés. À l'instar des zones humides intérieures, on observe une variation annuelle importante du niveau de la nappe qui entraîne dans certains cas une sécheresse extrême en surface. Mais, dans la dune, les fluctuations suivent aussi les marées pour l'Atlantique et la Manche. L'autre caractéristique de ces milieux est une exposition aux embruns et parfois aux remontées d'eau saline, ceci entraînant une teneur relative en sel dans le sol. Ces habitats humides dunaires sont plus représentatifs de la côte atlantique, mais peuvent également se rencontrer ponctuellement en Méditerranée sous la forme de petits creux inter-dunaires. Les végétations des étangs caractéristiques des dunes aquitaines se rapprochent des zones humides intérieures et ne seront pas traitées ici. On classe les dépressions dunaires en fonction de leur niveau d'engorgement. 


\section{Milieux aquatiques}

Les mares dunaires sont de petits plans d'eau avec une végétation flottante à lentilles d'eau (Lemna minor, L. trisulca...) ou enracinée : potamots (Potamogeton sp. pl.), zanichellie pédicellée (Zanichellia pedicellata), hottonie (Hottonia palustris) ou à characées. Les espèces qui les caractérisent ont en général la particularité d'être tolérantes à un certain niveau de salinité. Elles présentent un enjeu majeur pour la reproduction d'un crapaud, le pélobate cultripède (Pelobates cultripes).

Tableau 1.10. Liste des habitats concernés.

\begin{tabular}{|l|l|l|l|}
\hline $\begin{array}{l}\text { Code } \\
\text { EUNIS }\end{array}$ & $\begin{array}{l}\text { Code } \\
\text { EUR 28 }\end{array}$ & $\begin{array}{l}\text { Code Corine } \\
\text { Biotopes }\end{array}$ & Intitulé \\
\hline B1.81 & $2190-1$ & 16.31 & Mares dunaires \\
\hline
\end{tabular}

\section{Milieux amphibies}

Sur les berges des mares ou dans les mares temporaires, se développent des végétations annuelles ou vivaces avec le samole de Valerand (Samolus valerandi), le mouron délicat (Anagallis tenella), le scirpe épingle (Eleocharis acicularis), l'écuelle d'eau (Hydrocotyle vulgaris), les petites centaurées (Centaurium littorale, C. pulchellum), la chlore perfoliée (Blackstonia perfoliata), la sagine noueuse (Sagina nodosa)...

Tableau 1.11. Liste des habitats concernés.

\begin{tabular}{|l|l|l|l|}
\hline $\begin{array}{l}\text { Code } \\
\text { EUNIS }\end{array}$ & $\begin{array}{l}\text { Code } \\
\text { EUR 28 }\end{array}$ & $\begin{array}{l}\text { Code Corine } \\
\text { Biotopes }\end{array}$ & Intitulé \\
\hline B1.82 & $2190-2$ & 16.32 & Pelouses pionnières des pannes \\
\hline
\end{tabular}

\section{Bas-marais dunaires}

Organisés sous forme de ceintures ou occupant des dépressions, les basmarais prennent diverses formes dominées par des graminées (Calamagrostis epigeios, C. canescens, Agrostis stolonifera subsp. maritima), des cypéracées (Carex trinervis, C. scandinavica, C. lepidocarpa, Eleocharis palustris, E. quinqueflora, Schoenus nigricans, Scirpoides holoschoenus) ou des joncs (Juncus maritimus, Juncus anceps, Juncus subnodulosus). C'est aussi le milieu de plusieurs orchidées patrimoniales : liparis de Loesel (Liparis loeselii), spiranthe d'été (Spiranthes aestivalis), helléborine des marais (Epipactis palustris), orchis incarnat (Dactylorhiza incarnata)...

Tableau 1.12. Liste des habitats concernés.

\begin{tabular}{|l|l|l|l|}
\hline $\begin{array}{l}\text { Code } \\
\text { EUNIS }\end{array}$ & $\begin{array}{l}\text { Code } \\
\text { EUR 28 }\end{array}$ & $\begin{array}{l}\text { Code Corine } \\
\text { Biotopes }\end{array}$ & Intitulé \\
\hline B1.83 & $2190-3$ & 16.33 & Bas-marais dunaires \\
\hline
\end{tabular}

\section{Prairies humides dunaires}

Très proches de l'habitat précédent, les prairies humides dunaires diffèrent par l'absence de joncs et de scirpes. Les espèces structurantes sont des graminées, en particulier l'agrostide stolonifère (Agrostis stolonifera) et le chiendent du littoral (Elytrigia acuta). 
Tableau 1.13. Liste des habitats concernés.

\begin{tabular}{|l|l|l|l|}
\hline $\begin{array}{l}\text { Code } \\
\text { EUNIS }\end{array}$ & $\begin{array}{l}\text { Code } \\
\text { EUR 28 }\end{array}$ & $\begin{array}{l}\text { Code Corine } \\
\text { Biotopes }\end{array}$ & Intitulé \\
\hline B1.82 & $2190-4$ & 16.34 & Prairies humides dunaires \\
\hline
\end{tabular}

\section{Roselières et cariçaies}

Les végétations à grands hélophytes - scirpe maritime (Bolboschoenus maritimus), marisque (Cladium mariscus), phragmite (Phragmites australis) occupent des dépressions assez éloignées des embruns, dont la dynamique conduit au boisement ( $d^{\prime}$ abord par la saulaie). Certaines espèces des bas-marais peuvent encore s'y retrouver. C'est aussi le milieu de certains petits mollusques comme le vertigo de Desmoulins (Vertigo moulinsiana).

Tableau 1.14. Liste des habitats concernés.

\begin{tabular}{|l|l|l|l|}
\hline $\begin{array}{l}\text { Code } \\
\text { EUNIS }\end{array}$ & $\begin{array}{l}\text { Code } \\
\text { EUR 28 }\end{array}$ & $\begin{array}{l}\text { Code Corine } \\
\text { Biotopes }\end{array}$ & Intitulé \\
\hline B1.85 & $2190-5$ & 16.35 & Roselières et cariçaies dunaires \\
\hline
\end{tabular}

\section{Dunes à saule des dunes}

Caractérisées par le saule des dunes (Salix repens var. dunensis) qui constitue une strate uniforme inférieure à $1 \mathrm{~m}$ de hauteur, ces végétations occupent les dépressions inondées pendant l'hiver et une partie du printemps. Le nombre d'espèces est relativement réduit mais les stades les plus jeunes se caractérisent par la présence de nombreuses espèces des bas-marais, en particulier les orchidées.

Tableau 1.15. Liste des habitats concernés.

\begin{tabular}{|l|l|l|l|}
\hline $\begin{array}{l}\text { Code } \\
\text { EUNIS }\end{array}$ & $\begin{array}{l}\text { Code } \\
\text { EUR 28 }\end{array}$ & $\begin{array}{l}\text { Code Corine } \\
\text { Biotopes }\end{array}$ & Intitulé \\
\hline B1.62 & $2170-1$ & 16.26 & Dunes à saule des dunes \\
\hline
\end{tabular}

\section{Saulaies et aulnaies marécageuses}

Les dépressions les plus écartées des contraintes marines bénéficient d'un boisement par des saulaies ou des aulnaies marécageuses en fonction du niveau d'engorgement. La particularité de ces boisements humides, souvent plantés de peupliers, est de présenter une sécheresse estivale plus ou moins longue. La flore herbacée est similaire à celle des roselières et des cariçaies, la ronce à feuilles d'orme (Rubus ulmifolius) est bien recouvrante, les herbacées des forêts hygrophiles sont représentées : eupatoire chanvrine (Eupatorium cannabinum), berce (Heracleum sphondyllium), scutellaire casquée (Scutellaria galericulata), lysimaque des bois (Lysimachia nemorum), écuelle d'eau.

\section{Milieux humides au sein des dunes méditerranéennes}

On les rencontre soit au niveau des dépressions humides inter-dunaires, soit au tombant des dunes sous la forme d'un étroit liseré situé au-dessus des zones influencées par le sel. La végétation y est dominée par les scirpes (Bolboschoenus maritimus, Scirpoides holoschoenus ssp., Juncus acutus, Scoenus nigricans). C'est dans ce milieu qu'en Camargue et jusque dans I'Hérault se développe la canne de Ravenne (Saccharum ravennae). 


\section{Les dunes françaises}

\section{Les dunes de la Manche et de la mer du Nord}

\section{Yvonne Battiau-Queney}

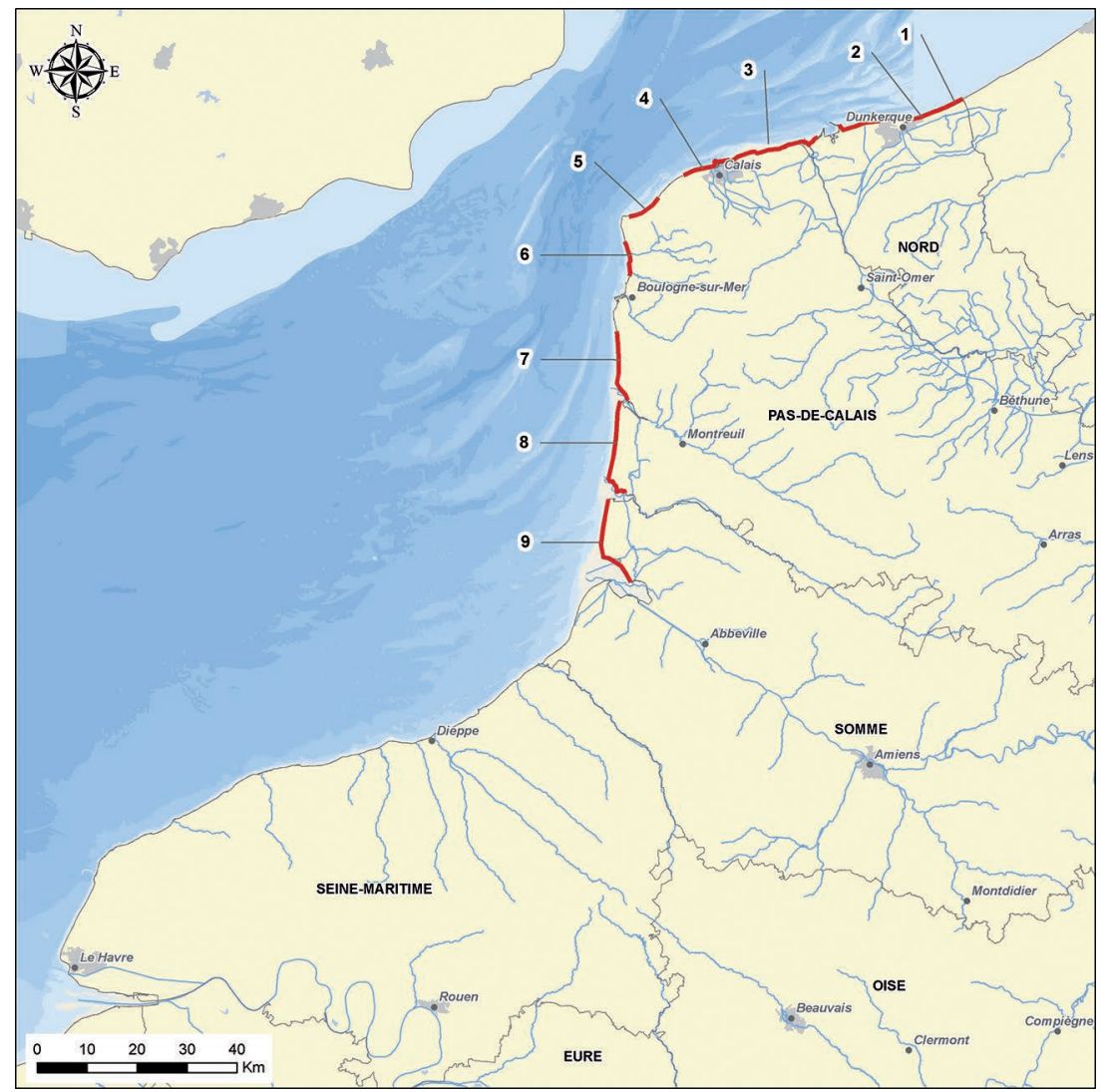

Figure 1.65. Emplacement des principales dunes du Nord de la France.

Dunes flamandes orientales : 1 . dunes du Perroquet; 2 . dune Marchand et dune Dewulf.

Dunes flamandes occidentales : 3 . dune du Platier d'Oye et dune Fort-Vert ; 4 . dune de Sangatte et dune de Blériot Plage ; 5 . dunes de Wissant ; 6 . dunes de la Slack.

Dunes picardes : 7. dunes d'Écault, dunes du mont Saint-Frieux ; 8. dunes du Montreuillois ;

9. dunes du Marquentere.

Sources : Cerema, ONF.

\section{Spécificités météo-marines}

Ce littoral est extrêmement varié, avec des côtes rocheuses à écueils, des plages sableuses plus ou moins larges, des estuaires et des falaises de hauteurs et de profils divers. Mais il existe un point commun : dans cette mer peu profonde, ouverte à la fois sur l'Atlantique et la mer du Nord, la marée joue un rôle majeur tant par l'étendue des espaces intertidaux que par les courants induits. Sur le territoire français, $c^{\prime}$ est ici que le marnage atteint ses plus grandes valeurs, créant des espaces potentiels d'envol favorables aux dunes. L'onde de marée principale se propage du sud-ouest vers le nord-est. Elle s'amplifie dans la baie du Mont-Saint-Michel et celle de la Somme, puis elle s'atténue vers le Pas-de-Calais où l'amplitude de la marée ne dépasse pas 6 m à Dunkerque. 


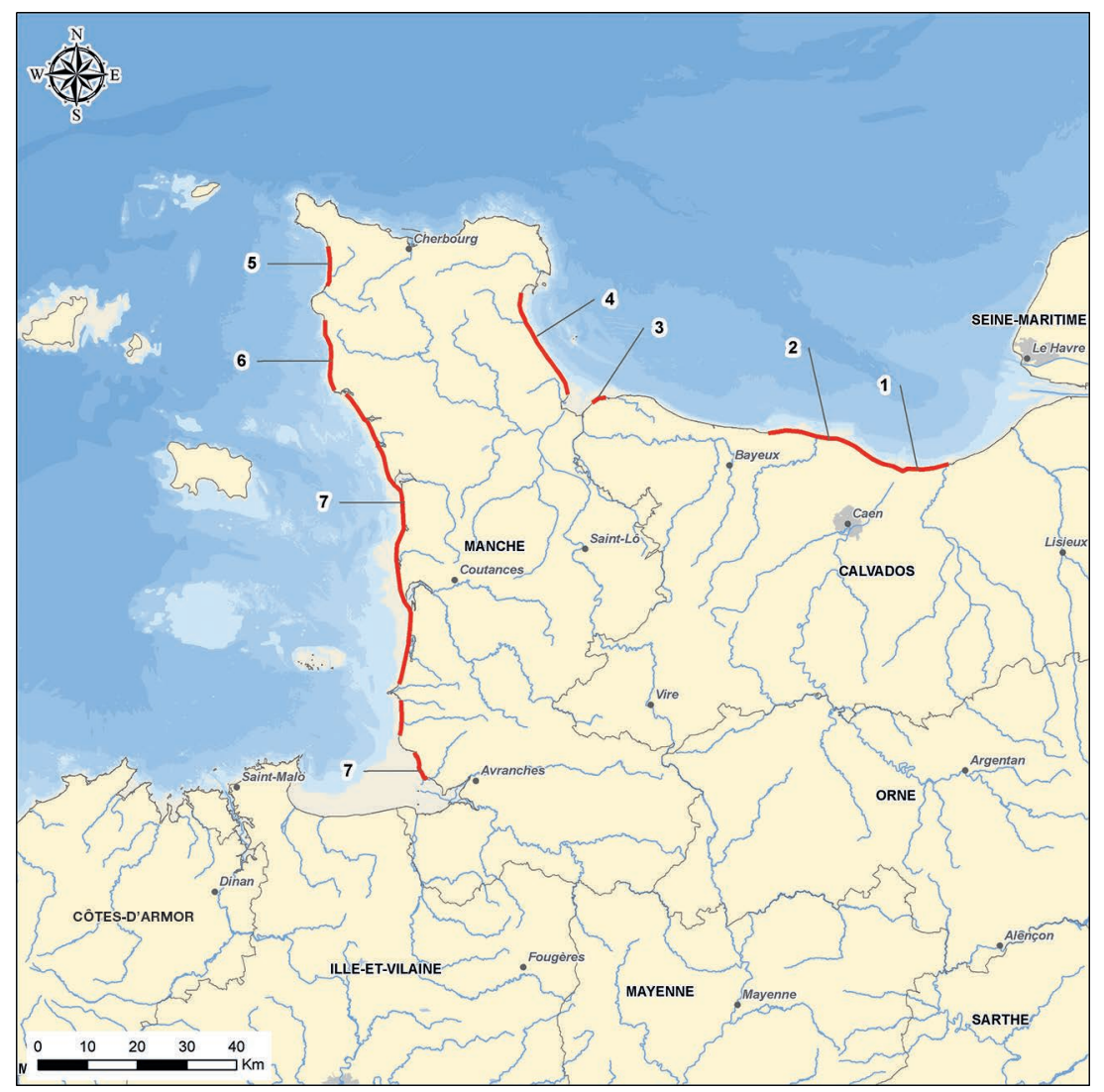

Figure 1.66. Emplacement des principales dunes de Normandie

1. Dunes de la Côte fleurie ; 2 . dunes de la côte de Nacre ; 3. cordon dunaire des Marais du Bessin ;

4. dunes de l'est du Cotentin ; 5 . dunes de Vauville-Biville ; 6 . dunes d'Hatainville ; 7 . dunes de la côte des havres.

Sources : Cerema, ONF.

Les houles dominantes d'ouest et de nord-ouest engendrent une dérive littorale dirigée vers l'est en Bretagne, vers le sud sur la côte ouest du Cotentin et vers I'est, le nord ou l'est-nord-est en Manche orientale et en mer du Nord. Cette dérive est d'autant plus puissante le long des côtes picardes, boulonnaises et flamandes qu'elle est renforcée par la progression de l'onde de marée canalisée dans le détroit du Pas-de-Calais.

\section{Une ressource en sable très contrastée de la Bretagne à la Flandre}

Les vents de mer dominants et la largeur de I'estran sont des facteurs très favorables à la formation de dunes littorales. Encore faut-il qu'il y ait du sable disponible sur les aires d'envol libérées à marée basse.

De ce point de vue, les côtes bretonnes de la pointe de Corsen à la baie du Mont-Saint-Michel et celles de la côte septentrionale du Cotentin sont les moins bien loties. Le littoral très découpé et parsemé d'écueils rocheux est typique du Léon et du Trégorrois. La pénurie de sable s'explique par l'absence de grand fleuve et le non-renouvellement des épandages fluviatiles de la dernière période froide. Par ailleurs la granulométrie parfois assez grossière des sables libérés par l'érosion des falaises de granite ou de grès restreint leur mobilisation par le vent. 
La façade ouest du Cotentin battue par les vents d'ouest est beaucoup plus riche en dunes, grâce à un régime mégatidal et à la relative abondance de sable apporté par une série de petits fleuves côtiers dont les estuaires (ou havres) sont barrés par une flèche* à pointe libre s'allongeant vers le sud. Il y a aussi une très abondante production biologique de sable dans tout le golfe normand-breton.

Le littoral bas-normand de la pointe de Barfleur à l'estuaire de la Seine possède de longues plages macrotidales (de 7 à $8 \mathrm{~m}$ de marnage en vive-eau), mais la ressource en sable est limitée, sauf aux abords des estuaires de l'Orne et de la Dives.

De la baie de Somme aux falaises du Boulonnais, en baie de Wissant, puis de Sangatte à la frontière belge, de larges plages de sable s'allongent sur des kilomètres, découvrant à marée basse de 500 à 1500 m d'estran (et même 2500 m en bordure de la Canche). C'est là que se développent les plus beaux systèmes dunaires des côtes de la Manche. L'originalité de ce littoral vient de l'abondance exceptionnelle de la ressource en sable en avant de la côte. Ces sables pré-littoraux sont en grande partie un héritage des périodes froides du Quaternaire et en particulier de la dernière («Weichsélien »), lorsque le niveau de la mer était à 130-135 m plus bas qu'actuellement et que l'énorme système fluviatile du Rhin et de ses affluents (Tamise, Meuse, Escaut et Seine entre autres) déversait des quantités considérables d'alluvions dans la Manche alors exondée. S'y ajoute aussi I'héritage des épandages sableux de l'Eocène. II n'y a donc pas ici de pénurie sédimentaire, mais le non-renouvellement de ce stock doit être pris en compte dans toute velléité d'exploitation. Des recherches ont montré que le lent déplacement des bancs de sable pré-littoraux vers la côte a une influence décisive sur les variations dans le temps du budget sédimentaire des plages. Ce stock est un véritable trésor qu'il faut utiliser avec parcimonie et réserver en priorité au rechargement* des plages fragilisées par l'élévation du niveau de la mer.

\section{Un potentiel dunaire souvent limité en Bretagne (côte nord) et en Basse-Normandie}

Il existe évidemment un lien étroit entre la ressource en sable des systèmes côtiers et le développement potentiel de dunes littorales.

Sur la côte nord de la Bretagne, les dunes sont rares, toujours étroites et peu élevées. On peut citer celles du Vougot, de Boutrouilles et de Ker Emma et, plus à l'est, celles de Pléneuf-Val-André et des Sables-d'Or-les-Pins. Ces dunes se forment au fond de baies assez fermées où les échanges sédimentaires sont fortement contraints par la topographie.

Sur la façade est du Cotentin, de beaux systèmes dunaires se sont formés sur les flèches sableuses des havres. L'un des plus beaux (mais aussi des plus menacés) est localisé sur la pointe d'Agon (figure 1.67).

Plus à l'est, les plages du débarquement (côte de Nacre) sont précédées de platiers et de petits-fonds rocheux. De plus, la plupart sont équipées de digues, perrés, épis qui ont profondément perturbé la dynamique naturelle et gênent considérablement le développement des dunes. Par contre, vers l'est, les sables apportés par l'Orne et la Dives alimentent les plages de la Côte fleurie, de Merville à Deauville. Le site de Merville qui jouxte l'estuaire de l'Orne est particulièrement riche en dunes. Le très large estran sableux est bordé vers le sud par un champ de dunes embryonnaires formant des îlots colonisés par les plantes pionnières (figure 1.68). En haut de plage, le contact se fait progressivement avec une avant-dune peu élevée. Ce système plage-dune fonctionne tout à fait naturellement. Seul le piétinement excessif peut l'affecter. 


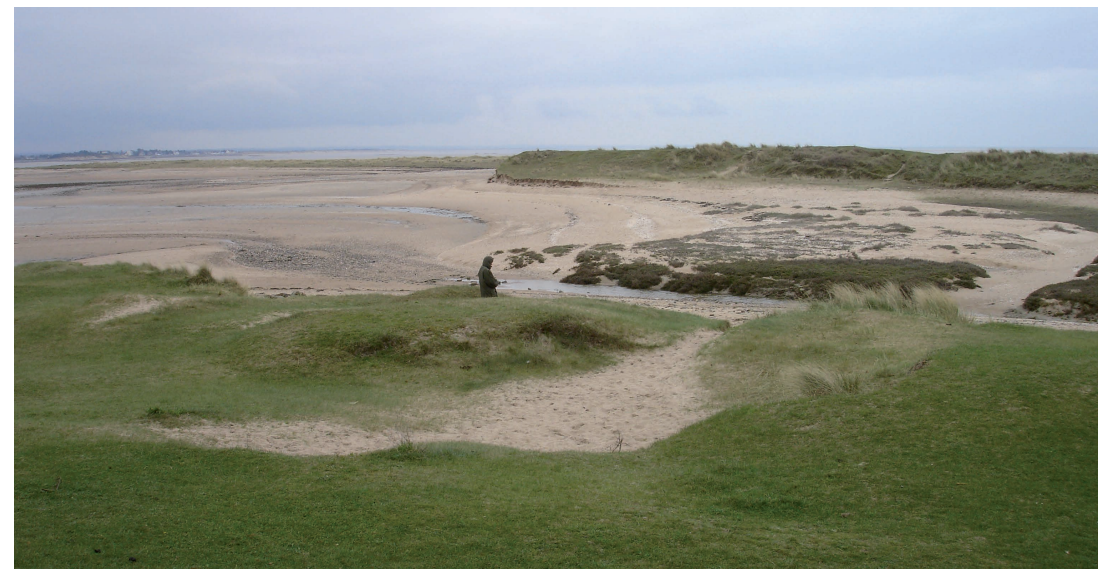

Figure 1.67. Pointe d'Agon.

Flèche sableuse à pointe libre façonnée en dunes et marais maritime avec schorre et slikke. (c) Y. Battiau-Queney. Prise pendant I'atelier EUCC-France de mars 2005.

En allant vers Cabourg, le système dunaire devient de plus en plus étroit. La plage a été équipée d'épis rocheux qui captent une partie du sable déplacé d'ouest en est par la dérive littorale, mais les échanges avec la dune sont freinés voire annihilés par des digues ou des enrochements (figure 1.69). Pourtant, ce mince cordon dunaire recèle encore une riche biodiversité qu'il convient de protéger et il joue un rôle essentiel de digue naturelle contre la submersion des terres basses du Pays d'Auge.

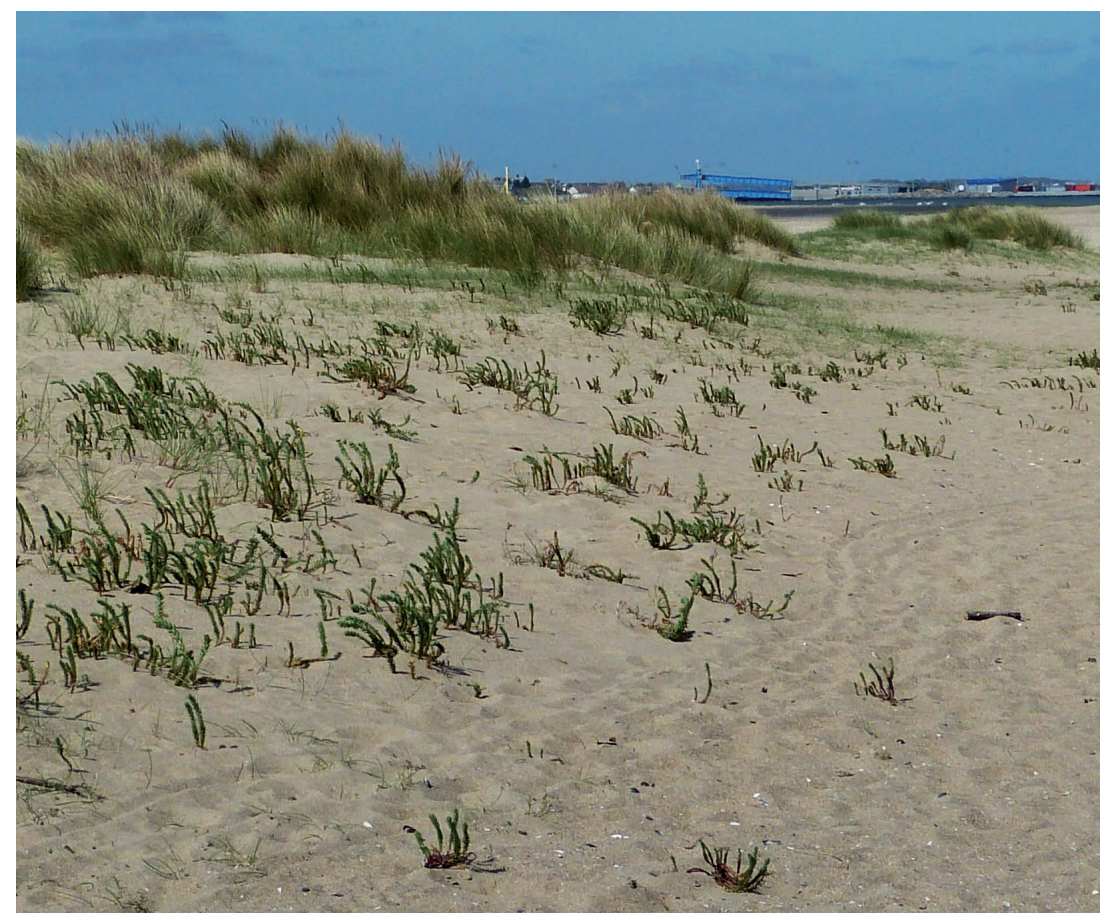

Figure 1.68. Contact de l'avant-dune et de la plage (Merville-Franceville-Plage, Calvados). On se trouve là dans une zone d'accrétion avec un budget sédimentaire positif. (C) Y. Battiau-Queney/EUCC-France, 16 avril 2014. 


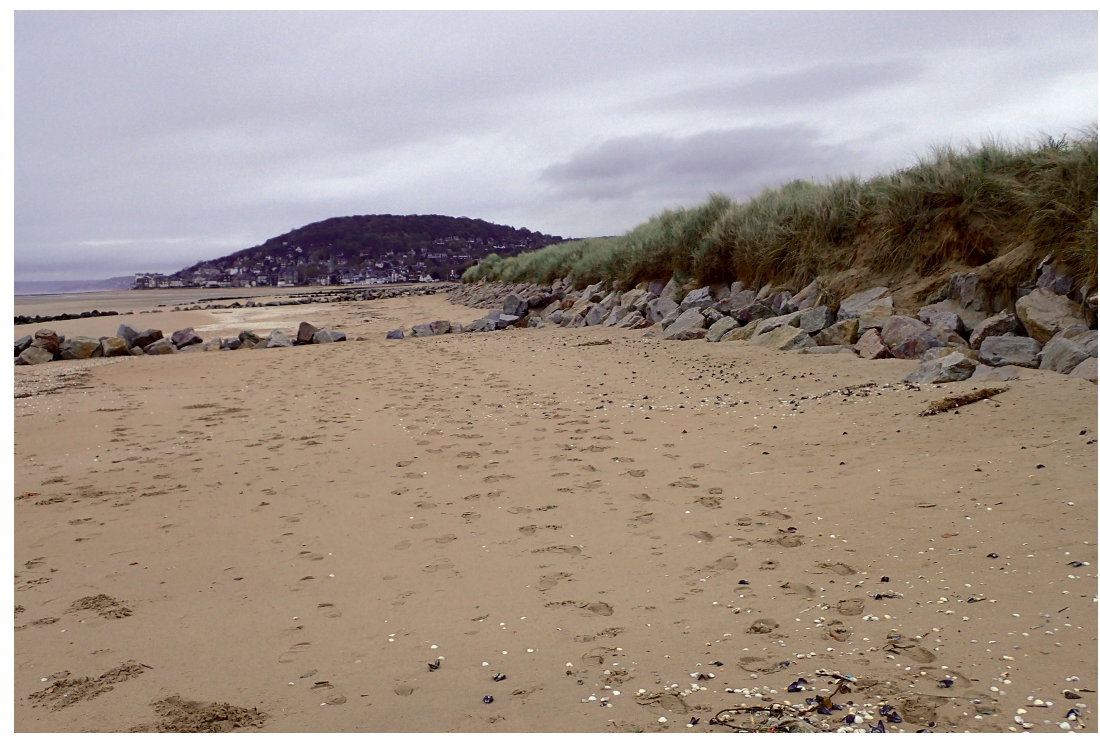

Figure 1.69. Le cordon dunaire de Cabourg (Calvados), vu vers l'est (falaise de Houlgate au fond). (C) Y. Battiau-Queney/EUCC-France, 16 avril 2014.

\section{Les grands systèmes dunaires de la côte d'Opale}

Trois facteurs expliquent le développement considérable des dunes tout le long de ce littoral :

- de vastes estrans sableux sont soumis à la déflation éolienne et sont bien alimentés par le stock sédimentaire pré-littoral ;

- les vents dominants soufflent vers la côte ;

- le climat favorise l'action fixatrice de la végétation littorale.

Une grande partie des 10000 ha de dunes épargnées par l'urbanisation est protégée, appartenant au Conservatoire du littoral, à l'ONF ou aux départements.

\section{De la baie de Somme aux dunes d'ÉCAult : Les dunes PICARdes}

Le rivage est orienté sud-nord, donc quasiment perpendiculaire aux vents dominants. Les dunes picardes forment deux systèmes grossièrement parallèles au trait de côte, séparés par une plaine sableuse que l'altitude de 8 à 10 m IGN $69^{3}$ situe au-dessus du niveau des plus hautes mers. Plus vers I'intérieur des terres, une zone marécageuse submersible (les Bas-Champs) sépare les dunes internes de la falaise morte qui marque le rebord du plateau crayeux de l'Artois (figure 1.70)

Les dunes externes, larges de $200 \mathrm{~m}$ au sud à plus de $1500 \mathrm{~m}$ au nord, offrent une grande diversité de formes éoliennes actives. La dune bordière, haute de 15 à 20 m au-dessus de la plage, est découpée par des couloirs de déflation orientés du sud-ouest vers le nord-est, selon la direction dominante des vents de tempête. Les vents chargés du sable de l'estran s'engouffrent dans ces couloirs et accumulent, en arrière, des pourrières, langues de sable plus ou moins massives, qui s'étalent en ensevelissant les fourrés d'argousiers de l'arrière-dune (figure 1.71).

3. Le nivellement général de la France (NGF) achevé par I'Institut géographique national en 1969 constitue le réseau officiel de repères altimétriques dont l'altitude est mesurée par rapport au niveau zéro officiel déterminé par le marégraphe de Marseille. On parle ainsi d'altitude IGN 69. 


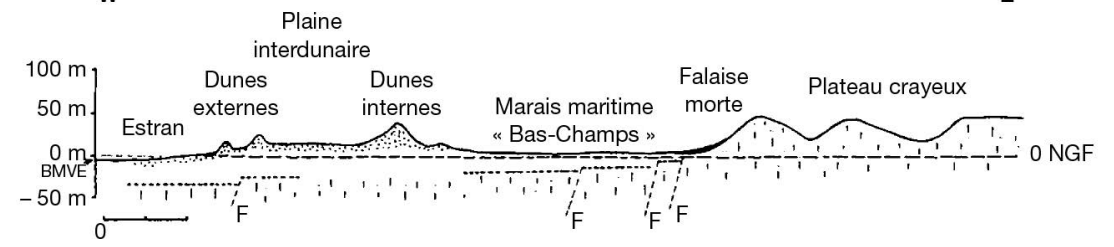

Figure 1.70. Coupe transversale montrant I'organisation des dunes picardes. Source : Y. Battiau-Queney/EUCC-France.

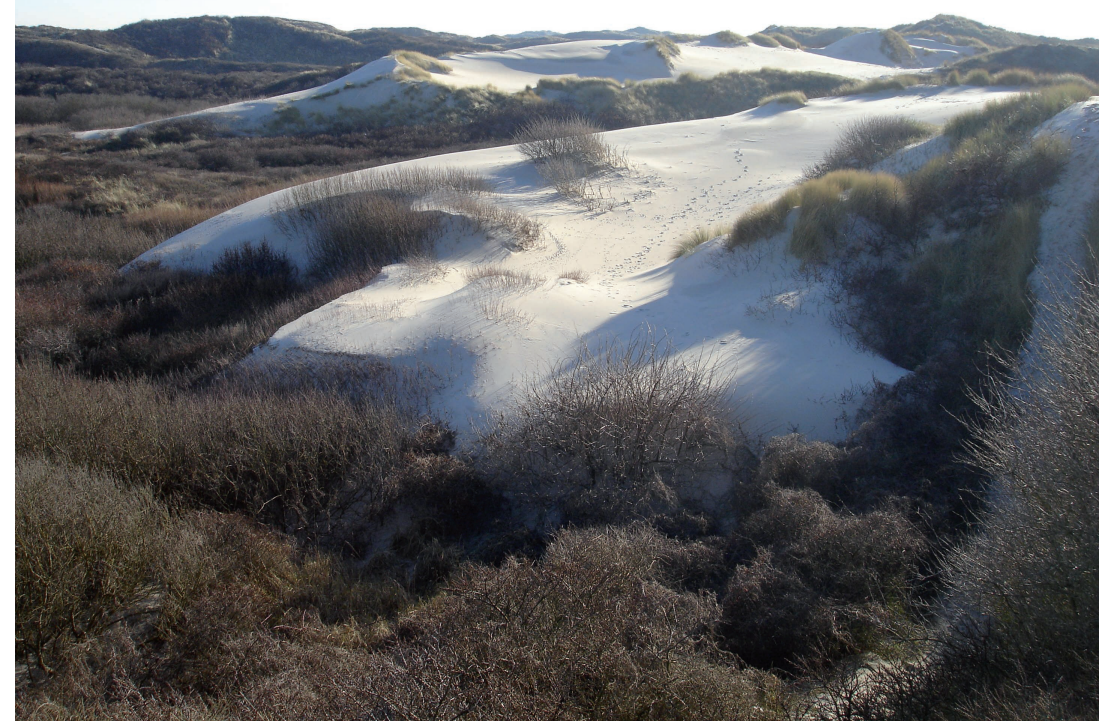

Figure 1.71. Dunes de Merlimont (Réserve biologique domaniale).

Pourrières formées au débouché d'un couloir traversant l'avant-dune (la plage est à droite de la photo) et s'avançant dans la direction des vents dominants.

(c) Y. Battiau-Queney/EUCC-France.

Cette dune bordière reçoit un apport continu de sable depuis l'estran et présente le profil caractéristique d'une avant-dune fonctionnelle. Elle peut néanmoins être taillée en falaise sableuse sous I'action des vagues, en période de tempête coïncidant avec une grande marée. Mais le suivi réalisé depuis plus de 20 ans montre que la dynamique éolienne alliée à une abondante ressource en sable permet à l'avant-dune de se reconstituer souvent très rapidement (figure 1.72).

Sur un même site, la morphologie dunaire peut changer en quelques mois, voire en quelques semaines, du fait de la complexité des échanges sédimentaires entre plage et dune. Entre Quend-Plage et Fort-Mahon-Plage, on passe en quelques centaines de mètres $d^{\prime}$ 'une falaise dunaire reculant rapidement sous l'action combinée des vagues et des glissements en paquets, à une avant-dune née de la coalescence de dunes embryonnaires dans un contexte sédimentaire équilibré. À Merlimont, aux abords immédiats de la base nautique, le modelé de falaise visible jusqu'en 1995 a, dans les quinze premières années du $x I^{e}$ siècle, fait place à un profil d'avant-dune, avec dunes embryonnaires et prismes d'accumulation éolienne à Agropyron (figure 1.73). Ceci montre que 


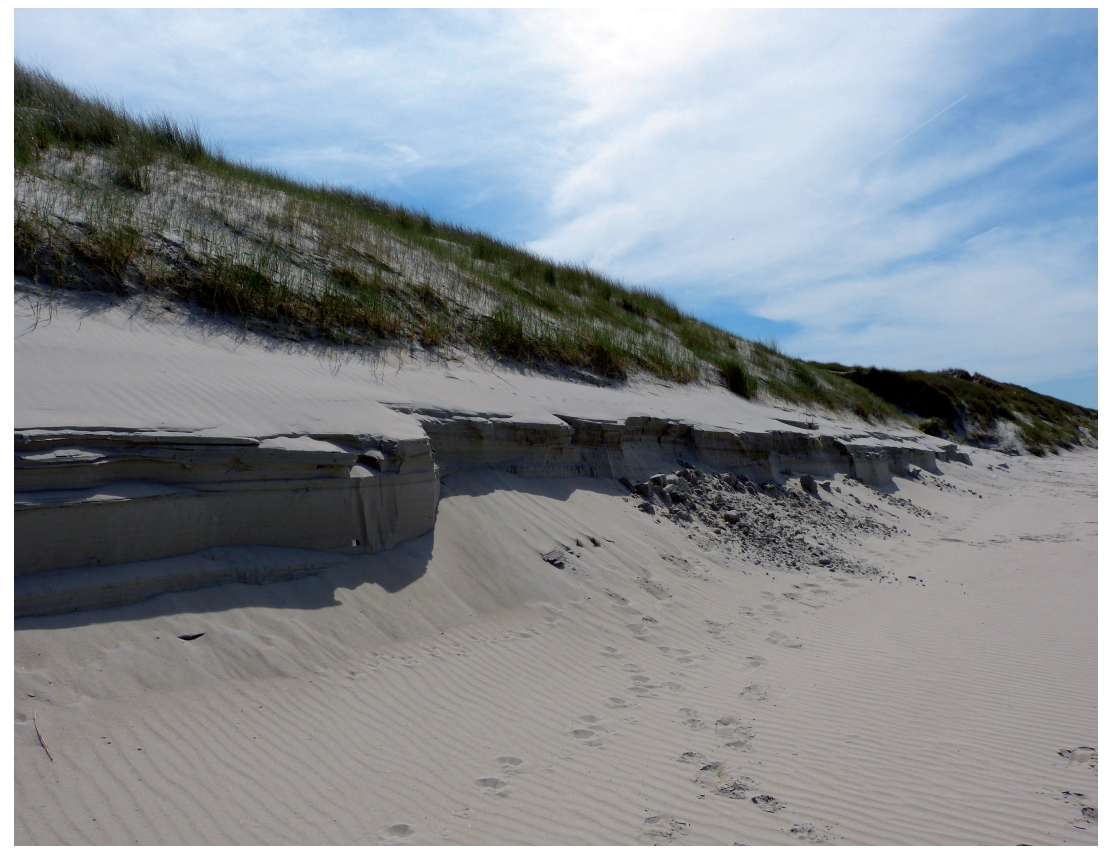

Figure 1.72. Plage de Merlimont, 6 mai 2016.

La photo traduit une séquence de trois épisodes successifs faisant alterner phases d'érosion marine et d'accumulation éolienne : A. en pied de dune, une importante accumulation éolienne s'était formée ; B. ce prisme d'accumulation a été taillé en falaise par l'érosion marine, laissant voir la stratification éolienne horizontale ; C. une nouvelle accumulation éolienne masque le pied de la mini-falaise. (c) Y. Battiau-Queney/EUCC-France.

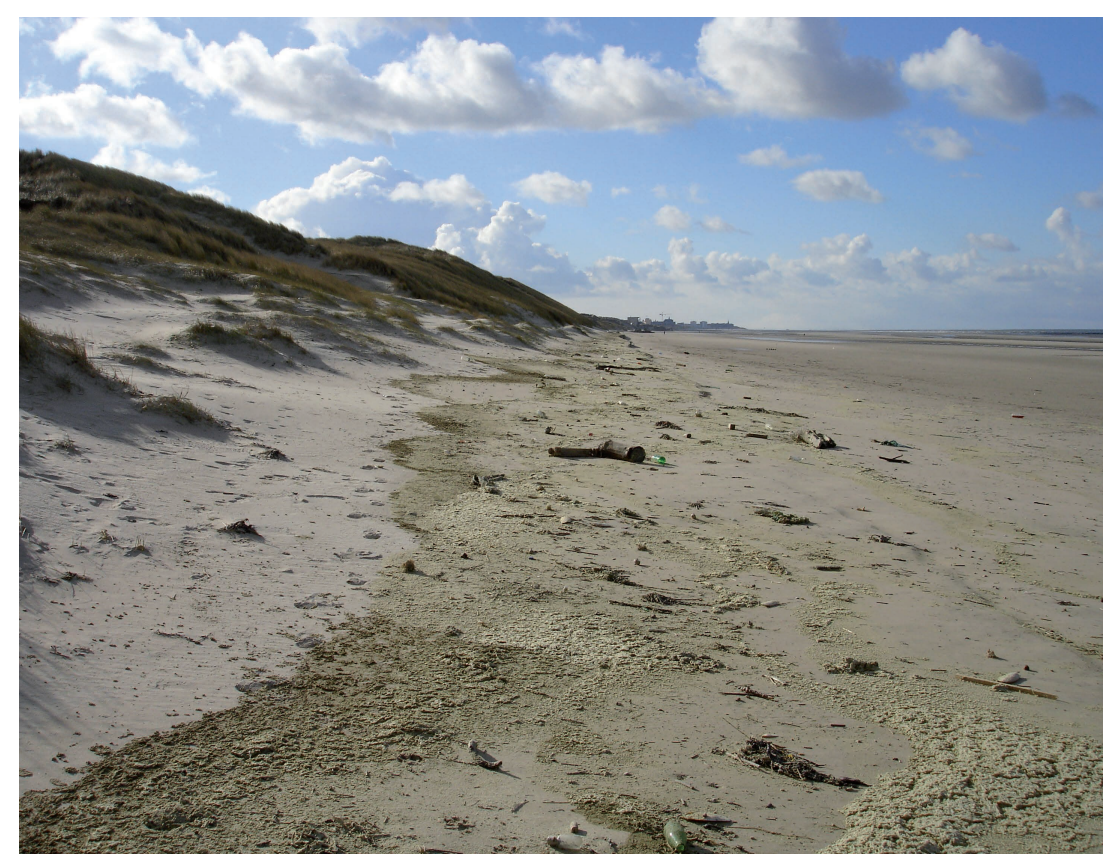

Figure 1.73. L'avant-dune au sud de Merlimont (Réserve biologique domaniale). Des dunes embryonnaires se sont formées au-dessus de la laisse de mer.

(C) Y. Battiau-Queney/EUCC-France. 

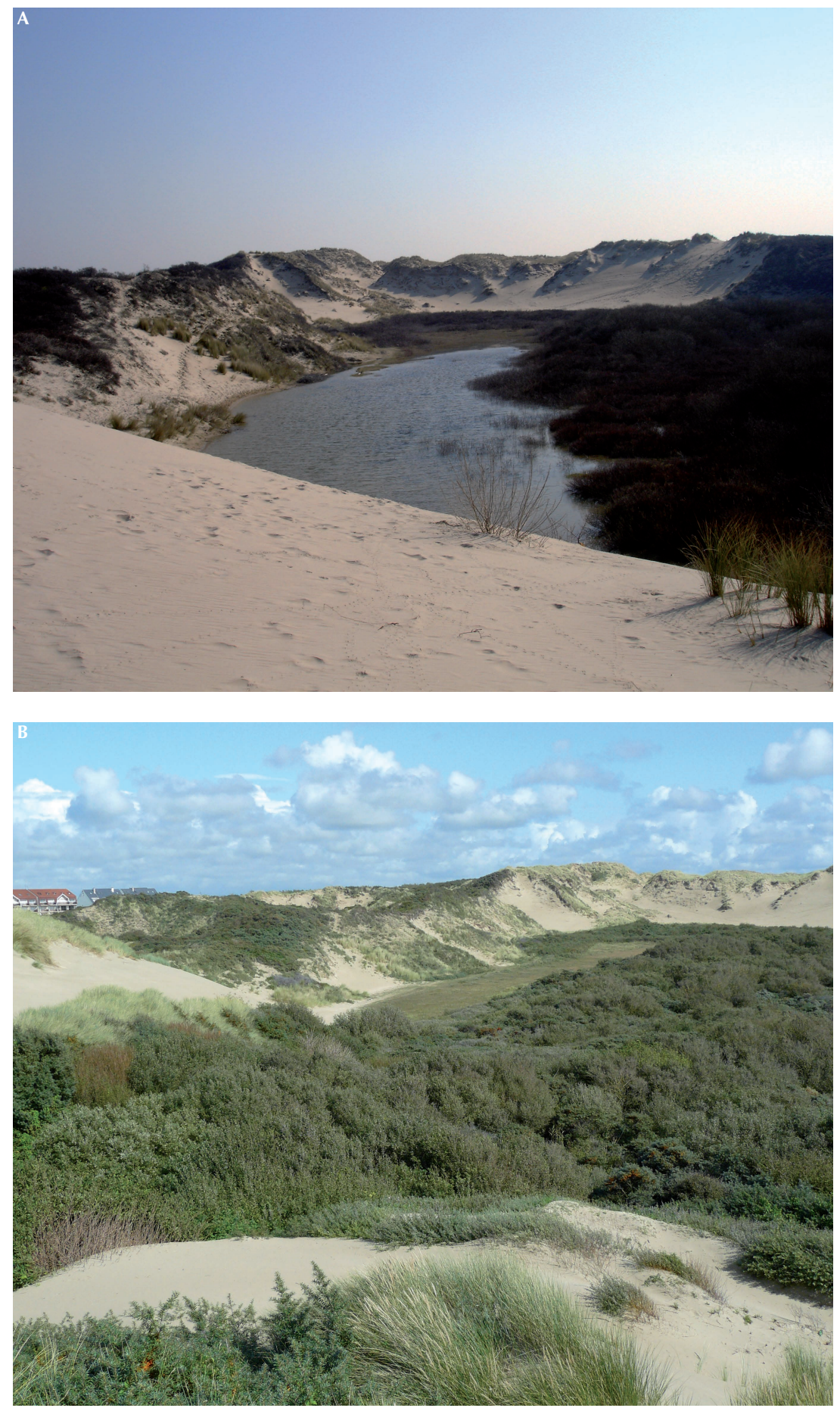

Figure 1.74. A. Dune parabolique au sud de Merlimont (en mars 2007 en haut, en septembre 2008 en bas).

En B, au premier plan, extrémité d'une pourrière. Les fluctuations du niveau de la nappe de l'aquifère dunaire expliquent le changement rapide de paysage.

(c) Y. Battiau-Queney/EUCC-France. 
des observations ponctuelles n'ont de signification que replacées dans un suivi sur le long terme.

Les dunes externes de deuxième ligne ou arrière-dunes sont extraordinairement variées dans cette région. Elles sont vives, entravées ou figées, selon l'état de la couverture végétale. Les cuvettes de déflation présentent tous les stades d'évolution, depuis le creux primitif, d'origine naturelle, animale ou anthropique, jusqu'à la caoudeyre, cuvette profonde fermée de tous côtés. Le sable soulevé s'accumule du côté sous le vent en créant un bourrelet d'autant plus haut que la cuvette est profonde. L'approfondissement se poursuit jusqu'à ce que la nappe affleure ou qu'une végétation dense l'envahisse. Quand elle est active, la cuvette a tendance à s'allonger dans la direction du vent dominant, évolution pouvant aboutir à une dune parabolique. La coalescence de plusieurs cuvettes voisines engendre de vastes dépressions aux contours irréguliers. De très belles dunes paraboliques sont présentes dans ces systèmes dunaires. Lorsqu'elles sont actives, la tête de la parabole continue à s'avancer dans la direction du vent, tandis que les bras, rapidement fixés par des oyats puis des fourrés d'argousiers, s'allongent dans le même sens. C'est le cas de celle située au sud de MerlimontPlage (figure 1.74).

Son grand axe orienté nord-est/sud-ouest s'allonge sur $600 \mathrm{~m}$. La tête de la parabole culmine à $27 \mathrm{~m}$ d'altitude. Au centre, à 7-8 m d'altitude, on trouve une vaste panne où la nappe aquifère, directement alimentée par les précipitations, affleurait plus ou moins largement jusqu'au début du $x \mathrm{xl}^{\mathrm{e}}$ siècle. Les pannes sont le domaine d'une végétation hygrophile souvent dense et fortement diversifiée. Ces dunes sont caractéristiques de ces littoraux relativement

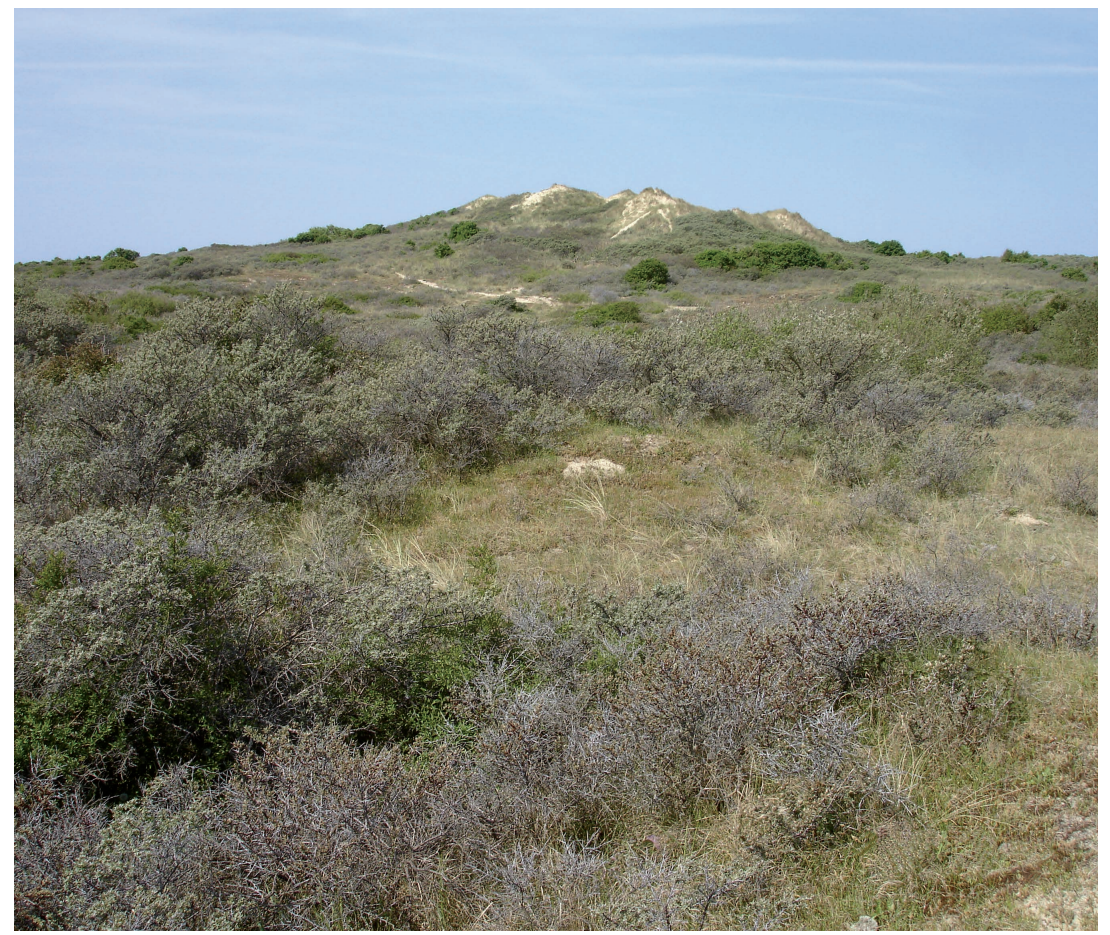

Figure 1.75. Un aperçu des dunes internes dans la Réserve biologique domaniale de Merlimont.

(c) Y. Battiau-Queney/EUCC-France. 
humides où la végétation entrave rapidement la dynamique éolienne. Depuis une quinzaine d'années, on observe une tendance généralisée à l'expansion des fourrés dominés par l'argousier.

Les dunes internes, mises en place depuis moins de 1000 ans, culminent à plus de 40 m IGN 69. Elles sont plus végétalisées que les dunes internes, sous l'effet des interventions humaines (dont des plantations forestières), mais il reste encore des dunes blanches de forme parabolique (figure 1.75).

Au nord de la baie de Canche, on trouve I'un des plus beaux exemples français de dune perchée*. Le sable soufflé par le vent depuis la plage a été plaqué contre le rebord escarpé du plateau crayeux culminant ici à plus de $150 \mathrm{~m}$ sur les communes de Camiers, Dannes et Neufchâtel-Hardelot. II est facile d'observer ce phénomène sur les versants du mont Saint-Frieux.

\section{Du CAP Gris-Nez À la frontière beLGe : Les dunes flamandes}

L'orientation du rivage, sud-ouest/nord-est, est presque parallèle aux vents dominants. Les dunes flamandes sont beaucoup moins larges que dans la plaine picarde et forment un système unique.

En baie de Wissant, le cordon dunaire, haut de 10 à 15 m, s'allonge de la pointe de Courte-dune, au sud-ouest, jusqu'à Strouanne au nord-est. II protège de la submersion marine le petit marais de Tardinghen. Ce cordon est façonné localement en petites paraboles. Il est actuellement le plus souvent taillé en falaise, ce qui traduit un déficit sédimentaire de la baie qui a été confirmé par les chercheurs et qui s'est fortement aggravé depuis les années 1990. L'évolution la plus spectaculaire concerne la dune d'Aval à proximité sud-ouest du village de Wissant. D'une situation d'abondance sédimentaire pendant la Seconde Guerre mondiale, concrétisée par un large champ de dunes embryonnaires, puis par l'ensevelissement des ouvrages du Mur de l'Atlantique, on est passé à une érosion chronique et à un recul extrêmement rapide du pied de la dune, découvrant à nouveau les bunkers allemands et menaçant un lotissement. Ce renversement de tendance est dû en grande partie à des destructions volontaires de l'avant-dune dans les années 1960-1970 et simultanément à des exportations massives de sable pour des usages industriels ou de génie civil. L'érosion de la dune d'Aval s'est considérablement aggravée depuis le démantèlement des bunkers au printemps 2013. Le site Internet de I'association des Amis de la baie de Wissant ${ }^{4}$ permet de suivre le recul du trait de côte qui menace directement un lotissement construit dans les années 1960.

À l'ouest de Calais, une étroite avant-dune haute de 10 à 15 m constitue un fragile rempart contre les inondations marines, constamment renforcé par I'homme depuis le $x \mathrm{VI}^{\mathrm{e}}$ siècle. II bénéficie depuis les années 1990 d'une très bonne alimentation en sable, dont le piégeage a d'abord été favorisé par l'installation de ganivelles* et de fascines, la plantation d'oyat et le reprofilage de la dune. Mais, depuis la fin du xxe siècle, on peut mettre en parallèle le déficit sédimentaire de la baie de Wissant avec les arrivées massives de sable sur ce secteur côtier.

Entre Calais et Gravelines, la côte s'engraisse en deux endroits : sur le site du Fort-Vert, un champ de dunes embryonnaires se développe en haut de plage préparant I'avancée de l'avant-dune vers la mer (figure 1.76); plus à l'est, la même dynamique s'observe aux deux extrémités du platier d'Oye.

4. www.amisdewissant.com, consulté le 13 septembre 2017. 


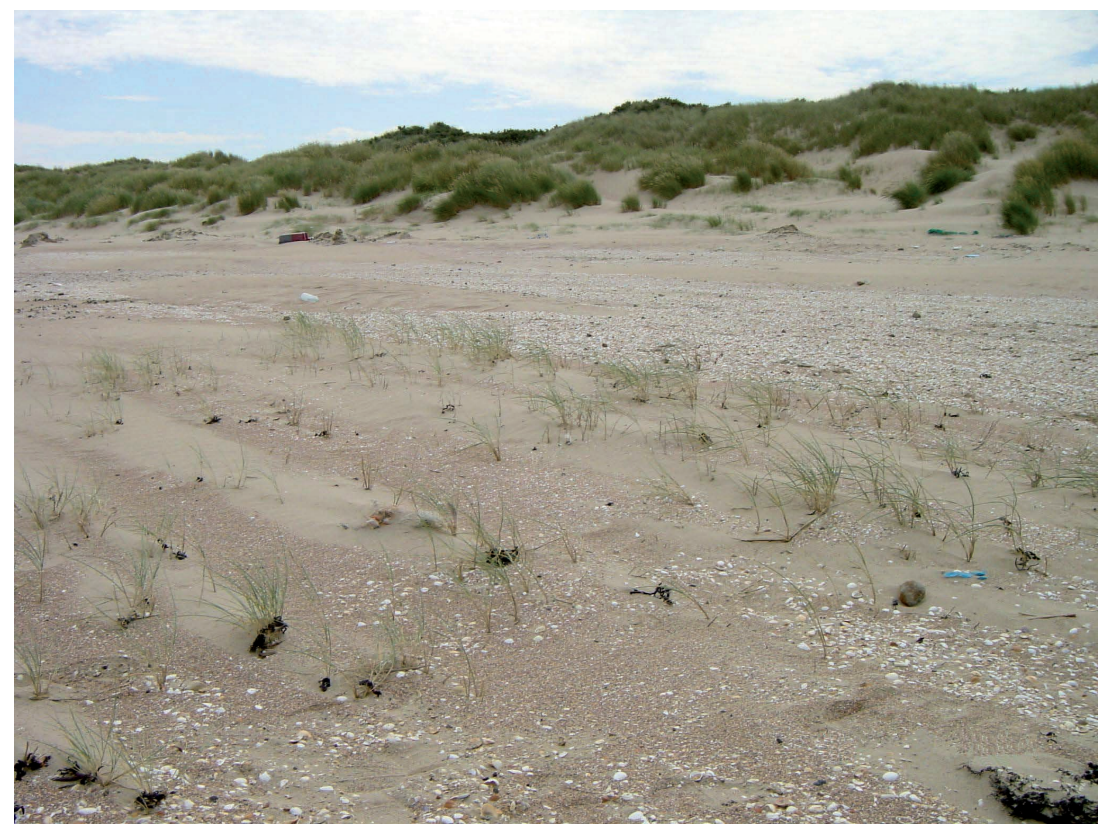

Figure 1.76. Plage du Fort-Vert à l'est de Calais.

Champ de dunes embryonnaires sur l'estran, avec tri par le vent de la fraction fine du sable et colonisation par l'Agropyron.

(C) Y. Battiau-Queney/EUCC-France.

À l'est de Dunkerque, le système dunaire s'élargit sensiblement. Sur le site de la dune Dewulf (Leffrinckoucke, Zuydcoote) un cordon dunaire, haut de 15 à $20 \mathrm{~m}$ et large de 50 à plus de $200 \mathrm{~m}$, s'est édifié en bordure de la plage entre 1937 et 1971. Il est érodé et forme une falaise depuis le début des années 1980, mais le recul dépasse rarement $1 \mathrm{~m}$ par an en moyenne. En arrière, des pannes humides sont associées à de grandes dunes paraboliques, actives tout au long de la première moitié du $x^{e}$ siècle, mais aujourd'hui stabilisées ou en cours de fixation, à l'exception de l'une d'entre elles. La rapide expansion naturelle des fourrés d'argousier est en grande partie responsable de cette moindre mobilité.

Plus à l'est, la dune Marchand (Bray-Dunes), aujourd'hui réserve naturelle nationale, a connu une évolution assez similaire. Au début du xxe siècle, de la tourbe affleurait sur la plage et une intense dynamique éolienne façonnait de petites dunes paraboliques en contact direct avec l'estran.

Une avant-dune continue s'est édifiée à partir des années 1960 et, simultanément, les dunes paraboliques, situées en arrière, encore très actives dans les années 1950, furent progressivement colonisées par la végétation et stabilisées. Dans les années 1990, le versant maritime de la dune était à nouveau taillé en falaise mais, depuis le début du $x \mathrm{I}^{\mathrm{e}}$ siècle, I'avant-dune s'est reconstituée. Encore plus à l'est, la dune du Perroquet, entre Bray-Dunes et la frontière belge, présentait, au début du xx $x^{\mathrm{e}}$ siècle et encore en 1938, un cordon linéaire continu, le long de la plage, et de grandes dunes paraboliques très actives, en arrière. Depuis la dernière guerre, les paraboles se sont décalées vers l'est à la vitesse moyenne de 5 à $6 \mathrm{~m}$ par an. Le trait de côte a reculé de moins de $20 \mathrm{~m}$ en soixante ans. Actuellement, ce site semble bénéficier $d^{\prime}$ un relatif équilibre sédimentaire. L'engraissement de l'avant-dune au droit d'un vaste camping très 


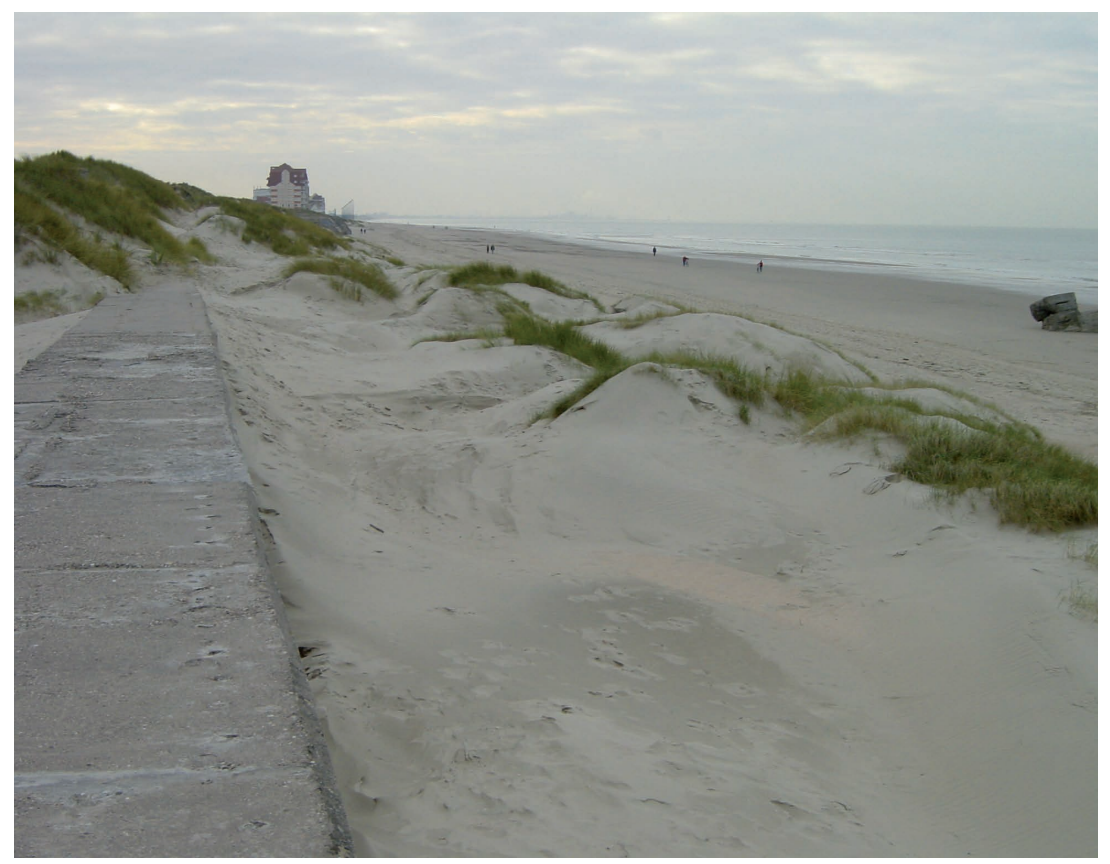

Figure 1.77. Dune du Perroquet (Bray, dunes est).

Fort engraissement du haut de plage et développement des dunes embryonnaires. Le petit ouvrage bétonné localisé sur l'estran date de la Première Guerre mondiale et était déjà dans cette position quand il a été construit par les Français. Par contre, le mur antichar a été construit par les Allemands et sa position actuelle témoigne de l'avancée du trait de côte depuis 75 ans.

(c) Y. Battiau-Queney/EUCC-France.

fréquenté a été favorisé par l'homme dans les années 1980-1990 (fascines, ganivelles, plantation d'oyat), mais il se poursuit naturellement grâce à l'abondance des apports éoliens de sable. Certains ouvrages du mur de l'Atlantique sont enfouis sous le sable et une ancienne brèche marine est maintenant fermée par des dunes embryonnaires (figure 1.77).

\section{Érosion et résilience des dunes de la Manche et de la mer du Nord}

L'observation et le suivi des dunes des côtes françaises de la Manche et de la mer du Nord montrent que, si le recul du trait de côte concerne une partie des plages, il n'est pas aussi généralisé que ce qui est dit généralement. La disponibilité en sable est le facteur prédominant de l'évolution des systèmes plagesdunes. La pénurie menace les côtes bretonnes et celles du Cotentin oriental. Par contre, d'une façon générale, l'abondance de la ressource sédimentaire caractérise la côte d'Opale. Elle explique la remarquable résilience de ses systèmes plages-dunes, capables de se reconstituer après les tempêtes. Le temps de récupération dépend de l'intensité et de la répétitivité des tempêtes. Mais le rythme de la résilience n'est pas toujours aisément accepté par les usagers. Par ailleurs, cette abondante ressource sédimentaire, longtemps considérée comme inépuisable, a été gaspillée et exploitée sans tenir compte de son nonrenouvellement. Le cas de Wissant est exemplaire : on est passé d'une surabondance de sable à la pénurie, en grande partie à cause de mauvaises pratiques (destruction de l'avant-dune pour y installer des lotissements et exportation massive du sable dunaire pour des usages commerciaux). 


\section{Les dunes atlantiques}

Loïc Gouguet

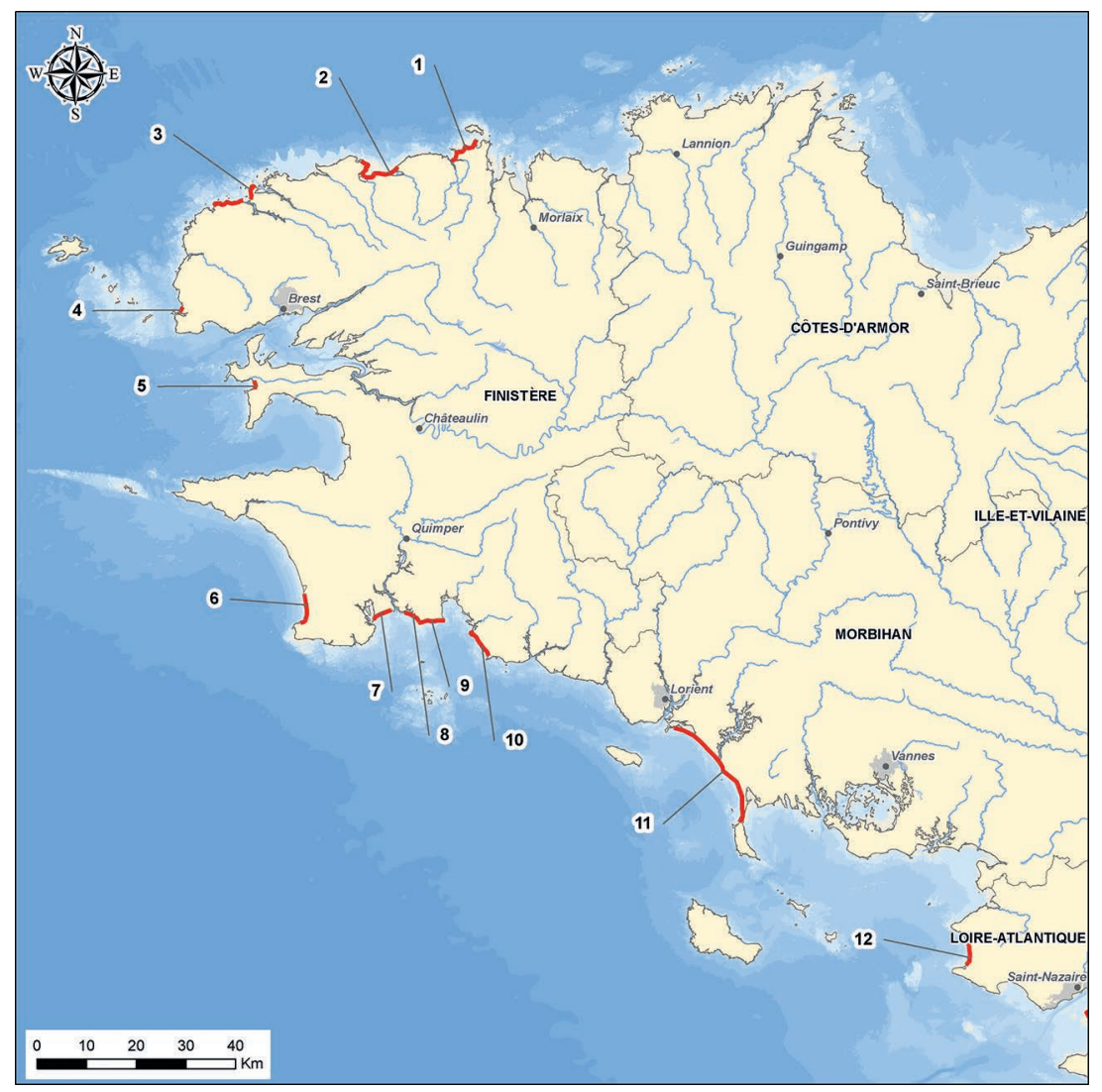

Figure 1.78. Emplacement des principales dunes de Bretagne.

1. Dunes de Santec ; 2 . dunes de Keremma ; 3 . dunes Sainte-Marguerite ; 4. dune des Blancs Sablons ; 5. dune de Dinan (Crozon) ; 6 . dunes de la baie d'Audierne ; 7. dune de Kermor ; 8 . dune de Mousterlin ; 9. dune de Beg-Meil ; 10. dune de Kerouiny ; 11. massif dunaire Gâvres-Quiberon ; 12. flèche de Pen Bron.

Sources : Cerema, ONF.

\section{Spécificités}

La façade métropolitaine atlantique, longue d'environ $450 \mathrm{~km}$, est avant tout caractérisée par une exposition aux phénomènes météo-marins venant principalement des secteurs nord-ouest à sud-ouest (vents, houles...). C'est une côte où l'amplitude des marées est comprise entre 2 et 4 mètres. Les vents édificateurs soufflent principalement de l'ouest et trouvent souvent les sédiments sableux sur un large estran découvert lors des marées basses.

La dérive littorale, engendrée par l'obliquité des houles arrivant à la côte, y est majoritairement orientée nord-sud, avec des exceptions en Bretagne et dans le Nord Médoc. Tous les petits fleuves côtiers, le débouché de la Leyre (Gironde), les courants landais (Landes), la Baisse (Vendée), ont vu leur sortie toujours déviée vers le sud voire obturée par l'accrétion de cordons dunaires, le plus long étant la flèche du Cap Ferret qui tend à fermer la lagune du bassin d'Arcachon. 


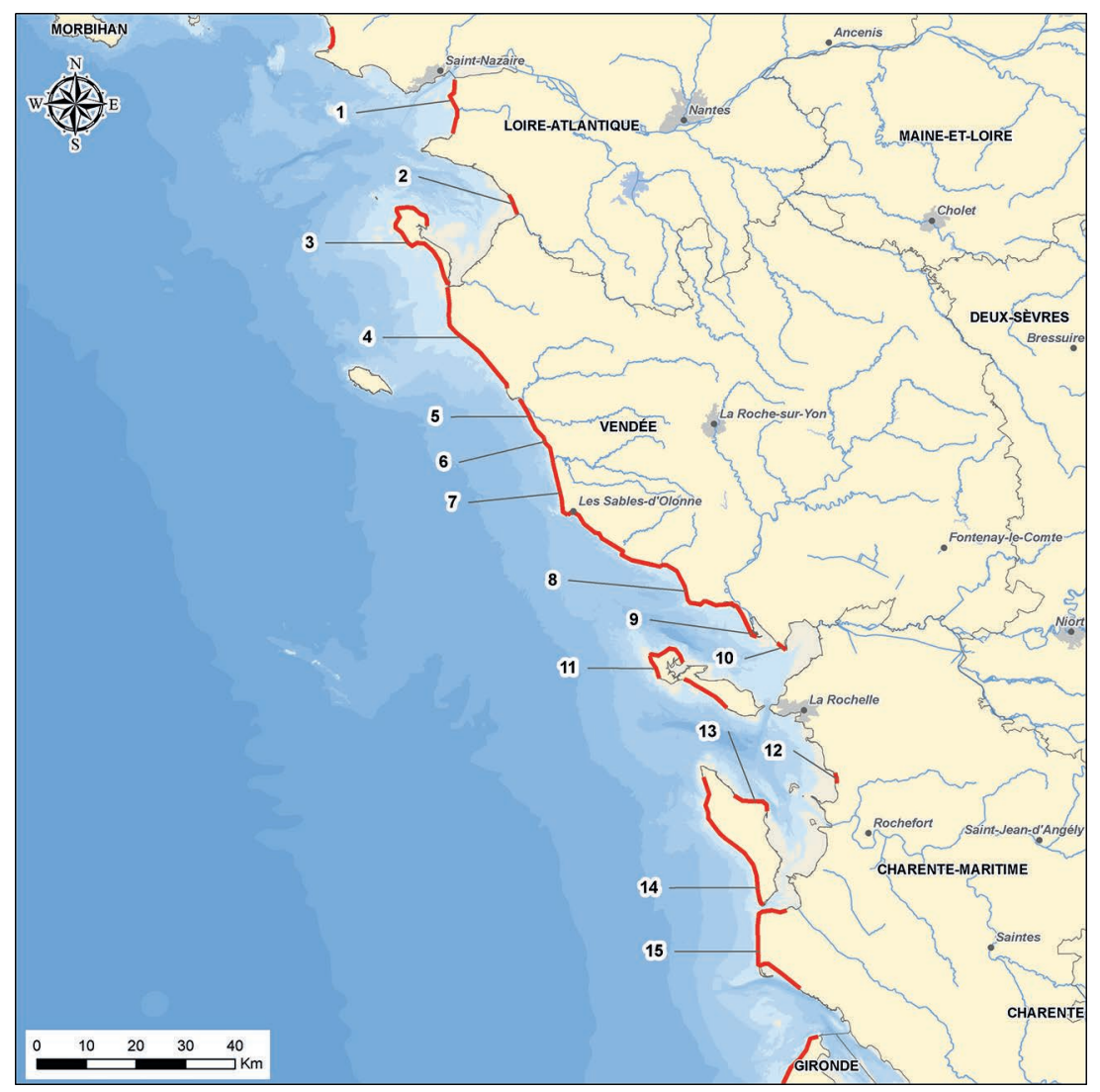

Figure 1.79. Emplacement des principales dunes du Centre Atlantique.

1. Dunes de Saint-Brévin ; 2 . dunes du Collet ; 3 . dunes de l'île de Noirmoutier ; 4. dunes des Pays de Monts ; 5 . dunes du Jaunay et de la Sauzaie ; 6 . dunes de Brétignolles ; 7. dunes d'Olonne ; 8. dunes de Longeville ; 9 . flèche de la pointe d'Arçay ; 10 . dune de la pointe de l'Aiguillon ;

11. dunes de l'île de Ré ; 12. dunes du Marais d'Yves; 13 . dunes des Saumonards ;

14. dunes de Saint-Trojan, ouest de l'île d'Oléron ; 15. dunes de la presqu'île d'Arvert.

Sources : Cerema, ONF.

Le climat y est de type océanique, les températures croissent du nord au sud. Dans le sud de l'Aquitaine, la proximité des Pyrénées renforce la pluviométrie (1 $500 \mathrm{~mm} / \mathrm{an}$ dans le sud des Landes et sur la côte basque contre 800 mm/an dans le Médoc). Les Charentes, la Vendée et la basse vallée de la Loire connaissent une pluviométrie plus faible du fait de l'éloignement de tout relief. Sur la façade atlantique, la pluviométrie est globalement favorable à une dynamique végétale, source de fixation des cordons dunaires.

\section{Répartition}

La variation de I'orientation de la côte atlantique et la présence d'un plateau continental* plus ou moins large expliquent la diversité des types de formes d'accumulation, ainsi que la présence/absence d'îles, îlots qui peuvent jouer un rôle dans l'atténuation des houles, et donc dans les transports de sédiments.

De plus, la côte atlantique est marquée par deux estuaires de grande dimension, celui de la Loire, en son centre, et celui de la Gironde dans sa partie sud. Ces fleuves, gros pourvoyeurs de sédiments par le passé (sédiments arrachés au Massif central pour le premier, et au Massif central et aux Pyrénées pour le 
second), ont largement contribué à l'édification des cordons dunaires littoraux et forment des jalons importants.

La côte sud de la Bretagne, située au nord de la Loire, se caractérise par quelques cordons littoraux qui se sont développés à partir de pointes rocheuses, îles, caps, formant des flèches et des tombolos*, mais aussi par des cordons de fond de baie, profitant de courants marins plus calmes. C'est au sud de la Loire que les massifs dunaires s'expriment le mieux et, progressivement à partir de la Gironde, qu'ils sont les plus massifs.

\section{Typologie}

\section{Les dunes du SUd BRETAGNe : DES MASSIFS MOdestes et FRAGMENTÉS}

Dans la baie d'Audierne entre Penhors et la pointe de la Torche, un cordon long de $10 \mathrm{~km}$ était initialement formé de galets, de graviers et de sable. II a fait l'objet d'une exploitation de graviers durant la Seconde Guerre mondiale, ce qui l'a fragilisé, son épaisseur passant de 50 (voire 100 m) à 30 mètres.

Dans le Sud Finistère, de fins cordons se sont érigés en fond de baie (cordon de Combrit, cordons de part et d'autre de la pointe de Mousterlin, de part et d'autre de la pointe de Trévignon...), d'une cinquantaine de mètres de largeur, et de seulement 5 mètres de hauteur en moyenne.

L'arc sableux de 25 km entre Gâvres et Quiberon (figure 1.80) est quant à lui le plus grand ensemble dunaire breton. Atteignant 1,5 km de largeur par endroits, il atteint exceptionnellement 22 mètres de hauteur près d'Étel. Les formes naturelles de ses dunes ont été profondément modifiées car, au cours de l'histoire, il a été utilisé comme terrain militaire, point d'appui du Mur de l'Atlantique, et même, plus anciennement, fortification lors de la Révolution française ! À son extrémité sud, le tombolo forme un isthme d'une vingtaine de mètres de large reliant la presqu'île de Quiberon au continent.

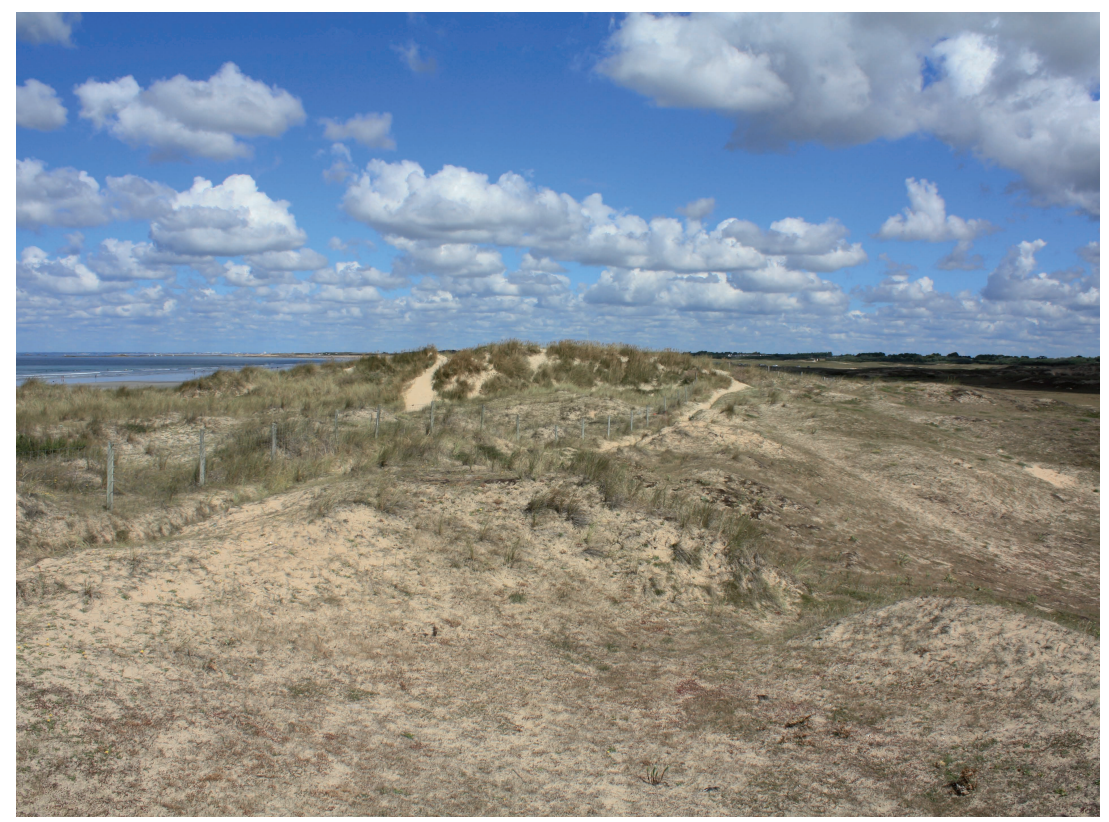

Figure 1.80. Massif dunaire Gâvres-Quiberon : dunes de Plouharnel.

(C) L. Gouguet/ONF. 


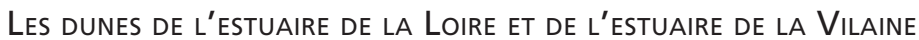

Autour des estuaires de ces deux fleuves, qui ont charrié beaucoup de sédiments (avant leur artificialisation), des petits cordons dunaires se sont établis, accrochés sur des îlots et des estrans rocheux : Kerpont, Suscinio, Damgan...

Au nord de la Loire, des accumulations remarquables forment le tombolo de Guérande et sont à l'origine du marais salant de Guérande : au nord-ouest la flèche sableuse accrochée à La Turballe, au sud les dunes de Batz, reliant I'îlot du Croisic et celui du Pouliguen, et au sud-est un arc sableux reliant le Pouliguen à Pornichet. Mais ce dernier massif dunaire est complètement urbanisé (La Baule).

Au sud de l'estuaire de la Loire, de Saint-Brévin à Tharon-Plage, des formations dunaires très basses constituent un petit massif accroché sur plusieurs pointes rocheuses ou plaqué contre une falaise.

\section{LES DUNES BARRIÈres deS MARAIS VendéENS et de NoIRMOUTIER}

Les massifs dunaires vendéens sont pour la plupart des cordons sableux qui sont venus s'accrocher sur des îlots rocheux et qui, du fait de leur élongation, ont souvent fermé des golfes, ayant ainsi permis leur colmatage et la formation de marais.

Les dunes de la façade ouest de l'île de Noirmoutier sont très étroites et peu hautes (figure 1.81). La partie sud de l'île est une flèche sableuse de près de $10 \mathrm{~km}$ de long, isolant les marais du centre de l'île. Toutes ces dunes sont fortement érodées par la mer, phénomène d'érosion aggravé par des équipements de défense parfois anciens (épis, perrés, enrochements, digues) qui ont perturbé la circulation et la répartition des sédiments marins le long de la côte.

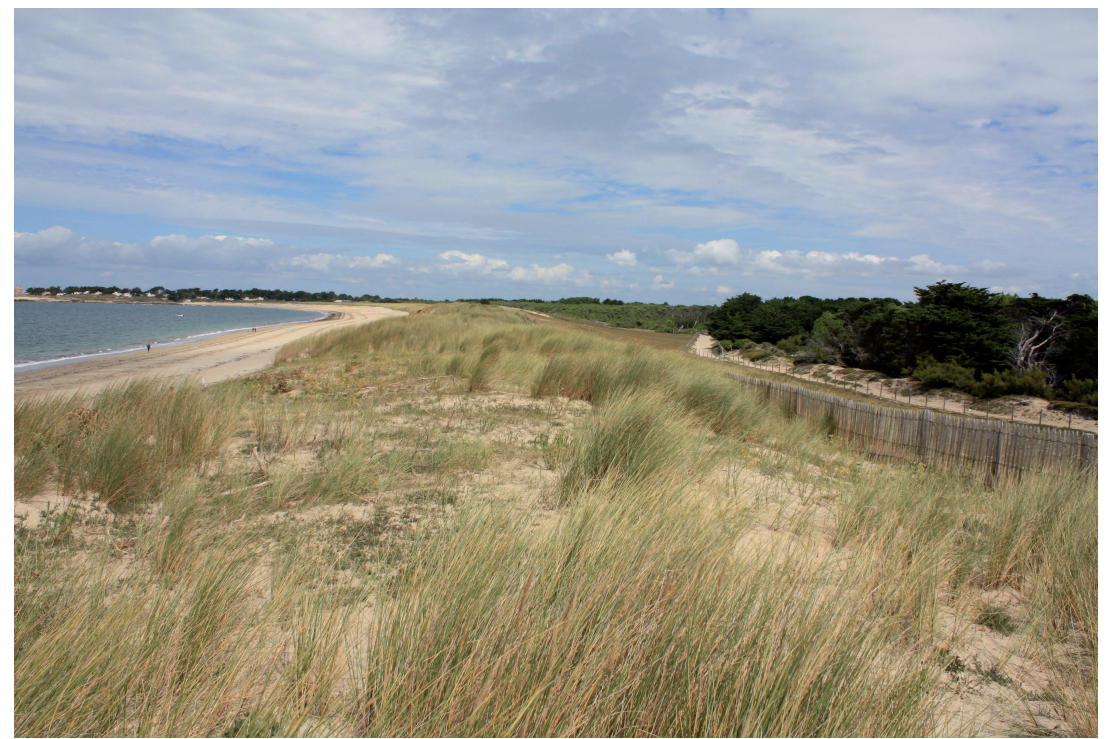

Figure 1.81. Dune domaniale de Luzéronde (Noirmoutier). (C) L. Gouguet/ONF.

Le massif dunaire des Pays de Monts s'est développé à partir de trois îlots rocheux, avec des sables amenés par la Loire provenant du Massif central, et en obturant l'exutoire de petits fleuves côtiers, il a progressivement fermé le golfe de Challans devenu le Marais breton-vendéen. Sur près de $30 \mathrm{~km}$ de longueur 
et jusqu'à $3 \mathrm{~km}$ de largeur (au nord de Notre-Dame-de-Monts), ce massif est peu élevé (20 mètres en moyenne pour les dunes anciennes les plus à l'est, et 41 mètres au point culminant, le Pey de la Blet à La Barre-de-Monts).

Plus au sud, la flèche du Jaunay (environ $6 \mathrm{~km}$ ), dans le prolongement des dunes perchées de la Sauzay, a détourné un petit fleuve en progressant vers le nord (rare exemple local de dérive littorale sud-nord).

Au nord des Sables-d'Olonne, le massif d'Olonne est formé de cordons littoraux successifs, édifiés par les houles et qui se sont ancrés sur une chaîne d'îlots à partir de 5000 ans BP jusqu'à la fin du Petit Âge glaciaire, sur près de 9 km de long et $2 \mathrm{~km}$ de large au maximum. Un double feston de dunes paraboliques culmine à 34 mètres et forme le corps principal du massif dunaire d'Olonne (figure 1.82). Cette barrière sableuse a freiné l'écoulement des eaux et bloqué le marais de l'île d'Olonne.

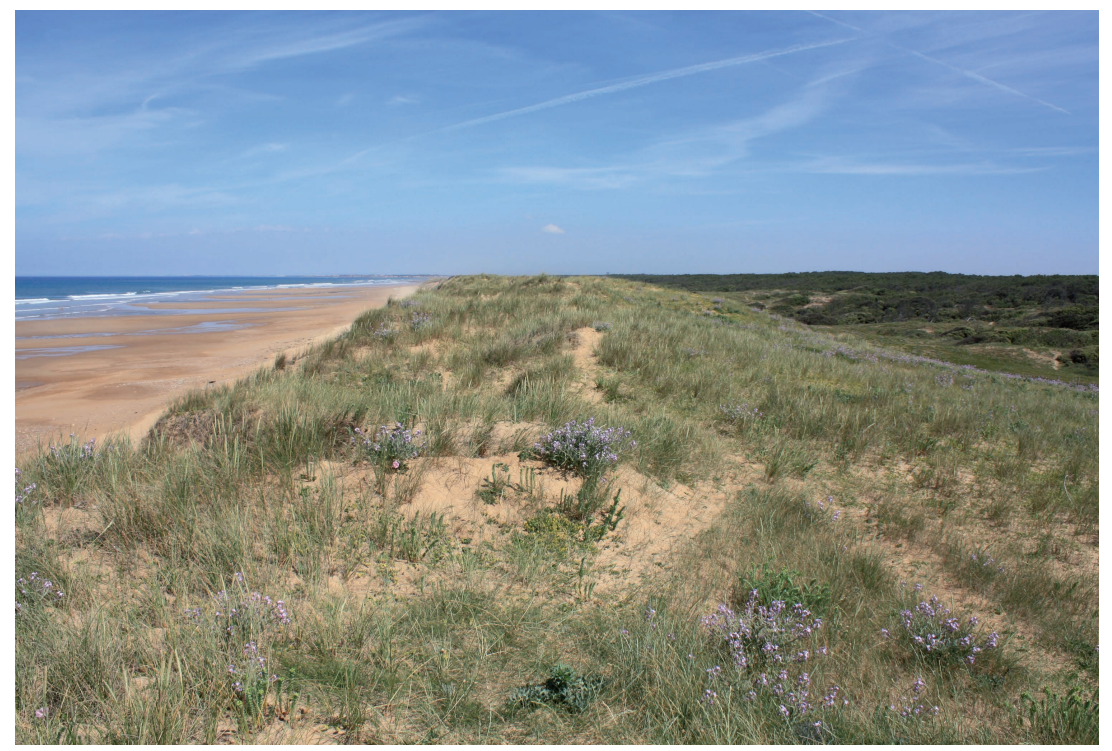

Figure 1.82. Massif dunaire d'Olonne.

(C) L. Gouguet/ONF.

Au sud des Sables-d'Olonne, des petits massifs dunaires anciens, perchés sur des falaises, s'échelonnent jusqu'à l'estuaire du Payré, où une belle flèche sableuse (non fixée et très fréquentée) se fait et se défait, et vient ensabler régulièrement le lit du fleuve au gré des assauts de la mer.

Le littoral du Sud Vendée est marqué par trois massifs dunaires liés dont l'édification s'est échelonnée dans le temps sous l'action de la dérive littorale :

- le massif de Longeville, de $9 \mathrm{~km}$ de long, série de cordons accrochés à deux extrémités rocheuses, où les dunes les plus anciennes peuvent atteindre 30 mètres de hauteur ;

- la longue flèche sableuse de la pointe d'Arçay (figure 1.83) : monument naturel quasi unique en France, longue de $7 \mathrm{~km}$, et qui s'accroît pratiquement de 20 mètres par an, repoussant vers le sud l'estuaire du Lay! À sa racine, elle a permis la formation d'une lagune, dont les connexions avec la mer s'effectuent au gré de l'érosion marine du cordon dunaire ; à son extrémité, se forme une succession de crochets sableux, les crochons, résultant de l'obliquité des houles qui repoussent le courant du fleuve vers le sud-est ; 
- la pointe de l'Aiguillon, enfin, petite pointe sableuse de près de $3 \mathrm{~km}$ qui borde l'anse de l'Aiguillon au nord, et dont l'évolution naturelle est entravée par des épis.

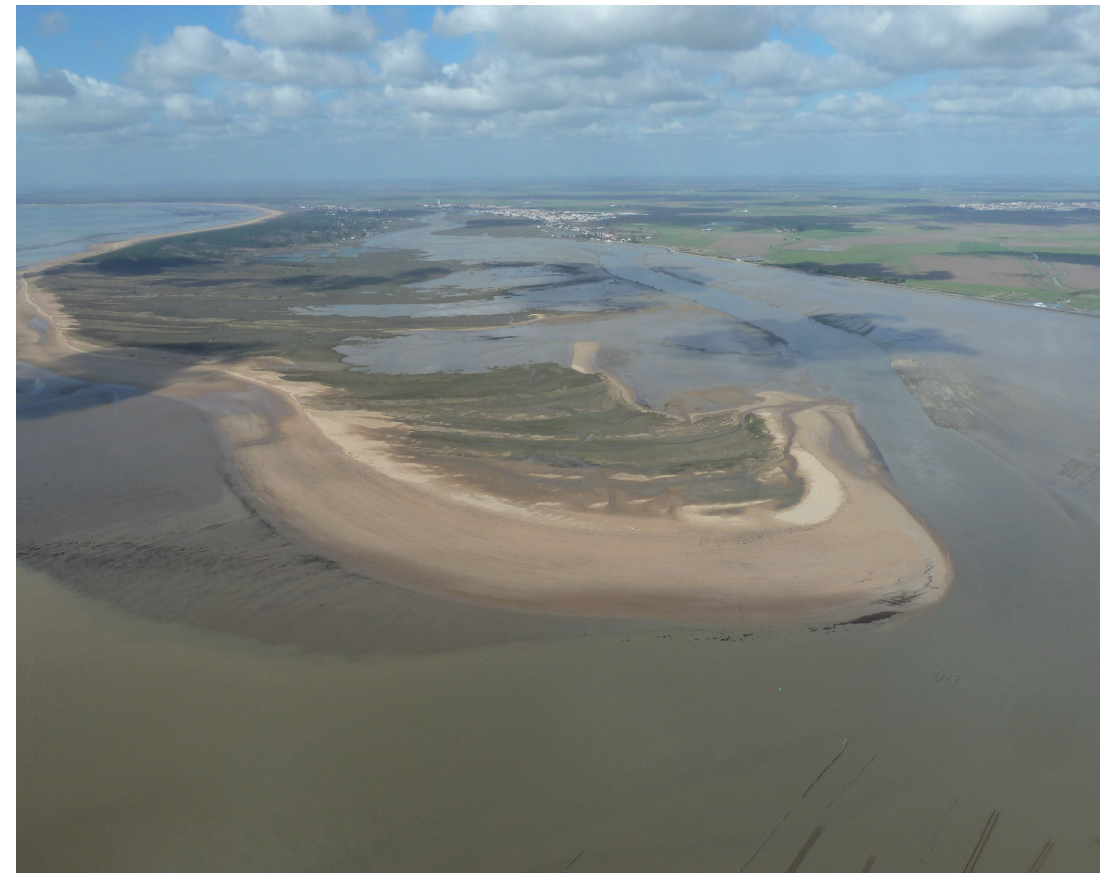

Figure 1.83. Flèche sableuse de la pointe d'Arçay.

(C) E. Joyeux.

\section{LES DUNES DES ÎLES CHARENTAISES}

Une des deux plus grandes îles du littoral charentais, I'île de Ré, entourée de platiers rocheux, est en réalité elle-même formée de deux îles (en fait cinq îles au moment du maximum transgressif) sur un substrat rocheux calcaire, reliées par le cordon dunaire du Martray (maintenant endigué). Les dunes y sont relativement basses (une vingtaine de mètres au sud de l'île et une quinzaine de mètres au nord) et perchées sur un socle rocheux.

L'île d'Oléron est à la limite entre les systèmes dunaires vendéens et les systèmes aquitains. Au sud, les apports massifs de sable conjugués aux efforts de fixation des dunes engagés à partir de 1850 ont permis au trait de côte de progresser vers l'ouest de plus de $1,5 \mathrm{~km}$ en un siècle ! Mais le phénomène s'est maintenant inversé, et il n'est pas rare de constater des érosions de plus de 20 mètres par an vers la pointe de Gatseau. La mer pénètre maintenant assez régulièrement en forêt dunaire, celle-ci ne bénéficiant plus de la protection du cordon bordier arasé (figure 1.84).

Au nord de la façade ouest de l'île d'Oléron, les dunes sont perchées. Elles sont étroites et leurs formes disparaissent souvent sous l'urbanisation.

Au nord-est, une flèche sableuse complexe s'est formée profitant des courants du pertuis d'Antioche (dérive ouest-est). Recouvert par la forêt des Saumonards, ce massif dunaire exposé aux vents d'est atteint 20 mètres d'altitude. II est régulièrement érodé et les submersions occasionnelles des dépressions dunaires sont maintenant constatées lors de certaines tempêtes. 


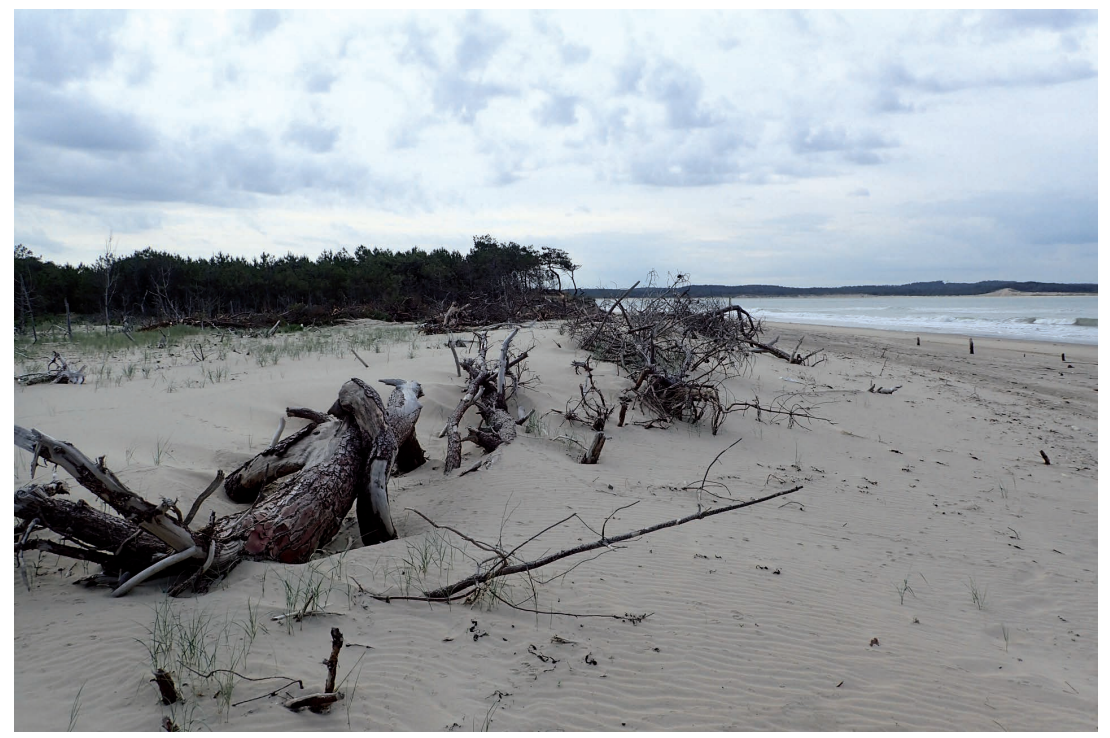

Figure 1.84. Pointe de Gatseau.

La dune $n^{\prime}$ offre plus de protection contre la submersion marine.

(C) L. Gouguet/ONF.

Sur les côtes est des îles, ainsi qu'en face sur le continent (Yves, Châtelaillon), l'énergie des houles atténuée par les îles ne mobilise que peu de sables, d'autant plus que la mer des Pertuis possède d'immenses estrans vaseux : les cordons dunaires y sont peu larges et peu hauts.

\section{LA PRESQU'îLE D'ARVERT, DÉBUT DU SYSTÈME AQUITAIN}

Entre le pertuis de Maumusson et l'estuaire de la Gironde, les systèmes dunaires en place préfigurent le système des dunes aquitaines. Le nord de la côte de la presqu'île d'Arvert (la Côte sauvage) est bordé par des cordons rectilignes

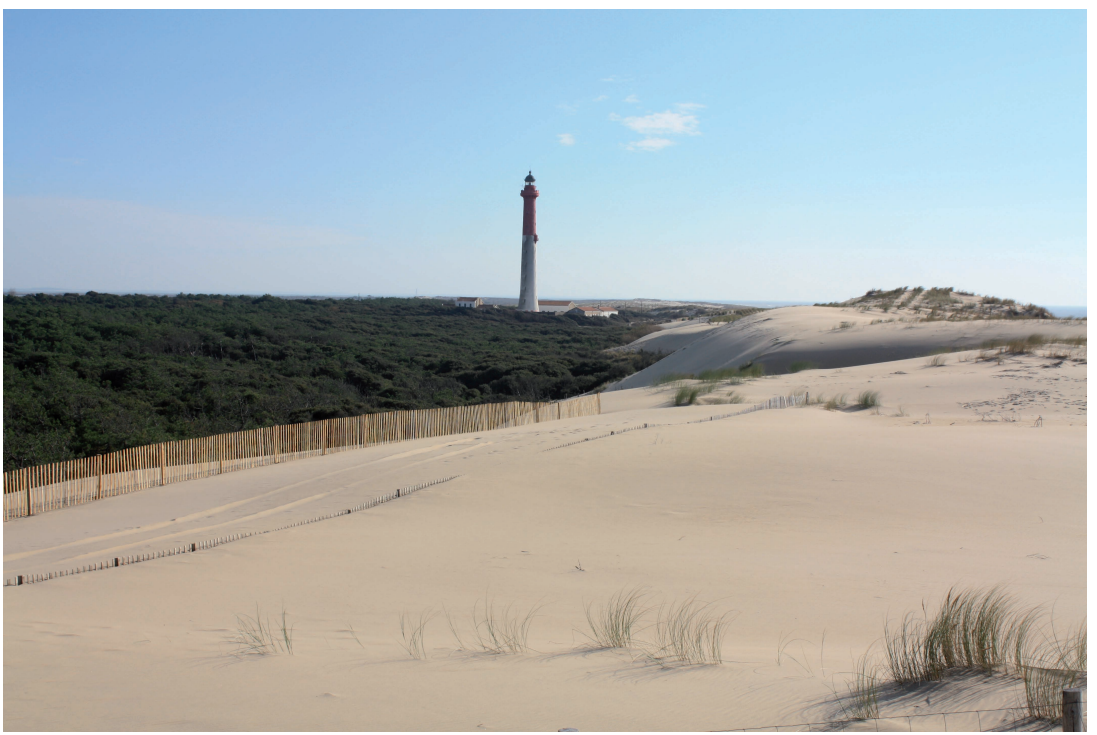

Figure 1.85. La dune au phare de la Coubre.

(C) L. Gouguet/ONF. 
calibrés dus aux actions de fixation engagées au xix $x^{\mathrm{e}}$ siècle. La forêt domaniale de la Coubre, à l'est de ces cordons, y occupe, sur plus de $3 \mathrm{~km}$ de large, des dunes allant jusqu'à 50 mètres d'altitude (figure 1.85). L'érosion est intense sur ce littoral, dont le recul est estimé par endroits à près de 500 mètres entre 1945 et 2010 ! Mais ce littoral est toutefois marqué par la présence de deux zones d'accrétion, I'une au nord (Pointe Espagnole), se nourrissant des sédiments arrachés à la côte sud du pertuis de Maumusson, et l'autre au sud (flèche de Bonne Anse), alimentée par les sables apportés par la dérive littorale nord-sud et repris par les courants de l'estuaire de la Gironde. Cette flèche, longue de plus de $5 \mathrm{~km}$, vient fermer la baie de Bonne Anse qui forme ainsi une lagune.

Le sud de la presqu'île d'Arvert (la côte de Beauté), d'une orientation nordouest/sud-est, est soumis à l'influence de l'estuaire de la Gironde. Les dunes y sont toutefois moins hautes qu'au nord (40 m) et sont occupées par les massifs forestiers de Saint-Augustin-les-Mathes et des Combots d'Ansoine.

\section{LES DUNES AQUITAINES : UNE SUCCESSION DE GÉNÉRATIONS DE DUNES}

\section{LARGES ET MASSIVES}

Le cordon littoral aquitain tel que nous le connaissons est en réalité le résultat de l'organisation et du remaniement de dépôts de sables parfois anciens, sous des climats différents.

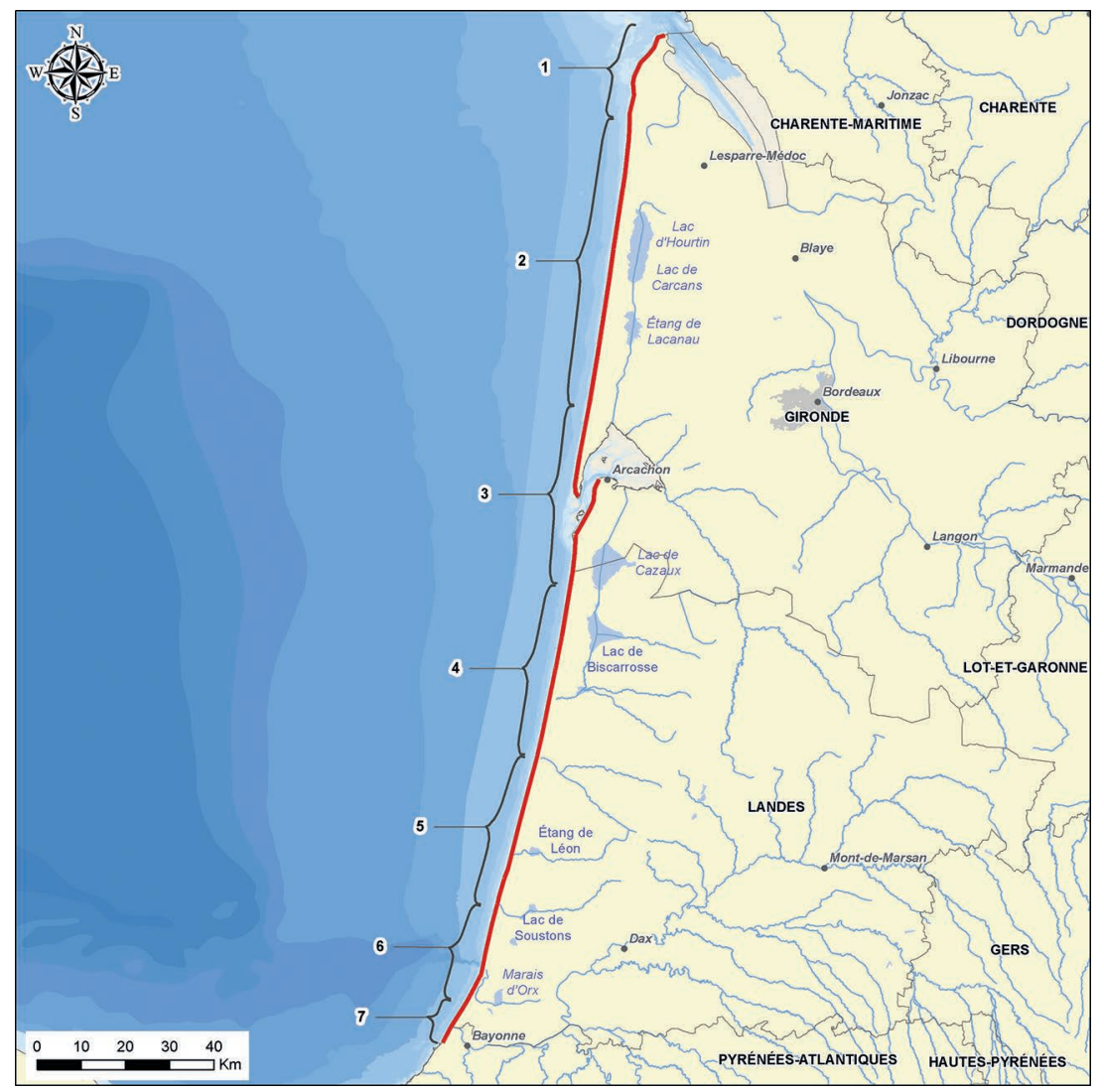

Figure 1.86. Emplacement des dunes aquitaines.

1. Dunes du nord Médoc ; 2. dunes du Médoc ; 3 . dunes du pays de Buch ; 4. dunes du pays de Born ; 5. dunes du Marensin ; 6 . dunes du pays de Maremme ; 7 . dunes du Seignanx et de l'Adour. Sources : Cerema, ONF. 
À partir de la transgression flandrienne, commencée il y a environ 18000 ans, le niveau marin s'élève et les houles remontent du sable qui va s'accumuler sur le littoral où il est repris par le vent et entraîné vers l'intérieur des terres. S'y ajoute le sable provenant du remaniement des dunes plus anciennes. Les dunes ainsi formées s'accolent les unes aux autres, formant des rides parallèles au rivage.

Les datations récentes ont permis d'identifier plusieurs périodes de mise en place des dunes aquitaines, au gré des variations du climat et de la remobilisation des sables. Ce sont les périodes de péjoration climatique (plus sèches et plus froides) qui sont les plus favorables.

Une première génération de dunes modestes s'est développée entre 3000 et 4000 ans BP, venant recouvrir le paléosol formé sur la nappe de "sables des Landes ». Mais l'essentiel du complexe dunaire aquitain correspond à des dunes plus récentes. Pendant le Haut Moyen Âge, du $\mathrm{VII}^{\mathrm{e}}$ au $\mathrm{XI}^{\mathrm{e}}$ siècle, une période de forte activité éolienne se traduit par la formation de dunes paraboliques, croissants dont la concavité est tournée vers l'ouest, et qui sont parfois accolées. Ces dunes, situées le plus à l'est, ont été fixées naturellement par une forêt mixte de pins et de chênes durant la dernière période, plus chaude, du Moyen Âge (Petit Optimum). Lors du Petit Âge glaciaire (du xve au début du xIx $x^{e}$ siècle), une nouvelle génération de dunes se met en place. Ce sont des dunes volumineuses, quelques barkhanes isolées, croissants dont la concavité est tournée vers l'est, mais surtout de grands cordons barkhanoïdes.

Ces différentes générations de dunes vont progressivement façonner le paysage littoral aquitain. Constituées de 5 rides (partie centrale du Médoc) et jusqu'à 10 cordons parallèles (entre le bassin d'Arcachon et Mimizan), pouvant s'étendre jusqu'à $6 \mathrm{~km}$ du littoral et atteindre 70 mètres de hauteur, les formations dunaires sont venues contrecarrer les écoulements des rivières et des fleuves, donnant ainsi naissance à une chaîne d'étangs et de marais, et aux nombreux lacs aquitains (Hourtin, Carcans, Lacanau, Cazaux, Biscarrosse, Parentis...) (figure 1.87).

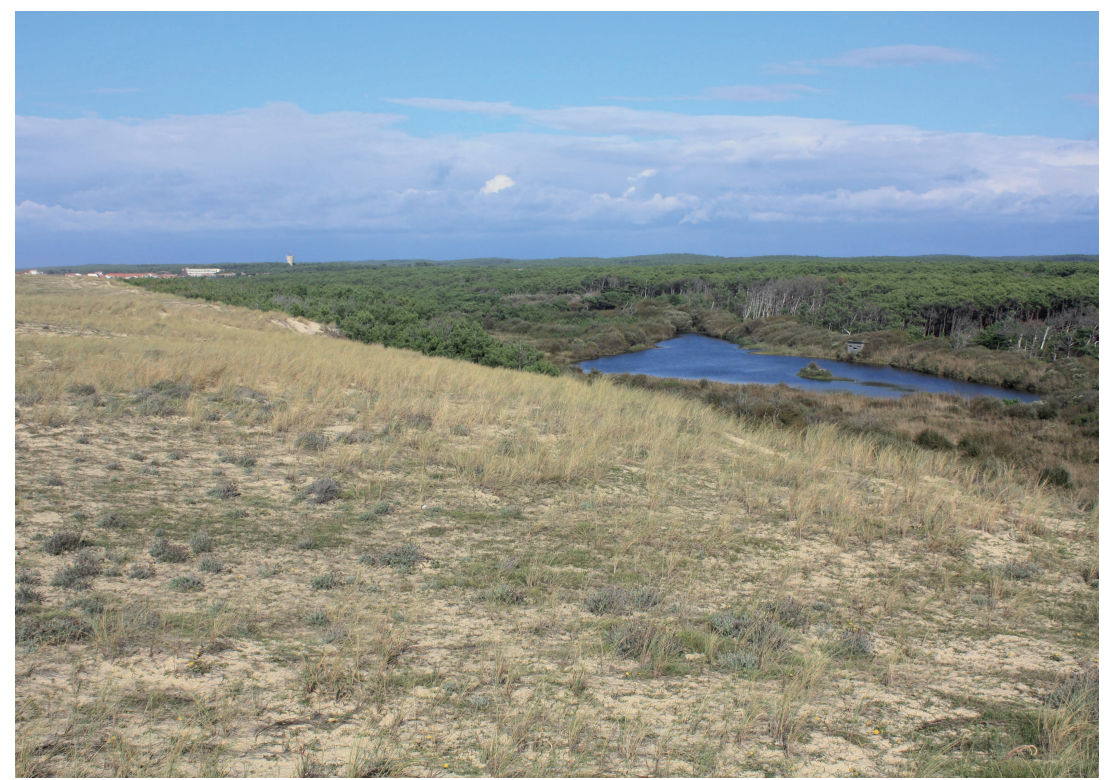

Figure 1.87. Étang de la Mailloueyre (Mimizan).

(C) L. Gouguet/ONF. 
À partir du début du xIX ${ }^{e}$ siècle, l'action de I'homme entreprise pour éviter I'ensablement des forêts nouvellement implantées va permettre la constitution d'un bourrelet littoral calibré (figure 1.88). À l'aide de systèmes de palissades (planches espacées de quelques centimètres les unes des autres, et rehaussées lorsqu'elles étaient ensablées) et grâce aux plantations de gourbet (nom local de l'oyat), un cordon homogène non boisé faisant 300 à 400 mètres de large va être édifié au plus près du littoral. Son entretien, qui a fluctué au gré des périodes selon les moyens techniques et financiers disponibles, a toutefois permis d'obtenir une relative diversité des formes frontales.

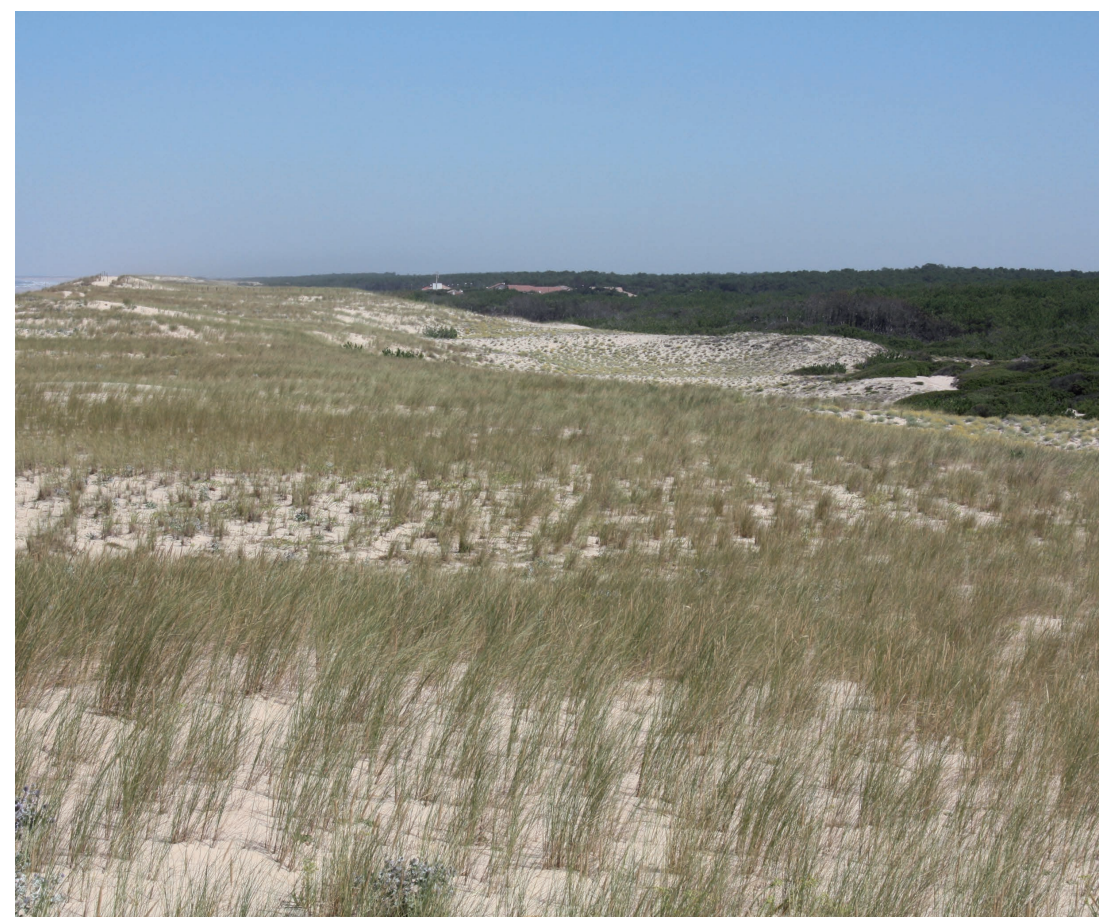

Figure 1.88. Cordon dunaire calibré (Hourtin).

(c) L. Gouguet/ONF.

\section{Évolution récente}

Après les actions de fixations entreprises au xix $x^{e}$ siècle, ce sont bien les actions liées au développement du tourisme, à partir de 1950, qui marquent les plus gros changements dans les paysages dunaires. De l'installation de cités balnéaires à l'organisation des accès aux plages tant recherchées, nombreuses sont les traces d'artificialisation qui apparaissent (figure 1.89).

C'est à partir des années 1980 que la prise de conscience de la valeur écologique de ces milieux a entraîné des modifications de pratiques, un renforcement de leur protection par la réglementation, et globalement une meilleure sensibilisation des populations.

Les tempêtes subies depuis le début du xxl ${ }^{\mathrm{e}}$ siècle, dans un contexte où l'érosion semble s'accélérer (ou du moins menace de plus en plus d'enjeux) et où des épisodes de submersion ont occasionné de douloureux dommages aux personnes et aux biens, donnent toute leur importance à l'entretien et à la conservation des dunes comme protection temporaire. 


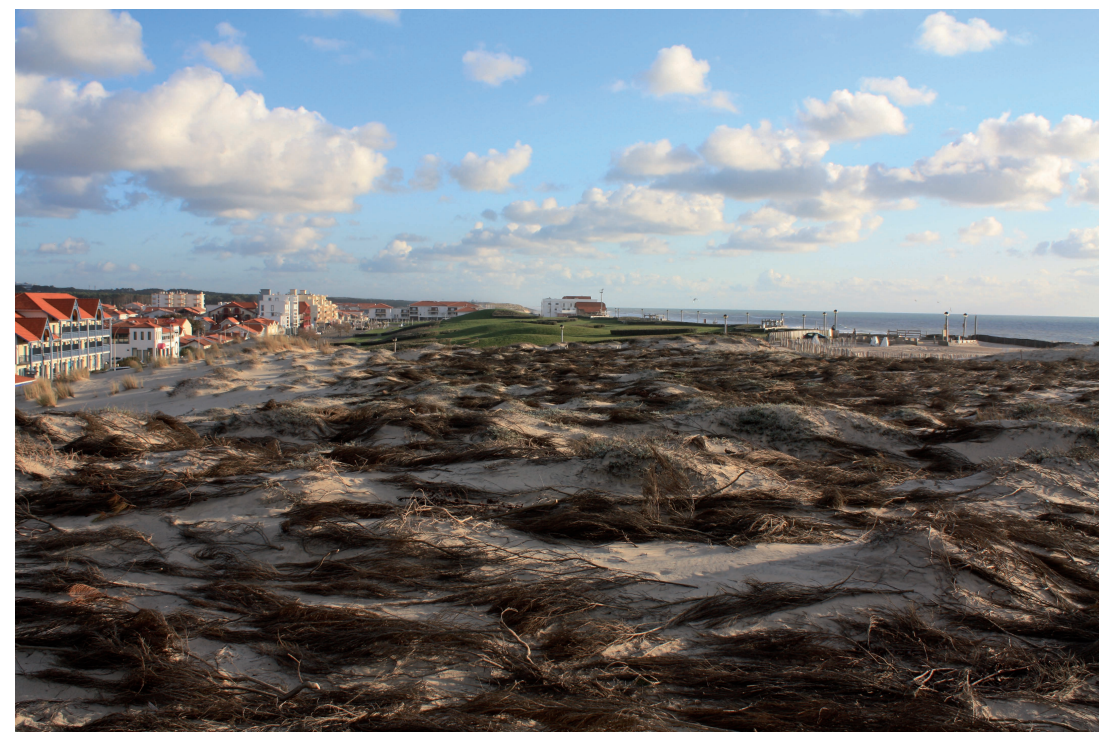

Figure 1.89. Dunes devant la station balnéaire de Biscarosse.

Au premier plan, dune naturelle recouverte de branchages pour piéger le sable, à l'arrière-plan, dune urbaine artificialisée.

(C) L. Gouguet/ONF.

\title{
Les dunes méditerranéennes
}

\author{
Philippe Richard
}

\section{Spécificités}

Les dunes de Méditerranée bordent une mer sans marée ; pour être précis, le marnage y est trop faible (quelques décimètres) pour être à lui seul un facteur influençant la dynamique littorale; en revanche, associé à un fort vent marin et à une pression atmosphérique basse, la surcote du niveau de la mer ainsi engendrée, conjuguée au déferlement des vagues, peut être déterminante dans I'intensité d'un épisode tempétueux, et par conséquent dans son impact sur la dune. Les autres éléments spécifiques aux dunes méditerranéennes tiennent aux conditions climatiques locales :

- le régime des vents a une action prépondérante sur l'évolution des dunes côtières, qui doivent s'accommoder d'une contrainte particulière : la présence de vents de terre, qui sur l'année soufflent nettement plus fréquemment et violemment que le vent marin ; la Tramontane à l'ouest du golfe du Lion, le Mistral à l'est, vents turbulents et desséchants, rendent difficile la formation des dunes et ont une action destructrice sur celles qui sont fragilisées par un couvert végétal insuffisant ;

- les conditions hydriques (pluviométrie plus faible et mal répartie sur l'année) sont moins favorables au développement de la végétation que pour les autres façades maritimes ;

- enfin, le faible marnage induit une largeur d'estran quasi nulle, et donc une étendue de sable disponible pour le transport éolien très réduite ; le vent marin s'accompagnant souvent d'une élévation du niveau de la mer, en général lors des épisodes tempétueux, la plage est submergée, le transit éolien de sable vers la dune s'en trouve bloqué. 

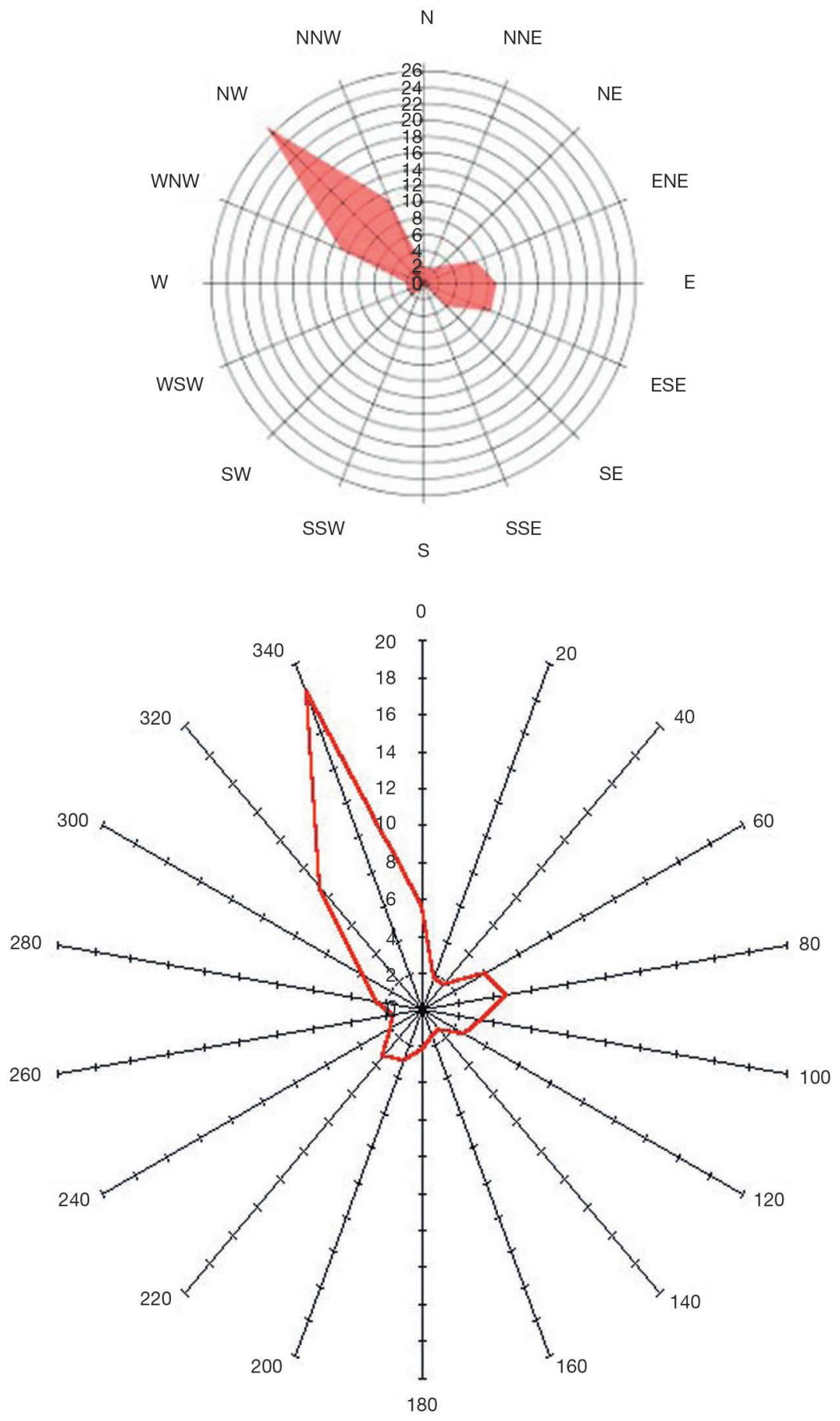

Figure 1.90. Rose des vents de Perpignan, en haut (windfinder.com) et de Salon-de-Provence, en bas (meteosudest.org). 
Il en résulte des dunes aux dimensions réduites : les plus hautes de Méditerranée française dépassent à peine $10 \mathrm{~m}$; la largeur des massifs atteint quelques centaines de mètres pour les plus grands d'entre eux. Elles sont le plus souvent constituées d'un cordon unique (dune vive et dune fixée) qui s'étire parallèlement au trait de côte, parfois précédé de dunes embryonnaires. Leur position est relativement figée car elle résulte de l'équilibre obtenu entre les vents dominants ; les espaces dunaires occupent donc souvent une bande étroite entre la plage et l'intérieur (zones humides ou urbanisation).

\section{Répartition}

Sur la côte métropolitaine française, le Rhône marque clairement une limite : les principaux cordons dunaires se localisent à l'ouest de son cours (golfe du Lion), où les côtes basses dominent ; en Provence-Alpes-Côte d'Azur et en Corse, les dunes restent cantonnées aux bassins-versants des cours d'eau côtiers, et encore uniquement pour ceux qui sont en mesure de fournir du matériel suffisamment fin pour que des processus éoliens puissent intervenir. La côte de la plaine orientale de la Corse fait figure d'exception; basse et sableuse, elle s'apparente davantage à celle du golfe du Lion.

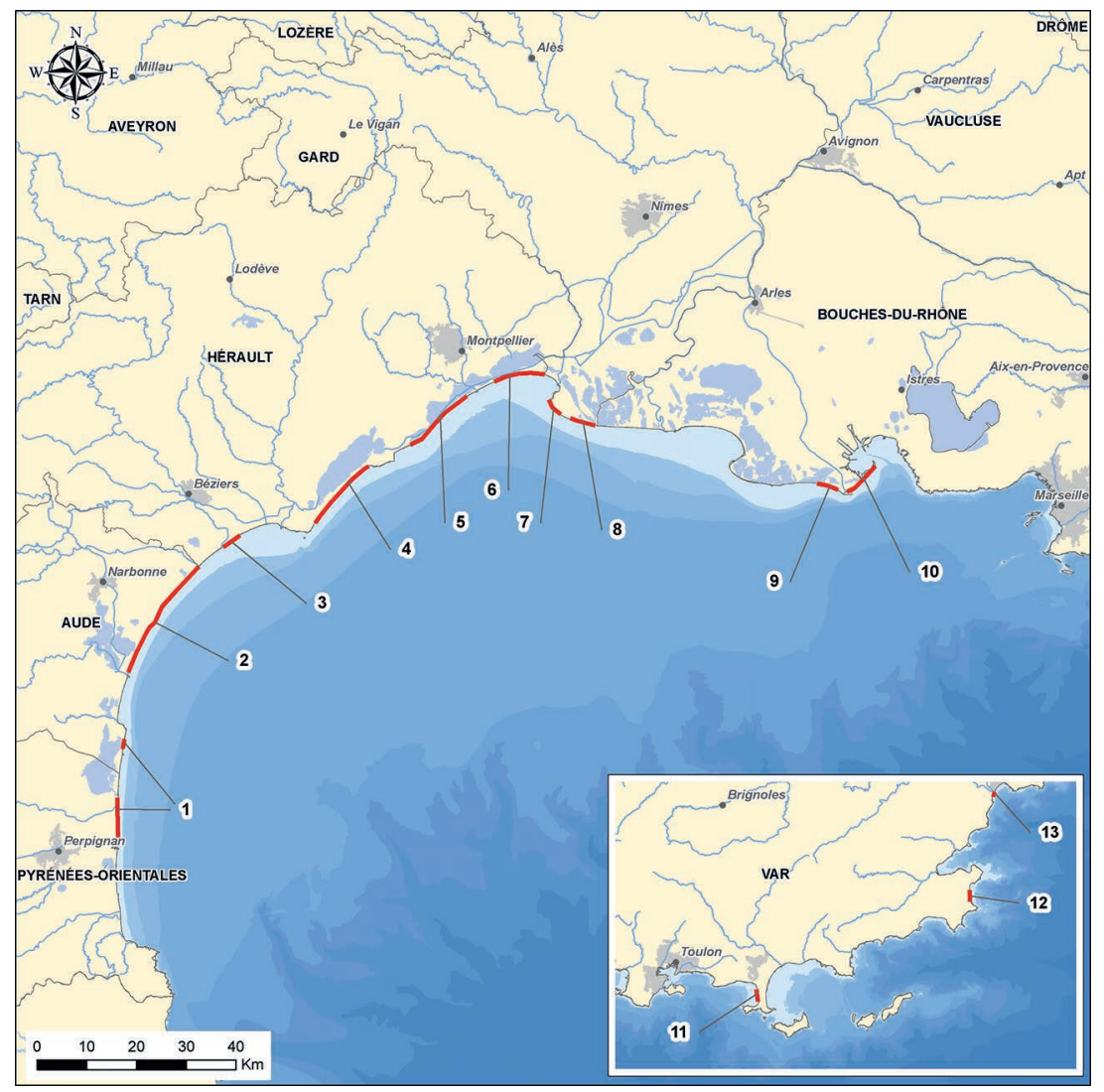

Figure 1.91. Emplacement des principales dunes méditerranéennes continentales.

1. Cordons dunaires roussillonais ; 2 . cordons dunaires audois ; 3 . les Orpellieres ; 4 . lido de Sète à Marseillan ; 5. lido de l'étang de Pierre-Blanche ; 6. lido des Travers ; 7. massif de l'Espiguette ; 8. cordon de Petite Camargue ; 9. cordon de Piémanson ; 10. flèche de la Gracieuse ; 11. presqu'île de Giens ; 12. dunes de Pampelonne (Ramatuelle) ; 13. dune des Esclamandes.

Sources : Cerema, ONF. 


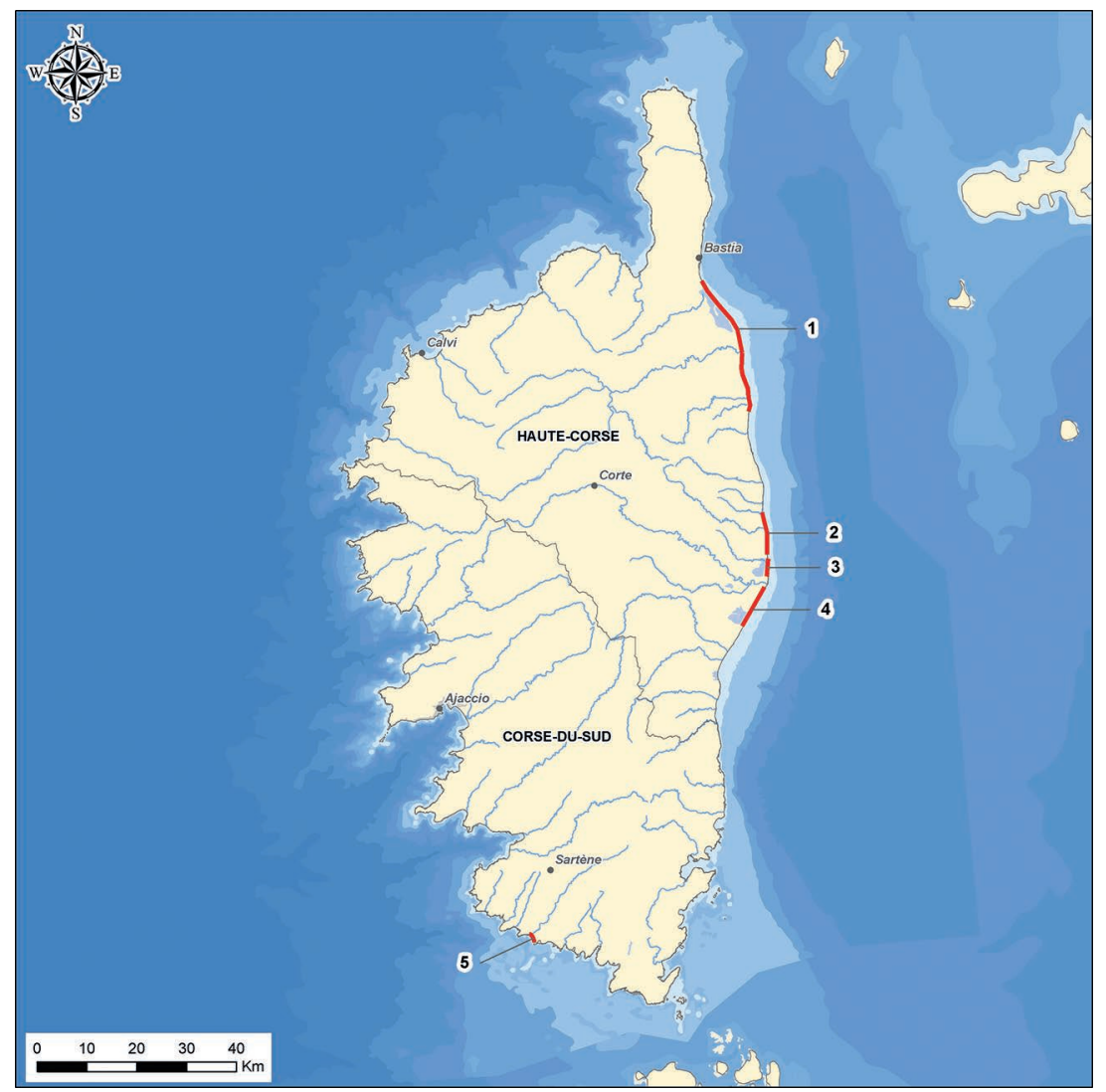

Figure 1.92. Emplacement des principales dunes méditerranéennes corses.

1. Lido de Biguglia ; 2 . dunes de Prunete ; 3 . dunes de l'étang de Diane ; 4. dunes de l'étang d'Urbino : 5. dunes d'Erbaju.

Sources : Cerema, ONF.

\section{Typologie}

Deux grands types de formations dunaires sont présents en Méditerranée.

\section{LES DUNES DE LIDOS}

Le golfe du Lion, ainsi que la côte de la plaine orientale de la Corse, et dans une moindre mesure certaines baies du sud-est (dunes du lido* de Santa-Giulia, Balistra et Rondinara), sont marqués par la présence d'un chapelet d'étangs (lagunes), héritage de la remontée progressive du niveau marin à la fin de la dernière glaciation. Poussé par cette transgression, un fin cordon de sédiments est venu s'accrocher aux pointements rocheux de la côte, isolant ces étangs de la mer. Appelés lidos en référence à celui de la lagune de Venise, ces cordons sableux constituent le support des dunes actuelles; ils sont interrompus par des passes qui font communiquer mer et étangs (les graus).

Peu élevés, ils sont parfois franchis par la mer lors des épisodes tempétueux qui entraînent les sédiments à l'intérieur de l'étang : le cordon roule sur luimême en conservant son volume. Dans ce cas, les processus marins prennent le pas sur les processus éoliens, le caractère dunaire de ces cordons tend alors à s'atténuer. 


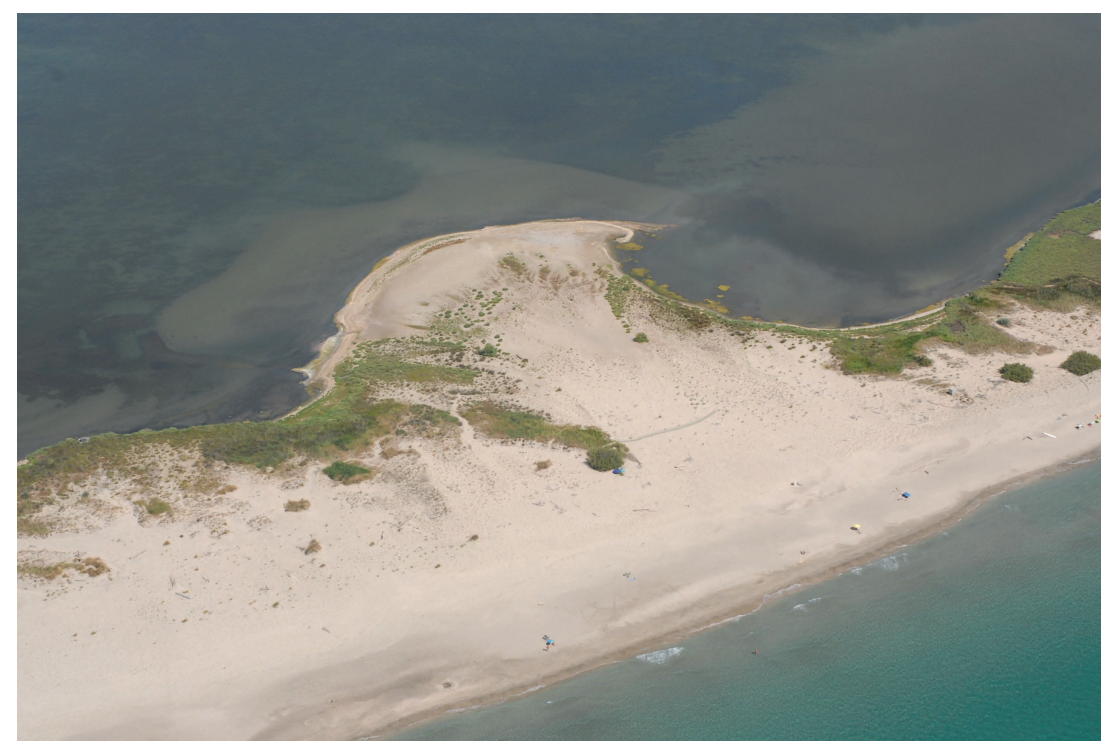

Figure 1.93. Photo aérienne du lido de l'étang de Pierre-Blanche (Villeneuve-lès-Maguelone). (c) EID Méditerranée.

\section{LES DUNES DE FLEUVES CÔTIERS}

Plus isolées, elles sont constituées des sédiments accumulés aux embouchures des fleuves, et occupent donc, suivant les cas, des fonds de baie (côtes rocheuses) ou des basses plaines (côtes sableuses). Dans le premier cas, les systèmes plage-dune sont autonomes, évoluant avec un stock de sédiments unique. Dans le second cas, les courants de dérive littorale redistribuent le sable sur de longues distances; les dunes de fleuves côtiers peuvent alors se connecter aux dunes de lidos, rendant la limite entre ces deux grands types peu évidente (cas des plages de poche de la région des Agriates le long du golfe de Saint-Florent en Corse).

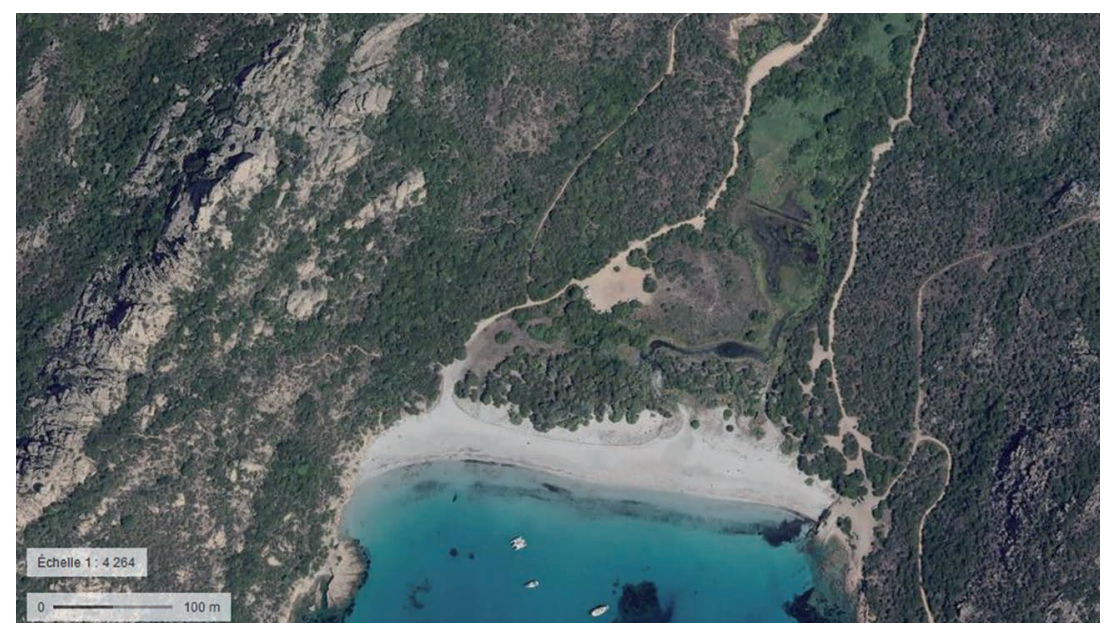

Figure 1.94. Photo aérienne de la plage de Roccapina, Sartène (Haute-Corse) : système fermé de baie.

Source : Géoportail. 


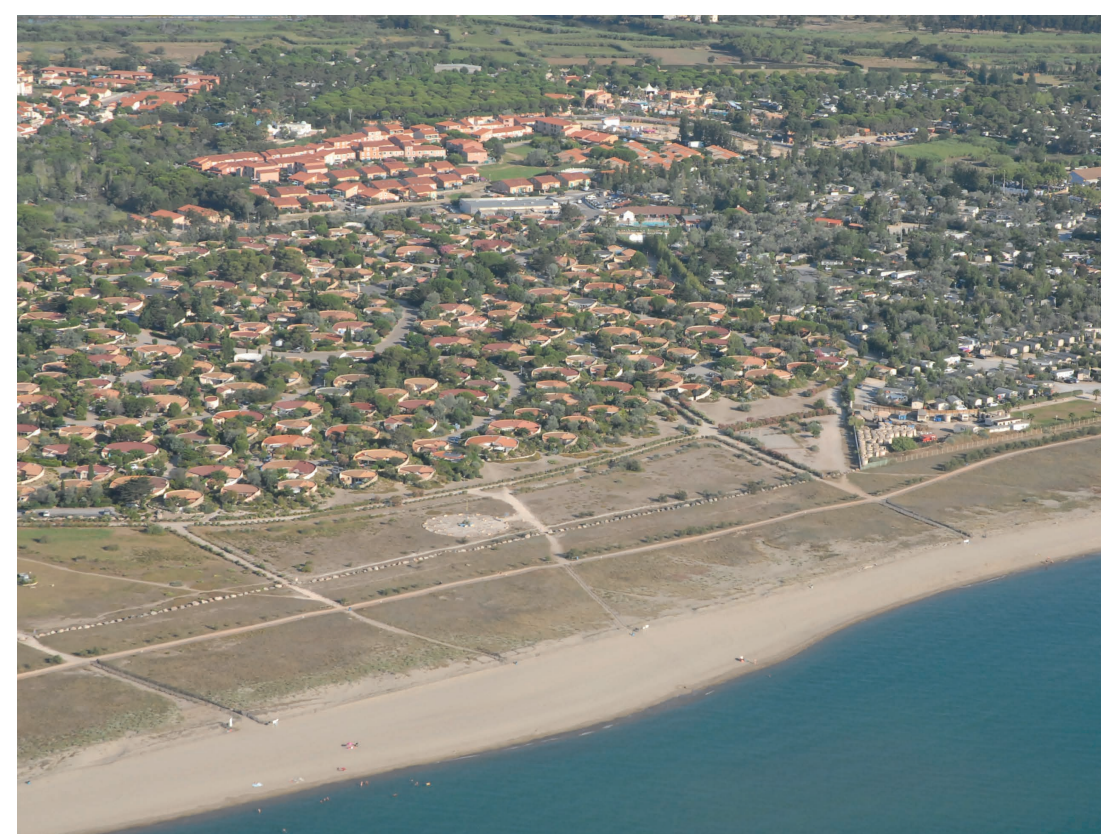

Figure 1.95. Photo aérienne de la plage de Torreilles (Pyrénées-Orientales) : système ouvert de basse plaine.

Source : EID Méditerranée.

D'autres types de dunes existent mais ne sont pas pris en compte ici : les barkhanes temporaires, formes fugitives localisées sur les plages les plus larges ouvertes aux forts vents de terre (les Chalets à Gruissan, I'Espiguette au Graudu-Roi), les dunes paraboliques fossiles de Camargue, aujourd'hui déconnectées du système plage-dune actif, les dunes perchées de certaines plages de poche des Agriates dans le nord-ouest de la Corse (Ghignu et Ostriconi).

\section{Évolution récente}

La majeure partie des dunes de Méditerranée ont été dégradées depuis les années 1960 par l'urbanisation touristique (fréquentation anarchique, pollution, occupation) quand elles elles n'ont pas été purement et simplement arasées pour les besoins de la construction ou de l'agriculture. Elles sont mieux considérées depuis les dernières décennies, à I'heure où érosion et submersion marine ont mis en relief le rôle essentiel des dunes pour la protection contre ces aléas. Elles font désormais l'objet d'opération de protection et de restauration, voire de recréation, à travers l'utilisation de techniques de génie écologique : renforcement des volumes par la mise en place d'ouvrages de piégeage sableux, stabilisation (paillages), aide à la végétalisation, gestion de la fréquentation (mise en défens, aménagements de passages, communication).

\section{Les dunes ultramarines}

Ywenn de La Torre

Ce guide ne serait pas complet s'il n'évoquait pas les dunes des départements d'outre-mer. En effet, les dunes constituent un milieu azonal qui peut se retrouver sous toutes les latitudes pour peu que le stock sableux soit suffisant. 
Ainsi, que ce soit dans les territoires ultramarins tropicaux ${ }^{5}$ ou sous des hautes latitudes ${ }^{6}$, des dunes ont pu se développer et font aujourd'hui l'objet de mesures de gestion, voire de protection, en raison de leur caractère patrimonial et des phénomènes d'érosion auxquels elles sont confrontées.

Dans les zones intertropicales, les matériaux ont la spécificité de pouvoir provenir des formations coralliennes présentes (sable dit biodétritique ou bioclastique) ou, pour une part importante, de l'altération, particulièrement active sous ces latitudes, de roches avoisinantes (sables fins repris facilement par le vent). Sous les hautes latitudes, la nature des sédiments peut également se distinguer de celles des contrées tempérées, avec des sables issus des formations détritiques glaciaires (moraines) ou liée à l'action mécanique du gel sur la roche (cryoclastie).

Parmi les particularités, notons également la présence d'événements extrêmes de types cycloniques, dont la houle et le vent, qui ont un fort impact sur les littoraux meubles lors de leur passage. Formés dans la zone intertropicale sur chacun de nos océans, ces cyclones peuvent aussi devenir extratropicaux et venir mourir dans les hautes latitudes comme c'est régulièrement le cas à SaintPierre-et-Miquelon, sur la côte atlantique d'Amérique du Nord.

Compte tenu de la diversité de milieux concernés et par conséquent de la difficulté de traiter le sujet de manière exhaustive, il est proposé de s'attacher à deux exemples caractéristiques d'environnements contrastés, à savoir les dunes de l'Étang-Salé à la Réunion et les dunes des Buttereaux à Saint-Pierreet-Miquelon.

Il faut noter par ailleurs que des formations dunaires bien développées sont également observées au sein des Antilles françaises (à Saint-Barthélemy notamment) ou en Nouvelle-Calédonie (île d'Ouvéa notamment, figure 1.96).

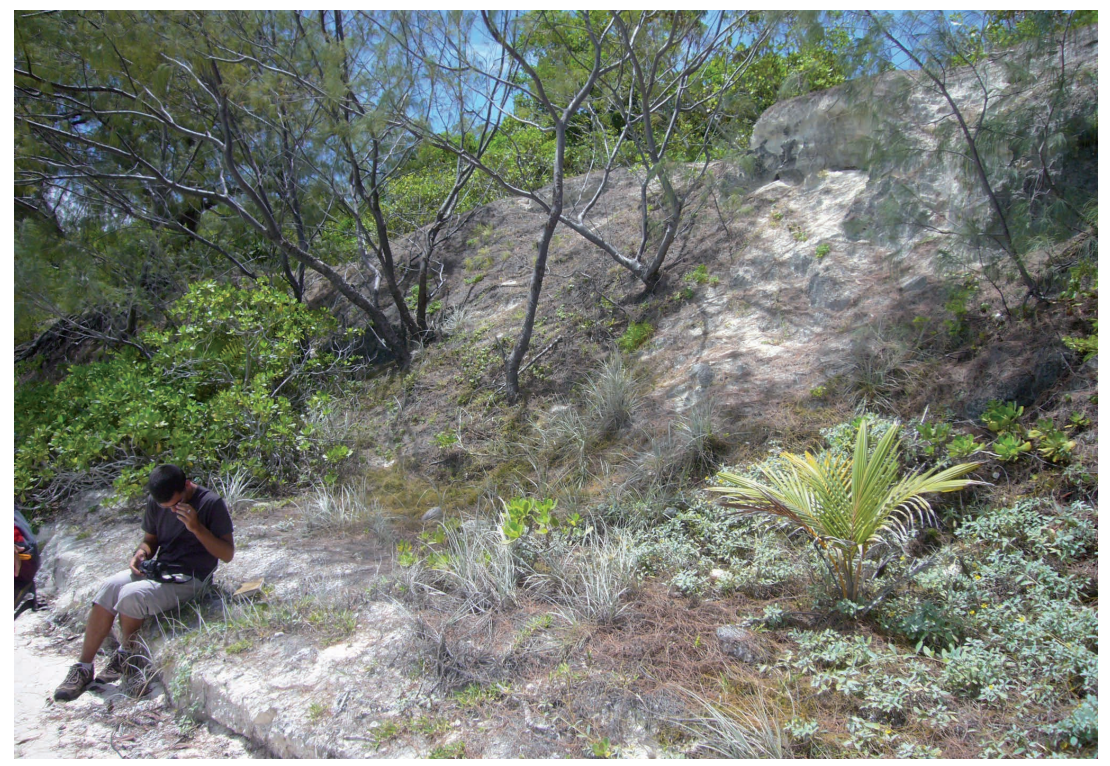

Figure 1.96. Front de dune composée de sable bioclastique à Ouvéa en Nouvelle-Calédonie. (C) Y. de La Torre/BRGM.

5. Guadeloupe, Martinique, Saint-Martin, Saint-Barthélemy, Guyane, La Réunion, Mayotte, Polynésie française, Nouvelle-Calédonie, Wallis-et-Futuna, etc.

6. Saint-Pierre-et-Miquelon, Terres australes et antarctiques françaises (Kerguelen, Crozet, etc.). 
Des formes associées (accumulations de sables en arrière du littoral) peuvent également être rencontrées en Guyane avec les cheniers ${ }^{7}$ ou sur les motus ${ }^{8}$ de Polynésie française. Mais elles ne sont à pas à considérer comme des formations dunaires car leur mode de mise en place est davantage lié au jeu des vagues et des courants. Toutefois, des dunes embryonnaires végétalisées y sont courantes grâce à l'action du vent sur ces édifices sableux.

\section{Les dunes de l'Étang-Salé (La Réunion)}

Les dunes de l'Étang-Salé à la Réunion se situent au sud-ouest de l'océan Indien, dans un contexte volcanique insulaire tropical.

Il s'agit du massif dunaire le plus important de l'île (figure 1.97), il s'étend sur une longueur de $6 \mathrm{~km}$ et une largeur pouvant atteindre $2,5 \mathrm{~km}$. II se singularise par son matériel sableux d'origine volcanique. En effet, les sables basaltiques qui le composent sont aussi appelés " sables verts » en raison de leur forte teneur minérale en olivine.

Ces dunes classiquement $d$ 'âge holocène se sont répandues alors que le niveau de la mer était plus bas et ont colonisé la planèze ${ }^{9}$ ouest de l'île depuis l'embouchure de la rivière Saint-Étienne au sud-est, soufflées vers le nord-ouest dans le sens dominant de l'alizé. Leur extension est telle que des sables sont observés sur des terrains allant jusqu'à 200 m d'altitude (Robert, 1974).

Ce massif est aujourd'hui rémanent ou fossile car il n'est pratiquement plus alimenté par les estrans actuels (Cazes-Duvat et Paskoff, 2004). Jean-Baptiste Bory de Saint-Vincent, naturaliste français du XIx siècle, décrit, lors de son passage en 1801, des dunes non végétalisées qui continuaient à migrer. Elles ont été artificiellement fixées à partir de 1870 par des plantations d'arbres, essentiellement des filaos originaires d'Australie.

Cette forêt domaniale, dite des Bas sous le vent, est gérée par l'Office national des forêts et couvre aujourd'hui 922 ha. Or, le filao a un principal inconvénient. Il évacue le surplus salé par ses feuilles qui, une fois tombées, rendent le sol infertile pour les autres espèces fixatrices. Le massif dunaire étant affecté par l'érosion marine et la déflation, des travaux expérimentaux sont en cours afin d'introduire une plus grande diversité en espèces indigènes dans les zones littorales, dans deux arboretums. Très fréquentées pour le tourisme et les loisirs, ces dunes accueillent également des activités agropastorales au sein de casiers agricoles.

\section{Les Buttereaux (Miquelon-Langlade)}

Le terme acadien de " butterreau » désigne à Saint-Pierre-et-Miquelon (et plus largement dans certaines régions du Canada) une butte de sable d'une certaine hauteur, associée à une dune. Ainsi, les Buttereaux, situés au nord de l'isthme reliant Miquelon à Langlade, s'avèrent être le champ de dune le plus élevé de I'archipel qui se situe au sud de Terre-Neuve (figure 1.98).

Ces dunes, pouvant atteindre une vingtaine de mètres de hauteur, constituent un cordon relativement étroit (50 m de largeur minimum) séparant la lagune du Grand Barachois de la mer. De type parabolique, elles résultent d'après Robin (2007) de la première phase d'édification de l'isthme grâce à l'abondance

7. Banc de sable se déposant sur la côte guyanaise entre deux phases d'envasement et typiquement séparé par la suite du rivage par un marais.

8. Île de sable corallien formée sur un platier récifal, caractéristique des atolls polynésiens.

9. Plateau basaltique d'origine volcanique. 

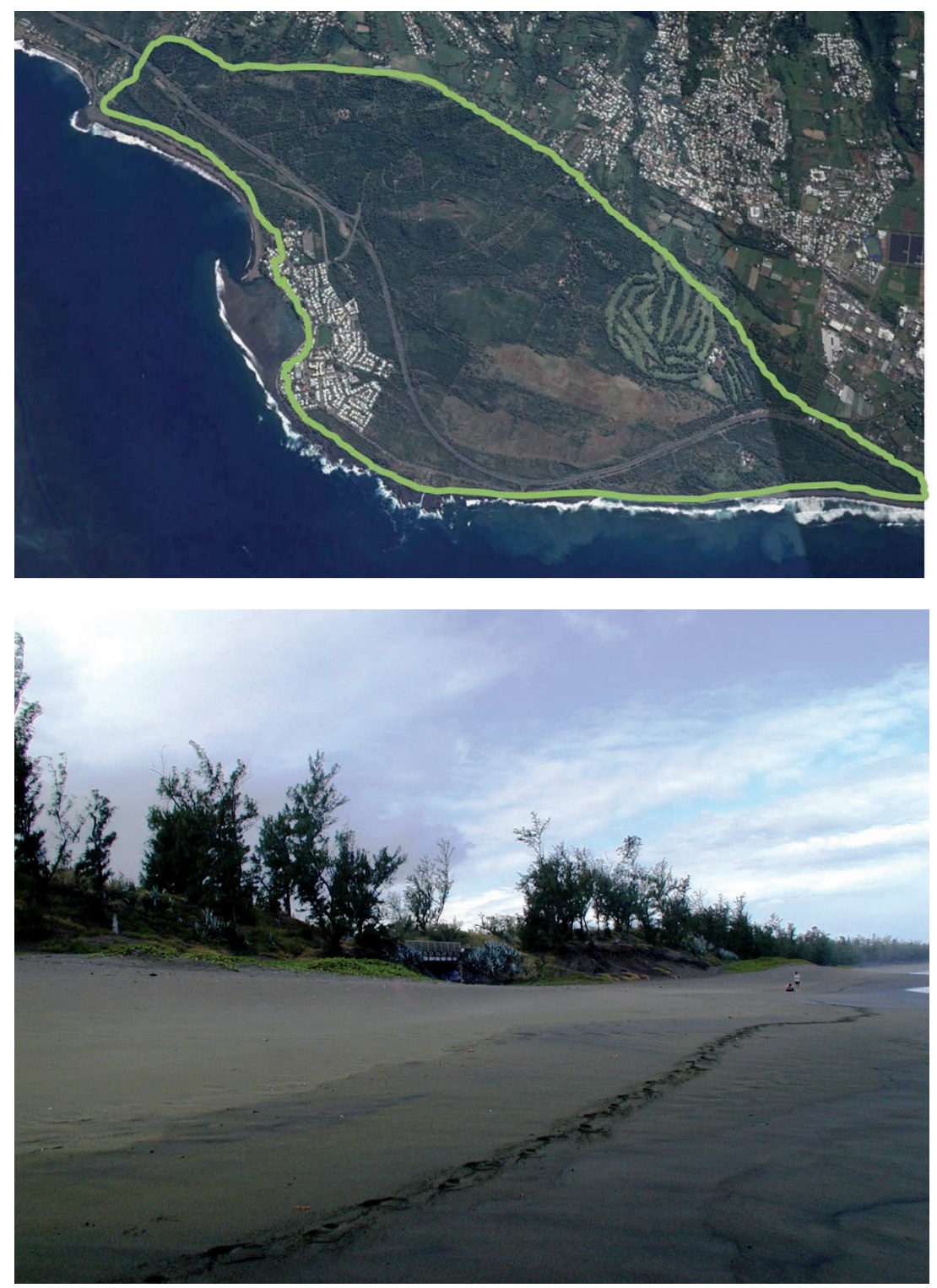

Figure 1.97. Massif dunaire de l'Étang-Salé (en haut, (C Google Earth, 2016) composé de sables « verts » volcaniques (en bas, (C) Y. de La Torre/BRGM) sur l'île de La Réunion.

de matériel sédimentaire d'origine glaciaire (moraines), probablement entre 1350 ans BP et 1140 ans BP.

Actuellement, leur dynamique est plutôt à l'érosion avec des morphologies caractéristiques telles que des caoudeyres, des siffle-vent et un escarpement en pied. Les causes de cette érosion seraient à rechercher en premier lieu du côté du changement climatique qui, avec des hivers plus doux, tend à limiter la formation d'un pied de glace et limite son rôle de protection vis-à-vis des tempêtes hivernales. En outre, I'utilisation de véhicules motorisés tout terrain sur la dune a été rapportée par le passé et pourrait avoir initié certaines cicatrices creusées ensuite par le vent. 


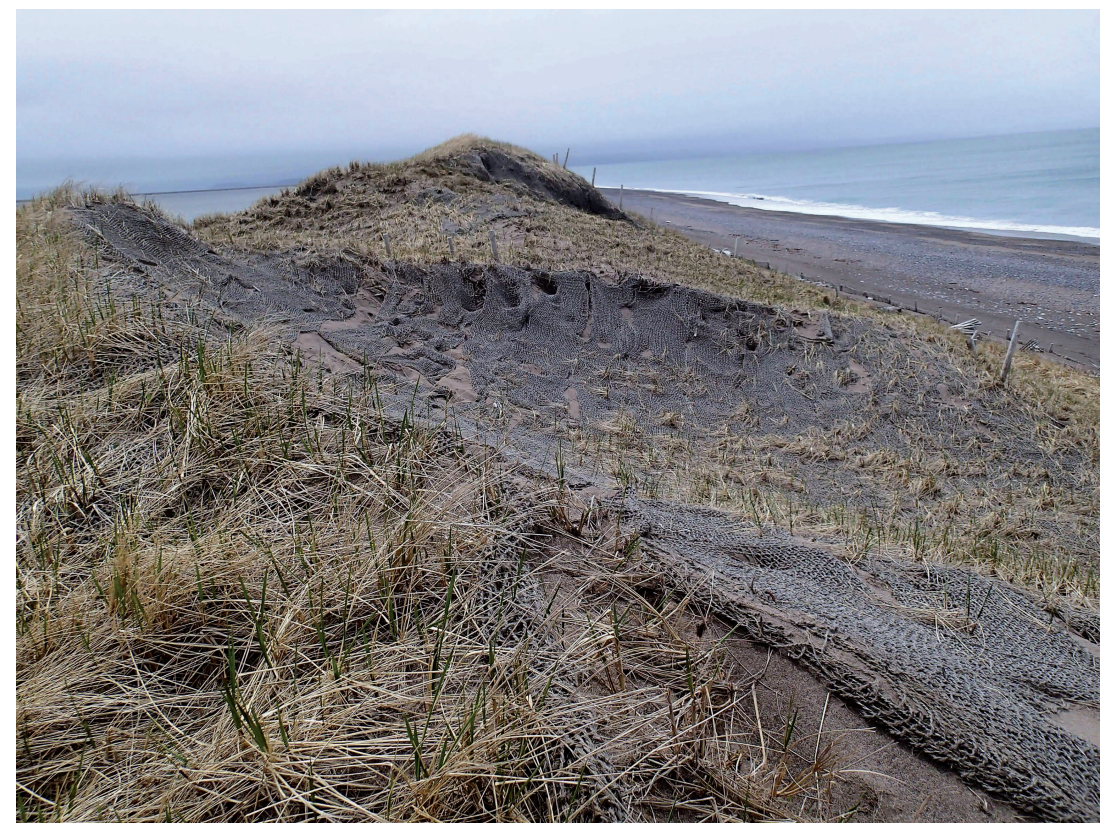

Figure 1.98. Les Buttereaux, dunes composées de sable d'origine glaciaire à Saint-Pierre-etMiquelon.

(C) Y. de La Torre/BRGM.

De 2006 à 2014, le Conservatoire du littoral a conduit des travaux de génie écologique (installation de filets de coco et de ganivelles) dans le but de les restaurer et de sensibiliser les usagers à l'intérêt de leur protection.

Les enjeux de leur préservation se posent ici à la fois sur le plan du patrimoine naturel, du fait des habitats que constituent les dunes d'une part et l'étang (danger de brèches), et d'autre part en termes d'aménagement car les buttereaux protègent la seule route desservant l'île de Langlade à l'autre bout de l'isthme. 



\title{
Les dunes et les hommes
}

\section{Du vide au trop-plein!}

\author{
Emmanuel Garnier
}

\section{Des zones inhospitalières...}

La connaissance ancienne des dunes, dans notre pays et en Europe, pourrait tout à fait se raconter à travers l'évolution sémantique qu'elle a subie au cours du dernier millénaire. Ce qui frappe, c'est bien sa précoce signification comme composante paysagère du littoral, au sens où nous l'entendons aujourd'hui.

De facto, le terme semble au moins daté du début du Moyen Âge à partir du mot flamand duin, lui-même provenant de la racine celte duno, la colline. Localement, bien d'autres termes sont employés pour désigner le cordon dunaire. En Cotentin par exemple, on utilise indifféremment les noms de dunes ou de mielles* quand il est assez large, ou encore de sillon et de banque lorsqu'il est étroit et consolidé artificiellement avec de la terre et des galets. Néanmoins, ces appellations locales tendent à disparaître assez tôt au profit de I'usage exclusif du mot dune.

Dans sa définition de 1694, le Dictionnaire de l'Académie françoise se fait plus précis en parlant de «collines sablonneuses qui s'étendent le long des bords de la mer », des paysages, dit-il, situés dans le Nord de la France pour lequel il cite d'ailleurs les dunes de Calais et celles de Dunkerque. Une cinquantaine d'années plus tard, elles deviennent des " hauteurs détachées des unes des autres » ou de "petites montagnes de sable » dans l'Encyclopédie qui, comme le précédent ouvrage, associe la présence de ces reliefs à la mer : "elles se trouvent le long d'une côte sur le bord de la mer ». Un siècle plus tard, le sens donné par le Dictionnaire universel de marine (1862), ouvrage maritime spécialisé s'il en est, n'évolue pas puisqu'il correspond à un rivage élevé de la mer et formé par des sables amoncelés.

Pour autant, il serait faux de penser que, parce qu'elle fut définie lexicalement très tôt, la dune formait forcément une composante positive des paysages littoraux. Bien au contraire, pour le pouvoir et les élites continentales, les espaces dunaires sont souvent perçus comme hostiles au point d'être assimilés au domaine de Satan. Quant aux populations qui vivent à proximité, elles ont très mauvaise réputation. II est alors de bon ton de désigner ces habitants comme étant des "naufrageurs ». Ces derniers étaient accusés de tromper les navires avec des feux allumés sur les plages pour provoquer leur naufrage et ensuite les piller, après avoir préalablement massacré leur équipage.

L'État royal ne s'intéresse pour sa part au littoral que sous l'angle stratégique car nos côtes restent soumises à un risque d'invasion par nos voisins espagnols et britanniques jusqu'aux années 1850. Dans ces conditions, il est considéré comme un espace de confins incontrôlé parce que sauvage sur le plan paysager. Néanmoins, dès le xvII siècle, à la faveur des nouvelles ambitions navales de la monarchie française, I'espace côtier est ponctuellement militarisé avec des fortifications et des ports arsenaux en eau profonde, comme Toulon, Brest, Rochefort ou Lorient, capables d'accueillir la flotte de guerre. 
Pour les populations littorales, la perception de leur environnement est totalement différente. La côte est avant tout un espace nourricier exploité de manière durable et en fonction d'un impératif incontournable : la sécurité. L'estran est une excroissance du finage villageois et les conflits d'usages entre les communautés sont légion. En effet, nombreux sont les enjeux liés à cette zone de contact entre la terre et la mer. La survie des habitants est largement conditionnée par la pêche, directement pratiquée sur le littoral sous la forme de pêcheries (littoral de la Manche) ou d'écluses à poissons (littoral atlantique). Ces infrastructures en dur constituées de pierres prélevées sur le platier permettent de capturer le poisson lorsque l'océan se retire à marée basse.

L'économie du littoral repose aussi sur les céréales, le vignoble, le sel produit dans de vastes marais salants, tant sur la façade maritime méditerranéenne qu'atlantique. Malheureusement, entre le xvı siècle et les années 1850, la proximité des dunes suscite de nombreuses convoitises de la part des paysans. Année après année, herbage et labours grignotent progressivement ces barrières naturelles sous l'effet d'une pression démographique croissante à compter des années 1750.

La dune intervient pour sa part comme espace nourricier dès l'époque médiévale sous la forme de garennes, des réserves cynégétiques où les seigneurs chassent les lapins qui pullulent, pour la plus grande exaspération des habitants qui voient le gibier détériorer les cultures et favoriser le délitement de la dune au détriment des terres labourées. Les dunes constituent aussi de vastes espaces collectifs. Contre le paiement d'un droit d'usage, la communauté villageoise peut y élever des moutons et y prélever différents végétaux comme le saule nain, les joncs ou encore les roseaux des sables désignés en Normandie sous le terme de chausses. Impact probablement plus négatif, les populations prennent (déjà) la mauvaise habitude d'y prélever le sable et les galets pour se procurer les matériaux nécessaires à l'érection de leurs habitations ou à la construction des chemins sous l'Ancien régime, puis des voies départementales après la Révolution française (1789).

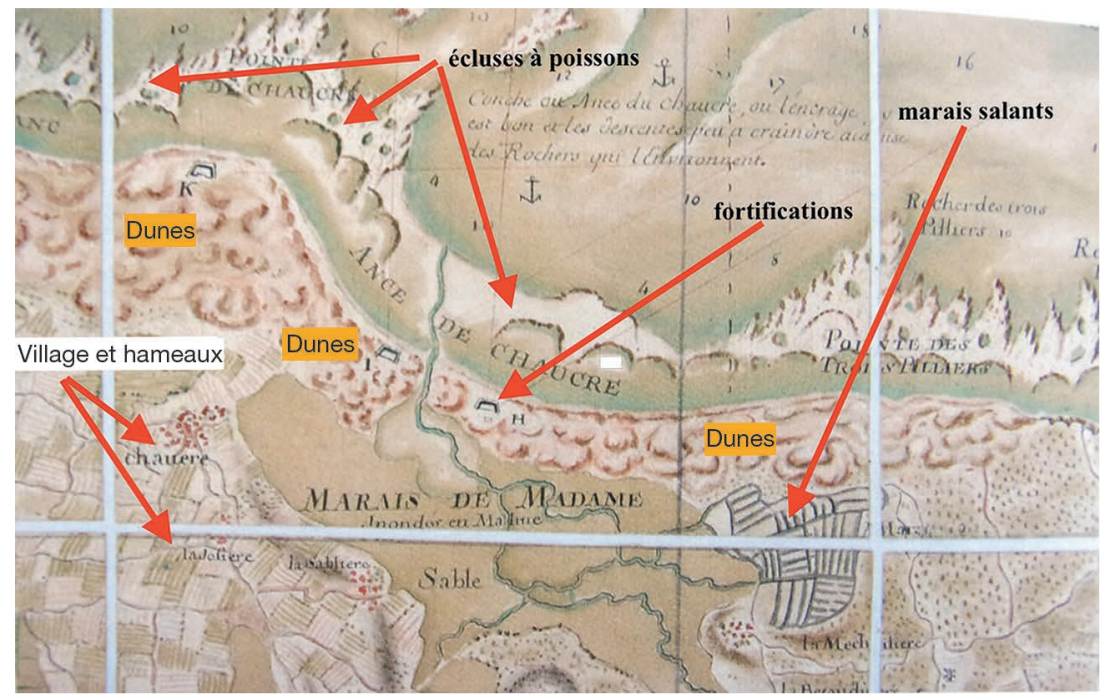

Figure 2.1. Plan anonyme du littoral de Charente-Maritime en 1757. Source : Médiathèque de La Rochelle, 1 PL 128. 
Pour l'aménageur et le gestionnaire contemporains, la militarisation du trait de côte par la monarchie (avant 1789) se traduit par une cartographie précoce qui permet de se faire une idée très précise de ces paysages dunaires anciens. Comme le montre la figure 2.1, les dunes littorales sont parfaitement représentées sous la forme de dunes massives moutonnées qui encadrent un marais. Les seules traces visibles d'anthropisation dans cet espace dunaire sont les fortins (lettres $\mathrm{H}$, I et $\mathrm{K}$ sur le plan) et les multiples écluses à poissons de forme semicirculaire. Outre leur fonction nourricière déjà évoquée, elles assurent une protection au cordon dunaire en jouant le rôle de brise-lames et de plateforme d'abrasion contre la houle. Enfin, distants d'au moins un kilomètre, les villages et les hameaux sont installés sur des terres situées au-dessus du niveau de la mer, en vertu d'un principe de précaution ancestral. Les zones humides participent également à la défense du littoral en faisant office de zones tampons lors des inondations fluviales et/ou des submersions marines.

\section{... à une ruée vers le littoral}

Les premières grandes mutations paysagères du littoral sont le fait du forestier qui, par son action, contribue à une valorisation sociale et économique des dunes à compter de la seconde moitié du xixe siècle.

Les pionniers sont l'abbé Desbiey et son frère, dont les expériences menées à Saint-Julien-en-Born (Landes) seront décrites dans un mémoire en 1774. Puis Charlevoix, baron de Villers, ingénieur de la marine envoyé à La Teste de Buch de 1778 à 1781 pour étudier la possibilité de créer un canal entre le bassin $\mathrm{d}^{\prime}$ Arcachon et l'Adour à des fins militaires, arrive à la conclusion que la fixation des dunes est le préalable à tout aménagement.

Mais c'est Nicolas-Thomas Brémontier (1738-1809), ingénieur des Ponts et chaussées, qui connaîtra la célébrité grâce à son œuvre de fixation des dunes en construisant des palissades formées de piquets et de clayonnages qui servent d'abri à des graines de pin. Fort de ses premiers succès à la fin des années 1780 , il propose, dans son Mémoire sur les dunes (1804), d'entreprendre de manière systématique la fixation des massifs dunaires du littoral entre la Bretagne et la frontière espagnole. Il faut dire que, depuis le Moyen Âge, les archives mentionnent de nombreux villages engloutis, d'églises déplacées ou ensevelies à I'image de celle de Soulac qui ne fut dégagée qu'en 1858. Des premiers travaux sont entrepris en Aquitaine sous l'égide de la Commission des dunes entre 1802 et 1814 (4 400 ha), puis les boisements sont relancés en 1817 sous la responsabilité des Ponts et chaussées, puis des Eaux et forêts à partir de 1862. Ainsi, sur la côte atlantique, une surface de 88000 ha de dunes dites "modernes » fut ensemencée par un mélange de graines à base de pin maritime (Pinus pinaster), arbre autochtone peuplant les vieilles dunes toujours présentes à I'arrière du nouveau cordon dunaire.

Il s'agit désormais, dans la bouche des ingénieurs des Eaux et forêts et des Ponts et chaussées, de "domestiquer » les dunes les plus littorales. De gigantesques travaux de calibrage sont engagés en vertu d'un profil dit "idéal » établi par les ingénieurs pour construire une dune bordière protectrice. Les techniques alors mises en œuvre reposent sur des clayonnages successifs implantés à 100$200 \mathrm{~m}$ de la laisse de haute mer. Ils permettent d'établir une ligne parallèle au littoral sur laquelle est érigée une palissade de planches relevée progressivement au fur et à mesure de la progression de l'ensablement. Le plateau qui en résulte est consolidé par la plantation de bourrée, des fagots végétaux. Enfin, lorsque l'ingénieur estime que le profil souhaité est atteint, le cordon dunaire 
est « fixé » par plantation de gourbet. Du fait de la pénurie de main-d'œuvre et de financement, l'entretien des dunes fut réduit entre 1914 et 1945.

Le mouvement reprend après la Seconde Guerre mondiale sous la forme d'un remodelage mécanique cette fois-ci, et il faut attendre la fin des années 1970 pour que cet idéal dunaire soit abandonné progressivement au profit d'une gestion plus durable favorisant des dunes semi-naturelles (plantation d'oyats, pose de couvertures de genêts à balais et de bruyères) plus complexes sur un plan écologique. C'est aussi à cette époque que l'Office national des forêts concentre (déjà) ses efforts sur l'érosion des plages et des dunes. Paradoxalement, c'est à la même époque qu'est décidée la construction de l'immeuble Le Signal à Soulacsur-Mer. Preuve supplémentaire de ce processus érosif, les photos aériennes du littoral atlantique montrent les blockhaus allemands de première ligne construits durant les années 1940 tombés des dunes et partiellement envahis par les vases et le sable de l'estran, voire même directement tombés dans l'océan.

Autre facteur de mutation, le double mouvement qui s'opère dans les années 1900 à la faveur d'un nouveau regard porté sur les espaces littoraux et qui se décline en une urbanisation nouvelle. Avec l'essor des bateaux à vapeur dotés de coques en fer, les ports commencent à remanier profondément les zones côtières en raison de la création de vastes bassins à flot, de terre-pleins, d'entrepôts, de dessertes ferroviaires des quais, etc. Cette première mutation d'ordre économique se double d'un nouvel intérêt social pour les anciens confins littoraux. L'usage ludique commence alors à marquer ces territoires en se fondant simultanément sur les bienfaits thérapeutiques de la mer et sur l'engouement des artistes et des écrivains.

En partie remodelés au siècle précédent, les espaces littoraux subissent des modifications beaucoup plus désastreuses après 1945. Ils sont progressivement jalonnés de routes côtières construites parallèlement au cordon dunaire. Le chemin de fer (arrivé dans la deuxième moitié du xIx ${ }^{e}$ siècle) bouleverse encore plus l'écosystème car il est construit au plus près du rivage au cœur même du système dunaire. La voie ferrée se mue ainsi en une véritable barrière coupant les dunes qui s'en trouvent affaiblies, sans compter son remblai qui aggrave l'impact des inondations en créant un effet de cuvette et en perturbant

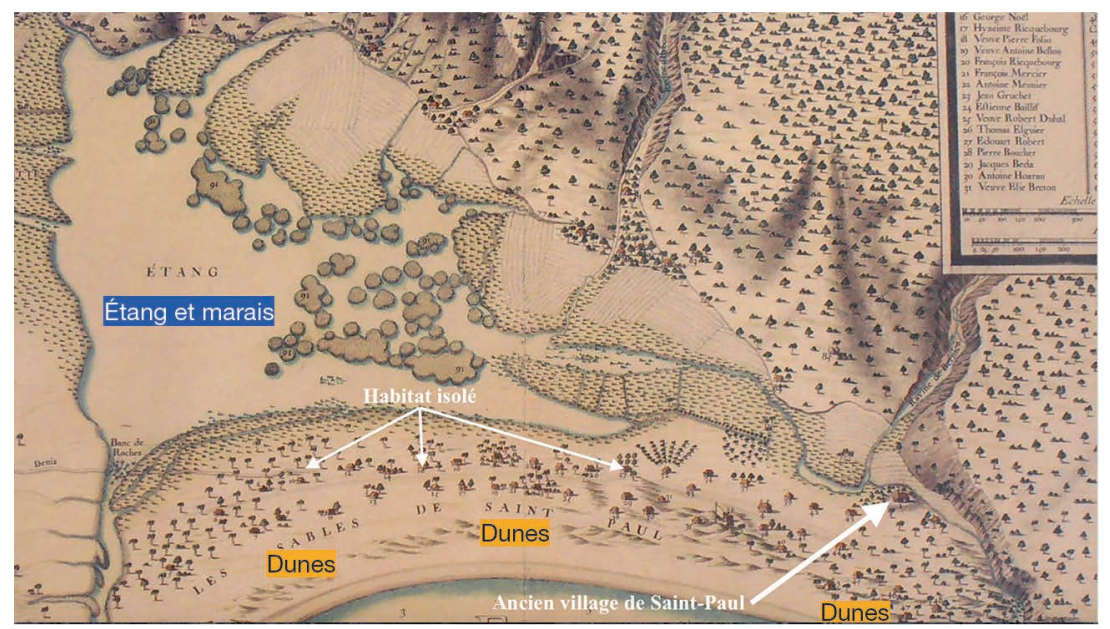

Figure 2.2. Le littoral de la commune de Saint-Paul de la Réunion au XIx siècle. Source : Archives départementales de la Réunion. 
irrémédiablement le réseau hydrographique. Ces nouvelles voies de communication desservent désormais de nouveaux pôles d'urbanisation liés à l'essor des villas et des lotissements en bord de mer. Ils sont construits sur les propriétés des dunes jusque-là dépeuplées en vertu d'un principe de précaution ancestral. Aux nouveaux habitants totalement ignorants en matière de risques littoraux, s'ajoutent les touristes de plus en plus nombreux en période estivale et qui exigent un accès facilité aux plages. Un peu partout sont ouverts des passages dans les dunes tandis que le piétinement des visiteurs se généralise.

Ce processus n'est pas l'apanage des littoraux métropolitains et il peut aisément se lire sur le plan ancien de I'actuelle ville de Saint-Paul de la Réunion (figure 2.2). Au milieu du xix ${ }^{\mathrm{e}}$ siècle, le paysage littoral se caractérise par un solide cordon dunaire s'étendant de la ravine de Bernica à un vaste étang derrière lequel s'abrite une première ligne $d^{\prime}$ 'habitat constitué de fermes isolées tournées vers une agriculture extensive et dont les terres font office de zone d'absorption des crues ou des submersions. Plus loin, en seconde ligne, le plan indique le village ancien de Saint-Paul symbolisé par son église $\left(n^{\circ} 1\right)$. Il est implanté en retrait du trait de côte sur un site élevé afin de parer au risque d'inondation torrentielle provenant de la ravine de Bernica dont les eaux peuvent s'épandre aisément dans une basse vallée encore très naturelle et quasiment inhabitée.

Un siècle et demi plus tard, c'est un territoire totalement métamorphosé qui l'a remplacé (figure 2.3). Les dunes ont quasiment disparu pour faire place à une intense urbanisation localisée au plus près du trait de côte et dont les multiples projets actuels de résidences de haut standing laissent penser qu'il n'est pas en passe de ralentir dans les années futures. Quant aux zones humides, qu'il s'agisse de l'étang, des marais ou des prairies cartographiées sur le plan du

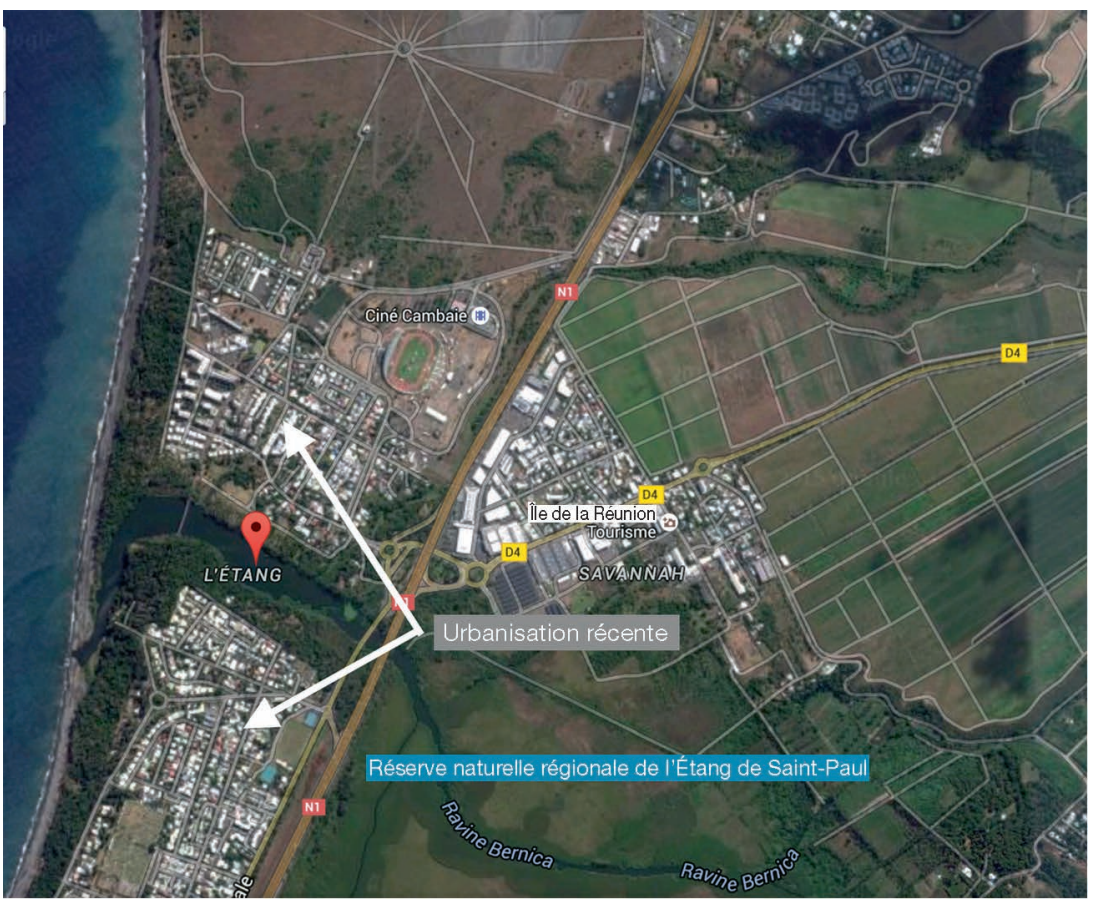

Figure 2.3. Le littoral de la commune de Saint-Paul de la Réunion en 2015. Source : Google Earth. 
XIX ${ }^{e}$ siècle, elles ont été en grande partie drainées et transformées en réserves foncières ou en cultures. De l'ancien étang, seul subsiste la partie congrue classée de nos jours réserve naturelle nationale.

Ainsi, au tournant des années 1980, que l'on soit en métropole ou bien dans les outre-mer, tous les facteurs sont désormais réunis pour une dégradation accélérée du trait de côte, souvent perçue à tort comme un effet du seul changement climatique alors même qu'elle procède, pour une large part, d'un développement effréné de ces territoires dunaires. Il faut voir, dans ce processus inexorable engagé depuis 1960, les racines de la vulnérabilité littorale contemporaine. En la matière, le cas d'école de cette exposition aux risques créée de toutes pièces est sans conteste la ville de La Faute-sur-Mer où périrent plusieurs dizaines d'habitants lors de la tempête Xynthia de février 2010, après que I'on ait détruit les dunes protectrices pour les transformer en terrains à bâtir situés sous le niveau de la mer cinquante ans plus tôt. La digue devait alors suppléer la dune naturelle...

\section{Des usages traditionnels et contemporains multiples}

\section{Les usages agricoles et forestiers}

\section{Loïc Gouguet}

Les milieux dunaires littoraux ont depuis longtemps été considérés comme des espaces hostiles et insalubres : terres salées et pauvres, mouvantes, exposées aux assauts du vent et des tempêtes. De plus, les marais qui leur étaient associés étaient sources de maladies et de fièvres véhiculées par les moustiques.

Les sociétés humaines s'installaient prudemment en retrait de ces milieux mobiles et à l'abri des envahisseurs venus de la mer. Les témoignages historiques qui nous sont parvenus (découvertes archéologiques, écrits...) traduisent soit des installations temporaires (atelier de production de sel découvert sous la dune du Pilat), soit des occupations ponctuelles par des populations exclues, cas des parées ${ }^{10}$ du littoral du Nord Vendée, où les indigents s'étaient installés et cultivaient des creux de dunes avant leur fixation au xIX ${ }^{e}$ siècle.

L'utilisation des dunes à des fins agricoles ou forestières, si elle est avérée depuis l'époque gallo-romaine, ne s'est confirmée qu'après les actions de fixation entreprises au début du xixe siècle.

Les espaces dunaires ont toujours servi de terrain de chasse : chasse au lapin, chasse aux oiseaux, chasse au grand gibier (cerf, chevreuil, sanglier...) pour ce qui concerne les plus grands massifs, et chasse aux oiseaux d'eau sur les dépressions humides et les lacs.

\section{L'agriculture}

Les utilisations des dunes dépendent bien entendu des régions dans lesquelles elles sont situées, mais l'une des plus répandues consistait à y mettre des animaux à paître : animaux de bâts nécessaires à l'exploitation d'autres ressources

10. Parée : nom vendéen des parties basses et planes enclavées dans les dunes, et souvent cultivées. En sud Vendée, on parle de conche. 
littorales (sel...), animaux destinés à produire du lait (vaches, brebis...). Bien que ces pâturages soient de faible valeur, cette pratique était répandue et néfaste à la végétation fixatrice ! Cet usage, en effet, s'il est compatible avec la dynamique végétale forte dans les dunes situées au nord de la France, est beaucoup plus dommageable pour les dunes xérophiles de la façade atlantique. Pour entreprendre la fixation du cordon dunaire de la façade atlantique, les autorités durent d'abord faire respecter l'interdiction de pâturage dans les dunes qui réduisait à néant les efforts de plantation des végétaux fixateurs !

Le pâturage peut contribuer à la gestion de la biodiversité d'un site (limitation de certaines espèces arbustives, contrôle de l'évolution naturelle en favorisant un stade peu évolué...). Ce sont par exemple les machairs écossais ou irlandais, sorte de plaines herbeuses sur dunes, où le pâturage ovin y est traditionnel.

Mal maîtrisé ou pratiqué dans des régions où la dynamique végétale n'est pas suffisante, le pâturage peut par contre engendrer beaucoup de dégâts (destruction de la végétation fixatrice, poinçonnement par les sabots des animaux...) et entraîner une reprise de l'érosion éolienne.

Dans le département de la Manche, les mielles (plaines sableuses littorales) sont en partie cultivées et permettent notamment la production de carottes.

Les sables dunaires ont donc été utilisés comme support de culture (marâ̂chage, asperges...). Lorsqu'à partir de 1863, les vignes furent attaquées par le phylloxéra (Phylloxera radicicole), puceron d'origine nord-américaine, des tentatives de culture de vigne furent entreprises dans les dunes car elles étaient exemptes de ce parasite, la structure du sable l'empêchant d'atteindre les racines des plans. Les vignes américaines, résistantes, furent également plantées dans les dunes et ont en particulier laissé leur nom à un canton de la forêt domaniale de l'île d'Oléron!

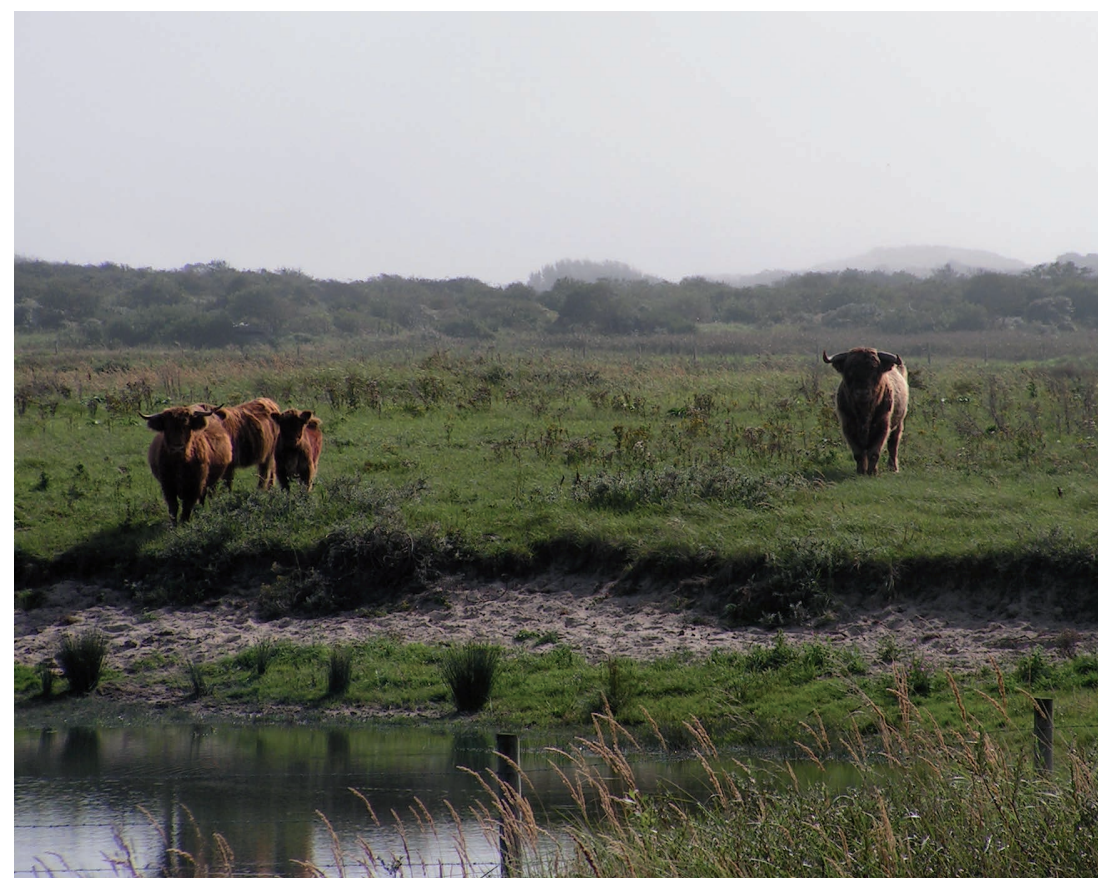

Figure 2.4. Pâturage dans les dunes de la Réserve biologique de Merlimont. (c) L. Gouguet/ONF. 
Il existe encore une production vinicole de vin des sables de Camargue et des Landes. Enfin, certaines dunes languedociennes ont, jusqu'à une époque récente, été utilisées pour la viticulture comme défense contre la mer ; elles ont alors été entretenues à cette fin par des vignerons (fixation, protection).

\section{La forêt}

Dans la lutte contre l'avancée des sables mobiles, la végétalisation a joué un rôle primordial. Une fois la stabilisation acquise et les envols de sable amoindris, I'installation d'une forêt a pu se faire essentiellement grâce à des semis de pin. Le pin maritime était présent dans les "vieilles dunes", sa rusticité et sa plasticité en ont fait un allié de choix pour lutter contre l'envahissement des sables.

Les forêts ainsi nouvellement créées au XIX siècle ont permis d'instaurer une économie basée sur la production de bois, bien sûr, mais avant tout basée, jusque dans les années 1950, sur l'exploitation de la résine, le gemmage. La technique avait été utilisée par les Romains pour récolter la résine permettant le calfatage des bateaux.

En blessant les pins, on permettait à la résine de s'écouler le long de la care, dans de petits pots fixés au tronc (figure 2.5). La résine ainsi récoltée permettait l'extraction de l'essence de térébenthine (entrant dans la composition de produits d'entretien, de peintures, de vernis, de certains produits cosmétiques

Figure 2.5. Une fois le pin scarifié, la résine s'écoule dans le pot. (c) L. Gouguet/ONF.

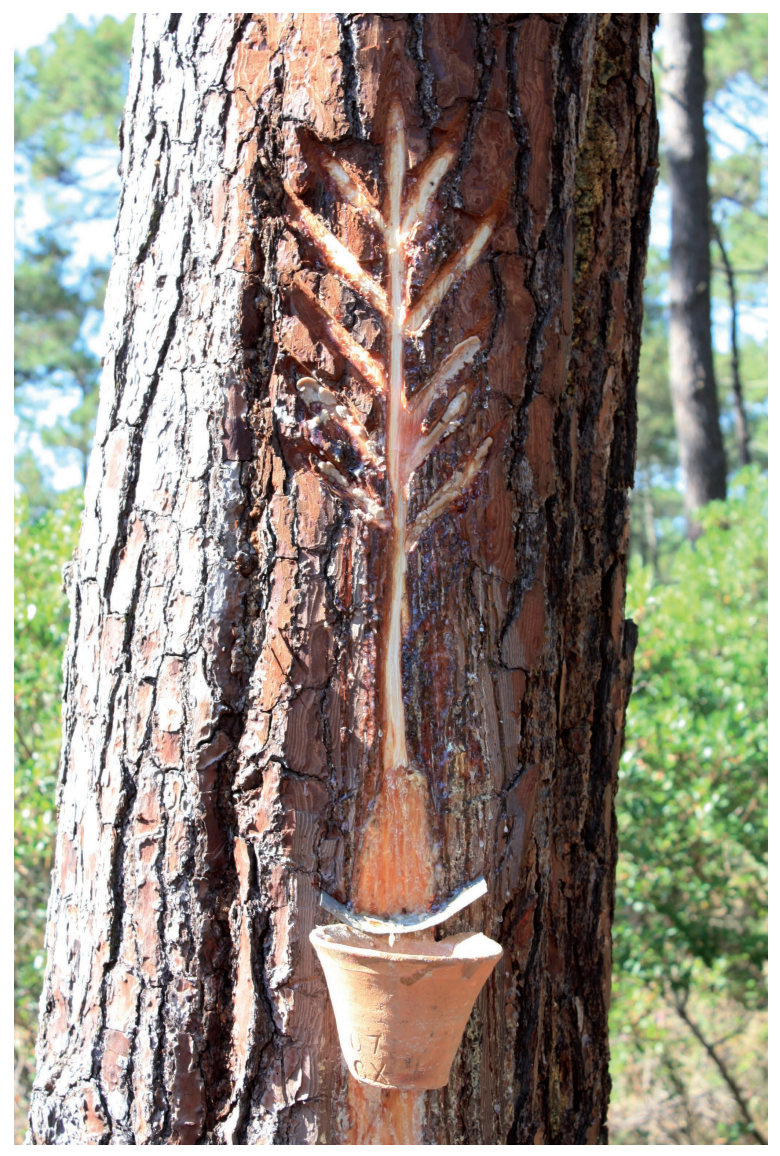


et pharmaceutiques) et de la colophane (nécessaire à la fabrication d'encres d'imprimerie, de savons, de chewing-gum...), ainsi que la fabrication d'huiles essentielles. Cette pratique fut surtout développée dans le massif forestier des Landes de Gascogne. L'avènement de la pétrochimie dans les années 1960, ainsi que la production de résine à moindres coûts en Chine et au Brésil ont mis un coup d'arrêt au gemmage, qui avait permis le développement d'une filière économique faisant vivre des milliers de familles (par exemple, il y avait 30000 gemmeurs en Aquitaine dans les années 1950).

Actuellement, les forêts dunaires produisent :

- du bois d'œuvre, destiné à l'emballage, aux parquets, aux lambris, aux charpentes, à la menuiserie et à l'ameublement ;

- du bois d'industrie, pour la papeterie, les panneaux de particules ou de fibres (MDF, medium density fiberboard).

En Aquitaine par exemple, on estime à 36000 les emplois directement liés à l'exploitation de la forêt.

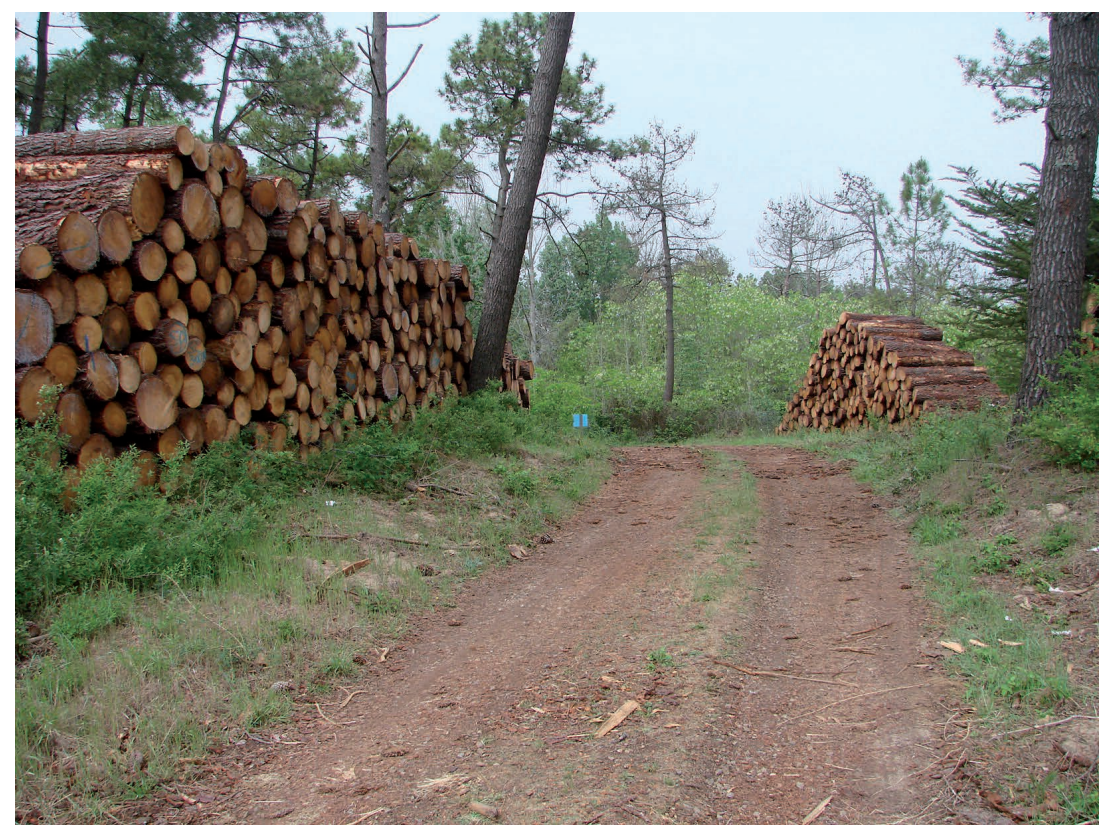

Figure 2.6. Tas de bois d'industrie en forêt dunaire.

(C) L. Gouguet/ONF.

\section{Des lieux de passage largement empruntés}

Christine Clus-Auby

Depuis que les plages sont devenues ces lieux incontournables du tourisme de masse qui a transformé les paysages littoraux, entre juin et septembre, des millions de pieds arpentent les dunes, piétinent et re-piétinent la végétation qui les recouvre. Passage obligé pour les baigneurs et autres amateurs de sports de glisse dans leurs déplacements pendulaires quotidiens plage-parking-camping, les dunes sont soumises à rude épreuve. Cependant, des efforts d'organisation des accès aux plages et de canalisation des flux piétonniers permettent le plus souvent de gérer efficacement les passages au travers de la dune. 


\section{En quoi le piétinement est-il préjudiciable à la santé de la dune ?}

Comme cela a été dit auparavant dans cet ouvrage, les dunes littorales sont le fruit d'un équilibre subtil entre le vent, le sable et la végétation ${ }^{11}$. Fragile et dynamique, cet équilibre est sans cesse remis en cause par les fluctuations de ces trois éléments. Si le piétinement n'a bien sûr aucun effet sur le vent, s'il peut certes être la cause du déplacement de petites quantités de sable (principalement sur les pentes), c'est essentiellement sur la végétation que ses effets se manifestent.

Le mécanisme de dépérissement de l'oyat (Ammophila arenaria) sous l'effet du piétinement est bien connu : la marche, plus facile entre les touffes, déchausse les plants et, si le piétinement se poursuit, l'espace entre les touffes s'élargit, et des chemins de sable nu se dessinent. Le vent n'a plus alors qu'à s'engouffrer sans entrave dans ces sillons pour y exercer son action érosive.

De nombreux auteurs se sont penchés sur l'impact du piétinement sur les écosystèmes dunaires. Ils ont montré comment une fréquentation excessive peut en appauvrir la couverture végétale.

Ainsi, I'étude conduite en 2003 sur un système dunaire de Bretagne par $\mathrm{S}$. Lemauviel et $\mathrm{F}$. Rozé a quantifié la réponse des communautés végétales à des intensités croissantes de piétinement (Lemauviel et Rozé, 2003). La figure 2.7 montre la variation de deux indices - résistance et résilience - selon l'intensité du piétinement, dans des dunes mobiles et dans des dunes fixées.
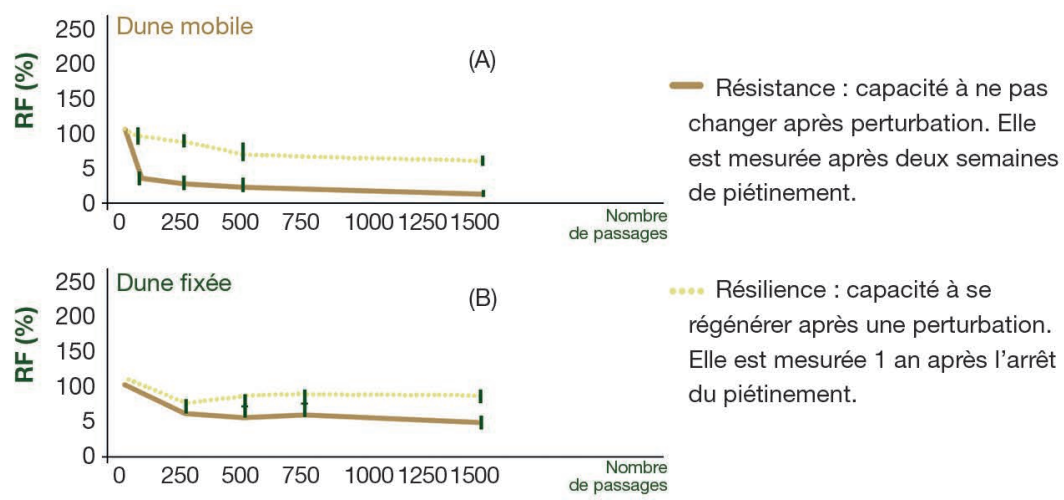

.... Résilience : capacité à se régénérer après une perturbation. Elle est mesurée 1 an après l'arrêt du piétinement.

Figure 2.7. Fréquence relative de la végétation (RF) de la dune mobile (A) et de la dune fixée (B) après deux semaines de piétinement et un an après l'arrêt du piétinement.

Source : Lemauviel et Rozé (2003).

Les constats sont clairs. La dune mobile résiste mal à deux semaines de piétinement : sa couverture végétale chute de $75 \%$ après 50 passages, de $83 \%$ après 250 passages, et de $95 \%$ après 1500 passages. Sa résilience est toute relative : un an après l'arrêt du piétinement, elle ne retrouve une couverture végétale proche de l'état initial que si le nombre de passages a été modéré. La dune fixée résiste mieux : sa couverture végétale est réduite de moitié après 250 passages, puis ne régresse plus même si les passages s'intensifient. En revanche, elle est moins résiliente puisque, même avec des intensités modérées de piétinement, elle ne retrouve pas sa couverture initiale.

11. Le mécanisme de piégeage du sable transporté par le vent a été expliqué dans la partie « La formation des dunes ", nous n'y reviendrons pas. 
Plus on se rapproche de la plage - sur les avant-dunes et sur les dunes embryonnaires où se développe une végétation pionnière -, plus les effets du piétinement sont sensibles, et quelques passages suffisent à détruire les jeunes pousses. Cette végétation fragile, qui sert d'amorce pour le piégeage du sable et l'édification des dunes, est également mise à mal par un nettoyage des plages trop intensif, surtout si des engins mécaniques sont utilisés.

En revanche, dans les secteurs de dune grise, là où le couvert végétal est bien installé, un piétinement très modéré peut parfois être bénéfique. En réduisant l'abondance de certaines espèces dominantes, il permet à des espèces moins compétitives de se développer (Doody, 1989).

\section{Les véhicules tout-terrain}

Mais les piétons ne sont pas les seuls à arpenter les dunes. La circulation des véhicules tout-terrain (vélos, motos, $4 \times 4$, quads) a longtemps été extrêmement préjudiciable à la végétation dunaire. Interdite depuis $1991^{12}$, elle a cependant perduré pendant plusieurs années, tant la surveillance des contrevenants était difficile à mettre en pratique et les dérogations nombreuses. Ainsi, par exemple, ce n'est qu'en 2005 que l'enduro du Touquet a modifié son parcours afin de ne plus labourer les dunes. Si I'on peut encore apercevoir quelques quads et VTT dans les dunes, il est heureux de constater que leur présence se fait de plus en plus rare. La disparition progressive de ces pratiques est à mettre au crédit de l'amélioration de la surveillance par les gestionnaires des dunes et des efforts de sensibilisation du public à la fragilité des milieux dunaires qui sont venus soutenir la mise en application de la loi de 1991.

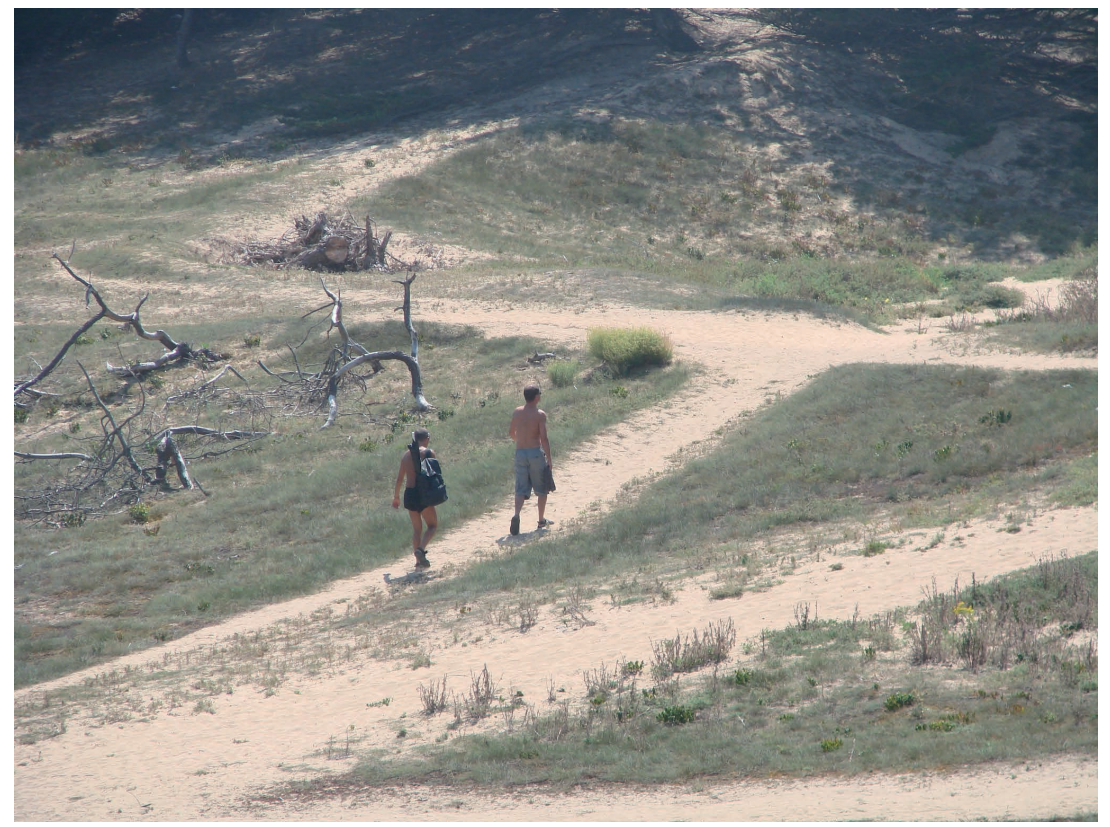

Figure 2.8. Impact du piétinement sur la dune grise de Saint-Hilaire-de-Riez. (c) L. Gouguet/ONF.

12. Loi du 3 janvier 1991 relative à la circulation des véhicules terrestres dans les espaces naturels, codifiée aux articles L. 362-1 à L. 362-8 du Code de l'environnement. 


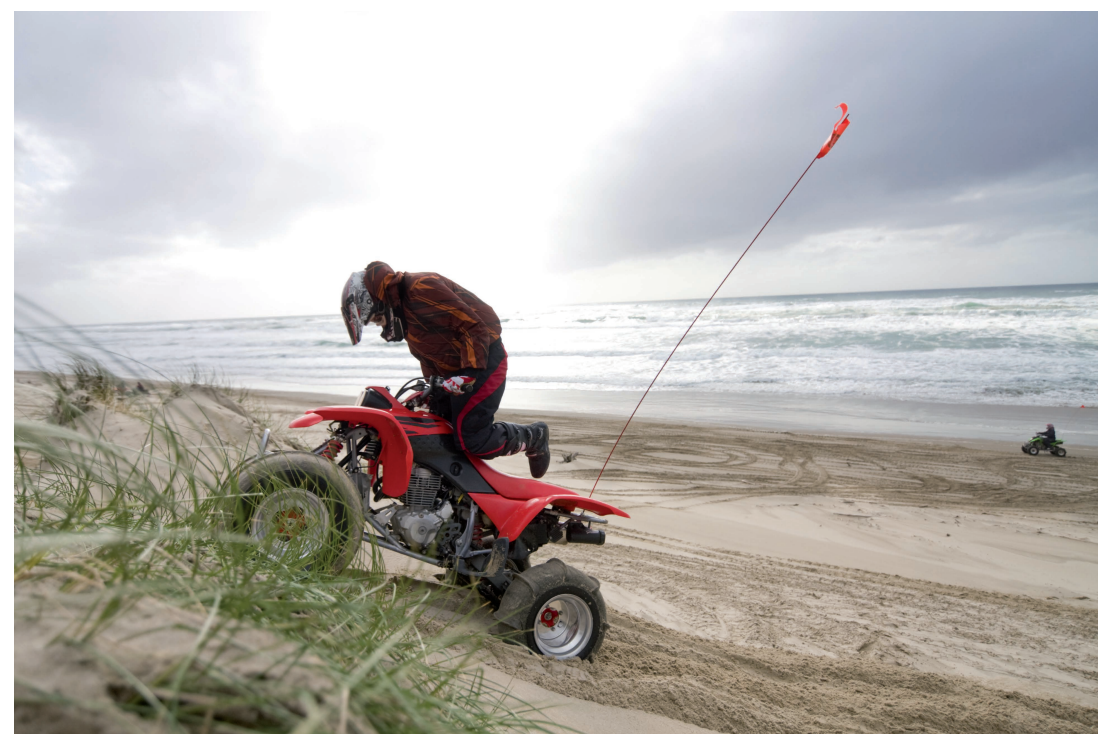

Figure 2.9. Quad dans les dunes.

(C) Shutterbugger/lstock.

Quand la végétation se fait rare, et plus encore quand elle disparaît, le vent venu de la mer retrouve sa force érosive. Il emporte le sable mis à nu, creuse des sillons, amorces de siffle-vent qui peuvent se transformer en vastes caoudeyres. Le sable enlevé de ces lieux de passages vient se déposer à l'arrière de la dune, là où le vent faiblit, et c'est ainsi que l'édifice dunaire se déplace vers l'intérieur des terres.

\section{Les prélèvements de sable}

Loïc Gouguet

\section{D'un usage traditionnel...}

Les sociétés anciennes ont su profiter depuis longtemps des matériaux que les dunes offraient :

- le sable calcaire était prélevé pour amender les terres agricoles trop acides ;

- le sable était utilisé pour alléger les terres cultivées trop lourdes ;

- incorporé au mortier, le sable servait pour la construction de bâtiments ;

- dans certaines régions, les dunes étaient étrépées (on prélevait la couche superficielle du sol, y compris la végétation et les racines), pour ensuite enrichir en humus les terres cultivées.

Ces usages étaient bien entendu dommageables pour les dunes, car destructrices de la végétation en place, et donc permettant la remobilisation du sable nu par le vent. De nombreux cas sont connus, notamment en Bretagne (cités par J.-P. Pinot, B. Hallegouët). Ces usages étaient toutefois limités et n'avaient qu'un impact faible sur les formes des massifs dunaires, hormis sur les sites ponctuels soumis à des usages intensifs et répétés lors des périodes de forte pression démographique.

\section{... à une exploitation plus intense}

Au cours de la Seconde Guerre mondiale, I'édification d'ouvrages militaires (le Mur de I'Atlantique) sur les massifs dunaires a marqué le début de 
I'intensification des prélèvements de sable. Pour construire ces blockhaus et les ouvrages de défense associés, on estime que 13 millions de $\mathrm{m}^{3}$ de béton ont été nécessaires pour fortifier les $4000 \mathrm{~km}$ de côtes du Danemark à la frontière franco-espagnole et, pour faire ce béton, le sable était la plupart du temps prélevé sur place!

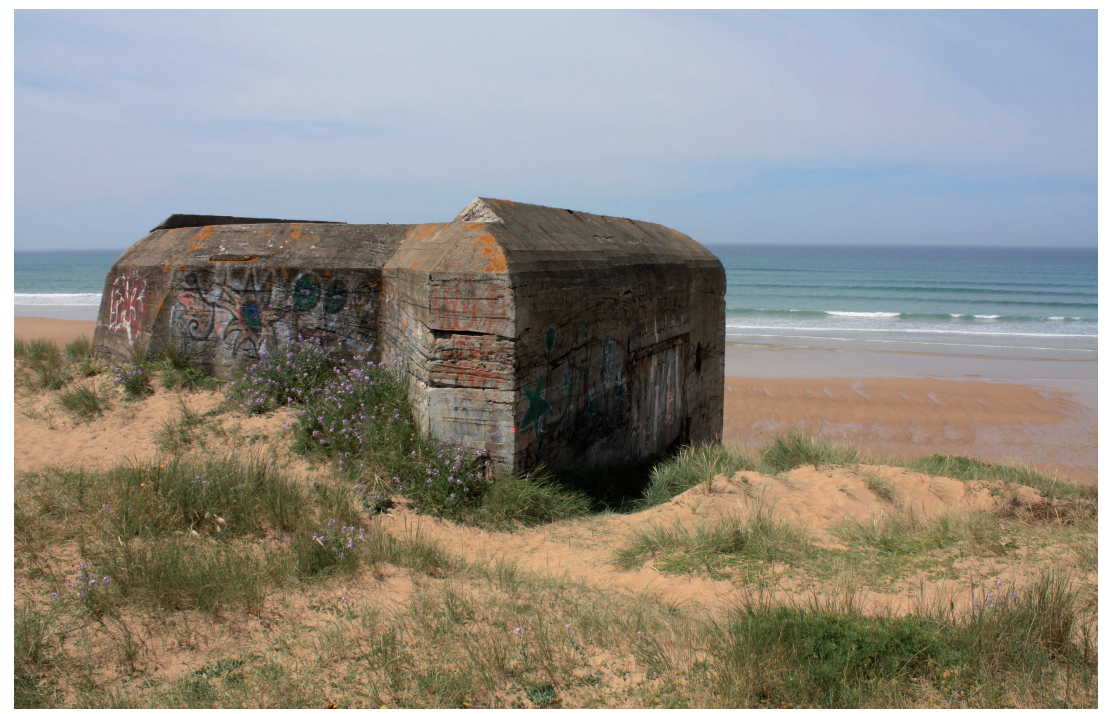

Figure 2.10. Blockhaus dans la dune.

La création de blockhaus contribua à une exploitation du sable des dunes.

(C) L. Gouguet/ONF.

Puis pour servir ensuite l'effort de reconstruction des villes littorales, puis l'extension de l'urbanisation pour répondre au développement des loisirs balnéaires, les prélèvements de sable se sont souvent poursuivis, parfois pendant des dizaines d'années.

De même, avec la mécanisation de l'agriculture à partir des années 1950, les prélèvements qui pouvaient être réalisés sur certains sites (baie de Goulven dans les Côtes-d'Armor par exemple) pour servir d'amendement et améliorer les terres cultivées se sont intensifiés.

À compter des années 2010, du fait de l'interdiction des extractions dans le lit des fleuves (fleuves dont la charge solide a diminué de façon drastique depuis que leurs lits sont barrés et endigués) et de la raréfaction des gisements terrestres (le cadre réglementaire contraignant rend plus difficile l'ouverture de nouvelles carrières, dont le nombre est passé en France de 3500 à 2300 entre 1982 et 2009), la tentation d'exploiter les sables marins est devenue plus grande et les demandes de prospection de granulats en mer ont augmenté. La France consommait 379 millions de tonnes de granulats, dont $2 \%$ étaient extraits en mer en $2011^{13}$.

Mais certains cas d'extraction de sable pour la construction, sur ou à proximité de cordons dunaires, ont suscité et suscitent de vives réactions de la part des populations qui observent les effets directs de l'érosion marine sur des cordons dunaires ainsi fragilisés (Peuple des dunes à Lorient, baie de Lannion...).

13. https://www.ifremer.fr/gm/Comprendre/Soutien-a-la-puissance-publique/Les-granulats-marins/ Granulats-marins, consulté le 13 octobre 2017. 
Pour ne pas trop impacter la cellule sédimentaire, les prélèvements ne devraient pas être réalisés à des profondeurs inférieures à 50 mètres, alors que les gisements exploités aujourd'hui sont entre 5 et 50 mètres de profondeur. En effet, les extractions de sable sur la plage ou dans des petits fonds ne peuvent que perturber le budget du prisme sédimentaire avant-plage/plage/dune (sans parler des effets sur la biodiversité marine), et donc modifier durablement les cordons dunaires.

Un autre phénomène diffus a certainement des conséquences non négligeables sur le stock de sable du littoral, le nettoyage des plages. La mécanisation a beau faire des progrès, une part non négligeable de sable est exportée à chaque nettoyage. On a calculé, par exemple, que lors du nettoyage des plages après la marée noire qui a suivi le naufrage du pétrolier de l'Erika (en 1999), 250000 tonnes de déchets ont été collectées, exportés des côtes et traités en raffinerie de Donges (Loire-Atlantique), alors que la cargaison n'était que de 30900 tonnes de fioul lourd.

Tous les nettoyages mécaniques des plages exportent du sable qui se trouve définitivement perdu pour le fonctionnement de la cellule sédimentaire.

\section{L'urbanisation}

Christine Clus-Auby

L'urbanisation des dunes littorales est relativement récente. Son développement, débuté au XIX ${ }^{\mathrm{e}}$ siècle, a été très rapide. Même si des restrictions importantes ont été imposées en France par la "loi littoral » (1986), la prolifération des immeubles en tous genres, de voies de communication et autres promenades panoramiques n'est pas sans conséquence sur les dunes elles-mêmes et sur les plages qui leur sont associées.

\section{Origine de l'urbanisation des dunes littorales}

Dès le début du xix ${ }^{\mathrm{e}}$ siècle, trois facteurs principaux sont venus se conjuguer pour que des formes d'urbanisation s'édifient sur les dunes: la fixation des dunes, la création du cadastre et l'engouement pour les bains de mer.

Instables et dangereuses, les dunes étaient des lieux bien peu propices à la construction. Si la littérature mentionne çà et là quelques villages engloutis par la marche des sables, ce n'est que pour souligner la précarité et le caractère hasardeux de ces implantations. L'essentiel de la frange littorale sableuse était un désert mouvant. Le $x x^{e}$ siècle a changé la donne. La vaste entreprise de fixation des dunes littorales, initiée dès 1801 sur les côtes de Gascogne en même temps que fut créée la Commission des dunes, a été étendue à l'ensemble des départements français par le décret impérial de 1810. Quelques décennies plus tard, les dunes, stabilisées, devenaient physiquement constructibles.

L'influence de la création du cadastre, en 1807, est souvent négligée. Pourtant, son apparition jouera un rôle essentiel et cela s'explique : comment envisager de construire un immeuble sans connaître les limites du terrain qu'il occupera, sans que la propriété de ce terrain soit établie? Instauré dans le but de lever l'impôt sur des parcelles publiquement identifiées, le cadastre a changé le statut foncier de ces espaces proches du rivage de la mer. En effet, tant qu'elles étaient mouvantes et inhospitalières, les dunes n'avaient que peu de valeur et nul n'en revendiquait la propriété. Considérant qu'il s'agissait de "biens vacants", I'Assemblée constituante de 1790 en a fait des biens de l'État, pour ensuite, 
après les avoir cadastrées, en concéder une partie aux communes ou à des personnes privées. L'inscription au cadastre a ainsi donné une "valeur » à ces dunes qui, dans la même période, étaient stabilisées. La côte Aquitaine porte encore la marque de cette appropriation des dunes littorales par l'État et des concessions qui ont suivi. Près des trois quarts des $240 \mathrm{~km}$ de littoral sableux y sont encore propriétés de l'État, non bâtis et gérés par l'Office national des forêts. Le quart restant correspond aux anciennes concessions, transformées par la suite en parcelles de pleine propriété et urbanisées.

Le troisième facteur est l'intérêt porté à la plage et aux bains de mer, visible dès la fin du XVIII ${ }^{\mathrm{e}}$ siècle mais qui s'est épanoui tout au long du siècle suivant. La dégradation des conditions de vie dans les villes industrielles, surpeuplées et décrites comme de véritables cloaques, a fait naître le désir de fuir les miasmes porteurs d'épidémies et de chercher remède dans les bains de mer et l'air pur des plages. Parti d'Angleterre, où le premier établissement de bains a été installé à Brighton en 1783, le mouvement s'est rapidement répandu dans toute l'Europe. Conjugué à un nouvel esthétisme issu du mouvement romantique qui s'enflamme pour le " pittoresque marin », il a conduit à l'édification des premiers quartiers balnéaires, puis de véritables stations balnéaires (le terme date de 1870). Les dunes, nouvellement fixées et faciles à aménager, étaient le support idéal pour l'édification de ces villes nouvelles propres à satisfaire les désirs d'hygiène et de pittoresque des citadins fortunés.

\section{Les trois étapes de l'urbanisation des dunes}

Si les premières villas de bord de mer s'élevèrent en Angleterre à la toute fin du $x v I^{e}{ }^{e}$ siècle, $c^{\prime}$ est principalement dans la seconde moitié du xIx ${ }^{e}$ siècle que naissent la plupart des stations balnéaires françaises. Villégiatures de I'aristocratie et de la nouvelle bourgeoisie née de la révolution industrielle, elles portent encore les traces de leurs bâtisseurs fortunés. À Deauville, créée par le duc de Morny, à Arcachon, qui doit sa naissance aux frères Pereire, à Cabourg, lancée par Durand-Morimbau, et dans bien des sites littoraux, des villas imposantes et parfois somptueuses, des casinos, des promenades de front de mer, aménagées pour le confort de ces élites mondaines, font aujourd'hui partie de notre patrimoine architectural. Leur dessin se retrouve presque à l'identique sur l'ensemble du littoral : un plan en damier, plus rarement en étoile, pour faciliter la circulation de l'air, une digue-promenade et un casino pour les loisirs mondains.

Avec l'avènement des congés payés (1936), qui ne se sont véritablement généralisés qu'après la Seconde Guerre mondiale, ce sont des millions de visiteurs qu'il faut accueillir et héberger. Le développement du tourisme de masse a nécessairement conduit à celui de l'urbanisation des dunes. Les stations anciennes se sont densifiées, étendues, d'autres ont vu le jour : lotissements, hôtels, campings, restaurants, parkings toujours plus nombreux ont occupé les espaces dunaires pour permettre aux vacanciers de s'installer au plus près des plages. Depuis les années 1950 jusqu'au milieu des années 1980, c'est une véritable ruée vers le littoral qui a grignoté les dunes.

La loi d'aménagement, de protection et de mise en valeur du littoral, dite loi littoral, du 3 janvier 1986 a mis un frein à l'urbanisation anarchique des espaces côtiers. Elle l'a fait en posant un certain nombre de principes. Le plus connu est l'interdiction, en dehors des espaces déjà urbanisés, de toute construction nouvelle sur une bande de 100 mètres à compter de la limite haute du rivage. Il est bien évident qu'en matière de dunes une distance de 100 mètres n'a pas 
grand sens : c'est toute la largeur des dunes « de première ligne » qu'il faut soustraire à l'urbanisation. En Aquitaine, par exemple, le schéma de cohérence à la loi littoral avait proposé que la largeur de la dune non urbanisée soit étendue à 500 mètres. Le plan local d'urbanisme peut porter la largeur de cette bande littorale à plus de 100 mètres lorsque des motifs liés à la sensibilité des milieux ou à l'érosion des côtes le justifient. Les dunes sont justement considérées comme des milieux sensibles et remarquables, à côté des plages, des lidos, des falaises, etc. Leur ouverture à l'urbanisation nouvelle est donc impossible, sauf dans des cas très particuliers (extension limitée de l'urbanisation existante, établissements nécessitant la proximité de la mer). En dépit de nombreuses critiques et des fortes pressions pour l'assouplir, la loi littoral résiste tant bien que mal et, même si l'urbanisation s'est poursuivie, nul ne peut nier qu'elle a permis de stopper les grands programmes immobiliers qui ont colonisé les dunes avant son avènement. Porté par une politique d'acquisition foncière ambitieuse, le Conservatoire du littoral, né en 1975, a également permis de soustraire à I'urbanisation les espaces les plus remarquables, les plus fragiles, parmi lesquels figurent de nombreux sites dunaires.

\section{Les conséquences de l'urbanisation des dunes}

L'urbanisation est sans aucun doute la pire des choses qui puisse arriver à une dune. Enfouie sous une carapace d'immeubles, de parkings, de rues, privée de son couvert végétal, coupée de ses connexions avec la plage, elle n'est plus que le soubassement statique des aménagements urbains : elle n'est plus une dune.

La première des conséquences visibles de I'urbanisation est la diminution, allant même jusqu'à la disparition, du couvert végétal. Au fur et à mesure de la densification du tissu bâti, il est bien évident que la végétation est éliminée pour laisser la place aux aménagements. Parallèlement, autour des immeubles, sur les places aménagées, des espèces exotiques sont parfois introduites et concurrencent la flore autochtone qui subsiste. C'est ainsi que l'on peut voir proliférer, entre autres exemples, I'herbe de la pampa (Cortaderia selloana), les doigts de sorcière (Carpobrotus sp.) et, dans les secteurs plus internes, le baccharis (Baccharis halimifolia) dont les capacités envahissantes sont bien connues, notamment dans les zones humides.

L'urbanisation s'est également accompagnée de la modification des formes, allant parfois jusqu'à l'arasement des dunes, pour garantir au mieux la circulation automobile, le stationnement et la « vue sur mer» depuis les immeubles.

Une troisième conséquence est l'exportation du sable en dehors de la morphoséquence plage-dune. En effet, le niveau du sol étant stabilisé pour recevoir les constructions, les déformations naturelles de la dune ne peuvent plus être admises. Le sable, apporté par le vent et qui s'accumule autour de tous les obstacles physiques qu'il rencontre, doit être enlevé pour que les voies de communication restent praticables et les immeubles accessibles. En dépit d'une interdiction formelle issue de la loi littoral ${ }^{14}$, $\mathrm{d}^{\prime}$ énormes quantités de sédiments sont ainsi régulièrement exportées au-delà du système plage-dune. Ces sables devraient être systématiquement déposés sur les plages, d'où ils proviennent.

14. Article L. 321-8 du code de l'environnement : les extractions de matériaux non visés à l'article 2 du code minier sont limitées ou interdites lorsqu'elles risquent de compromettre, directement ou indirectement, l'intégrité des plages, dunes littorales, falaises, marais, vasières, zones d'herbiers, frayères, gisements naturels de coquillages vivants et exploitations de cultures marines. 
Enfin, et plus grave encore, les structures rigides de front de mer ont pour effet $d^{\prime}$ interrompre totalement les échanges sédimentaires entre la plage et la dune. Passé inaperçu au moment de la création des premières stations balnéaires, ce phénomène a eu de très lourdes conséquences. Les digues promenades, perrés, murs soutenant des terrasses panoramiques, ont progressivement entraîné l'abaissement et le rétrécissement des plages, allant jusqu'à la disparition de certaines d'entre elles. La raison en est simple et aujourd'hui bien connue. Dans les secteurs en érosion, que celle-ci soit continue ou temporaire, l'avancée de la mer conduit au déplacement vers I'intérieur des terres de la morphoséquence dune/plage/avant-plage. Les constructions installées sur les dunes, de quelque nature qu'elles soient, ne peuvent pas suivre ce mouvement et se retrouvent alors en position très vulnérable, directement exposées aux assauts des vagues et menacées de basculer sur les plages. Pour les protéger, des murs de soutènement et des enrochements divers ont été installés, déclenchant l'engrenage conduisant à l'aggravation de l'érosion. La plage, séparée de sa réserve terrestre de sédiments (la dune), voit son équilibre sédimentaire rompu. La réflexion des vagues sur les structures rigides amplifie la turbulence à leur pied, facilitant la fuite des sédiments, et l'estran, par conséquent, se creuse et donc rétrécit. Les vagues étant plus agressives sur un estran étroit qui dissipe moins facilement leur énergie, l'abaissement se poursuit, conduisant inéluctablement à la disparition pure et simple de la plage, support essentiel de l'activité touristique qui est la raison d'être de l'urbanisation des massifs dunaires.

\section{Les ouvrages et les systèmes de défense contre la mer}

\section{Yann Deniaud}

Le développement de I'urbanisation et des enjeux sur les littoraux accroît les risques générés par les aléas côtiers (submersion marine, recul du trait de côte) et la demande corrélative de protection par les populations. Les cordons dunaires sont des éléments morphologiques et des milieux naturels qui peuvent contribuer à une fonction de défense contre la mer, notamment pour les zones basses arrières-littorales, mais dont la résilience aux aléas dépend de leur possibilité d'adaptation et de leur espace naturel de mobilité. Ils sont sensibles aux modifications engendrées par les aménagements humains sur le littoral, particulièrement lorsque ceux-ci sont localisés directement sur le système plage-dune. Un cordon dunaire naturel forme en effet, avec l'estran et I'avant-plage, un système dont les composants interagissent de manière complexe, nous l'avons vu précédemment. Ce système concentre la majeure partie des échanges sédimentaires côtiers, et joue plusieurs rôles directs et indirects face à l'érosion côtière et aux submersions marines. Il favorise notamment la dissipation de l'énergie des vagues à la côte et participe à la résilience du littoral grâce aux échanges sédimentaires internes au système (réalimentation en stock sableux de la plage après le passage de tempêtes, puis reconstruction dunaire à partir de la plage).

La pérennité et la capacité d'ajustement du système plage-dune sont directement liées à la liberté des échanges sédimentaires entre ses différentes composantes, or cette dernière est souvent perturbée par les ouvrages. Tout élément anthropique positionné entre la plage et le cordon dunaire perturbe ces échanges, diminue la capacité de résilience du système, voire favorise l'érosion par abaissement de l'estran et ainsi les franchissements par la mer. 

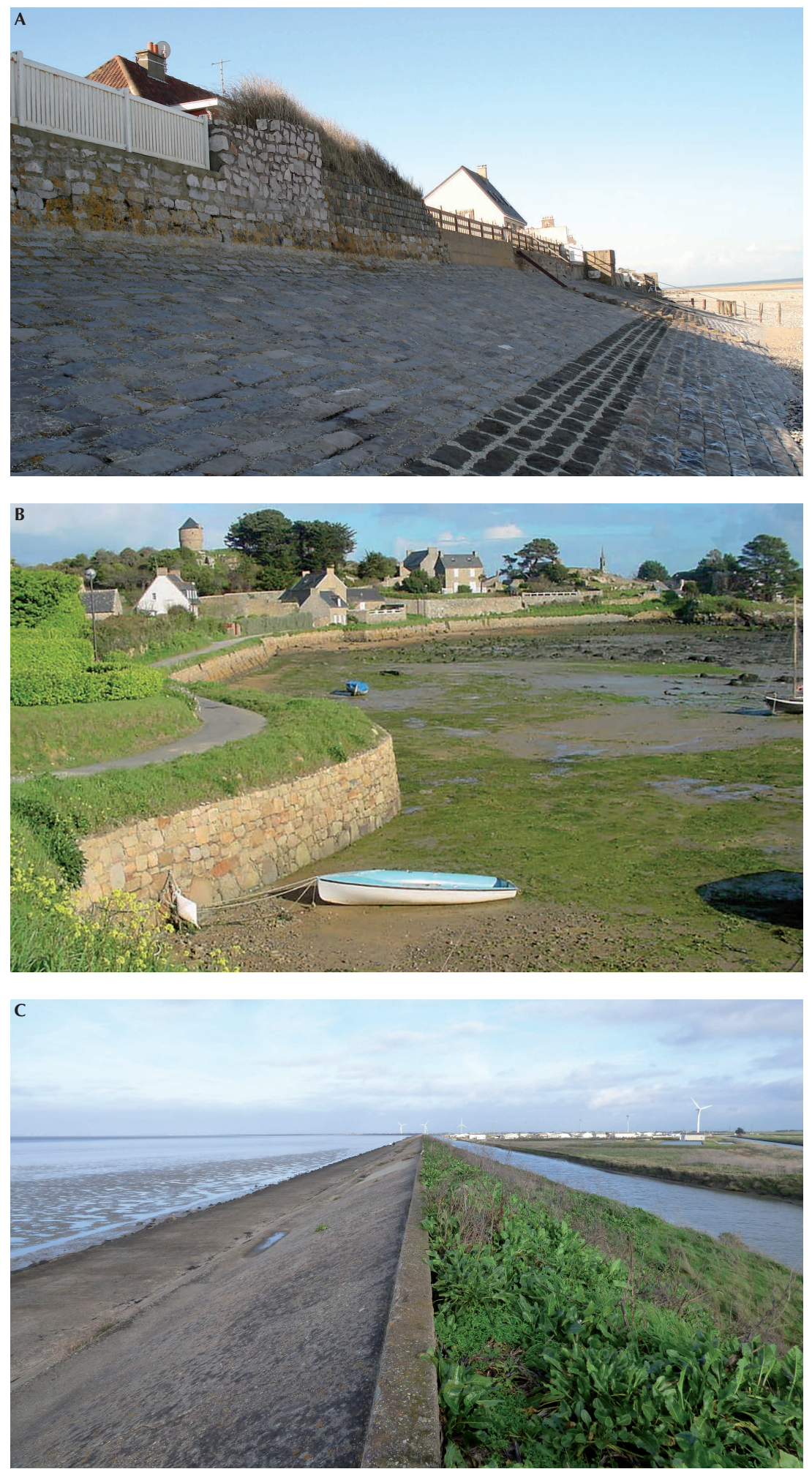

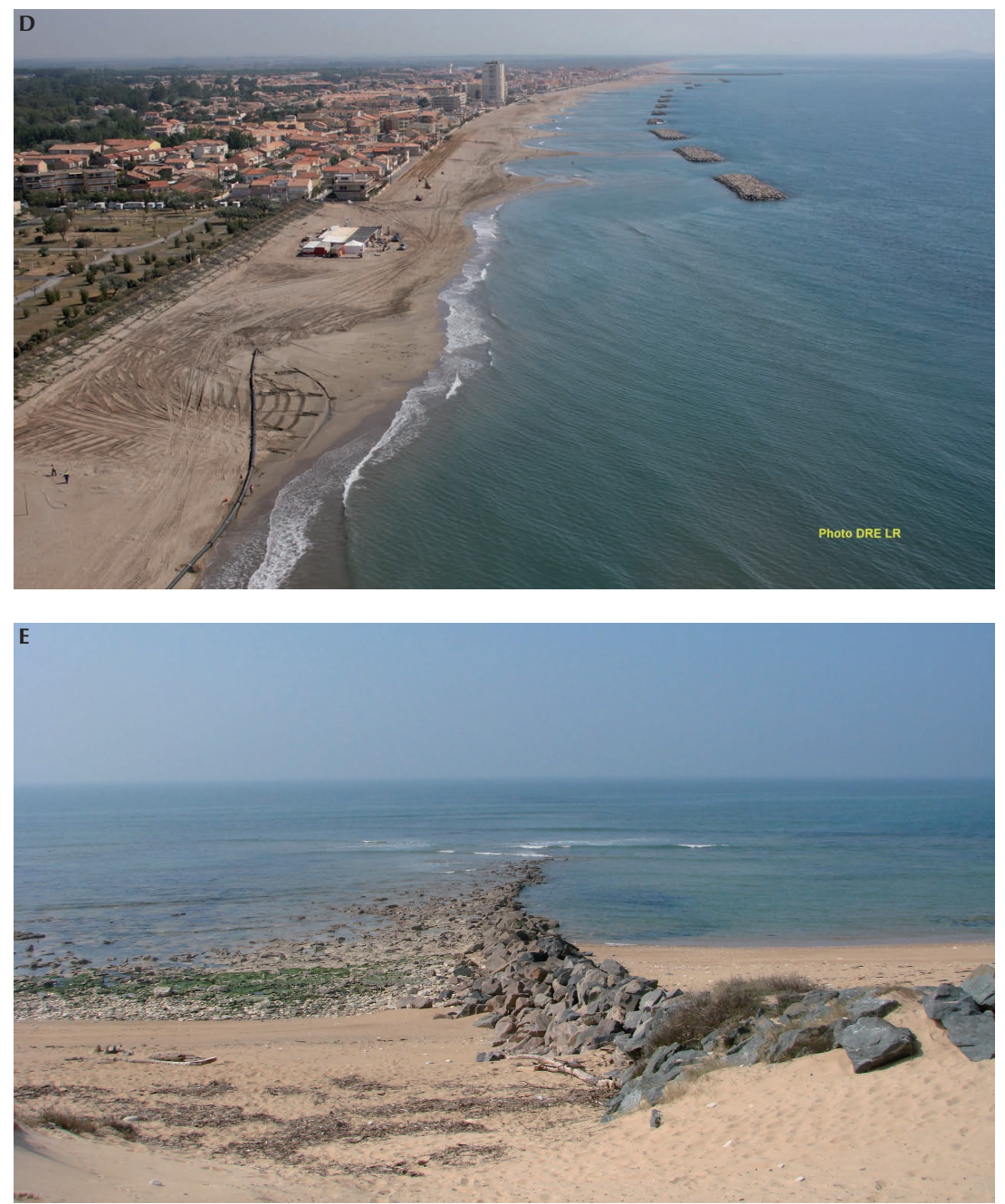

Figure 2.11. Principaux types d'ouvrages présents sur le littoral.

A. Perré de Sangatte (Pas-de-Calais).

Ouvrages longitudinaux inclinés, constitués d'un revêtement recouvrant un talus auto-stable.

Le revêtement correspond à une protection superficielle du talus sans fonction de soutènement.

B. Mur de la Corderie (Côtes-d'Armor).

Ouvrages généralement verticaux, différents de simples clôtures, offrant une résistance à la poussée exercée soit par le niveau d'eau en crue ou période de hautes eaux (mur anti-submersion),

soit par la poussée des terres (mur de soutènement participant au maintien du trait de côte).

C. Digue frontale de Beauvoir-sur-Mer (Vendée).

Ouvrage longitudinal constituant un obstacle aux écoulements vers la terre, construit en surélévation topographique et disposant de deux talus identifiables, éventuellement revêtus. Ces ouvrages sont rattachés au rivage par au moins une extrémité ou se rencontrent en arrière-côte (digue en retrait du rivage dit de second rang).

D. Brise-lames de Valras (Hérault, Dreal Occitanie).

Ouvrages longitudinaux au trait de côte mais non rattachés à la terre. En partie émergés ou totalement immergés, ils diminuent l'énergie de la houle incidente en provoquant son déferlement. L'agitation plus faible en arrière de l'ouvrage permet parfois aux sédiments de s'accumuler sous la forme d'un tombolo. E. Épi isolé en maçonnerie (Oléron, Charente-Maritime).

Les épis peuvent être plus ou moins perméables. Ils présentent une grande diversité de géométrie en plan (en forme de I, L, T, Y) et de matériaux constitutifs (enrochements, maçonnerie, bois, géosynthétiques, etc.).

Sources : A, B et D : ( C Cerema ; C ( ) J. Magne ; E $\odot$ L. Gouguet/ONF. 
C'est pourquoi aujourd'hui, si la réglementation n'intègre pas les éléments naturels comme les cordons dunaires dans la définition des systèmes d'endiguement assurant des fonctions de protection contre les submersions (art. R562-13 du Code de l'environnement), elle impose cependant de prendre en compte le comportement de ceux situés à proximité des systèmes d'endiguements dans I'étude de dangers (art. R.214-116-III du Code de l'environnement).

Les " ouvrages de défense contre les aléas littoraux » sont des structures côtières construites et dimensionnées par l'homme pour répondre à des vocations initiales de maintien du trait de côte (lutte contre l'érosion ou fixation et soutènement des terres), de réduction de l'agitation du plan d'eau (dissipation de l'énergie des houles incidentes ou des courants) ou de défense contre les inondations (réduction des franchissements, obstacle aux écoulements).

Les actions des ouvrages côtiers sur le milieu naturel sont généralement définies par leurs effets perpendiculairement (actions dans le profil) ou longitudinalement (actions longitudinales) au trait de côte. En raison de leurs multiples effets sur l'environnement et les processus marins, ces ouvrages combinent fréquemment les fonctions : un brise-lames, en contribuant à la réduction de l'agitation du plan d'eau, peut ainsi favoriser la stabilisation du trait de côte et limiter les franchissements en front de mer. Du fait de leurs fonctions et de leurs modes $\mathrm{d}^{\prime}$ actions multiples, les typologies des ouvrages s'appuient le plus souvent sur leur géométrie vis-à-vis de l'orientation de la côte (ouvrages longitudinaux ou transversaux) et sur leur matériau constitutif principal (enrochements, béton, perré...). La figure 2.11 présente les ouvrages les plus couramment rencontrés sur les côtes.

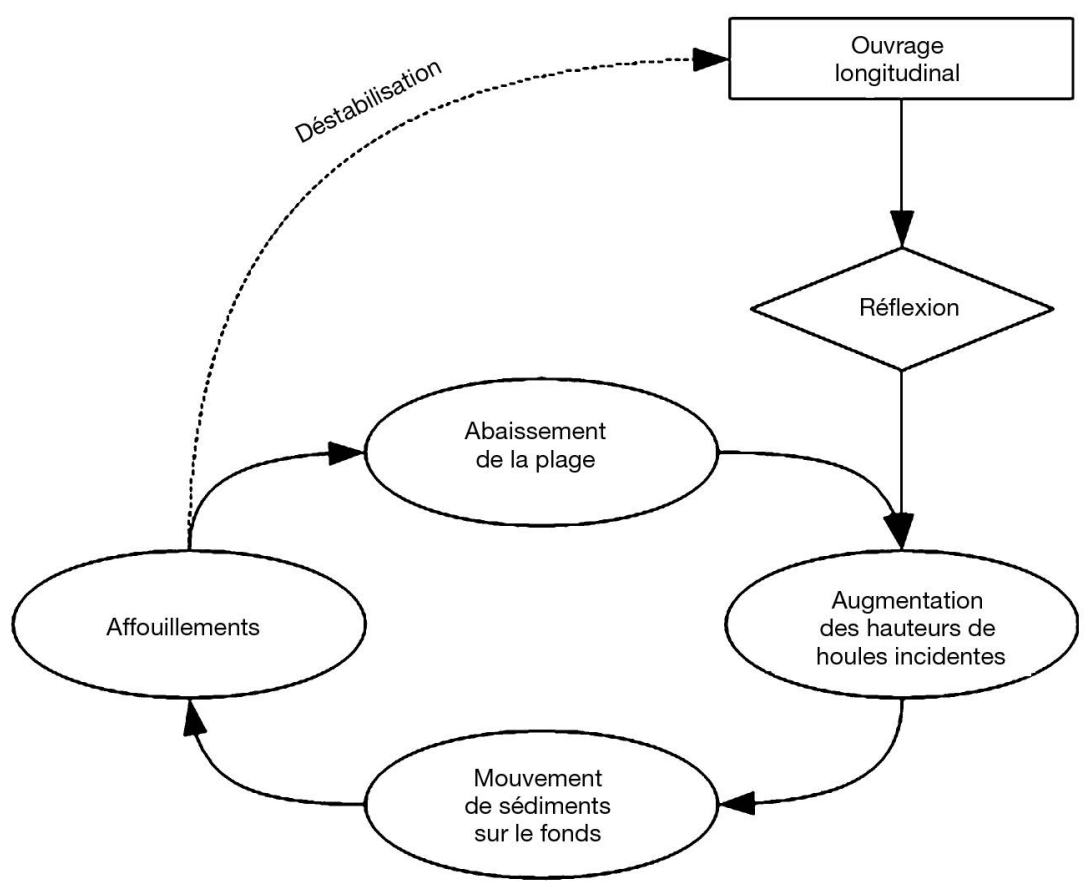

Figure 2.12. Cycle érosif vicieux potentiellement induit par la présence d'un ouvrage longitudinal côtier de haut de plage. (c) Y. Deniaud/Cerema. 

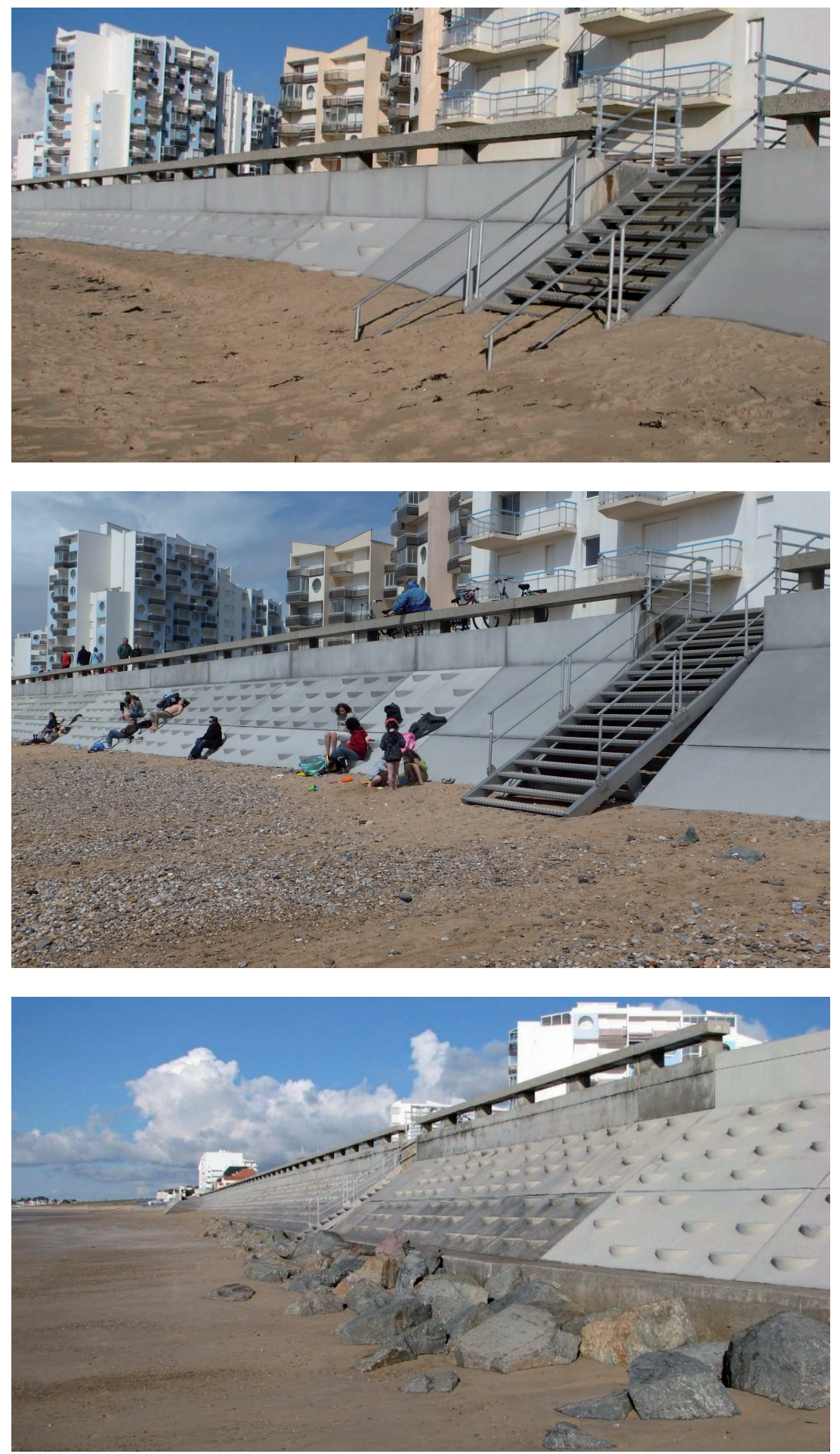

Figure 2.13. Abaissement d'estran à Saint-Gilles-Croix-de-Vie.

Photo du haut, novembre 2010 ; photos du milieu et du bas, avril 2012. Photo : (C) Cerema. 


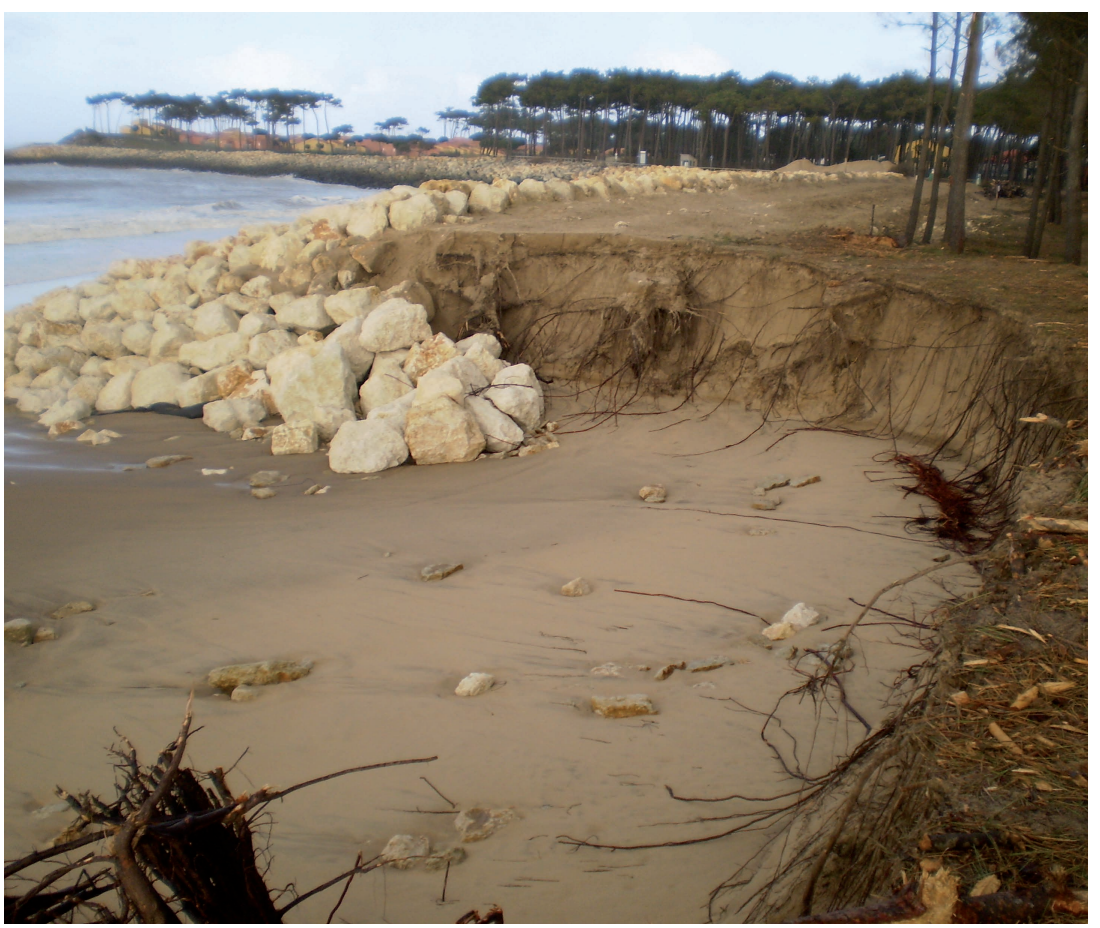

Figure 2.14. Enrochement à La Palmyre (Charente-Maritime).

CD. André.

L'implantation d'ouvrages sur le littoral conduit à introduire une perturbation dans l'équilibre dynamique du milieu naturel. Avant toute implantation, il faut en identifier les conséquences ultérieures, afin de les prendre en compte dans les programmes de remédiation. L'adaptation des processus naturels peut générer des effets aux conséquences souvent indésirables, ainsi :

- I'implantation d'ouvrages longitudinaux en haut de plage favorise la réflexion des vagues et des houles incidentes. Le renforcement de l'agitation en pied d'ouvrage accroît les mouvements sédimentaires sur le fond et les phénomènes d'affouillement. Cet accroissement des phénomènes érosifs, aggravé par la coupure sédimentaire avec la zone arrière littorale du fait de la présence même de l'ouvrage, entraîne progressivement un abaissement de I'estran, voire une disparition de la plage. L'accroissement de la profondeur d'eau induit au droit de l'ouvrage renforce les effets néfastes de l'agitation en pied, dans un cycle vicieux pouvant conduire à la déstabilisation de la structure ;

- l'implantation d'ouvrages longitudinaux sur l'estran ou en mer génère des phénomènes de diffraction aux extrémités susceptibles de générer des courants et une érosion localisée importante ;

- l'implantation d'ouvrage perpendiculairement au trait de côte va induire une limitation du transit sédimentaire associé à la dérive littorale. $\mathrm{Si}$, en amont, des engraissements sédimentaires peuvent être observés, en aval, la reprise du transit se manifeste généralement par une érosion accrue susceptible à terme de déstabiliser la tête d'ancrage de l'ouvrage à terre.

Les interdépendances observées entre les évolutions des cordons dunaires et les implantations d'ouvrages anthropiques incitent à rechercher et à construire 


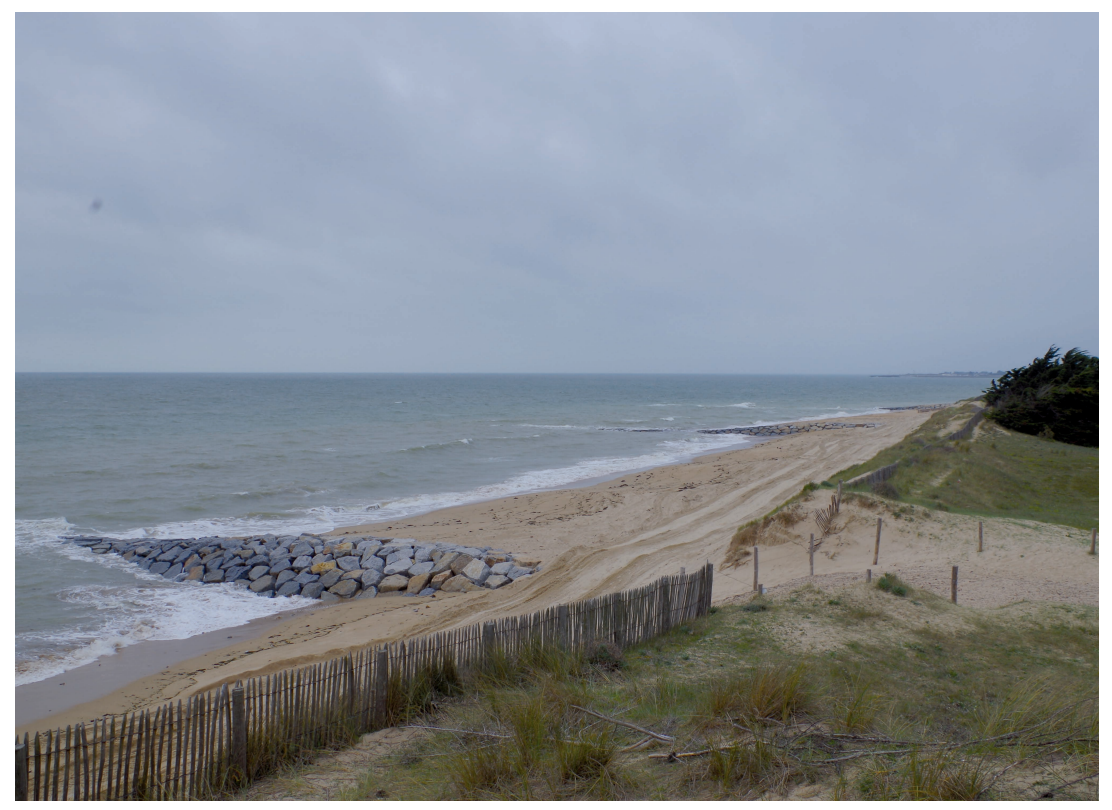

Figure 2.15. Épi sur la plage des Éloux, Noirmoutier.

(C) Y. Deniaud/Cerema.

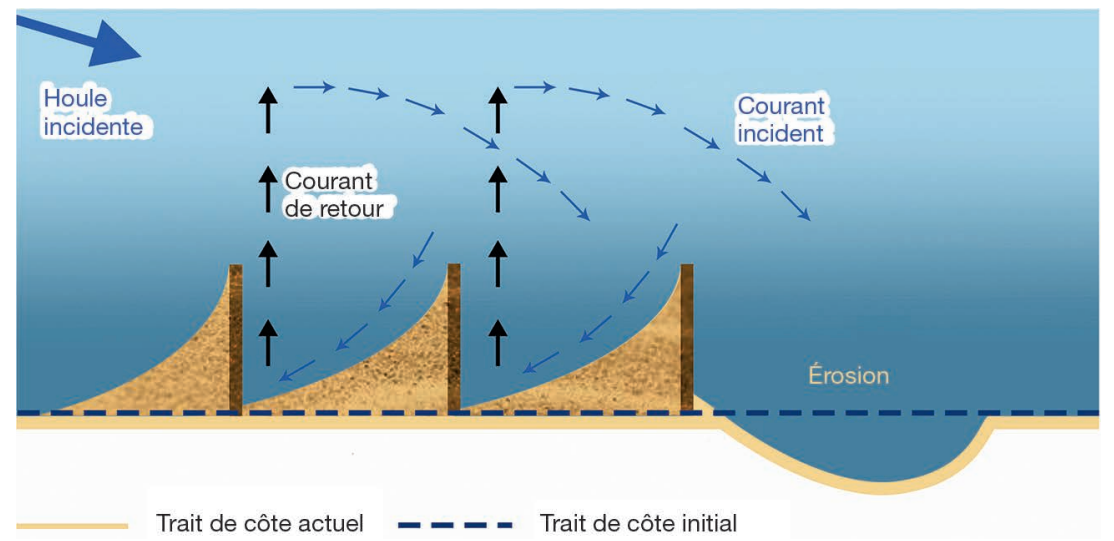

Figure 2.16. Houle incidente et épis.

Source : MEEDDM, 2010.

une véritable politique de gestion intégrée du trait de côte prenant en compte, au-delà du seul besoin de protection immédiat, les tendances évolutives du littoral à moyen et à long terme, les usages et les bénéfices attendus des milieux, et les intérêts et les responsabilités des différents acteurs des territoires. Cette réflexion ne peut se mener qu'à l'échelle de cellules hydrosédimentaires délimitant des compartiments du littoral dont la description et I'analyse peuvent être conduites de manière autonome sur le plan des transports sédimentaires. L'établissement de bilans des échanges de sédiments au sein de chaque cellule permet de prendre en compte l'ensemble des facteurs d'évolution du littoral sur un secteur géographique donné et concourt à la définition de la bonne échelle géographique de prise de décision en matière d'aménagement côtier. 


\section{Protéger les dunes: les politiques publiques de protection}

Les dunes présentent, nous l'avons vu, de multiples intérêts. À travers plusieurs réglementations thématiques, la société a reconnu l'importance que présente la préservation des dunes. Nous allons voir comment leurs rôles en matière de préservation de la biodiversité et de prise en compte des risques naturels sont actuellement intégrés.

\section{Préserver une biodiversité remarquable}

\section{Loïc Gouguet}

La biodiversité, ou diversité biologique, recouvre l'ensemble des formes de vie sur Terre, et les relations qui existent entre elles et avec leurs milieux depuis l'origine commune de la vie.

La notion de biodiversité comprend donc de façon indissociable :

- la diversité génétique, c'est-à-dire la diversité des gènes au sein des organismes vivants ;

- la diversité spécifique, soit la multitude des formes du vivant, des microorganismes les plus petits aux espèces les plus grandes ;

- la diversité des écosystèmes, c'est-à-dire la complexité et l'organisation des interactions entre toutes les espèces vivantes (y compris l'être humain), ainsi qu'entre ces espèces et leurs milieux naturels.

À cette diversité du vivant qui est de plus en plus reconnue, il faut également ajouter le concept de géodiversité*, qui désigne les diversités géologique, géomorphologique et pédologique, ainsi que les différents processus dynamiques qui les génèrent.

$\mathrm{S}^{\prime}$ il est un milieu terrestre qui évolue en permanence sous les yeux de l'homme, $c^{\prime}$ est bien le milieu dunaire, et la préservation de la diversité des formes des dunes est aussi la garantie de préserver les espèces vivantes qui colonisent chaque stade d'évolution du cordon dunaire. Ainsi, les suivis floristiques mis en place lors d'un chantier de restauration de dune à Capbreton (Landes) en 2017 ont clairement démontré que les travaux lourds de reprofilage et de couverture de branchage, loin de porter atteinte aux espèces patrimoniales, ont au contraire favorisé le développement (voire à profusion !) de nombreuses espèces patrimoniales protégées : linaire à feuille de thym, astragale de Bayonne, œillet de France...

Du haut de plage à la dune boisée, les formes de vie dans les dunes sont multiples. Dans ces biotopes totalement dépendants des éléments (vent, embruns salés...), les habitats et les espèces se répartissent en fonction des conditions de vie des milieux qui vont fluctuer en permanence.

\section{Les dispositifs de préservation de la biodiversité}

Le littoral bénéficie de plusieurs outils législatifs, réglementaires ou fonciers, de portée nationale ou internationale, concourant à la protection des milieux dunaires et aux espèces qui leur sont associées, soit directement au regard des objectifs recherchés par ces outils, soit indirectement par le maintien d'espaces naturels.

En particulier, depuis les années 1990 (Conférence internationale de Rio en 1992), une prise de conscience de plus en plus grande de la nécessité de 
protéger la biodiversité, et notamment le haut intérêt écologique des milieux dunaires, s'est généralisée, favorisant l'émergence d'outils spécifiques.

Les espaces dunaires sont ainsi concernés par différentes mesures de protection qui peuvent parfois se superposer. Voici un petit aperçu des différents dispositifs les plus courants.

\section{La directive Habitats : le Réseau Natura 2000}

Le réseau Natura 2000 est un ensemble de sites naturels, terrestres et marins, qui vise à assurer la protection et la conservation à long terme des espèces et des habitats menacés en Europe. Ce réseau est fondé sur la mise en application de deux directives européennes :

- la directive Oiseaux 2009/147/CE du 30 novembre 2009 (qui a recodifié la directive initiale du 2 avril 1979) a pour objet la conservation de toutes les espèces d'oiseaux sauvages et définit les règles encadrant leur protection, leur gestion et leur régulation. Elle s'applique aux oiseaux ainsi qu'à leurs œufs, à leurs nids et à leurs habitats. Certaines espèces nécessitant une attention particulière afin d'assurer leur survie, précisées à l'annexe I, font l'objet de mesures spéciales concernant leur habitat. Ces espèces, ainsi que les espèces migratrices dont la venue est régulière, sont protégées dans des sites Natura 2000 dits zones de protection spéciale (ZPS) ;

- la directive Habitats faune flore 92/43/CEE du 21 mai 1992 a pour objet la conservation des habitats naturels et de la faune et de la flore sauvages. Les annexes I et II de cette directive listent les types d'habitats naturels et les espèces animales et végétales dont la conservation nécessite la désignation de sites Natura 2000 dits zones spéciales de conservation (ZSC). Certains habitats ou certaines espèces dits prioritaires sont identifiés comme en danger de disparition et répondent à des règles particulières. La directive établit un cadre pour les actions communautaires de conservation de ces espèces et de ces habitats en cherchant à concilier les dimensions scientifiques qui fondent les délimitations des sites avec les exigences économiques, sociales et culturelles des territoires.

La dune fixée, la dune embryonnaire, la dune blanche et la dune boisée sont ainsi classées à l'annexe I de la directive Habitats comme habitat d'intérêt communautaire prioritaire.

Dans l'annexe II de la directive, des espèces animales et végétales d'intérêt communautaire, dont la conservation nécessite la désignation de zones spéciales de conservation, sont énumérées. Parmi elles, certaines sont dites prioritaires. C'est le cas par exemple de l'omphalode du littoral (Omphalodes littoralis ssp. littoralis), petite fleur blanche, qui n'existe dans le monde que sur le littoral atlantique français, entre l'archipel des Glénan au nord et l'île d'Oléron au sud.

En France, la mise en œuvre du réseau Natura 2000 s'est construite sur une approche concertée et une gestion contractuelle et volontaire. La transposition française de l'application de la directive Habitats organise donc la concertation avec les acteurs du site concerné avec pour objectif de définir les objectifs du site qui concourront au maintien ou à l'amélioration de l'état de conservation des habitats naturels et des espèces pour lequel ce site a été désigné. Cette concertation, dans le cadre du comité de pilotage et au sein des réunions d'élaboration du document d'objectifs (Docob), a pour objectif de prendre en compte l'ensemble des aspirations des parties prenantes, qu'elles soient écologiques, économiques, culturelles ou sociales. 
Cette participation effective permet d'envisager les solutions et les mesures concrètes à mettre en œuvre pour réaliser ces objectifs. Par voie contractuelle, le propriétaire d'un site s'engage ensuite dans un programme d'actions en faveur des habitats et des espèces d'intérêt communautaire.

\section{PROTECTIONS DES ESPÈCES}

Au-delà de protections apportées par les directives européennes Habitats et Oiseaux, il existe également des listes d'espèces protégées au niveau national (cas de Dianthus gallicus, figure 2.17) et régional (Pancratium maritimum, Silene thorei...). Enfin, il existe par département des arrêtés préfectoraux qui fixent des listes d'espèces dont la cueillette ou la commercialisation sont interdites (par exemple Asparagus prostratus en Vendée).

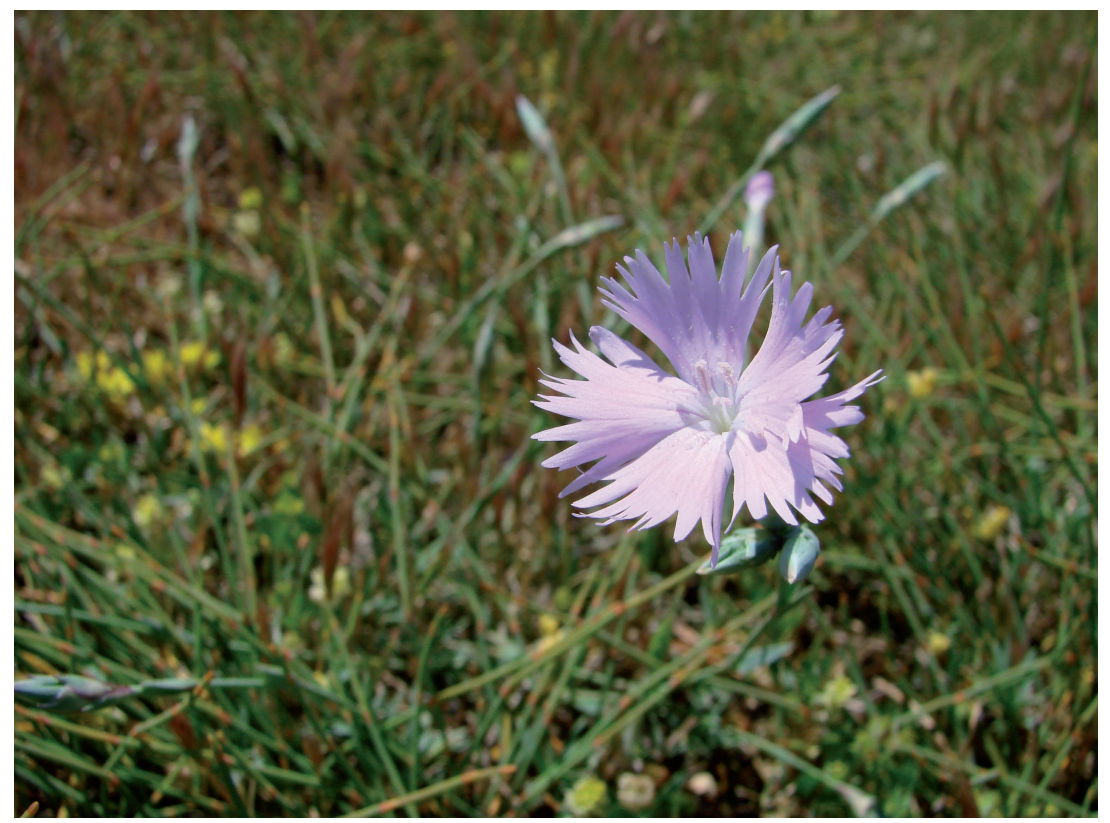

Figure 2.17. CEillet des dunes (Dianthus gallicus).

(C) L. Gouguet/ONF.

\section{Encadré 2.1. Protections des milieux.}

Les milieux eux-mêmes, du fait de leur statut foncier ou de leur emplacement, peuvent faire l'objet de protections réglementaires.

Code de l'urbanisme :

- inconstructibilité sur une bande de 100 mètres à compter de la limite haute du rivage (c'est le cas des dunes) ;

- espace remarquable de la loi littoral ;

- les plans locaux d'urbanisme peuvent renforcer la protection des milieux en classant " espaces boisés à conserver », au titre de l'article L. 130.1 du Code de I'urbanisme, des espaces boisés ou non, à créer ou à protéger.

Code de l'environnement :

- loi du 2 mai 1930 sur les sites inscrits et les sites classés;

- la réserve naturelle régionale est de la compétence du conseil régional qui peut, de sa propre initiative ou à la demande des propriétaires concernés, classer 
des territoires présentant un intérêt pour la faune, la flore, le patrimoine géologique ou paléontologique ou, d'une manière générale, pour la protection des milieux naturels ;

- la réserve naturelle nationale est créée par décret en Conseil l'État ou par décret simple ; c'est un espace protégé pour l'intérêt de la conservation de son milieu, des parties de territoire d'une ou de plusieurs communes dont la faune, la flore, le sol, les eaux, les gisements de minéraux ou de fossiles ou le milieu naturel présente une importance particulière ;

- le parc naturel marin qui peut concerner des parties du domaine public maritime (haut de plage...) ;

- dans certains cas (arrêté préfectoral de protection de biotope), le préfet peut fixer les mesures tendant à favoriser, sur tout ou partie du territoire d'un département, la conservation des biotopes nécessaires à l'alimentation, à la reproduction, au repos ou à la survie d'espèces protégées ;

- I'interdiction d'extraction de sable, de la circulation de véhicules à moteur, etc. Code forestier : le régime forestier qui vise à une gestion multifonctionnelle et durable des espaces boisés publics et des milieux qui leur sont associés, le statut de réserve biologique qui peut s'appliquer lorsque la valeur patrimoniale particulièrement élevée d'un site requiert une protection réglementaire renforcée ou une gestion conservatoire spécifique...

\section{LES PROTECTIONS FONCIÈRES}

Des politiques d'acquisition peuvent également entrer dans les mesures de protection des milieux : c'est le rôle du Conservatoire de l'espace littoral et des rivages lacustres, ainsi que des dispositifs concernant les espaces naturels sensibles des départements.

Du fait de son appartenance au domaine public maritime naturel, la plage relève du statut de cet espace public et des principes de gestion durable et intégrée qui lui sont appliqués. En particulier, elle bénéficie du caractère inaliénable et imprescriptible attaché à ce domaine.

\section{LES DOCUMENTS D'INFORMATION}

Des outils de connaissance, les ZNIEFF (zones naturelles d'intérêt écologique, faunistique et floristique), sont élaborés depuis 1982 pour mettre à la disposition de tous, et en particulier des élus et des administrations, un outil d'alerte permettant de mettre en évidence les éléments les plus importants du patrimoine naturel et d'ouvrir à une définition plus rationnelle des démarches de protection, de planification, d'aménagement, de gestion ou de valorisation de l'espace. Une ZNIEFF correspond à l'identification scientifique $d^{\prime}$ 'un secteur du territoire national particulièrement intéressant sur le plan écologique.

\section{Encadré 2.2. Quelques exemples de la biodiversité des milieux dunaires.}

Le lézard ocellé (Timon lepidus) (figure 2.18) vit dans les dunes grises du sud du littoral atlantique ; sa taille peut atteindre plus de $70 \mathrm{~cm}$ chez les mâles. Se nourrissant majoritairement d'insectes, il s'adapte aux conditions locales : sur l'île d'Oléron par exemple (limite nord de son aire de répartition), il consomme beaucoup de raisin de mer. Il est malheureusement menacé d'extinction par la disparition de ses habitats et par le braconnage visant à pourvoir des collectionneurs indélicats. II bénéficie d'une protection nationale. 


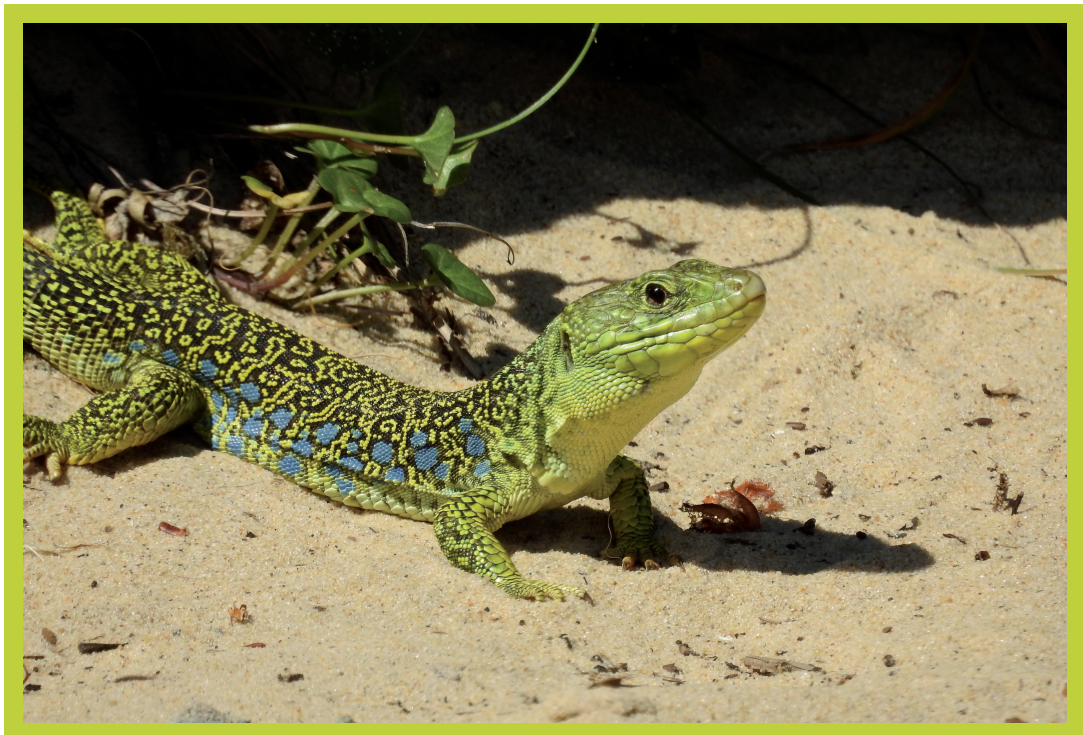

Figure 2.18. Le lézard ocellé (Cap Ferret).

Le lézard ocellé peut atteindre $70 \mathrm{~cm}$ de long.

(c) C. Baudran.

Un habitant surprenant de la dune grise est un crapaud, le pélobate cultripède (Pelobates cultripes) (figure 2.19). II affectionne les milieux sableux dunaires et arrières dunaires très secs, mais au contact de marais ou parsemés de points d'eau. Le pélobate est particulièrement discret. Nocturne, il s'enterre en journée ou se dissimule sous les pierres, et peut rester ainsi, inactif, jusqu'à deux ou trois mois si les conditions climatiques lui sont défavorables. Pour cela, il est doté de deux onglets cornés sur ses pattes arrière, des couteaux, qui lui permettent de creuser le sable. Il stoppe son activité lors des périodes estivales de forte chaleur et lors des vagues de froid.

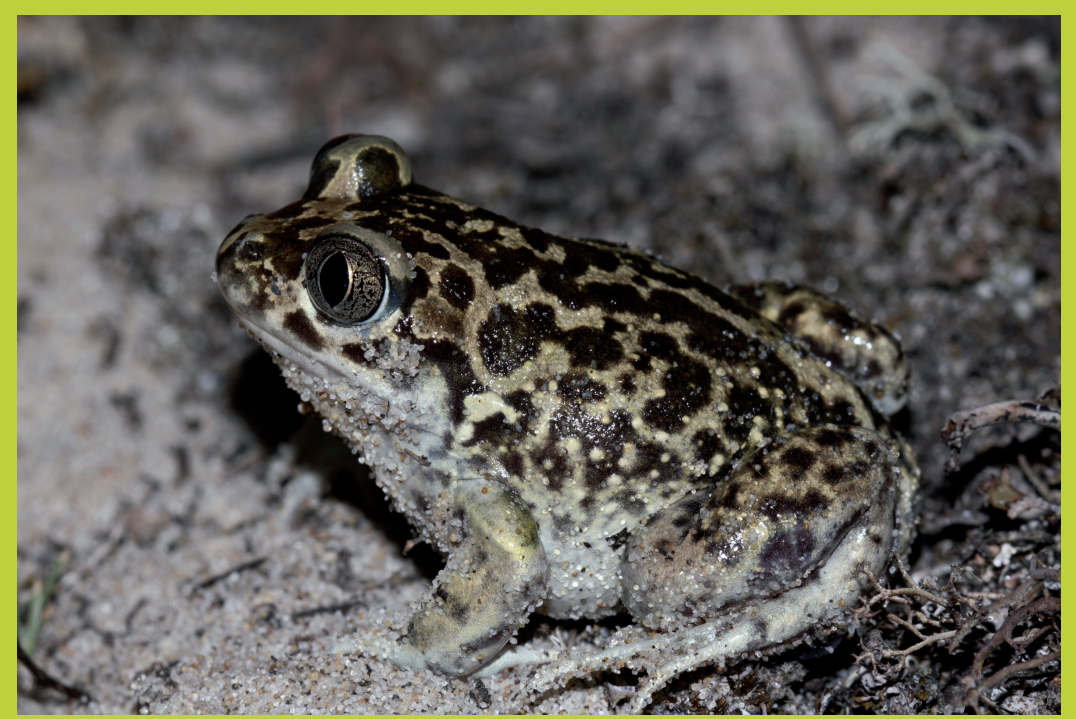

Figure 2.19. Le pélobate cultripède (Pelobate cultripes).

(C) C. Baudran, Cap Ferret. 
La femelle pond des œufs dans des mares dunaires en février et les larves peuvent s'y développer (durant 4 mois) avant la sécheresse estivale.

Sur la façade atlantique, le pélobate n'est présent que sur une vingtaine de sites, répartis entre le nord des Landes et la Vendée. Le principal ennemi de ce crapaud est l'urbanisation, qui fait disparaître les mares où il peut pondre et les zones de dunes grises où il peut chasser la nuit.

L'euphorbe peplis (Euphorbia peplis) (figure 2.20) est une petite plante estivale des hauts de plage et des dunes embryonnaires, présente en Méditerranée essentiellement dans le golfe du Lion, et sur le littoral atlantique dans le sud des Landes et en Vendée. Espèce protégée au niveau national, elle a fait l'objet de plusieurs opérations expérimentales (Aude, Hérault) d'essaimage : en préalable à des interventions de reconstitution dunaire, le sable censé contenir les graines de cette plante (haut de plage) a été prélevé puis stocké en lieu sûr avant d'être remis en place au même endroit, une fois les travaux réalisés. Des germinations se sont produites... mais pas aux endroits prévus : les mouvements sableux qui ont suivi I'opération (notamment par les coups de mer) avaient déplacé les graines.

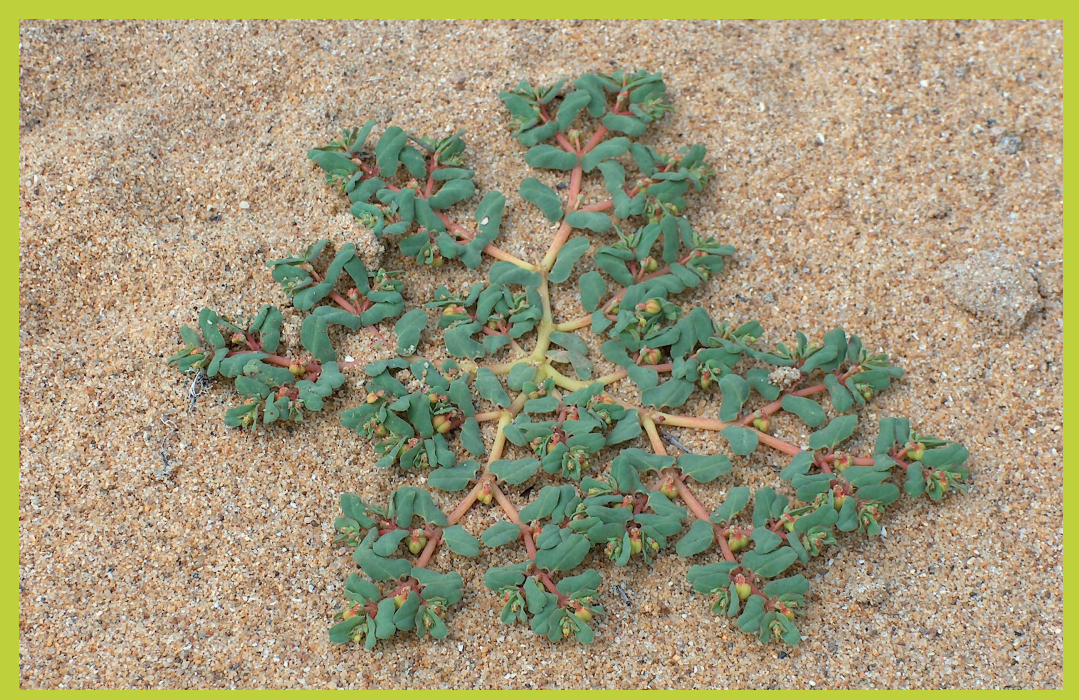

Figure 2.20. L'euphorbe peplis.

(c) L. Gouguet/ONF, Olonne, juillet 2004.

\section{Prendre en compte les risques naturels}

Boris Leclerc

La prévention des risques d'inondation et de submersion constitue un des domaines d'action majeurs de la prévention des risques naturels en France. Parmi les territoires exposés à de tels risques, les territoires littoraux ont pris une place importante du fait de leur développement souvent très dynamique et de leur exposition à un aléa supplémentaire, l'érosion côtière.

\section{Les enjeux de la prévention des risques sur le littoral}

\section{LES PRINCIPAUX FAITS MARQUANTS}

En 2010, près de 7,8 millions de personnes habitent en bord de mer (métropole et Dom), dont plus de 6,1 millions de métropolitains, soit près de $12 \%$ de la population métropolitaine sur $4 \%$ du territoire. La population passe à plus de 
14 millions d'habitants en période estivale, portant la densité de la population littorale à près de 2,5 fois plus que la moyenne de la métropole. Sur le plan touristique, 85 des 100 premières villes touristiques sont littorales et représentent une capacité d'accueil de 7 millions de lits.

Le littoral est soumis à des aléas d'inondation par submersion marine, de débordements de cours d'eau et d'estuaires ainsi qu'à des aléas de recul du trait de côte. Le risque d'inondation par submersion marine a été analysé à l'échelle du pays durant l'évaluation préliminaire du risque inondation, réalisée en 2011 dans le cadre de la mise en œuvre de la directive européenne relative à l'évaluation et à la gestion des risques d'inondation, dite " directive inondation »(DI 2007/60/CE du 23 octobre 2007). Cette évaluation a montré que 1,4 million de résidents permanents en métropole et 129000 dans les Drom (départements et régions d'outre-mer), ainsi que plus de 850000 emplois en métropole sont potentiellement exposés aux submersions marines. Ces aléas naturels peuvent également conduire à des risques de ruptures de digues et d'ouvrages de protection.

Les départements littoraux pourraient compter près de $40 \%$ de la population française d'ici 2040, générant des enjeux plus importants, mais aussi l'apport $d^{\prime}$ 'une population nouvelle, pas toujours familière des risques encourus sur le littoral. Le littoral est ainsi un espace soumis à des pressions très importantes (démographiques, économiques, écologiques), mais c'est avant tout un espace vivant et mobile qu'il s'agit de bien appréhender.

En métropole (hors Corse), sur les territoires où les tendances d'évolution passée ont pu être estimées, $22 \%$ des côtes sont en recul avec des vitesses variant de 0,1 à $8 \mathrm{~m} / \mathrm{an}$. Les côtes d'accumulation, notamment sableuses, sont les plus évolutives : $39 \%$ de ces environnements affichent des tendances en érosion contre $31 \%$ en accrétion. Leur vitesse de régression dépasse localement $3 \mathrm{~m} / \mathrm{an}$. Les côtes rocheuses aux matériaux plus consolidés constituent $68 \%$ des environnements à évolution non perceptible ( $\pm 0,1 \mathrm{~m} / \mathrm{an})$. En excluant ce type de côte et en ne tenant compte que des littoraux qui peuvent librement évoluer, ce sont alors $36 \%$ des côtes françaises qui subissent une érosion de 0,1 à 8 mètres par an.

\section{LA DIVERSITÉ DES ENJEUX À CONSIDÉRER}

Les politiques de prévention des risques poursuivent un objectif structurant, celui de préserver les vies humaines et, dans la mesure du possible, les biens. Outre la question des biens, d'autres enjeux sont présents sur le littoral. Certains sont particulièrement sensibles aux aléas littoraux ; sans viser l'exhaustivité, $c^{\prime}$ est le cas des réseaux et autres infrastructures de transport, du maintien des fonctionnalités des écosystèmes littoraux ou bien encore de la préservation de la qualité des paysages.

Sur ces points, il n'existe pas d'étude nationale à même de quantifier l'impact des aléas littoraux. À l'échelle des territoires à risques importants d'inondation, de premières valeurs peuvent être approchées. Environ $1000 \mathrm{~km}$ de routes principales sont susceptibles d'être touchées par une submersion marine de période de retour centennale. Ce sont plus de 13700 km qui pourraient l'être en considérant le réseau routier secondaire. S'agissant des voies ferrées, ce sont près de $470 \mathrm{~km}$ qui pourraient être impactés.

Toujours sur ces territoires particuliers, les approches utilisées indiquent que 250000 ha de zones Natura 2000 et 285000 ha de ZNIEFF seraient touchés. L'importance de ces chiffres ne doit pas faire oublier que, plus que pour les 
enjeux humains, la notion de résilience des milieux naturels est à souligner. En cela, les structures naturelles jouant un rôle de protection sont à protéger de toute urbanisation.

\section{LES GRANDS PRINCIPES NATIONAUX}

Sur le littoral comme sur l'ensemble du territoire national, la prévention des risques naturels a pour objectif de concilier au mieux développement territorial et maîtrise de la vulnérabilité face aux risques. Pour prévenir les risques littoraux, tous les piliers de la prévention des risques sont mobilisés : connaître, informer, surveiller, alerter, gérer les crises, protéger, aménager, tout en assurant la cohérence de ces actions entre elles à l'échelle du littoral.

La mise en œuvre de la directive inondation restructure progressivement la politique de prévention des risques et ses outils, avec une dynamique d'autant plus

forte sur le littoral qu'elle tire les enseignements de la catastrophe de la tempête Xynthia de février 2010 et s'appuie sur les actions du plan submersion rapide qui lui ont fait suite. La prévention des risques littoraux se fonde sur des responsabilités distinctes et des missions partagées entre État et collectivités territoriales. Risques littoraux et gestion intégrée du trait de côte doivent être appréhendés de manière coordonnée et cohérente avec la dynamique sédimentaire des systèmes littoraux. Aussi, la politique de prévention des risques littoraux repose pour partie sur la "stratégie nationale de gestion intégrée du trait de côte » (SNGITC), plan d'actions lancé en mars 2012 par le ministère de la Transition écologique et solidaire et renouvelé en 2017. Elle bénéficie également de la "stratégie nationale de gestion des risques d'inondation » (SNGRI) adoptée en 2014. Cette stratégie est déclinée sur chaque bassin hydrographique par les "programmes de gestion des risques d'inondation » (PGRI), puis à l'échelle des 122 " territoires à risque important d'inondation » (TRI), dont 34 TRI littoraux arrêtés dans le cadre de la mise en œuvre de la directive inondation.

Les zones naturelles ne doivent pas être oubliées des politiques de gestion du littoral. En cela, la poursuite de la réalisation de l'objectif du tiers naturel est également un objectif important pour la préservation des espaces naturels sur le littoral (choix de la France de préserver un tiers naturel de son littoral, notamment grâce à l'action du Conservatoire du littoral) face à une artificialisation et à une urbanisation de plus en plus importante.

\section{Limiter les enjeux pour prévenir les risques}

\section{LE PRINCIPE DES PLANS DE PRÉVENTION DES RISQUES LITTORAUX (PPRL)}

En matière de prévention des risques naturels, l'État fonde son action sur des enjeux de sécurité des personnes et des biens, mais également sur des objectifs de réduction des dommages aux biens et aux activités économiques par la réglementation des projets existants et l'encadrement des projets nouveaux sur le territoire communal.

Le titre VI du code l'environnement (article L. 562-1 et suivants), dans sa partie législative, complété par le titre VI de la partie réglementaire (article R. 561-1 et suivants), posent le cadre juridique d'action des services de l'État en matière de réalisation de plans de prévention des risques naturels.

L'article L. 562-1 du code de l'environnement pose le cadre général d'intervention du PPR :

« I.- L'État élabore et met en application des plans de prévention des risques naturels prévisibles tels que les inondations, les mouvements de terrain, les avalanches, les incendies de forêt, les séismes, les éruptions volcaniques, les tempêtes ou les cyclones. » 
Suite à la tempête Xynthia de 2010 et à ses conséquences dramatiques sur le littoral Atlantique, la circulaire du 27 juillet 2011 est venue compléter et préciser les règles applicables en matière de prise en compte du risque de submersion marine dans les plans de prévention des risques naturels littoraux. En effet, pour réaliser les 303 PPRL prioritaires identifiés, puis publiés en août 2011, et dans I'attente de la mise à jour de l'ensemble du guide méthodologique, la circulaire a posé un premier cadre méthodologique.

Parmi les apports majeurs de cette circulaire, on peut noter :

- la prise en compte des ouvrages de protection dans la dynamique de submersion ;

- la prise en compte des conséquences liées au changement climatique dans I'aléa de référence, mais également en anticipant les conséquences à plus long terme de l'aléa à échéance 100 ans (dit aléa 2100).

\section{LA DÉTERMINATION DES ALÉAS DANS LES PPRL}

Afin d'accompagner leur réalisation, la direction générale de la prévention des risques (DGPR) du ministère de la Transition écologique et solidaire en charge des risques a élaboré un nouveau guide méthodologique (DGPR, MEDDE, 2014) qui vient compléter la circulaire du 27 juillet 2011 relative à la prise en compte du risque de submersion marine dans les plans de prévention des risques naturels littoraux, en intégrant l'impact du changement climatique sur I'aléa "submersion marine » et en précisant les modalités de sa prise en compte dans les PPRL. Il y expose la démarche générale de réalisation d'un PPRL, la caractérisation des aléas considérés (submersion marine, recul du trait de côte, migration dunaire), leur qualification, l'étude des enjeux sur le territoire concerné et l'élaboration du dossier en lien avec le guide PPR général.

En matière de recul du trait de côte (érosion), les différentes méthodes de calcul du taux moyen de recul (Tx) sont présentées. De la même manière, le recul maximal (Lmax) suite à un événement majeur (tempête exceptionnelle) doit être quantifié en choisissant une méthode de type Fema (Federal Emergency Management Agency), Duros (érosion de dune), Kriebel (1985) ou Dean (1991). L'obtention de ces deux valeurs Tx et Lmax permet de calculer l'aléa de référence à un horizon de 100 ans. Concernant la qualification de l'aléa submersion marine, elle se fait sur la base d'un niveau marin de référence, d'occurrence centennale, ou de l'événement historique s'il est supérieur. Afin de prendre en compte les évolutions du climat, le niveau marin de référence intègre $20 \mathrm{~cm}$ d'augmentation du niveau d'eau et $60 \mathrm{~cm}$ à l'horizon 2100 . Ces valeurs proviennent du scénario intermédiaire établi par le Giec (Groupe d'experts intergouvernemental sur l'évolution du climat) et repris comme hypothèse pessimiste par l'Onerc (Observatoire national sur les effets du réchauffement climatique).

L'impact de l'aléa 2100 porte sur les prescriptions pour les nouvelles constructions et le caractère inconstructible $d^{\prime}$ une zone non urbanisée en aléa actuel nul, mais en aléa 2100 fort. En revanche, les zones urbanisées ne sont pas rendues inconstructibles sur la base de cet aléa (lesquelles sont déterminées sur la base de l'aléa actuel). Trois niveaux de zonage découlent du niveau de l'aléa (faible, modéré, fort/très fort). Ils déterminent la portée des mesures que le règlement doit prendre en matière de maîtrise de l'urbanisation. Cela peut conduire à l'inconstructibilité sur certains secteurs soumis à des niveaux d'aléas élevés. Lorsqu'ils sont plus faibles, le règlement porte davantage sur des mesures de réduction de vulnérabilité par adaptation du bâti (zone refuge, surélévation des compteurs...). 
UN OUTIL DE SYNTHÈSE ET D'ACTION : LA STRATÉGIE LOCALE

Bien que reposant sur des outils éprouvés, la politique de prévention des risques littoraux a été profondément rénovée suite à la tempête Xynthia. Face à des contraintes particulièrement concentrées et complexes sur les littoraux, les responsables locaux sont encouragés à développer des stratégies adaptées à leur territoire pour permettre un développement harmonieux et sûr des communes et des territoires concernés.

La politique de prévention des inondations a proposé des outils opérationnels avec le développement de stratégies locales de gestion du risque inondation. Ces stratégies mises en œuvre sur des territoires exposés à des risques importants doivent conduire à un diagnostic de la vulnérabilité de ces territoires. Ce diagnostic réalisé à l'échelle intercommunale permet, une fois partagé, de déboucher sur un programme d'action. Ces programmes peuvent prendre la forme d'un programme d'actions de prévention des inondations (Papi) qui permet de financer un ensemble cohérent d'actions sur un territoire et d'encourager l'émergence de gestionnaires des ouvrages de protection sur ce territoire.

À l'échelle locale, le dispositif de labellisation Papi, mis en place par l'État en 2011, succède à une première génération lancée en 2002. Les Papi permettent d'aider les collectivités territoriales dans la réalisation de leurs projets de prévention des inondations, dès lors que ces projets respectent le cahier des charges Papi. Ce cahier des charges est structuré en sept axes qui visent à traiter le risque inondation de manière globale, à travers des études et des actions combinant la gestion de l'aléa (réhabilitation des zones d'expansion des crues, ralentissement dynamique, ouvrages de protection...), et la réduction de la vulnérabilité au sens large des personnes, des biens et des territoires. Un nouveau cahier des charges est mis en place à partir de janvier 2018. Les programmes proposés par les collectivités sont étudiés par la commission mixte inondation, chargée du pilotage de la politique nationale de prévention des inondations.

En dehors de ce cadre, certaines collectivités initient des stratégies locales de gestion du trait de côte. Ces stratégies sont destinées à n'en former qu'une en cas de risque inondation sur le littoral. Il est probable que ces démarches se multiplient à l'avenir dans un souci d'intervention concertée et cohérente des pouvoirs publics face aux risques littoraux.

\section{Les cordons dunaires dans les systèmes de protection}

\section{LE RÔLE DES CORDONS DUNAIRES}

Les "structures naturelles", ou éléments naturels de protection contre les aléas côtiers, désignent ici l'ensemble des entités géomorphologiques ou topographiques naturellement présentes sur le littoral et susceptibles d'atténuer les effets des aléas de submersion marine et de recul du trait de côte lorsqu'ils surviennent. Les cordons naturels, qu'ils soient dunaires ou de galets, font partie de ces éléments naturels pouvant assurer une protection. Leur évolution morphologique est dynamique et s'adapte en permanence aux forçages météorologiques et hydro-sédimentaires (MEDDM, 2010). Cette adaptation continuelle s'effectue dans les trois dimensions par des modifications de hauteur, de largeur et de position. Elle est souvent dépendante de la morphologie initiale (Bruzzi, 1999 ; Claudino-Sales et al., 2008 ; Sabatier et al., 2008 ; Debaine et Robin, 2012 ; Houser, 2013). Les rythmes d'évolution vont de l'événement tempétueux à l'évolution séculaire en passant par le cycle saisonnier annuel d'engraissement et de démaigrissement. 


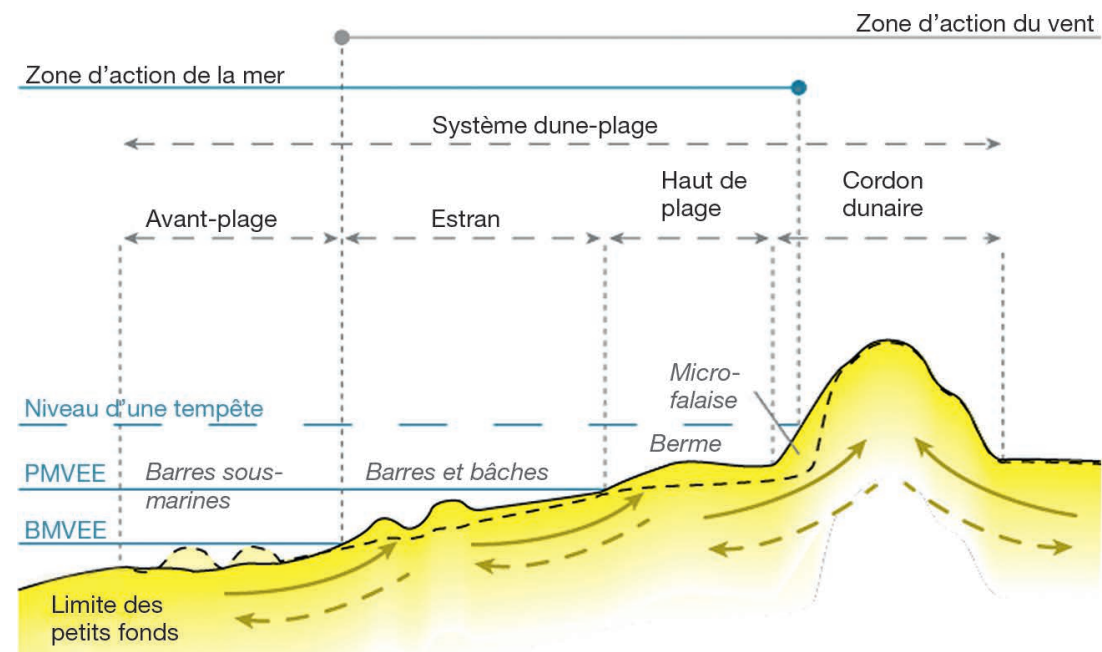

- Profil de plage d'été

$\longrightarrow$ Transits sédimentaires positifs

- - - Profil de plage d'hiver
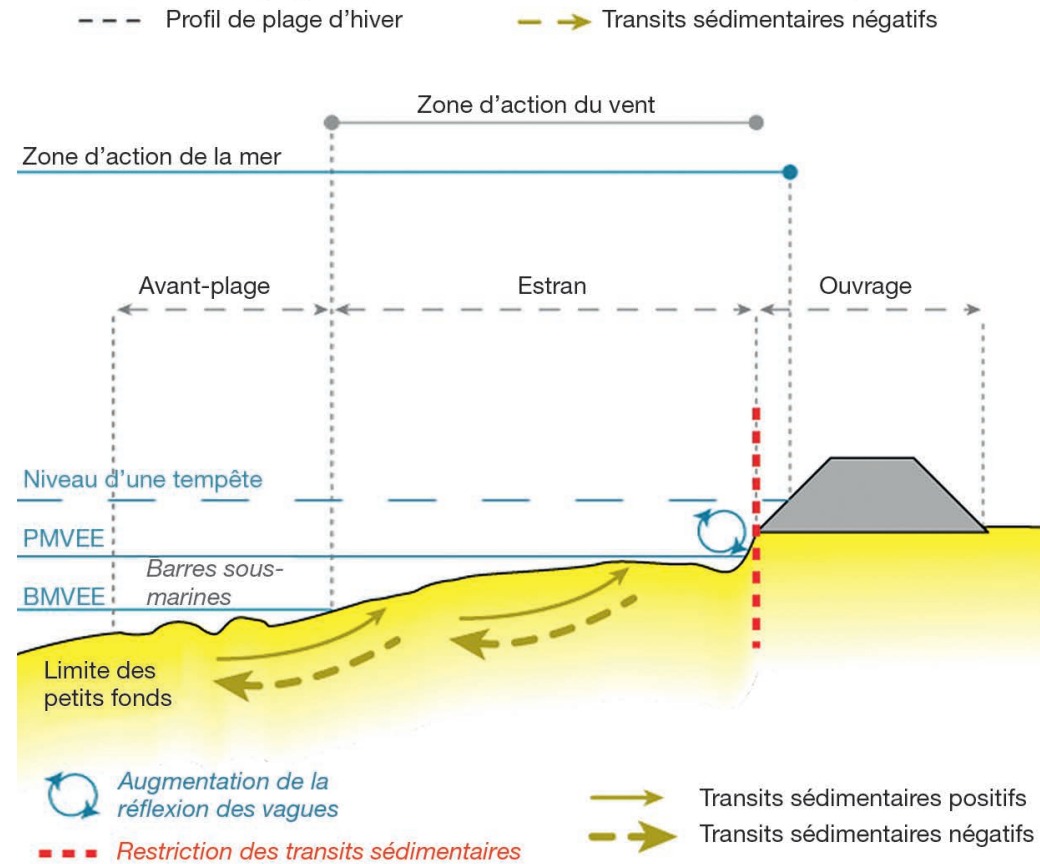

Figure 2.21. Transits sédimentaires transversaux sur un système dune-plage.

PMVEe : pleine mer de vive-eau exceptionnelle ; BMVEe : basse mer de vive-eau exceptionnelle.

Source : R. Perrot/ONF d'après B. Leclerc.

Le cordon dunaire naturel est un composant du système dune-plage qu'il forme avec l'estran et l'avant-plage le précédant. Ce système rassemble la majeure partie du stock sédimentaire littoral et joue plusieurs rôles directs et indirects face aux aléas de recul du trait de côte et de submersion marine (Bruzzi, 1999 ; Claudino-Sales et al., 2008 ; Gouguet, 2011), tels que :

- la dissipation de l'énergie hydrodynamique sur la côte ; 
- la participation à la résilience du littoral grâce aux échanges sédimentaires internes au système (réalimentation en stock sableux de la plage après le passage de tempêtes, puis reconstruction dunaire à partir de la plage) ;

- la protection de zones basses en arrière-littoral contre la submersion marine.

Le caractère naturel du système dune-plage est essentiel pour permettre les libres-échanges sédimentaires entre les différentes parties du système (cordon dunaire/haut de plage/estran-plage/avant-plage, figure 2.21). Tout élément anthropique pérenne positionné entre la plage et le cordon bordier perturbe ces échanges et diminue la capacité de résilience du système. À ce titre, tout cordon aménagé durablement par des ouvrages fixes ne pourra pas être considéré comme naturel mais anthropisé à des degrés divers allant du cordon "perreyé » au cordon entièrement urbanisé avec présence de voies de circulation et d'habitations.

PRISE EN COMPTE DES CORDONS DANS LA PRÉVENTION DES RISQUES LITTORAUX

La prise en compte des structures naturelles (ici les cordons naturels) comme élément de protection, dans le cadre de la prévention des risques littoraux et plus particulièrement des PPR, pose de nombreuses interrogations liées à la nature, à l'évolution et aux comportements particuliers de ce type d'objet morphologique du littoral. Sur le plan de l'aléa recul du trait de côte, les cordons naturels constituent un stock mobilisable lors des événements hydrosédimentaires érosifs, qui pourra éventuellement se reconstituer naturellement dans des conditions de plus faible agitation. La caractérisation de l'aléa recul du trait de côte dans ce contexte très évolutif implique donc d'étudier, à différentes échelles de temps et d'espace, la dynamique de cette entité morphologique particulière.

Par ailleurs, si les cordons naturels, séparant des zones terrestres topographiques basses de la mer, peuvent protéger contre la submersion marine en limitant les entrées d'eau, en atténuant l'énergie des vagues et en servant de zone d'expansion potentielle des débits franchissants, ils peuvent également aggraver les

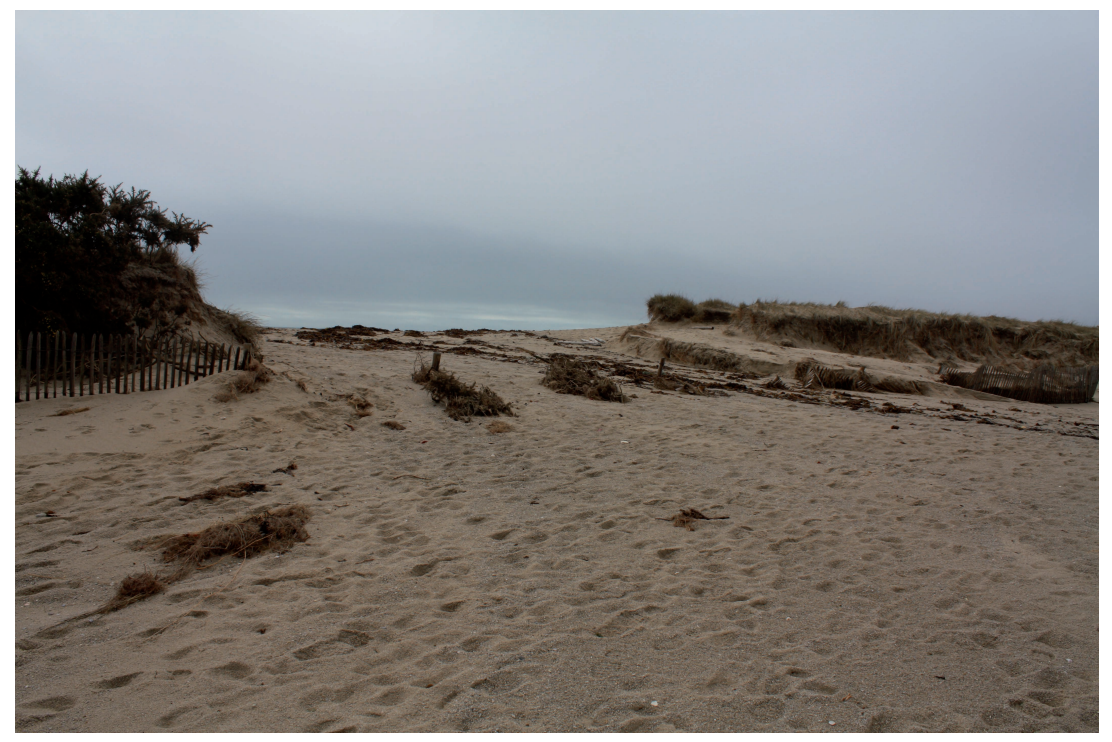

Figure 2.22. Brèche dans le cordon dunaire de Mousterlin (Finistère).

(C) L. Gouguet/ONF. 
phénomènes du fait des entrées d'eau générées par leur disparition brutale, partielle (brèche) ou totale (arasement) lors d'un événement tempétueux. Une des difficultés majeures réside dans l'identification et la prise en compte des points de faiblesse de ces structures naturelles en constante évolution. Au-delà des points bas topographiques, premières portes d'entrée de la submersion, une réflexion doit ainsi être menée sur la prise en compte de l'évolution des volumes sédimentaires mobilisables lors des événements météo-marins tempétueux. Le comportement de ces éléments naturels de protection du littoral se caractérise donc par des relations très étroites entre les phénomènes d'érosion et de submersion, ce qui rend complexe la détermination de critères de ruines, de brèches ou d'arasement pour la cartographie de l'aléa submersion.

\section{La compétence Gemapi et LA PRISE en COMPTE des CoRdons dUNAIRES}

Au-delà des cartographies d'aléas, l'intégration de structures naturelles, telles que des cordons dunaires, comme élément de protection d'un système d'endiguement impliquerait, pour garantir la sécurité des personnes, la définition d'un cadre de gestion adapté à ces entités à grande variabilité spatiale et temporelle.

La compétence Gemapi est définie par les 4 alinéas suivants de l'article L. 211-7 du code de l'environnement. Dans le cadre de cette nouvelle compétence, le décret $n^{\circ}$ 2015-526 du 12 mai 2015 relatif aux règles applicables aux ouvrages construits ou aménagés en vue de prévenir les inondations et aux règles de sûreté des ouvrages hydrauliques, dit décret digues, clarifie la place des cordons dunaires dans les systèmes d'endiguement.

Il stipule que :

"Ne sont toutefois pas inclus dans le système d'endiguement les éléments naturels situés entre des tronçons de digues ou à l'extrémité d'une digue ou d'un ouvrage composant le système et qui en forment l'appui. »

En confiant aux établissements publics de coopération intercommunale (EPCI) à fiscalité propre, déjà en charge de l'aménagement de leurs territoires, le soin de mettre en œuvre la compétence " gestion des milieux aquatiques et prévention des inondations »(Gemapi), le législateur a souhaité donner aux collectivités territoriales, parmi d'autres compétences locales importantes, les moyens d'une politique d'aménagement, au niveau local, intégrant la prévention des risques d'inondation. Dans le cadre de la compétence Gemapi qui a été confiée aux $\mathrm{EPCl}$, ceux-ci auront la possibilité de définir avec précision celles de leurs actions qui $s^{\prime}$ inscrivent dans cette compétence. II n'en demeure pas moins que leurs interventions ne se limiteront pas aux seules actions de cette compétence et qu'ils pourront, à juste titre, y intégrer les différentes démarches et compétences qui s'appliquent sur le littoral. La compétence Gemapi est composée des missions visées aux alinéas $1^{\circ}, 2^{\circ}, 5^{\circ}$ et $8^{\circ}$ du I de I'article L. 211-7 du code de I'environnement.

L'alinéa $5^{\circ}$ portant sur la défense contre la mer doit être interprété comme englobant, notamment pour les côtes basses, les opérations de gestion intégrée du trait de côte contribuant à la prévention de l'érosion des côtes, notamment par des techniques dites "souples » mobilisant les milieux naturels, ainsi que des techniques dites "dures » qui contribuent à fixer le trait de côte ou à ralentir son évolution. Par ailleurs, I'alinéa $8^{\circ}$ du I de I'article L. 211-7 vise la protection et la restauration des sites, des écosystèmes aquatiques et des zones humides, ainsi que des formations boisées riveraines. Or le littoral comporte $d^{\prime}$ importantes zones humides et milieux aquatiques littoraux. Les actions de gestion du trait de côte peuvent également porter sur les actions en lien avec la gestion de ces milieux qui contribuent notamment à maintenir leurs 
fonctionnalités en termes d'atténuation des effets du recul des côtes. Ainsi, la compétence Gemapi confiée aux collectivités territoriales intègre bien la gestion de tous les ouvrages naturels ou artificiels de défense contre la mer destinés à sauvegarder les territoires des effets des submersions marines ou des reculs du trait de côte. L'objectif est donc de favoriser la bonne coordination des actions appelées à être mises en œuvre sur un même territoire en faveur de la prévention des risques d'inondation et de submersion marine, de la gestion des milieux aquatiques et de la gestion du trait de côte.

La prévention des risques littoraux se fonde de plus en plus sur les fonctionnalités des écosystèmes. La connaissance de ces milieux ainsi que la compréhension de leurs mécanismes d'évolution demeurent encore à approfondir. Anticiper la défaillance des cordons dunaires face à un événement exceptionnel constitue encore un défi même si des travaux ont déjà été initiés par l'ONF et le Cerema.

\section{Les dunes face aux tempêtes}

On ne peut évoquer les dunes et les risques naturels littoraux sans parler de ce qui a pu se dérouler dans le passé, ni sans envisager ce que pourrait être l'avenir, à la lumière des connaissances scientifiques actuelles.

\section{Le cas aquitain : protection et vulnérabilité, $\mathrm{XIX} \mathrm{e}^{\mathrm{e}} \mathrm{XX} \mathrm{e}^{\mathrm{e}}$ siècles}

\section{Emmanuel Garnier}

Les dépouillements dans les archives de la Gironde indiquent que 23 tempêtes frappèrent les systèmes dunaires aquitains entre 1840 et 1940. Les descriptions des dommages contenues dans les documents autorisent un classement en fonction d'une grille d'indices de vulnérabilité élaborée dans le cadre du programme européen FP 7 "Resilience-Increasing Strategies for Coasts - toolKIT » (Garnier et al., 2017).

Sur un total de 23 tempêtes à I'origine de dégâts jugés suffisamment graves pour faire l'objet d'expertises et de campagnes de réparations, près de $30 \%$ concernent des aléas de forte intensité compris entre les indices 4 et 5 qui donnèrent lieu à de dispendieux travaux de remise en état. Parmi ces événements extrêmes particulièrement sévères, la figure 2.23 indique que le paroxysme tempétueux concerna la période des années 1920-1930 avec quatre catastrophes de grande ampleur respectivement en 1924, 1927 et 1934, qui affectèrent d'ailleurs l'ensemble du littoral atlantique.

Comme l'affirment les rapports, la « situation à peu près stable de la côte n'a véritablement commencé à inspirer des inquiétudes graves qu'à partir du raz de marée du 9 janvier 1924 ». Il amena des modifications profondes dans les fonds sous-marins à l'embouchure de la Gironde, spécialement dans les bancs entre lesquels s'ouvre la passe du sud, de telle sorte que la mer venait désormais frapper, avec une violence nouvelle, la zone des dunes comprise entre le sud de Soulac et l'épi Saint-Nicolas, l'un des ouvrages de la pointe de Grave.

Lors de la tempête des 18-19 novembre 1927, les dunes du front de mer de Soulac furent considérablement "rongées » et plusieurs immeubles et habitations en partie écroulés en raison du recul dunaire. L'ingénieur du port de 


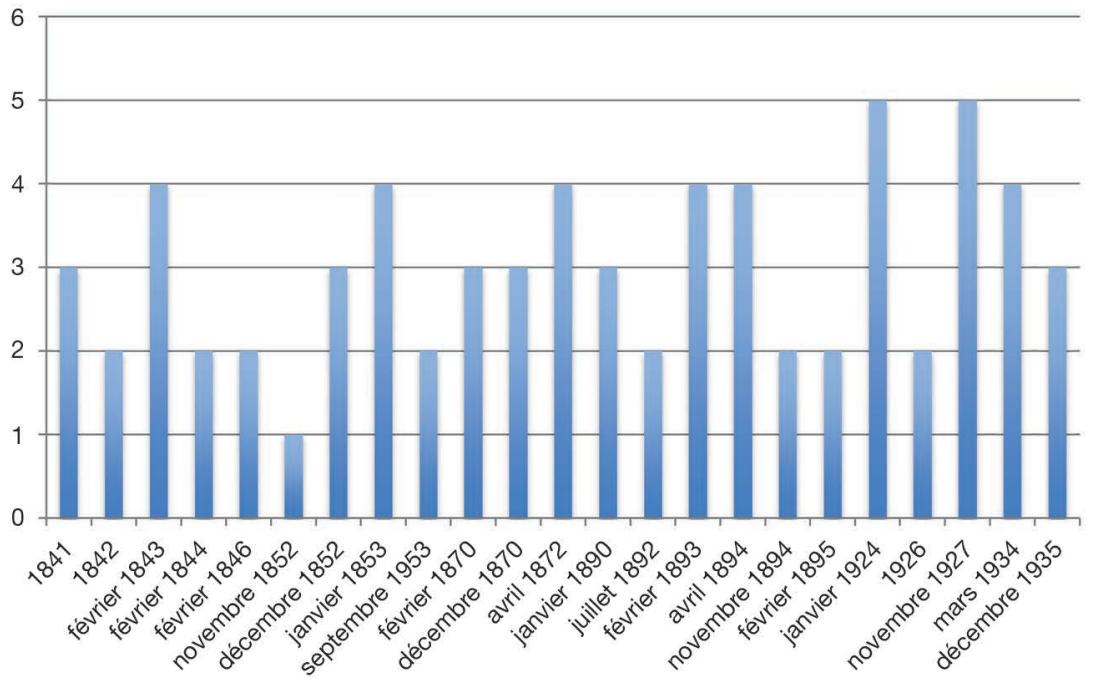

Figure 2.23. Tempêtes à I'origine de dommages (érosion, rupture de digues, recul du trait de côte, submersion) recensées dans les archives entre 1840 et 1940.

À chaque tempête est alloué un indice de sévérité.

Source : E. Garnier/CNRS

Bordeaux en charge de l'expertise des dommages déclare pour sa part qu'outre une brèche d'environ 120 mètres dans les digues des Huttes, les lames déferlaient sur les ouvrages à des hauteurs d'une vingtaine de mètres et qu'elles firent reculer la dune d'au moins 8 mètres. Dans son rapport adressé aux autorités, il ne peut s'empêcher de souligner le caractère très préoccupant de la situation en ces termes :

"Or, à ce point [Soulac], il ne reste plus d'autres cordons de dunes élevés à franchir avant de retomber dans la partie sud de la grande cuvette intérieure du Bas-Médoc. »

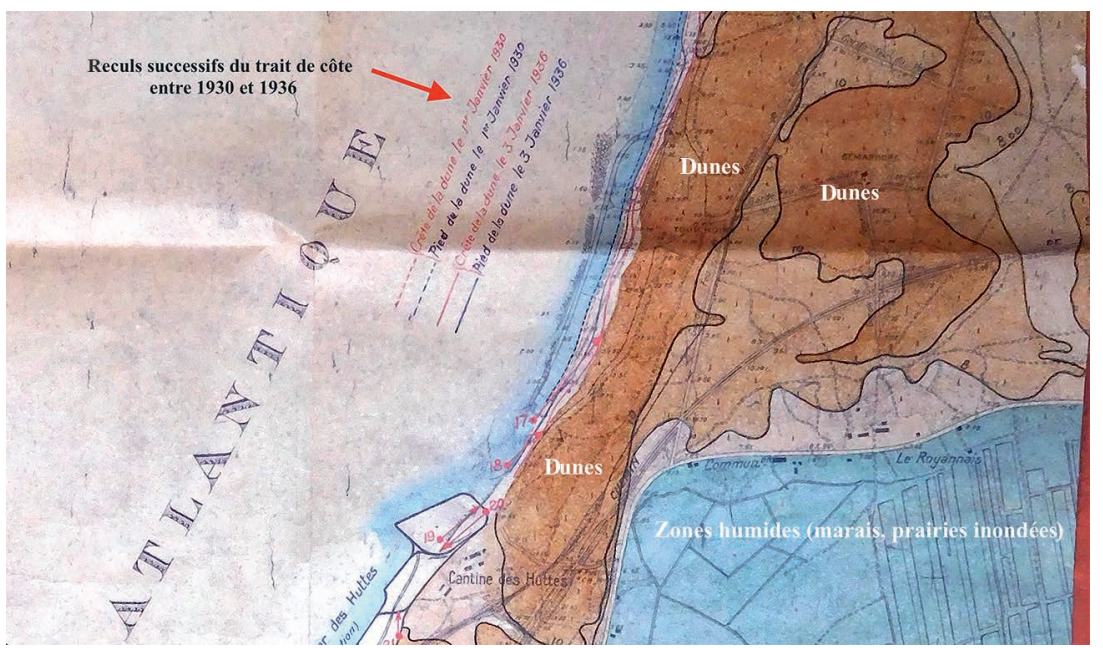

Figure 2.24. Carte au $1 / 10000^{\mathrm{e}}$ du littoral du Bas-Médoc indiquant successivement le système dunaire, les zones humides, ainsi que les reculs successifs du trait de côte après les tempêtes des années 1930.

Source : 2002/086 Archives départementales de la Gironde. 
À titre de comparaison, l'épisode exceptionnel des huit fortes tempêtes qui ont frappé le littoral aquitain pendant I'hiver 2013-2014 avait entraîné un recul de la côte d'environ 10 mètres. Ce retrait, jugé exceptionnel, faisait d'ailleurs dire au BRGM d'Aquitaine, "nous n'avons pas trouvé d'exemple comparable dans notre base de données, qui existe depuis 1958 » (Le Monde du 21 novembre 2014). Cette déclaration montre à l'envi tout l'intérêt d'une approche historique digne de ce nom, autrement dit inscrite dans le temps long, pour appréhender la réalité chronologique de ces phénomènes trop souvent qualifiés " d'inédits ».

Phénomène général, le mouvement de retrait brutal des années 1920-1930 remet en cause le développement urbain de la ville de Soulac-sur-Mer, ainsi que de toute la zone située sur la côte nord. La presse régionale se fait largement l'écho de ce bouleversement par des articles aux titres pour le moins catastrophistes qui ne sont d'ailleurs pas sans rappeler les manchettes du journal Sud-Ouest au lendemain des tempêtes hivernales de 2014. Ainsi, le journal La Petite Gironde sort son numéro du 23 mai 1934 sous le titre "La presqu'île du Bas-Médoc est-elle destinée à disparaître d'ici quelques années? ».

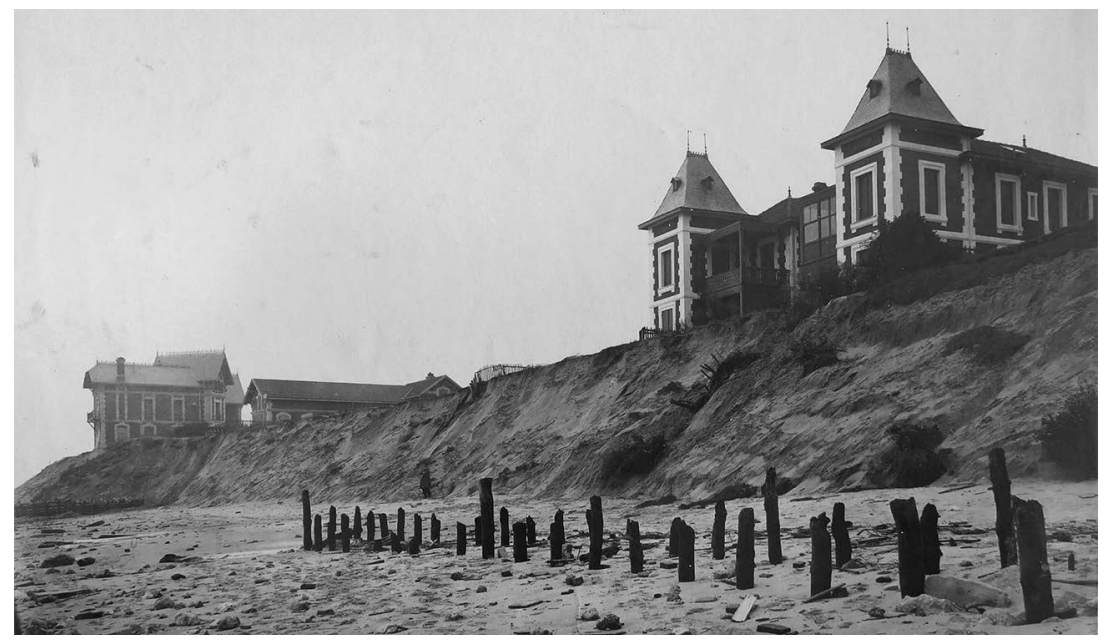

Figure 2.25. Recul de la dune à Soulac après les tempêtes de novembre 1926. Les villas installées au plus près de la plage sont directement menacées d'effondrement. Source : 2002/086 Archives départementales de la Gironde.

Les habitants de I'agglomération sont encore plus préoccupés par le caractère inédit de la situation, eux qui voient leur habitat construit sur les dunes menacé directement d'être englouti par les flots. À cet égard, emblématique est le rapport de l'ingénieur des Ponts et chaussées Lévêque, expert affecté en 1926 à la reconnaissance des avaries causées par les tempêtes aux ouvrages de la pointe de Grave et au front de mer de Soulac-les-Bains :

« II est tout naturel que ce soient les habitants de Soulac qui se soient ému les premiers, car la chute d'immeubles jusqu'alors en sécurité, construits depuis longtemps sur la dune, comporte en elle une émotion beaucoup plus vive et plus compréhensible, que la perception d'un recul de quelques dizaines de mètres d'une dune violemment corrodée, mais non habitée. Cependant, le phénomène est le même. Bien que le péril soit moins imminent que devant une agglomération, il n'en reste pas moins que sa gravité est tout aussi sérieuse, tant dans la partie de côte comprise entre Soulac-sur-Mer et les ouvrages de pointe de Grave, que dans la zone des Huttes déjà défendues par l'État, et où les ouvrages ont été bouleversés en 1924, en 1925 et en novembre dernier d'une manière malheureusement si importante. » 


\section{D'après le cinquième rapport du Giec,}

« il est extrêmement probable que l'influence de l'homme est la cause principale du réchauffement observé depuis le milieu du xxe siècle.

On détecte l'influence des activités humaines dans le réchauffement de l'atmosphère et de l'océan, dans les changements du cycle global de l'eau, dans le recul des neiges et des glaces, dans l'élévation du niveau moyen mondial des mers et dans la modification de certains extrêmes climatiques."

Les cordons dunaires de notre littoral actuel sont I'héritage de processus anciens, dont notamment les variations du niveau marin. Alors que l'océan était environ 120 à 130 mètres plus bas qu'actuellement, la fin de la période glaciaire, il y a 18000 ans, a vu débuter une plus ou moins rapide remontée du niveau des mers. Cette variation a entraîné avec elle une partie du stock de sable déposé sur le plateau continental, sable qui s'est accumulé progressivement autour de la position du rivage actuel.

Le taux d'élévation s'est sensiblement stabilisé à environ $0,5 \mathrm{~mm} / \mathrm{an}$ au cours des 2-3 derniers millénaires jusqu'à la période la plus récente. Mais au $\mathrm{xx}^{\mathrm{e}}$ siècle, ce rythme s'est accéléré pour atteindre 1,7 [1,5 à 1,9] $\mathrm{mm} / \mathrm{an}$ entre 1901 et 2010, 2 [1,7 à 2,3] mm/an entre 1971 et 2010, et 3,2 [2,8 à 3,6] mm/an entre 1993 et 2010.

\section{... et l'avenir?}

\section{Loïc Gouguet}

Le même rapport du Giec ${ }^{15}$ souligne que la hausse du niveau des mers projetée au cours du xxl ${ }^{\mathrm{e}}$ siècle (les prévisions pour 2100 montrent que cette hausse pourrait atteindre près d'un mètre), mais aussi au-delà de 2100, aura un impact très important sur les systèmes côtiers, avec une multiplication des phénomènes de submersion, d'inondations côtières et d'érosion des côtes.

Les modélisations actuelles ne permettent pas de conclure à une augmentation de l'activité cyclonique globale dans les territoires ultramarins, mais d'après Météo France l'intensité maximum potentielle des cyclones pourrait cependant augmenter de 10 à $20 \%$.

Les modifications générales, telles que l'augmentation des températures moyennes, la potentielle augmentation des événements extrêmes (tempêtes, vagues de chaleur...), entraîneront une nécessaire adaptation des écosystèmes dunaires littoraux. Et plusieurs aléas peuvent déjà être identifiés.

L'aggravation des phénomènes d'érosion marine liée à l'évolution des événements extrêmes va entraîner une perte de terrains. On constate que certaines zones dunaires fixées au $x_{1 x}{ }^{e}$ siècle lors des phases d'apports de sable conséquents sont maintenant régulièrement en érosion sur la façade atlantique.

Sur l'île d'Oléron par exemple, la datation précise des différents dispositifs de fixation (les palissades) érigés du début du XIx $x^{e}$ siècle jusqu'à 1945 permet de constater l'érosion depuis le milieu du xxe siècle (figure 2.26). Cette érosion s'accompagne d'une reprise de l'érosion éolienne sur les littoraux sableux qui pourrait s'accélérer. Le contrôle de la végétalisation des cordons dunaires sera

15. Groupe d'experts intergouvernemental sur l'évolution du climat (http://www.ipcc.ch/home_languages_main_french.shtml). 
donc primordial pour éviter la remise en mouvement brutale de stocks de sable menaçant d'ensablement l'arrière-pays, et donc les infrastructures et l'urbanisation, mais aussi les forêts littorales.

Les risques de submersion des zones basses seront augmentés. On assiste déjà, lors de tempêtes, à l'envahissement de peuplements forestiers par la mer dans certaines îles du Centre Atlantique (Oléron en particulier).

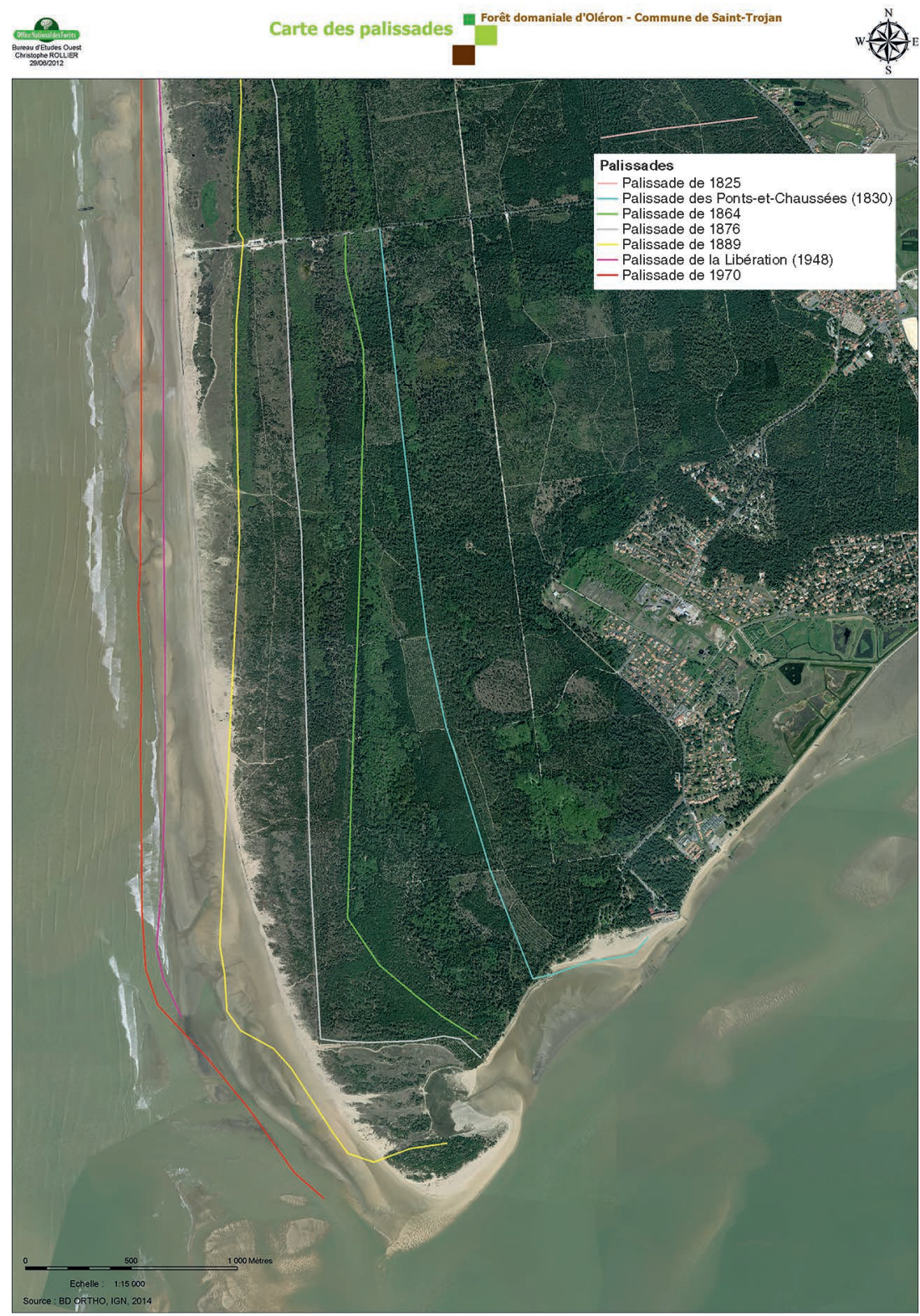

Figure 2.26. Sur le sud de l'île d'Oléron, les anciennes palissades (figurés de couleur) ont été édifiées au fur et à mesure de l'évolution de l'emplacement du trait de côte.

Source : C. Rollier/ONF. 


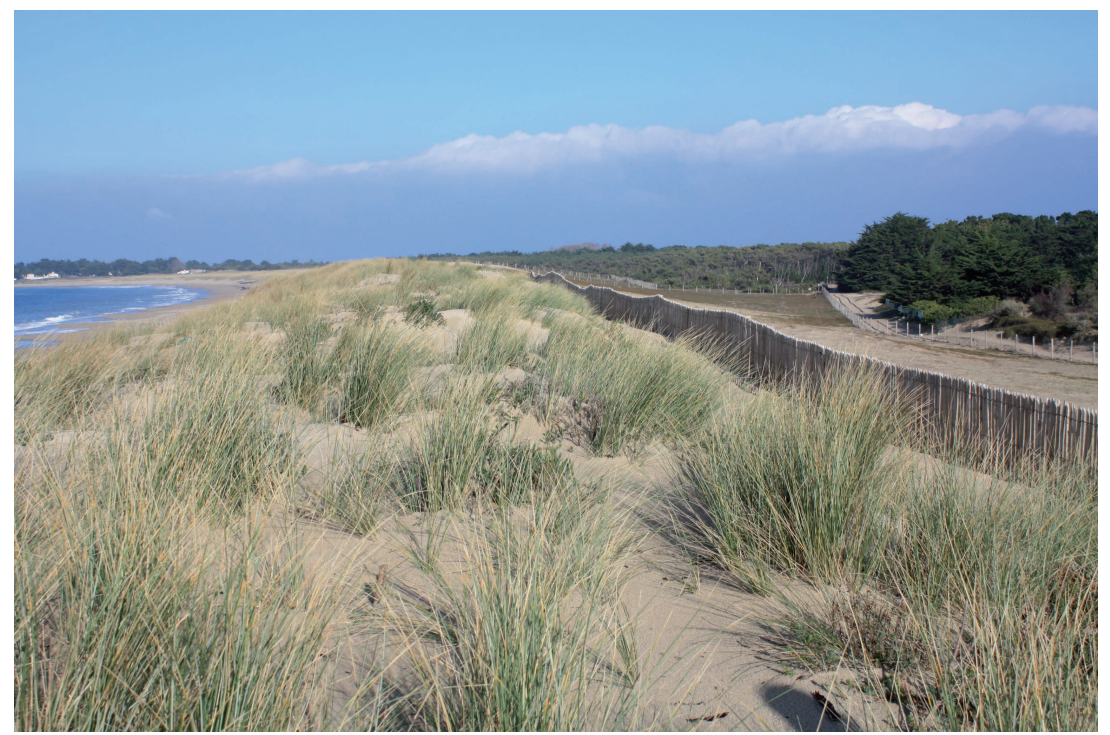

Figure 2.27. Cordon étroit protégeant une zone basse (Noirmoutier).

(C) L. Gouguet/ONF.

L'élévation du niveau de l'océan pourrait aussi se traduire par une remontée de la nappe d'eau salée dans les massifs dunaires, entraînant des dépérissements de la végétation en place, et donc une moindre fixation des sables par cette végétation.

De même, l'augmentation des températures et l'aggravation prévue des cycles de sécheresse auront un impact notable sur la végétation fixatrice qui devra s'adapter à ces modifications, sous peine de disparaître et donc de ne plus jouer le rôle attendu.

Les évolutions prévisibles liées au changement climatique exigent de la part des gestionnaires d'imaginer les conséquences directement sur le terrain et de prévoir des adaptations, et l'atténuation des effets négatifs prévisibles à long terme. Ainsi, que ce soit au niveau de la gestion des milieux naturels (gestion forestière, risques d'incendie...) ou au niveau des aléas littoraux (érosion, submersion...), une adaptation prudente doit être entreprise dès à présent. Il s'agit notamment de ne pas entreprendre d'actions pouvant entraver définitivement l'évolution des cordons dunaires, de ne pas obérer l'avenir et d'envisager les différents scenarii. 


\title{
Les modalités de gestion
}

\section{Acteurs et stratégies de gestion des dunes}

\author{
Patrick Bazin et Loïc Gouguet
}

Comme on l'a vu à travers la description des différents systèmes dunaires et de leur fonctionnement naturel, la principale caractéristique des dunes est leur mobilité, leur continuelle adaptation morphologique aux conditions de vent, de mer et de disponibilité sédimentaire. Or, la mobilité n'est pas un paramètre facile à gérer dans les territoires. Les politiques publiques comme les actions privées s'accommodent bien mieux de la stabilité ; aussi, lorsqu'il a été possible d'agir sur les dunes, l'objectif a bien été de les fixer afin de stopper la progression des sables vers l'intérieur des terres.

Cependant, les qualités des dunes en tant que système dynamique sont aujourd'hui mises en lumière. Face au changement climatique et à l'élévation du niveau de la mer, leur capacité à suivre les évolutions du trait de côte pourrait se révéler précieuse tandis que la fixité recherchée depuis deux cents ans deviendrait inadaptée, au moins dans certains contextes géographiques où des espaces de respiration existent en arrière des dunes. Les gestionnaires de sites et, plus généralement, les entités responsables de l'aménagement du territoire se retrouvent ainsi devant un défi de taille : comment concilier la mobilité avec les dispositifs classiques de gestion de l'espace?

Les dunes se retrouvent donc à la croisée de plusieurs enjeux, environnementaux, paysagers, touristiques et de gestion des risques, dans un contexte mouvant et pas toujours prévisible. Heureusement, elles disposent également d'atouts. Tout d'abord, leur notoriété et l'attachement que beaucoup de Français et d'Européens leur témoignent sont une chance que n'ont pas tous les milieux naturels. En second lieu, les dunes bénéficient le plus souvent d'un statut de propriété domaniale (publique ou privée), ce qui facilite la mise en œuvre de politiques coordonnées. Enfin, les pressions qui se concentrent sur le littoral sont porteuses de menaces mais aussi d'opportunités, car l'attention et les moyens se portent vers cette bande fragile à l'interface entre la mer et la terre, ouvrant des possibilités d'action nombreuses.

Comme il sera montré ci-après, les stratégies de gestion sont diverses en fonction de la configuration des lieux. La confrontation entre la mobilité et la stabilité prendra des formes variées. De même que chaque dune requiert un projet spécifique, le système dunaire doit être considéré au sein de l'ensemble territorial auquel il appartient et avec lequel il entretient de nombreuses relations fonctionnelles, dont le bon équilibre est le garant de la réussite du projet.

\section{Les principaux gestionnaires et propriétaires}

La domanialité est majoritaire dans la plupart des massifs dunaires de France. Les dunes domaniales gérées par l'Office national des forêts couvrent plus de 
70000 ha sur $380 \mathrm{~km}$ de côtes; elles représentent environ 12000 ha dans le domaine du Conservatoire du littoral et sont également nombreuses à appartenir à des communes. La surface totale des dunes maritimes (boisées et non boisées) était estimée à 142000 ha en 1928 (Perrin, 1928) et même à un peu d'avantage en 1999 (Favennec, 1999).

La gestion dunaire devient un objectif de la puissance publique à partir de la fin du XVIII ${ }^{e}$ siècle et du début du XIX ${ }^{\mathrm{e}}$ siècle. Entre cette période et 1860 , d'importants travaux de fixation des dunes sont menés afin de stopper la progression des sables vers l'intérieur des terres et de garantir le bon écoulement des eaux arrière littorales vers la mer. Près de 88000 ha de dunes sont ainsi végétalisés sur la côte atlantique pour fixer le sable, essentiellement par la plantation ou le semis d'oyat, et, partout où c'est possible, par l'installation de pin maritime, donnant naissance à un important massif forestier littoral exploité pour le bois et la résine.

Au cours de la première moitié du xxe siècle, la gestion sylvicole va perdre une partie de son intérêt économique, notamment du fait du déclin de l'exploitation de la résine et des difficultés de mécanisation liées au relief prononcé des dunes. Parallèlement, la gestion va intégrer les dimensions paysagères et d'accueil du public, tout en gardant son rôle premier de fixation du massif sableux.

L'apparition du classement juridique de "forêt de protection » (1922) confirme la volonté d'assurer la conservation des forêts dunaires (quel qu'en soit le propriétaire) reconnues comme nécessaires pour la défense contre les érosions et les envahissements des eaux et des sables. Ce terme évoque également, même s'il n'en a pas la signification juridique, la prise de conscience d'un patrimoine naturel et paysager à protéger pour le bien-être des populations. Cette nouvelle préoccupation devient particulièrement palpable avec l'essor du tourisme balnéaire.

En mettant en œuvre le contrôle de l'érosion éolienne pour le compte de l'État, à travers une mission d'intérêt général confiée par le ministère en charges des forêts, I'Office national des forêts assure l'entretien des dunes et la gestion des forêts dunaires. Les dunes et les forêts domaniales dunaires sont gérées dans un objectif de multifonctionnalité (protection, accueil du public, production). De plus, certaines zones à très forts enjeux écologiques font l'objet de classement en réserves biologiques; il en existe plusieurs réparties sur le littoral sableux, depuis Merlimont dans le Pas-de-Calais jusqu'à Mimizan dans les Landes, en passant par la pointe d'Arçay en Vendée et l'île d'Oléron en Charente-Maritime.

L'action foncière du Conservatoire du littoral, qui vient compléter celle beaucoup plus ancienne de l'État mise en œuvre par l'Administration forestière, met encore plus nettement l'accent sur la dimension naturelle et paysagère des sites acquis, boisés ou non, en mettant la production sylvicole au second plan. Les sites acquis par le Conservatoire sont gérés en majorité par les collectivités territoriales qui sont particulièrement attentives à leurs qualités paysagères et récréatives.

Les « espaces naturels sensibles » des départements sont aussi un outil de protection foncière des espaces dunaires. Mis en place par une loi de 1976, ce dispositif permet aux conseils départementaux de «préserver la qualité des sites, des paysages, des milieux naturels et des champs naturels d'expansion des crues et d'assurer la sauvegarde des habitats naturels ». Ce sont plus de 53000 ha (en 2006, Assemblée des départements de France, 2014) qui étaient protégés à ce titre dans les départements littoraux.

Ainsi, la propriété foncière et les modalités de gestion des dunes françaises jouissent d'une certaine stabilité dans le temps, qui tend à se renforcer avec 
I'accroissement de la part de propriété publique. Pour autant, les modes de gestion n'échappent pas aux évolutions de la société et prennent de plus en plus en compte la qualité environnementale dans leurs objectifs. La notion de protection contre les aléas naturels évolue aussi. Elle est plus présente que jamais mais pourrait changer de forme et d'ingénierie grâce à la recherche de nouvelles modalités d'utilisation des dunes comme rempart souple face à l'élévation du niveau de la mer. Ces modalités sont en germe dans les stratégies présentées ci-après, mais continueront à évoluer au fur et à mesure de l'accroissement des connaissances sur les changements globaux et le comportement géomorphologique des dunes, encore imparfaitement modélisable.

\section{Les stratégies de gestion}

\section{Jean Favennec et Philippe Richard}

La réflexion stratégique menée ici ne concerne pas les systèmes dunaires dans leur globalité, elle est centrée sur la partie la plus littorale des « champs de dunes »: la bande dunaire non boisée, dont le fonctionnement est corrélé à celui de la plage. C'est une bande relativement étroite sur laquelle les contraintes écologiques sont fortes (vents, sel...), et dotée d'une végétation basse adaptée à de constants réajustements.

Définir une stratégie de gestion, c'est définir les modalités d'action qui permettent d'atteindre un objectif. Mais pourquoi intervenir sur les dunes littorales? Quels sont les objectifs poursuivis?

Les premières interventions historiques visaient à fixer les dunes pour lutter contre le fléau que représentait l'envahissement des sables. De grands chantiers de fixation des dunes ont concerné presque tous les pays littoraux européens, en France principalement, au $\mathrm{xIx}^{\mathrm{e}}$ siècle. Les techniques de lutte contre la mobilité des sables ont fait leurs preuves sur ces « mers de sable » dont la majeure partie est aujourd'hui peuplée de forêt ou de pelouses diverses. C'est à l'occasion de ces chantiers que certains acteurs ont proposé de standardiser le mode de gestion de la dune bordière, toujours mobile, pour lui faire jouer un rôle de piège à sable empêchant de nouvelles incursions sableuses dans les dunes fixées. Ce fut, en Aquitaine principalement, la période des reprofilages, selon un profil aérodynamique considéré alors comme le meilleur garant d'efficacité et de durabilité.

Cet objectif de fixation, qui faisait l'unanimité au cours du xixe siècle et d'une grande partie du $x x^{e}$ siècle, est devenu aujourd'hui très marginal. Les dunes littorales, qui ont pourtant gardé une partie des caractéristiques de ces « déserts menaçants ", sont devenues aujourd'hui un habitat d'intérêt communautaire que l'on veut conserver à titre patrimonial. C'est ainsi qu'une des actions de réhabilitation mise en exergue en Europe du Nord-Ouest, principalement aux Pays-Bas, consiste à remettre en mouvement une partie de ces dunes littorales. Même si les surfaces concernées sont faibles, cette stratégie illustre bien le basculement des concepts.

Sous l'impulsion de quelques éclaireurs scientifiques, notamment les géographes Pierre Barrère et Roland Paskoff dans les années 1980, on a pris conscience de l'importance des relations entre plages et dunes, et de leur rôle majeur en termes de bilan sédimentaire. De façon plus récente, le système dune-plage est considéré comme un élément naturel susceptible de jouer un rôle de protection des côtes basses menacées par les risques de submersion. La dune littorale peut ainsi être considérée comme un milieu à protéger, ou comme un outil de protection, ou bien comme les deux à la fois. 


\section{De multiples choix stratégiques de gestion des dunes sont possibles}

La stratégie est fortement conditionnée par les objectifs des propriétaires ou des organismes de gestion, chacun donnant une importance variable aux différents services rendus par les dunes. Ainsi par exemple, sur un site dunaire classé réserve naturelle, la libre expression des processus pourra être privilégiée ; sur un site dunaire intra-urbain géré par une commune, un contrôle maximum de la mobilité sera recherché ; sur un site domanial géré par l'ONF, on visera à répondre conjointement aux différentes attentes sociales par des actions de " contrôle souple ».

Les stratégies sont par ailleurs fortement dépendantes des conditions régionales et locales, des processus dynamiques particuliers du secteur concerné (disponibilité en sable, vents, végétation...), de la pression anthropique, etc. C'est pourquoi les stratégies diffèrent en Atlantique et en Méditerranée, et entre sites en érosion et sites en accrétion.

Face à chaque situation particulière, il n'existe donc pas une seule stratégie, mais plusieurs choix possibles; ils émanent du croisement conjoncturel des connaissances techniques, des attentes et des modes de pensée de la société du moment. Les possibilités de choix seront plus ou moins ouvertes selon l'espace littoral dont on dispose pour que s'exprime la mobilité du système dune-plage, et aussi selon les moyens que la société consent à mettre dans leur gestion.

La définition de diverses stratégies de gestion des dunes peut s'établir à partir de plusieurs entrées : le degré de souplesse des choix, les propriétaires, les zones géographiques...

Nous proposons une approche s'appuyant sur le degré de naturalité du site dunaire concerné, classement qui permet d'établir une gradation de la stratégie, de la non-intervention à l'intervention lourde.

La typologie des dunes sur laquelle s'appuie notre réflexion stratégique est simplificatrice par rapport à la très grande diversité des situations, mais elle permet de structurer le raisonnement, elle est basée sur la distinction entre :

- les systèmes dunaires «naturels » : ce sont les moins influencés par les actions anthropiques passées et/ou actuelles. Ce type de situation peut exister quel que soit le bilan sédimentaire (érosion ou accrétion), il est assez peu fréquent.

- Les dunes gérées de façon souple : en France, comme à l'échelle européenne, la plupart des dunes littorales sont marquées depuis plusieurs siècles par un certain degré d'intervention humaine. Cependant, une grande partie de celles qui n'ont pas subi de destruction par l'urbanisation ont conservé une majorité des attributs vitaux, caractères fondateurs des dunes littorales : source de sable naturelle, pas de rupture entre plage et dune, possibilité de migration, développement notable des habitats potentiels, naturalité de la végétation... En dehors des zones urbaines, une majorité des dunes littorales métropolitaines se rattache à ce type, ce sont les dunes gérées qui ont gardé un grand degré de naturalité.

- Les dunes « urbaines » : ces systèmes dunaires tronqués ont perdu une grande partie des processus naturels fondateurs, ce sont souvent des éléments relictuels dissociés et fortement rudéralisés... Ce type comprend notamment les dunes, souvent étroites, qui séparent les plages urbaines et le bâti des villes balnéaires (par exemple Seignosse, Mimizan et Biscarrosse dans les Landes ; Lacanau, Carcans et Hourtin en Gironde ; Saint-Jean-de-Monts et Noirmoutier en Vendée ; Saintes-Maries-de-la-Mer, La Grande-Motte, Barcarès et Leucate en Méditerranée, etc.). Leur degré d'artificialisation est variable ; souvent, des murs ou des empierrements séparent plage et dune ; dans tous les cas, le système ne 
dispose plus de capacité de migration. Le degré de résilience de ces dunes est très faible, souvent nul.

\section{Les choix stratégiques s'appuient sur un diagnostic préalable}

L'établissement d'un état des lieux constitue un des fondements des choix stratégiques. Divers outils d'analyse (imagerie, relevés de terrain...) permettent de dresser une cartographie de l'état zéro, base de réflexion et outil d'évaluation ultérieure des actions réalisées. Les cartes écodynamiques, mises au point par les géographes de l'université de Bordeaux, peuvent être par exemple la clé de voûte de cette démarche (Prat et Barrère, 2002). Ce diagnostic préalable comprend plusieurs types d'examen, notamment :

- de la dynamique sédimentaire du site concerné, place dans la cellule sédimentaire,

- une identification claire des problèmes à traiter : nature, position et surface, - une définition de l'écosystème qui correspond le mieux aux objectifs poursuivis, paysage de référence construit à partir de situations locales considérées comme optimales,

- une estimation de l'impact potentiel de divers choix stratégiques et une comparaison avec l'absence d'intervention.

Le diagnostic préalable permet aussi de fonder un plan d'action qui décrit les techniques à mettre en œuvre, leur organisation spatiale et temporelle. II doit aussi prévoir le suivi et les entretiens ultérieurs au chantier proprement dit.

Examinons quelques types de choix stratégiques, par degré d'intervention croissant, en les croisant avec la typologie des dunes proposée précédemment (tableau 3.1).

Tableau 3.1. Représentation schématique des choix stratégiques de gestion selon les types de dunes.

\begin{tabular}{|l|l|l|l|l|}
\cline { 2 - 5 } \multicolumn{1}{c|}{} & \multicolumn{4}{c|}{ Type de stratégie } \\
\hline Type de dunes & $\begin{array}{l}\text { Dynamique } \\
\text { libre }\end{array}$ & $\begin{array}{l}\text { Contrôle } \\
\text { souple }\end{array}$ & $\begin{array}{l}\text { Contrôle } \\
\text { renforcé }\end{array}$ & $\begin{array}{l}\text { Interventions } \\
\text { lourdes }\end{array}$ \\
\hline Dunes «naturelles » & À privilégier & Concevable & & \\
\hline $\begin{array}{l}\text { Dunes gérées } \\
\text { (cas général) }\end{array}$ & À privilégier & & \\
\hline $\begin{array}{l}\text { Dunes gérées (zone } \\
\text { à risque submersion) }\end{array}$ & & Concevable & À privilégier & \\
\hline Dunes « urbaines » & & & Concevable & Souvent inévitable \\
\hline
\end{tabular}

- Dynamique libre. ce choix stratégique consiste à laisser se développer librement les processus dynamiques des dunes : érosion, transit et accumulation de sable, échange de sédiments entre la plage et la dune, progression ou régression de la couverture végétale, etc. C'est ce mode de non-intervention qui génère des dunes littorales «naturelles». Sur le territoire métropolitain français, on rencontre quelques sites de dune littorale en dynamique libre; ils peuvent résulter d'un choix volontaire ou d'une absence de gestion.

- Contrôle souple. c'est le choix stratégique dominant, notamment pour la gestion des dunes domaniales par l'ONF. Ce choix vise à concilier au mieux les différentes fonctions des dunes littorales et des plages qui leur sont associées, sans rupture des processus naturels qui génèrent des dunes de hautes biodiversité et géodiversité. 

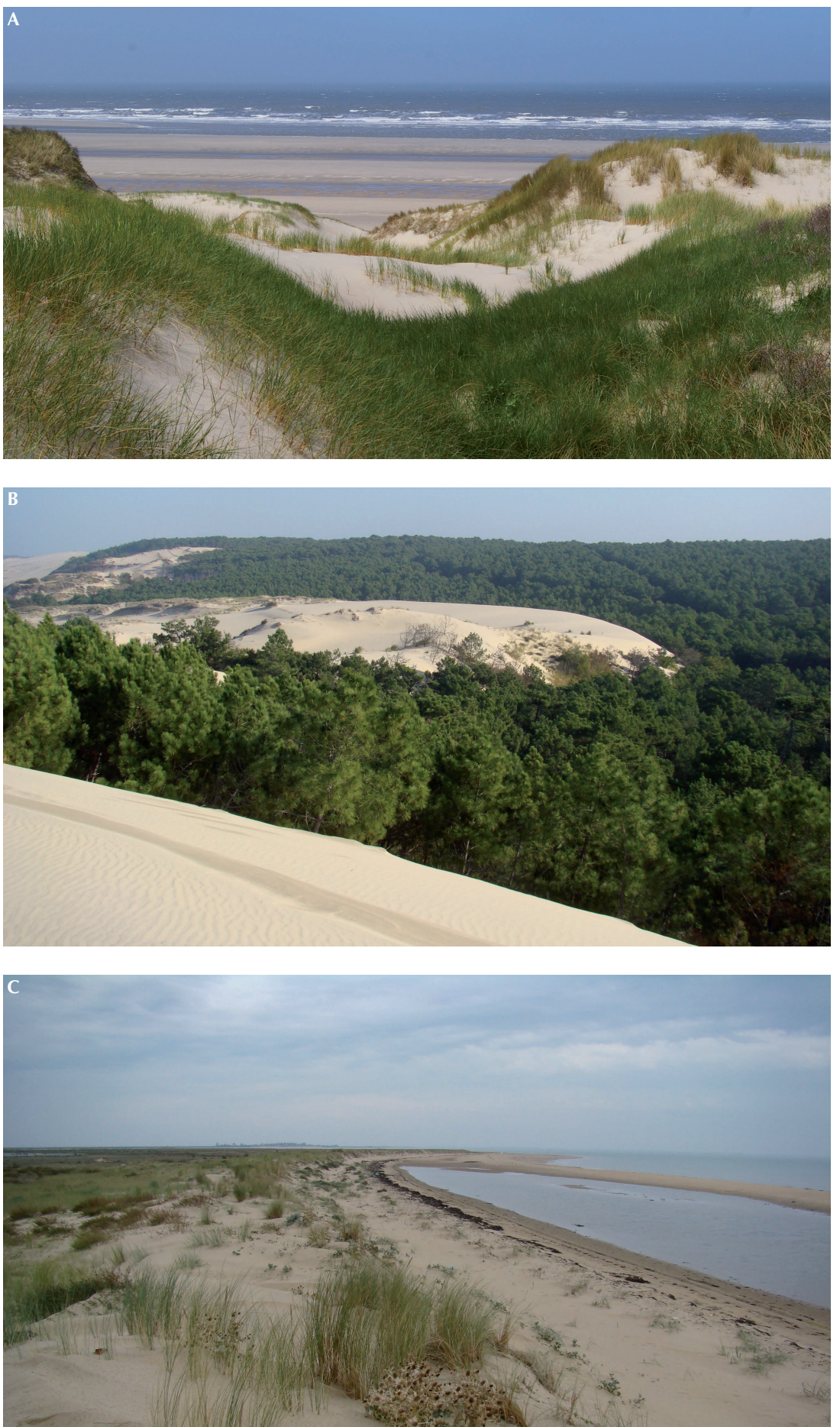

Figure 3.1. Illustration de différents sites de dunes " naturelles ». Systèmes de dunes " naturelles " résultant de choix volontaires.

A. Réserve biologique domaniale de la Côte d'Opale, Merlimont (Pas-de-Calais).

B. Sud de la dune du Pilat, La Teste (Gironde).

C. Réserve de la Pointe d'Arçay (flèche à pointe libre), Vendée. 

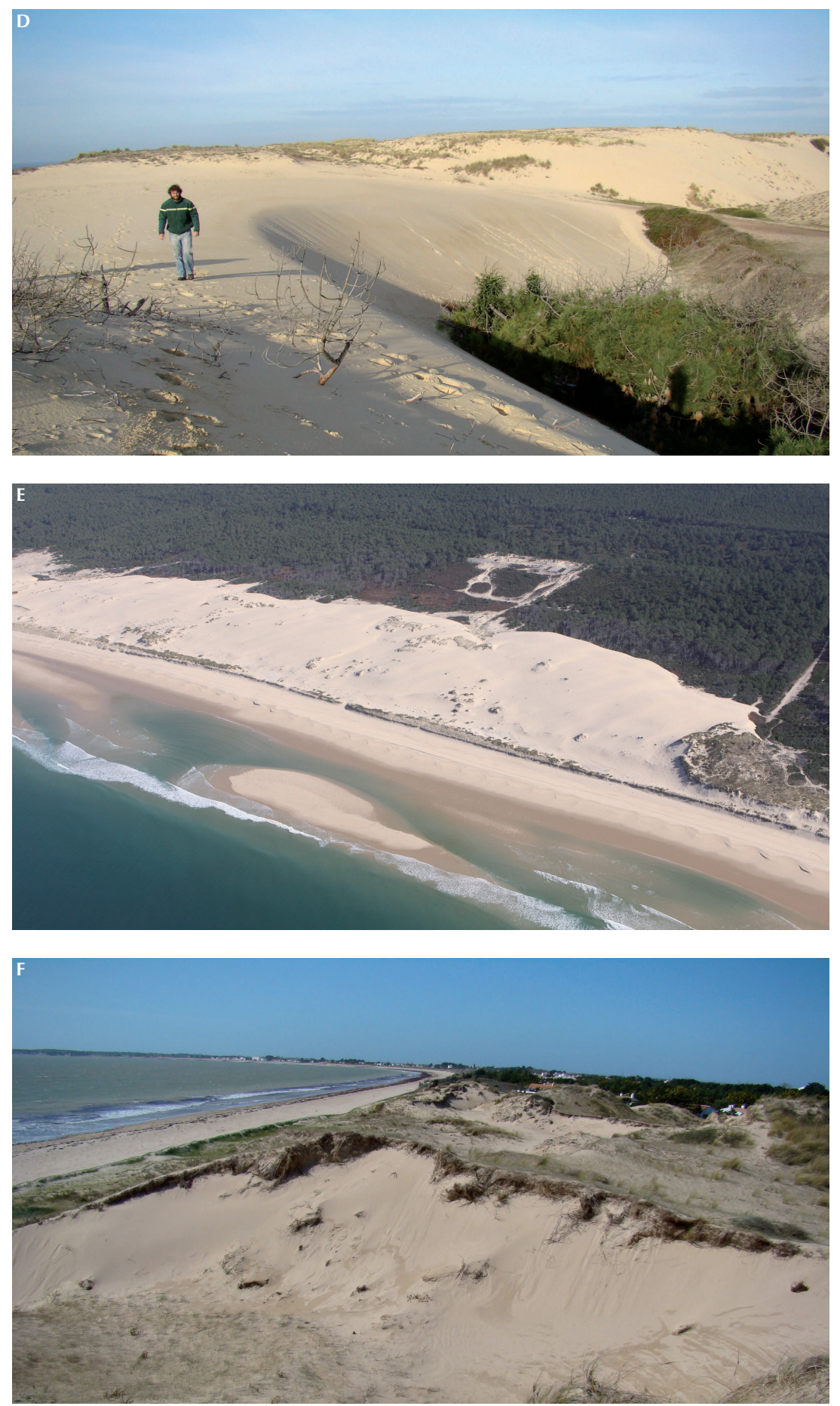

Systèmes de dunes « naturelles " résultant d'absence de gestion.

D. Dune communale du nord de Vieux-Boucau (Landes).

E. Dunes du Trencat, La Teste (Gironde).

F. Dunes de La Tresson, île de Noirmoutier (Vendée).

C J. Favennec/EUCC-France, sauf A ( ) F. Veille et D C M. Le Collen, OCA. 
- Contrôle souple renforcé. c'est une variante du contrôle souple lorsque, dans des situations particulières à risques pour les biens et les personnes, il est choisi de privilégier la fonction de protection par rapport à la biodiversité/géodiversité. Ce type de choix concerne notamment les systèmes dunaires étroits qui précèdent des zones basses avec risques de submersion.

- Interventions lourdes. cette dénomination générale regroupe de nombreux types d'intervention qui induisent tous une artificialisation des dunes avec souvent une perte, importante ou totale, de processus vitaux. II s'agit par exemple de : la création/re-création de cordons dunaires de défense construits avec des matériaux exogènes et qui ont perdu toute capacité de remobilisation ; de murs, $d^{\prime}$ enrochements, de tubes en géotextile... en pied de dune, avec rupture des échanges de sédiment entre plage et dune ; ou d'apports de terre et d'implantation de pelouses de type urbain.

Certaines interventions sont coûteuses, sans forcément entrer dans cette catégorie. Il peut s'agir par exemple de rechargements en sable des plages. Ce peut aussi être le cas de chantiers de remobilisation (rares en France) qui visent à "re-naturaliser » un système dont un processus vital, le mouvement de sable, ne fonctionne plus.

Toutes ces stratégies doivent s'inscrire dans un cadre de gestion raisonnée des stocks sédimentaires, question qui sera abordée par ailleurs.

\section{Stratégie de gestion des dunes " naturelles ॥}

Les dunes littorales naturelles sont des systèmes plus mobiles que les dunes gérées ; en général, les faciès de dune blanche, voire de dune vive (quasi sans végétation), y sont dominants, au détriment notamment des faciès de dune grise. On peut distinguer deux grandes catégories de dunes "naturelles », celles qui émanent d'un choix raisonné de non-intervention, et celles qui résultent d'une absence de gestion (figure 3.1).

Dans le premier cas, le choix stratégique de dynamique libre a vocation à être poursuivi, ce n'est que dans le long terme qu'il peut être évalué. Les plans de non-intervention programmée concernent en général des espaces protégés par divers statuts réglementaires : réserves naturelles, sites Natura 2000, réserves biologiques domaniales, sites du Conservatoire du littoral. Ce choix n'est possible qu'en l'absence de menaces pour des enjeux humains, et lorsque tous les habitats dunaires peuvent malgré tout s'y exprimer à proximité du site (pas de perte de biodiversité).

Lorsque les dunes «libres » sont fortuites, les stratégies de gestion envisageables dépendent des risques induits par la mobilité du système, et de l'intérêt pour la société de conserver un paysage témoin de la dynamique naturelle. Plusieurs choix sont possibles:

- intervention pour stopper la progression de talus d'envahissement qui menacent des équipements. Ce fut par exemple le cas du grand chantier de réhabilitation des $5 \mathrm{~km}$ de dunes du Conservatoire du littoral au Cap Ferret en Gironde, dans les années 1989-1995, dont le plan d'action visait à concilier l'objectif de conservation d'une « entité paysagère remarquable » avec les attentes des "ensablés » et de la commune. La grande largeur de ces dunes a permis le maintien d'un grand degré de naturalité ; après sa "réhabilitation ", ce site est entretenu selon les principes du contrôle souple...

- conservation volontaire d'un champ de dunes mobiles, en raison de sa valeur patrimoniale et scientifique. Ce sera le choix probable pour les dunes de l'ancien camp militaire du Trencat, au sud du bassin d'Arcachon en Gironde, au titre de suivi d'une évolution naturelle. 


\section{Stratégie de gestion des dunes gérées de façon souple, cas général}

\section{QUELS SONT LES OBJECTIFS POURSUIVIS ?}

Exercer un contrôle souple des dunes littorales, c'est pratiquer une gestion multifonctionnelle en s'appuyant sur les flux naturels d'énergie et de matière qui génèrent ces dunes. Les objectifs couramment poursuivis, de façon conjointe, sont la protection de l'arrière-pays contre les incursions sableuses, la conservation de paysages originaux et attractifs, et le soutien du budget sédimentaire du système dune-plage.

\section{QUELLES SONT LES CARACTÉRISTIQUES DE CE CONTRÔLE SOUPLE ?}

Le principal levier d'action consiste à utiliser l'énergie du vent, moteur majeur des dunes, le plus souvent pour réduire sa vitesse, donc sa capacité érosive, mais aussi pour guider sa force de transport. Cette modération de l'érosion éolienne permet un développement spontané des ceintures végétales adaptées.

L'action est ciblée sur des faciès particuliers de déflation (caoudeyres...) et, pour être pertinente (ni trop tôt, ni trop tard), elle doit être précédée d'un suivi régulier de l'ensemble du système.

Les interventions ne cherchent pas un résultat immédiat, mais les travaux minimums qui permettent d'orienter la dynamique naturelle vers un itinéraire d'auto-correction ; le temps laissé pour permettre une cicatrisation naturelle est un facteur clé de la réussite.

Le contrôle souple s'appuie sur l'interdépendance des différents compartiments de l'écosystème ; sur la côte atlantique, on donne la priorité aux faciès externes les plus exposés aux vents, ces actions amont ont un impact progressif sur tout le transect. Le contrôle souple tient également compte des relations de la dune avec la plage ; les interventions seront nettement différenciées selon le budget sédimentaire du secteur concerné.

Les zones en déficit sédimentaire étant dominantes, le recul du système duneplage est inéluctable ; le contrôle souple ne pourra donc s'appliquer que si l'on dispose d'un " espace de liberté » (ou " espace d'accommodation ») suffisant pour conserver une mosaïque dunaire de bons niveaux de naturalité et de résilience.

Les techniques d'intervention sont les plus discrètes (matériaux biodégradables...) et les moins coûteuses possible, elles excluent les grands remodelages mécaniques sur de grandes longueurs, l'introduction de barrières rigides. La naturalité des espèces végétales est respectée, toute introduction d'espèces végétales exogènes est exclue.

En résumé, le contrôle souple correspond à des interventions ciblées, minimales, s'appuyant sur les processus naturels pour faire jouer aux dunes plusieurs rôles de façon conjointe. Ce mode d'entretien permanent, de "jardinage », nécessite une bonne connaissance des tendances évolutives à court et à moyen terme.

\section{COMMENT CES PRINCIPES SE TRADUISENT SUR LE TERRAIN ?}

Sans entrer dans les détails techniques qui seront abordés plus loin, nous décrirons les modalités générales du contrôle souple à partir de divers exemples de la côte atlantique (figures 3.2, 3.3 et 3.4) et méditerranéenne (figure 3.5).

La majeure partie des travaux concerne les faciès externes. Les principales techniques d'intervention sont des dispositifs brise-vent : rideaux perméables disposés verticalement, ou bien couvertures de branchages morts recouvrant le sable nu... 
Le savoir-faire de ce contrôle souple consiste à choisir la technique la mieux adaptée, le bon moment (brise-vent avant les tempêtes...) et le bon endroit (sable nu en déflation, mais pas en accumulation...). Le recours aux plantations est très limité, la modération de l'érosion éolienne suffit en général pour activer une recolonisation naturelle par les végétaux (sur la côte atlantique).

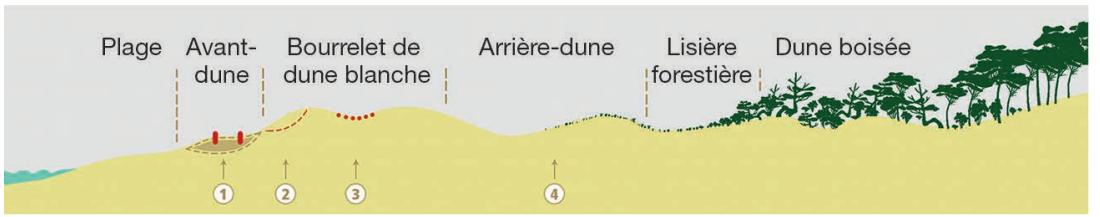

Figure 3.2. Schéma général du contrôle souple des dunes littorales sur la côte atlantique.

1. En phase de répit de l'érosion marine, aide au développement des avant-dunes.

2. Contrôle des caoudeyres frontales les plus importantes pour favoriser le développement naturel d'un versant externe aérodynamique.

3. Cicatrisation des principales caoudeyres sommitales.

4. Dynamique libre de l'arrière-dune dont la mobilité est modérée par les actions à l'amont. Source : J. Favennec/EUCC-France.

Sur la côte atlantique, on peut distinguer trois grands types de choix stratégiques dépendants du budget sédimentaire du secteur concerné (figure 3.3).

Les secteurs en accrétion sont assez rares, cependant on rencontre plusieurs zones en accrétion telles que les bancs de la Salie et de Saint-Nicolas en Gironde, le banc de la Pointe Espagnole en Charente-Maritime, etc. De nouvelles avantdunes viennent s'accoler au bourrelet dunaire, ces sites offrent l'opportunité de conserver une dynamique libre, choix stratégique décrit ci-dessus.

Dans les secteurs en fort déficit sédimentaire, le recul de la côte est important, continu et inéluctable. Ce cas est assez fréquent, le front de dune est entaillé $d^{\prime}$ 'une falaise d'érosion marine, les avant-dunes sont totalement absentes et le volume du bourrelet dunaire tend à se réduire. Dans ce cas, la stratégie est d'accompagner la tendance évolutive, en modérant le recul de la dune (sans chercher à trop la fixer) pour permettre à la mosaïque des habitats de s'adapter dans sa translation vers l'intérieur.

Dans les secteurs côtiers qui connaissent une alternance entre phases d'érosion marine et phases de répit, situation relativement fréquente, l'action consiste principalement à donner un coup de pouce aux processus naturels de formation des avant-dunes en phase de répit (figure 3.4).

Ces trois stratégies principales correspondent aux pratiques de l'Office national des forêts, responsable de la gestion d'une grande partie des dunes littorales de la côte atlantique.

En Méditerranée, sur la côte du golfe du Lion, un contrôle souple des cordons dunaires est organisé en secteurs naturels.

Dans les secteurs dunaires dégradés ou insuffisamment protégés, où la faiblesse de l'érosion laisse une dynamique littorale s'exprimer correctement, les interventions aujourd'hui les plus répandues cherchent à favoriser et à utiliser les processus naturels du système plage-dune, pour que cette dernière cicatrise et se régénère. La dune est abordée sous trois angles différents : morphologie, biologie et usages, en combinant sur le même site une panoplie de mesures adaptées et minimales.

En ce qui concerne la morphologie, les interventions vont se concentrer sur les zones de déflation, qui seront traitées par stabilisation : casiers de ganivelles si 

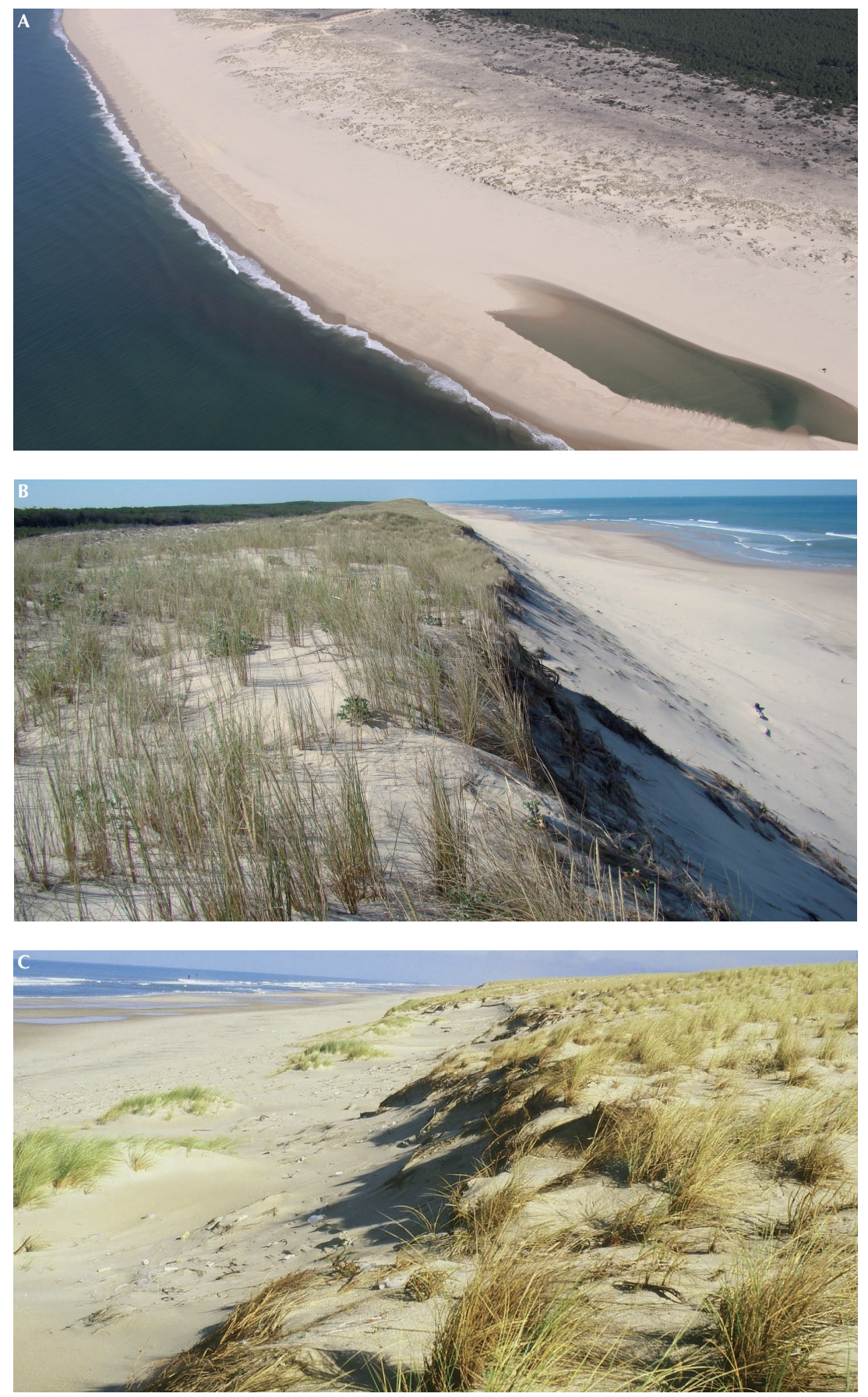

Figure 3.3. Trois types de contexte sédimentaire sur la côte atlantique.

A. Banc d'accrétion de La Salie, La Teste (Gironde).

Bilan positif, accrétion.

B. Falaise d'érosion marine, Hourtin (Gironde).

Bilan fortement négatif, recul.

C. Nouvelles avant-dunes, en phase de répit d'érosion marine, Lacanau (Gironde).

Alternance érosion/répit.

(C) J. Favennec/EUCC-France, sauf A : ( ) M. Le Collen, OCA. 

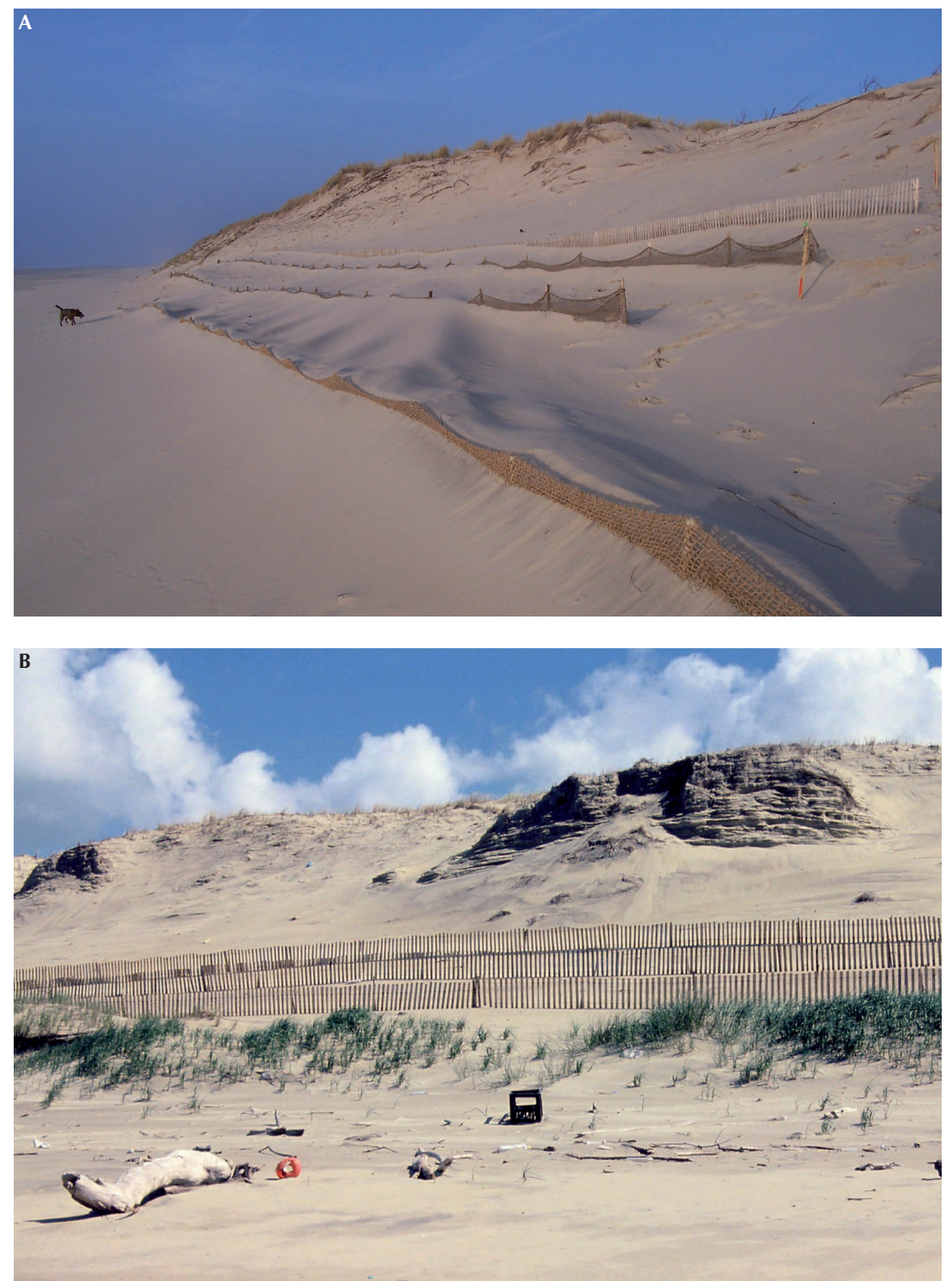

Figure 3.4. Exemples de travaux d'aide à la formation d'avant-dunes (Médoc/Gironde).

A. Pose de filets brise-vent en fibre de coco.

B. Pose de brise-vent en ganivelles de châtaignier.

C) J. Favennec/EUCC-France.

I'objectif est de renforcer le volume sableux, par piégeage éolien ; sinon simples paillages (roseaux étalés, filets géotextiles biodégradables, copeaux de bois) pour fixer le sable en place.

Pour la biologie, I'objectif étant de favoriser les processus de reconquête végétale, un coup de pouce va être donné dans ce sens grâce à l'utilisation des paillages. Mais le climat méditerranéen, peu favorable au développement rapide de la végétation, rend cette reconquête plus difficile que sur les autres littoraux français; I'intervention pourra donc aller jusqu'à l'amorçage de la végétalisation (semis, plantations d'espèces adaptées). 

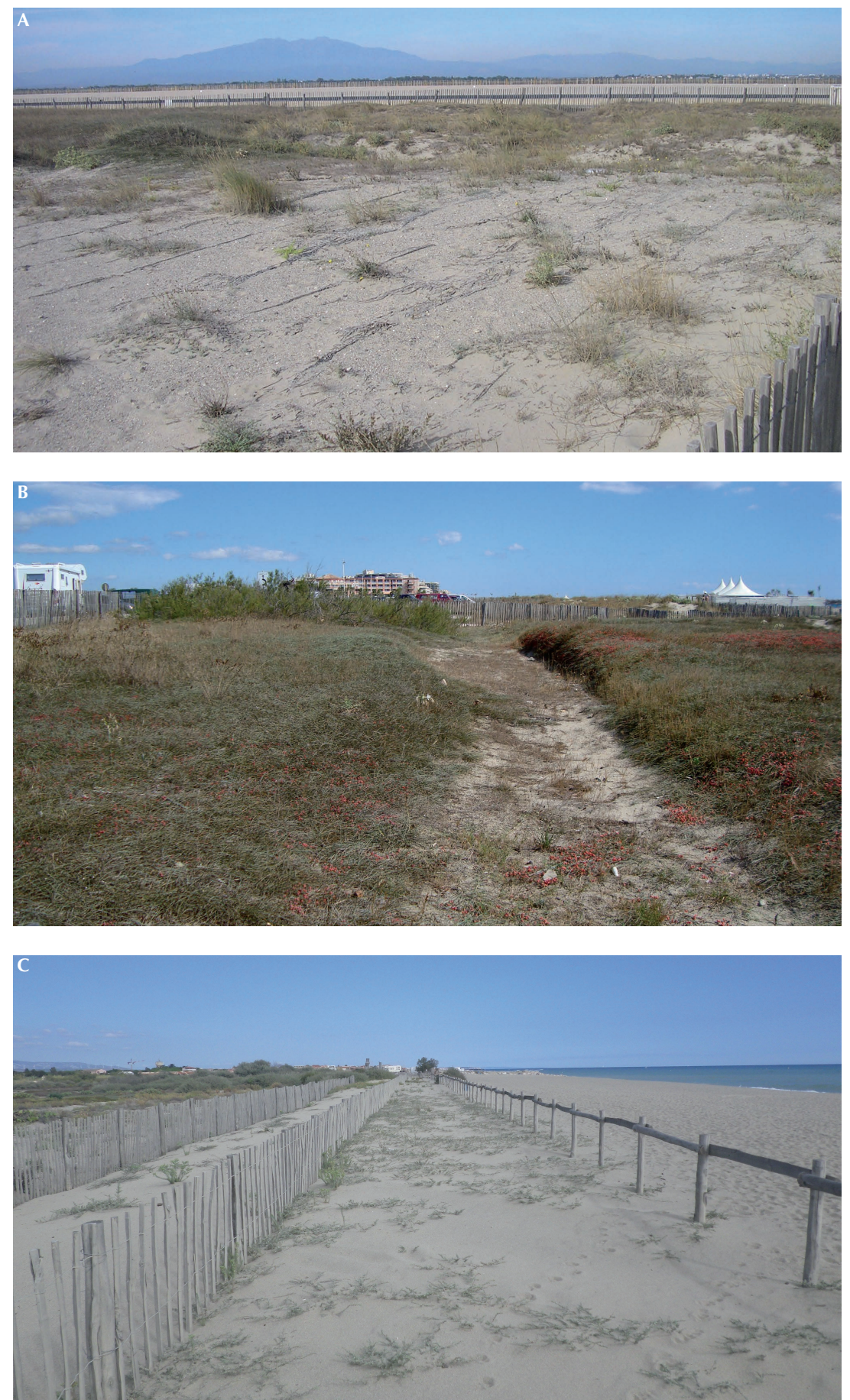

Figure 3.5. Exemples de restauration de cordon dunaire par actions de contrôle souple, dans les Pyrénées-Orientales à Canet-en-Roussillon et à Toreilles.

A. Paillage par filet géotextile biodégradable (Canet-en-Roussillon).

B. Après fermeture d'un accès-plage, cicatrisation naturelle du milieu dunaire (Canet-en-Roussillon).

C. Mise en défens légère (lisses bois) et début de colonisation végétale naturelle (Torreilles).

(C) P. Richard/EID Méditerranée. 
Du point de vue des usages, l'essentiel des interventions concerne la mise en défens des cordons dunaires, pas sous la forme d'îlots de végétation clôturés, mais plus globalement par la délimitation d'une bande continue et homogène, la plus large possible. Espace de respiration de la dune, elle sera simplement interrompue par des sentiers d'accès à la plage, dont le nombre et la localisation seront précisément établis (les projets récents ont prévu la fermeture d'accès estimés trop nombreux). Concrètement, cette délimitation sera bien souvent réalisée par la mise en place d'une ligne de ganivelles. Néanmoins, une autre alternative a été testée sur certains sites : la simple délimitation de la dune, côté plage, par une lisse en bois, certes plus franchissable par le public, mais offrant l'avantage de laisser le sable circuler librement entre la plage et la dune.

Enfin, une attention particulière doit être portée au respect des laisses de mer, propices au développement des dunes embryonnaires, à travers des préconisations de gestion pour les collectivités en charge du nettoyage des plages (suppression du criblage, au moins en haut de plage...).

\section{Stratégie de gestion des dunes gérées de façon souple dans les zones avec risque de submersion : un contrôle souple renforcé}

La problématique du xIx ${ }^{\mathrm{e}}$ siècle était le risque d'avancée des dunes sur les terres. $L^{\prime}$ inquiétude du $x_{1} l^{e}$ siècle est de deux ordres : d'une part, l'érosion côtière qui $\mathrm{s}^{\prime}$ accentue et qui est de plus en plus ressentie du fait de la multiplication des aménagements littoraux; d'autre part, le risque de submersion, qui s'accroît avec la pénurie sédimentaire et la tendance à l'élévation du niveau de la mer. Le risque de submersion concerne les secteurs côtiers dans lesquels un cordon dunaire étroit, ou un système discontinu, précède un arrière-pays de basse altitude. C'est une situation relativement fréquente en Méditerranée, en Flandre, et dans le secteur centre-ouest de la côte atlantique, notamment en Vendée et sur les îles (Noirmoutier, Ré, Oléron...).

Les dunes ne sont pas des digues, ni d'un point de vue juridique, ni d'un point de vue fonctionnel. Cependant, dans certaines situations, elles sont, ou seront, impliquées dans des dispositifs de protection contre les risques de submersion. La stratégie doit alors être renforcée pour jouer au mieux ce rôle particulier ; dans une logique de contrôle souple, on conservera la vitalité des processus naturels, mais avec des contraintes particulières de dimension et de continuité de l'ouvrage. Le choix d'enrocher le haut de plage n'est pas inclus dans cette stratégie, il sera évoqué avec les actions lourdes pour les dunes "urbaines". La traduction pratique de cette stratégie de contrôle souple renforcé sera illustrée par plusieurs exemples : sur la côte atlantique dans l'île de Noirmoutier (figure 3.6) et sur la côte méditerranéenne en Petite Camargue (figure 3.7) et sur le lido de Sète (figure 3.8).

Quand les cordons dunaires jouent un rôle de protection contre les risques majeurs d'inondation, il faut prendre en compte l'ensemble du système, de la plage à la zone exposée aux risques et considérer la zone frontale comme un fusible précédant une zone d'amortissement sur laquelle on prévoit des interventions plus durables et moins coûteuses. Les principales différences avec le contrôle souple évoqué précédemment tiennent aux moyens plus radicaux employés pour atteindre les objectifs et à l'étroitesse de la marge de manœuvre du cordon dunaire, souvent bordé à l'arrière par des infrastructures.

Dans la plupart des cas, l'opération est réalisée sur un secteur conjuguant les risques érosion et submersion. Le cordon dunaire est renforcé, voire reconstitué 
mécaniquement, par apport sableux (ce qui peut poser un problème de sources de sédiments). Cet apport est nécessairement calibré dans ses dimensions pour assurer un rôle de protection face à l'érosion et à la submersion (jonction avec les dunes adjacentes, plage parfois en recul, urbanisation très proche). II doit ensuite être protégé de l'action éolienne (vents de terre et marins) et du passage du public, en général grâce à la mise en place d'un assemblage de lignes de ganivelles servant à la fois de piège à sable et de mise en défens. Les pentes assez fortes du cordon nécessitent souvent la mise en place d'équipements de franchissement (escaliers, rampes PMR, accès véhicules). Enfin, I'aide au développement de la végétation est peu pratiquée dans ce cas, car jugée moins prioritaire. Deux opérations emblématiques ont été menées en Occitanie dans la dernière décennie.

En 2015, une opération innovante a été réalisée sur la commune du Grau-du-Roi (Gard), en Petite Camargue. La problématique était double : anticiper le risque de submersion marine tout en recréant des conditions favorables aux processus naturels du système plage-dune. Un " cordon de seconde ligne de défense » a ainsi été édifié en arrière du cordon dunaire actuel (la " première ligne »), en reliant les points hauts existants (dunes fossiles, levées sablo-argileuses et pistes d'accès au site ; certains d'entre eux ont été surélevés) avec des cordons de sédiments. Le secteur compris entre les deux lignes est quant à lui devenu un espace d'amortissement pour les aléas érosion et submersion. Le cordon dunaire (de première ligne) dispose désormais d'une marge de manœuvre plus ou moins large, et les interventions y seront réduites au strict minimum. Sur ce dernier point, l'opération s'apparente au contrôle souple, voire à la gestion " en dynamique libre ». Cependant, l'objectif global de réduire les risques de submersion et la façon dont est aménagé le cordon de seconde ligne en font bien une action de contrôle souple renforcé.

En 2010, une opération qualifiée de « repli stratégique » a concerné le secteur du lido de Sète à Marseillan (Hérault). Pour lutter contre l'érosion, il a été choisi de faire reculer l'enjeu menacé (une route départementale fréquentée et régulièrement attaquée par la mer, ainsi qu'un camping) et, sur l'espace ainsi libéré, de recréer entièrement un système plage-dune. Le rechargement en sable et le positionnement plus en arrière de l'axe principal du cordon dunaire a permis l'élargissement de la plage. Le cordon reconstitué a été équipé de casiers de ganivelles et végétalisé, des accès-plage ont été aménagés, ainsi qu'une piste cyclable et des aires de stationnement. Sur l'ensemble du linéaire concerné, l'espace de « respiration » de la dune n'est pas uniforme : certains secteurs présentent une marge de manœuvre intéressante au cas où la dune devrait reculer, mais la majeure partie du lido reste contrainte, notamment par le positionnement de la piste cyclable, proche, voire accolée au cordon dunaire reconstitué, qui s'en trouve de fait figé. Quelques années après la fin des travaux, les ouvrages de piégeage sableux ayant joué leur rôle, le cordon dunaire s'est étoffé et vient désormais empiéter sur... la piste cyclable ! Ce blocage partiel de la possibilité de déplacement de la dune vers l'intérieur rendra obligatoire des modes d'actions adaptés aux dunes « urbaines » décrits ci-après.

\section{Stratégie de gestion des dunes " urbaines "}

Lorsque des constructions ou des équipements urbains (routes, parkings...) occupent une partie des dunes, les principes du contrôle souple ne sont plus applicables car ces dunes ne disposent plus de possibilités de migration, et leur patrimoine végétal est souvent fortement dégradé. Le système dunaire, tronqué, n'a plus de capacité de résilience. 

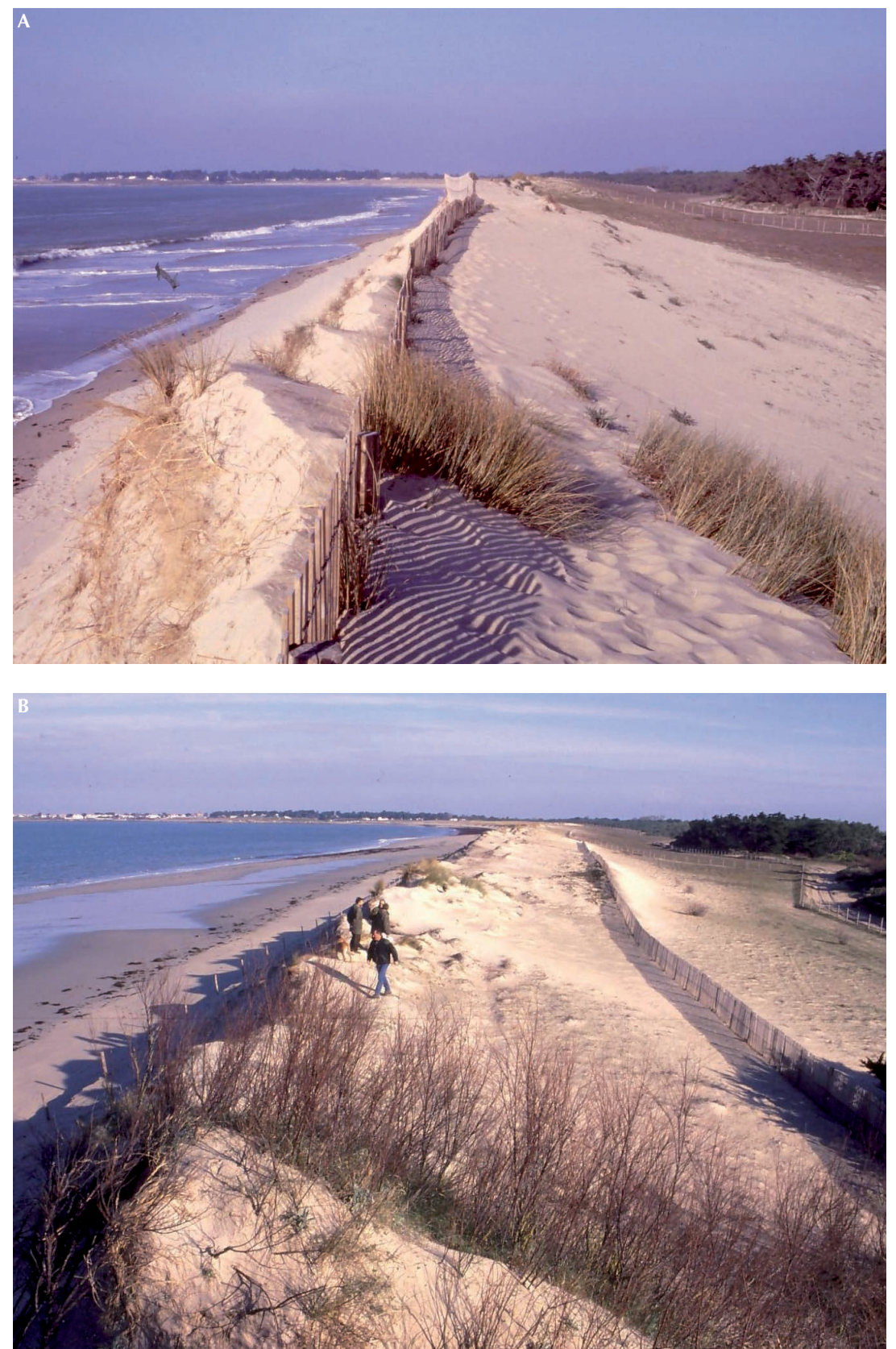

Figure 3.6. Exemple de travaux de contrôle renforcé de la dune de Luzéronde (côte nord-ouest de l'île de Noirmoutier) qui joue un rôle de protection contre les risques de submersion.

A. Un cordon étroit soumis à une forte érosion marine, entre la plage et des terres basses; la ganivelle raidit le profil et limite trop la mobilité.

B. Organiser la translation pour conserver le volume et la hauteur de la dune de protection : la ganivelle est placée en recul, le vent peut adoucir le versant externe. 

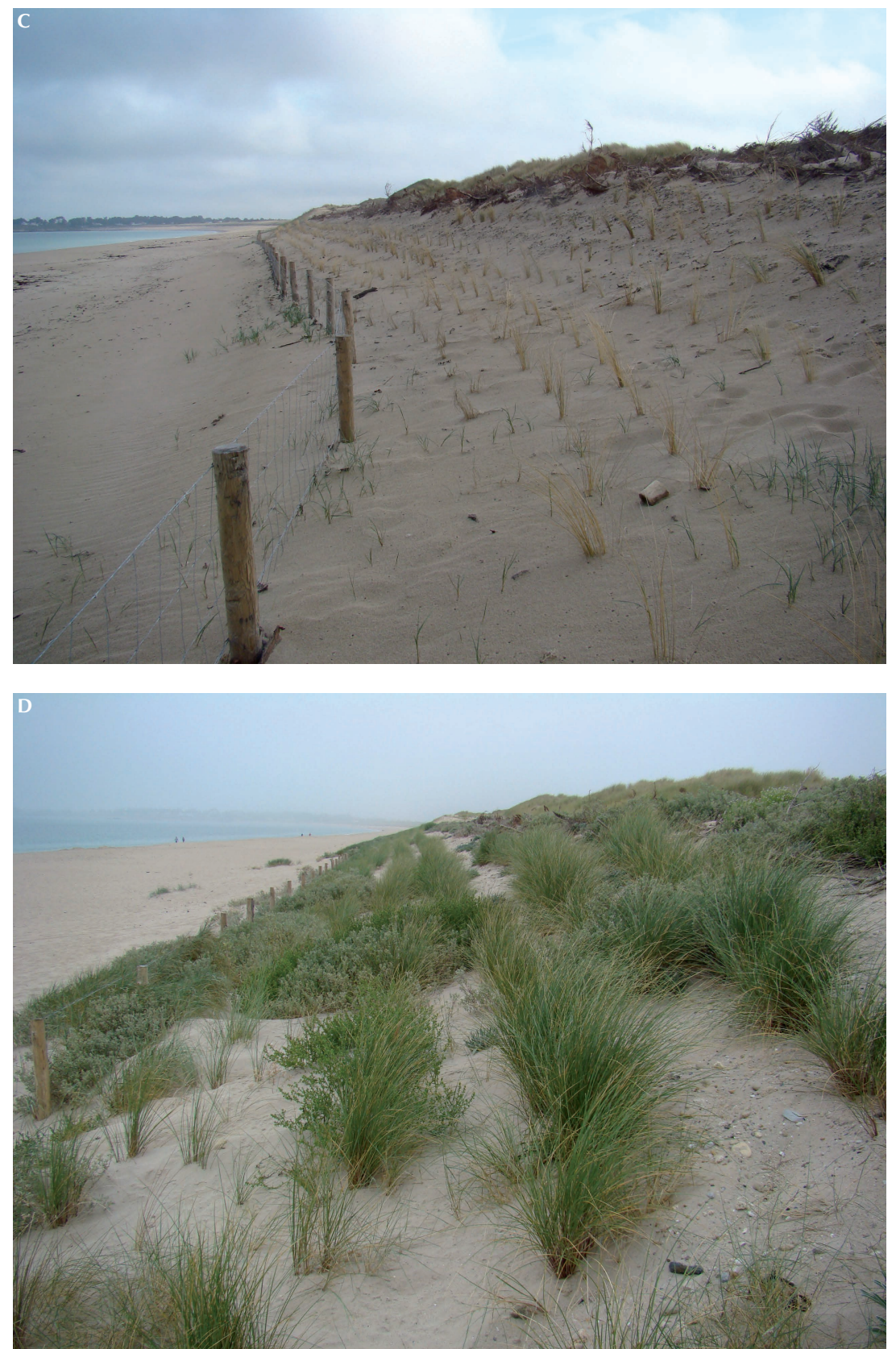

Figure 3.6.

C. Quand le cordon est suffisamment en retrait et son profil satisfaisant, des couvertures de branchages et des plantations de confortement.

D. La dune repositionnée et renforcée peut efficacement jouer son rôle de protection, à condition de conserver la possibilité de retrait progressif.

(C) J. Favennec/EUCC-France. 

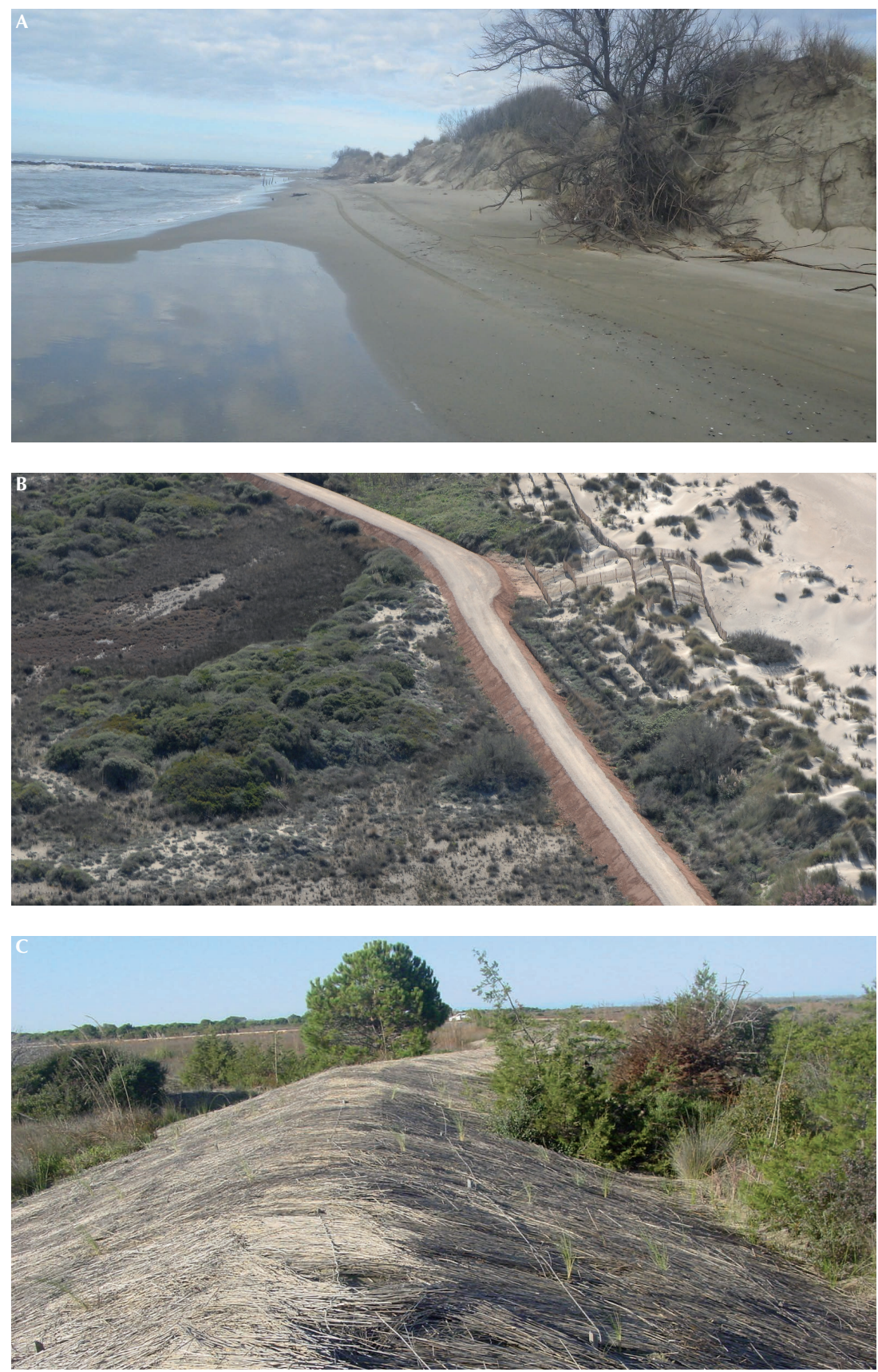

Figure 3.7. Contrôle souple renforcé mené sur le littoral de Petite Camargue, au Grau-du-Roi, au cours de l'hiver 2015-2016.

Défense souple sur une bande littorale de $10 \mathrm{~km}$ de long, combinant rôle fusible du premier cordon (A), espace d'amortissement (B), et seconde ligne de défense par mise en continuité des dunes de l'arrière $(C)$.

A. Cordon de première ligne, en érosion, désormais géré a minima (La Capelude, le Grau-du-Roi).

B. Cordon de seconde ligne (ici une piste surélevée) jouxtant le cordon dunaire (La Capelude,

le Grau-du-Roi).

C. Cordon de seconde ligne implanté en zone humide (La Capelude, le Grau-du-Roi).

(c) P. Richard/EID Méditerranée. 

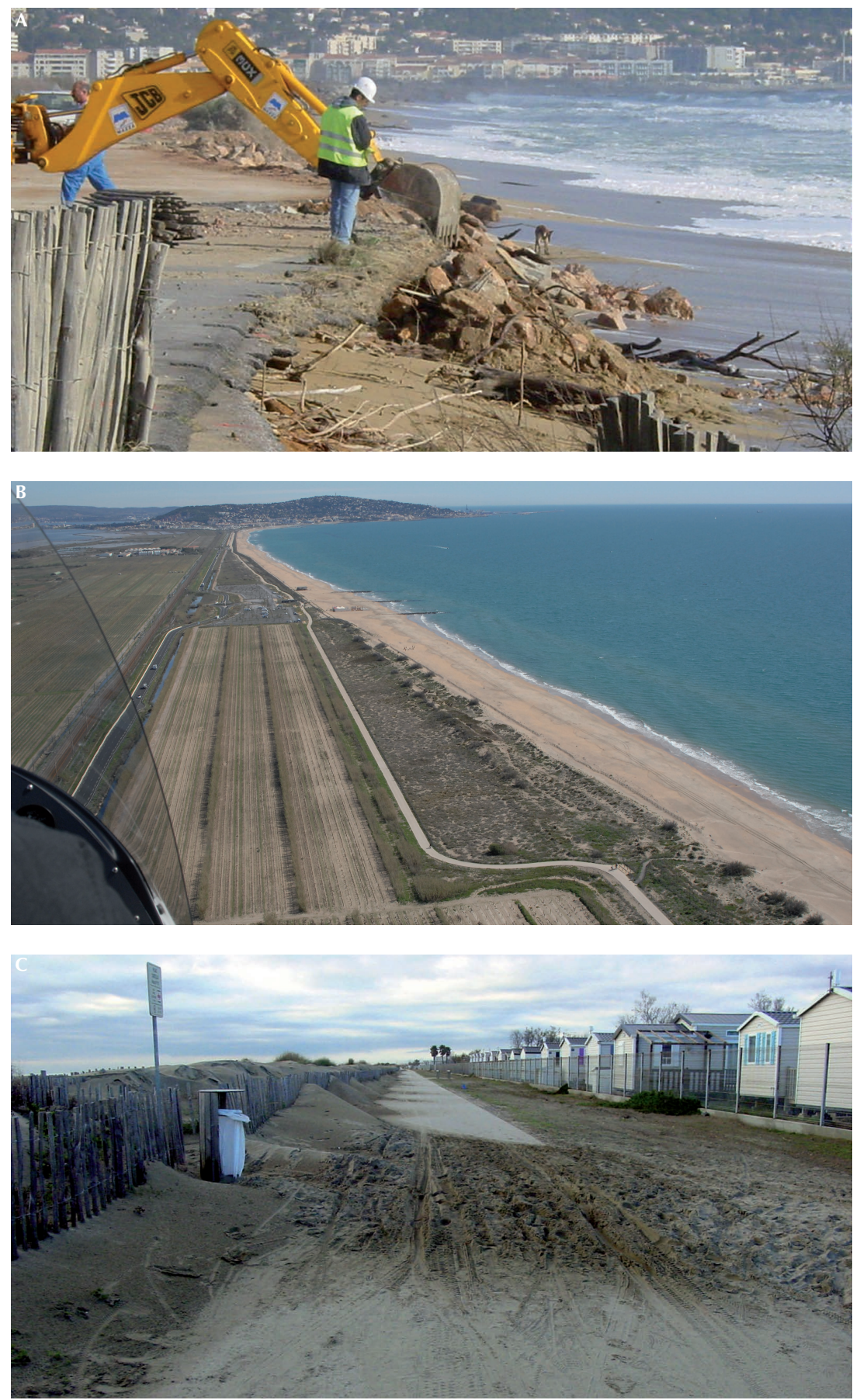

Figure 3.8. Recréation du système dune-plage du lido de Sète : du contrôle souple renforcé à la gestion de dunes "urbaines ».

A. Avant les travaux, la route départementale affouillée suite à un coup de mer (plage du Lido, Sète). B. Le cordon dunaire restauré suite à l'enlèvement de la route, sa largeur varie selon la position des équipements en arrière (plage du Lido, Sète).

C. Le cordon reconstitué déborde ses limites et ensable la piste cyclable qui le longe (plage du Lido, Sète). (C) P. Richard/EID Méditerranée. 
Cependant, parfois, ces dunes " urbaines » sont relativement larges et jouent encore leur rôle d'amortissement de l'énergie marine. Alors, seul le risque d'ensablement est ressenti et il est possible de le gérer en conservant une partie du caractère des dunes (couverture végétale typique, continuité entre plage et dunes...). Ces interventions peuvent être notamment :

- des prélèvements de sable dans les talus d'envahissement trop proches des équipements urbains (on veillera alors à remettre ce sédiment sur la plage),

- des reprofilages de cordons dunaires dont, par manque de place, on a provoqué un surélèvement qui les fragilise par rapport à la capacité érosive du vent.

Mais, dans la majorité des cas, en situation de pénurie sédimentaire, le système plage-dune tend à migrer vers l'intérieur. Cette translation est rendue impossible par des fronts urbains que les collectivités tentent de protéger avec des systèmes de défense contre l'érosion marine. L'impact de ces défenses « dures » est décrit dans la partie «Les ouvrages et les systèmes de défense contre la mer ». II en résulte des dunes résiduelles de plus en plus étroites, limitées côté mer par des empierrements et côté terre par la zone urbaine... Les dunes ont alors définitivement perdu leurs caractères d'origine ; souvent, elles sont transformées en jardin public, espace de loisir urbain précédant la plage, avec recouvrement du sable par des matériaux, ou de la terre, qui dénaturent totalement la surface dunaire.

Cependant, même dans ces situations de contrainte extrême, diverses actions sont de nature à modérer l'impact de cette artificialisation, citons notamment :

- le nettoyage raisonné des plages ;

- la pose de rideaux brise-vent en haut de plage avant la période de tempête. Ils ont plusieurs avantages : le sédiment bloqué en haut de plage amortit l'érosion marine ; ce sable ne se répand pas à l'arrière aux dépens des équipements où il doit être balayé, sans pouvoir être récupéré pour recharger la plage car il est trop pollué.

Les collectivités consacrent des moyens financiers importants pour entretenir des dunes diversement imbriquées dans le tissu urbain, mais ces méthodes lourdes et coûteuses ont une efficacité de durée très limitée. La relocalisation des enjeux est le plus souvent la meilleure stratégie à long terme.

\section{Organisation de la gestion}

Loïc Gouguet

Une gestion raisonnée des cordons dunaires doit se penser sur le long terme. Même si la complexité du fonctionnement des systèmes côtiers ne permet pas de se projeter dans un futur trop lointain du fait de la multitude des critères intervenant dans leur évolution (force et direction des vents efficaces, orientation des houles à la côte, granulométrie du sable, vitalité de la végétation, et bien sûr événements climatiques brutaux...), c'est un entretien régulier qui sera garant $d^{\prime}$ une gestion économe et respectueuse des milieux.

\section{La connaissance et le diagnostic}

Pour gérer correctement, il faut avant tout savoir positionner le cordon dunaire dans son contexte hydrosédimentaire et dans sa région biogéographique. Se situer dans la cellule sédimentaire doit être le premier réflexe du gestionnaire. Ainsi il pourra organiser la gestion en fonction des évolutions passées et des prévisions probables. 
De même, la connaissance des formations végétales et de leur dynamique va orienter les techniques d'interventions ultérieures. L'idéal sur le terrain est de pouvoir bénéficier d'un recul d'observation assez long, les structures de type « observatoire du littoral » permettant par exemple de collecter des données très précieuses. En effet, les réactions à chaud, immédiatement après un épisode érosif, conduisent souvent à des interventions inadaptées (en dehors de la sécurisation des sites). La connaissance des phases de respiration des cordons dunaires permet de positionner l'événement dans des cycles plus large.

\section{La surveillance et l'évaluation}

Pouvoir qualifier l'état du cordon dunaire est bien entendu le point de départ du déclenchement des actions. Il faut pour cela, en fonction des situations et des contextes sédimentaires, se fixer au préalable un certain nombre d'indicateurs, pour lesquels des seuils d'alerte (mesurables) seront aussi déterminés. Ces indicateurs seront différenciés selon les fonctions dominantes attendues : dans le cas général en matière de géo et de biodiversité, ce peut être la présence optimale des différentes unités paysagères potentielles; par contre, si la dune littorale est intégrée dans un dispositif de prévention des submersions, les données de largeur et de hauteur du cordon seront prioritaires.

Les descripteurs les plus pertinents relèvent de la forme de la dune (de sa " géométrie »), sa hauteur et sa largeur, et d'une description sommaire de l'organisation du contact plage-dune. Pour ce qui est de la hauteur, cela peut être celle de la crête, ou par exemple du point le plus bas du cordon dunaire considéré, puisque $c^{\prime}$ est elle qui pourrait constituer la première brèche en cas de submersion marine. La largeur est un indicateur de la «stabilité » de la dune. On mesurera la largeur du premier cordon bordier, si cette donnée est pertinente. Le contact plage-dune, révélateur des grands processus sédimentaires en jeu (érosion, accrétion, équilibre), donne des indications sur le cycle en cours (falaise vive, falaise régularisée, profil aérodynamique d'équilibre, avantdune/banquette...). Les formes et surfaces des zones dévégétalisées ainsi que leur position sur le cordon seront également des éléments indiquant l'état de conservation facilement mesurables sur le terrain. Des indicateurs sur l'intensité de piétinement pourront aussi compléter les descripteurs. Sur chaque site, l'observation sur le long terme par le gestionnaire doit permettre d'établir une typologie des cas de figure et, pour chacun d'eux, de mettre au point une ligne stratégique qui guidera ses actions.

\section{Les entretiens}

\section{Planifier les travaux d'entretien}

En appuyant son action sur la dynamique végétale et sa capacité à fixer le sable, le gestionnaire peut s'aider des processus naturels pour s'assurer d'un entretien à moindre coût. L'absence d'entretien peut rapidement réduire à néant les efforts précédemment entrepris, du fait de la force érosive du vent. En effet, on constate, lors de la disparition de la végétation fixatrice sur la dune, que la remobilisation du sable est très rapide et peut s'emballer jusqu'à provoquer une remise en mouvement complète du cordon sableux.

Compte tenu de la constante évolution du littoral, aucune solution ne peut être définitive. Il faut s'inscrire dans une démarche itérative, où l'observation du comportement des dunes après chaque événement peut déclencher l'action. 
En règle générale, des actions très régulières sont plus efficaces que des actions ponctuelles espacées dans le temps, qui seront forcément plus lourdes et plus coûteuses.

\section{DÉFINITION DES OBJECTIFS AVANT INTERVENTION}

Il faut que les objectifs assignés à la dune soient clairement définis :

- maintien d'un stock sableux au plus près du rivage (rôle d'obstacle joué par la dune) ;

- importance de maintenir les échanges plage-dune ;

- contrôle des envols de sable et de la migration dunaire ;

- préservation de milieux, d'espèces et de formes rares (biodiversité, géodiversité) ;

- support d'une activité touristique ne portant pas atteinte au site.

Dans le cadre d'une gestion multifonctionnelle telle que celle mise en œuvre par l'ONF, ces différentes fonctions sont évaluées pour chaque site et les actions sont programmées en conséquence.

\section{Programmer LES INTERVENTIONS}

La difficulté d'établir un programme annuel de travaux dunaires réside dans les évolutions rapides du terrain qui doivent dicter les interventions. Une véritable gestion dynamique doit être mise en place, avec une surveillance des sites (importance des observations sur le long terme et de conserver la mémoire de ces observations) et des ajustements continuels. C'est seulement après les événements de la fin de l'hiver que l'on peut définir les actions à entreprendre, pour répondre au mieux aux objectifs assignés. Les actions d'entretien à engager vont toutes viser, selon les objectifs et les choix stratégiques :

- à piéger le sable en transit éolien afin qu'il se dépose aux endroits voulus, pour que la dune se rapproche de la forme souhaitée tout en maintenant une diversité de formes favorisant la naturalité du système ;

- à traiter les zones non végétalisées sujettes à érosion, potentielles zones d'envol de sable, et donc de reprise de l'érosion éolienne ;

- à contenir les mouvements trop vifs du sable en organisant son piégeage ;

- à protéger du piétinement les zones végétalisées.

En fonction de la méthode à employer, les interventions seront réalisées de préférence en hiver, là où le vent est le meilleur allié pour remplir les pièges à sable. Les plantations d'oyat seront, elles, réservées au tout début d'année, avant le printemps, période précédant la reprise de croissance printanière favorable à une bonne reprise.

\section{Raisonner le nettoyage des plages}

Nous l'avons vu au début de ce guide, les dunes naissent en haut de plage, profitant du dépôt des laisses de mer. C'est donc dire l'importance que I'on doit accorder au maintien de ces dépôts, source de vie et de biodiversité. Bien entendu, les plages sont aussi facteur d'attractivité touristique des territoires. Elles sont fonctionnellement rattachées aux dunes bordières, au sein des cellules sédimentaires. Une gestion raisonnée s'appuie sur une approche globale qui prend en compte les multiples fonctions jouées par les plages:

- maillon important des cellules sédimentaires,

- amortisseur souple de l'énergie marine,

- écosystème original de haute valeur patrimoniale,

- paysage attractif, support d'activités touristiques... 
Il est donc important d'adapter les interventions de nettoyage (période, fréquences, types : mécanique et/ou manuel) selon les enjeux écologiques, d'érosion et touristiques de chaque plage.

L'information et la sensibilisation des usagers de la plage sont aussi des éléments importants sans lesquels toute action risquerait d'être réduite à néant par les réactions hostiles du public (figure 3.9). Une plage " propre » d'un point de vue esthétique est malheureusement une plage où la biodiversité est restreinte.

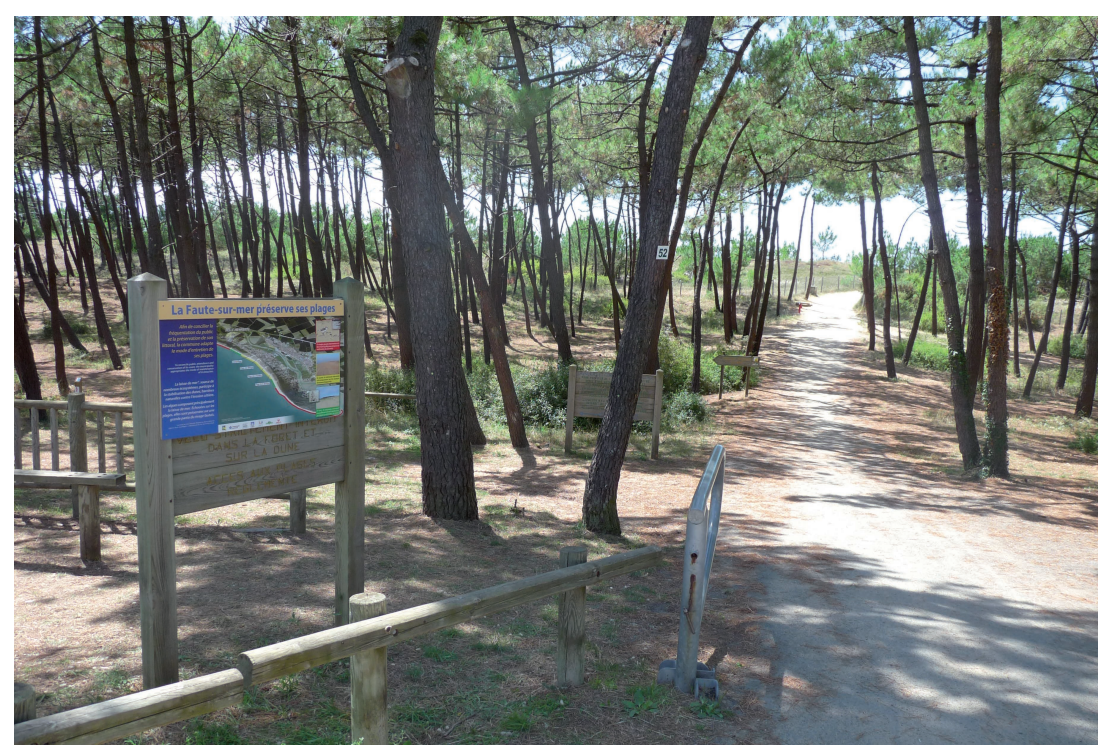

Figure 3.9. Panneau d'information sur le nettoyage des plages.

(c) F. Geffroy/Rivages de France.

Un guide de nettoyage raisonné des plages a été réalisé par Rivages de France (association de gestionnaires de terrains littoraux) et le Conservatoire du littoral ${ }^{16}$. Il propose un protocole pour mettre en œuvre un nettoyage raisonné des plages au sein des collectivités, des conseils pour convaincre de l'importance de la démarche et des fiches techniques expliquant cette démarche.

De façon synthétique, il est souhaitable de respecter des grands principes lors des nettoyages de plage associée à un cordon dunaire :

- adapter la fréquence et l'intensité du nettoyage aux différents enjeux ;

- interdire tout passage d'engin sur les avant-dunes et les hauts de plage ;

- ne pas extraire de sable du compartiment sédimentaire (en développant le nettoyage manuel sélectif et en améliorant les techniques de nettoyage mécanique...) ; - laisser en place la matière organique ;

- aider le grand public à connaître le fonctionnement des plages, car un public informé prend conscience de ces enjeux écologiques et change de point de vue sur la question du nettoyage ; progressivement, publics locaux et touristes peuvent accepter un nettoyage raisonné et donc admettre la présence de débris organiques sur les plages.

Porter un nouveau regard sur la plage et ses fonctions multiples, c'est aussi préserver les cordons dunaires qui leur sont associés.

16. Téléchargeable sur le site : http://www.rivagesdefrance.org/association-rivages-de-france/actions/ nettoyage-raisonne-des-plages/, consulté le 21 août 2017. 


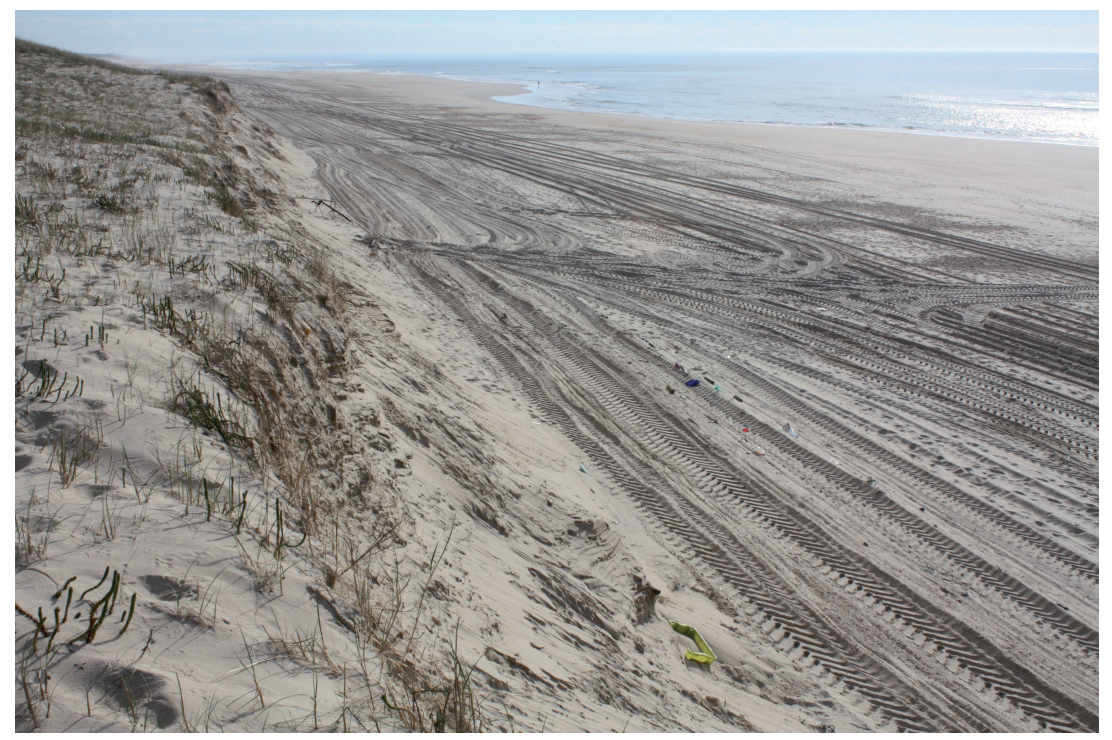

Figure 3.10. Lorsque le nettoyage et le passage d'engins risquent de déstabiliser le pied de dune (Mimizan, Landes).

(C) L. Gouguet/ONF.

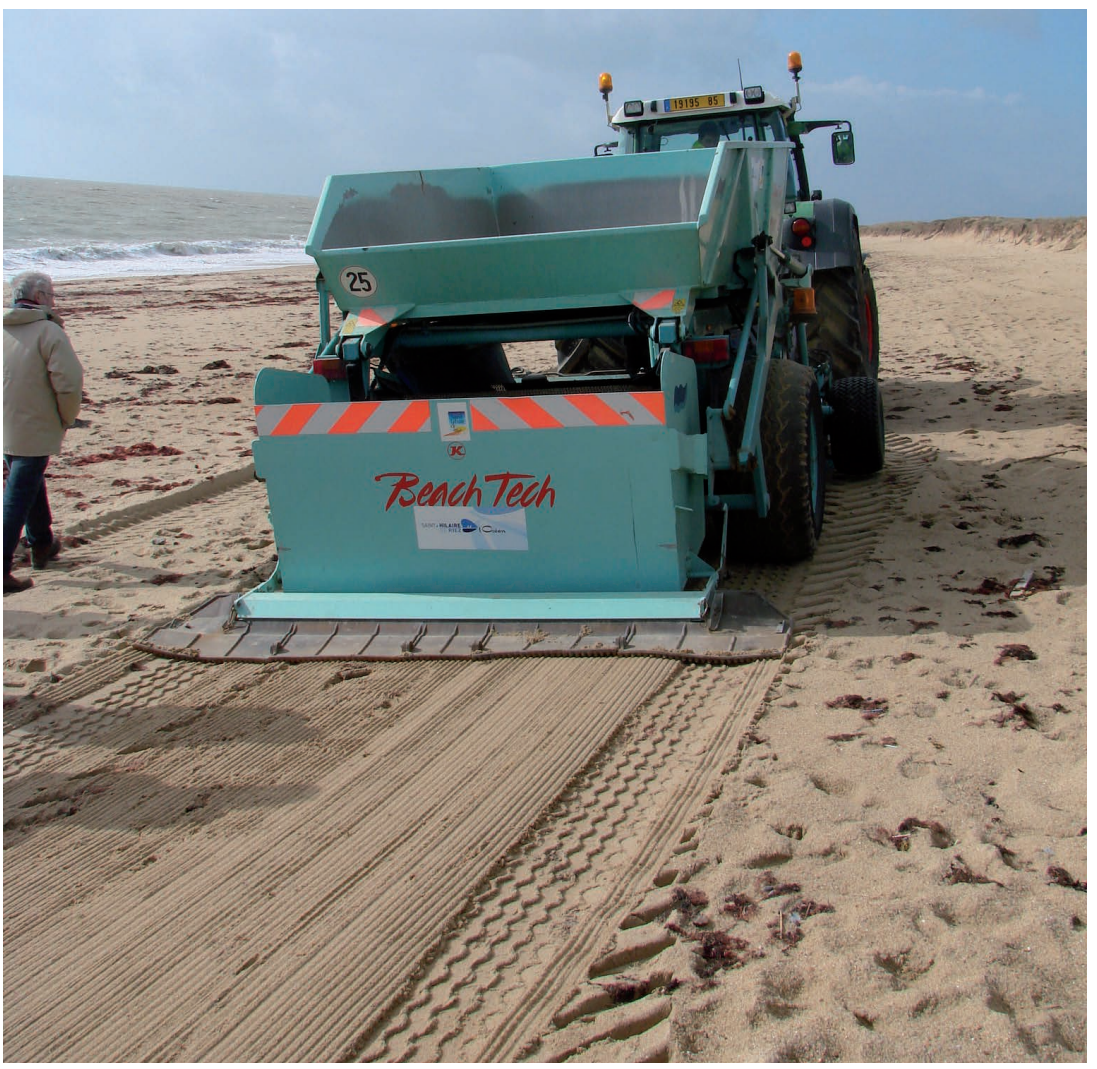

Figure 3.11. La mécanisation du nettoyage peut produire des plages propres mais sans vie. (C) L. Gouguet/ONF. 


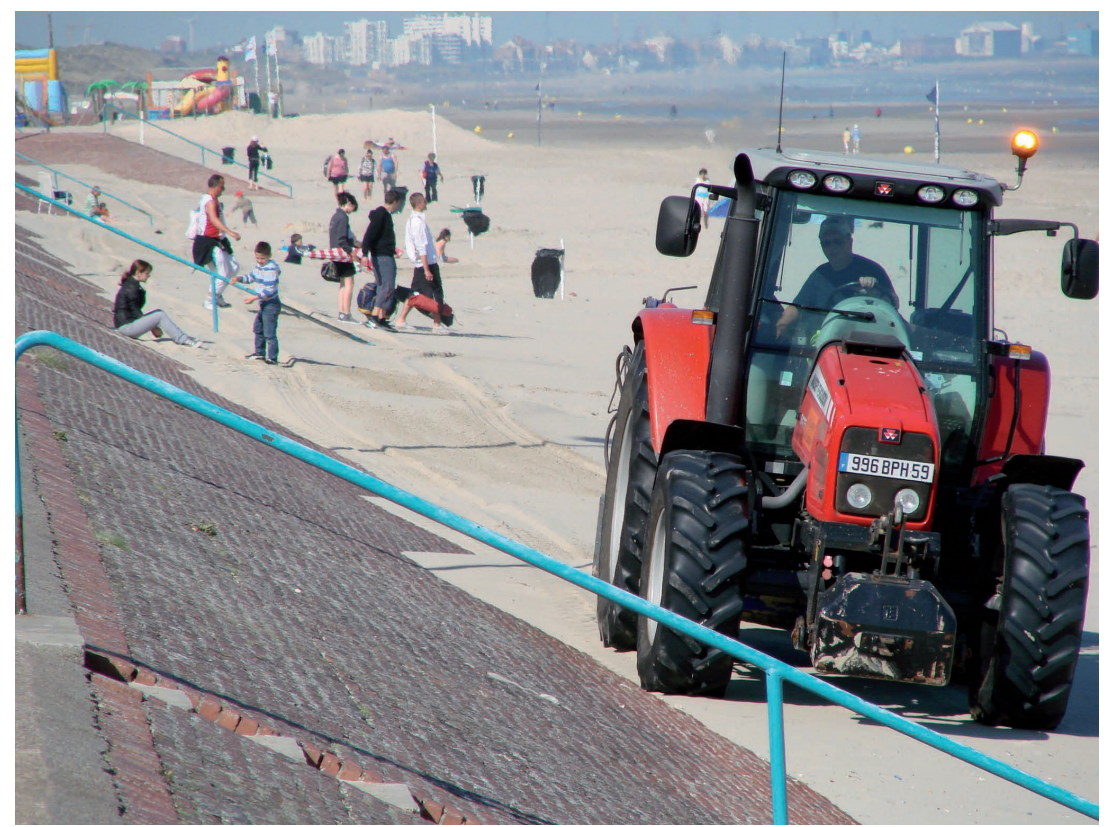

Figure 3.12. Le nettoyage d'une plage urbaine répond à des impératifs liés à une forte pression balnéaire et à la nécessaire sécurité du public.

(c) L. Gouguet/ONF.

\section{Les travaux d'aménagement}

Lorsqu'un cordon dunaire a quasiment disparu du fait des érosions (marine, éolienne, anthropique...) ou lorsque l'on veut le reconstituer (après le démontage d'un ouvrage par exemple ou dans le cadre d'un réalignement stratégique), il est parfois nécessaire d'entreprendre des travaux importants qui vont au-delà du simple entretien : apports de sable, reprofilage lourd sur une grande surface, organisation complète de l'accueil du public...

Ces actions de génie écologique, comme toute opération d'envergure, doivent toutefois être précédées d'une analyse des besoins, ce qui permettra de répondre au mieux aux attentes du maître d'ouvrage. Le déroulé de la phase travaux, ainsi que les suivis ultérieurs sont bien entendu connus de tous les porteurs de projet. Nous nous contenterons ici d'attirer leur attention sur les spécificités liées aux milieux littoraux et dunaires.

\section{Phase étude : analyse du besoin}

Il convient dans un premier temps de procéder à un état des lieux et de remettre le site dans son contexte hydrosédimentaire, dont la caractérisation va aider à définir les objectifs. Pour cela, plusieurs types d'éléments vont servir au gestionnaire :

- la connaissance du site va être grandement favorisée par l'utilisation des photos aériennes et des photos obliques ; une étude diachronique sur l'évolution du littoral grâce aux photos d'archives et aux photos récentes permettra de caractériser l'évolution sur un pas de temps le plus long possible (plusieurs dizaines d'années), d'un point de vue géomorphologique, mais également du point de vue de l'évolution de la couverture végétale fixatrice ; 
- la connaissance de l'évolution du trait de côte et du risque côtier sur un pas de temps suffisamment long sera facilitée lorsqu'une structure de type "Observatoire du littoral " aura été mise en place, au sein de laquelle des relevés annuels du trait de côte auront été réalisés; à défaut, l'interprétation de photos aériennes (en conservant un pas de temps significatif) donnera également de bonnes indications ; cet observatoire, lorsqu'il existe, sera un fournisseur de données incontournables pour le maître d'ouvrage ;

- un aperçu des contraintes réglementaires doit être réalisé dès I'amont du projet, car certaines procédures réglementaires peuvent parfois nécessiter un délai d'instruction assez long; on citera notamment les obligations en matière d'urbanisme (loi littoral, site classé...), en matière de biodiversité (Natura 2000, loi sur les espèces protégées...) ou relatives à la loi sur l'eau, des demandes liées à l'utilisation du domaine public maritime, qui entraînent parfois des études préalables d'incidence; les services instructeurs de ces études devront obligatoirement être associés au projet dès les prémices et les premières réunions préparatoires ;

- une cartographie des usages doit également être réalisée, pour identifier certains aspects (usagers éventuels ou flux anthropiques sur le site, urbanisation adjacente, patrimoine historique et culturel, sociaux...), afin de les prendre en compte dans le projet ;

- un outil à la disposition du gestionnaire a été mis au point par l'université de Bordeaux à la fin des années 1970 : la carte écodynamique ; ces cartes sont le moyen de transmettre de façon immédiate la connaissance fondamentale du site au gestionnaire et permettent de produire facilement un plan d'intervention ; il s'agit de représenter sur une même carte trois éléments qui se superposent : les formes du relief et les dynamiques marine et éolienne ; l'état et la composition de la couverture végétale ; les traces de l'action de l'homme (cheminements, types de travaux réalisés, aménagements et édifices divers).

Cet état des lieux va permettre de réaliser une cartographie et une sectorisation des dunes en fonction de leur dynamique et des enjeux présents.

Ce n'est qu'ensuite que les réflexions sur les grandes lignes d'un aménagement global peuvent être émises. En se fixant des objectifs (topographie du cordon souhaité, organisation de l'accueil et répartition des cheminements, préservation de zones à fort intérêt patrimonial...), l'opérateur définira un plan d'action, tronçon par tronçon, précisant :

- les opérations de transfert/rechargement/reprofilage de sable (volumes et linéaires concernés) ;

- les opérations liées à la fixation du sable (couvertures de branchages, plantations) ;

- les opérations indispensables de canalisation du public (accès plage, cheminements, guidage...);

- les actions d'information des usagers.

Une fois les objectifs définis et validés, le chiffrage des opérations devra tenir compte des contraintes et d'un calendrier de mise en œuvre dépendant des conditions naturelles qui peuvent parfois ralentir ou décaler les actions (tempêtes hivernales, horaires et coefficients de marées pour l'accessibilité, périodes de repos végétatif...).

Plusieurs exemples récents de travaux réalisés sur le littoral atlantique (Capbreton) ont démontré qu'une mobilisation citoyenne était aussi un gage d'acceptation de modifications significatives des habitudes d'utilisation d'un site et d'un changement du paysage. Des volontaires sont intervenus pour 
disposer des couvertures de branchages et des clôtures de guidage sur une dune reprofilée, avec un encadrant technique pour les diriger. Cette implication de la population locale a facilité une large communication autour du projet et une sensibilisation au respect ultérieur du travail réalisé.

\section{Mise en œuvre}

La réalisation de travaux, une fois toutes les autorisations requises obtenues, doit faire l'objet d'attention particulière. Bien entendu, le respect des « règles de l'art " dans la mise en œuvre des techniques est un préalable. Au-delà, plusieurs spécificités liées au caractère littoral des travaux doivent être prises en compte.

\section{JUGER DE LA BONNE DISTANCE À LA MER}

Une des difficultés en matière de gestion des milieux dunaires consiste à estimer la limite océanique de l'intervention : trop près de la mer, les dispositifs risquent d'être emportés en cas d'érosion marine ; trop loin, ils risquent de ne pas être efficaces à $100 \%$. Une bonne analyse du contexte érosif et de la forme du cordon dunaire doit permettre de positionner les dispositifs judicieusement.

\section{Piqueter les zones d'INTERVENTION}

La matérialisation par des piquets des zones à traiter, ainsi que des zones à protéger (espèces patrimoniales) doit être réalisée au plus tôt. Il faut toutefois être en capacité d'adapter les zones d'intervention si survient un coup de vent qui redistribue les reliefs. Ce piquetage permet de calculer des surfaces pour la préparation des dispositifs à mettre en place et indique clairement aux équipes d'ouvriers les zones où intervenir.

\section{DÉLIMITER DES CHEMINEMENTS D'ACCÈs}

Il faut délimiter des cheminements d'accès et $d^{\prime}$ 'approvisionnement du chantier pour éviter de multiplier les zones de passage des engins et ainsi limiter au maximum l'impact sur le milieu naturel, et pour éviter, une fois les engins de reprofilage intervenus, que les dispositifs de piégeage du sable ne soient trop tassés par le roulement.

\section{ENCHAÎNER LES INTERVENTIONS}

Les interventions doivent débuter au plus près de la mer pour se terminer par le côté « terre » de la dune. Du fait de l'extrême mobilité du sable non fixé et de la soudaineté des coups de vent, il est primordial de faire succéder la mise en place de couvertures (ou autres dispositifs) dès que la dune a été profilée selon la topographie souhaitée. Même s'il est illusoire de vouloir figer complètement le sable, ces dispositifs atténueront les plus gros mouvements sédimentaires.

\section{DÉFINIR LES PÉRIODES D'INTERVENTION}

Les dates de réalisation des travaux doivent tenir compte de plusieurs facteurs : la période hivernale est la période la plus propice aux coups de vent, donc aux mouvements de sable. Une intervention à l'automne permettra aux dispositifs d'être mis en place avant les grandes tempêtes hivernales, et donc d'être pleinement efficaces dans le piégeage du sable.

La période estivale, elle, n'est pas la meilleure période $d^{\prime}$ intervention à double titre, du fait d'une part de la fréquentation qui y est très importante et rend difficile toute intervention, et d'autre part, c'est la période de pleine végétation peu propice aux plantations de végétaux fixateurs. 


\section{Suivis ultérieurs}

Comme pour tout projet d'aménagement, il est important de prévoir dès le début de l'intervention les dispositifs qui seront mis en place pour juger de la pertinence des travaux réalisés et de leurs effets ultérieurs. Il peut s'agir en particulier :

- d'un suivi topographique régulier du cordon dunaire (transects, profils...) pour quantifier les mouvements de sable ;

- d'un suivi des espèces patrimoniales impactées par les travaux ;

- de l'évaluation régulière de la fréquentation pour éventuellement redimensionner les équipements d'accueil ;

- un suivi photographique (en conservant, tout au long de la phase chantier ainsi qu'après, le point et l'angle de prise de vue) peut également être un bon moyen de surveiller l'évolution du site.

Le coût de ces suivis est à intégrer au projet dès son montage financier.

\section{La gestion des situations d'urgence}

Les massifs dunaires côtiers sont des environnements naturels fortement mobiles susceptibles de contribuer localement à la protection de zones basses arrièrelittorales en formant une barrière à l'écoulement des eaux (submersion). Bien que n'entrant pas dans la constitution des systèmes d'endiguement au sens de la réglementation (art. R562-13 du Code de l'environnement), leur contribution à la protection des populations et leur risque de défaillance au regard de cette fonction doivent être étudiés, évalués et pris en compte dans leur gestion. En cas d'érosion marine intense, les équipements installés (imprudemment) sur les cordons dunaires peuvent aussi être menacés.

La gestion des crises susceptibles de mettre en danger les populations protégées par un cordon dunaire se doit d'être largement anticipée. En situations d'urgence, les modes d'intervention sur ces environnements fragiles ne peuvent pas être improvisés dans la précipitation, au risque de rompre le fragile équilibre de ces milieux naturels. Il convient également d'éviter la mise en œuvre de solutions lourdes et irréversibles potentiellement efficaces à très court terme, mais dont les implications à long terme seraient dommageables à la pérennité du milieu et à sa résilience. La remise en cause des équilibres naturels du système dune-plage est ainsi susceptible de dégrader fortement et même $\mathrm{d}^{\prime}$ annihiler totalement la capacité du système à se reconstituer naturellement après des épisodes tempétueux. La gestion des situations d'urgence impose des actions sur différentes temporalités couvrant :

- la préparation à la crise,

- la gestion de la situation d'urgence,

- la gestion de l'après-crise et du retour à une situation normale.

\section{La préparation à la crise}

Les actions de préparation ont pour objectifs d'identifier et de disposer des méthodes et des moyens de surveillance et d'intervention nécessaires à la gestion du risque pour les populations en période d'événements hydrométéorologiques particulièrement morphogènes pour le milieu. Elles se concrétisent par l'établissement d'un plan de gestion en période de crise. Celui-ci comprend les principales consignes ou informations indispensables aux actions de surveillance et de mise en œuvre de solutions prédéfinies et opportunes, permettant de limiter ou de pallier les risques induits par 
la défaillance du cordon dunaire. La préparation et la mise à jour de ces éléments reposent sur des réflexions, des études, des retours d'expérience et des exercices permettant d'identifier :

- les points faibles en fonction des différents aléas et des enjeux menacés, et les modes de surveillance (conditions d'accès, caractéristiques à observer...) du cordon et de son environnement ;

- les moyens humains et matériels disponibles et nécessaires aux interventions, tant pour la surveillance que pour la réalisation de travaux d'urgence particuliers (par exemple, le comblement de siffle-vent ou de brèches particulièrement sensibles aux franchissements...) ;

- les techniques d'intervention possibles en fonction des contraintes du milieu et de la situation, des contraintes de sécurité pour les agents, ainsi que des modes opératoires particuliers (par exemple, dans le cadre d'un rechargement ponctuel en sable, les sources de matériaux disponibles, les conditions d'accès au site, les conditions de marée propice, les conditions et les temps de mise en œuvre, ainsi que les moyens nécessaires, tant humains que matériels...).

Les travaux préparatoires doivent également permettre $d^{\prime}$ identifier les seuils d'alerte spécifiques aux différents points faibles identifiés (distance aux enjeux, largeur de cordon dunaire intact restant, passage de paquets d'eau, altitude et forme de la plage, hauteur du cordon dunaire, pente externe du cordon...). II faut également préalablement examiner les conditions de leurs observations, par exemple en disposant des repères sur le terrain. II faut aussi préparer les messages d'informations graduels que le gestionnaire se devra d'adresser aux autorités compétentes pour la gestion de crise aux échelles supérieures, qu'elles soient communales (maire) ou départementales (préfet), et inventorier les différentes actions à entreprendre au fur et à mesure de l'atteinte des seuils d'alerte.

La réalisation d'exercices et de simulations dans le cadre de la préparation à la crise permettra d'assurer la formation des agents en charge des interventions, d'identifier les difficultés organisationnelles et techniques nécessitant des adaptations du plan d'intervention.

\section{Les interventions en situation d'urgence}

Le premier type d'intervention en période de crise concerne d'abord la mise en place et la réalisation d'une surveillance renforcée et particulière permettant de disposer d'une information objective et fiabilisée sur l'évolution du milieu. Celle-ci est favorisée par le recours à des protocoles préalablement définis appliqués par des agents formés à leur mise en œuvre. Les conditions opérationnelles de cette surveillance doivent évidemment permettre de garantir en toutes circonstances la sécurité des agents mobilisés. La réalisation de relevés topographiques de repères préalablement installés, la prise de photographies en des points particuliers et selon des angles de prise de vue définies ou pour localiser des processus particuliers (franchissements, affouillements, départs de sables...) sont par exemple particulièrement utiles à la compréhension et à la documentation des phénomènes.

Le second type d'intervention porte sur la réalisation de travaux en urgence afin de fiabiliser le comportement du massif ou du cordon dunaire vis-à-vis de la protection des populations. Sur le plan réglementaire, les travaux d'urgence sont encadrés par l'article R 214-44 du Code de l'environnement qui stipule que :

"Les travaux destinés à prévenir un danger grave et présentant un caractère d'urgence peuvent être entrepris sans que soient présentées les demandes d'autorisation ou les 
déclarations auxquelles ils sont soumis, à condition que le préfet en soit immédiatement informé. Celui-ci détermine, en tant que de besoin, les moyens de surveillance et d'intervention en cas d'incident ou d'accident dont doit disposer le maître d'ouvrage ainsi que les mesures conservatoires nécessaires à la préservation des intérêts mentionnés à l'article L. 211-1. Un compte rendu lui est adressé à l'issue des travaux. »
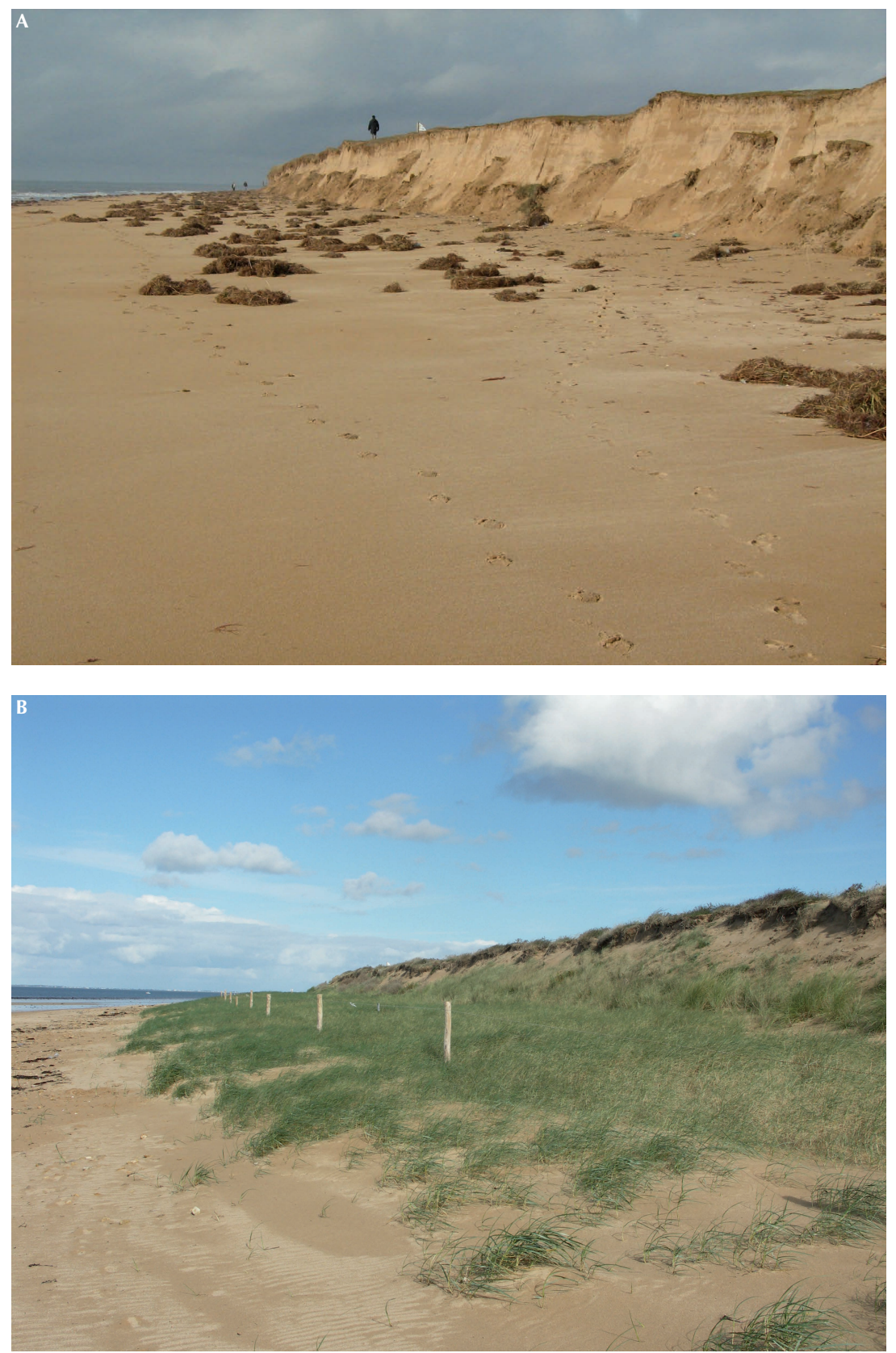

Figure 3.13. Évolution de la dune à Notre-Dame-de-Monts (Vendée).

A. État de la dune le $1^{\text {er }}$ mars 2010 : la tempête Xynthia a provoqué une érosion généralisée.

B. Octobre 2012 : la pose d'un fil lisse a permis à la végétation de s'installer et de piéger le sable.

(C) J. Magne. 
Cependant, la circulaire du 7 avril 2010 indique bien que «les procédures d'urgence ne sauraient conduire à la construction d'ouvrages nouveaux voire au rehaussement d'ouvrages existants ».

Techniquement, les travaux d'urgence à mettre en œuvre sur les environnements dunaires devraient s'appuyer sur des techniques adaptables et réversibles (ouvrages souples et temporaires : big bag de sable ou autres dispositif similaires...), et ce afin de permettre un retour rapide à l'état naturel de l'environnement, sans risque de générer de déséquilibres majeurs et pérennes du milieu provoquant sa modification en profondeur.

Dans tous les cas, l'utilisation des moyens humains et matériels disponibles au cours d'un événement doit tenir compte des risques tant pour les personnels que pour les équipements mobilisés. Les efforts doivent également se concentrer naturellement sur les secteurs où l'état du cordon dunaire peut laisser craindre une évolution aux conséquences les plus importantes pour les populations.

\section{L'après-crise et le retour à une situation normale}

Après le passage $d^{\prime} u n$ événement particulièrement destructif, la réalisation d'une visite de contrôle dans les jours suivants, et l'établissement d'un diagnostic des désordres et des évolutions constatées permettront d'orienter les futures actions de gestion à entreprendre à court, moyen et long terme. Ce retour d'expérience doit permettre une meilleure adaptation aux nouveaux épisodes de crise.

C'est ainsi que l'exemple d'actions de la collectivité Océan-Marais de Monts est assez parlant en ce qui concerne les dunes des Pays de Monts (Vendée). Alors que la tempête Xynthia avait occasionné (en 2010) un recul généralisé du cordon dunaire de 5 à 10 mètres selon les zones, la pose d'un simple fil lisse en haut de plage au cours du printemps suivant a permis de protéger la zone concernée, et de ce fait de favoriser l'installation d'une végétation fixatrice, de la protéger, et, profitant des conditions sédimentaires favorables, de reconstituer une avant-dune de 7 mètres de largeur. Ce matelas de sable a permis au cordon dunaire d'être en partie protégé au cours des épisodes tempétueux suivants (figure 3.13) et a réalimenté la plage.

\section{Fiches des techniques d'intervention}

\section{Utiliser le vent et la végétation pour piéger le sable}

\section{David Rosebery}

Pour limiter l'avancée des sables mobiles, le principe de base de la gestion des dunes va consister à modérer l'érosion éolienne en réduisant la vitesse du vent par plusieurs types de dispositifs. Ainsi freiné, le vent sera moins érosif et déposera le sable transporté. En favorisant ensuite la végétalisation, le gestionnaire assurera le développement de plantes qui limiteront les départs de sable et s'adapteront naturellement au rythme d'accumulation du sable. Nous allons voir les différentes techniques utilisées, ainsi que leurs avantages et leurs conditions d'utilisation. 


\section{Les rideaux brise-vent}

LEUR RÔLE

Ce sont des obstacles verticaux qui permettent de piéger le sable dans les secteurs à fort transit sableux. On les utilise essentiellement dans les secteurs frontaux pour provoquer de la sédimentation et éviter ainsi la déflation. Leur fonctionnement est simple ; à proximité du sol, ils réduisent la vitesse du vent qui ne peut plus transporter le sable. Celui-ci se dépose sur l'obstacle ou juste en arrière.

Les différents types de brise-vent : rappel historique

L'utilisation de rideaux brise-vent dans la lutte contre l'érosion éolienne est ancestrale, avec des matériaux très diversifiés suivant les régions et même les pays.

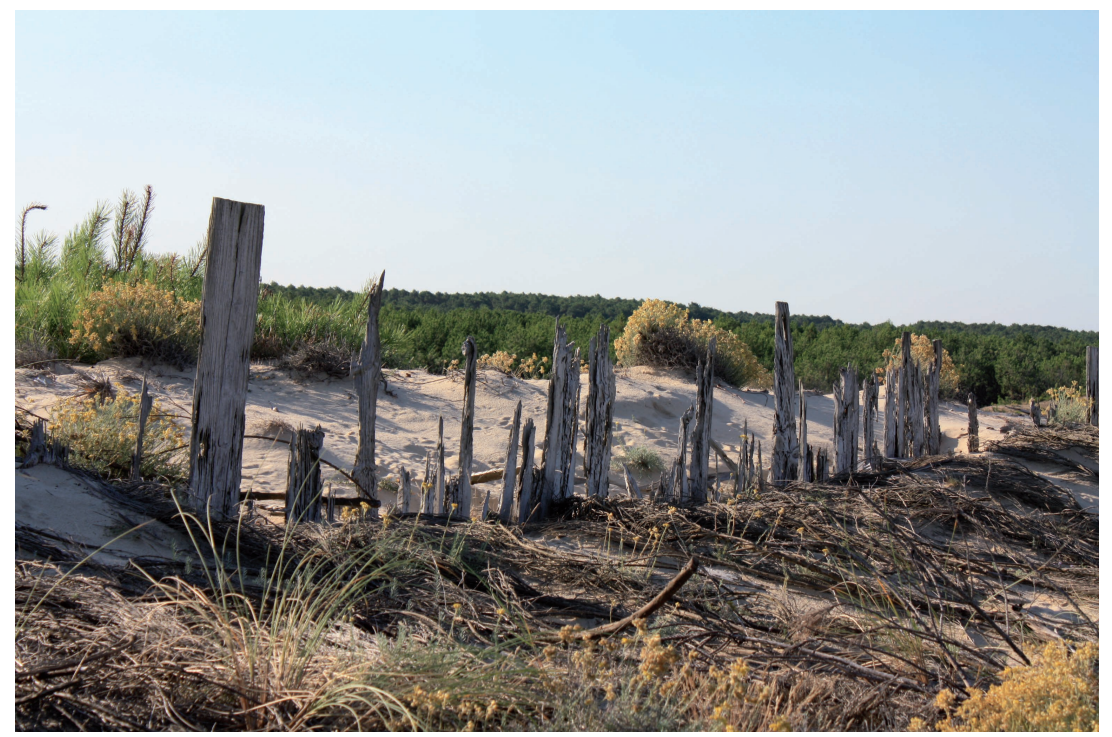

Figure 3.14. Vestiges d'une ancienne palissade destinée à piéger le sable.

(C) L. Gouguet/ONF.

L'usage des palissades de planches et des cordons tressés, courant dans le passé pour protéger les ateliers de reboisement du XIXe siècle et édifier la dune bordière calibrée, est aujourd'hui exceptionnel. Ces techniques efficaces, mais lourdes à mettre en œuvre, ont été relayées par la pose de dispositifs brise-vent plus légers et donc plus faciles à mettre en œuvre, à base de palissades de végétaux (bruyère à balais, lattes de châtaignier...).

Utilisés au début des années 1980, les treillis plastiques ont été abandonnés à partir des années 1990 au profit des palissades en matériaux naturels et biodégradables telles que les ganivelles de châtaignier, puis les filets en fibres de coco.

Les principaux types de brise-vent utilisés actuellement

Par définition, les brise-vent ont vocation à être ensablés plus ou moins rapidement. Les matériaux utilisés doivent donc être choisis en fonction de leur durabilité et de la vitesse d'ensablement escomptée. Une fois ensevelis, les brise-vent ne peuvent plus remplir leur fonction, de nouveaux rideaux de brisevent doivent donc être installés si on veut continuer à piéger du sable. 


\section{LES GANIVELLES}

Ce sont des clôtures perméables constituées de lattes de châtaignier reliées par du fil de fer torsadé. Très efficaces pour le guidage du public, mais aussi pour la lutte contre l'érosion éolienne, elles ont de multiples qualités : matériau renouvelable local, durabilité, biodégradabilité et bonne intégration paysagère.

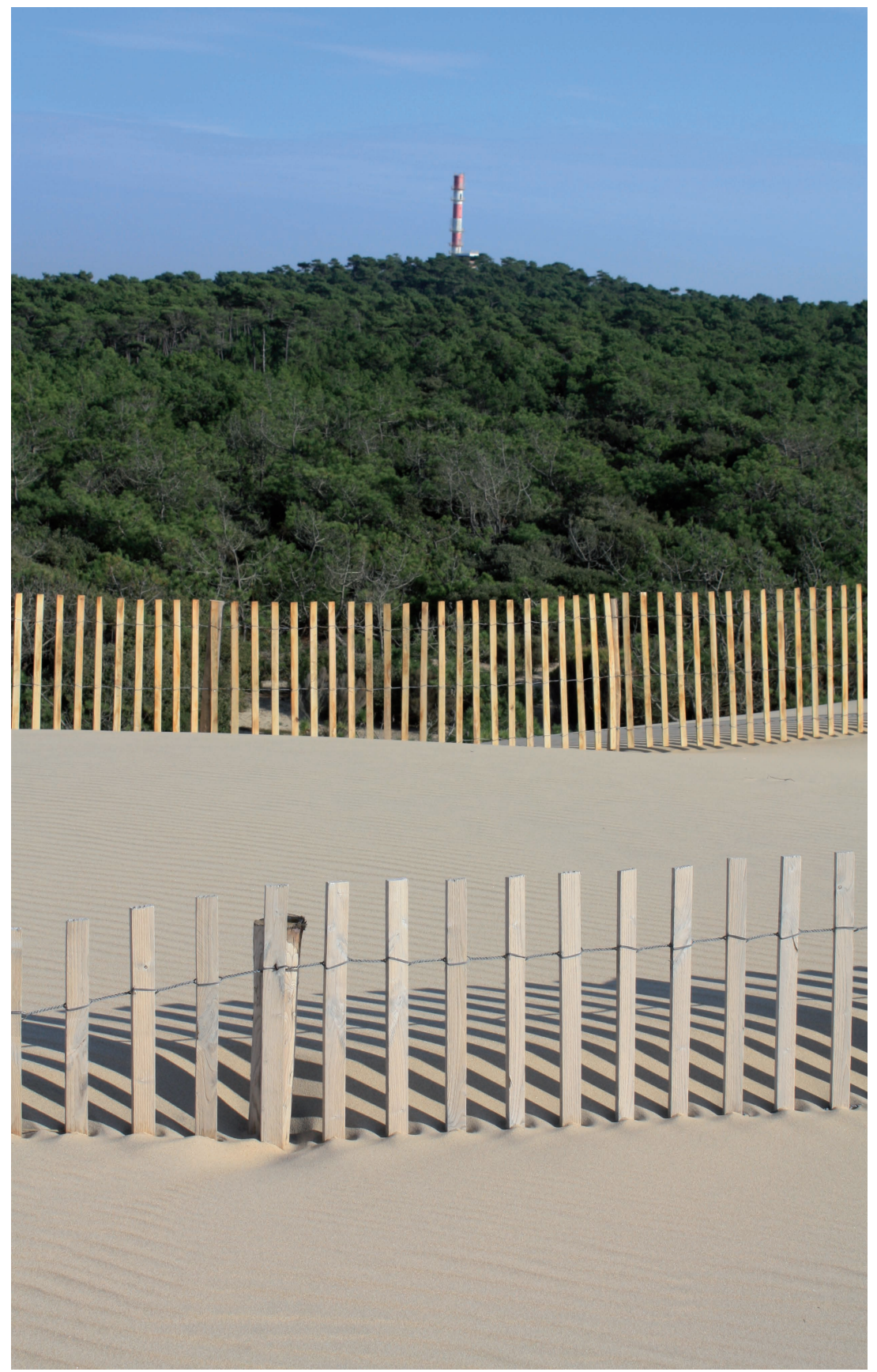

Figure 3.15. Ganivelle (La Coubre).

(C) L. Gouguet/ONF. 
LES FILETS EN FIBRE DE COCO

Ce sont des filets souples fabriqués en fibres de coco. Ce matériau a commencé à être utilisé en Aquitaine à la fin des années 1990, pour se développer sur l'ensemble du littoral.

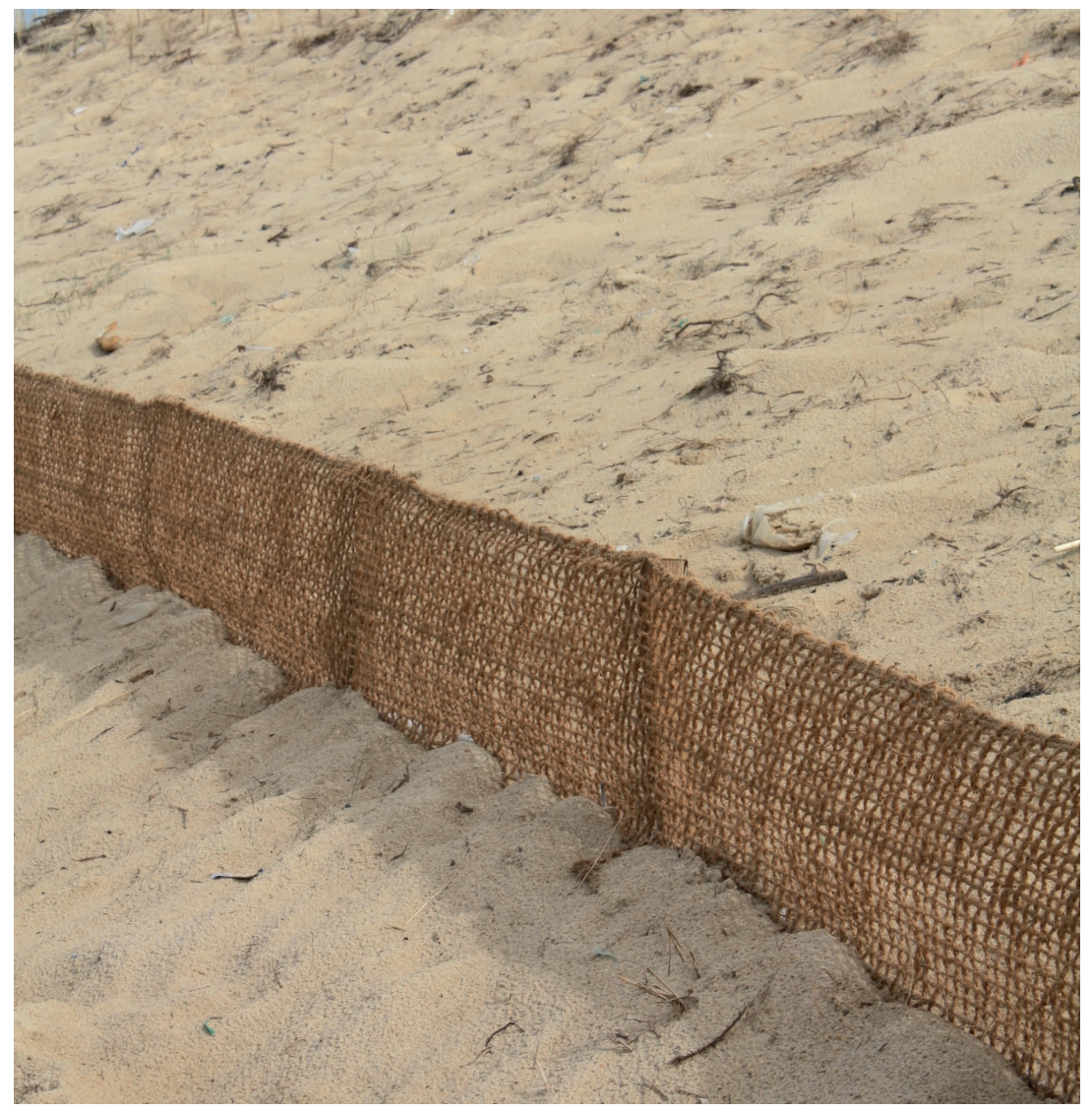

Figure 3.16. Filet en fibre de coco.

(C) L. Gouguet/ONF.

\section{LES AIGRETTES ET LES FASCINES}

Ce sont des branchages isolés (aigrettes) ou en fagots (fascines) fichés verticalement dans le sable, en quinconce ou en rideau. Ces techniques, demandant une grande manutention et une matière première facilement disponible, ne sont pratiquement plus utilisées en France depuis une cinquantaine d'années. Par contre, les brise-vent en osier sont largement utilisés sur les côtes d'Espagne en raison de leur coût relativement bas, de leur acquisition facile et de leur montage simple.

\section{Méthodes de mise en œuvre des différents types de brise-vent}

Principes généraux : Situations optimales d'Utilisation des BRISE-VENT

Les rideaux brise-vent sont opérationnels dans les zones de transit sableux où ils peuvent rapidement se charger de sable. C'est principalement en zone frontale, pendant les phases de répit de l'érosion marine, que la pose de brise-vent est fréquente et efficace. Par ailleurs, cette technique est bien adaptée pour combler des zones déprimées que l'on souhaite surélever. 


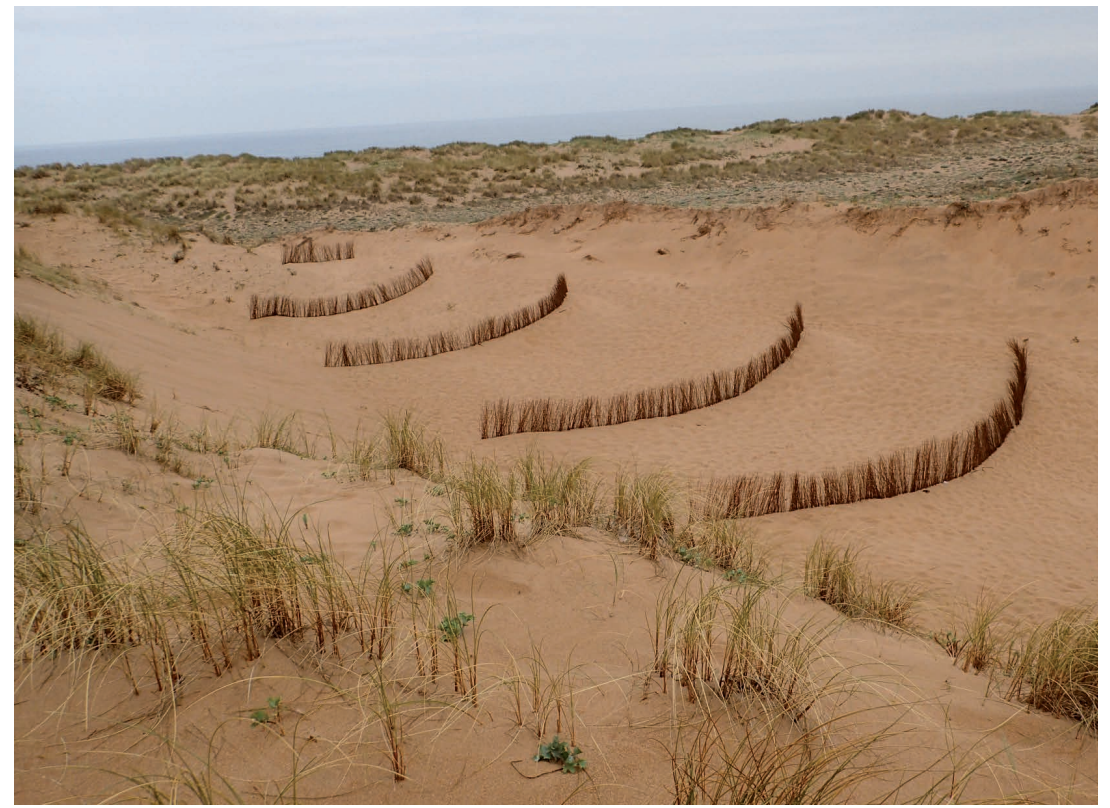

Figure 3.17. Fascines d'osier utilisées en Espagne.

(c) L. Gouguet/ONF.

La pose de brise-vent peut être associée à d'autres techniques, par exemple : - couvertures de branchages dans une zone déprimée lorsqu'une altitude satisfaisante est obtenue ;

- plantation d'oyat (et/ou d'Agropyron), qui complète et naturalise l'action des brise-vent...

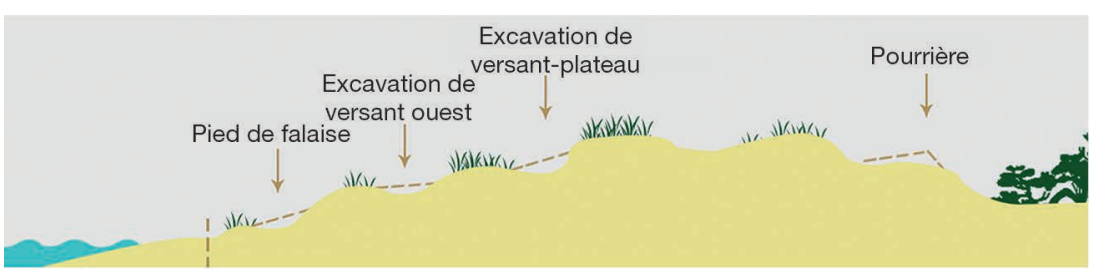

Figure 3.18. Sites favorables à l'implantation de brise-vent.

Source : J. Favennec/EUCC-France.

Il y a également des situations mal adaptées à l'usage de brise-vent (voir encadré 3.1).

\section{MOdES D'IMPLANTATION}

De multiples modalités existent suivant la configuration locale et les objectifs : lignes parallèles, maillage, zigzag, en courbes de niveau... L'implantation la plus efficace des rideaux brise-vent, lorsque les mouvements de sable sont importants, est une succession de lignes parallèles, perpendiculairement aux vents dominants.

La hauteur des brise-vent utilisés est fonction de l'intensité du transit de sable et de la profondeur des dépressions à combler. Dans la pratique, les hauteurs les plus courantes sont de $1 \mathrm{~m}$ pour les forts transits et de $0,5 \mathrm{~m}$ pour les transits modérés. 


\section{LES BRISE-VENT EN GANIVELLES}

On trouve deux grands types de ganivelles:

- ganivelles en échalas triangulaires de châtaignier refendus, écorcé et épointé, de différentes perméabilités et hauteurs ;

- ganivelles en lattes sciées de châtaignier (et parfois d'autres essences), de différentes perméabilités et hauteurs.

On doit bien choisir le type de ganivelle selon le but poursuivi. Pour le freinage du vent et le blocage de sable en transit, un dispositif opérationnel est rapidement ensablé, le matériau peut donc être très rustique et peu coûteux. Les ganivelles sciées, de coût inférieur pour une efficacité équivalente, seront préférées.

Les ganivelles sont accrochées sur des fils de fer tendus entre des piquets de châtaignier fixés régulièrement.

Les ganivelles basses $(50 \mathrm{~cm})$ présentent le plus d'avantages :

- transport et mise en place plus facile,

- adaptation plus fine des interventions selon le résultat des premières lignes posées,

- bonne résistance au vent et à la fréquentation,

- meilleure intégration paysagère.
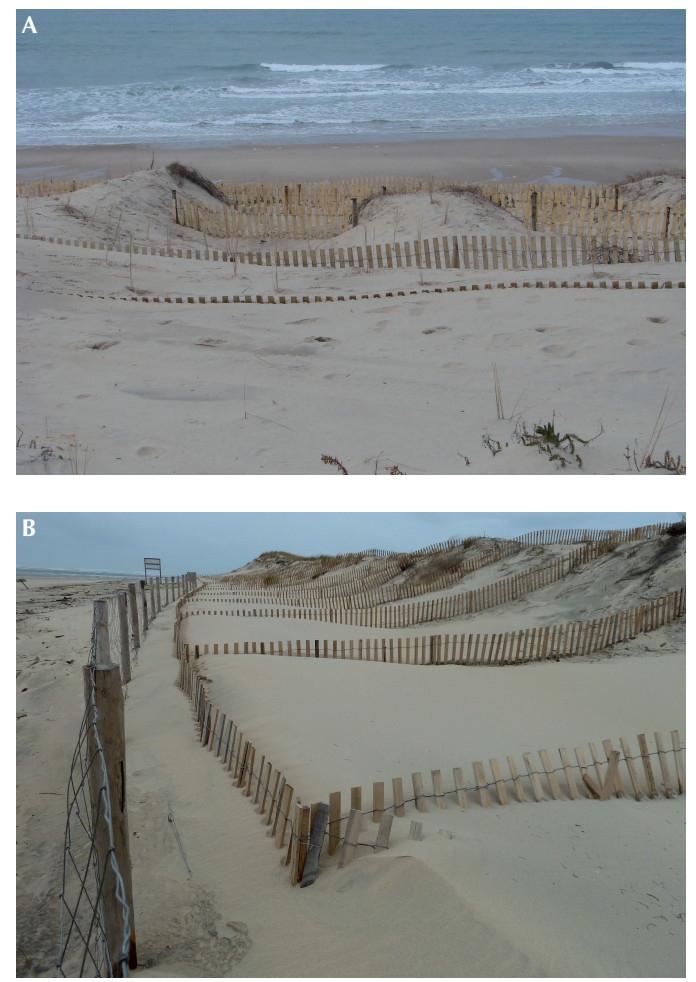

Figure 3.19. Brise-vent utilisés en zone frontale pour recharger le profil dunaire.

$C^{\prime}$ est en zone frontale, dans les secteurs de côte qui connaissent une alternance entre phases d'érosion marine et phases de répit, que l'usage de brise-vent est le plus fréquent.

A. Ganivelles utilisées en zone frontale (Hourtin, Gironde).

B. Les ganivelles disposées en casier sont destinées à reconstituer la dune (Cap Ferret, mars 2007).

(C) L. Gouguet/ONF. 

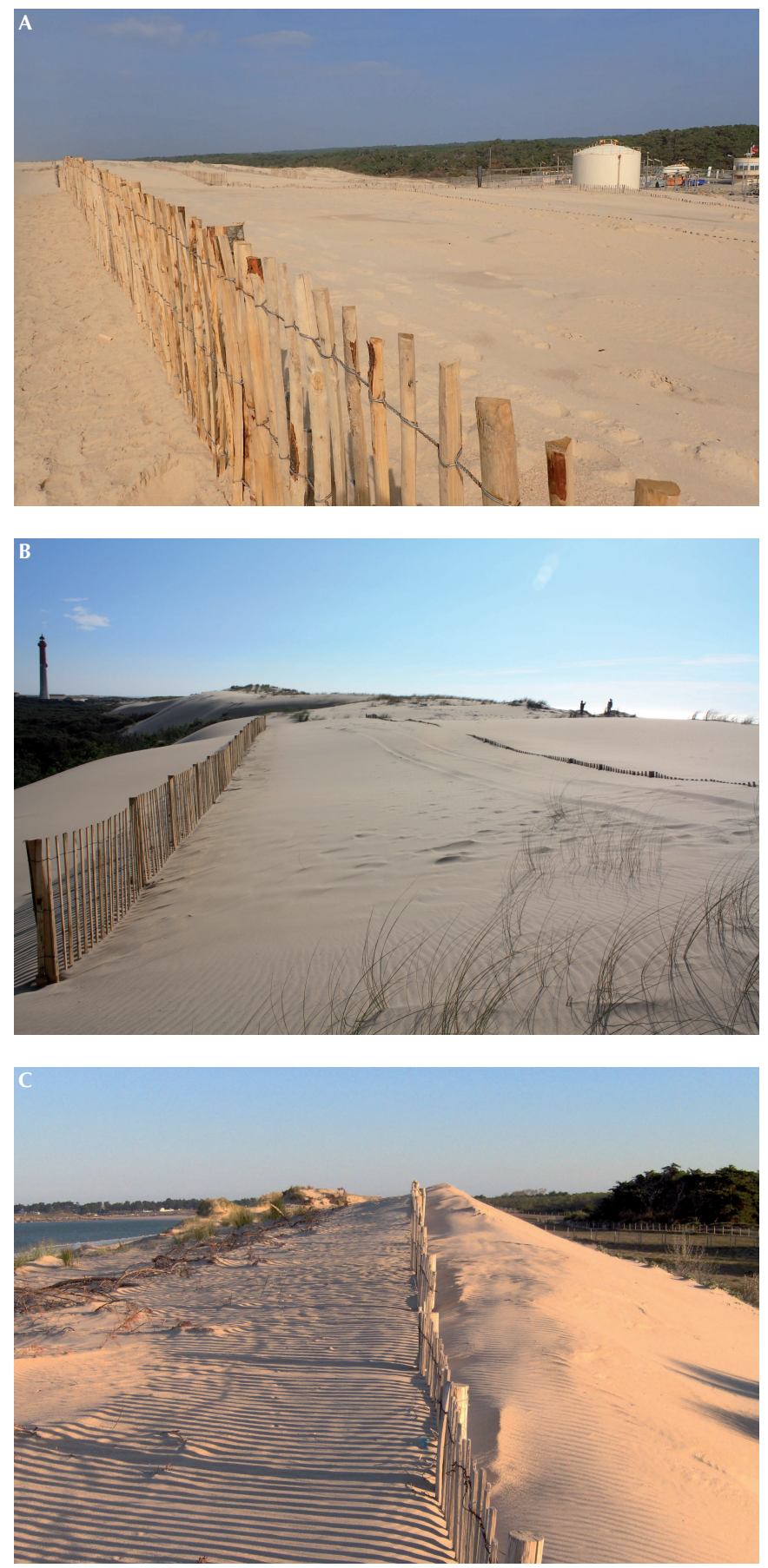

Figure 3.20. Brise-vent en ganivelles utilisés hors de la zone frontale pour limiter l'étalement du sable en arrière-dune et/ou pour maintenir la continuité longitudinale du cordon.

A. Ganivelles destinées à limiter l'étalement du sable (Cap Ferret).

B. La Coubre (Charente-Maritime), octobre 2015.

C. Noirmoutier (Vendée), Luzéronde, janvier 2004.

(C) L. Gouguet/ONF. 


\section{BRISE-VENT EN FIBRE DE COCO}

Alternative aux ganivelles, les brise-vent en filets de coco donnent satisfaction et présentent plusieurs avantages : bonne intégration paysagère, biodégradabilité, coût plus faible que celui des ganivelles, facilité de mise en œuvre. Cette facilité de mise en œuvre permet des interventions rapprochées : en cas de forte sédimentation, on peut revenir deux à trois fois au cours de l'hiver pour remettre des filets au même endroit.

Avec les filets coco, la sédimentation se fait sur des surfaces plus réduites que les ganivelles : pas plus d'un mètre derrière le filet, contrairement aux ganivelles où la sédimentation s'étale sur 2-3 mètres. Ces filets sont à réserver aux situations dans lesquels ils seront très rapidement ensablés (quelques semaines), car leur tenue dans le temps est médiocre.

Le matériau est en fibre de coco tressée, la perméabilité du filet est proche de $60 \%$ (mailles de l'ordre de $3 \mathrm{~cm} \times 3 \mathrm{~cm}$ ). Il est nécessaire de bien veiller lors de la pose à avoir un bon contact de la base des filets avec le sol, afin d'éviter leur déchaussement.
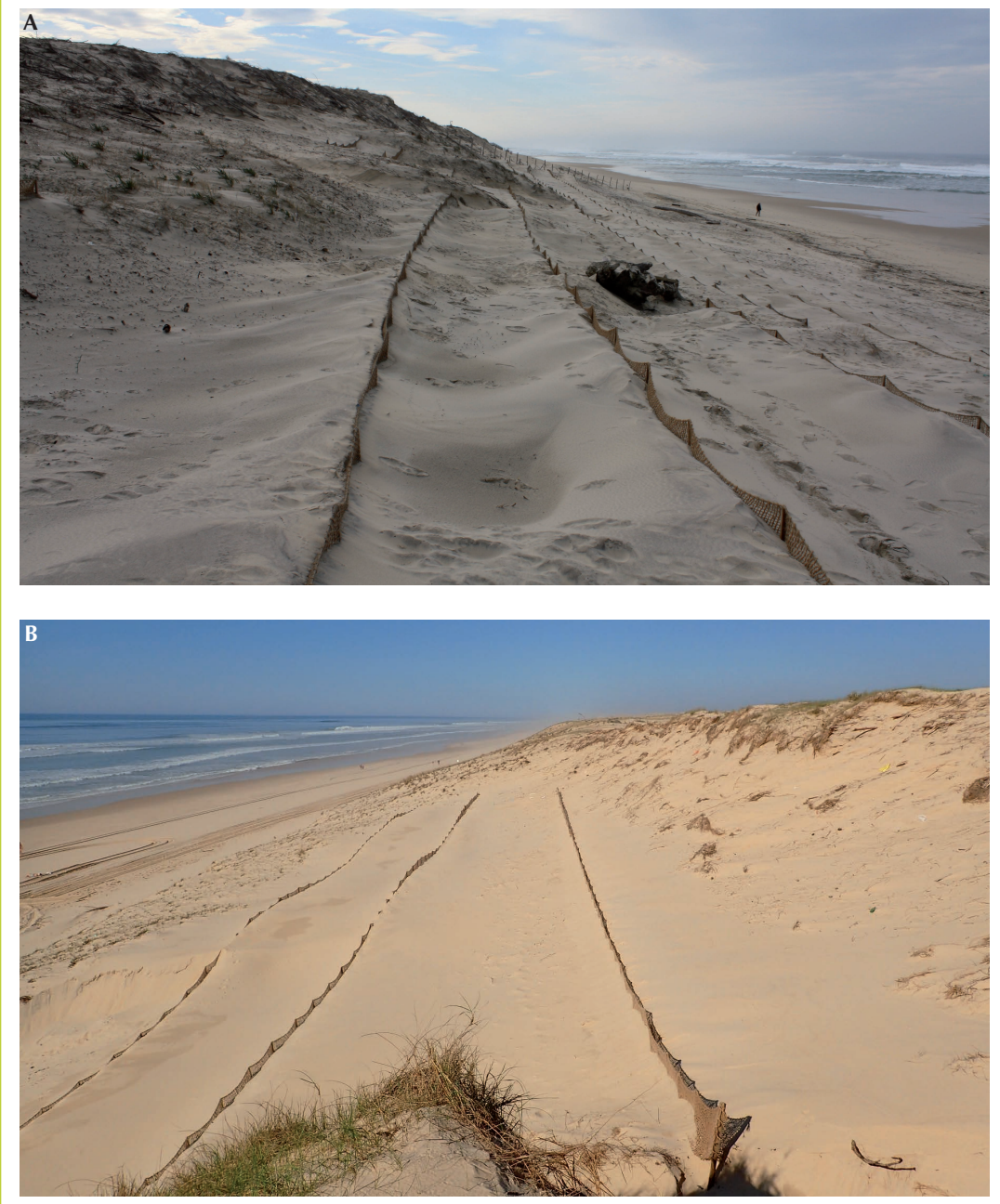

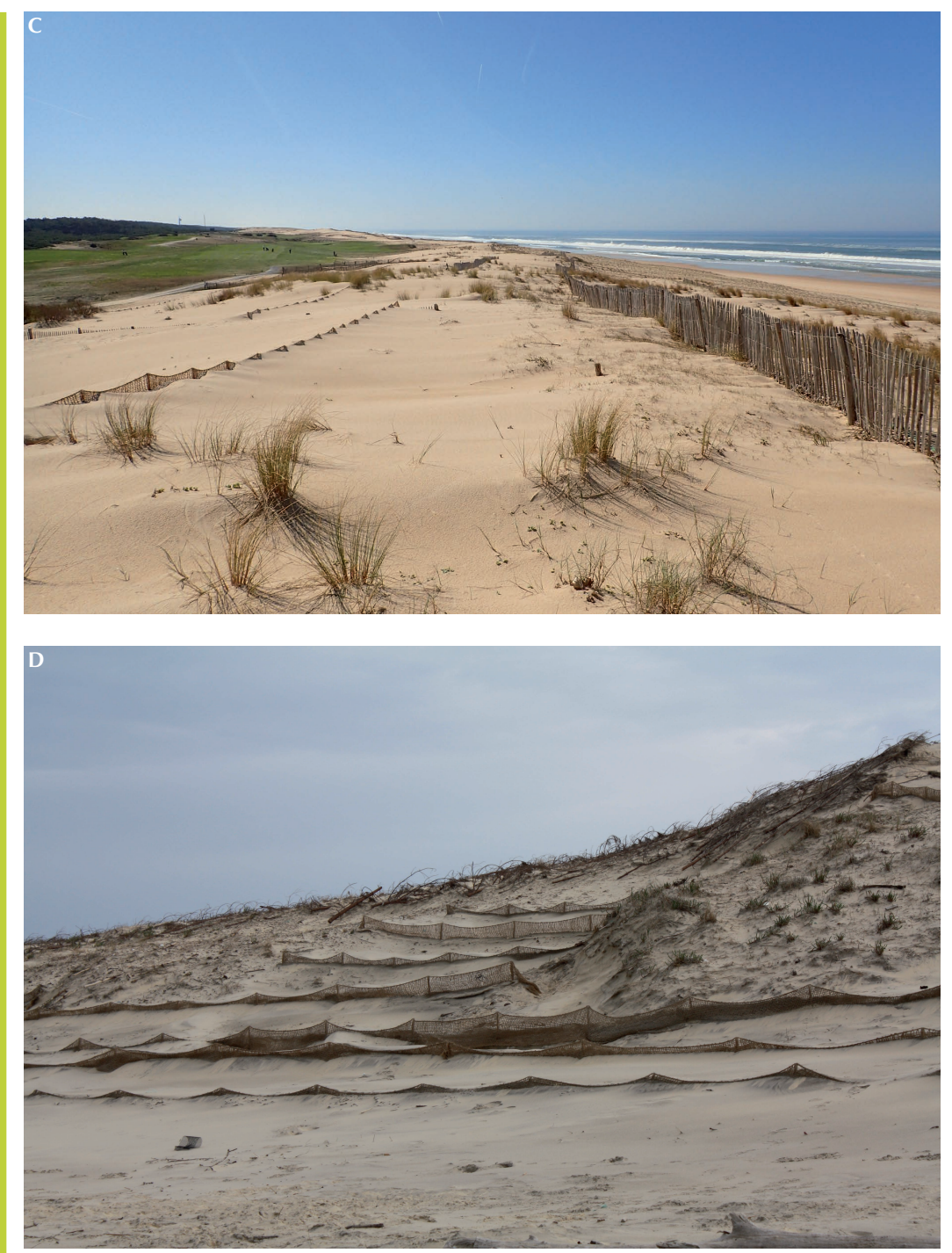

Figure 3.21. Exemples de brise-vent en fibre de coco.

A. Brise-vent en fibre de coco disposés en zone frontale (Biscarosse, janvier 2016).

B. Brise-vent en fibre de coco sur versant ouest (Cap de l'Homy, mars 2017).

C. Utilisation de brise-vent en fibre de coco en complément de la ganivelle disposée préalablement, devant le golf de Moliets et Maa (Landes).

D. Filets en fibre de coco disposés en zone frontale afin de combler une caoudeyre en formation (La Teste, Gironde).

(c) L. Gouguet/ONF.

\section{BRISE-VENT EN OSIER}

Ils sont composés de branches d'osier sec, plantées verticalement dans le sol, $\mathrm{d}^{\prime}$ une longueur moyenne de 1,80 $\mathrm{m}$, dont $0,60 \mathrm{~m}$ est enfoui et 1,2 $\mathrm{m}$ reste au-dessus du sol. Ils sont disposés en rangées parallèles avec une séparation entre eux de 8 mètres environ. 


\section{Encadré 3.1. Les écueils à éviter pour la pose de brise-vent.}

Les écueils à éviter pour la pose de brise-vent sont :

- la pose de brise-vent dans un secteur où le guidage du public est mal mâ̂trisé ;

- la pose de brise-vent dans un secteur de forte pente où domine l'érosion ;

- la pose de brise-vent près du trait de côte en phase d'érosion marine ;

- la pose de brise-vent dans des couloirs d'érosion étroits ;

- la pose simultanée d'un trop grand nombre de lignes.

\section{Les couvertures}

LEUR RÔLE

Les couvertures de branchages réduisent fortement la vitesse du vent au niveau du sol, ce qui modère - ou supprime - l'érosion éolienne dans les secteurs en déflation. Elles favorisent la reprise et le développement des communautés végétales assurant la fixation pérenne de la dune en piégeant les graines portées par le vent et en leur offrant un substrat favorable en se décomposant.

Par ailleurs, dans les zones de transit sableux, elles provoquent une accumulation de sédiment, ce qui permet de combler des zones déprimées pour reconstituer des profils aérodynamiques.

\section{MATÉRIAUX}

La plupart des débris et des branchages végétaux sont efficaces pour freiner la vitesse du vent. Cependant, le souci de conserver au milieu un grand degré de naturalité réduit les possibilités (voir encadré 3.2).

Les branchages les plus utilisés sont ceux dont on dispose à proximité, dans les forêts à l'arrière de la dune littorale. Ils sont de plusieurs types : les rémanents de coupes d'arbres (pin maritime, chênes), les pins de dépressage, les arbustes du sous-bois (principalement genêt et brande)...

\section{DifFÉRENTS TYPES DE COUVERTURES ET MÉTHOdES DE MISE EN đUUVE}

La méthode de mise en place la plus courante est l'épandage en plein sur des zones de sable dénudé ou très peu végétalisé, les modalités les plus fréquentes sont de trois types.

\section{LES COUVERTURES PLANES DE BRANCHAGES FINS (ESPÈCES BUISSONNANTES ET ARBUSTIVES) ÉTALÉS MANUELLEMENT}

- Matériaux, collecte et transport

Les branchages d'espèces buissonnantes les plus utilisés sont les rameaux de genêt à balais (Cytisus scoparius), abondants en sous-bois, notamment dans les parcelles en régénération. La brande (bruyère à balais, Erica scoparia) est également un très bon matériau, dont la décomposition est plus lente que celle du genêt, mais il est peu abondant. On doit éviter la récolte de printemps (faible lignification et risque d'échauffement). La longueur optimale des rameaux est de 1,2 à 2 mètres. Les grosses tiges sont à exclure. 
- Épandage, densité

L'épandage des rameaux se fait en quinconce, pied vers les vents dominants, ramure d'une ligne recouvrant le pied de la ligne précédente, une pelletée de sable sur les ramures bien étalées au sol. Suivant la situation, les densités réalisées varient. La densité sera plus forte dans des secteurs très exposés et dénudés, et plus faible sur des secteurs de plateau ou d'amorces de déflation.

- Époque favorable

La période optimale de mise en place est l'automne-hiver, avant les tempêtes qui ensablent les couvertures. Si la couverture doit être suivie de plantation, préférer l'automne de façon à assurer un bon sablage avant la plantation en décembre-janvier.

- Exemples de réalisations

Historiquement, ce type de couverture a connu un très grand développement, systématiquement mis en œuvre lors des plantations de versant externe et de plateau lors des remodelages mécaniques des années 19601980. Aujourd'hui, ces couvertures sont principalement utilisées en entretien, elles présentent une très bonne intégration paysagère.
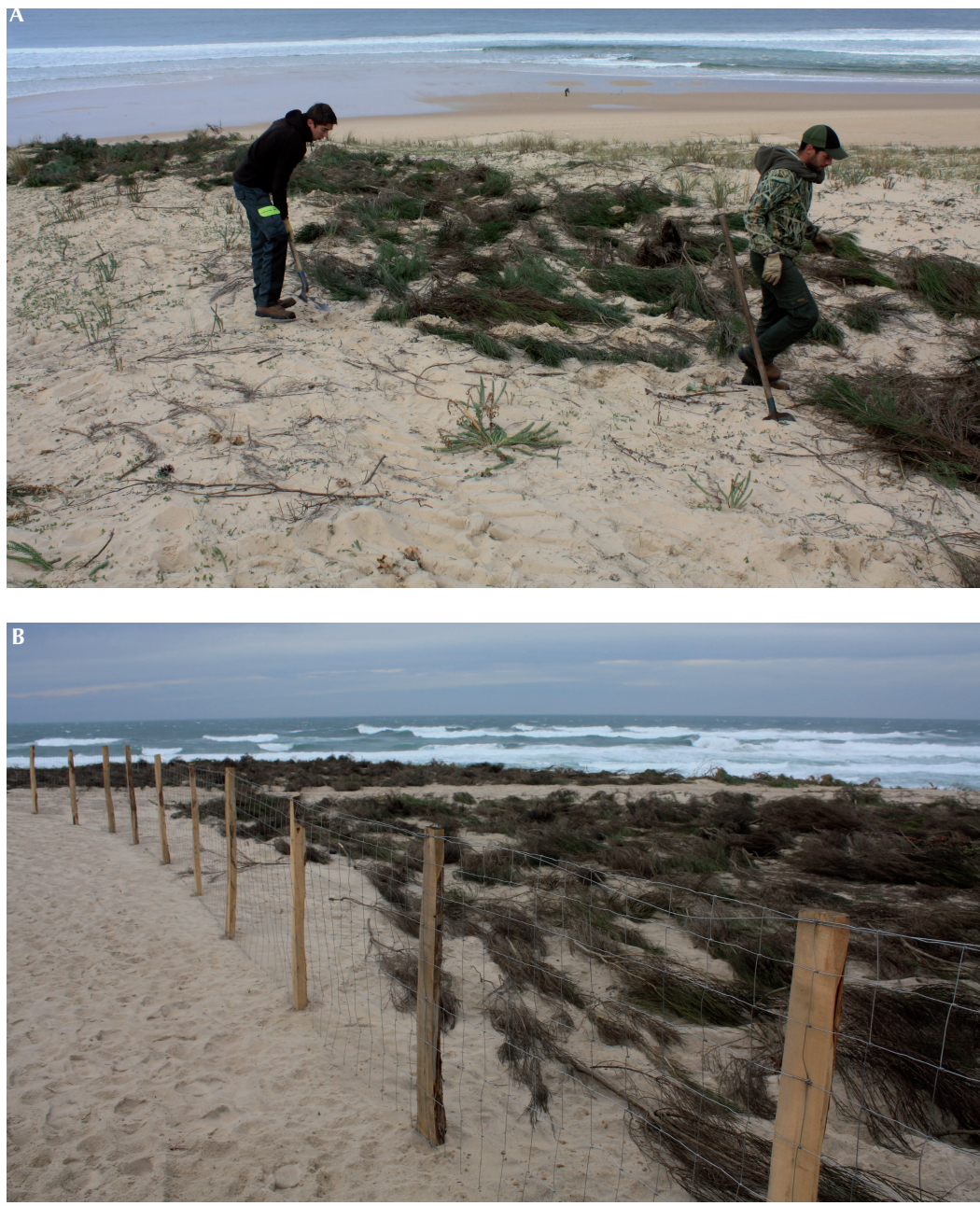


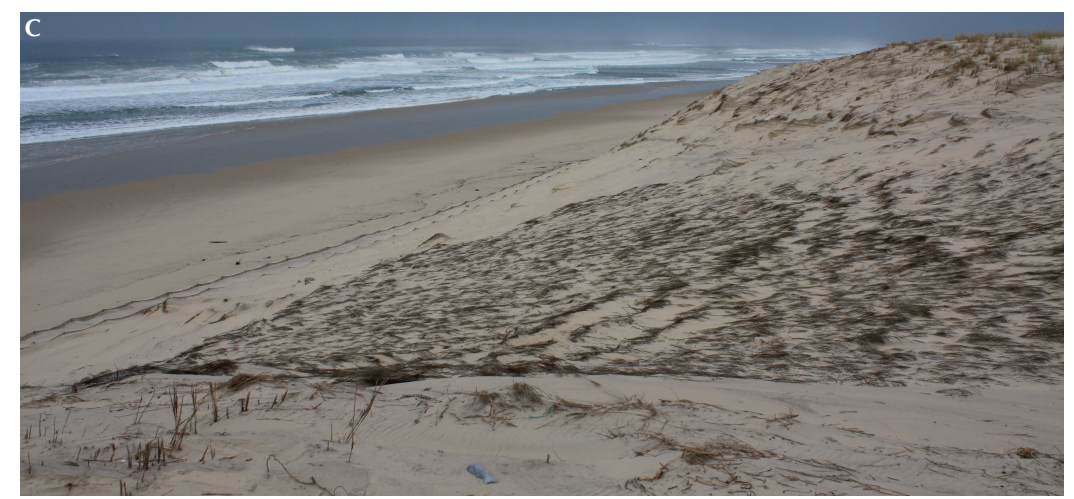

Figure 3.22. Exemples de couvertures planes de genêt.

A. Couverture de genêts sur un passage (Landes), 2015.

B. Couverture plane de genêts (Capbreton, janvier 2016).

C. Couverture de genêt ensablée en zone frontale à faible pente (La Teste, janvier 2016).

Sources : A et C. @ L. Gouguet/ONF ; B. (C) L. Rosebery/ONF.

\section{LES COUVERTURES DE PINS DE DÉPRESSAGE ÉTALÉS MANUELLEMENT}

C'est une technique intermédiaire entre les couvertures planes de genêt et les couvertures de branchages grossiers de pin. Elle peut être utilisée avant plantation d'oyat.

- Collecte et transport

Le matériau provient des premières opérations culturales dans les semis de pin maritime, ce sont des pins de dépressage (âgés d'environ 4-8 ans) de 2 à $3 \mathrm{~m}$ de long. On doit exclure l'usage de pins chétifs, faiblement ramifiés, ou de pins plus âgés, matériaux devenant trop grossiers.

- Épandage, densité

Les pins de dépressage sont étalés manuellement sur les zones de sable nu ou très peu végétalisé. Ils sont disposés en quinconce, avec léger recouvrement. La densité, comme pour le cas de branchages fins, peut varier en fonction du contexte dynamique.

- Époque favorable

De préférence en automne et en hiver, lorsque les branchages ont le plus de chance d'être ensablés, puis colonisés naturellement par les végétaux.

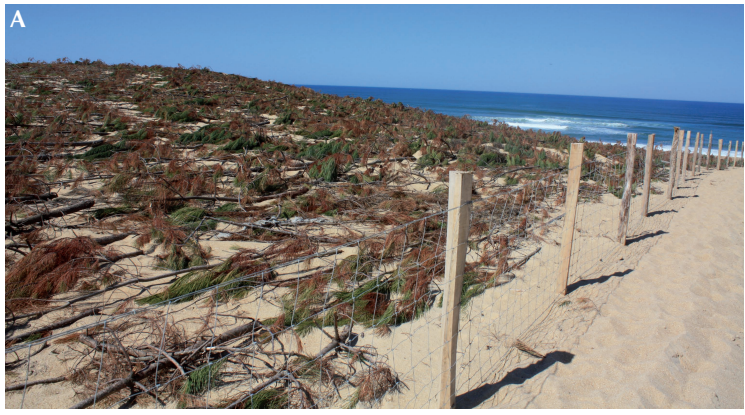




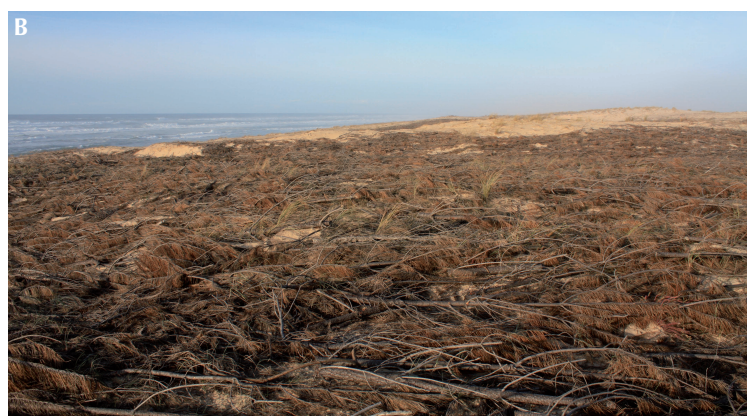

Figure 3.23. Exemples de couvertures planes de pins de dépressage.

A. Couverture plane de pins de dépressage, sur déflation sommitale (Capbreton, Landes).

B. Couverture plane de pins de dépressage en plateau (Seignosse, Landes, 2015).

(C) L. Gouguet/ONF.

\section{LES COUVERTURES DE BRANCHAGES DE LIGNEUX (RÉMANENTS D'EXPLOITATION DÉMONTÉS) ÉPANDUS MÉCANIQUEMENT}

Ces matériaux plus grossiers servent à lutter durablement contre l'érosion éolienne sur les secteurs de sable nu. On les utilise généralement après reprofilage de la dune sur les zones de plateau, en arrière des secteurs exposés au vent qui sont traités avec des matériaux fins et des plantations.

- Matériaux, collecte et transport

Ce type de couverture concerne principalement les houppiers de pin maritime, provenant de rémanents de coupes de régénération dans la forêt dunaire. Ce sont des branchages grossiers à décomposition lente. Ces matériaux peuvent être source durable de rudéralisation* par apport de végétaux exogènes (graines).

Des branchages d'autres essences arborées sont également utilisés avec des résultats comparables : rémanents de chênes, voire d'arbousiers.

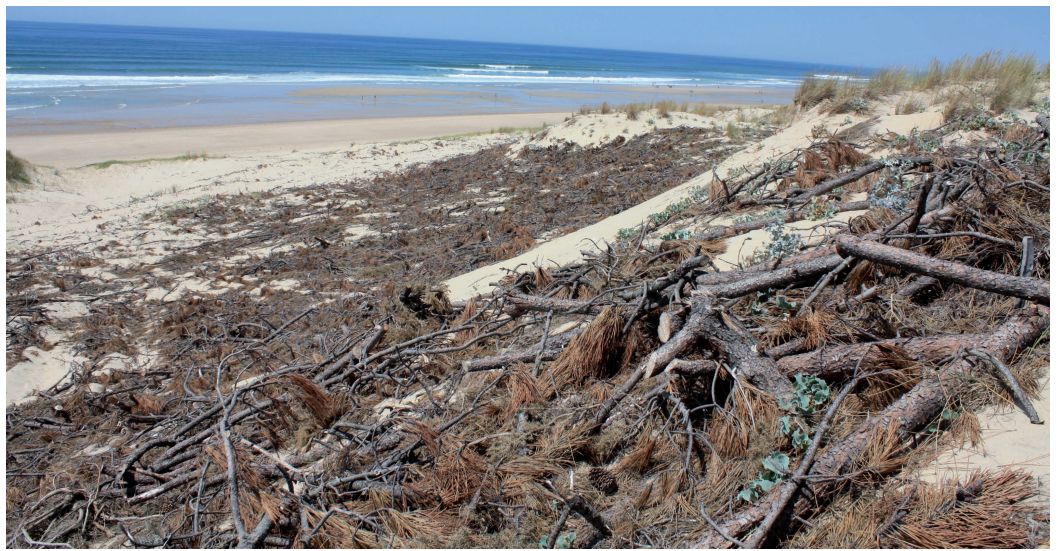

Figure 3.24. Couverture dense de branchages grossiers (Hourtin, Gironde, juillet 2012). (C) L. Gouguet/ONF. 
- Épandage, densité

L'épandage est réalisé mécaniquement par des porteurs forestiers équipés de grues avec grappin, qui ont l'avantage d'effectuer transport et épandage sans rupture de charge. Les quantités mises en œuvre sont très variables, allant de 450 à $1000 \mathrm{~m}^{3} / \mathrm{ha}$.

- Époque favorable

Comme pour les autres couvertures, la période la plus favorable est l'automne-hiver.

\section{Encadré 3.2. Les écueils à éviter pour la pose de branchages.}

Les écueils à éviter pour la pose de branchages sont

- un apport d'espèces exogènes indésirables,

- une couverture trop dense,

- des matériaux trop grossiers et des souches qui se décomposeront difficilement,

- des dégâts de transport démesurés,

- une couverture trop systématique des zones à végétation claire,

- sur les grands chantiers, épandre au fur et à mesure des apports pour éviter l'ensablement des dépôts trop anticipés...

\section{LA VÉGÉTATION}

Afin de favoriser la cicatrisation de la dune dans les secteurs perturbés, on peut utiliser des plantations de végétaux endogènes.

L'espèce végétale la plus utilisée, en France et en Europe, pour contrôler le mouvement des dunes bordières sous l'action du vent est l'oyat (Ammophila arenaria), appelé aussi gourbet (en Aquitaine).

L'Agropyron ou " chiendent des sables » (Agropyrum junceum ou Elymus farctus), herbacé des avant-dunes qui - loin derrière l'oyat - est le plus utilisé sur les parties les plus proches de l'océan.

D'autres végétaux indigènes peuvent être plantés ou semés sur les dunes, tels que I'armoise de Lloyd (Artemisia campestris maritima), I'immortelle (Helichrysum stoechas)... Mais ces plantations restent anecdotiques, puisque I'on cherche avant tout à fixer les sables mobiles en utilisant les végétaux de dune mobile.

- Les plantations d'oyat (gourbet)

L'oyat est une poacée (graminée) cespiteuse omniprésente sur les dunes blanches des côtes d'Europe. Elle est dotée de fortes adaptations au milieu : très grande résistance à l'ensablement par émission de rhizomes et de racines au fur et à mesure de son recouvrement, long et dense réseau racinaire, tolérance des feuilles au mitraillage et à la salinité, aptitude à réduire sa transpiration.

L'oyat est une espèce psammophile (amie des sables) par excellence. C'est la mobilité du substrat qui conditionne sa croissance, son développement est optimal dans les zones de transit et d'accumulation de sable. Par contre, elle ne supporte pas le déchaussement, dans les secteurs de forte déflation. 
Elle ne supporte pas non plus la compétition interspécifique, c'est pour cela qu'on ne la retrouve pas dans les secteurs de dune fixée à fort recouvrement

végétal. L'oyat est doté de plusieurs modes de dissémination :

- une multiplication sexuée : les inflorescences d'oyat, panicules en forme de longs épis, sont mûres vers mi-juillet; les graines disséminées à l'entour produisent de nombreux semis naturels ;

- une multiplication végétative : I'oyat se propage puissamment par rhizomes (tiges souterraines).

C'est ce dernier mode de dissémination qui est utilisé lors des travaux de dunes.

- Conditions favorables aux plantations d'oyat

Les sites favorables sont les zones d'accumulation et les zones de transit de sable frais.

Dans les faciès de déflation-transit, des couvertures préalables sont nécessaires. L'oyat, de façon générale, résiste mal au déchaussement, c'est d'autant plus vrai pour des boutures récentes (ou de jeunes semis), il est donc préférable de prévoir systématiquement des couvertures planes avant plantation (ou semis).

La largeur plantée ne doit pas être trop forte, car la bande frontale engraisse très vite et la partie arrière souffre de déficit sableux, voire de déflation.

\section{- Techniques de plantation}

Les boutures sont prélevées localement, dans des touffes denses d'oyat, en repos végétatif hivernal (de novembre à février).

La plantation est manuelle. Plusieurs modalités existent, la plus fréquente est la plantation en quinconces $(80 \times 80 \mathrm{~cm})$. On peut aussi planter en lignes ou selon des méthodes mixtes. L'espacement des boutures peut varier de $50 \mathrm{~cm}$ à 1 mètre.

Le dispositif en quinconces 80 × $80 \mathrm{~cm}$ est le plus fréquent : lignes espacées de $80 \mathrm{~cm}$, boutures espacées de $80 \mathrm{~cm}$.

La plantation manuelle consiste à introduire dans des trous de $25 \mathrm{~cm}$ de profondeur des touffettes* de 4 à 6 brins. Le sable doit ensuite être bien tassé avec le talon.

La plantation en lignes est aujourd'hui peu fréquente. Cette méthode peut constituer une bonne alternative, ou un complément, à la pose de rideaux brise-vent dans les dépressions ou caoudeyres que l'on souhaite gommer par accumulation de sable.

L'espacement entre les lignes est variable selon la pente et l'importance du transit sableux... Le plus fréquent est de 2 mètres. L'espacement entre les trous de plantation sur les lignes est de 15 à $20 \mathrm{~cm}$. La reprise de ce type de plantation est améliorée par une couverture des interlignes (genêt ou brande).

La plantation totalement aléatoire, parfois recherchée pour conserver un aspect naturel au site, est aussi pratiquée. Elle est toutefois plus difficile à réaliser en matière d'organisation de chantier : le contrôle de la bonne répartition de densité de plantation est moins évident, les équipes de planteurs préfèrent souvent disposer de guides d'implantation. En tout état de cause, lorsque l'oyat est installé dans un secteur à forte accumulation, il est très dynamique et l'aspect « ligne artificielle » disparaît au bout de quelques années. 


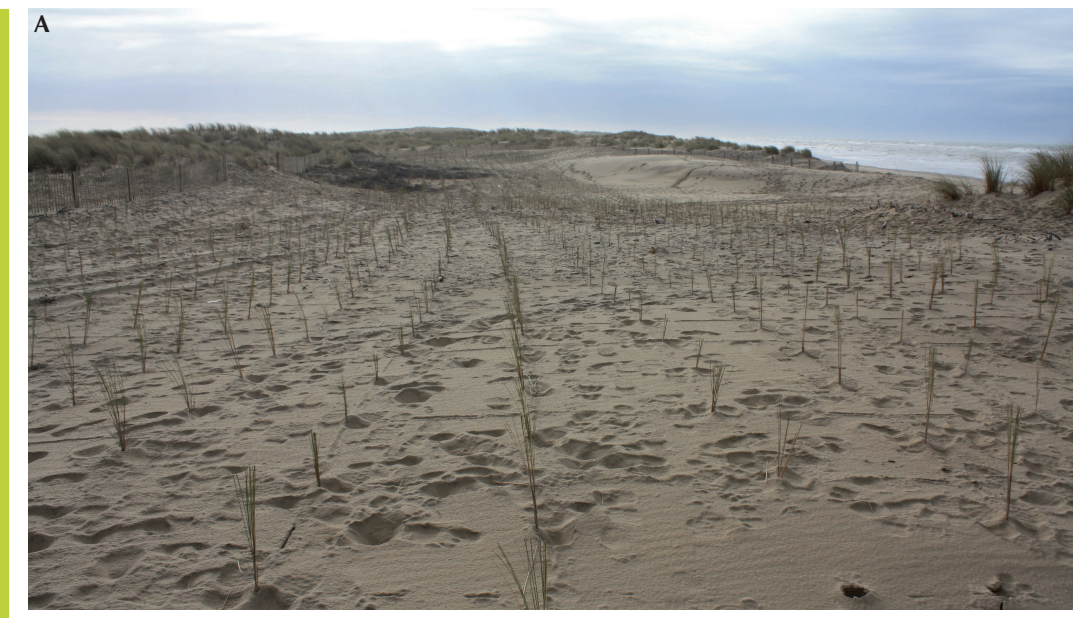

B
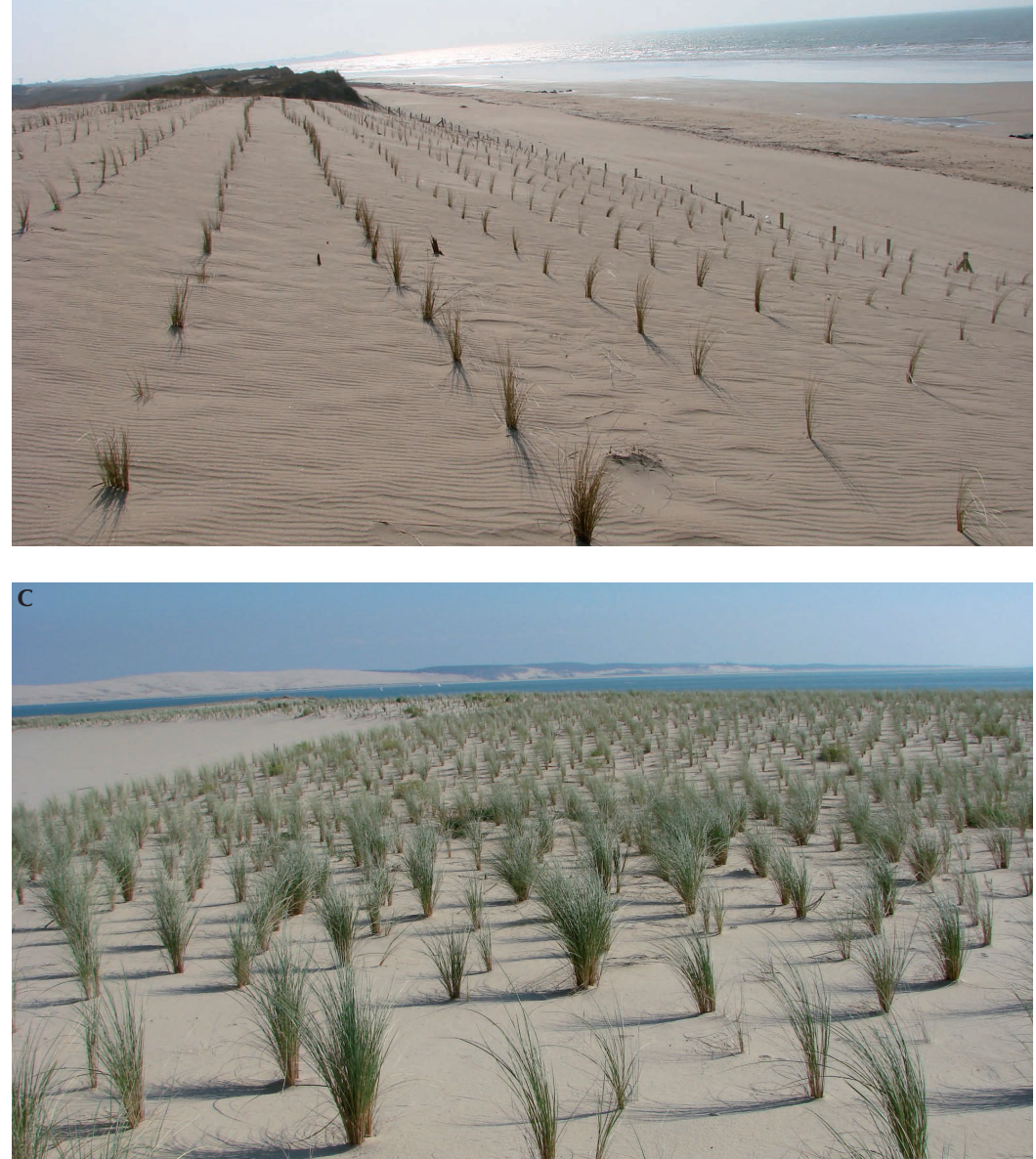

Figure 3.25. Exemples de plantations d'oyat en quinconces $80 \times 80 \mathrm{~cm}$.

A. Plantation récente d'oyat (La Coubre, Charente-Maritime, janvier 2015).

B. Plantation récente d'oyat (Saint-Hilaire-de-Riez, mars 2022).

C. Plantation d'oyat après trois années de végétation (Cap Ferret).

(C) L. Gouguet/ONF. 


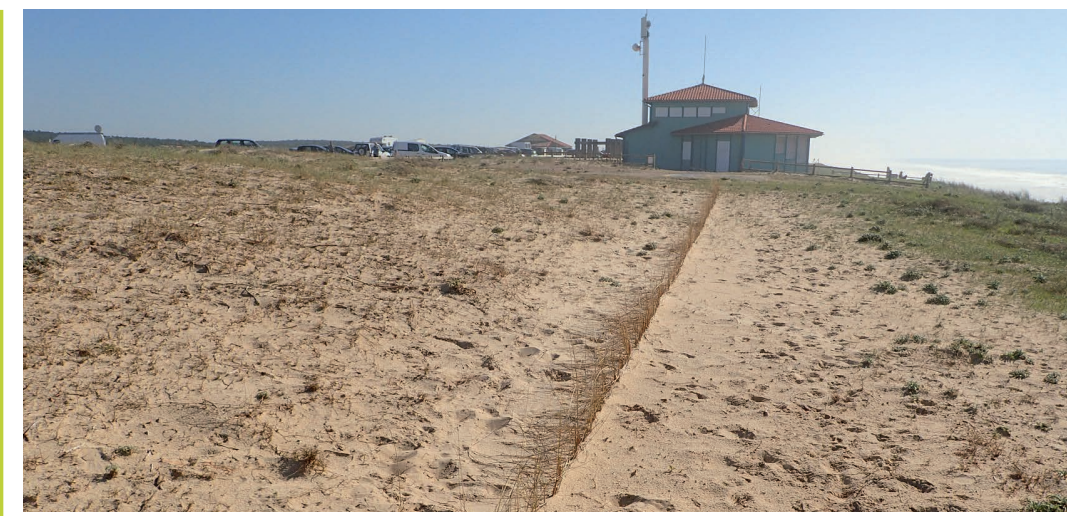

Figure 3.26. Exemple de plantation d'oyat en lignes (Cap de l'Homy, Landes).

(C) L. Gouguet/ONF.

\section{- Période de plantation}

Les plantations d'oyat sont effectuées en hiver durant le repos végétatif, soit en général de novembre à février.

- Les plantations d'Agropyron

L'Agropyron ou " chiendent des sables » (Agropyron junceum ou Elymus farctus) est une poacée (graminée) halophile caractéristique des premières dunes qui se forment en haut de plage pendant les périodes de répit de l'érosion marine. Espèce beaucoup plus tolérante au sel que l'oyat, il est mieux adapté que ce dernier pour les plantations effectuées en pied de versant externe car il va mieux supporter d'être temporairement atteint par les vagues lors des forts coefficients de marée.

Après des expérimentations probantes dans le Sud landais dans les années 1987-1989, I'Agropyron a été utilisé avec succès sur d'autres sites. II constitue une bonne alternative à l'oyat, sur l'ensemble du littoral AtlantiqueManche français, dans les parties frontales des cordons dunaires (pied de dune) en phase de répit de l'érosion marine.

La technique de plantation est proche de celle de l'oyat, enfouissement d'éclats prélevés dans d'importantes banquettes à Agropyron situées à proximité.

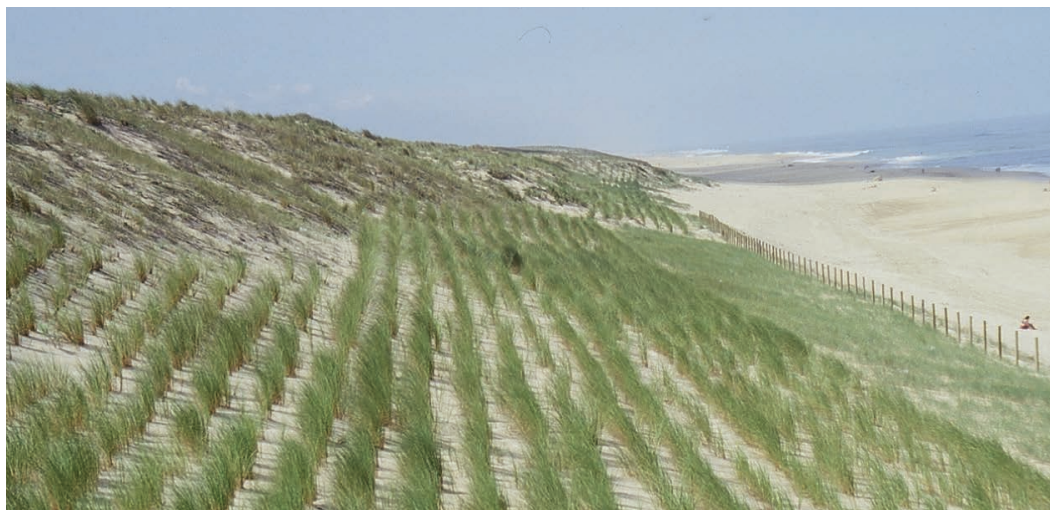

Figures 3.27. Plantation d'Agropyron à la base du versant externe et plantation d'oyat dans la partie médiane (Messanges, 1995).

(c) G. Granereau. 


\section{REPROFILAGES LÉGERS OU ÉCRÊTAGES PONCTUELS}

Si les interventions sur la dune sont essentiellement manuelles, il est parfois nécessaire d'y réaliser des travaux mécanisés. Deux grandes techniques de travaux sont utilisées.

- Les écrêtages ponctuels

Ils concernent les secteurs frontaux dégradés avec des caoudeyres frontales importantes. Les points hauts entre couloir de déflation ou caoudeyres et niveau du sol dunaire encore végétalisé sont écrêtés afin de limiter les points d'appui du vent et de faciliter le retour à un profil aérodynamique qui permet la mise en œuvre d'une couverture de branchages sur l'ensemble des zones en sable nu.

Parfois, on interviendra pour " écrêter » une corniche végétalisée au-dessus d'une falaise sableuse récente, afin de permettre à la dune de retrouver plus rapidement un profil aérodynamique et de limiter les risques d'effondrement de la falaise. On veillera au passage des engins par les chemins d'accès et les chemins d'entretiens afin de limiter leur impact sur le milieu naturel.

- Les reprofilages

Encore régulièrement en usage jusque dans les années 1980 comme outil de gestion, les grands reprofilages systématiques ne sont plus utilisés, sauf pour des cas extrêmes de restauration complète d'un cordon. La gestion des dunes se fait par un accompagnement des processus naturels afin de laisser s'exprimer la diversité des paysages et des habitats naturels propres à ces milieux. Toutefois, il peut encore être nécessaire de réaliser des reprofilages : - soit légers, pour la création ou la reprise d'une descente à la plage, par exemple,

- soit plus lourds, pour le remodelage intégral d'un cordon dunaire.

Ce dernier cas de figure existe dans des contextes très spécifiques, pour des dunes urbaines où l'évolution de la dune vers les biens et les équipements nécessite son reprofilage à pas de temps régulier (20 à 30 ans).

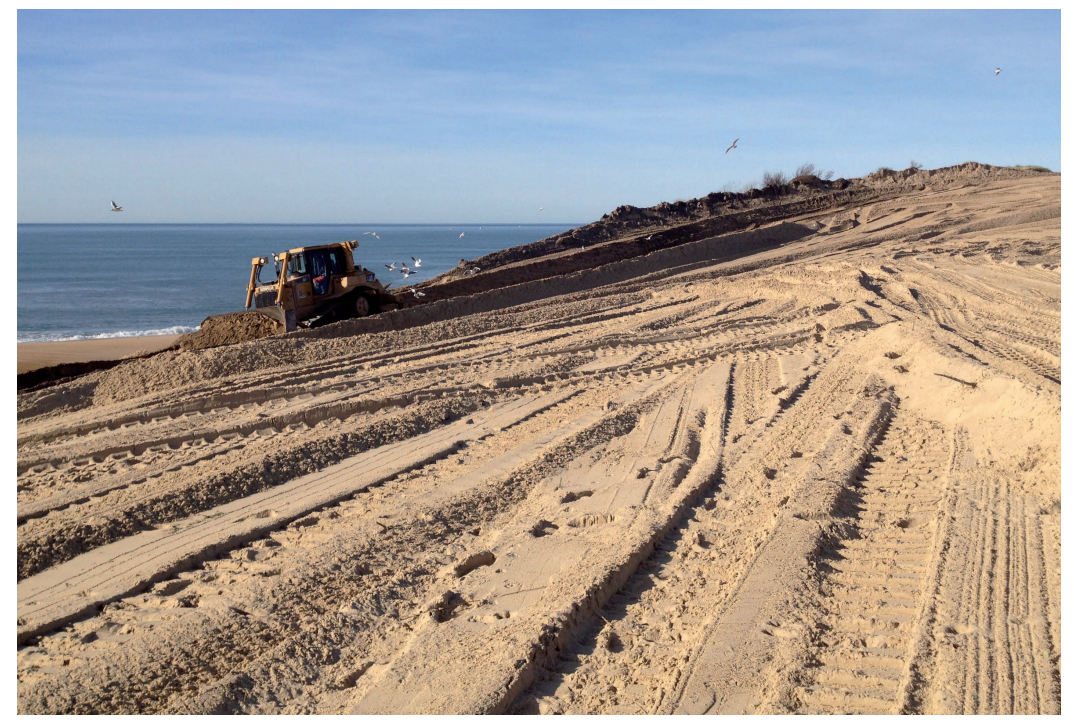

Figure 3.28. Reprofilage de la dune (Capbreton, Landes).

(C) D. Rosebery/ONF. 
En effet, les travaux importants de limitation de l'ensablement de l'arrièredune (plantations d'oyat, couvertures, rideaux brise-vent...) finissent par créer un haussement du cordon dunaire qui entraîne des instabilités difficilement contrôlables. Le versant interne tend alors à envahir inexorablement les enjeux urbains.

Un reprofilage est alors nécessaire pour rétablir un profil aérodynamique et éloigner le versant interne des enjeux urbains. Ces reprofilages s'accompagnent de couvertures de branchages sur les sables nus du versant externe et du plateau. Des plantations peuvent ensuite être réalisées sur les secteurs au vent.

Sur des secteurs de dune très mobile en abandon de gestion, ces techniques de reprofilage peuvent permettre la stabilisation du cordon dunaire. Les sédiments en surplus sont remis dans la cellule sédimentaire pour alimenter le littoral situé en aval de la dérive.

\section{Organiser la fréquentation}

\section{David Rosebery}

\section{Les zones d'accueil}

\section{LE LITTORAL, ESPACE CONVOITÉ MAIS FRAGILE}

L'espace littoral est un milieu convoité. Selon I'Insee, en 2005, près de $12 \%$ de la population française vivait sur le littoral (sur $4 \%$ du territoire métropolitain) et l'attractivité de ces espaces entraîne une fréquentation des zones côtières extrêmement forte, surtout en période estivale. Certaines cités balnéaires voient leur population multipliée par 10 ou 20 l'été, et certains grands sites d'accueil en Aquitaine peuvent avoir des fréquentations journalières de plus de 30000 personnes (figure 3.29).

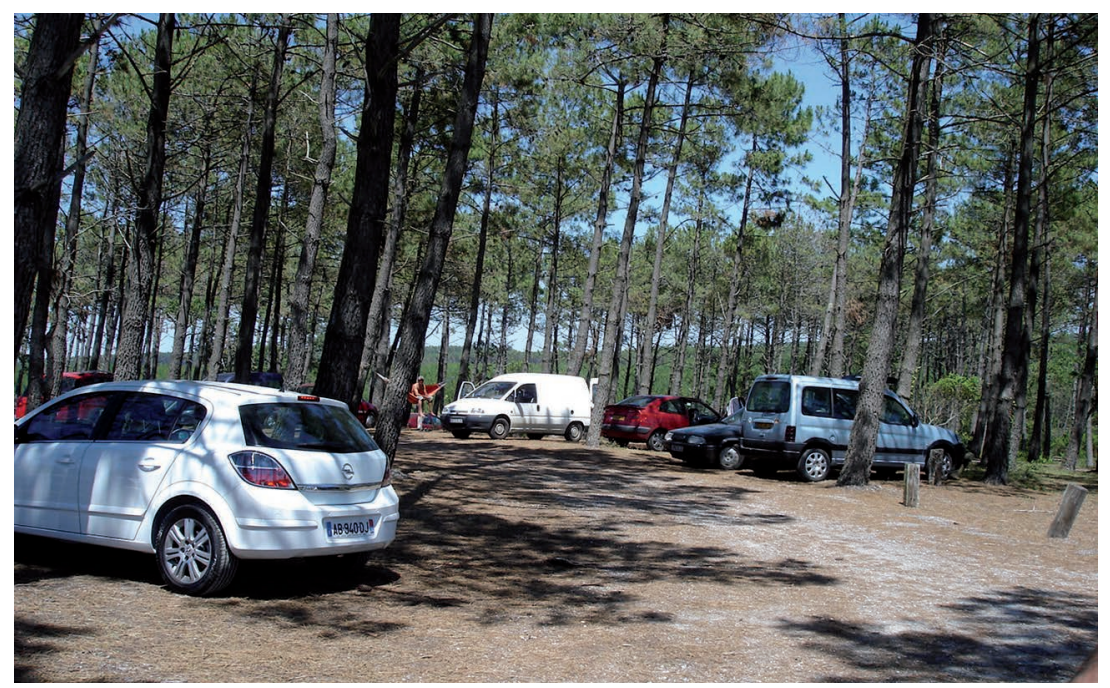

Figure 3.29. Parking sous couvert forestier. (c) J. Favennec/EUCC-France. 
Les milieux dunaires littoraux sont des corridors de biodiversité. Ils présentent des habitats naturels rares qui sont considérés comme prioritaires pour leur conservation au sens de la directive européenne " Habitats ». De nombreuses espèces animales ou végétales sont endémiques de ces milieux.

Les milieux littoraux sont aussi le lieu d'expression des dynamiques naturelles. L'érosion marine et, sur les côtes sableuses, les mouvements de sables sont des risques littoraux pouvant entraîner des atteintes sur les biens et les personnes. L'impact anthropique peut aggraver ces risques.

Aussi, la grande vulnérabilité de ces milieux oblige le gestionnaire à être vigilant sur l'impact de la fréquentation dans ces espaces, et donc à anticiper l'organisation de l'accueil en veillant à préserver les milieux naturels.

\section{L'ORGANISATION D'UN SITE D'ACCUEIL}

Accéder à la plage est le souhait de tous les estivants et, la plupart du temps, ils doivent pour ce faire traverser des milieux naturels fragiles. L'organisation de l'accueil du public vers les plages doit donc se faire de manière locale à l'échelle d'un site, mais aussi en cohérence à l'échelle d'un territoire.

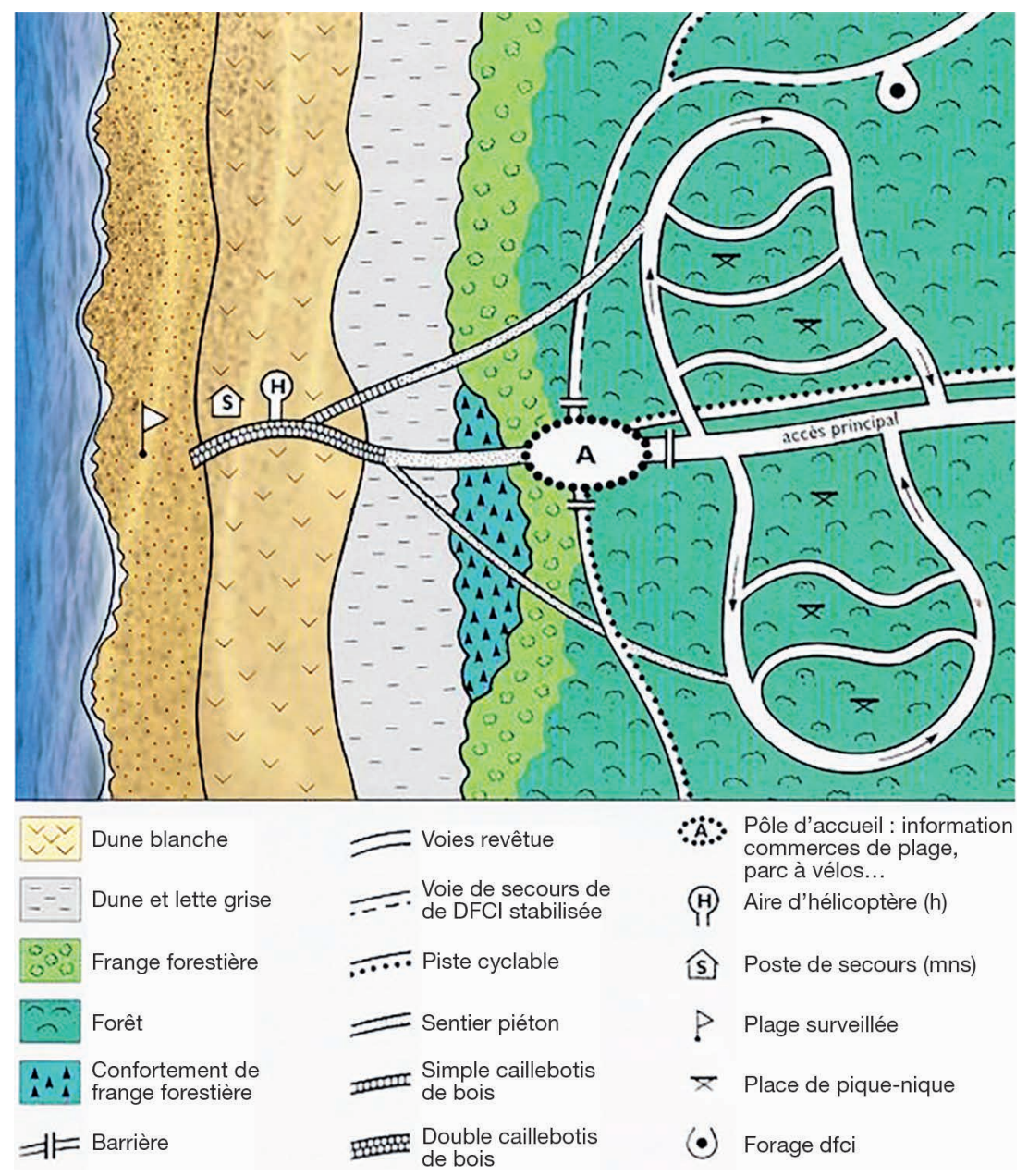

Figure 3.30. Organisation théorique du plan plage. Source: ONF. 
Prenons l'exemple de la côte aquitaine. Dès les années 1970, la Miaca (Mission interministérielle pour l'aménagement de la côte Aquitaine) a réfléchi à un aménagement concerté des espaces littoraux au travers d'un "Schéma d'aménagement de la côte Aquitaine » (1972), structurant le littoral en secteurs d'équilibres naturels, zones dédiées à la préservation d'un cadre naturel, et d'unités principales d'aménagement, zones de développement économique et social, permettant l'installation de fenêtres urbaines ou de stations balnéaires.

Ce schéma a en particulier introduit la notion d'organisation concertée de l'accueil du public à la plage en milieu naturel : le " plan plage », modèle d'accueil à l'échelle nationale.

Le plan plage a pour objectif général d'assurer l'accueil du public allant à la plage, dans un milieu naturel fragile, dans de bonnes conditions de sécurité et de protection de l'environnement.

Les aménagements réalisés permettent :

- de gérer les flux : voitures, vélos, transports en commun et piétons vers le site et sur le site ;

- d'organiser l'accès à la plage sans atteinte aux milieux naturels ;

- d'offrir des services et des équipements de confort ou de loisir en adéquation avec les attentes du public ;

- de gérer la sécurité du public (équipements de surveillance, de secours, d'évacuation...) ;

- d'apporter une information de qualité sur les milieux littoraux et leurs richesses.

La loi dite « littoral » de 1986 a aussi permis de faciliter un aménagement léger et raisonné de la bande côtière et d'orienter la politique d'aménagement des sites d'accueil.

\section{L'ÉTUDE PRÉALABLE À L'AMÉNAGEMENT D'UN SITE}

Afin de définir au mieux les programmes d'aménagement, des études préalables sont indispensables pour évaluer les caractéristiques du site et adapter les équipements.

Au préalable, une phase de diagnostic fournira un état des lieux général du fonctionnement du site :

- connaissance des richesses faunistiques et floristiques ;

- connaissance de l'état de conservation des milieux dunaires et de l'impact du public sur ceux-ci ;

- connaissance des dynamiques naturelles sur le site (évolution du trait de côte, instabilités en milieu rocheux, ou ensablement ou mobilité en milieu sableux) ; - connaissance des contraintes réglementaires et foncières (plan d'urbanisme, loi littoral, classements divers) ;

- connaissance des flux de circulation sur le site et vers le site (niveau de fréquentation en saison et hors saison, offre touristique à l'échelle locale ou intercommunale, types d'accès et modalités de déplacement, utilisateurs du site et leurs attentes...) ;

- connaissance de l'état des équipements existants et des points noirs organisationnels ;

- dans certains cas, une phase de concertation avec les acteurs (sportifs, baigneurs...) peut également venir compléter cette phase de diagnostic, afin d'essayer de répondre ultérieurement aux besoins des utilisateurs du site tout en préservant les milieux naturels. 


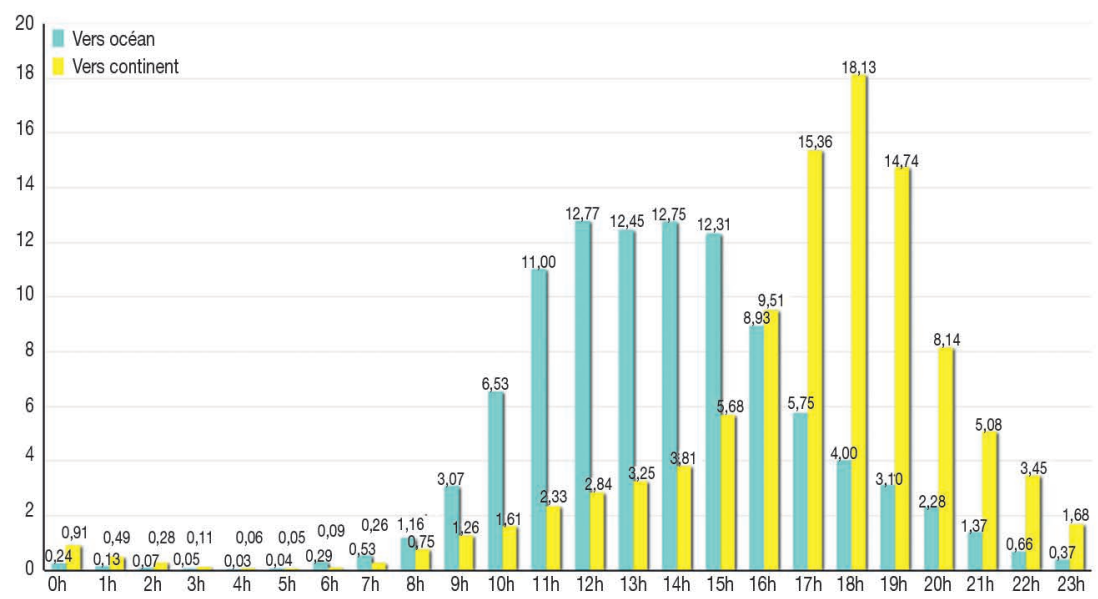

Figure 3.31. Exemple de comptage des véhicules arrivant/partant sur le site existant. Source : ONF.

Dans un second temps, une phase de propositions d'actions permettra, en lien avec les collectivités locales et les utilisateurs du site, à chaque étape de la démarche :

- la définition des objectifs par grande thématique (protection, accueil, sécurité) ; - la traduction en actions par grande thématique, budgétisées en investissement initial et en entretien annuel.

Un des éléments de réussite du projet est la concertation : elle permet I'appropriation des enjeux de protection par les acteurs locaux et l'expression de la demande de publics (sportifs, baigneurs...) qui n'ont pas forcément tous les mêmes besoins. Mieux les connaître peut là aussi permettre d'avoir un ciblage plus performant pour répondre aux enjeux de protection.

En résumé, il est indispensable d'adapter l'aménagement d'un site aux besoins des publics (niveau de fréquentation, type de public, modalités d'accès...) et aux caractéristiques naturelles (degré de fragilité, dynamique marine, richesses biologiques), mais aussi aux capacités financières du gestionnaire et de ses partenaires éventuels. L'étude préalable permet d'éviter les erreurs encore trop fréquentes de surdimensionnement ou sous-dimensionnement des infrastructures, et de positionnement d'équipements dans une zone à risque.

\section{Le guidage}

\section{ÉLÉMENT ESSENTIEL POUR LA PRÉSERVATION DES MILIEUX NATURELS}

Si I'organisation générale d'un site (stationnements, flux, équipements) est importante pour la sécurité du public et le bon fonctionnement général de I'accueil, la canalisation du public est le point essentiel de l'aménagement. En effet, I'objectif principal est bien la défense des milieux naturels. Une notion fondamentale en matière de guidage est qu'il n'existe pas un niveau de guidage, mais des niveaux de guidages. Comme mentionné précédemment, c'est la configuration du site qui va conditionner le niveau de mise en défens.

On ne va pas aménager un site fréquenté par 200 personnes/jour comme un site fréquenté par 10000 personnes/jour, ni un site stable du point de vue de l'évolution du trait de côte comme un site en érosion, ou un site avec des dunes très basses et peu évolutives comme un site avec des massifs dunaires puissants et mobiles. 
Sur des sites très vulnérables, il sera nécessaire de guider fortement le public avec des clôtures dissuasives sur l'ensemble de l'espace d'accueil ; sur des sites peu vulnérables, le guidage pourra être plus discret.

Le choix des types de matériaux de mise en défens se fera en fonction de la dynamique du site et des possibilités du gestionnaire. Sur des zones à fort transit sableux, on privilégiera par exemple des matériaux perméables afin de limiter leur ensablement, et donc augmenter leur efficacité.

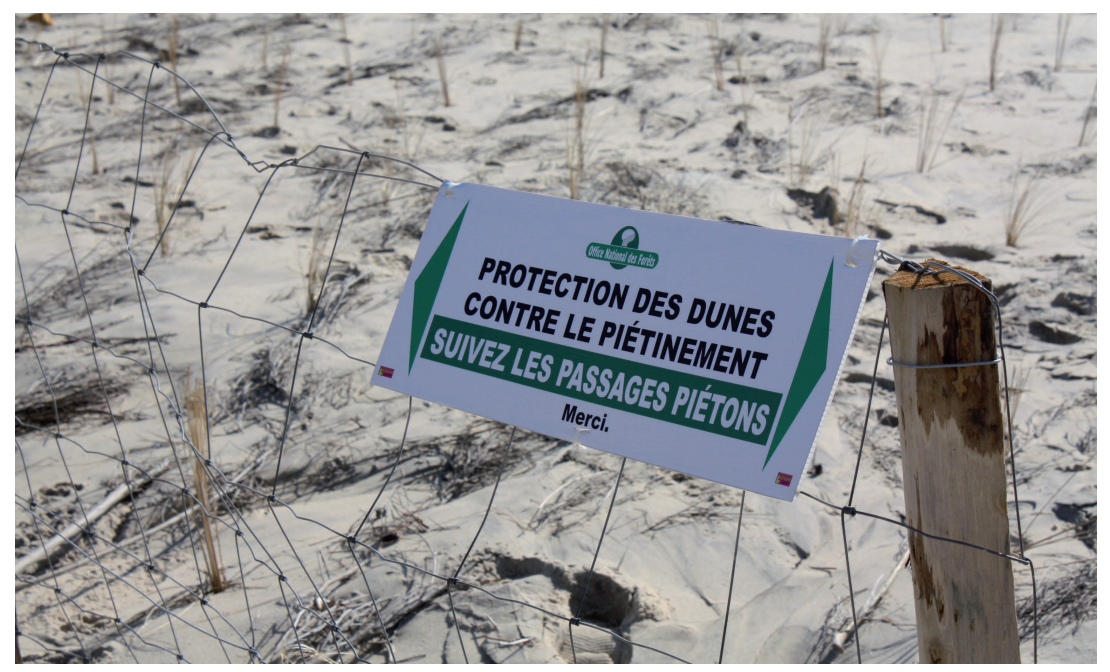

Figure 3.32. Clôture de canalisation du public et panneau de guidage.

(C) L. Gouguet/ONF.

Toutefois, sur certains sites où l'on recherchera la reconstitution d'un cordon dunaire (en Méditerranée par exemple), on pourra utiliser des matériaux peu perméables comme les ganivelles pour jouer à la fois un rôle de piège à sable et de guidage. Mais il sera alors nécessaire d'entretenir plus fréquemment les clôtures servant au guidage.

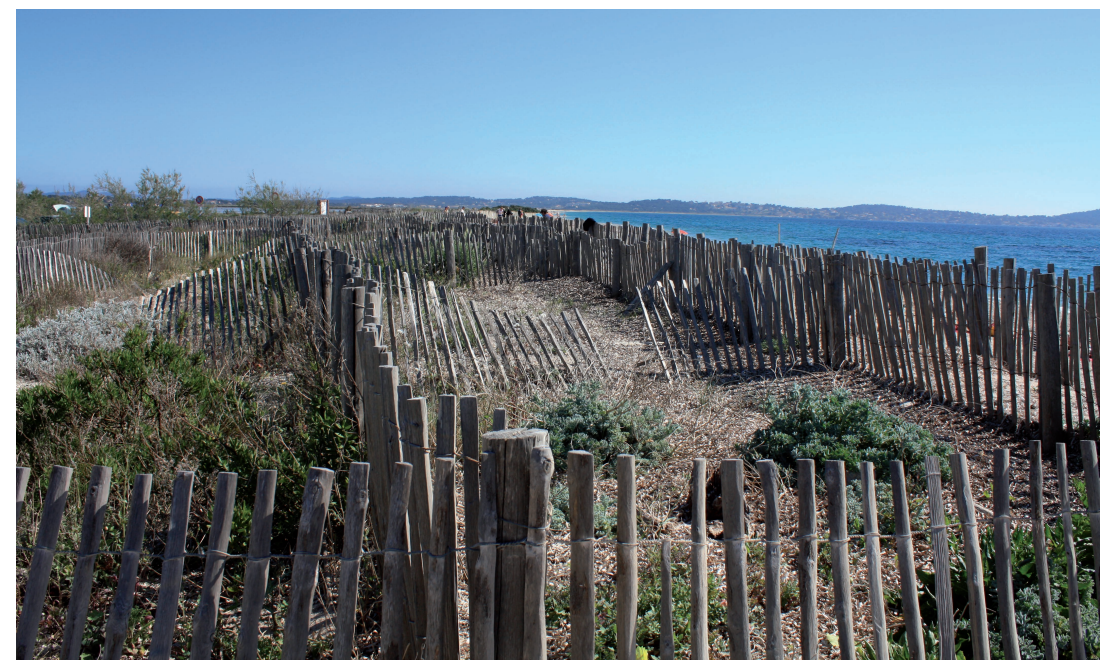

Figure 3.33. Les ganivelles piègent le sable et servent de clôture (Presqu'île de Giens). (C) L. Gouguet/ONF. 
Sur des milieux ouverts, on privilégiera des clôtures peu visibles afin de limiter l'impact paysager. Au contraire, en milieu fermé arboré, on utilisera préférentiellement des clôtures à base de bois comme les ganivelles. Sur des sites peu vulnérables ou peu fréquentés, des clôtures en fils lisses à un ou deux fils suffisent à limiter le piétinement diffus.

Parfois, il n'est même pas nécessaire de faire une mise en défens, la mise en place d'un cheminement confortable (caillebotis par exemple) ou bien visible suffit à gérer la problématique des accès. Les utilisateurs iront naturellement vers la solution de progression qui est la plus aisée.

Les choix faits lors de l'aménagement d'un site ne sont pas figés, il est impératif de réaliser un suivi régulier sur le fonctionnement du site afin de corriger les éventuelles erreurs.

Par exemple, si le niveau choisi de mise en défens des milieux était bas et que des impacts négatifs sur les habitats naturels apparaissent, il sera alors nécessaire de relever ce niveau et de revoir les systèmes de clôture.

On remarque, quand on observe le guidage en zone littorale à l'échelle nationale, et même à l'échelle européenne, que les choix d'aménagements sont souvent liés aux pratiques locales en matière de gestion. Il est important de prendre de la hauteur et de s'inspirer des exemples proches mais aussi lointains!

\section{LES PRINCIPALES TECHNIQUES DE GUIDAGE DU PUBLIC}

Clôtures

On distingue trois grands types de clôtures.

Les clôtures dites " en fil lisse », de hauteur très variable suivant le nombre de fils utilisés (30 cm à 1,20 m), en général en fil de fer galvanisé, et rarement en matériau fibreux tressé, sont totalement perméables au vent. Elles limitent donc la sédimentation du sable et leur ensablement. Elles sont utilisées dans des secteurs de dune, en zone de traversée de dune ou, côté plage, en pied de dune car elles sont discrètes et permettent de limiter leur impact visuel en milieu ouvert. Toutefois, elles sont facilement franchissables, et souvent utilisées sur des sites peu vulnérables ou à faible pression de fréquentation.

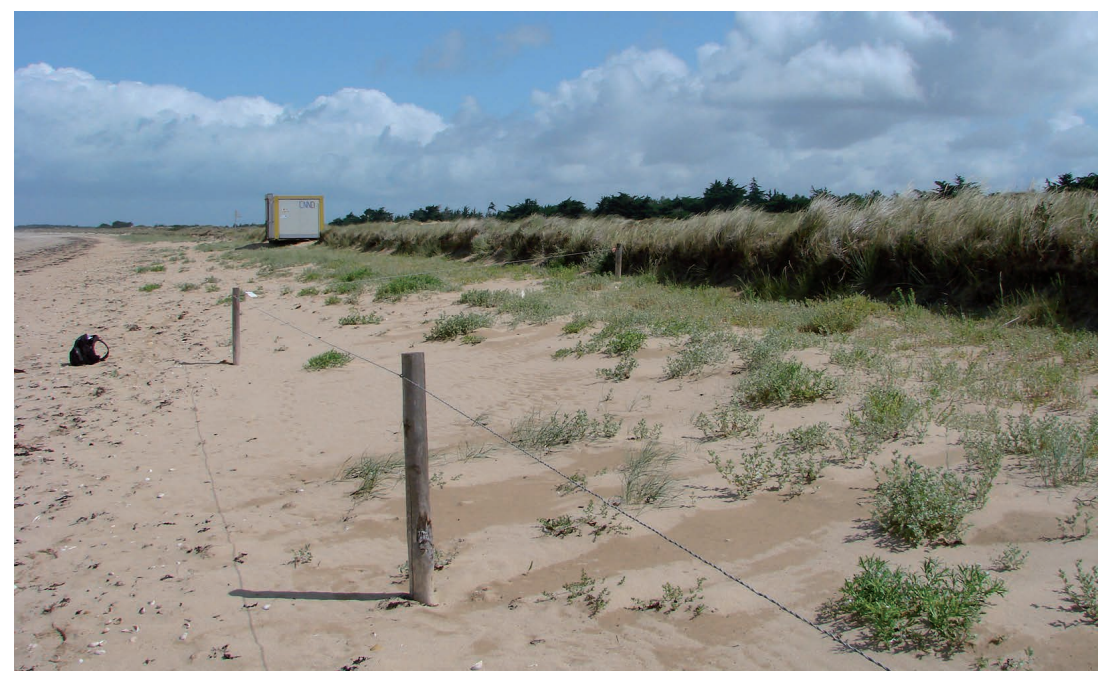

Figure 3.34. Protection du pied de dune par un fil lisse (Notre-Dame-de-Monts, 2011). (C) L. Gouguet/ONF. 


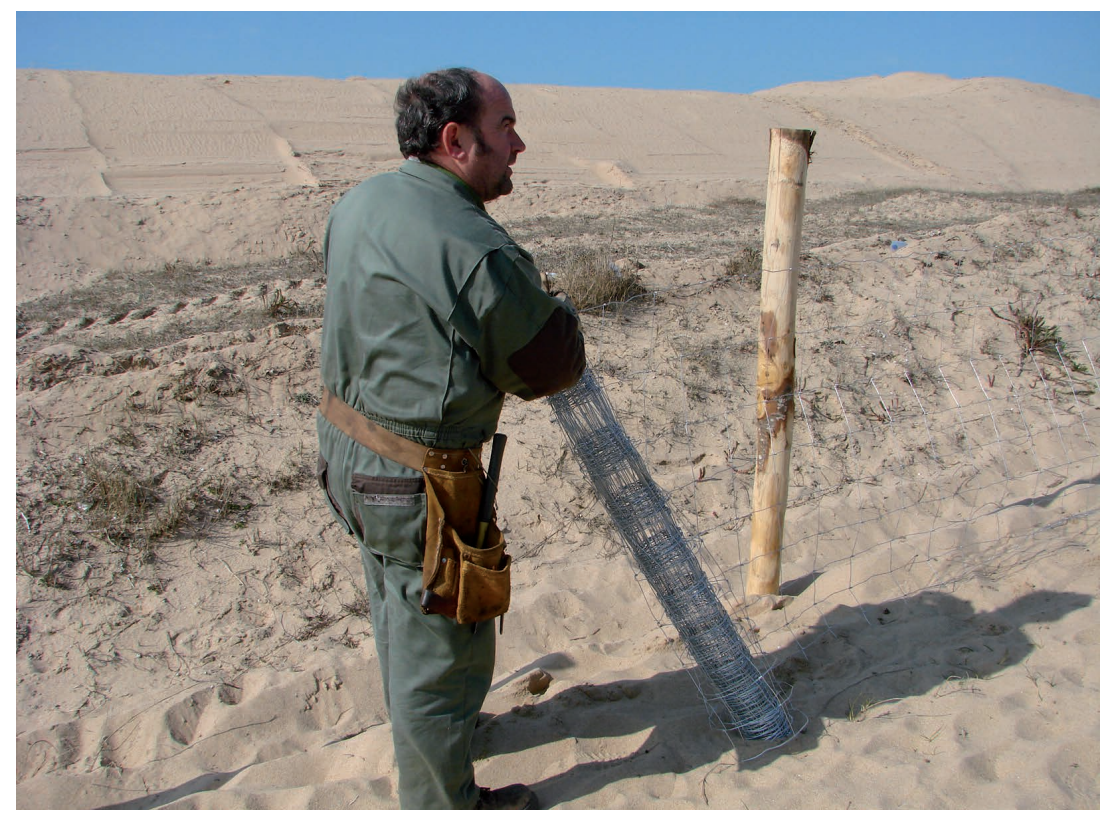

Figure 3.35. Pose de grillage pour canaliser le public. (c) L. Gouguet/ONF.

Les clôtures grillagées, 1 m à 1,20 m de hauteur, en fil galvanisé, essentiellement à maille carrée large type " grillage à moutons », sont très perméables au vent et s'ensablent lentement. Elles sont utilisées pour les traversées de dune. Elles ont un impact paysager important, mais elles ne sont pas franchissables et servent donc surtout sur les sites à forte fréquentation.

Les clôtures girondines ou ganivelles, $1 \mathrm{~m}$ ou 1,20 m de hauteur, faites d'échalas de châtaignier refendus assemblés par des rangées de fils de fer

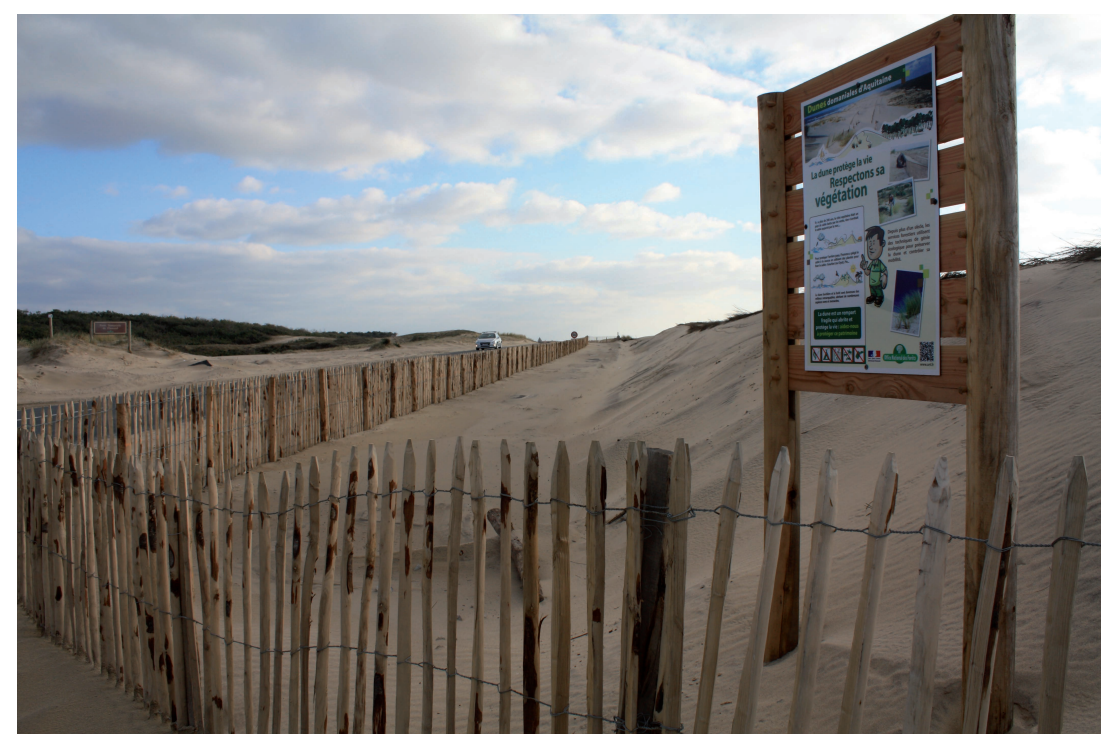

Figure 3.36. Ganivelles servant à canaliser le public et panneau d'information (Montalivet). (C) L. Gouguet/ONF. 
torsadés, prévues pour jouer le rôle de brise-vent, sont peu perméables au vent et s'ensablent rapidement.

Elles sont surtout utilisées dans des secteurs boisés, où elles présentent une bonne intégration paysagère, ou en secteur très stable. On peut aussi les utiliser au démarrage des traversées de dune, côté parking, afin de bien matérialiser les accès plage et ainsi faciliter le guidage du public. Elles ne sont pas franchissables.

Il semble toutefois, de l'avis des usagers, que leur image est parfaitement associée à la protection de la dune, ce qui facilite leur acceptation par le public, même parfois mieux que les clôtures grillagées pourtant plus transparentes.

On peut utiliser en secteur peu fréquenté ou peu vulnérable, en délimitation de cheminement, un modèle bas $(50 \mathrm{~cm})$ en lattes sciées.

\section{Cheminements}

Les aménagements des cheminements sont très variables suivant la configuration des sites, les pratiques locales, les usagers et les objectifs.

La plupart des cheminements sont laissés en sol naturel. Le piétinement, en détruisant la végétation sur ces accès, crée une ligne visuelle facilitant le guidage.

Dans des sites fréquentés, en général en milieu sableux, on préférera créer un cheminement confortable pour " attirer » le public vers des accès autorisés en lui facilitant la progression. La plupart des dispositifs utilisés nécessitent un montage en début de saison et un démontage en fin de saison, pour éviter des ensablements qui seraient préjudiciables à leur entretien et à leur durabilité.

Le caillebotis (platelage en latte de bois) est le principal équipement utilisé. Il est constitué de modules emboîtables facilitant sa maintenance à la dépose après la période estivale. Il s'intègre bien dans l'environnement naturel.

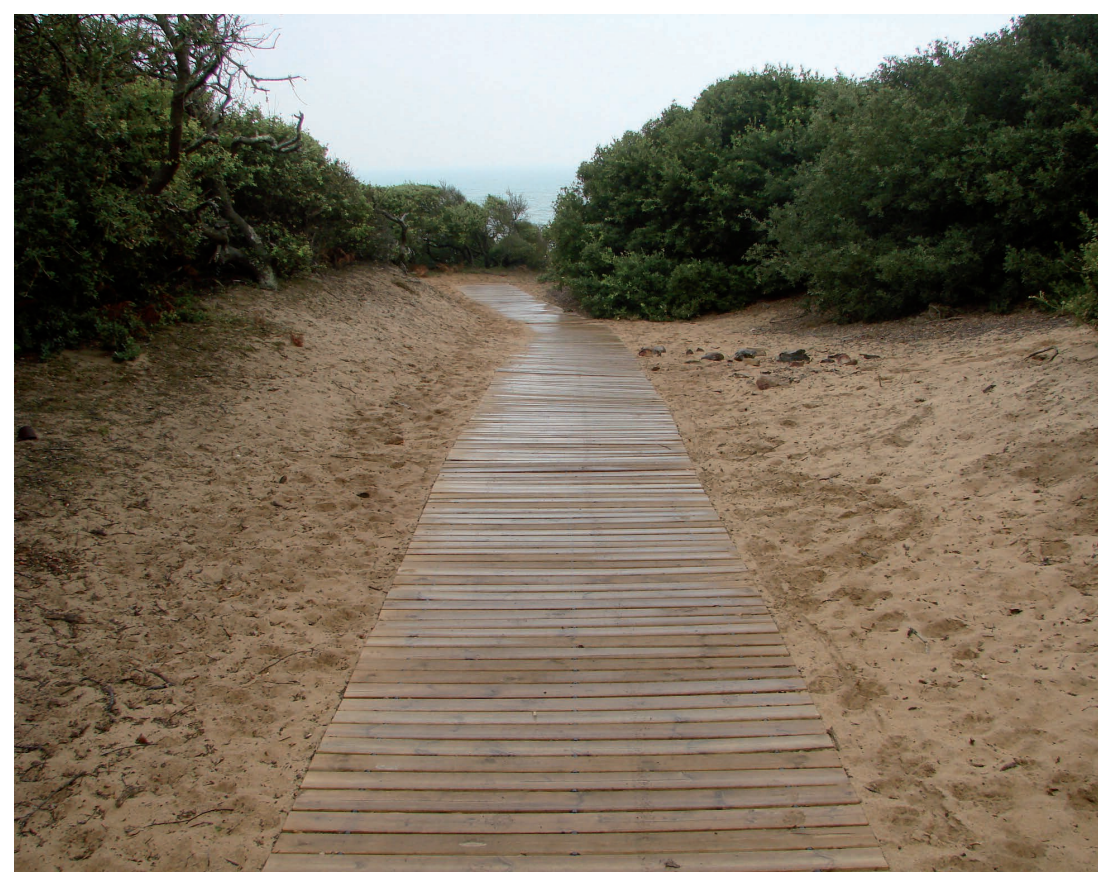

Figure 3.37. Caillebotis pour faciliter le cheminement dans la dune (Bois Saint Jean, Vendée). (c) L. Gouguet/ONF. 


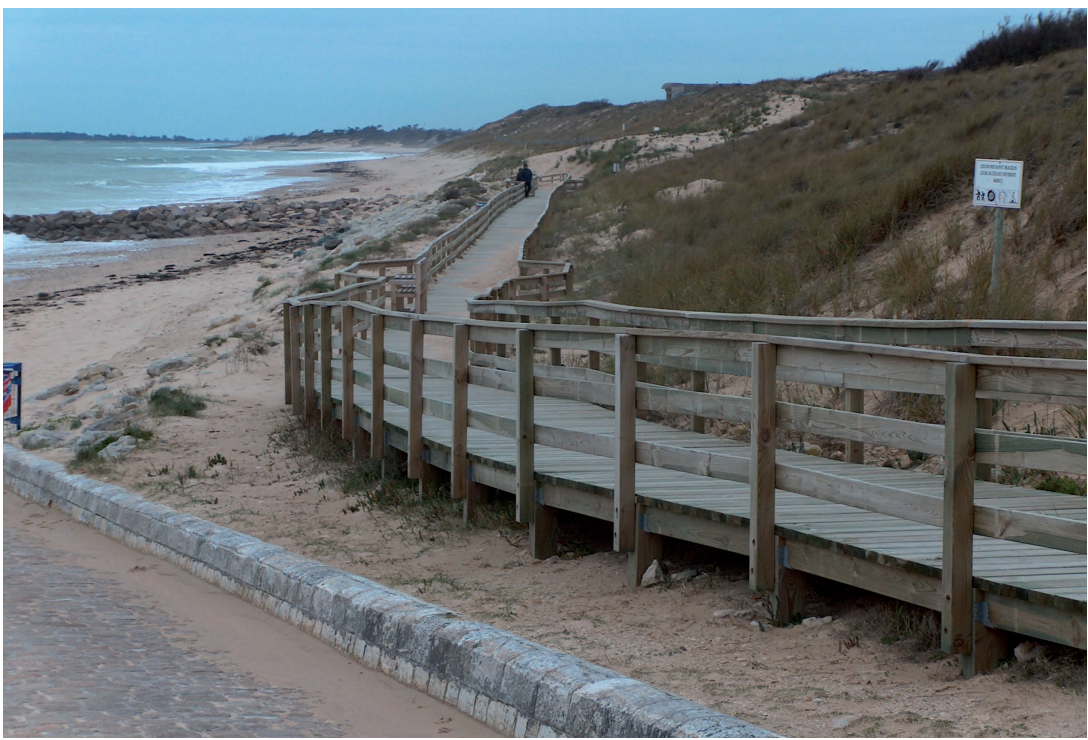

Figure 3.38. Caillebotis surélevé sur l'île de Ré.

(c) L. Gouguet/ONF.

Certains sites sont équipés de caillebotis sur pilotis, souvent sans clôtures de guidage. Ce choix est utilisé sur des sites sans fortes dynamiques naturelles. L'effet du platelage surélevé présente l'intérêt de dissuader l'utilisateur de sortir du cheminement autorisé.

La stabilisation du cheminement peut aussi se faire par l'épandage de matériel végétal (broyats ligneux ou aiguilles de pins). Ces cheminements peuvent être utilisés en milieu sableux dans des accès peu fréquentés, sans trop de contraintes topographiques ni écologiques. Ils sont une bonne alternative aux caillebotis, avec un coût peu élevé. II faut toutefois faire attention à l'origine

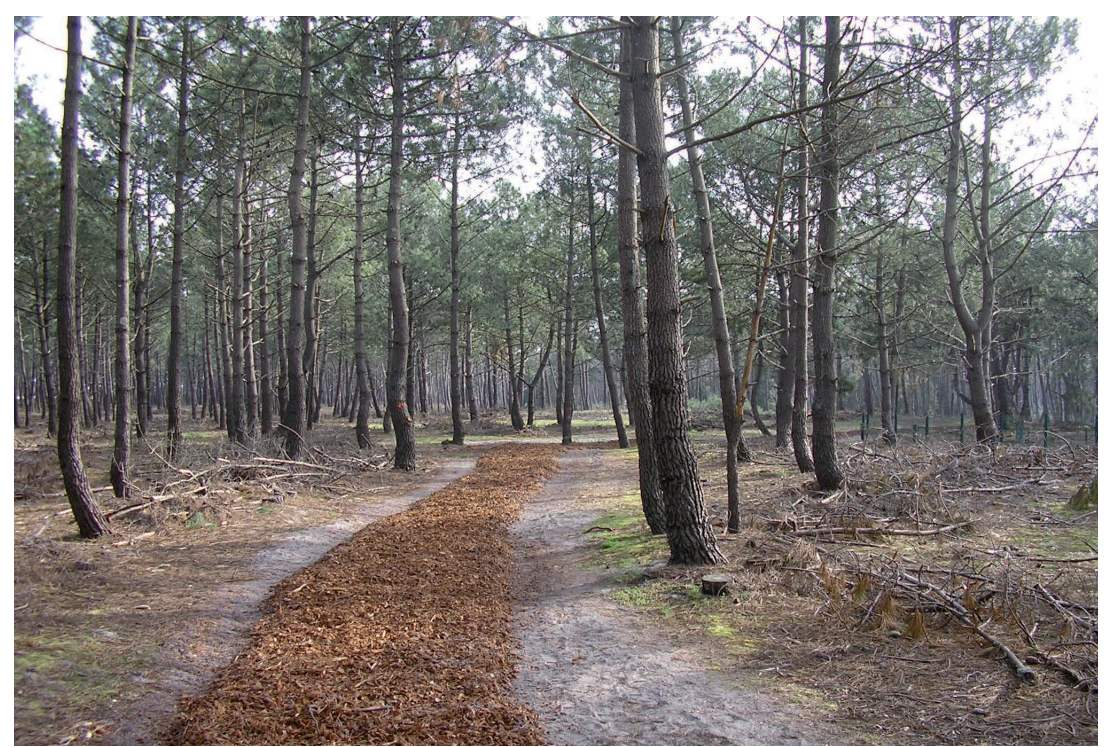

Figure 3.39. Cheminement en broyat (Pen Bron, Loire-Atlantique). (c) L. Gouguet/ONF. 
des matériaux utilisés, pour ne pas rudéraliser les milieux proches par apport de fragments de végétaux exogènes.

On utilise aussi parfois des matériaux synthétiques en tapis déroulables type nylon tressé qui peuvent s'adapter à de nombreuses configurations de cheminements. Ils ne peuvent toutefois pas être installés dans des secteurs à forte pente. Leur coût est élevé, ce qui les réserve à des utilisations ponctuelles, mais ils présentent une assez grande durabilité.

Signalétique de guidage

La signalétique de guidage est essentielle pour éviter les cheminements sauvages et orienter le public vers les accès autorisés. Son aspect est très variable suivant les sites et les objectifs. II est nécessaire de réaliser un plan de guidage préalablement à l'aménagement du site prenant en charge l'usager depuis les zones de stationnement jusqu'à la plage.

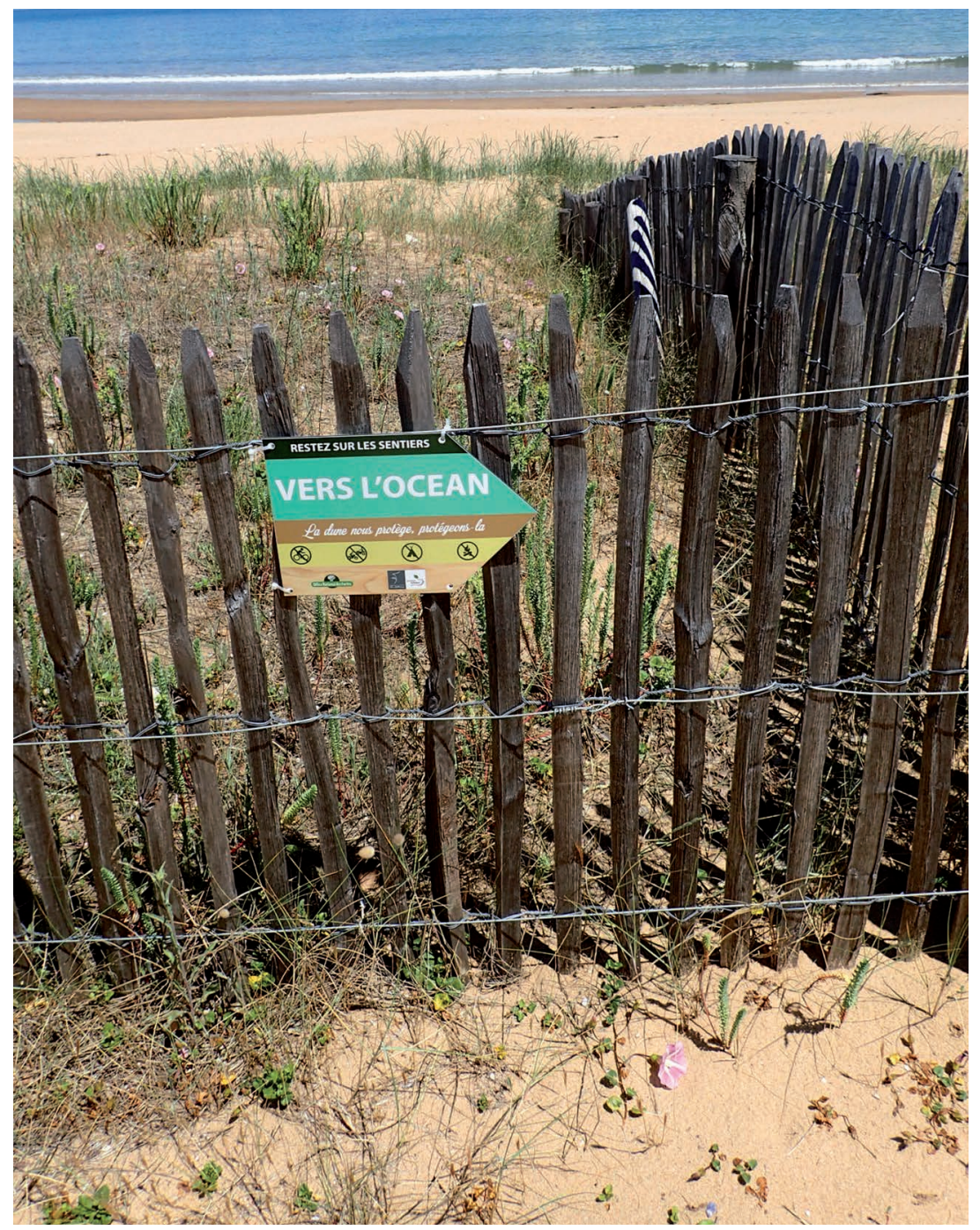

Figure 3.40. Panneau de guidage (Île d'Oléron).

(C) L. Gouguet/ONF. 


\section{L'information du public}

Le littoral est un espace de loisir. Mais l'utilisateur doit savoir que cet espace est fragile, et que sa gestion et l'organisation de l'accueil sont nécessaires. Le message doit non seulement porter sur l'interdiction de certaines pratiques, mais aussi sur les raisons de cette réglementation, c'est-à-dire sur la vulnérabilité et sur les richesses des milieux naturels présents. La signalétique doit être claire, simple et adaptée au message.

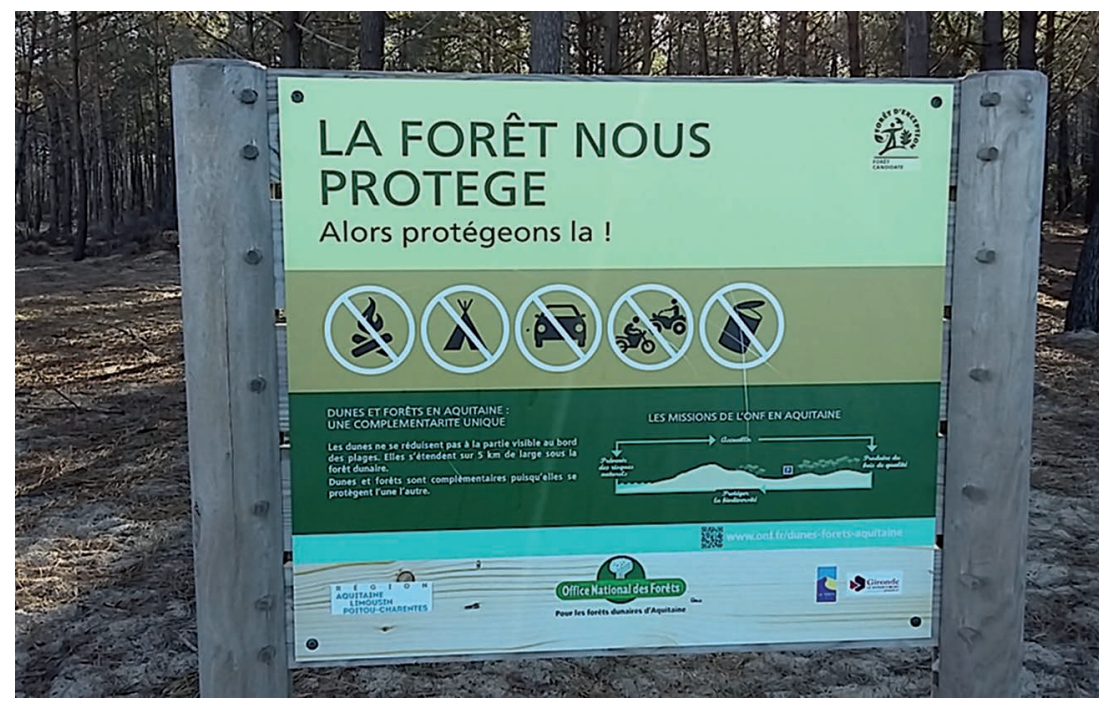

Figure 3.41. Exemple de panneau réglementaire. (C) I. Pichard.

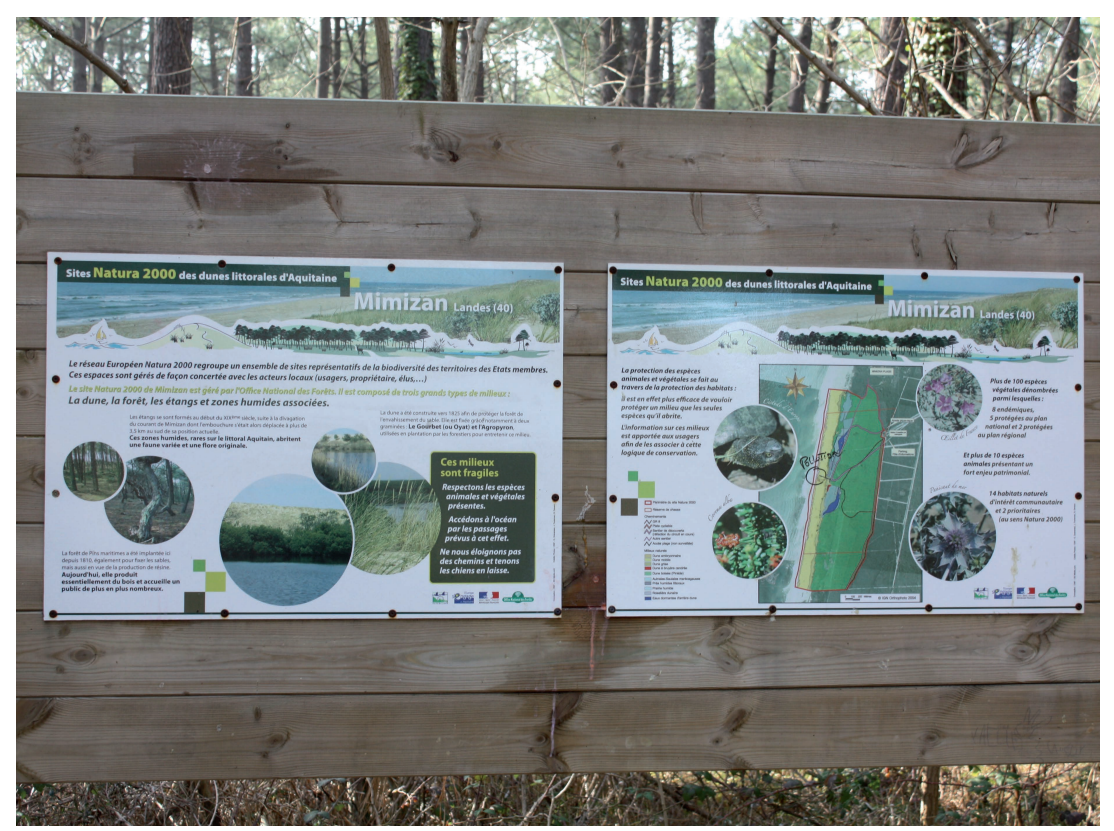

Figure 3.42. Exemples de panneaux ou d'outils pédagogiques. (c) L. Gouguet/ONF. 


\section{PANNEAUX D'INTERDICTION OU RÉGLEMENTAIRES}

Les panneaux, de divers formats pouvant être disposés directement sur les clôtures de guidage ou sur des supports, doivent être incitatifs, donc visibles, clairs, avec des textes courts et/ou des pictogrammes. Ils doivent être positionnés sur les secteurs fréquentés à proximité des cheminements. Les messages doivent pouvoir être exprimés en plusieurs langues, en fonction des publics étrangers qui fréquentent le site.

\section{OUTILS PÉDAgogIQUES}

Les panneaux en grands formats (A2 à A0), ou des outils pédagogiques variés utilisant les sens ou le matériel naturel in situ, doivent faire l'objet d'une étude spécifique mettant en cohérence les potentialités du site (naturelles, historiques...) et les publics cibles. Ils doivent être ludiques, clairs, sans trop d'information pour garder I'attention des utilisateurs. Ils peuvent utiliser les nouvelles technologies (smartphone, tablette tactile) pour proposer des outils innovants (réalité augmentée, sentier virtuel, renvoi sur des sites interactifs).

\section{PANNEAUX D'INFORMATION}

La pose de panneaux d'information ne doit pas aboutir à la création d'une " forêt » de panneaux sur le site. Ils doivent être concentrés sur des pôles spécifiques, sur des supports bois adaptés et bien identifiables :

- pôle d'accueil à proximité de l'entrée du site (près des stationnements en général), présentant le plan du site et des équipements ou des services, les accès plage, et éventuellement les principales informations réglementaires ou pédagogiques ;

- pôle d'accueil à proximité des équipements principaux (poste MNS, douches...), reprenant les informations de baignades, les consignes de sécurité, et les éventuelles informations de loisirs et d'activités.

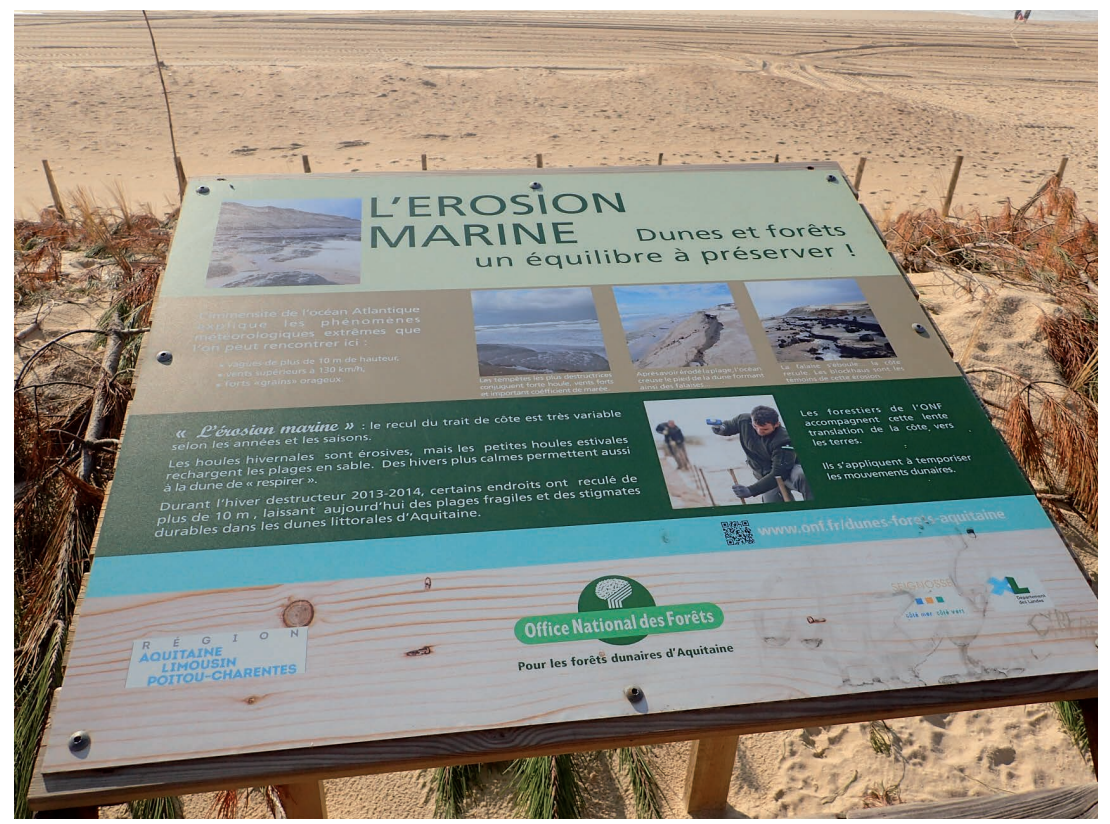

Figure 3.43. Exemple de panneau d'information ou de baignade. (C) L. Gouguet/ONF. 


\section{Gérer le stock de sable}

Éric Palvadeau

Depuis quelques années déjà, l'ONF oriente sa stratégie de gestion des systèmes dunaires, domaniaux pour l'essentiel, selon un principe de base qui est le « contrôle souple» pour préserver leur multifonctionnalité (rôle d'abris d'écosystèmes typiques, importance dans la protection de l'arrière-pays vis-à-vis des submersions marines et rôle " tampon », d'amortissement des phénomènes d'érosion marine). Une des conditions importantes du maintien de ces fonctionnalités est la préservation des échanges de sédiments entre la plage et la dune, et donc une gestion raisonnée et durable du stock de sable disponible dans ce système.

Mais, lorsque les cordons dunaires sont peu épais ou très érodés, il arrive que les collectivités locales veuillent les renforcer en procédant à des apports de sable. Ces mouvements artificiels de sable peuvent être organisés au sein de la cellule sédimentaire ou faire appel à des apports extérieurs.

Lorsque des opérations de réensablement sont envisagées, quelle que soit leur finalité, elles doivent observer un certain nombre de principes dans la conception du projet et de règles de bonne pratique dans sa mise en œuvre pour maintenir les équilibres et les fonctionnements naturels en place, mais aussi pour aboutir à un choix adapté aux enjeux, qu'ils soient naturels, liés à la sécurité et aux risques et/ou socio-économiques, et viable financièrement. Le propos est ici organisé selon un cheminement décisionnel pour guider un gestionnaire dans sa construction de projet.

\section{Définir la problématique}

Lorsque l'état d'un cordon dunaire est jugé insuffisant pour maintenir sa multifonctionnalité, deux cas s'offrent au gestionnaire :

- le secteur en arrière du cordon dunaire présente peu d'enjeux ; on peut choisir soit de "laisser faire " l'évolution naturelle du cordon, soit d'organiser le recul du cordon en ayant recours à des techniques de consolidation et de remodelage dunaire (réensablements ponctuels par retroussage* et revégétalisation) associées à un contrôle de la fréquentation ;

- le secteur en arrière du cordon dunaire présente des enjeux importants non déplaçables; on privilégiera le recours à des techniques souples de confortement ou de restauration dunaire : rechargements en sable et plantations.

\section{Encadré 3.3. Quel est le besoin en réensablement/finalités ?}

Les besoins de réensablement peuvent être variés et répondre à plusieurs finalités. Travaux d'urgence, suite à une érosion lors d'une tempête ou une submersion marine. Cela concerne des secteurs de faible étendue généralement et il y a donc de faibles volumes de sable à prévoir.

Travaux moins urgents et/ou planifiables :

- entretien pour la protection des enjeux (cas d'une dune protégeant des enjeux situés en arrière d'un cordon dunaire) ;

- confort balnéaire. Il s'agit là de préparer la plage (plus que la dune) pour les pratiques et la fréquentation touristiques estivale (élargissement, reprofilage).

Ces travaux peuvent être d'ampleur variée selon que l'on souhaite simplement consolider un cordon dunaire, le restaurer entièrement voire y associer un rechargement d'ensemble du système plage-dune (voire y compris les petits fonds) pour pallier un déficit sédimentaire important et chronique. 
Volume nécessaire : la cellule peut-elle subvenir au besoin?

- Si oui, on aura recours à des transferts de sable internes à la cellule sédimentaire du site ; on parlera de " transferts de proximité » ;

- si non, on recherchera une source externe en dehors de la cellule sédimentaire du projet ; on parlera de " rechargement ».

Source de sable :

- doit répondre à des critères quantitatifs : disponibilité d'un volume suffisant et sans impact majeur lié au prélèvement ;

- doit répondre à des critères qualitatifs : nature, couleur, granulométrie.

\section{Identifier les gisements possibles}

Un des préalables aux opérations de rechargement est la recherche d'une source de sable de nature, $\mathrm{d}^{\prime}$ aspect (couleur) et de granulométrie sensiblement identiques à ceux du secteur à traiter.

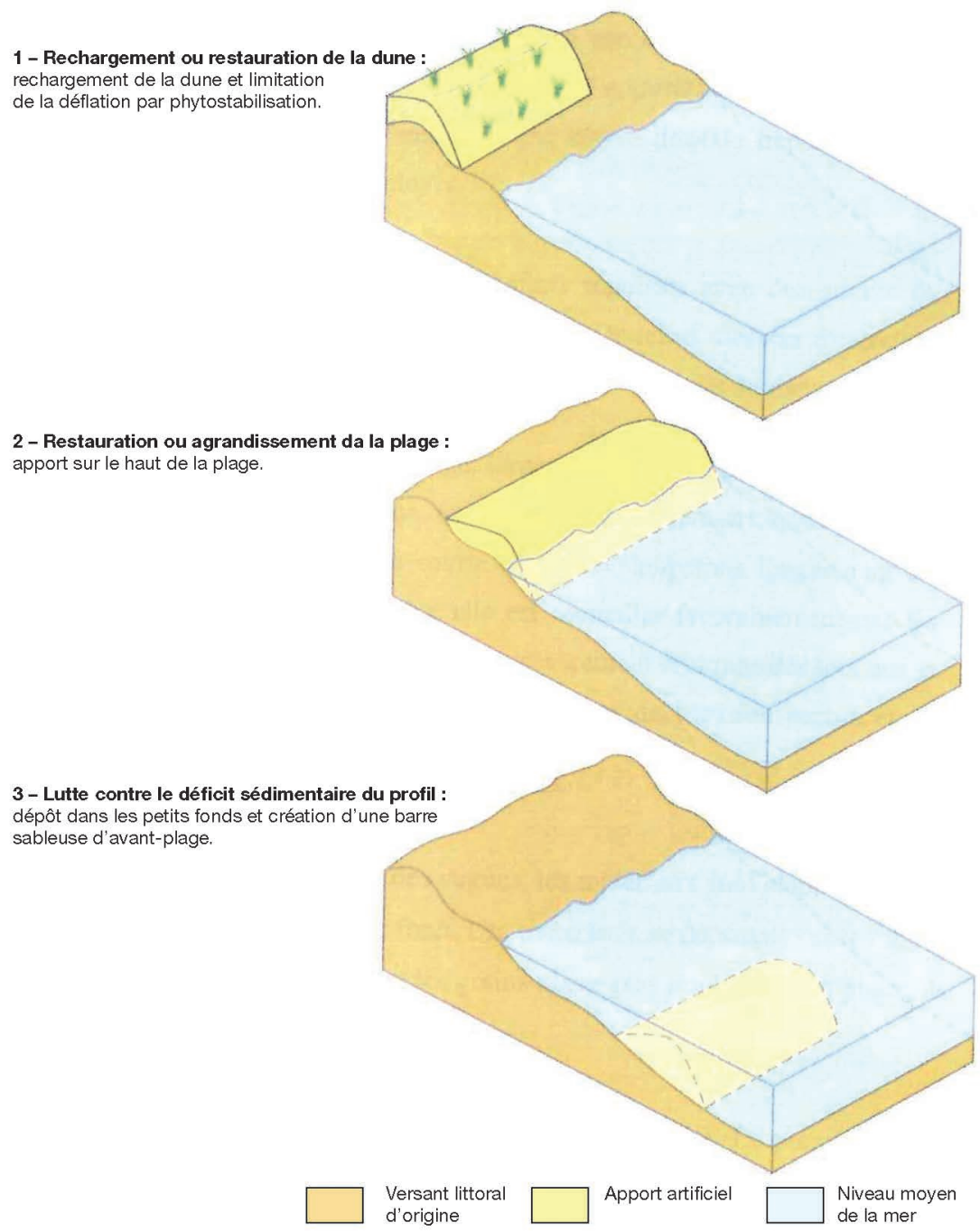

Figure 3.44. Les différents modes de rechargement sur le versant littoral. Source : d'après Pupier-Dauchez (2002). 
Tableau 3.2. Terminologie générale autour de la notion de réensablement.

\begin{tabular}{|c|c|c|c|c|}
\hline Notions & Principe & $\begin{array}{l}\text { Mode de } \\
\text { transport }\end{array}$ & Avantages & Inconvénients \\
\hline $\begin{array}{l}\text { Le rechar- } \\
\text { gement } \\
\text { sédimen- } \\
\text { taire }\end{array}$ & $\begin{array}{l}\text { Réalimen- } \\
\text { tation en sable } \\
\text { du littoral en } \\
\text { comblement } \\
\text { du déficit } \\
\text { sédimentaire } \\
\text { à l'origine } \\
\text { de l'érosion }\end{array}$ & $\begin{array}{l}\text { 1. Voie } \\
\text { terrestre : } \\
\text { camions, } \\
\text { pelleteuses, } \\
\text { bulldozers. } \\
\text { 2. Voie } \\
\text { maritime : } \\
\text { by-pass } \\
\text { hydraulique } \\
\text { (conduites } \\
\text { enterrées), } \\
\text { dragages } \\
\text { (clapages } \\
\text { et/ou } \\
\text { refoulement) }\end{array}$ & $\begin{array}{l}\text { Élargissement } \\
\text { de la plage } \\
\text { Impact visuel } \\
\text { faible (by-pass } \\
\text { hydraulique) } \\
\text { Coût faible } \\
\text { et moyens } \\
\text { techniques } \\
\text { mobilisables } \\
\text { (by-pass } \\
\text { mécanique) } \\
\text { Rétablit le } \\
\text { transport } \\
\text { naturel des } \\
\text { sédiments }\end{array}$ & $\begin{array}{l}\text { Nuisances } \\
\text { sonores et } \\
\text { visuelles } \\
\text { Perturbations } \\
\text { biodiversité } \\
\text { littorale } \\
\text { Pollution des } \\
\text { sédiments } \\
\text { (dragages) } \\
\text { Coût élevé } \\
\text { (by-pass) }\end{array}$ \\
\hline Reprofilage & $\begin{array}{l}\text { Récupération du } \\
\text { sable sur le bas } \\
\text { pour l'étaler sur } \\
\text { le haut de plage } \\
\text { en érosion }\end{array}$ & $\begin{array}{l}\text { Camions, } \\
\text { pelleteuses, } \\
\text { bulldozers }\end{array}$ & $\begin{array}{l}\text { Maintien des } \\
\text { processus } \\
\text { naturels } \\
\text { côtiers/côte } \\
\text { protégée } \\
\text { Proximité des } \\
\text { sédiments/ } \\
\text { coûts transports } \\
\text { faibles } \\
\text { Élargissement } \\
\text { de la plage }\end{array}$ & $\begin{array}{l}\text { Une solution } \\
\text { temporaire } \\
\text { à l'érosion } \\
\text { Longévité } \\
\text { courte de cette } \\
\text { technique } \\
\text { Nuisances } \\
\text { sonores } \\
\text { et visuelles }\end{array}$ \\
\hline Recyclage & $\begin{array}{l}\text { Déplacement } \\
\text { régulier de } \\
\text { petits volumes } \\
\text { de matériaux } \\
\text { afin d'entretenir } \\
\text { les chenaux de } \\
\text { navigation et de } \\
\text { maintenir l'état } \\
\text { des plages }\end{array}$ & $\begin{array}{l}\text { Camions, } \\
\text { pelleteuses, } \\
\text { bulldozers }\end{array}$ & $\begin{array}{l}\text { Technique } \\
\text { rapide et } \\
\text { efficace avant } \\
\text { la saison } \\
\text { estivale } \\
\text { Dynamique } \\
\text { côtière } \\
\text { faiblement } \\
\text { perturbée }\end{array}$ & $\begin{array}{l}\text { Une solution } \\
\text { temporaire } \\
\text { à l'érosion } \\
\text { Longévité } \\
\text { courte de cette } \\
\text { technique } \\
\text { Nuisances } \\
\text { sonores } \\
\text { et visuelles }\end{array}$ \\
\hline
\end{tabular}

Source : d'après Parain (2013).

La granulométrie est une clé essentielle de l'efficacité de l'opération de rechargement. En effet, la granulométrie des sédiments d'une plage modèle la morphologie de cette plage, en lien avec l'action des houles, et tout apport de sable doit s'intégrer aux processus sous peine d'être rapidement perdu pour la cellule sédimentaire.

Il faut donc garder à l'esprit qu'un apport en sable d'une granulométrie supérieure à celle du sable du secteur à recharger aura pour résultat à terme d'augmenter la pente du profil de la plage mais de diminuer la possibilité d'entraînement et de perte de sable. À l'inverse, I'utilisation d'une granulométrie inférieure à celle du site à recharger permettra d'adoucir la pente du profil (profil plus dissipatif de l'énergie des vagues), mais pourra augmenter les pertes à moyen-long terme et raccourcir dans le temps les bénéfices du rechargement. 
L'étude Eurosion commandée par la Commission européenne en 2004 a préconisé de mettre en place des Plans de gestion des sédiments côtiers (PGSC). Les plans de gestion des sédiments côtiers donnent une occasion de développer la gestion intégrée des zones côtières. Outre le renforcement de la résilience côtière, un aspect clé d'un PGSC est de permettre une évaluation à grande échelle des risques associés aux processus côtiers et de les inclure dans une politique à long terme. Un plan de gestion des sédiments côtiers devrait être un document élaboré au minimum à l'échelle régionale constituant un élément important dans une stratégie globale de prévention contre les inondations et l'érosion côtière d'une manière durable.

La première étape d'élaboration du PGSC consiste à établir le diagnostic le plus précis possible sur les zones en érosion ou en accumulation, les quantités de sédiments en mouvement et les stocks, et à identifier tous les paramètres principaux déterminant la vitesse à laquelle les sédiments quittent (ou parviennent dans) le système et la manière dont les dynamiques opèrent. Ces paramètres devraient être évalués :

- sur une échelle de temps d'au moins 30 ans, allant jusqu'à 50 ou 100 ans dans certains cas ;

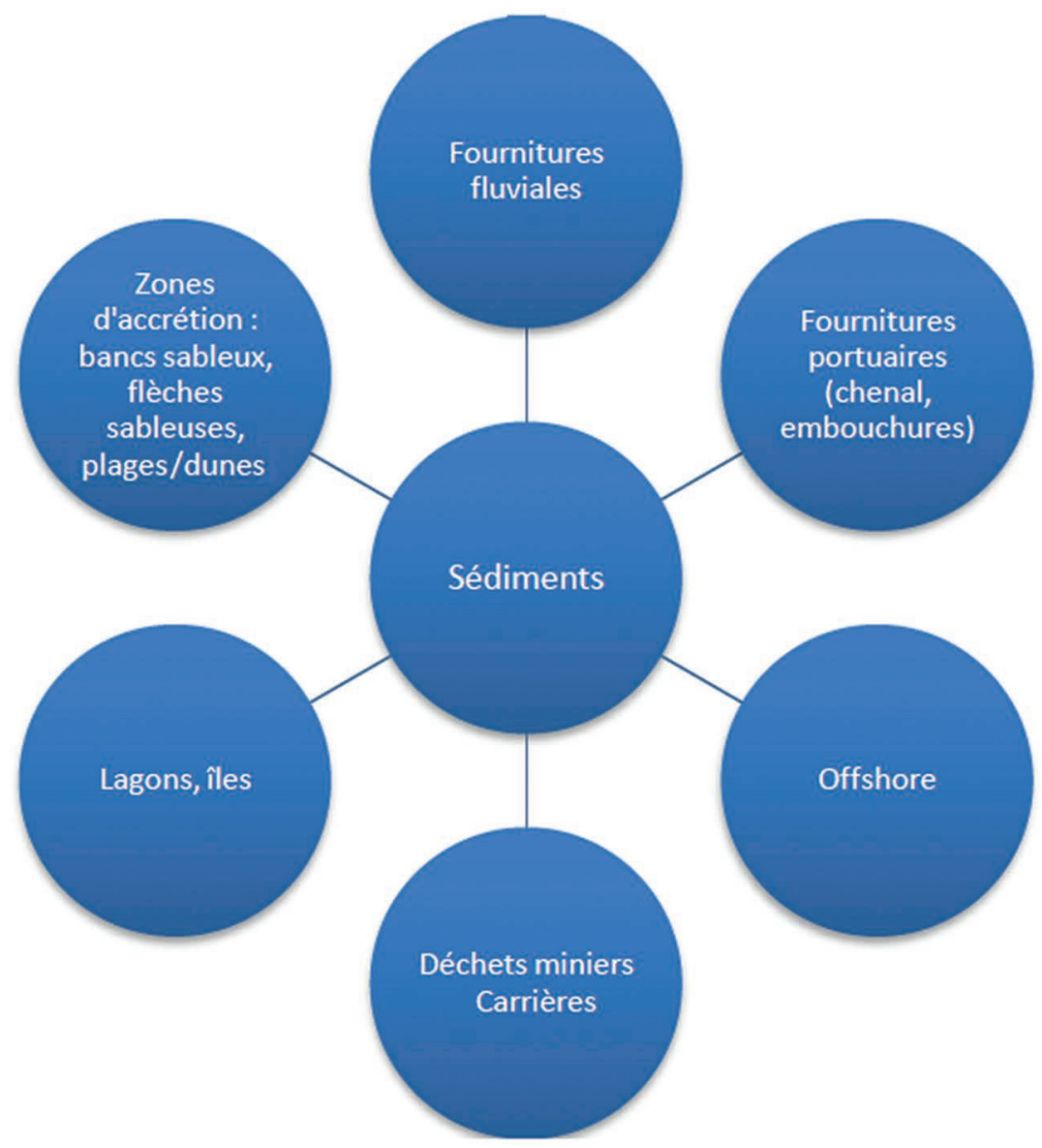

Figure 3.45. Identifier les sources de sédiments. Source : É. Palvadeau/BRGM. 
- avec une compréhension de tout le système sédimentaire depuis le bassin versant jusqu'à la côte et en incluant l'environnement marin littoral ;

- en intégrant les conséquences économiques, sociales et environnementales.

Sur la base de cette information, il est ensuite possible, cellule sédimentaire par cellule sédimentaire, de développer des lignes de conduite adaptées pour gérer le risque d'érosion et d'inondation pour chaque segment de littoral. Cette gestion devrait être basée sur un certain nombre d'options qui peuvent être résumées de la manière suivante :

- maintien du trait de côte ;

- avancée vers la mer ;

- repli programmé ;

- laisser faire.

À ce jour, bien que répandu à l'international, le principe de PGSC n'a été que peu utilisé en métropole, à l'exception notable de la région LanguedocRoussillon.

\section{Les techniques de réensablement}

Plusieurs procédés peuvent être utilisés en fonction des objectifs et des moyens techniques et financiers mis en œuvre.

\section{RECHARGEMENT PAR VOIE TERRESTRE}

L'acheminement des matériaux sableux se fait par camion depuis la zone de prélèvement vers la zone de dépôt. Cette méthode est généralement réservée à des travaux de faible ampleur (inférieure à $20000 \mathrm{~m}^{3}$ ) ou pour lesquels la source de prélèvement est proche, en raison des coûts de transport mais aussi des nuisances inhérentes au va-et-vient des camions (bruit, vibrations, gène à la circulation, dégâts mécaniques sur les chaussées). C'est le mode le plus couramment utilisé pour les opérations de rechargement en France.

On privilégiera un prélèvement dans une cellule sédimentaire adjacente en amont-dérive, pour préserver/accompagner au maximum les phénomènes naturels. Une source d'apport idéale est une zone d'accumulation de sédiments bloqués par des obstacles naturels ou anthropiques (digues portuaires en particulier) située en amont-dérive du site de rechargement. L'opération va donc avoir comme principal avantage de rétablir artificiellement le transport de sédiments normalement assuré par le courant de dérive littorale. On désignera alors ce type d'opération "by-pass mécanique ».

Le by-pass hydraulique est une alternative au by-pass mécanique. II consiste en une installation hydraulique terrestre permettant de pomper un mélange de sable et d'eau dans la zone de prélèvement, de transporter ce mélange par une canalisation et de le refouler en aval de l'obstacle jusqu'à la zone de dépôt. La commune de Capbreton (Landes), par exemple, transfère en moyenne $70000 \mathrm{~m}^{3}$ par an de sable à travers l'embouchure du Boucarot pour réensabler la plage sud.

\section{RECHARGEMENT PAR VOIE MARITIME}

Le rechargement par voie maritime associe une opération de prélèvement en mer, et une opération de transport et de refoulement du sable sur le site à traiter. Ces étapes sont assurées par une drague qui, par un système hydraulique, va pomper un mélange sable-eau de mer sur le site de prélèvement et refouler ensuite ce mélange sur la plage au moyen d'une canalisation flottante et/ou fixée à terre. 


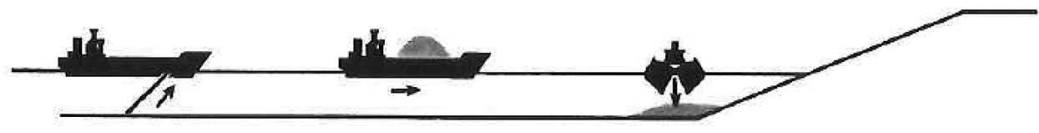

Transport direct, rejet par pompe relais sur la plage

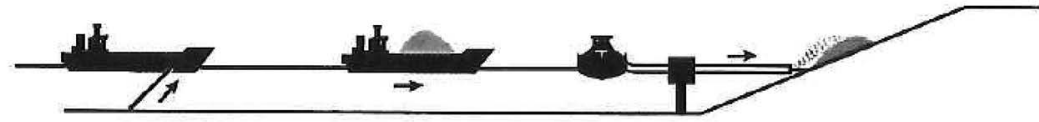

Transport direct, système de rejet " rainbow "

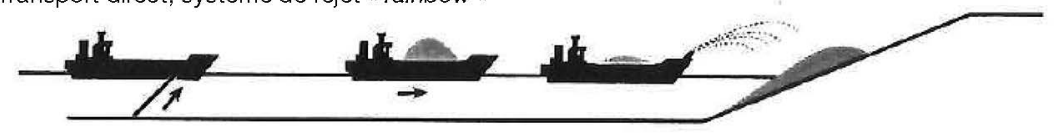

Transport en deux temps:

reprise des sédiments puis système de rejet " rainbow "

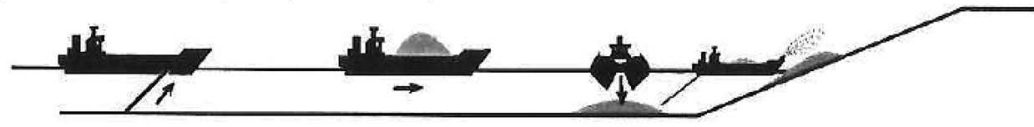

Transport direct, rejet par pompe relais puis acheminement par pipeline pour rejoindre le site à recharger

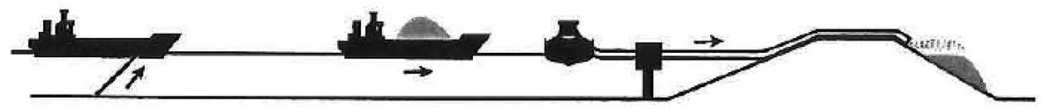

Dragage, transport sur barge et clapage dans les petits fonds

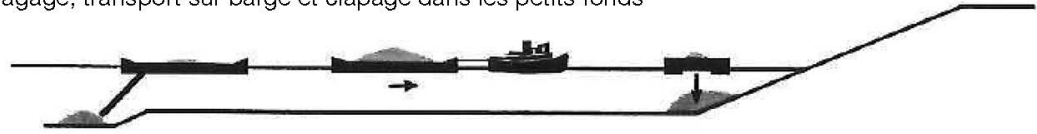

Dragage et acheminement direct par pipeline jusqu'à la plage :

système du «back passing "

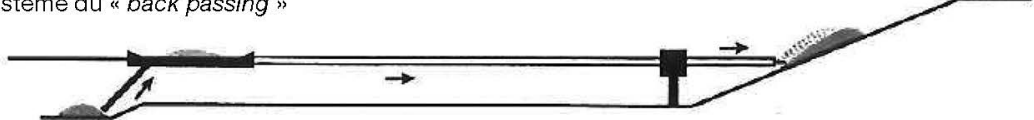

Figure 3.46. Les solutions techniques pour le rechargement : dragage, transport, dépôt, exemples de scenarii.

Source : Pupier-Dauchez (2002).

Le mélange sable-eau peut aussi être projeté sur la plage directement depuis la drague par le biais d'un système de rejet "rainbow » (fixé à l'avant de la drague). Cette technique est appelée opération de « rainbowing ".

Selon les contraintes du site à traiter (éloignement de la zone de prélèvement, contrainte de navigation, présence d'ouvrage de protection, etc.), il peut 
s'avérer nécessaire de mettre en œuvre un transport intermédiaire par barge entre le site de prélèvement et le site à recharger.

De nombreuses combinaisons et scénarii techniques sont possibles, alliant les usages des différents types de drague (refoulement, système de rejet "rainbow », transport par barges, etc.) afin d'adapter l'opération aux contraintes du site et aux contraintes budgétaires du projet : drague stationnaire ou en marche, drague pleine, avec un chaland amarré à une barge, avec une canalisation directe ou avec des pompes relais, avec des zones de dépôt intermédiaires ou définitives, etc. (CETMEF, 2008 et 2011 ; FFPP, 2005 ; Géode, 2012 ; STCPMVN, 1993).

Dans le cas d'un déficit sédimentaire avéré du site, il peut être envisagé de recharger également les petits fonds pour créer une barre sableuse d'avant-côte destinée à réalimenter progressivement la plage. Une drague ou une barge spécifique (équipée d'une cale à ouverture par le fond) est alors utilisée pour déverser en masse les volumes sableux précédemment dragués. Ce procédé est appelé " opération de clapage ». Le choix de la profondeur de clapage est essentiel pour l'efficacité du rechargement à long terme. II faut veiller à ce que les sédiments ne soient pas déposés dans des fonds trop importants pour éviter un transport définitif du sable vers le large.

\section{TRANSFERTS SÉDIMENTAIRES DE PROXIMITÉ}

On aura typiquement recours à ce mode de réensablement pour des opérations d'urgence pendant la période hivernale à la suite d'un épisode érosif. On procède à une répartition mécanique (bulldozer, tractopelle) du sable longitudinalement ou transversalement à la plage.

Ces travaux peuvent aussi être réalisés de manière planifiée en fin de période hivernale : le principe étant d'adoucir la pente du profil de plage, généralement concave et plus redressée au sortir de la saison d'agitation hivernale. Cependant, ce type de techniques est le plus souvent utilisé à des fins de confort balnéaire pour préparer la saison touristique estivale. On trouve ainsi, dans la littérature et les ouvrages traitant de la gestion du trait de côte, le terme de « reprofilage de plage » pour désigner cette pratique. On y substitue parfois également les termes de « remodelage ou nivellement d'estran ».

Le retroussage de plage est un cas particulier du reprofilage de plage. II consiste à remonter mécaniquement le sable accumulé dans le bas de plage sur certaines plages, après une tempête ou la saison hivernale, vers le pied de dune, et non du pied de dune vers le bas de plage comme cela se fait généralement pour élargir artificiellement la plage. Cette pratique permet de renforcer un cordon dunaire après un ou une série d'épisodes érosifs en constituant un bourrelet sableux tampon qui favorise l'installation d'une végétation dunaire embryonnaire (cas de la plage de Luzéronde sur l'île de Noirmoutier ; EUCC-France, 2012).

Il faut toutefois garder à l'esprit que le retroussage de plage déstructure et abaisse le bas de plage, et peut donc avoir ultérieurement un impact fort sur la zone à protéger. Cette pratique doit être réservée à des plages de poches (sans possibilité de transfert) ou à des situations de crise (confortement de pied de dune avant une grosse tempête avec des enjeux majeurs en arrière).

D'autres sources de sédiments peuvent être utilisées pour réaliser ces opérations $\mathrm{d}^{\prime}$ entretien des plages au sortir de la période hivernale. C'est le cas notamment des matériaux sableux extraits lors des dragages d'entretien des chenaux de navigation, ou des sables transportés et déposés par le vent sur les voiries adjacentes 
au littoral et qui sont récupérés par les services techniques communaux après un épisode de tempête. Le terme de « recyclage » est employé pour ces cas précis.

\section{Identifier et anticiper les impacts (zone de prélèvement, transport, dépôt)}

Avant tout travaux de réensablement visant à restaurer, consolider un cordon dunaire et/ou recharger une plage, il convient d'identifier les différents impacts sur le milieu et les infrastructures qui peuvent potentiellement être générés à chaque étape de l'opération.

\section{IMPACTS GÉNÉRÉS PAR LE PRÉLÈVEMENT DE SABLE}

Pour le rechargement, il conviendra :

- de s'assurer que les volumes à prélever ne vont pas créer un déficit dans le bilan sédimentaire du site de prélèvement. Une bonne connaissance préalable de la dynamique sédimentaire de la zone de prélèvement est donc nécessaire ; - d'identifier les impacts potentiels générés par le prélèvement du sable sur la faune et la flore (destruction d'habitats ou biocénose, turbidité...).

Pour les transferts sédimentaires, il conviendra d'évaluer l'impact local du prélèvement sur la faune et la flore et la morphologie de la plage. Sur la zone de prélèvement, il faudra veiller à ne pas créer un déséquilibre du profil de plage qui tendrait à augmenter l'énergie des vagues sur la plage.

\section{IMPACTS GÉNÉRÉS PAR LE TRANSPORT DU SABLE}

Le transport par camion est la méthode susceptible de générer les impacts les plus importants en matière de nuisance sonore, vibration, détérioration des chaussées, circulation routière et pollution atmosphérique.

Le transport par drague ou barge et/ou système de refoulement (pipeline) permet un transport de volume sableux plus important évitant les norias de camion sur le réseau routier. Il faut cependant veiller à ce que les impacts sur le fond (et en particulier sur les herbiers) des ancrages des conduites de refoulement soient minimalisés.

\section{IMPACTS GÉNÉRÉS PAR LE DÉPÔT DU SABLE}

Le rejet par refoulement ou clapage d'un mélange sable-eau peut générer une forte turbidité des eaux marines au droit de la zone à traiter. Celle-ci peut être limitée par la mise en place de barrages flottants et/ou de filets ou géotextiles permettant de capter les particules fines en bordure de plage.

Il faudra veiller à ce que les impacts générés par les va-et-vient d'engins sur la plage pour la répartition des sédiments soient minimisés, en particulier sur le pied de dune lorsque le réensablement ne concerne que la plage.

L'aspect final du site devra autant que possible approcher morphologiquement les caractéristiques d'origine du site (cordon dunaire, plage), et en particulier les pentes de la plage et du front dunaire.

Les impacts sur l'avifaune peuvent être importants si ces opérations sont mises en œuvre au début de la période de nidification de certaines espèces : cas du gravelot à collier interrompu nichant spécifiquement sur les laisses de tempêtes proches du pied de dune.

\section{Analyse multicritère et analyse coût/bénéfices}

En amont de l'élaboration d'un projet de restauration/consolidation dunaire et/ou de rechargement de plage, il est conseillé de procéder à une analyse multicritère coûts/bénéfices des différentes solutions qui s'offrent au maître d'ouvrage pour gérer une problématique dunaire. Cette analyse lui permet de 
guider son choix et de construire une solution technique adaptée aux enjeux (naturels et/ou de sécurité des biens et des personnes et/ou économiques) et aux moyens techniques et, surtout, financiers dont il dispose.

\section{Conduite et suivi du projet}

La conception et la bonne conduite d'un projet de réensablement pour la gestion des dunes relèvent donc d'un processus qui ne doit pas être improvisé au regard des enjeux en présence, des impacts des opérations qui peuvent être décidées, mais également des aspects réglementaires qui, selon les cas (type d'opération, volumes, impacts, etc.), peuvent être particulièrement contraignants. À chaque étape, les bonnes questions doivent être posées pour concevoir une réponse technique raisonnée répondant aux objectifs initiaux de gestion et de contrôle souple des systèmes dunaires et du système plage-dune au sens large.

La mise en place d'un suivi topographique est également indispensable pour pouvoir juger de la pertinence et de l'efficacité des actions engagées.

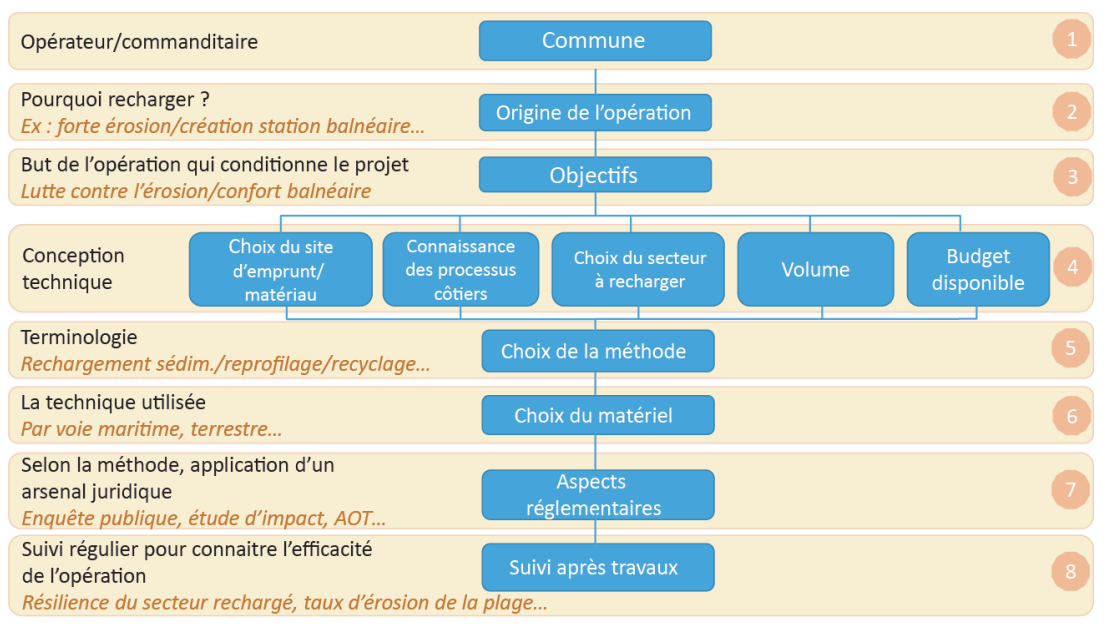

Figure 3.47. Arborescence des étapes indispensables à la bonne conduite d'une opération de réensablement.

Source : BRGM. 



\section{Conclusion}

Notre société, qui, en un peu plus d'un siècle et demi, est passée d'un rejet de ces milieux jugés inhospitaliers à une attirance souvent immodérée pour ces espaces littoraux, est aussi de plus en plus exigeante à juste titre sur la prise en compte de toutes les dimensions du développement durable : être à la fois économiquement efficace, socialement équitable et écologiquement cohérent.

En matière de gestion des dunes et des plages associées, les actions doivent aussi être conçues de manière à assurer la pérennité du bénéfice de ces milieux particuliers pour les générations futures dans un contexte de changement climatique dont les effets pourraient être particulièrement importants sur les côtes.

Le gestionnaire a donc un rôle délicat d'articulation de ces différents enjeux et une responsabilité particulière pour maintenir durablement les fonctionnalités des milieux littoraux.

La gestion des dunes, comme bon nombre de milieux naturels peu ou pas anthropisés, doit avant tout être basée sur une observation fine des évolutions, sur la recherche d'une adaptation aux conditions écologiques et sur la mise en œuvre de techniques adaptées aux processus naturels. L'objectif est de préserver les grandes fonctionnalités des milieux dunaires, afin de maintenir leur capacité de résilience, face aux évolutions en cours.

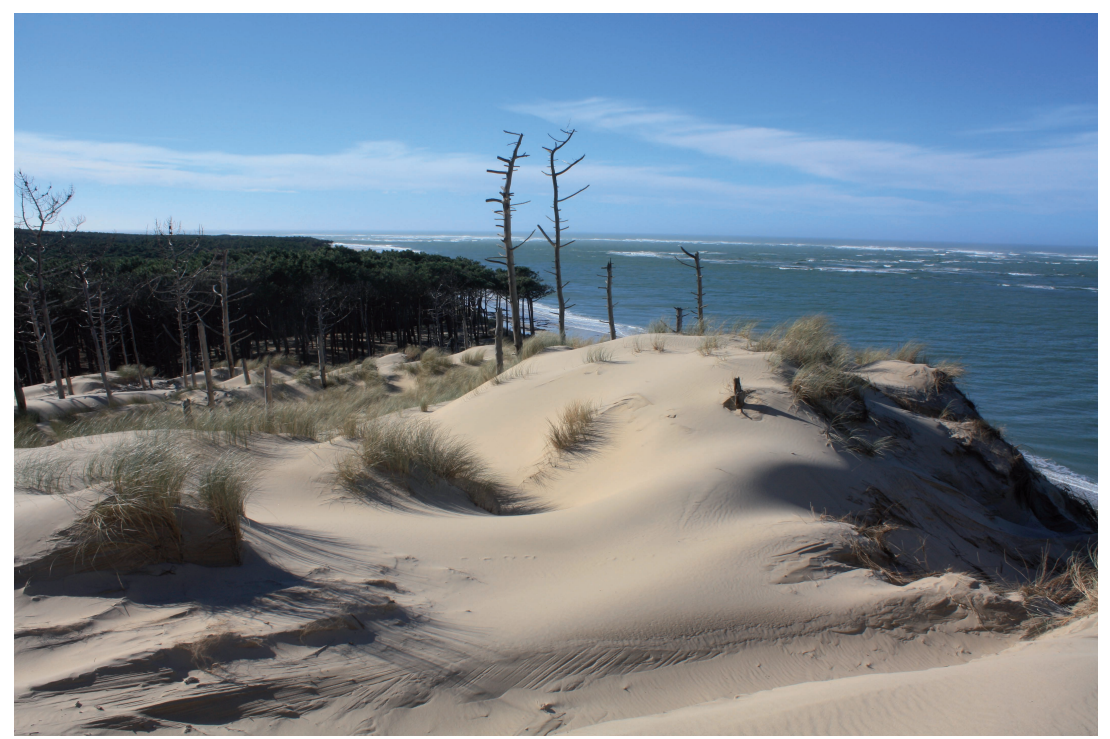

Figure 3.48. Vers la plage du Petit Nice au sud de la dune du Pilat.

(C) L. Gouguet/ONF. 



\section{Glossaire}

\section{Accrétion}

\author{
Abrupt \\ d'envahissement \\ (ou talus interne)
}

\section{Arrière-dune}

Avant-dune

Baïne (ou bâche)

Banquette

Barkhane

Barre

Berme

Biotique

Budget sédimentaire (ou bilan sédimentaire)

\section{Caoudeyre}

progression de la ligne de rivage vers la mer du fait de l'apport de sédiments.

c'est le versant non ou peu végétalisé de la dune littorale situé sous le vent. II présente une pente d'équilibre proche de $33^{\circ}$. II « envahit » plus ou moins rapidement la dune grise ou la forêt dunaire situées en arrière.

ensemble complexe situé à l'arrière et à l'abri de la dune bordière (lette, dunes plus anciennement formées...).

cordon dunaire parallèle au rivage, au contact de la plage et en interaction directe avec elle (échanges sédimentaires permanents).

terme gascon signifiant " petite bassine » et désignant une dépression topographique située dans la zone intertidale d'une plage, orientée longitudinalement ou obliquement par rapport aux barres sableuses et à la côte, dans laquelle subsiste de l'eau à marée basse.

accumulation éolienne de sable en haut de plage qui, en l'absence d'érosion marine, peut être végétalisée par le chiendent des sables ou d'autres espèces pionnières halophiles.

dune en forme de croissant à pointes effilées dans le sens du vent.

banc ou haut-fond de forme allongée sur lequel les vagues peuvent déferler.

accumulation marine de sable ou de galets en haut de plage au niveau des pleines mers de vives eaux.

relatif aux êtres vivants et à leur action (contraire : abiotique).

c'est le résultat comparé des entrées et des sorties de sédiments dans un système littoral supposé relativement clos (une cellule sédimentaire).

terme gascon désignant une cuvette de déflation éolienne en forme de chaudron creusée dans la dune. 
Cellule

hydrosédimentaire

\section{Charriage}

Croissants de plage

\section{Déflation}

\section{Dérive littorale}

\section{Dune}

\section{Dune bordière}

Dune perchée

\section{Édaphique \\ Endémique}

Engraissement

Érosion éolienne

Érosion marine

Espace de respiration (ou espace d'accommodation) compartiment sédimentaire littoral séparé des secteurs voisins par des limites plus ou moins étanches (caps, embouchures fluviales par exemple). Les sédiments peuvent se déplacer à l'intérieur de la cellule sous I'action du vent, des vagues ou des courants. Le bilan sédimentaire peut être équilibré, excédentaire ou déficitaire, en fonction des transferts sédimentaires de ou/et vers le large ou l'intérieur des terres. Une source de sédiments (secteur en érosion, embouchure fluviale), une zone de transport et un puits (secteur en accrétion, canyon sous-marin) s'y succèdent.

déplacement d'une particule au contact du sol sous I'action du vent ou de l'eau.

formes d'accumulations de sédiments sur la plage, liées à l'existence de courants giratoires (rip-currents) dans la zone de déferlement et du jet de rive. Les croissants de plage se succèdent à intervalle régulier, parfois sur de grandes distances sur certaines plages.

phénomène d'érosion éolienne où les grains de sable sont arrachés et déplacés par le vent.

courant côtier longitudinal engendré par une houle incidente oblique à la côte à laquelle peut s'ajouter l'effet de la marée. La dérive littorale peut entraîner des déplacements plus ou moins importants de sédiments le long de la côte.

du moyen néerlandais Duin (colline), accumulation de sable sous l'action du vent (dunes éoliennes) ou de l'eau (dunes hydrauliques).

dune de première ligne, en arrière de la plage.

accumulation de sable plaquée contre une falaise à mipente ou à son sommet.

relatif au sol.

se dit d'une espèce dont l'aire de répartition est limitée. augmentation du volume de sédiments constituant une plage.

érosion provoquée par le vent (on parle aussi de déflation éolienne).

érosion provoquée principalement par l'action des vagues et des courants côtiers.

espace de recul nécessaire à l'évolution de la dune au gré des événements (érosion marine, envols de sable...). 
Estran

Flèche littorale

Ganivelle

Géodiversité

Glacis externe

Gradins de haut de plage

Houle

Laisse de mer

Lette (ou lède, terme gascon)

Lido

Marnage

Méplat

Mielles

Nebka (ou nebkha)

Oyat (ou gourbet en Aquitaine, milgreu en Normandie) zone de balancement des marées comprise entre les niveaux des plus basses et des plus hautes mers. On parle aussi de zone intertidale.

forme d'accumulation de sédiments entre un point d'ancrage à une extrémité et une pointe libre à l'autre extrémité qui s'avance en mer.

brise-vent constitué de lattes de bois (souvent du châtaignier) reliées entre elles, destiné à freiner le vent pour l'obliger à déposer le sable transporté. Les ganivelles permettent de reconstituer les dunes.

diversité du monde abiotique terrestre, géologique et sous-marin.

versant ouest de la dune calibrée d'Aquitaine.

accumulation successive de sédiments en haut de plage, formant des dénivellations.

oscillations régulières de la surface de la mer.

dépôt d'algues et de matériaux organiques ou non organiques laissés en haut de plage par la marée haute ou par une tempête.

dépression subhorizontale située entre deux bombements dunaires, souvent allongée en couloir parallèle à la côte. cordon littoral sableux isolant une lagune.

différence de hauteur d'eau entre une pleine mer et une basse mer consécutives.

partie plane.

terme normand désignant les dunes du Cotentin.

petite accumulation de sable déposé par le vent derrière un obstacle (plante ou laisse de mer).

Ammophila arenaria, espèce caractéristique de la dune blanche mobile, elle est abondamment utilisée pour les travaux de fixation des sables du fait de sa parfaite adaptation aux conditions difficiles régnant sur la dune bordière. 
Paléosol

Palissade

Panne

Parabolique (ou dune parabolique)

Petit Âge glaciaire

Plage

Plateau

Plateau continental

Pourrière

Progradation

Rechargement de plage

Reptation

Retroussage de plage vieux sol formé dans un climat ou un environnement topographique différents de l'actuel. En milieu dunaire, il a pu être fossilisé sous le sable et réapparaître en falaise. Les paléosols sont des repères essentiels pour dater les dunes.

ancienne technique de brise-vent, constitué de planches de bois presque jointives, fichées dans le sable et surélevées au fur et à mesure de l'accumulation de sédiments. $C^{\prime}$ est ainsi que la dune aquitaine a été édifiée.

écosystème humide en milieu dunaire, souvent une dépression creusée par le vent jusqu'au niveau de la nappe phréatique.

dune en croissant à concavité orientée face au vent dominant. On parle aussi de dune entravée car sa formation est contrainte par la végétation.

période climatique froide survenue notamment dans I'hémisphère nord, du début du xIve siècle jusqu'au milieu du xIXe siècle.

partie du rivage correspondant à l'accumulation de sédiments dont la taille est supérieure à celle des constituants de la vase (des sables fins aux galets). Elle comprend une partie subaérienne, l'estran, et une partie toujours immergée, I'avant-plage.

partie centrale du profil de la dune calibrée aquitaine (entre le glacis externe et l'abrupt d'envahissement). Zone presque horizontale.

$c^{\prime}$ est le prolongement du continent sous la surface de l'océan.

langue de sable nu qui progresse dans l'axe des vents dominants vers l'intérieur des dunes. Elle est souvent associée à un couloir transversal creusé dans l'avantdune.

avancée du rivage en direction de la mer.

technique qui consiste à prélever des sédiments à l'extérieur de la cellule sédimentaire pour venir l'alimenter.

processus de déplacement d'un grain de sable à la surface du sol sous l'action du vent ou de la gravité.

technique qui consiste à prendre du sédiment sur le bas de l'estran et à le remonter en pied de dune pour conforter le cordon dunaire. Les mouvements de sable sont internes à la cellule sédimentaire. 
Rudéralisation

Sable

Saltation

Sédiments

Siffle-vent

Système côtier

Tombolo

Touffette

Trait de côte

Vivace dégradation d'un milieu ou d'un sol sous l'influence humaine (par apport direct ou indirect d'azote surtout), favorable aux plantes rudérales : orties, ronces... et défavorable à la flore et à la faune originelles.

ensemble de grains provenant de la désagrégation de roches du continent ou plus rarement de l'activité biologique (coquillages ou coraux). Leur taille s'étend de $0,2 \mathrm{~mm}$ pour les sables les plus fins à $2 \mathrm{~mm}$ pour les plus grossiers.

processus d'entraînement $d^{\prime}$ un grain de sable par le vent par petits sauts successifs.

dépôts continentaux ou marins, provenant de l'altération ou de la désagrégation des roches préexistantes ou de l'activité biologique.

brèche taillée par le vent dans la dune ou dans I'avantdune, pouvant s'élargir et évoluer vers une caoudeyre.

on entend ici par système côtier tous les compartiments sédimentaires (avant-plage, plage, dune) qui sont interdépendants.

flèche sableuse reliant une île à la côte voisine, résultant de la réfraction des houles derrière l'obstacle que constitue l'île.

assemblage de plusieurs brins d'oyat (5 à 6) en vue de la plantation dans un trou préalablement fait grâce à un plantoir.

limite entre la terre et la mer. Il en existe de nombreuses définitions : niveau moyen de la mer (zéro NGF en France métropolitaine), laisse de mer, niveau des plus hautes mers, limite de végétation, pied de dune...

végétal qui vit plusieurs années, s'oppose à « annuelle ». 



\section{Bibliographie}

Assemblée des départements de France, 2014. Les départements face au défi littoral : rapport final de la Mission mer et littoral. Paris, Assemblée des départements de France.

Barrère P., 1989. Mémento technique des dunes du littoral aquitain. Paris, ONF.

Battiau-Queney Y., 2004. Haut de plage et front dunaire : enregistrement morphologique de la dynamique éolienne et marine dans un milieu macrotidal. Géographies. Bulletin de I'AGF, 81 (3), 393-404.

Battiau-Queney Y., 2010. Les avant-dunes de la Côte d'Opale. In : Roland Paskoff et les littoraux : regards de chercheurs (Duvat V., Battiau-Queney Y., Clus-Auby C., Prat M.-C., dir.). Paris, L'Harmattan, 213-229.

Battiau-Queney Y., Clus-Auby C. (coord.), 2010. Les ateliers de l'EUCC-France : de la connaissance des systèmes littoraux à la gestion intégrée des zones côtières. Paris, Union des océanographes de France.

Battiau-Queney Y., Favennec J. (coord.), 2015. Coastal dunes management strategies and practices: perspectives and case studies. Dynamiques environnementales, 33.

Brivois O., Palvadeau E., 2014. Évaluation de l'effet d'ouvrages de protection sur l'évolution du littoral. Rapport final. Orléans, BRGM.

Bruzzi C., 1999. Bilan des impacts morphologiques des tempêtes de novembre et décembre 1997 sur les plages orientales du delta du Rhône. Méditerranée, 93 (4), 5-10.

Buffaut P., 1942. Histoire des dunes maritimes de la Gascogne. Paris, Éditions Delmas.

Cazes-Duvat V., Paskoff R., 2004. Les littoraux des Mascareignes entre nature et aménagement. Paris, L'Harmattan.

CETMEF, 2008. Dragage en milieu marin, immersion et code de l'environnement : le guide des procédures préalables. Compiègne, CETMEF.

CETMEF, 2011. Dragage : recueil de textes relatifs à l'établissement d'un document d'incidences. Compiègne, CETMEF.

Claudino-Sales V., Wang P., Horwitz M.H., 2008. Factors controlling the survival of coastal dunes during multiple hurricane impacts in 2004 and 2005: Santa Rosa barrier island, Florida. Geomorphology, 95 (3-4), 295-315.

Dean R.G., 1991. Equilibrium beach profiles: characteristics and applications. Journal of Coastal Research, 7 (1), 53-84.

Debaine F., Robin M., 2012. A new GIS modelling of coastal dune protection services against physical coastal hazards. Ocean \& Coastal Management, 63, 43-54

De La Torre Y., Falguière S., Le Roy M., 2013. Vulnérabilité du littoral de Saint Pierre et Miquelon face aux risques côtiers. Phase 1 : état des lieux de la dynamique côtière et des enjeux. Orléans, BRGM.

Desmazes F., Balouin Y., Nicolae Lerma A., Vinchon C., Chateauminois E., Mallet C., 2015. Gestion des sédiments et prévention des risques de recul du trait de côte. Rapport phase 1. Orléans, BRGM.

DGPR, MEDDE, 2014. Guide méthodologique : plans de prévention des risques littoraux. Paris, DGPR, MEDDE.

Doody P., 1989. Conservation and development of the coastal dunes in Great Britain. In : Perspectives in Coastal Dune Management (Van der Meulen F., Jungerius P.D., Visser J.H., dir.). La Hague, SPB Academic Publishing, 53-67.

EUCC-France, 2012. Connaissance et gestion des dunes littorales : risques d'érosion et de submersion. Compte-rendu des journées EUCC-France, Noirmoutier, 4-5 avril 2012, Biarritz, EUCC. 
Favennec J., 1999. Aménagement des forêts littorales : cas des forêts dunaires du littoral atlantique français. Nancy, École nationale du génie rural, des eaux et des forêts.

Favennec J. (dir.), 2002. Connaissance et gestion durable des dunes de la côte atlantique. Paris, Office national des forêts.

Favennec J. (dir.), 2012. Guide de la flore des dunes littorales. Bordeaux, Éditions SudOuest.

FFPP, 2005. Guide pour la gestion des opérations de dragage. La Forêt-Fouesnant, In Vivo Environnement.

Garcin M., Vendé-Leclerc M., 2014. Observatoire du littoral de Nouvelle-Calédonie. Rapport préliminaire : observations, état des lieux et constats. Orléans, BRGM.

Garnier E., Ciavola P., Armaroli C., Spencer T., Ferreira O., 2017 (en cours de publication). Historical analysis of storms events: case studies in France, England, Portugal and Italy. Coastal Engineering.

Géode, 2012. Guide méthodologique sur le dragage par injection d'eau. Nantes, Groupe d'études et d'observation sur les dragages et l'environnement.

Gouguet L., 2011. Les dunes domaniales jouant un rôle de digue en Centre-Atlantique : un nouveau regard sur la gestion. Les RDV techniques de l'ONF, 31, 3-9.

Guilcher A., 1954. Morphologie littorale et sous-marine. Paris, Presses universitaires de France.

Hesp P., 2002. Foredunes and blowouts: initiation, geomorphology and dynamics. Geomorphology, 48 (1-3), 245-268.

Houser C., 2013. A longshore variation in the morphology of coastal dunes: implications for storm response. Geomorphology, 199, 48-61

Kriebel D.L., 1985. Numerical simulation of time-dependant beach and dune erosion. Coastal Engineering, 9 (3), 221-245.

Lemauviel S., Rozé F., 2003. Response of three plant communities to trampling in a sand dune system in Brittany (France). Environmental Management, 31 (2), 227-235.

Lobato Gómez P. (dir.), 2011. Manual de restauración de dunas costeras. Sandanter (Espagne), Ministerio de Medio Ambiente Rural y Marino.

MEEDDM (Ministère de l'Écologie, de l'énergie, du développement durable et de la mer), 2010. La gestion du trait de côte. Versailles, Éditions Quæ.

Parain L., 2013. Rechargement en sédiments des plages de la côte aquitaine : bilan des connaissances et des pratiques. Mémoire de master 2, La Rochelle, Université de La Rochelle.

Paskoff R., 1993. Côtes en danger. Paris, Éditions Masson.

Paskoff R., 1994. Les littoraux : impact des aménagements sur leur évolution. Paris, Éditions Masson.

Paskoff R., Clus-Auby C., 2007. L'érosion des plages : les causes, les remèdes. Paris/Monaco, Institut océanographique.

Pedreros R., Lenôtre N., Aubié S., Rançon J.-P., 2002. Étude morphologique des plages à l'arrière des formations récifales de la côte ouest de la Réunion. Orléans, BRGM.

Perrin H., 1928. La fixation des dunes maritimes en France. Nancy, École nationale des eaux et forêts.

Pinot J.-P., 1998. La gestion du littoral. Paris/Monaco, Institut océanographique.

Prat M.-C., 2002. Transferts sableux, échanges entre plage et dune, bilan sédimentaire In : Connaissance et gestion durable des dunes de la côte atlantique (Favennec J., dir.). Paris, Office national des forêts, 37-56.

Prat M.-C., 2014. The French Atlantic coastal dunes: a remarkable geodiversity. Dynamiques environnementales, 33, 17-49.

Prat M.-C., Barrère P., 2002. Les cartes écodynamiques. In : Connaissance et gestion durable des dunes de la côte atlantique (Favennec J., dir.). Paris, Office national des forêts, 109-121. 
Prat M.-C., Lageat Y, Auly T., 2014. Le littoral : paysages et dynamiques naturelles. Bordeaux, Éditions Confluences.

Psuty N.P., 2004. The coastal foredune: a morphological basis for regional coastal dune development. In : Coastal Dunes: Ecology and Conservation (Martínez M.L., Psuty N.P., dir.). Dordrecht, Springer, 11-27.

Pupier-Dauchez S., 2002. Le rechargement sédimentaire : de la défense des côtes à l'aménagement du littoral : analyse des pratiques sur la côte atlantique française. 2 tomes, Thèse de doctorat de géographie, Brest, Université de Bretagne occidentale.

Robert R., 1974. Morphologie littorale de l'île de La Réunion. Thèse de doctorat en géographie, Montpellier, Université Paul Valéry.

Robin N., 2007. Morphodynamique des systèmes de flèches sableuses : étude comparative entre les embouchures tidales de l'Archipel de Saint-Pierre et Miquelon et de la côte ouest du Contentin (Manche). Thèse de doctorat en sciences de la terre et de l'univers, Caen, Université de Caen Normandie.

Sabatier F., Heurtefeux H., Hanot B., 2008. Dépôts d'overwash et tempêtes à moyen terme sur deux lidos méditerranéens. In : Xe journées nationales génie côtier-génie civil, 1416 octobre 2008, Sophia Antipolis, 477-486.

STCPMVN, 1993. Étude bibliographique sur les rechargements de plage à l'aide des produits de dragage, Rapport du STCPMVN. Paris, STCPMVN. 


Édition : Yann Lézénès

Mise en page

Desk (www.desk53.com.fr) 
Le cordon dunaire forme, avec l'estran et l'avant-plage, un système sédimentaire complexe en perpétuelle évolution. La préservation et l'entretien de ces milieux naturels présentent une grande importance, notamment pour protéger les territoires littoraux vis-à-vis de l'érosion côtière et de la submersion marine.

Dans le cadre des missions d'intérêt général "Biodiversité » et «Prévention des risques naturels », le ministère en charge de l'Écologie a confié à l'Office national des forêts la rédaction d'un guide technique sur la gestion des dunes littorales atlantiques destiné à tous les gestionnaires des milieux dunaires.

Fruit de l'expérience de l'ONF dans la gestion des milieux dunaires littoraux, du Cerema et du BRGM dans la prévention des risques naturels, ainsi que de nombreux organismes gestionnaires et experts, il présente des outils utiles pour résoudre les problèmes liés à la gestion quotidienne des dunes et des préconisations concernant les plages associées aux cordons dunaires. Ni traité de géomorphologie, ni étude botanique, cet ouvrage doit permettre au praticien d'appréhender très concrètement la problématique de la gestion d'un milieu complexe et en évolution permanente, tout en fournissant les clés de compréhension nécessaires et en précisant le vocabulaire lié au domaine.

Véritable boîte à outils d'actions qui utilisent les processus naturels pour gérer et restaurer les dunes, ce guide a pour vocation de faire un panorama des techniques et de leur évolution afin de prendre en compte les attentes de la société face à la gestion des risques naturels et à la préservation de la biodiversité en milieu dunaire.

Chef du pôle Littoral du département Risques naturels de l'Office national des forêts, expert national auprès du ministère en charge des Forêts,

Loïc Gouguet met en œuvre plusieurs missions d'intérêt général

sur le littoral pour le compte de l'État, dont la gestion des $380 \mathrm{~km}$ de dunes domaniales de la façade atlantique. Au sein de l'ONF, il organise la gestion multifonctionnelle des milieux littoraux.
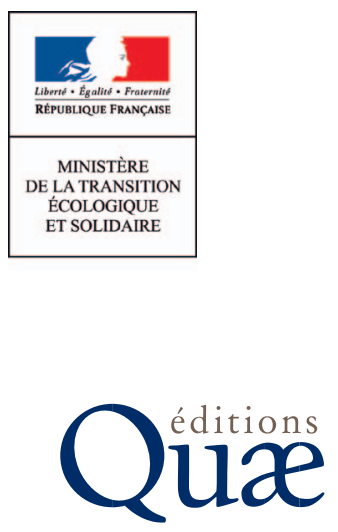